\title{
Evaluación del impacto de las bibliotecas escolares en España: aproximación desde una doble perspectiva metodológica cuantitativa y cualitativa
}

\section{Tesis doctoral}

\author{
Autora: Beatriz Albelda Esteban \\ Directora de tesis: Dra. Marta de la Mano González
}

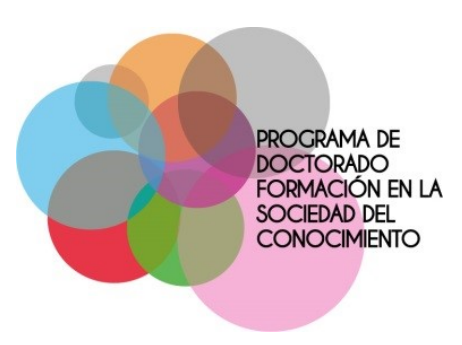



Evaluación del impacto de las bibliotecas escolares en España: aproximación desde una doble perspectiva metodológica cuantitativa y cualitativa

Tesis doctoral

Doctoranda: Beatriz Albelda Esteban

Directora: Dra. Marta de la Mano González

Diciembre de 2019 
Doña Marta de la Mano González, Profesora Titular de Universidad del Departamento de Biblioteconomía y Documentación de la Universidad de Salamanca, en calidad de directora del trabajo de tesis doctoral titulado "Evaluación del impacto de las bibliotecas escolares en España: aproximación desde una doble perspectiva metodológica cuantitativa y cualitativa" y realizado por Doña Beatriz Albelda Esteban.

\section{HACE CONSTAR}

Que dicho trabajo tiene suficientes méritos teóricos contrastados adecuadamente mediante las validaciones oportunas, publicaciones relacionadas y aportaciones novedosas. Por todo ello considera que procede su defensa pública.

En Salamanca, diciembre de 2019.

Dra. Doña Marta de la Mano González

Universidad de Salamanca 


\section{Agradecimientos}

En la redacción del cierre de esta tesis quiero expresar mi agradecimiento a quienes me han acompañado en este camino de aprendizaje, descubrimiento e intenso disfrute.

En primer lugar, ha sido un privilegio para mí trabajar bajo la dirección de la Doctora Marta de la Mano. Su guía y enseñanzas, y su calidad humana han alentado el trabajo paciente y riguroso y han sido la ayuda necesaria en las dificultades del camino.

Asimismo, agradezco al Programa de Doctorado Formación en la Sociedad del Conocimiento, al Departamento de Biblioteconomía y Documentación y al Instituto Universitario de Ciencias de la Educación de la Universidad de Salamanca que aceptaran mi tema de tesis entre sus líneas de investigación y que me hayan proporcionado los recursos y herramientas necesarias para llevar este trabajo a buen puerto.

Para la elaboración de la investigación ha sido esencial poder contar con la colaboración de la comunidad educativa del CEIP Virrey Morcillo (Villarrobledo, Albacete). Expreso mi profunda gratitud a Carmen Cebrián, su directora, y a su profesorado, que me abrieron las puertas del centro para compartir su interesantísima experiencia de éxito con su biblioteca escolar. Del mismo modo, expreso mi reconocimiento y agradezco al Grupo Bibliotecas Escolares en Red de Albacete, BERED, y especialmente a su coordinador, José Manuel Garrido. Conscientes de la importancia de hacer investigación en torno al valor de las bibliotecas escolares, compartieron su prolongada experiencia, conocimiento e implicación en este ámbito, y proporcionaron información valiosa para el desarrollo de esta tesis. Su trabajo entusiasta y constante con las bibliotecas escolares en pro de sus respectivas comunidades educativas genera esperanza y es un ejemplo para la sociedad.

Por último, añado un emocionado recuerdo a mis seres queridos, y en especial a quienes me enseñaron la importancia del estudio y la curiosidad para la vida.

A todos ellos mi gratitud 
A mis padres y hermanos

A Érick, futuro niño lector A la fiel Gárgol 
Cita recomendada:

Albelda Esteban, B. (2020). Evaluación del impacto de las bibliotecas escolares en España: aproximación desde una doble perspectiva metodológica cuantitativa y cualitativa (Tesis doctoral, Universidad de Salamanca). Recuperado de https://www.usal.es/repositorio-documental-gredos 


\section{Resumen}

En esta tesis se aborda la evaluación del impacto de las bibliotecas en su dimensión educativa, utilizando la norma ISO 16439 sobre impacto bibliotecario como marco conceptual y metodológico.

Se revisa el estado de la cuestión sobre la evaluación en bibliotecas, y la evolución de esta materia desde la perspectiva de la evaluación del rendimiento y de la calidad en los primeros estudios evaluativos hasta la evaluación del impacto en los distintos tipos de bibliotecas.

Se desarrolla una investigación sobre el impacto de las bibliotecas escolares empleando un enfoque metodológico que integra una doble visión cuantitativa y cualitativa. Como objetivo general, se pretende evaluar la contribución de las bibliotecas escolares al sistema educativo en España. Se analiza su efecto en cada uno de los tres niveles de impacto que se establecen en la mencionada norma internacional: 1 ) impacto sobre los individuos (se incluye el efecto sobre las habilidades y competencias, sobre las actitudes y comportamientos, sobre el bienestar individual, y sobre la carrera académica y profesional a medio y largo plazo); 2) impacto sobre la comunidad o institución de la que depende la biblioteca; y 3) impacto sobre el conjunto de la sociedad. Para explicar estos tres niveles de impacto, se plantean once preguntas de investigación.

Para la realización de la investigación cuantitativa se emplean los conjuntos de datos de los estudios internacionales PIRLS 2016 (para el alumnado de educación primaria) y PISA 2009 (para el alumnado de educación secundaria), seleccionando los datos correspondientes a España. Con estos datos se comparan los resultados medios en competencia lectora de dos grupos: por un lado, el alumnado que dispone de biblioteca escolar y de diferentes recursos bibliotecarios, y hace uso de ellos; y, por otro lado, el alumnado que carece de biblioteca escolar o de determinados recursos bibliotecarios, o que, aun teniéndolos no hace uso de ellos.

En el ámbito de la evaluación primaria, se confirma que la existencia de biblioteca escolar es un factor que contribuye positivamente al rendimiento en competencia lectora general y a cuatro dimensiones de esta competencia: "Tener una experiencia literaria", "Adquirir y usar la información", "Obtener información e inferencias directas", e "Interpretar, integrar y evaluar". La mayor contribución del factor biblioteca escolar se produce sobre la dimensión "Adquirir y usar la información" en todos los análisis realizados. En cuanto al uso y acceso a los distintos recursos bibliotecarios, se demuestra que los factores tener acceso a una colección bibliográfica amplia, y tener acceso a libros electrónicos, influyen positivamente sobre ese rendimiento competencial.

En el ámbito de la educación secundaria, se confirma que existe relación entre el rendimiento en competencia lectora general y el factor tener biblioteca escolar. El alumnado con una actitud positiva hacia las bibliotecas registra mejores resultados. En cuanto al uso y acceso a los distintos recursos bibliotecarios, se confirma la influencia positiva del préstamo de libros para leer por ocio y para hacer trabajos de clase. 
La investigación cualitativa complementa el alcance del primer abordaje cuantitativo e introduce una visión naturalista desde dentro del contexto educativo.

Para la realización de la investigación cualitativa se emplea un estudio de caso centrado en la biblioteca del CEIP Virrey Morcillo (Villarrobledo, Albacete), integrada en una red cooperativa de bibliotecas escolares, el Grupo Cooperativo Bibliotecas Escolares en Red $B E R E D$ - de Albacete. La estrategia consiste en registrar el impacto bibliotecario tal y como es percibido por el profesorado. El caso escogido responde a los criterios preestablecidos de representatividad e intensidad informativa, y se selecciona entre una muestra de centros educativos españoles con biblioteca escolar seleccionados con criterios de muestreo cualitativo.

La investigación se orienta a la obtención de evidencias solicitadas, combinado con el análisis de materiales documentales. Se emplean diferentes técnicas para la obtención de la información: encuesta en remoto, entrevistas y grupo de discusión con profesorado, y análisis de documentos oficiales y de contenidos de un blog.

En el análisis y posterior interpretación de los datos cualitativos se sigue un procedimiento en cuatro fases, con ayuda del programa especializado ATLAS.ti, que consiste en la identificación de la información relevante, su categorización mediante descriptores; la síntesis y verificación de contenidos, y su interpretación a la luz de las preguntas de investigación.

Los datos cualitativos corroboran que desde el contexto educativo se percibe que la biblioteca escolar contribuye a mejorar la competencia lectora general del alumnado y las distintas dimensiones de esta competencia, especialmente la informacional. Asimismo, se refuerzan otras competencias afines, como el pensamiento crítico y la creatividad, las competencias digitales, comunicativas y lingüísticas.

El recurso más valorado por los docentes es la colección bibliográfica, combinada con el trabajo por proyectos e integrada en las actividades formativas y de animación a la lectura programadas desde un plan de lectura.

La biblioteca escolar contribuye a producir cambios de carácter intangible en las actitudes y en el comportamiento, especialmente sobre la motivación de alumnado y profesorado, y favorece la implicación de las familias en el proceso de aprendizaje. El alumnado interioriza valores y normas de convivencia y refuerza su sentido de pertenencia; se refuerza la formación del profesorado y se da visibilidad a la labor docente.

Respecto a la influencia de la biblioteca sobre la institución de la que depende, contribuye a que se cumplan los fines y objetivos educativos, en torno a tres ejes principales: 1) apoya los objetivos de enseñanza y aprendizaje, incluyendo el refuerzo curricular y la implantación de nuevas metodologías de trabajo y aprendizaje con el uso de las nuevas tecnologías; 2) refuerza la cohesión entre los miembros de la comunidad educativa en torno a los objetivos y proyectos comunes, potenciando valores comunitarios y de convivencia y actuando como un compensador de desigualdades; y 3) contribuye a establecer redes de cooperación.

Respecto de la influencia de la biblioteca escolar sobre su entorno social próximo, se observa la colaboración con otras entidades educativas y culturales en redes de cooperación. 
Con vistas a la evaluación comparativa, se precisan nuevas investigaciones sobre el impacto de las bibliotecas escolares en contextos geográficos y socioculturales diversos (en España se precisa investigación comparativa entre los distintos sistemas educativos autonómicos). Futuras investigaciones deberán contemplar la contribución de la biblioteca escolar sobre otras competencias curriculares y sobre otros aspectos del desarrollo formativo del alumnado, diferenciando entre niveles educativos.

Por último, se recomienda emplear el marco conceptual y las opciones metodológicas reseñadas en la norma ISO 16439 para abordar nuevas investigaciones en el campo de la evaluación del impacto educativo en bibliotecas. Asimismo, se recomienda emplear una doble visión cuantitativa y cualitativa para comprender el impacto bibliotecario en sus distintas dimensiones.

Palabras clave: Bibliotecas; Bibliotecas escolares; CEIP Virrey Morcillo (Villarrobledo, Albacete); Competencia lectora; Educación Primaria; Educación Secundaria; España; Estudios de caso; Evaluación; Evaluación bibliotecaria; Evaluación del impacto; Grupo Cooperativo Bibliotecas Escolares en Red de Albacete; Investigación cualitativa; Investigación cuantitativa; Norma ISO 16439; PIRLS 2016; PISA 2009. 


\section{Abstract}

This research deals with the school libraries impact evaluation, by adopting the international standard on library impact ISO 16439 as a conceptual framework and methodological guide.

The state of the art of library evaluation as well as the evolution of this matter from the perspective of performance and quality evaluation to impact evaluation studies is reviewed.

The main objective of this research is to evaluate the contribution of school libraries to the educational system in Spain, by combining both quantitative and qualitative methodological approaches.

According to ISO 16439, three areas of library impact are analysed: 1) impact on individuals (including changes in skills and competences, changes in attitudes and behaviour, higher success in study or career and individual well-being); 2) impact on the library's institution or community; and 3) impact on society.

Firstly, we used the Spanish datasets released from the PISA 2009 and PIRLS 2016 international studies to perform the quantitative analysis. Then, average results on reading literacy of two different groups were compared: pupils that have access to library resources and use them, and those pupils that don't have access to library resources or, even if they could, they hardly use them.

The results confirm that, in Primary School, school libraries positively influence four dimensions of reading skills: Reading for literary experience; Reading to acquire and use information; Retrieving and Straightforward Inferencing and Interpreting, Integrating, and Evaluating. The positive effect on reading to acquire and use information is confirmed as the main impact. Concerning library resources, the quality of library collection as well as having access to digital books positively influence reading performance. As for Secondary School, pupils that have a positive attitude towards libraries get better results in reading performance. Concerning library resources, borrowing books for reading for pleasure as well as borrowing books for school work positively influence reading performance.

Secondly, a case study which is focused on a Spanish school library is performed. The school library from the Virrey Morcillo Primary School (Villarrobledo, Albacete, Spain) forms part of a school library network: the Grupo Cooperativo Bibliotecas Escolares en Red - BERED(Albacete). This representative, information-rich case was selected from a sample of Spanish school libraries.

As a research strategy, we registered the libraries impact as it was perceived by the teachers. Different techniques were used for questioning them about their perception and experience of library effects. Among them, online surveys, interviews, focus groups, and analysis of documents, including official documents and a blog.

Then, four steps procedure was performed to analyse qualitative data: identification of relevant information, their categorization, verification and synthesis, and interpretation. The special software ATLAS.ti, was used to run the analysis. 
Results corroborate that school library is perceived as an efficient resource which contributes to improve reading literacy skills, especially those informational skills. Also, it is perceived to foster related competencies, i.e., critical thinking, creativity, digital skills and communicative and linguistic skills.

The quality of library collection is the most valued library resource, when it is used in specific projects and when formative and reading promotion activities are planned.

Also, the school library encourages changes in attitudes and behaviour. It is perceived to foster pupils and teacher's motivation. Moreover, it is considered to encourage the families involvement in pupils' learning process. Pupils learn values and behavioural rules and strengthen their sense of belonging towards their school. Also, it is perceived to give visibility to educational work.

As for the impact on the library's institution or community, it is perceived to contribute to the achievement of educational goals and objectives: 1) it gives support to learning and teaching objectives, including curricular enhancement, learning and teaching methodologies and working with new technological resources; 2) it fosters cohesion among all learning community members and helps equity; 3 ) it helps create cooperative alliances and networks.

Concerning the impact on the society, it is perceived that the school library collaborates with other learning and cultural entities for cooperation projects.

Further research on the impact of school libraries in different geographical and sociocultural contexts should be done for comparative purposes. For example, comparing the impact of school libraries in different Spanish regions. It also should be studied their impact on other competencies, comparing educational levels.

Finally, it is recommended to use the ISO 16439 as a conceptual framework and methodological guide in further research on school libraries impact. Moreover, it is recommended to combine both quantitative and qualitative approaches for a better understanding of libraries' impact.

Keywords: Case studies; Evaluation; Impact evaluation; ISO Standard 16439; Libraries; Library evaluation; PIRLS 2016; PISA 2009; Primary School; Qualitative research; Quantitative research; Reading literacy; School libraries; Secondary School; Spain; Virrey Morcillo (Primary School) (Villarrobledo, Albacete, Spain). 


\section{Índice}

Evaluación del impacto de las bibliotecas escolares en España: aproximación desde una doble perspectiva metodológica cuantitativa y cualitativa

Índice

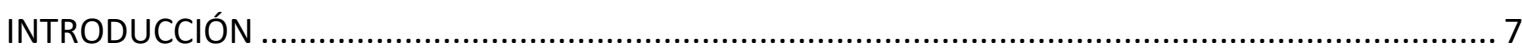

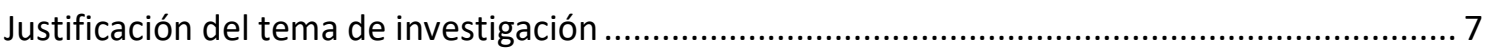

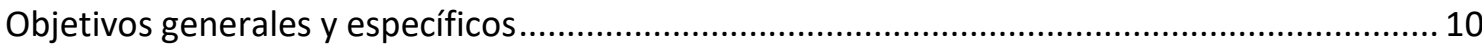

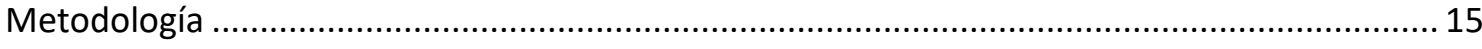

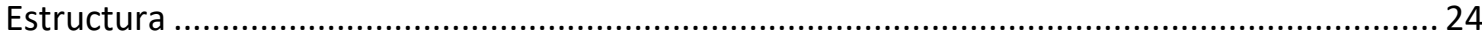

PRIMERA PARTE. Estado de la cuestión sobre la evaluación en bibliotecas: de la medida del

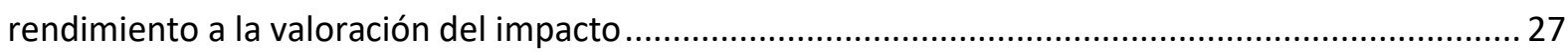

CAPÍTULO 1. Primeras iniciativas en la evaluación de bibliotecas ................................................ 27

1.1. Principales fuentes para el estudio de la evaluación en bibliotecas ................................ 27

1.2. La importancia de la normalización para la evaluación en bibliotecas ............................ 31

1.3. Estudios de evaluación bibliotecaria orientados al rendimiento …................................... 36

1.3.1. La introducción de la evaluación del rendimiento en bibliotecas .36

1.3.2. La introducción de la perspectiva del usuario en los estudios de evaluación de bibliotecas: la importancia de la calidad

1.3.3. Estudios de rendimiento y calidad aplicados a los distintos tipos de bibliotecas 47

CAPÍTULO 2. Estudios de evaluación del impacto en el ámbito de las bibliotecas 54

2.1. Contexto de los estudios sobre impacto bibliotecario ................................................... 54

2.2. Terminología y conceptos empleados en la evaluación del impacto en bibliotecas.........57

2.3. Cuestiones metodológicas en la evaluación del impacto en bibliotecas ...........................65

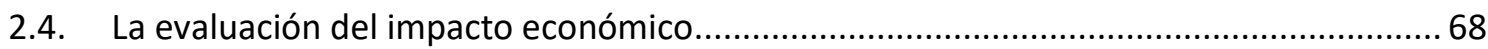

2.4.1. Aproximación al valor económico en bibliotecas: marco conceptual ..............68

2.4.2. Metodologías de los estudios sobre el impacto económico ...........................71

2.4.3. Limitaciones de los estudios sobre el impacto económico .............................75

2.5. La evaluación del impacto en los distintos tipos de bibliotecas ....................................... 77

2.5.1. Estudios sobre el impacto de las bibliotecas universitarias 
2.5.1.1. Estudios sobre el impacto económico de las bibliotecas universitarias ...84

2.5.2. Estudios sobre el impacto de las bibliotecas públicas.

2.5.2.1. Estudios sobre el impacto de la biblioteca pública en el marco conceptual del capital social. .98

2.5.2.2. Estudios sobre el impacto económico de las bibliotecas públicas... 104

2.5.3. Estudios sobre el impacto de las bibliotecas escolares 110

2.5.3.1. Estudios del impacto sobre los resultados académicos 111

2.5.3.2. Estudios del impacto sobre el proceso de aprendizaje y el desarrollo integral del alumnado 115

2.5.4. Estudios de impacto en bibliotecas especializadas 118

2.5.5. Estudios de impacto en bibliotecas nacionales

2.5.6. Estudios de impacto bibliotecario en España. 120

Conclusiones de la primera parte.

SEGUNDA PARTE. Desarrollo de la investigación sobre el impacto de la biblioteca escolar desde una doble perspectiva: la aproximación cuantitativa y cualitativa.

CAPÍTULO 3. La perspectiva cuantitativa: el análisis del impacto de las bibliotecas escolares a partir de los estudios PIRLS y PISA

3.1. Introducción.

3.2. Análisis en el ámbito de la educación primaria

3.2.1. Las bibliotecas en el estudio PIRLS 2016 131

3.2.2. Selección de variables para el análisis cuantitativo con los datos PIRLS 2016 135

3.2.2.1. Variable dependiente: rendimiento del alumnado en competencia lectora general y en cuatro dimensiones de esta competencia 135

3.2.2.2. Variable explicativa 1: el centro educativo dispone de biblioteca escolar (sí/no) $\quad 138$

3.2.2.3. Variable explicativa 2: intensidad con la que el alumnado hace uso de la biblioteca 139

3.2.2.4. Variable explicativa 3: el alumnado tiene acceso al préstamo de materiales bibliográficos impresos (sí/no) 140

3.2.2.5. Variable explicativa 4: el alumnado tiene acceso a libros electrónicos desde su centro educativo 141

3.2.2.6. Variable explicativa 5: tamaño de la colección 142

3.2.3. Hipótesis y procedimiento de análisis 143

3.2.4. Resultados. 145

3.2.4.1. Comprobación de la $\mathrm{H} 1$. El alumnado que dispone de una biblioteca integrada en su centro educativo obtiene mejores resultados académicos en 
competencia lectora, si se compara con el alumnado que no dispone de biblioteca escolar 145

3.2.4.2. Comprobación de la H2. El alumnado que más utiliza la biblioteca escolar obtiene mejores resultados académicos en competencia lectora, comparado con el alumnado que no tiene este hábito 151

3.2.4.3. Comprobación de la H3. El alumnado que tiene acceso a préstamo de materiales bibliográficos impresos en su escuela obtiene mejores resultados académicos en competencia lectora, comparado con el alumnado que no dispone de este recurso 157

3.2.4.4. Comprobación de la $\mathrm{H} 4$. El alumnado que tiene acceso a libros electrónicos en su escuela obtiene mejores resultados académicos en competencia lectora, comparado con el alumnado que no dispone de este recurso 163

3.2.4.5. Comprobación de la H5. El alumnado con acceso a colecciones bibliográficas amplias y de calidad demuestra mayor competencia lectora, comparado con el alumnado que carece de este recurso o que accede a una colección más precaria 169

3.3. Análisis en el ámbito de la educación secundaria

3.3.1. Las bibliotecas en el estudio PISA 2009 176

3.3.2. Selección de variables para el análisis cuantitativo con los datos PISA 2009 179

3.3.2.1. Variable dependiente: rendimiento del alumnado en competencia lectora general 179

3.3.2.2. Variable explicativa 1: el centro educativo tiene biblioteca escolar (sí/no) 180

3.3.2.3. Variable explicativa 2: intensidad con la que el alumnado hace uso de la biblioteca 181

3.3.2.4. Variable explicativa 3: frecuencia con la que el alumnado acude a la biblioteca para tomar en préstamo libros para leer por ocio 181

3.3.2.5. Variable explicativa 4: frecuencia con la que el alumnado acude a la biblioteca para tomar en préstamo libros para hacer trabajos de clase.

3.3.2.6. Variable explicativa 5: frecuencia con la que el alumnado acude a la biblioteca para realizar trabajos o investigaciones 183

3.3.2.7. Variable explicativa 6: frecuencia con la que el alumnado acude a la biblioteca para leer periódicos o revistas. 184

3.3.2.8. Variable explicativa 7: frecuencia con la que el alumnado acude a la biblioteca para leer por ocio. 185

3.3.2.9. Variable explicativa 8: frecuencia con la que el alumnado acude a la biblioteca para informarse sobre contenidos nuevos que no se explican en clase, como deportes, aficiones o música 
3.3.2.10. Variable explicativa 9: frecuencia con la que el alumnado acude a la biblioteca para usar Internet

3.3.2.11. Variable explicativa 10: actitud (positiva/negativa) del alumnado hacia las bibliotecas 188

3.3.3. Hipótesis y procedimiento de análisis 189

3.3.4. Resultados.

3.3.4.1. Comprobación de la $\mathrm{H} 1$. El alumnado que dispone de biblioteca integrada en su centro educativo obtiene mejores resultados académicos en competencia lectora, si se compara con el alumnado que no dispone de biblioteca escolar 191

3.3.4.2. Comprobación de la H2. El alumnado que más utiliza la biblioteca escolar obtiene mejores resultados académicos en competencia lectora, comparado con el alumnado que no tiene este hábito

3.3.4.3. Comprobación de la H3. El alumnado que acude a la biblioteca para tomar en préstamo libros para leer por ocio obtiene mejores resultados académicos en competencia lectora, si se compara con el alumnado que no tiene este hábito.

3.3.4.4. Comprobación de la H4. El alumnado que acude a la biblioteca para tomar en préstamo libros para hacer trabajos de clase obtiene mejores resultados académicos en competencia lectora, si se compara con el alumnado que no tiene este hábito. 194

3.3.4.5. Comprobación de la H5. El alumnado que acude a la biblioteca para realizar trabajos o investigaciones obtiene mejores resultados académicos en competencia lectora, si se compara con el alumnado que no tiene este hábito. 195

3.3.4.6. Comprobación de la H6. El alumnado que acude a la biblioteca para leer periódicos o revistas obtiene mejores resultados académicos en competencia lectora, si se compara con el alumnado que no tiene este hábito. 196

3.3.4.7. Comprobación de la H7. El alumnado que acude a la biblioteca para leer por ocio obtiene mejores resultados académicos en competencia lectora, si se compara con el alumnado que no tiene este hábito. 197

3.3.4.8. Comprobación de la H8. El alumnado que acude a la biblioteca para informarse sobre contenidos nuevos que no se explican en clase, como deportes, aficiones o música, obtiene mejores resultados académicos en competencia lectora, si se compara con el alumnado que no tiene este hábito. 198

3.3.4.9. Comprobación de la H9. El alumnado que acude a la biblioteca para usar Internet obtiene mejores resultados académicos en competencia lectora, si se compara con el alumnado que no tiene este hábito. 199

3.3.4.10. Comprobación de la $\mathrm{H} 10$. El alumnado que tiene una actitud más positiva hacia las bibliotecas obtiene mejores resultados académicos en competencia lectora, comparado con el alumnado que tiene una actitud menos positiva respecto de las bibliotecas 200

3.4. Conclusiones de la aproximación cuantitativa 
CAPÍTULO 4. La perspectiva cualitativa: el caso de la biblioteca escolar del CEIP "Virrey

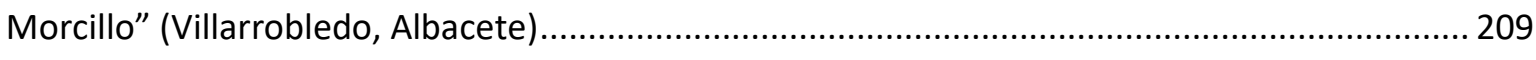

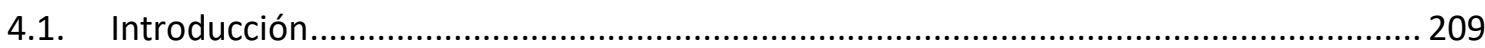

4.2. Primeros pasos de la investigación cualitativa ............................................................ 213

4.2.1. Elaboración de una muestra de centros educativos con biblioteca escolar 213

4.2.2. Toma de contacto y respuesta de los centros educativos.............................221

4.2.3. Selección y presentación del caso de estudio ...............................................226

4.2.3.1. El caso de estudio: la biblioteca del CEIP Virrey Morcillo (Villarrobledo, Albacete) $\quad 228$

4.2.3.1.1. El entorno del CEIP: el municipio de Villarrobledo y el Grupo Cooperativo Bibliotecas Escolares en Red (BERED) ..................................................228

4.2.3.1.2. El CEIP Virrey Morcillo .....................................................................230

4.2.3.1.3. La biblioteca del CEIP y el Plan de Lectura ..........................................231

4.3. Trabajo con los datos cualitativos

4.3.1. Estrategias y técnicas para la obtención de los datos y su análisis 235

4.3.1.1. Respuestas enviadas por el profesorado responsable de las bibliotecas del CEIP Condesa de Fenosa (O Barco de Valdeorras, Orense) y del CEIP Gerardo Diego (Los Corrales de Buelna, Cantabria) 242

4.3.1.2. Análisis de documentos oficiales de centros educativos integrados en el Grupo Cooperativo Bibliotecas Escolares en Red - BERED de la provincia de Albacete 244

4.3.1.3. Encuesta dirigida al profesorado que integra el Grupo Cooperativo Bibliotecas Escolares en Red - BERED de la provincia de Albacete 247

4.3.1.4. Análisis de documentos oficiales y noticias del blog del CEIP Virrey Morcillo 252

4.3.1.5. Entrevistas a la dirección del CEIP Virrey Morcillo y al coordinador de su biblioteca y del Grupo Cooperativo Bibliotecas Escolares en Red - BERED...................256

4.3.1.6. Grupo de discusión con profesorado del CEIP Virrey Morcillo ................259

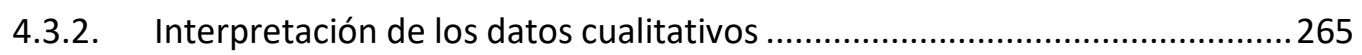

4.3.2.1. Influencia de la biblioteca sobre las habilidades y competencias individuales 267

4.3.2.1.1. Influencia sobre la competencia lectora del alumnado

4.3.2.1.2. Influencia de los distintos recursos, actividades o prácticas vinculadas a la biblioteca sobre el desarrollo de la competencia lectora del alumnado...... 268

4.3.2.1.3. Influencia sobre habilidades y competencias en el profesorado 271

4.3.2.2. Influencia de la biblioteca sobre cambios en actitudes y comportamiento individuales 272 
4.3.2.2.1. Influencia sobre actitudes y comportamientos del alumnado

4.3.2.2.2. Influencia sobre actitudes y comportamientos del profesorado

4.3.2.3. Influencia de la biblioteca sobre la formación académica a medio y largo plazo y sobre la carrera profesional del alumnado y del profesorado 275

4.3.2.4. Influencia de la biblioteca (en particular, la biblioteca como lugar) sobre el bienestar individual 275

4.3.2.5. Influencia de la biblioteca sobre la institución de la que depende y en su entorno social próximo 276 CONCLUSIONES..

Listado de legislación. 337

Anexos 


\section{INTRODUCCIÓN}

\section{Justificación del tema de investigación}

En el marco de la sociedad del conocimiento, se produce una convergencia entre las necesidades formativas de la sociedad y la dimensión educativa de las bibliotecas. Desde el ámbito educativo existe un doble interés: por un lado, se busca identificar y evaluar las competencias necesarias para las distintas etapas formativas hasta la educación superior; $y$, por otro lado, se persigue medir el impacto de los diferentes factores sobre el rendimiento académico del alumnado en las diferentes competencias curriculares.

La investigación educativa ha abordado el impacto de los distintos factores sociodemográficos y socioeconómicos sobre el rendimiento del alumnado, incluyendo el estatus socioeconómico y el nivel educativo de padre y madre, los recursos educativos y culturales del entorno familiar. Junto al entorno familiar del alumnado, el principal foco de interés se centra sobre el sistema educativo, y el impacto de su configuración y recursos, incluyendo los nuevos recursos digitales.

Entre los recursos del sistema educativo, el impacto de la biblioteca escolar no ha sido suficientemente abordado por la investigación educativa. No obstante, sí se ha demostrado la importancia de la lectura como competencia fundamental para el desarrollo del resto de competencias curriculares. En el contexto europeo, la estrategia de crecimiento Europa 2020 reconoce que la lectoescritura es la base para el aprendizaje y la puerta de acceso al empleo y la inclusión social, junto con el cálculo, la ciencia y la tecnología (Comisión Europea, 2012).

Desde el ámbito de la Biblioteconomía, tradicionalmente las bibliotecas han necesitado conocer su rendimiento y demostrar su valor para la sociedad. La evaluación bibliotecaria ha dado respuesta a esta necesidad, primero desde la evaluación del rendimiento con estadísticas e indicadores, y posteriormente desde la evaluación del impacto bibliotecario. La visión mecanicista de las primeras evaluaciones del rendimiento mediante inputs y outputs que daban cuenta de la eficiencia del sistema bibliotecario, dejó paso a una nueva concepción de la evaluación del rendimiento donde primaba la perspectiva del usuario, y donde se evaluaba su satisfacción respecto a los servicios bibliotecarios. Así pues, la visión inicial, mecanicista y exclusivamente cuantitativa, fue dejando paso a una visión valorativa que introducía la subjetividad del usuario. Sin abandonar el interés por la evaluación 
del rendimiento, los estudios más recientes de evaluación bibliotecaria han profundizado en esta visión valorativa abordando la evaluación del impacto.

Si bien se puede decir que en la evaluación bibliotecaria ha predominado la evaluación del rendimiento y la calidad de los servicios, en los últimos años ha crecido el interés por demostrar el impacto de las bibliotecas, proliferando los estudios en los que se presentan sus beneficios directos e indirectos sobre sus comunidades de usuarios y sobre el conjunto de la sociedad.

La mayor parte de los estudios sobre impacto hasta la fecha se han centrado en la dimensión socioeconómica de los sistemas bibliotecarios. En ellos se suele calcular el retorno a la inversión para demostrar la aportación de las bibliotecas a las economías locales y a la riqueza regional o nacional. Y una línea de investigación más reciente está explorando el impacto de la biblioteca como espacio público generador de capital social (Johnson, 2015). Entre las diferentes dimensiones del impacto bibliotecario identificadas en la literatura profesional (Huysmans y Oomes, 2013), la dimensión educativa, es decir, la contribución de la biblioteca a la adquisición y desarrollo de competencias y al aprendizaje, ha sido la menos explorada.

Existe abundante bibliografía sobre la contribución de la biblioteca universitaria en el ámbito de la educación superior y la investigación. Son estudios donde se evalúa su impacto sobre la productividad de la comunidad investigadora, sobre el rendimiento del alumnado y sobre el prestigio de la institución universitaria en su conjunto. $Y$ en una línea de investigación más reciente se está explorando la dimensión espacial (física y virtual) de la biblioteca universitaria y su repercusión sobre los procesos de aprendizaje.

Con relación a las bibliotecas escolares, su impacto en el ámbito de la educación primaria y secundaria no ha sido estudiado suficientemente, con la única excepción del contexto estadounidense. No se ha medido aún el efecto que puede tener sobre el sistema educativo el factor disponer de biblioteca escolar en los centros de enseñanza. Con esta investigación queremos contribuir a arrojar luz sobre esta cuestión abierta. En último término, nos interesa conocer hasta qué punto se puede establecer una relación entre construir un sistema bibliotecario desarrollado y mejorar los resultados del sistema educativo.

Si consideramos el ámbito geográfico, vemos que la mayoría de los estudios de evaluación bibliotecaria, y en particular de los estudios sobre impacto en bibliotecas escolares, se han realizado en países de cultura anglosajona. No existe un corpus suficientemente amplio de trabajos empíricos que nos permitan realizar estudios de evaluación comparativa, teniendo en cuenta la diversidad de sociedades con sistemas educativos distintos y con diferentes grados de desarrollo socioeconómico y cultural. Con esta investigación contribuimos a construir este necesario corpus de trabajos empíricos. 
Si observamos el caso de España, comprobamos que las bibliotecas escolares han quedado fuera de los estudios sobre impacto bibliotecario realizados en los últimos años (Gómez Yáñez, 2014; Hernández Sánchez, 2016; Luria Roig y Pintor González, 2013). No obstante, el interés por conocer los beneficios que puede reportar a la sociedad la inversión en un buen sistema de bibliotecas escolares es un tema que no pierde actualidad (Marzal García Quismondo, Colmenero Ruiz y Jorge García Reyes, 2016).

Desde las instituciones educativas españolas se ha impulsado la recopilación de datos estadísticos sobre bibliotecas escolares de forma regular. Muestra de ello es la inclusión de la serie de estadísticas sobre bibliotecas escolares en el Plan Estadístico Nacional ${ }^{1}$, en cuya elaboración participan el Estado y las comunidades autónomas. Si bien contamos con datos estadísticos actualizados sobre la configuración y funcionamiento de las bibliotecas escolares españolas, el estudio de su impacto sobre el sistema educativo español es una cuestión pendiente.

En esta investigación se aplican al contexto educativo español elementos metodológicos y conceptuales recogidos en la normativa internacional bibliotecaria, en particular en la norma ISO 16439 (Organización Internacional de Normalización, 2014b) sobre evaluación del impacto, con vistas a su consolidación y para posibilitar la elaboración de futuros estudios comparativos.

Esta tesis se enmarca en el estudio de la evaluación bibliotecaria, y profundiza sobre la línea de investigación abierta en torno a la evaluación del impacto de las bibliotecas, en particular el impacto educativo. La evaluación bibliotecaria ha evolucionado como materia de estudio de la Biblioteconomía de la mano de los proyectos internacionales de normalización impulsados desde la Organización Internacional de Normalización (ISO) a través de su Subcomité 8 de Evaluación Bibliotecaria. La publicación del corpus de estándares internacionales sobre evaluación bibliotecaria ha contribuido a la consolidación terminológica, conceptual y metodológica de esta materia, y ha sido clave para su avance teórico y práctico.

La norma ISO 16439 ha sintetizado el conocimiento teórico y práctico en torno a la evaluación del impacto bibliotecario, y actualmente proporciona el marco teórico y conceptual más completo en esta materia. Además, es una compilación exhaustiva de las distintas opciones metodológicas que se ofrecen al investigador, y reúne las técnicas tanto cuantitativas como cualitativas válidas para la realización de evaluaciones del impacto. A este respecto, hay que añadir que la visión metodológica

\footnotetext{
${ }^{1}$ La estadística de bibliotecas escolares se recoge en el Plan Estadístico Nacional de los años 20132016 y en el Plan de los años 2017-2020. En su elaboración intervienen el ministerio y las consejerías o departamentos con competencias en educación de todas las comunidades autónomas http://www.ine.es/ss/Satellite?L=es_ES\&c=INEPlanEst_C\&p=1254735995577\&pagename=INE\%2FINELa yout \&_charset_=utf-8\&cid=1259935317768\&submit=Ir
} 
predominante en las evaluaciones del impacto en bibliotecas escolares ha sido cuantitativa. En nuestra investigación decidimos complementar la perspectiva cuantitativa con una visión naturalista, acorde con una comprensión global y multidimensional de la realidad socioeducativa.

Por todo ello, esta investigación se construye tomando la norma ISO 16439 como referente vertebrador, tanto para su marco conceptual como para su soporte metodológico.

Resumiendo todo lo dicho en los párrafos anteriores, dedicamos esta tesis al estudio del impacto de la biblioteca escolar en el contexto educativo español. Por tratarse de un campo de estudio no suficientemente explorado, consideramos que este trabajo es una contribución de interés para el estudio de la evaluación bibliotecaria.

Asimismo, al trabajar con la norma ISO 16439 contribuimos a la validación y consolidación del texto normativo y de sus propuestas conceptuales y metodológicas mediante su aplicación a casos concretos.

Por último, ya se ha mencionado la necesidad de realizar investigación que arroje luz sobre el valor de las bibliotecas. En el contexto educativo de nuestro país es una cuestión pendiente. Nuestra tesis propone un enfoque metodológico en el que se integra una doble visión cualitativa y cuantitativa para evaluar el impacto de la biblioteca escolar en tanto que recurso funcional de nuestro sistema educativo, para evaluar su valor en el ámbito de la formación y en la adquisición de competencias necesarias para la sociedad del conocimiento.

\section{Objetivos generales y específicos}

La finalidad de esta tesis es profundizar sobre la dimensión educativa del impacto bibliotecario. Hemos tomado el concepto de impacto bibliotecario de la norma ISO 16439 (Organización Internacional de Normalización, 2014b), donde se define como: "la transformación o cambio que se produce en un individuo o en un grupo como resultado del contacto con servicios bibliotecarios. El cambio puede ser tangible o intangible" $e^{2 \prime}($ p. 4).

El objetivo general es arrojar luz sobre la contribución de las bibliotecas escolares al sistema educativo. Para ello hemos centrado el objeto de estudio sobre la evaluación

\footnotetext{
2 Traducido del original: "3.25 impact: difference or change in an individual or group resulting from the contact with library services. The change can be tangible or intangible" (Organización Internacional de Normalización, 2014b, p. 4).
} 
del impacto de las bibliotecas escolares españolas, empleando datos cuantitativos del conjunto de España y datos cualitativos extraídos de un estudio de caso.

A partir de este objetivo general, nos hemos planteado como objetivos específicos analizar la contribución de la biblioteca escolar en cada uno de los tres niveles de impacto que se establecen en la mencionada norma internacional: 1) impacto sobre los individuos, 2) impacto sobre la comunidad o institución de la que depende la biblioteca y 3 ) impacto sobre el conjunto de la sociedad ${ }^{3}$ (Organización Internacional de Normalización, 2014b, pp. 14-17). Se explican a continuación los tres objetivos específicos:

1) Analizar el impacto de la biblioteca escolar sobre los individuos:

a) Identificar $y$ analizar cambios en habilidades y competencias que se producen como resultado o guardan relación con el uso de la biblioteca escolar

En primer lugar, queremos evaluar la contribución de la biblioteca escolar al rendimiento del alumnado en competencias básicas, y en particular sobre la adquisición y desarrollo de la competencia lectora en cuatro dimensiones: 1) comprensión de textos literarios; 2) comprensión de textos informativos; 3 ) competencia en obtención de información y realización de inferencias directas; y 4) competencia en interpretación, integración y evaluación de la información.

En segundo lugar, nos interesa analizar cómo influyen los distintos recursos de la biblioteca escolar sobre el rendimiento del alumnado en competencia lectora, incluyendo los recursos tradicionales, los nuevos recursos digitales, y las distintas actividades programadas por la biblioteca.

$\mathrm{Y}$, en tercer lugar, nos interesa conocer si la biblioteca escolar influye sobre las habilidades y competencias en el profesorado.

b) Identificar $y$ analizar cambios en actitudes y comportamiento que se producen como resultado o guardan relación con el uso de la biblioteca escolar: nos interesa conocer si se produce alguna transformación en la actitud general del alumnado respecto a su propio proceso formativo y de aprendizaje.

c) Identificar y analizar la contribución de la biblioteca escolar a los resultados académicos, la investigación y la carrera profesional de alumnado $y$ profesorado: nos interesa conocer si la biblioteca escolar ayuda a mejorar sus oportunidades académicas, profesionales y laborales en el medio y largo plazo, e identificar posibles beneficios sobre la promoción profesional del

\footnotetext{
${ }^{3}$ Hemos dejado fuera de esta tesis el estudio del impacto económico, debido a su especificidad metodológica descrita en la norma ISO 16439 (Organización Internacional de Normalización, 2014b, pp.57-64).
} 
profesorado y sobre la empleabilidad, y el acceso a estudios superiores del alumnado.

d) Identificar $y$ analizar la contribución de la biblioteca escolar al bienestar individual en el ámbito educativo: queremos conocer cómo interiorizan el alumnado y el profesorado el espacio físico de la biblioteca, su percepción del bienestar que puede proporcionar este espacio en la vida cotidiana.

2) Analizar el impacto de la biblioteca escolar sobre la institución de la que depende la biblioteca, buscamos evidencias sobre la contribución de la biblioteca escolar, como recurso del sistema educativo ${ }^{4}$, a los fines específicos de los centros educativos.

3) Analizar el impacto de la biblioteca escolar sobre la sociedad, queremos conocer si la biblioteca ayuda a fomentar determinados valores sociales en la escuela. Asimismo, queremos conocer cómo contribuye la biblioteca a la mejora de su entorno social próximo.

Una vez establecidos el objetivo general y los objetivos específicos, se han formulado las preguntas de investigación vinculadas a cada uno de los objetivos. En la Tabla 1 se recogen las preguntas de investigación de esta tesis, agrupadas para cada uno de los tres niveles de impacto mencionados en la norma ISO 16439.

Hay que decir que, para la formulación de las preguntas de investigación se han tenido en cuenta las recomendaciones que hace la norma internacional respecto al tipo de cuestiones que deben abordarse en los estudios de impacto que se realizan en el ámbito académico (Organización Internacional de Normalización, 2014b, p.36). Entre otros aspectos, la norma recomienda preguntar por la adquisición de nuevos conocimientos y habilidades; por la percepción de la biblioteca como espacio para el estudio, el aprendizaje y la socialización; la contribución de la biblioteca en el reclutamiento y retención de estudiantes, en sus resultados académicos, así como su impacto sobre la calidad de la enseñanza y la reputación de los centros educativos.

Por último, diremos que, en la formulación de los objetivos y preguntas de investigación, hemos contemplado las diferentes dimensiones del impacto

\footnotetext{
${ }^{4}$ En la legislación educativa española, las bibliotecas escolares se constituyen como recursos del sistema educativo para el desarrollo de las competencias curriculares, principalmente de las competencias lingüística y digital, tal y como se observa en el Real Decreto 126/2014, de 28 de febrero, por el que se establece el currículo básico de la educación primaria y en el Real Decreto 1105/2014, de 26 de diciembre, por el que se establece el currículo básico de la educación secundaria obligatoria y del bachillerato. Además, la Ley Orgánica de Educación de 2006, en su artículo 113, les otorgó un papel activo en el desarrollo de los planes lectores de los centros y como recurso fundamental para el acceso a la información.
} 
establecidas en la norma, tal y como resumimos a continuación (Organización Internacional de Normalización, 2014b, pp.13-14):

- Dimensión temporal. Se ha contemplado el impacto inmediato, como, por ejemplo, la adquisición de competencias informacionales. También se ha contemplado el impacto a largo plazo, como, por ejemplo, el beneficio sobre la empleabilidad del alumnado y del profesorado. Dada la limitación temporal de esta tesis, hemos asumido la complejidad de encontrar evidencias del impacto a largo plazo.

- Alcance. Se ha contemplado tanto el impacto de alcance limitado (sobre una persona o un grupo restringido), como el impacto de amplio alcance.

- Intencionalidad. Se ha incluido tanto el impacto intencionado (cuando es planificado por la biblioteca y responde a programas bibliotecarios específicos) como el impacto no intencionado (cuando surge como resultado de la experiencia del usuario).

- Potencialidad. Se han incluido tanto evidencias de impactos reales como impactos potenciales sobre los usuarios y sobre la colectividad. Hemos asumido que, al analizar los impactos potenciales, se introduce un mayor nivel de subjetividad y de provisionalidad a la hora de establecer conclusiones. 
Tabla 1. Preguntas de investigación agrupadas para cada uno de los tres niveles de impacto mencionados en la norma ISO 16439

\begin{tabular}{|c|c|}
\hline $\begin{array}{l}\text { Niveles de impacto (según la } \\
\text { norma ISO 16439) }\end{array}$ & Preguntas de investigación \\
\hline \multicolumn{2}{|l|}{ 1. Impacto sobre los individuos } \\
\hline $\begin{array}{l}\text { a) cambios en habilidades y } \\
\text { competencias }\end{array}$ & $\begin{array}{l}\text { 1. ¿Tiene alguna influencia el hecho de tener biblioteca en el centro } \\
\text { educativo sobre el rendimiento académico en competencia lectora? Y } \\
\text { en caso afirmativo, ¿sobre qué dimensiones competenciales se } \\
\text { observa este impacto? } \\
\text { - comprender e interpretar textos literarios e informativos } \\
\text { - ser competentes en obtener e inferir información a partir de la } \\
\text { lectura } \\
\text { información obtenida en el entorno papel y en el entorno digital y } \\
\text { con los distintos tipos de material y soportes bibliográficos } \\
\text { 2. ¿Cómo influyen los distintos recursos, actividades o prácticas } \\
\text { vinculadas a la biblioteca sobre el desarrollo de la competencia } \\
\text { lectora? } \\
\text { 3. ¿En qué medida se producen cambios en habilidades y competencias } \\
\text { en el profesorado? }\end{array}$ \\
\hline $\begin{array}{l}\text { b) cambios en actitudes y } \\
\text { comportamiento }\end{array}$ & $\begin{array}{l}\text { 4. ¿En qué medida frecuentar la biblioteca escolar produce cambios en } \\
\text { actitudes y comportamientos en el alumnado? } \\
\text { 5. ¿En qué medida frecuentar la biblioteca escolar produce cambios en } \\
\text { actitudes y comportamientos en el profesorado? }\end{array}$ \\
\hline $\begin{array}{l}\text { c) mejores resultados en los } \\
\text { estudios, la investigación } \\
\text { y la carrera profesional }\end{array}$ & $\begin{array}{l}\text { 6. ¿Contribuye la biblioteca escolar a mejorar el rendimiento académico } \\
\text { del alumnado a medio y largo plazo? } \\
\text { 7. ¿Contribuye la biblioteca escolar a mejorar el rendimiento y la carrera } \\
\text { profesional del profesorado a medio y largo plazo? }\end{array}$ \\
\hline 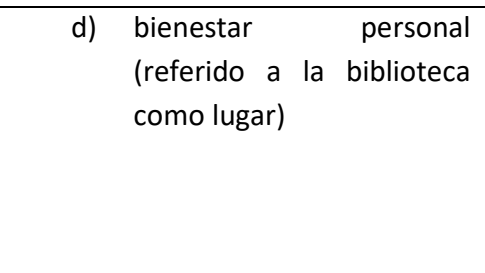 & $\begin{array}{l}\text { 8. ¿Qué beneficios reporta la biblioteca escolar como lugar físico? } \\
\text { - ¿cómo es percibido este espacio físico por el alumnado? } \\
\text { - ¿cómo es percibido el espacio físico por el profesorado? }\end{array}$ \\
\hline
\end{tabular}




\begin{tabular}{|l|l|}
\hline \multicolumn{2}{|c|}{ 2. Impacto sobre el centro educativo del que depende la biblioteca } \\
\hline & $\begin{array}{l}\text { 9. ¿Contribuye la biblioteca a los fines del centro educativo? Y, en caso } \\
\text { afirmativo, ¿sobre qué aspectos se observa esta contribución? }\end{array}$ \\
\hline 3. Impacto sobre la sociedad & $\begin{array}{l}\text { 10. ¿Contribuye la biblioteca a fomentar determinados valores sociales en } \\
\text { la escuela? } \\
\text { 11. ¿Contribuye la biblioteca a mejorar el entorno social en el que se ubica } \\
\text { el centro educativo? }\end{array}$ \\
\hline
\end{tabular}

\section{Metodología}

Partiendo de nuestros objetivos y una vez formuladas las preguntas de investigación, explicamos en este apartado el abordaje metodológico.

En esta tesis hemos optado por la integración de métodos, siguiendo la tradición de aquellos autores que abogan por la superación de la antigua disyuntiva entre los dos grandes paradigmas de investigación cuantitativo y cualitativo, y por la adopción de ambas perspectivas para una mejor comprensión de los fenómenos sociales (Álvarez Méndez, 1986; Alvira Martín, 1983; Anguera Argilaga, 1986; Bericat, 1998; Bryman, 1984; Cook y Reichardt, 1986; De Miguel, 1988; Frías y Borrego, 2004; Greene, Caracelli y Graham, 1989; Sandín Esteban, 2010). Así, siguiendo a Cook y Reichardt (1986) en su redefinición del debate entre cuantitativistas y cualitativistas, aceptamos que:

la elección de métodos no debe hallarse determinada por la adhesión a un paradigma arbitrario. $\mathrm{Y}$ ello es así tanto porque un paradigma no se halla inherentemente ligado a una serie de métodos, como por las características del entorno específico de la investigación cobran la misma importancia que los atributos de un paradigma a la hora de escoger un método (...) un investigador no tiene por qué adherirse ciegamente a uno de los paradigmas polarizados que han recibido las denominaciones de "cualitativo" y "cuantitativo", sino que puede elegir libremente una mezcla de atributos de ambos paradigmas para atender mejor a las exigencias del problema de la investigación con que se 
enfrenta. Parece entonces que no existe tampoco razón para elegir entre métodos cualitativos y cuantitativos. Los evaluadores obrarán sabiamente si emplean cualesquiera métodos que resulten más adecuados a las necesidades de su investigación, sin atender a las afiliaciones tradicionales de los métodos. En el caso de que ello exija una combinación de métodos cualitativos y cuantitativos, hágase así pues (p. 41).

Del mismo modo, siguiendo a Sabariego Puig (2016), asumimos que "actualmente, en el plano técnico y procedimental de la investigación educativa está ampliamente aceptada una actitud integradora, con la posibilidad de utilizar diseños multimétodo ante una realidad que se presenta compleja, dinámica y plantea problemas difíciles de resolver" (pp. 76-77).

En el abordaje metodológico de esta tesis hemos asimilado el contenido de la norma ISO 16439, que dedica un capítulo a la integración de métodos en la evaluación del impacto en bibliotecas (Organización Internacional de Normalización, 2014b, pp.53-57). De acuerdo con la norma, hemos sopesado las ventajas e inconvenientes que presenta esta opción metodológica y que planteamos a continuación.

Como principales ventajas, hemos considerado las siguientes:

- Usar diferentes métodos ayuda a corroborar resultados: hemos partido de un objeto de estudio multidimensional, y consideramos que la integración de métodos aporta confianza a las conclusiones de la investigación.

- Emplear datos de fuentes diferentes contribuye a contextualizar y a comprender mejor los resultados.

- La información cualitativa aporta matices y enriquece la información que aportan los datos cuantitativos. Asumimos que nuestro conocimiento de la realidad es parcial, y que nuestra comprensión se construye a partir de múltiples datos e informaciones de naturaleza cuantitativa y cualitativa. Consideramos que la integración de métodos es necesaria para poder aprehender e interpretar esa realidad en su complejidad 5 .

En cuanto a las desventajas que según la norma se pueden producir al utilizar varios métodos, hemos valorado lo siguiente (Organización Internacional de Normalización, 2014b, p. 57):

\footnotetext{
${ }^{5}$ Según Tójar Hurtado (2006), el conocimiento reúne una serie de atributos, entre los cuales, es "Contextual: el conocimiento se construye sobre y para un espacio único (...). Multimetódico: el conocimiento se construye por multitud de procedimientos (...). Holístico: el conocimiento debe ser global más que analítico" (pp. 148-150).
} 
- En la norma se advierte que los conjuntos de datos pueden no ser compatibles. No obstante, en nuestra investigación no se produce este problema. Hemos analizado por separado los conjuntos de datos cuantitativos y los datos cualitativos. Las muestras proceden del universo del alumnado español de educación primaria y secundaria. Los conjuntos de datos cuantitativos proceden de fuentes externas y la información cualitativa procede de un estudio de caso elaborado en el transcurso de la investigación. No se produce incompatibilidad, más bien se complementan los conjuntos de datos utilizados.

- En la norma se advierte que el análisis de los datos puede arrojar evidencias de correlación, pero no necesariamente de causalidad. En este punto asumimos como principio básico de la investigación cuantitativa que, como señala Morales Vallejo (2008, p. 131), de una correlación significativa entre variables no debe deducirse una explicación causal. Por tanto, consideramos que no cabe pensar que se produce desventaja alguna, ya que en nuestra investigación hemos buscado la comprensión y la interpretación de los fenómenos en su complejidad, y no tanto causas.

- En la norma se dice que, para llevar a cabo una investigación empleando varios métodos, se precisa de una formación específica en análisis de datos. En efecto, para el análisis de los datos ha sido necesario adquirir formación en análisis estadístico de datos cuantitativos, en análisis de datos cualitativos, y en herramientas específicas como SPSS, IEA IDB Analyzer y ATLAS.ti.

- Otro aspecto sobre el que advierte la norma es que puede ser necesario trabajar con grupos de control. No obstante, nuestra investigación no lo ha precisado pues no se ha basado en el diseño de estudios experimentales.

- La norma avisa de que puede ser necesaria la colaboración de otros agentes para obtener datos. En efecto, distintos agentes del ámbito educativo han proporcionado la información cualitativa necesaria para la investigación. La aplicación de metodologías de tipo cualitativo implica siempre una mayor inversión de tiempo en el diseño de la investigación y en la elaboración del trabajo de campo.

- Por último, la norma indica que se suelen requerir ciertos permisos cuando se recaban datos sobre el uso de la biblioteca. En efecto, se han respetado los protocolos éticos necesarios para la realización del estudio cualitativo. Hay que decir que el cumplimiento de estos protocolos es un requerimiento fundamental de cualquier investigación cualitativa. Al igual que en el punto anterior, entendemos que esto no supone una desventaja, aunque signifique una mayor inversión de tiempo en la investigación.

Una vez valoradas las ventajas y desventajas de emplear la integración de métodos a la luz de la norma internacional, nos hemos basado en los postulados de Bryman 
(1984, tomado de Bericat, 1998, pp. 117-142) para acabar de justificar la idoneidad de aplicar esta opción metodológica en esta tesis:

- La integración de métodos contribuye a dar consistencia y robustez a los resultados de la investigación: en nuestra investigación hemos realizado una primera aproximación de corte cuantitativo, para la cual empleamos conjuntos de datos tomados de fuentes externas. El trabajo con datos procedentes de fuentes externas suele plantear limitaciones al investigador, cuando se necesitan determinadas informaciones que no se pueden obtener a partir de estos datos. Para tratar de superar esta limitación, hemos realizado una segunda aproximación cualitativa con la que cubrir las lagunas informativas que han quedado después de explotar los datos cuantitativos de fuentes externas.

- Las dos perspectivas metodológicas se retroalimentan: con la primera aproximación cuantitativa hemos alcanzado un conocimiento general del problema y hemos obtenido las primeras evidencias. Sobre esta primera aproximación hemos incorporado una investigación cualitativa para profundizar y comprender mejor esos primeros resultados. La investigación cualitativa ayuda a interpretar las relaciones que se producen entre las variables cuantitativas.

- Las dos perspectivas se complementan para producir una imagen de conjunto: de esta manera se supera la aparente rigidez de los resultados cuantitativos a la hora de explicar los procesos complejos que se producen en el ámbito educativo. La visión cualitativa complementa el conocimiento parcial y provisional que arroja la primera visión cuantitativa. Hemos sorteado así la limitación que supone utilizar la significación estadística como único criterio de validez para la validación de hipótesis ${ }^{6}$.

- La investigación cuantitativa es adecuada para captar estructuras y la cualitativa es adecuada para captar procesos de la realidad social: en nuestro caso, el análisis estadístico ha apuntado a una serie de indicios sobre el impacto - en términos de rendimiento académico - que las bibliotecas escolares producen sobre el alumnado. La información cualitativa ha venido a mostrar las distintas dimensiones de este impacto - más allá del rendimiento académico - sobre los procesos de aprendizaje del alumnado. Se ha obtenido así una visión multidimensional del problema.

- La integración de métodos permite conocer los fenómenos desde una doble perspectiva, desde fuera y desde dentro del contexto educativo. Con el abordaje cualitativo se ha introducido la perspectiva subjetiva de los agentes receptores del impacto de las bibliotecas.

${ }^{6}$ En esta misma línea, Vilà Baños y Bisquerra Alzina (2016, p. 261) recomiendan realizar un análisis de significación en dos niveles, complementando la significación estadística con un segundo nivel de significación sustantiva que se debe obtener mediante métodos cualitativos. 
- La integración de métodos ayuda a resolver el llamado "problema de la generalización", es decir, la dificultad de generalizar a partir de una investigación cualitativa cuando ésta se elabora con una muestra pequeña. En nuestro caso, el empleo de los dos métodos nos ha ayudado a distinguir entre los resultados más atípicos y los más generalizables.

- La integración de métodos permite establecer relaciones ente los niveles macro y micro de un mismo problema: en nuestro trabajo, la investigación cualitativa nos ha ayudado a contextualizar y a humanizar con casos concretos los resultados estadísticos que se obtuvieron a partir de las muestras representativas de la población de alumnado en España.

- Los métodos se integran en las distintas fases del proceso de investigación: en una primera fase hemos planteado una aproximación cuantitativa para obtener una primera visión del problema y para explorar las posibilidades explicativas del análisis estadístico de datos. Posteriormente, según se ha avanzado en la investigación, se ha procedido a una segunda fase con contenidos cualitativos, donde se han verificado y complementado las conclusiones obtenidas en la primera fase, para responder de una forma más matizada a las preguntas de investigación.

Concluimos por tanto que, lejos de ser visiones excluyentes, ambas perspectivas cuantitativa y cualitativa aportan información relevante para nuestra investigación. Por ello, hemos decidido utilizar más de un método aprovechando las principales ventajas de cada uno de ellos.

Entre las posibilidades que se plantean en la integración de métodos, Bericat (1998) distingue tres estrategias ${ }^{7}$, según el grado de integración: la complementación, la

\footnotetext{
${ }^{7}$ Bericat (1998) propone tres estrategias distintas de integración metodológica: complementación triangulación y combinación:

Existe COMPLEMENTACIÓN cuando, en el marco de un mismo estudio, se obtienen dos imágenes, una procedente de métodos de orientación cualitativa y otra de métodos de orientación cuantitativa. Así, obteniendo esta doble y diferenciada visión de los hechos completamos nuestro conocimiento sobre los mismos (...) En la complementación el grado de integración metodológica es mínimo, y su legitimidad se soporta sobre la creencia de que cada orientación es capaz de revelar diferentes e interesantes zonas de la realidad social, así como que es necesario contar con esta doble visión para un mejor entendimiento del fenómeno (...).

En la estrategia de convergencia, o TRIANGULACIÓN, el motivo es bien diferente. No se trata de completar nuestra visión de la realidad con dos miradas sino de utilizar ambas orientaciones para el reconocimiento de un mismo e idéntico aspecto de la realidad social. En esta estrategia, por tanto, se pretende un solapamiento o convergencia de los resultados. Los métodos son implementados de forma independiente, pero se enfocan hacia una misma parcela de la realidad, parcela que quiere ser observada o medida con dos instrumentos diferentes (...)

La estrategia de la COMBINACIÓN (...) se trata de integrar subsidiariamente un método, sea el cualitativo o en cuantitativo, en el otro método, con el objeto de fortalecer la validez de este
} 
triangulación y la combinación. En nuestra investigación hemos optado por una estrategia de complementación, que supone un nivel mínimo de integración ${ }^{8}$ en los métodos empleados, y que consiste en aplicar dos visiones, una con métodos de orientación cuantitativa y otra con métodos de orientación cualitativa, para obtener dos imágenes complementarias del mismo fenómeno.

Hay que decir que los métodos utilizados tienen el mismo nivel de importancia en nuestra investigación. Se complementan en cuanto al nivel de información que arrojan, y no se da una subordinación de uno respecto del otro.

Con relación a su implementación dentro de esta tesis, como se verá en los próximos capítulos, hemos introducido las dos aproximaciones metodológicas en dos fases consecutivas: una primera fase de análisis cuantitativo seguida de una segunda fase cualitativa que trata de aportar luz sobre las zonas que han quedado en sombra en la primera fase, como se expone a continuación.

\section{Aproximación cuantitativa}

En primer lugar, hemos abordado el problema de investigación con un enfoque metodológico cuantitativo. Para ello se han utilizado conjuntos de datos tomados de fuentes externas: los datos arrojados por los estudios internacionales PIRLS 2016 (para educación primaria) y PISA 2009 (para educación secundaria) ${ }^{9}$.

En la decisión de usar estos conjuntos de datos hemos valorado la ventaja de trabajar con muestras grandes y representativas elaboradas con garantías metodológicas. Además, al proceder de evaluaciones internacionales que se repiten periódicamente, se abre la posibilidad de replicar los análisis con vistas a realizar comparaciones entre países y épocas distintas. Por otra parte, se han tenido en cuenta las limitaciones de trabajar con datos tomados de fuentes externas. Los conjuntos de

último compensando sus propias debilidades mediante la incorporación de informaciones que proceden de la aplicación del otro método a tenor de sus fortalezas metodológicas. Por tanto, en la estrategia de combinación se busca, no la convergencia de resultados, que finalmente procederán de un solo método, sino de una adecuada combinación metodológica (pp. 37-38).

${ }^{8}$ Las dos aproximaciones presentadas en esta tesis se complementan mutuamente, aportando información sobre el mismo objeto de estudio. No obstante, se pueden publicar como estudios independientes.

9 El estudio PIRLS (acrónimo de Progress in International Reading Literacy Study) de la IEA (Asociación Internacional para la Evaluación del Rendimiento Educativo), evalúa cada cinco años el rendimiento en competencia lectora del alumnado de cuarto curso de educación primaria en cerca de cincuenta países, entre ellos, España. El cuarto curso de educación primaria corresponde a los nueve años de edad en España. El estudio PISA (acrónimo de Programme for International Student Assessment) de la OCDE evalúa cada tres años el rendimiento educativo en competencias clave del alumnado de quince años a nivel internacional. En su edición de 2009 evaluó el rendimiento en competencia lectora. En ambos estudios se puede obtener información sobre las bibliotecas escolares. 
datos utilizados no arrojan toda la información que sería necesaria para responder a todas las preguntas de nuestra investigación, por lo que hemos asumido que quedarían algunas cuestiones sin responder después de esta primera aproximación.

Utilizando los conjuntos de datos, se ha realizado un análisis estadístico con contraste de hipótesis, tratando de hallar evidencias o indicios de la contribución de las bibliotecas escolares al rendimiento del alumnado.

Como variable dependiente del análisis se ha tomado la puntuación en competencia lectora en sendas muestras de alumnado español de educación primaria y secundaria. Se han definido distintas variables explicativas, todas ellas relacionadas con el factor biblioteca escolar. El análisis estadístico ha consistido en comparar los resultados medios en competencia lectora de dos grupos: por un lado, el alumnado que dispone de biblioteca escolar y de diferentes recursos bibliotecarios, y hace uso de ellos; y, por otro lado, el alumnado que carece de biblioteca escolar o de determinados recursos bibliotecarios, o que, aun teniéndolos no hace uso de ellos.

Se ha establecido un nivel mínimo de significación estadística. Hemos trabajado con el nivel de confianza del $95 \%$ y el nivel de significación $p=0,05$. Para la explotación de los datos se han empleado los siguientes programas especializados de análisis estadístico: International Database Analyzer (Versión 4.0) de la IEA, e IBM SPSS Statistics for Windows (Versión 22.0)

Con el análisis estadístico se han obtenido unas primeras evidencias sobre el impacto de la biblioteca escolar sobre el rendimiento del alumnado, correspondiendo a las preguntas de investigación 1 y 2 (véase la Tabla 1). No obstante, este enfoque no ha podido dar respuesta a las preguntas de investigación 3 a 11, por carecer de los datos necesarios. Por ello se ha complementado esta primera aproximación con una segunda aproximación de corte cualitativo.

\section{Aproximación cualitativa}

Siguiendo a Tójar Hurtado (2006, p. 155), entendemos que los fenómenos objeto de nuestra investigación tienen una naturaleza dinámica, poliédrica y holística, de manera que se ha precisado de una segunda aproximación naturalista para su comprensión e interpretación. Para ello hemos utilizado datos cualitativos obtenidos como resultado de nuestro trabajo de campo ${ }^{10}$.

Como sostienen Cook y Reichardt (1986, p. 29), la visión cualitativa permite introducir la subjetividad del sujeto investigador, obtener una visión holística e integral de la realidad, obtener una perspectiva desde dentro de los fenómenos,

${ }^{10}$ El trabajo con datos obtenidos por nosotros mismos nos permite un mayor control sobre su producción, alcance y significado, aunque no nos asegura por sí mismo que obtengamos suficiente información para poder responder a todas las preguntas formuladas. 
aplicar una observación naturalista, atender a procesos y realidades dinámicas, y comprender la conducta humana desde el propio marco de referencia de quien actúa. Según reza la norma ISO 16439:

Los métodos cualitativos aportan textura y significado a los datos cuantitativos y ayudan a identificar los impactos de la biblioteca. Utilizadas conjuntamente, son herramientas potentes para el análisis y la comprensión de la interacción del usuario con la biblioteca (Organización Internacional de Normalización, 2014b, p.54) $)^{11}$.

Con esta segunda aproximación de tipo naturalista, se ha procurado comprender e interpretar los fenómenos en su complejidad, obteniendo la información desde dentro del contexto educativo donde se produce el impacto bibliotecario, e introduciendo la voz de los sujetos que reciben directa e indirectamente ese impacto. La perspectiva ha sido indagar sobre el efecto de las bibliotecas escolares en tanto que impacto percibido por los docentes.

Para la obtención de la información cualitativa se ha recurrido a un estudio de caso centrado en el Colegio de Educación Infantil y Primaria (CEIP) Virrey Morcillo (Villarrobledo, Albacete), perteneciente a la red cooperativa de bibliotecas escolares $B E R E D$ de la provincia de Albacete. El caso escogido responde a los criterios de representatividad e intensidad informativa, habiéndose comprobado la fuerte presencia de la biblioteca escolar en las dinámicas educativas y su trayectoria consolidada de trabajo con buenas prácticas bibliotecarias y planes de lectura.

El caso de estudio se ha seleccionado a partir de una muestra de centros educativos españoles con biblioteca escolar, para cuya elaboración se ha seguido la lógica del muestreo cualitativo (Flick, 2014), procurando la objetividad del procedimiento de muestreo con el fin de garantizar la representatividad tanto de la muestra como de los datos resultantes.

Una vez seleccionado en caso, para la obtención de datos se han empleado dos tipos de técnicas:

a) Técnicas de obtención de evidencias solicitadas (se ha preguntado a distintos agentes del ámbito educativo sobre su experiencia respecto a la biblioteca): entrevistas individuales, grupo de discusión con docentes del centro educativo, encuesta a los docentes de la red cooperativa de bibliotecas. Aplicando estas técnicas, se ha conseguido una doble ventaja. Por un lado, extraer la información desde dentro del contexto natural donde se produce el impacto, y,

11 [Traducido del original: "Qualitative methods add texture and meaning to the quantitative data and help identify library impacts. Together, they offer the potential of powerful tools for analysis and understanding of user interaction with the library"]. 
por otro lado, escuchar la voz subjetiva de quienes lo perciben, para una comprensión en profundidad de los motivos y las circunstancias en las que se produce ese impacto.

b) Análisis de documentos oficiales del CEIP Virrey Morcillo y de otros centros educativos de la red cooperativa de bibliotecas, en busca de evidencias que guardaran relación con las preguntas de investigación de esta tesis.

En el desarrollo del trabajo de campo, nuestra posición como investigadora ha mantenido un equilibrio entre las posiciones emic y etic (Tójar Hurtado, 2006, p. 156). En parte se han compartido las valoraciones de los participantes (perspectiva emic), y en parte se ha mantenido una posición reflexiva y distante respecto de estas valoraciones (perspectiva etic), respetando en todo caso las consideraciones éticas que comporta toda investigación cualitativa.

En el análisis de los datos obtenidos se ha seguido un procedimiento en fases consecutivas (Massot Lafon, Dorio Alcaraz y Sabariego Puig, 2016, pp. 350-352; Simons, 2011, pp. 168-172; Tójar Hurtado, 2006, pp. 287-323):

1) Fase 1. Reducción de la información mediante la separación de las unidades de contenido relevante: subrayado de los fragmentos de los materiales cualitativos que son relevantes para responder a las preguntas de investigación.

2) Fase 2. Categorización de las unidades de contenido: etiquetado de los fragmentos seleccionados según los temas clave de la investigación.

3) Fase 3. Síntesis y verificación de los contenidos: comprobación de los términos, expresiones y conceptos repetidos, y búsqueda de posibles patrones y relaciones entre las unidades de contenido.

4) Fase 4. Interpretación de los datos a la luz de las preguntas de investigación.

Con esta segunda aproximación se ha complementado la información estadística obtenida en la primera fase cuantitativa. Por una parte se han añadido contenidos que han ayudado a matizar y a comprender los primeros resultados cuantitativos en respuesta a las preguntas de investigación 1 y 2 (véase la Tabla 1). Por otra parte, hemos obtenido información complementaria para responder al resto de preguntas planteadas en la investigación (preguntas 3 a 11) para las cuales no disponíamos de datos suficientes en las fuentes externas utilizadas.

En los capítulos 3 y 4 se desarrollan en detalle sendos abordajes metodológicos cuantitativo y cualitativo. 


\section{Estructura}

En este apartado presentamos la organización general del contenido de la tesis, que, como se verá a continuación, se compone de una introducción y dos partes, cada una de ellas dividida en dos capítulos, a las que siguen el apartado de conclusiones, el apartado bibliográfico y varios anexos.

En la introducción se define el objeto de estudio de la tesis dentro del campo de la evaluación en bibliotecas, justificando su interés tanto para el campo de la Biblioteconomía como para la investigación educativa; se establecen los objetivos generales y específicos, así como las preguntas de investigación que vertebran el contenido de la tesis. Seguidamente, se explica la integración de métodos que se ha escogido para la investigación, justificando los motivos que nos han llevado a elegir esta opción metodológica, valorando sus ventajas e inconvenientes. La introducción se cierra con una explicación de la metodología utilizada, en una primera fase de carácter cuantitativo y en una segunda fase de tipo cualitativo (en los capítulos 3 y 4 se desarrollan en detalle sendos abordajes metodológicos), y con la presentación de la estructura general de la tesis.

En la primera parte se aborda el estado de la cuestión sobre la evaluación en bibliotecas y las principales fuentes para su estudio. El contenido se organiza en dos capítulos, en los que se explica la evolución de esta materia desde la perspectiva de la evaluación del rendimiento hasta la evaluación del impacto. El capítulo 1 se dedica a las primeras iniciativas en la evaluación bibliotecaria, incluyendo los estudios orientados a evaluar el rendimiento y la calidad en los distintos tipos de bibliotecas. El capítulo 2 se centra en la evaluación del impacto, su contexto, aspectos terminológicos, conceptuales y metodológicos, incluyendo el impacto económico, y su aplicación a los distintos tipos de bibliotecas.

En esta primera parte se hace hincapié en la importancia de la normalización, y en particular, de la norma ISO 16439 de evaluación del impacto, que es referente principal para el marco conceptual y metodológico de esta tesis.

Para la elaboración de esta primera parte de la tesis se han consultado tanto fuentes publicadas como literatura gris, en formato impreso y electrónico. La revisión incluye la búsqueda en bases de datos, localización, selección, lectura y breve recensión de las distintas fuentes bibliográficas tanto españolas como internacionales. Por su relación con el tema de esta tesis, se ahonda en el estudio del impacto aplicado a los distintos tipos de bibliotecas, profundizando en las cuestiones conceptuales, terminológicas y metodológicas más utilizadas en la literatura especializada.

Se cierra la primera parte con un apartado donde se resumen las principales conclusiones de los dos primeros capítulos. 
En la segunda parte desarrollamos nuestra investigación sobre el impacto de la biblioteca escolar desde una doble perspectiva: cuantitativa y cualitativa. El contenido se organiza en dos capítulos, el primero de ellos desarrolla la perspectiva cuantitativa y el segundo la perspectiva cualitativa, como se expone a continuación:

El capítulo 3 aborda el objeto de investigación desde una perspectiva cuantitativa utilizando datos extraídos de fuentes externas. Con estos datos se obtienen unos primeros resultados con los que se da respuesta a las preguntas 1 y 2 de la investigación.

El capítulo 3 se compone de dos apartados: un primer apartado en el que se analizan los datos PIRLS 2016 para evaluar el impacto de la biblioteca escolar sobre la competencia lectora del alumnado de educación primaria; y un segundo apartado en el que se analizan los datos PISA 2009 para evaluar el impacto de la biblioteca escolar sobre la competencia lectora del alumnado de educación secundaria. En sendos apartados se detallan los conjuntos de datos utilizados, se definen las variables empleadas para el análisis, se plantean las hipótesis y se explican los resultados obtenidos. Se cierra el capítulo 3 con las conclusiones extraídas a partir del análisis estadístico de los conjuntos de datos PIRLS 2016 y PISA 2009.

El capítulo 4 complementa la visión del capítulo anterior abordando el objeto de investigación desde una perspectiva cualitativa a partir de datos extraídos de un estudio de caso. Con estos datos se obtienen resultados con los que responder a las preguntas 1 a 11 de la investigación.

A lo largo del capítulo 4 se detallan los sucesivos pasos de la investigación, desde el diseño de partida hasta su conclusión. Se explican la estrategia de muestreo cualitativo y los criterios utilizados para la selección del caso de estudio. Le sigue la presentación del caso y la fase de trabajo con los datos cualitativos. Se explican las técnicas utilizadas para la obtención de las evidencias y su análisis, y se concluye el capítulo con el análisis e interpretación de los datos obtenidos a la luz de las preguntas de investigación planteadas.

A continuación de la segunda parte de la tesis, se incluye un apartado donde se exponen las conclusiones globales de la investigación, sintetizando los resultados obtenidos en sendos abordajes cuantitativo y cualitativo, en respuesta a las preguntas de investigación planteadas. Se abordan el alcance y los límites de la investigación, los hallazgos y dificultades encontradas, y las preguntas que quedan abiertas para futuras investigaciones.

La tesis se cierra con la bibliografía citada. Para su elaboración se han seguido las directrices del estilo APA (American Psychological Association, 2010). Al final de la bibliografía, se incluye un listado que recoge la legislación citada. 
Se incluyen en anexos los distintos materiales empleados en el capítulo 4 para llevar a cabo la investigación cualitativa:

- Anexo 1. Documentación enviada a una muestra de 19 centros educativos españoles

- Anexo 2. Información enviada por el profesorado responsable de las bibliotecas del CEIP Condesa de Fenosa (O Barco de Valdeorras, Orense) y del CEIP Gerardo Diego (Los Corrales de Buelna, Cantabria)

- Anexo 3. Documentos oficiales de centros educativos del Grupo Cooperativo Bibliotecas Escolares en Red (provincia de Albacete) - BERED

- Anexo 4. Encuesta a los representantes del Grupo Cooperativo Bibliotecas Escolares en Red (provincia de Albacete) - BERED

- Anexo 5. Documentos oficiales del CEIP Virrey Morcillo

- Anexo 6. Selección de noticias del blog del CEIP Virrey Morcillo

- Anexo 7. Entrevistas en el CEIP Virrey Morcillo

- Anexo 8. Grupo de discusión con profesorado del CEIP Virrey Morcillo

- Anexo 9. Datos del INE (estadísticas territoriales)

Junto al texto impreso de esta tesis se entregan en un DVD-R los conjuntos de datos informáticos que se han utilizado para desarrollar la investigación en los capítulos 3 y 4 :

- Conjuntos de datos utilizados en el análisis cuantitativo (capítulo 3): conjuntos de datos del estudio PIRLS 2016 y del estudio PISA 2009 en formatos Excel, .sav, .sps, .spv, legibles con el programa SPSS.

- Conjuntos de datos cualitativos (capítulo 4) analizados con el software Atlas.ti, en formato .atlproj, legible con dicho programa. 


\section{PRIMERA PARTE. Estado de la cuestión sobre la evaluación en bibliotecas: de la medida del rendimiento a la valoración del impacto}

\section{CAPÍTULO 1. Primeras iniciativas en la evaluación de bibliotecas}

\subsection{Principales fuentes para el estudio de la evaluación en bibliotecas}

La evaluación bibliotecaria empezó siendo una materia de interés minoritario ${ }^{12}$ tanto en el ámbito académico como entre los profesionales de las bibliotecas, y en las últimas décadas se ha extendido como una práctica común en la Biblioteconomía. Desde sus inicios en los años 70 del pasado siglo XX, las principales aportaciones en este campo se han producido en países de cultura anglosajona, y desde allí se ha extendido a sistemas bibliotecarios de todo el mundo, siendo muy destacable la contribución de los países nórdicos al desarrollo de esta materia.

Las principales fuentes para su estudio se concentran en un número relativamente reducido de títulos de libros y revistas científicas del campo de la Documentación y la Biblioteconomía ${ }^{13}$, aunque una revisión en profundidad de la literatura especializada

\footnotetext{
${ }^{12}$ En España la investigación sobre la evaluación bibliotecaria no ha sido muy abundante hasta la fecha. Como muestra de ello, la base de datos TESEO (https://www.educacion.gob.es/teseo/irGestionarConsulta.do) arroja una veintena de tesis doctorales sobre esta materia leídas entre 2001 y 2016.

13 La base de datos LISA: Library and Information Science Abstracts (https://www.proquest.com/products-services/lisa-set-c.html) arroja cerca de quinientos artículos científicos publicados entre 1975 y 2018 como resultado de una búsqueda por la materia "Library Evaluation". Una búsqueda por la materia "Libraries Evaluation" en el catálogo OCLC (https://www.oclc.org/es/worldcat.html) arroja cerca de 2.000 títulos de libros publicados entre 1970 y
} 
permite encontrar trabajos que abordan la evaluación bibliotecaria incorporando elementos de otras disciplinas afines de las Ciencias Sociales, como la Economía Aplicada, la Sociología o el Marketing. Desde estos enfoques multidisciplinares, la teoría y la práctica de la evaluación de los servicios de información se ha ido enriqueciendo con nuevos marcos conceptuales y diferentes aproximaciones metodológicas.

Junto a las publicaciones científicas, los estándares internacionales constituyen una fuente fundamental para el estudio de la evaluación bibliotecaria. Los proyectos internacionales de normalización en este campo se han realizado a instancias de organismos e instituciones de ámbito nacional e internacional. Entre ellas, cabe destacar el papel de la Organización de las Naciones Unidas para la Educación, la Ciencia y la Cultura (UNESCO) y la Organización Internacional de Normalización, que fueron desde fechas muy tempranas grandes impulsoras ${ }^{14}$ de estudios de evaluación.

En esta línea, el corpus de normas elaboradas por el Subcomité 8 de Evaluación Bibliotecaria de la ISO constituye la compilación de los conceptos y términos específicos de esta disciplina, y es una síntesis de las metodologías y las prácticas evaluativas más utilizadas a nivel internacional en los distintos tipos de bibliotecas (Organización Internacional de Normalización, 1974, 1991, 1998, 2003a, 2003b, 2006, 2008, 2009, 2012, 2013a, 2013b, 2014a, 2014b).

2018 en el campo de la Biblioteconomía y la Documentación. De ellos, cerca de 250 títulos corresponden a tesis y disertaciones.

${ }^{14}$ Como ejemplo de ello, la primera edición de la norma ISO 2789 (Organización Internacional de Normalización, 1974) de estadísticas internacionales de bibliotecas fue un proyecto auspiciado por la UNESCO, en colaboración con la ISO y la Federación Internacional de Asociaciones Bibliotecarias y Bibliotecas (IFLA). El proyecto había sido adoptado por la Conferencia General de la UNESCO en su XVI reunión de París en noviembre de 1970. Basándose en la norma ISO 2789, la División de Estadísticas de la UNESCO elaboró una serie de cuestionarios para la recopilación de datos en los distintos tipos de bibliotecas a nivel mundial (Organización de las Naciones Unidas para la Educación, la Ciencia y la Cultura, 1981, 1983, 1992) y posteriormente publicó entre 1996 y 2005 tres series de estadísticas bibliotecarias dedicadas a bibliotecas nacionales, bibliotecas públicas y bibliotecas de instituciones académicas. En estas series se recogían datos estadísticos básicos de colecciones, edificios y uso de los servicios.

La Sección de Estadísticas y Evaluación de la IFLA, la UNESCO y la ISO volvieron a colaborar en el proyecto Global Library Statistics (2006-2008), para la selección de datos estadísticos fiables que sirvieran para demostrar la contribución de las bibliotecas en los programas de alfabetización de las regiones en desarrollo. Por su parte, la ISO ha venido impulsando la elaboración de proyectos de normalización desde la publicación en 1974 de la norma ISO 2789, y con la creación del Subcomité 8 de Estadísticas y Evaluación del Rendimiento en bibliotecas en el año 1987. Desde esta fecha, el citado Subcomité ha sido el responsable de elaborar y actualizar los distintos proyectos de normalización en el ámbito de la evaluación bibliotecaria (Organización Internacional de Normalización, 1991, 1998, 2003a, 2003b, 2006, 2008, 2009, 2012, 2013a, 2013b, 2014a, 2014b). 
Además de las publicaciones científicas y las normas, otra fuente importante para el estudio de la evaluación bibliotecaria es la literatura gris generada por las distintas bibliotecas y organizaciones y asociaciones bibliotecarias, en forma de estudios e informes, así como documentos de carácter colectivo, como actas de grupos de trabajo y congresos, borradores de textos normativos, etc. Gran parte de esta documentación es de difícil acceso, y con frecuencia tiene una difusión restringida dentro de las organizaciones. No obstante, la progresiva expansión de las políticas de transparencia está propiciando paulatinamente el acceso abierto a estas fuentes a través de repositorios y sitios web institucionales.

Entre las promotoras de estudios y herramientas de evaluación destacan las asociaciones de profesionales de las bibliotecas de ámbito internacional, como la Federación Internacional de Asociaciones e Instituciones Bibliotecarias (IFLA), el European Bureau of Library Information and Documentation Associations (EBLIDA), la Association of Research Libraries (ARL) y las asociaciones de ámbito nacional, como la American Library Association (ALA), o la Federación Española de Sociedades de Archivística, Biblioteconomía, Documentación y Museística (Fesabid). Estas organizaciones han actuado como interlocutoras en proyectos de normalización evaluativa y han contribuido a la difusión de herramientas ${ }^{15}$ para la evaluación entre los profesionales de las bibliotecas. Además, han impulsado estudios de impacto de redes y sistemas bibliotecarios, con el fin de mostrar su valor social y económico a las autoridades y poderes públicos y a la sociedad en general (Cottrill et al., 2015) ${ }^{16}$. Con

15 La IFLA fue impulsora de la publicación de la norma ISO 2789:1974, primer proyecto de normalización de estadísticas internacionales para bibliotecas junto a la UNESCO y la ISO. Asimismo, la IFLA lanzó en 2010 su Manifiesto sobre Estadísticas de Bibliotecas (Federación Internacional de Asociaciones de Bibliotecarios y Bibliotecas, 2010). La Association of Research Libraries (ARL) (Kyrillidou y Cook, 2008) ha estado en la vanguardia de la evaluación de bibliotecas universitarias y de investigación. Desde su actuación en el área de Estados Unidos y Canadá, sus proyectos han tenido una repercusión internacional. A la ARL estuvieron vinculadas figuras tan destacadas como F. Wilfrid Lancaster, y, desde siempre, la compilación de datos estadísticos y el desarrollo de herramientas para la evaluación de bibliotecas han sido unas de sus líneas principales de actuación. La ARL fue impulsora del proyecto LibQUAL, que evaluaba la satisfacción de los usuarios respecto de los servicios ofrecidos por las bibliotecas. Por su parte, el European Bureau of Library Information and Documentation Associations (EBLIDA), lanzó entre 2013 y 2015 una encuesta a nivel europeo para recabar información estadística de utilidad para defender los beneficios de las bibliotecas frente a las autoridades europeas.

Entre las asociaciones de bibliotecarios de carácter nacional se puede destacar la labor de la American Library Association y la Public Library Association, que publicaron ya en los años 70 y 80 las primeras guías sobre medición de rendimiento en bibliotecas públicas (De Prospo, Altman y Beasley, 1973; Zweizig y Rodger, 1982). En España, la Federación Española de Sociedades de Archivística, Biblioteconomía, Documentación y Museística (Fesabid) fue impulsora del primer estudio sobre el valor económico y social de las bibliotecas españolas (Gómez Yáñez, 2014).

${ }^{16}$ En este sentido, la Declaración de Lyon, lanzada en el marco del Congreso Mundial de la IFLA y firmada por más de 600 instituciones de todo el mundo, abogaba por "el desarrollo de objetivos e indicadores que permitan medir el impacto del acceso a la información y a los datos e informen sobre 
frecuencia estos estudios suelen estar dirigidos por evaluadores especialistas procedentes del ámbito académico o del ámbito de las empresas de consultoría, y en su financiación y coordinación intervienen las asociaciones profesionales y otros organismos e instituciones responsables de políticas públicas educativas y culturales de ámbito local, nacional o internacional.

Entre las instituciones políticas de carácter supranacional impulsoras de proyectos de evaluación bibliotecaria destacaremos el papel de la Comisión Europea, que fue promotora de varios proyectos ${ }^{17}$ relacionados con la evaluación de bibliotecas desde los años 90 .

Entre los promotores de estudios evaluativos no hay que dejar de mencionar las fundaciones privadas financiadoras de proyectos bibliotecarios. Entre ellas se pueden mencionar la Laser Foundation, impulsora de un estudio de evaluación del impacto de bibliotecas en Reino Unido (PricewaterhouseCoopers LLP, 2005) y la Fundación Bill y Melinda Gates, impulsora de la Iniciativa Global Libraries para el desarrollo de las tecnologías de la información en bibliotecas de regiones en desarrollo, y a la que está vinculada una red internacional de especialistas en evaluación bibliotecaria. Como se verá más adelante, los proyectos del Programa Global Libraries han ido acompañados de estudios de evaluación del impacto (Streatfield et al., 2015) que demostraban la contribución de las bibliotecas a la mejora de las condiciones educativas, sanitarias y económicas de comunidades en desarrollo.

Hecho este sucinto repaso de las distintas tipologías de fuentes documentales para el estudio de la evaluación bibliotecaria, hay que decir que, a pesar del avance de las políticas de transparencia, el investigador se encuentra con frecuencia con el problema de la inaccesibilidad de los conjuntos de datos originales en los estudios empíricos publicados sobre esta materia. Este hecho dificulta enormemente que se puedan realizar réplicas experimentales, que se puedan perfeccionar y consolidar nuevas metodologías, e impide la reutilización de datos y su incorporación a estudios longitudinales.

los progresos realizados cada año en los objetivos en un informe sobre el Desarrollo y el Acceso a la Información" (Federación Internacional de Asociaciones de Bibliotecarios y Bibliotecas, 2014).

17 Entre los proyectos financiados por la Comisión Europea en el ámbito de la evaluación de bibliotecas se pueden mencionar: DECIDE (Decision support models and a DSS for European academic and public libraries) (1995-1998); CAMILE (Concerted Action on Management Information for Libraries in Europe) (1996-1998); DECIMAL (Decision making in libraries; decision research for the development of integrated library systems) (1995-1997); EQLIPSE (Evaluation and Quality in Library Performance Systems) (1995-1997); MINSTREL (Management Information Software Tool - Research in Libraries) (1995-1997); EQUINOX (Library Performance Measurement and Quality Management System) (19981999); NUMERIC (2007-2009), ENUMERATE (2011-2014) y EUROPEANA (Poll, 2010). 
En el siguiente apartado se profundiza sobre el corpus de normas internacionales sobre evaluación bibliotecaria. Su contribución a la creación de marcos conceptuales y al desarrollo de metodologías evaluativas específicas para bibliotecas les convierten en fuentes fundamentales para comprender la evolución de esta materia hasta nuestros días.

\subsection{La importancia de la normalización para la evaluación en bibliotecas ${ }^{18}$}

En su clásico manual sobre evaluación bibliotecaria, Lancaster y Joncich (1977) lamentaban que no existieran unos estándares para la evaluación del rendimiento más allá de la obtención de datos estadísticos de inputs y outputs, y subrayaban la necesidad de contar con normas o estándares para realizar una correcta evaluación:

Los actuales estándares se basan en prácticas actuales desarrolladas en instituciones, que, de algún modo se consideran "buenas". Éstas enfatizan inputs más que outputs (servicios). También, la gran diversidad de bibliotecas hace difícil, e incluso peligroso, intentar establecer estándares precisos. Consecuentemente, los estándares bibliotecarios, tal y como son actualmente, aunque tienen cierto valor como guías procedimentales o para establecer unos requerimientos mínimos para varios tipos de bibliotecas, son demasiado generales e imprecisos para ser utilizados en una evaluación detallada de servicios bibliotecarios. Quizá, lo que se necesita son normas con las que cada institución pueda evaluar su propio rendimiento en función con las necesidades de su población ${ }^{19}$ (pp.296-297).

En efecto, en el proceso de evolución de la evaluación bibliotecaria en su doble vertiente teórica y práctica, los practicantes de esta disciplina en los distintos tipos de bibliotecas han encontrado con frecuencia una fuerte dispersión y escasa unidad

${ }^{18} \mathrm{El}$ contenido de este apartado se toma de otro trabajo publicado por la autora de esta tesis (Albelda Esteban, 2014).

19 Traducido del original: "Present standards are largely based on current practices at existing institutions that, in some sense, are considered "good." They emphasize inputs rather than outputs (services). Also, the great diversity among libraries makes it extremely difficult, and even dangerous, to attempt development of precise, quantifiable standards. Consequently, library standards as they now exist, while having some value as procedural guidelines or in establishing absolute minimal requirements for various types of libraries, are too general and imprecise to be used in the detailed evaluation of library services. Perhaps what is needed is standards by which individual institutions can evaluate their own performance in relation to the needs of their user population; that is, standards or guidelines are needed for conducting the type of evaluation studies discussed in this book" (Lancaster y Joncich, 1977, pp. 296-297). 
terminológica y metodológica. En este sentido, se puede decir que las sucesivas iniciativas de normalización que se han producido desde los años 70 del pasado siglo XX hasta la actualidad en el marco de la gestión de la calidad de las instituciones y servicios bibliotecarios, han impulsado el desarrollo y el reconocimiento de esta materia.

La historia de la evaluación bibliotecaria está jalonada por una sucesión de estándares internacionales, que, como grandes hitos, han contribuido a su consolidación terminológica, conceptual y metodológica, y, por tanto, a su avance teórico y práctico en el ámbito académico y profesional. En los estándares internacionales se han tomado siempre como referentes los conocimientos y las experiencias evaluativas previas que habían sido ya probadas en distintos tipos de bibliotecas de forma más o menos aislada. Mediante la elaboración de los sucesivos estándares se ha dado respuesta a la comunidad bibliotecaria, que necesitaba conocer la práctica de la evaluación ante la presión creciente de gestores y poderes públicos por mostrar la eficiencia y el valor de las bibliotecas.

El corpus de normas internacionales sobre evaluación en bibliotecas se ha desarrollado dentro del marco de la gestión de la calidad, y, en la configuración de este corpus, se observa una evolución desde el enfoque cuantitativo basado en datos estadísticos e indicadores de rendimiento, hasta un enfoque cualitativo que incorpora la visión del usuario. Se analiza a continuación este corpus de normas siguiendo un orden cronológico:

a) La norma ISO 2789 Information and documentation, International library statistics, fue publicada en 1974 bajo los auspicios de la UNESCO, la ISO y la IFLA, y tuvo carácter de "recomendación" para todos los países miembros de la UNESCO. La norma se componía de un capítulo de términos y definiciones comunes de los distintos elementos que configuraban la realidad de la biblioteca y que eran susceptibles de cuantificación en términos estadísticos. Junto a estas definiciones, se describían los procedimientos para la toma de datos estadísticos, su presentación e interpretación en los distintos tipos de bibliotecas. Esta norma proporcionaba la base de términos y definiciones sobre la que se fundamentaría todo el corpus de normas sobre evaluación bibliotecaria que se publicarían a continuación.

El contenido de la norma ha ido evolucionando e incorporando nuevos conceptos a medida que ha evolucionado la realidad de las bibliotecas. La segunda edición (Organización Internacional de Normalización, 1991) fue adoptada por el Comité Europeo de Normalización (CEN) como Norma Europea en 1994. La tercera edición (Organización Internacional de Normalización, 2003a), también fue adoptada como Norma Europea en 2003 y en ella se incorporaron contenidos sobre la medición del uso de los recursos y servicios electrónicos. 
La cuarta edición (Organización Internacional de Normalización, 2006) ampliaba los contenidos relacionados con los recursos electrónicos, y la quinta edición (Organización Internacional de Normalización, 2013a) incorporaba nuevos conceptos relacionados con los servicios interactivos, con las redes sociales, y con los nuevos servicios relacionados con la transformación del espacio físico y las nuevas funciones de la biblioteca en el comienzo del siglo XXI: provisión de servicios para usuarios con necesidades especiales, potenciación de las actividades culturales, etc.

b) La norma ISO 11620 Information and documentation, Library Performance Indicators, fue publicada en 1998 en medio de un creciente interés de los profesionales por la incorporación de la gestión de la calidad en el campo de las bibliotecas. En este contexto, la evaluación de la calidad de las bibliotecas se identificaba con la medición del rendimiento mediante indicadores de calidad.

La segunda edición de la norma (Organización Internacional de Normalización, 2008) incorporaba indicadores para servicios y recursos electrónicos y presentaba una estructura basada en el Modelo del Balanced Scorecard o Cuadro de Mando Integral ${ }^{20}$ creado por Kaplan y Norton (1996) para la dirección estratégica y evaluación del desempeño en las organizaciones. De acuerdo con este enfoque conceptual, los indicadores aparecían organizados en torno a cuatro ejes de evaluación:

1) La evaluación de la infraestructura y recursos materiales y humanos disponibles, las colecciones bibliográficas, su accesibilidad, preservación y nivel de uso.

2) La evaluación del uso de los servicios y recursos, tanto tradicionales como del entorno digital.

3) La evaluación de la eficiencia en la provisión de servicios y recursos y su adaptación a las necesidades de los usuarios.

4) La evaluación del potencial y desarrollo, es decir, la capacidad de la biblioteca para ofrecer nuevos servicios y recursos mediante la inversión en nuevas tecnologías, la formación y la cooperación con otras instituciones y organismos.

El contenido de la tercera edición (Organización Internacional de Normalización, 2014a) se enriqueció con una serie de conceptos tomados de la gestión de la calidad en el ámbito de las organizaciones. Además del Cuadro de Mando Integral, se incorporaron los conceptos de coste-efectividad, eficiencia, productividad, eficacia, y se incluyó entre sus indicadores la evaluación de la satisfacción del usuario o calidad percibida, lo cual abría una puerta a la incorporación de información de carácter cualitativo en las evaluaciones.

20 El Balanced Scorecard o Cuadro de Mando Integral se ha adoptado en bibliotecas como instrumento de gestión aplicado a la medición del rendimiento (La Mano González y Creaser, 2016). 
c) La norma ISO 11620 se adaptaba a las necesidades de las bibliotecas universitarias y públicas, pero no se ajustaba suficientemente a las particularidades propias de las bibliotecas nacionales: su misión patrimonial, el deber de creación de bibliografías nacionales, el perfil no predefinido de sus usuarios. La necesidad de contar con una norma de evaluación del rendimiento aplicable a bibliotecas nacionales llevó al Subcomité de Evaluación de la ISO a elaborar un Informe Técnico (Organización Internacional de Normalización, 2009) que adaptaba la norma ISO 11620 de indicadores para bibliotecas a las necesidades específicas de las bibliotecas nacionales: el Informe Técnico ISO/TR 28118 Information and documentation, Performance indicators for national libraries. Una década después, la actualización de este informe ha dado lugar a la publicación de la norma ISO 21248:2019 Information and documentation, Quality assessment for national libraries, que incluye metodología específica para la evaluación del rendimiento e impacto en bibliotecas nacionales.

d) Como complemento a las normas sobre evaluación mediante estadísticas e indicadores de rendimiento, el Subcomité de Evaluación de la ISO publicó dos nuevos informes técnicos que ampliaban el alcance de la evaluación de las bibliotecas tanto en su dimensión física como en su dimensión virtual. El primero de ellos, el Informe Técnico ISO/TR 11219 Information and documentation, Qualitative conditions and basic statistics for library buildings, space, function and design (Organización Internacional de Normalización, 2012), se planteó como una guía aplicable a la planificación y evaluación del espacio físico de las bibliotecas, recogiendo las nuevas funcionalidades y la transformación de los edificios y espacios bibliotecarios para atender a las nuevas necesidades.

El segundo de los informes técnicos, el Informe Técnico ISO/TR14873 Information and documentation, Statistics and quality issues for web archiving (Organización Internacional de Normalización, 2013b), surgió en el contexto de la proliferación de proyectos de archivado web en todo el mundo como forma de preservación del patrimonio digital. El Informe Técnico se planteó como una guía que recogía directrices para la gestión y la evaluación de productos y actividades resultantes de los proyectos de archivado de la web. El Informe incluía una recopilación de términos normalizados procedentes del campo de la tecnología web con su correspondiente definición, acompañados de sus métodos de medición estadística, y de una batería de indicadores de calidad aplicables a la evaluación del archivo de la web.

e) La última de las normas internacionales publicada sobre evaluación bibliotecaria fue la norma ISO 16439 Information and documentation, Methods and procedures for assessing the impact of libraries (Organización Internacional de Normalización, 2014b). Se concibió en un contexto de interés creciente por demostrar el valor social y económico de las bibliotecas ante los poderes públicos y ante la sociedad en su conjunto. Con esta norma se ampliaban las posibilidades de evaluación bibliotecaria, pues proporcionaba un vocabulario normalizado y una selección y descripción de 
metodologías y técnicas provenientes de las ciencias sociales, que habían sido ya probadas para la evaluación del impacto bibliotecario (Creaser, 2018; Poll, 2012; Poll y Payne, 2006).

Desde la publicación en 1974 de la primera norma sobre estadísticas internacionales de bibliotecas, los sucesivos proyectos de normalización han tenido una buena acogida en el ámbito profesional y han servido de base para la evaluación de servicios bibliotecarios tradicionales y de los nuevos servicios de la biblioteca digital. Al mismo tiempo han suscitado el interés por explorar nuevas áreas de evaluación y por ensayar nuevos procedimientos para medir las diferentes dimensiones del rendimiento y el impacto (Berghaus-Sprengel, 2001; Bertot, 2001; Bertot, Dalton, McClure y Shim, 2003; Calenge, 1999; Carbone, 1995, 1998; Clarke, 2001; La Mano González (Coord.), Albelda Esteban, Pérez Morillo y Romero Garuz, 2014; Laitinen, 2013; Laitinen y Saarti, 2014; Mathur, 2005; Poll, 2001a, 2001b, 2001c, 2001d, 2008a, 2008b, 2008c, 2011; Renard, 2008; Sheppard, 1990; Zorica, Ivanjko y Spiranec, 2014).

Los proyectos de normalización han permitido ampliar la perspectiva de los estudios de evaluación mediante la realización de estudios de benchmarking o evaluación comparativa entre instituciones bibliotecarias, sobre la base de conceptos y procedimientos comunes (Poll, 2007). Entre los diferentes proyectos de benchmarking de carácter nacional, se pueden destacar las iniciativas de los sistemas bibliotecarios de Australia (Ellis, 1998), Reino Unido (Creaser, 2001; Garrod y Kinnell, 1996), Alemania (Klug, 2000), Suecia (Adrial, Edgren, Nilsson y Mânsby, 2005), las bibliotecas universitarias de Austria (Erasimus y Bauer, 2006; Seissl, 2006), las bibliotecas universitarias de Noruega (Landøy y Raade, 2014) y las bibliotecas públicas de la región de Flandes (Stroobants y Bouckaert, 2014). Estos estudios se enfrentaron a la dificultad de comparar realidades a veces dispares, a pesar de que se circunscribían a bibliotecas con características semejantes en su misión y funciones, y a sistemas bibliotecarios en los que se compartía un mismo marco socioeconómico y normativo.

Entre los proyectos de benchmarking de carácter internacional se puede destacar el proyecto LIBECON (Library Economics for International Benchmarking), que se desarrolló entre julio de 2001 y junio de 2004 y que fue liderado por el Institute of Public Finance de Reino Unido, con la implicación de la IFLA, la UNESCO y la Dirección General XIII de la Comisión Europea, y con la financiación del Quinto Programa Marco para la Investigación y el Desarrollo Tecnológico de la Comisión Europea. El objetivo de LIBECON fue difundir datos estadísticos normalizados de bibliotecas de los distintos Estados Miembros de la Unión Europea y facilitar su evaluación comparativa. El proyecto se fundamentó sobre las normas internacionales ISO 2789 de estadísticas e ISO 11620 de indicadores de rendimiento para bibliotecas. 
No se puede cerrar este apartado sin mencionar otras iniciativas de normalización de alcance internacional orientadas a la evaluación que fueron desarrolladas fuera del ámbito de la ISO. Entre ellas hay que mencionar el proyecto COUNTER (Counting Online Usage of Networked Electronic Resources) (Shepherd, 2003), que comenzó en 2002 con el objetivo de normalizar los datos estadísticos suministrados por los editores, comercializadores y agregadores de recursos electrónicos. Esta iniciativa daba respuesta a la necesidad de las bibliotecas de contar con datos normalizados para evaluar la utilización de las colecciones electrónicas licenciadas, en un contexto de crecimiento exponencial en los accesos a las bases de datos y revistas científicas en formato electrónico. El resultado del proyecto fue el Código de Prácticas de COUNTER, para el suministro normalizado de datos estadísticos de uso de recursos electrónicos, al que desde entonces podían adherirse editores, agregadores de recursos, comercializadores y bibliotecas.

En los siguientes apartados se aborda la evolución de los estudios sobre evaluación bibliotecaria. En primer lugar, se abordan los estudios orientados a la evaluación del rendimiento, desde los primeros trabajos de los años 70 y 80 basados en estadísticas e indicadores, y la posterior introducción de la perspectiva del usuario en el contexto de los estudios de calidad de las organizaciones y servicios. En la parte final, se abordan los estudios orientados a la evaluación del impacto, incluido el impacto económico, en los distintos tipos de bibliotecas, en el contexto internacional y en España.

\subsection{Estudios de evaluación bibliotecaria orientados al rendimiento}

\subsubsection{La introducción de la evaluación del rendimiento en bibliotecas}

La evaluación del rendimiento fue uno de los pilares fundamentales de la corriente del New Public Management (Hood, 1991), que dominó en los años 80 en el ámbito de las administraciones públicas de los países de la Organización para la Cooperación y el Desarrollo Económicos (OCDE), principalmente entre los países anglosajones. Esta corriente incorporaba una serie de prácticas inspiradas en modelos de gestión privada con los que se buscaba mejorar la eficiencia y optimizar el rendimiento de las administraciones en la provisión de los servicios públicos. Hood (1991, p. 5) enumeraba los pilares fundamentales del New Public Management:

1) Profesionalización del sector público. 
2) Estándares explícitos y medidas del rendimiento para la rendición de cuentas, definición de objetivos y uso de indicadores principalmente cuantitativos.

3) Énfasis en los resultados y no en los procesos.

4) Organización de las administraciones públicas en unidades funcionales.

5) Búsqueda de mayor competitividad en el sector público.

6) Empleo de herramientas y técnicas de gestión del ámbito privado en el ámbito público.

7) Economía de recursos y eficiencia.

La corriente del New Public Management tuvo una importante repercusión en el ámbito de las bibliotecas públicas y universitarias. La creciente demanda de rendición de cuentas que se vivía en el sector público fue calando al mismo tiempo en los servicios públicos bibliotecarios. La planificación estratégica y la evaluación del cumplimiento de los objetivos cobró una gran importancia en la gestión de bibliotecas (Bloor, 1991; McClure, Owen, Zweizig, Lynch y Van House, 1987; McClure y Reifsnyder, 1984). En este contexto, los responsables de las bibliotecas necesitaban nuevas herramientas para la toma de decisiones de gestión y para la rendición de cuentas ante los gobiernos y otras entidades financiadoras de programas bibliotecarios.

Los primeros estudios teóricos sobre evaluación en bibliotecas datan de los años 70, y se dan principalmente en el ámbito de las bibliotecas universitarias y públicas de los países anglosajones. En ellos se investigan métodos cuantitativos y su aplicación a la práctica de la gestión de las bibliotecas de una forma sistematizada. En esta década, la evaluación bibliotecaria aún se encontraba en un estado empírico y teórico embrionario y exploratorio, y los estudios existentes respondían a alguno de los siguientes fines (Swanson, 1975, p. 143):

1) Evaluar un conjunto de objetivos, un programa o plan antes de su implementación. En la literatura profesional también se habla de evaluación ex - ante.

2) Evaluar el cumplimiento de objetivos y el rendimiento esperado.

3) Determinar las razones de posibles logros o fallos (evaluación ex -post).

4) Descubrir las claves principales para el éxito de un programa.

5) Explorar técnicas para incrementar la efectividad de un programa.

6) Establecer un punto de partida para futuras investigaciones sobre posibles procedimientos alternativos de éxito.

7) Mejorar los medios utilizados para alcanzar objetivos o redefinir objetivos. 
Entre los iniciadores de la evaluación bibliotecaria, hay que recordar la figura de F.W. Lancaster. La publicación de su clásico manual sobre evaluación de servicios bibliotecarios (Lancaster y Joncich, 1977) fue un hito en la historia de la Biblioteconomía y sigue siendo una obra de cabecera para los profesionales de este campo. El libro explicaba de una forma sistematizada los conceptos y técnicas básicas para la evaluación con datos cuantitativos, incluyendo la elaboración de muestras, los procedimientos para la obtención de datos y su interpretación. Para Lancaster, la evaluación debía comprender los distintos elementos de la biblioteca: recursos e instalaciones, colecciones y servicios, sistemas automatizados. El autor dedicó buena parte de su vida académica a la enseñanza de esta materia, a investigar sobre la obtención de evidencias en nuevas áreas de evaluación y al ensayo de nuevas metodologías, incluyendo los análisis de coste-efectividad y coste-beneficio ${ }^{21}$ (Baker y Lancaster, 1991; Lancaster, 1988, 1993).

Junto a la figura sobresaliente de Lancaster, otros especialistas de la Biblioteconomía investigaron sobre nuevos conceptos y procedimientos para la toma de decisiones basadas en evaluación del rendimiento (De Prospo et al., 1973; Orr 1973; Van House, 1987, 1989; Zweizig y Rodger, 1982). Algunas figuras relevantes provenían del campo de la Economía y del estudio de sistemas complejos (Baumol y Marcus, 1973; Getz, 1980; Hamburg et al., 1974; Leimkuhler, 1972; Morse, 1968). Desde nuestra perspectiva actual, su visión puede resultar algo mecanicista, la biblioteca se concebía como un sistema de procesos automatizados que arrojaba datos de funcionamiento (inputs y outputs) evaluables mediante modelos matemáticos.

El análisis de los datos cuantitativos permitiría no solamente tomar decisiones eficientes, sino también, incorporar modelos probabilísticos para evaluar con rigor si la biblioteca estaba satisfaciendo las necesidades de sus usuarios, e incluso, incorporar métodos de análisis tomados de la física y la ingeniería para proyectar el futuro funcionamiento del sistema bibliotecario y anticiparse a las necesidades. En esta línea, Morse (1968) confiaba en la fiabilidad de los datos cuantitativos para la toma de decisiones de gestión $y$, por el contrario, mostraba cierto escepticismo hacia la fiabilidad de la información cualitativa obtenida mediante encuestas: "A menudo, el encuestado se ha convencido a sí mismo y al encuestador de que usaría un nuevo

\footnotetext{
${ }^{21}$ Como explica Matthews (2002), la finalidad del análisis coste-beneficio es "identificar el impacto potencial de una decisión (...). El análisis requiere que se cuantifique cada uno de los costes y beneficios" (p. 78). Para el autor, el análisis coste-beneficio mide tres tipos de costes y beneficios según la dificultad para ser cuantificados: 1) "hard impacts": son costes y beneficios fáciles de cuantificar, por ejemplo, el coste del equipamiento informático; 2) "soft impacts": son costes o beneficios que dependen de múltiples factores, por lo que su cuantificación solo puede ser estimativa, por ejemplo, las ganancias en productividad; 3) "unquantifiable impacts": son impactos donde no es posible hacer una cuantificación mediante el análisis coste-beneficio, por ejemplo, mejorar la satisfacción de los usuarios.
} 
servicio que se le ofreciera, pero, una vez puesto en marcha, rara vez se acerca a usarlo22" (p. 4).

En contraposición a esta desconfianza en los datos cualitativos, Morse apostaba por la posibilidad de recopilar y analizar grandes masas de datos cuantitativos, propiciada por la llegada de la informatización a las bibliotecas. En la misma línea, Bommer, Chorba y Grattidge (1979) enmarcaron la evaluación del rendimiento de las bibliotecas universitarias dentro de la toma de decisiones operativas para la planificación y asignación eficiente de recursos. Su visión de la biblioteca universitaria se correspondía con un modelo donde los diferentes recursos y servicios constituían un sistema de interrelaciones funcionales. Cada uno de los elementos del sistema y sus diferentes interrelaciones sería objeto de evaluación.

Si bien este modelo funcional era más receptivo a las necesidades de los usuarios, hay que decir que, al igual que los autores anteriores, éstos contemplaban un tipo de evaluación cuantitativa y una visión sistematizada y mecanicista de la biblioteca. Dentro de esta tendencia general hacia el sistematismo, se exploraron nuevas fórmulas para medir el rendimiento de sistemas y procesos. Así, por ejemplo, Levine (1980) propuso la ratio circulación/adquisición como nuevo indicador para medir el rendimiento de la biblioteca. Esta ratio proporcionaba mucha más información que los simples datos estadísticos aislados, al poner en relación los datos de inputs (obras ingresadas) y los datos de outputs (obras en circulación). Otros autores desarrollaron evaluaciones de costes para resolver el problema de la correcta asignación de recursos y su optimización dentro del sistema (Hindle y Raper, 1976).

De lo expuesto se puede deducir que, durante décadas, el enfoque predominante ${ }^{23}$ en la evaluación bibliotecaria fue la medición del rendimiento mediante datos cuantitativos. Dentro de esta visión mecanicista, la biblioteca se presentaba como un sistema complejo gobernado por una planificación estratégica, y de cuyo rendimiento había que rendir cuentas con cifras.

A la vista de la literatura especializada, observamos que, el concepto de "rendimiento" (traducción del término inglés performance) siempre ha sido poliédrico dentro del campo de la Biblioteconomía. Según Hannabuss (1987) se presta a tres niveles de interpretación:

22 Traducido del original: "Too often has the questionee persuaded both himself and the questioner that he would use some proposed new service, only to find that he seldom gets around to using it, once installed" (Morse, 1968, p. 4).

${ }^{23}$ Como se verá más adelante, a principios de los años 2000 se produciría un cambio de enfoque con la introducción de la perspectiva del usuario en el marco de la evaluación de calidad de los servicios. Con este nuevo enfoque se introducía la calidad percibida por los usuarios como principal información cualitativa. Con ello se ampliaba la visión predominantemente cuantitativa de las evaluaciones desarrolladas hasta entonces. 
1) Un primer nivel que consistiría en la simple ejecución de una actividad. Esta actividad sería descrita mediante un dato cuantitativo o dato estadístico (inputs y outputs aislados).

2) Un segundo nivel que consistiría en la realización de distintas acciones orientadas a conseguir un efecto determinado. El foco ya no se pondría sobre los inputs y outputs aislados sino sobre los procesos. El conjunto de acciones constituiría un proceso, en el que una serie de recursos (inputs) producirían una serie de productos o resultados (outputs) o beneficios (outcomes).

3) Un tercer nivel que consistiría en la ejecución de unas acciones determinadas con un determinado grado de eficiencia y éxito. En el contexto de la gestión, el rendimiento esperado sería equivalente a productividad, eficiencia y beneficio económico.

Si observamos los primeros estudios sobre evaluación, veremos que se suele utilizar el término "rendimiento" en una doble dimensión, tanto para evaluar los procesos internos de la biblioteca, como los servicios a usuarios externos. En ambos casos se utilizaron como medidas de rendimiento los datos estadísticos básicos ${ }^{24}$ que informaban sobre inputs (datos de entrada sobre infraestructuras materiales, recursos económicos y humanos) y outputs (datos de salida sobre resultados producidos, como la formación colecciones y la provisión y frecuencia de uso de los servicios). A partir de la visión general del concepto de rendimiento, proliferaron estudios donde se profundizaba sobre sus distintas dimensiones, como, por ejemplo, la disponibilidad de los recursos (Revill, 1987), la eficacia (Sebastiani, 1993), la excelencia (McIntyre, 1994), y la mejora de la calidad de los servicios (Meera, 1998).

Junto a los datos estadísticos básicos, las bibliotecas empezaron a incorporar indicadores para medir su rendimiento respecto a objetivos previamente definidos. La publicación en 1998 del primer estándar internacional de indicadores de rendimiento bibliotecario (Organización Internacional de Normalización, 1998) ${ }^{25}$ supuso una puesta en común de experiencias dispersas de trabajo con este tipo de instrumentos. La norma vino a cubrir la necesidad creciente de sistematización metodológica y unificación de criterios entre los profesionales de las bibliotecas. También sirvió de guía práctica para el trabajo con estos nuevos instrumentos de gestión.

\footnotetext{
${ }^{24}$ La publicación del primer estándar de estadísticas internacionales de bibliotecas (Organización Internacional de Normalización, 1974) contribuyó a extender la cultura de la evaluación y a sistematizar y normalizar la recopilación de los datos estadísticos comunes en todo tipo de bibliotecas.

${ }^{25}$ En esta norma se recoge la siguiente definición de indicador de rendimiento: "expresión (que puede ser numérica, simbólica o verbal) derivada de las estadísticas bibliotecarias y los datos utilizados para caracterizar el rendimiento de una biblioteca". [Traducido del original: "performance indicator: numerical, symbolic, or verbal expression derived from library statistics and data used to characterize the performance of a library" (Organización Internacional de Normalización, 1998, p. 7)].
} 
En general se puede decir que la evaluación del rendimiento con indicadores tuvo una buena acogida entre los profesionales de las bibliotecas, generalizándose su práctica con la publicación de los estándares internacionales. No obstante, hubo que sortear el problema de la falta de experiencia con las nuevas herramientas (Goodall, 1988; Lynch, 1983). Como respuesta a este problema, desde las asociaciones profesionales se impulsó la publicación de manuales prácticos, con el fin de acercar a los profesionales los conceptos y procedimientos básicos de la medición del rendimiento en bibliotecas y los fundamentos para la correcta interpretación y presentación de resultados. Entre los manuales destinados a bibliotecas públicas, cabe destacar De Prospo et al. (1973), publicada por la Public Library Association; los manuales publicados por la American Library Association (Van House 1987; Zweizig, Johnson, Robbins y Besant, 1996; Zweizig y Rodger, 1982); y el manual de Moore (1989), publicado por la UNESCO.

En el ámbito de las bibliotecas universitarias se vivía un contexto similar de presión creciente sobre la rendición de cuentas y la mejora de la calidad de los servicios (Jouguelet, 2008; Kyrillidou, 2002a, 2002b). En este ámbito se publicaron los manuales de Van House, Weil y McClure (1990), publicado por la American Library Association, y el manual de Poll y te Boekhorst (2007), publicado a instancias de la IFLA.

Si bien hubo una buena aceptación de estas nuevas herramientas desde el ámbito profesional, no obstante, hubo algunas voces críticas hacia estas corrientes de cambio en la gestión bibliotecaria. Como explicaban Midwinter y McVicar (1990) respecto del caso del Reino Unido, las bibliotecas tuvieron que enfrentarse entonces a drásticos recortes presupuestarios. La introducción de herramientas de evaluación en un contexto tan incierto fue percibida a veces por los trabajadores de las bibliotecas como meros instrumentos de control y no de mejora. Pero entre los profesionales hubo también voces entusiastas que interpretaron estos cambios como una oportunidad para fortalecer a la profesión. Con estas palabras, Redfern (1990) proclamaba la importancia del trabajo con indicadores de rendimiento para mejorar y avanzar en la gestión externa e interna de las bibliotecas:

Los trabajos con indicadores de rendimiento no sólo se utilizan para evaluar los costes: los necesitamos también como bibliotecarios. Los necesitamos para nuestra autoestima como profesionales, o al menos como gestores que necesitamos ser capaces de rendir cuentas de lo que hacemos. Debemos poder rendir cuentas para nosotros mismos, para el personal del servicio y para la autoridad local o la entidad que financia nuestro servicio. Esto es necesario no para tenerlos contentos, sino para garantizar la continuidad de la financiación. También debemos rendir cuentas a nuestra comunidad de usuarios, para que clientes y proveedores comprendan que hay una diferencia entre sus expectativas y el servicio que reciben. Es un concepto básico de marketing. Rendir cuentas de nosotros mismos es una parte esencial de la inteligencia: 
debemos entender qué está sucediendo, los procesos que se producen como resultado de nuestras decisiones. ¿'Por qué necesitamos comprender esto? porque se van a producir cambios. En primer lugar, necesitamos mejorar nuestros servicios: hay siempre cosas que mejorar. Esta es nuestra decisión. En segundo lugar, porque cada vez hay mayor presión a medida que el dinero escasea. Esta es su decisión. Para cambiar algo debes entenderlo ${ }^{26}$ (p. 7)

En el siguiente apartado se aborda la introducción de la perspectiva del usuario en los estudios de evaluación bibliotecaria. Hasta ahora hemos visto el alcance de los primeros estudios de evaluación del rendimiento, que se fundamentaba sobre una visión mecanicista de los procesos y recursos de la biblioteca. Esta aproximación fue dejando paso a una nueva visión de tipo cualitativo, con la introducción de las primeras encuestas de satisfacción de usuarios.

\subsubsection{La introducción de la perspectiva del usuario en los estudios de evaluación de bibliotecas: la importancia de la calidad}

En su manual sobre evaluación de bibliotecas, Lancaster y Joncich (1977) expresaron la importancia de completar las evaluaciones de bibliotecas aportando a la visión aséptica de los datos cuantitativos la visión valorativa de los usuarios. Los autores recomendaban la elaboración de encuestas para ayudar a los responsables de bibliotecas a identificar áreas de mejora en la provisión de servicios:

Una encuesta bien realizada puede producir un número considerable de datos que tienen un valor potencial en la evaluación de los servicios bibliotecarios. Esto es cierto si la encuesta va más allá de los datos puramente cuantitativos sobre volúmenes, tipos de uso, y características generales de los usuarios y trata

\footnotetext{
${ }^{26}$ Traducido del original: "Performance indicators not only are used to assess value for money: we need them also as librarians. We need them for our own self-esteem as professionals, or at the very least as managers we need to be able to give an account of what we are doing. We must be able to account to ourselves, to the staff of the service, and to the local authority or company which founds our service. This is necessary, not to keep them happy but to ensure continued funding. We must also account to our user community so that the gap between expectations and provisions is understood by both clients and providers. This is a basic marketing concept. Giving an account of ourselves is an essential part of intelligence: we must understand what is happening; the processes that occur as a result of our decision making. Why do we need to understand this? Because changes will occur. First, we need to improve our services: there are always things to improve. This is our decision. Second, because pressure is applied as money decreases. This is their decision. In order to change something, you have to understand it" (Redfern, 1990, p.7).
} 
de evaluar el grado en el que los servicios bibliotecarios satisfacen las necesidades de la comunidad a la que dan $\operatorname{servicio}^{27}$ (p. 309).

Abundando en la misma idea, para Bommer et al. (1979), el rendimiento esperado se podría interpretar como el grado con el que las bibliotecas satisfacían las necesidades de los usuarios. En la misma línea, Hannabuss (1987) opinaba que: "en la preocupación por el rendimiento, es esencial el grado en el que el sistema satisface las necesidades de los usuarios" 28 (p.155).

Se puede decir que estas opiniones de autores comprometidos con la evaluación del rendimiento son una muestra de la preocupación por el usuario que tradicionalmente ha alentado el campo de la Biblioteconomía. No obstante, hubo que esperar algunos años más, hasta los años 90, para encontrar la perspectiva del usuario dentro de los estudios de evaluación de bibliotecas. Entre los autores que fueron preparando el camino para esta nueva visión, destacan las figuras de Van House y Childers. La visión de estos autores contribuyó a superar el excesivo mecanicismo de las primeras evaluaciones. Desde su perspectiva, la evaluación bibliotecaria debía encuadrarse dentro de los estudios de evaluación de la efectividad organizativa ${ }^{29}$, donde rendimiento se consideraba como una dimensión más dentro de la efectividad.

En su investigación sobre la efectividad de las bibliotecas públicas, financiada por el Departamento de Educación del Gobierno de Estados Unidos, Van House y Childers $(1993,1994)$ lanzaron una encuesta a nivel nacional a representantes de los distintos grupos de interés (usuarios, responsables políticos y administrativos, líderes locales, gestores, profesionales de las bibliotecas). La finalidad del estudio era, por una parte, conocer la percepción general sobre lo que significaba la efectividad en las bibliotecas, $y$, por otra parte, establecer las evidencias más relevantes para dar cuenta de esa efectividad. Del estudio se desprenderían una serie de criterios con los que trabajar en los futuros estudios evaluativos.

\footnotetext{
${ }^{27}$ Traducido del original: "A well conducted library survey can produce considerable number of data that are of potential value in the evaluation of library services This is especially true if the survey goes beyond purely quantitative data on volumes and types of use, and general characteristics of the users, and attempts to assess the degree to which the library services meet the needs of the community served" (Lancaster y Joncich, 1977, p. 309).

${ }^{28}$ Traducido del original: "whatever else we care to make performance into, it is essentially that, the degree to which the system contributes to user needs" (Hannabuss, 1987, p. 155).

${ }^{29}$ Van House y Childers (1993) adoptaron el concepto de efectividad del ámbito de los estudios sobre la efectividad de las organizaciones, donde se definían las diferentes dimensiones de este concepto, de acuerdo con distintos modelos explicativos: la efectividad como el logro de objetivos; efectividad de los procesos; efectividad como respuesta a las necesidades del entorno; efectividad como satisfacción de las necesidades de los grupos de interés. En el ámbito de las bibliotecas, la efectividad se evidenciaba de acuerdo con dos aproximaciones principales: 1) comparando con unos estándares de efectividad predefinidos; y 2) en relación con su propia misión y objetivos.
} 
El enfoque de Childers y Van House (1989) y Van House y Childers $(1990,1993)$ fue un avance importante en los estudios de evaluación, ya que se daba voz a los grupos de interés para establecer los criterios estratégicos de efectividad de las bibliotecas públicas. Siguiendo la línea abierta por estos autores, Calvert presentó un estudio de efectividad de las bibliotecas públicas de Nueva Zelanda donde recogió la percepción de los distintos grupos de interés (Calvert, 1994; Cullen y Calvert, 1995). Para este autor, las mediciones de rendimiento resultaban insuficientes, porque dejaban a un lado el entorno social y político en el que se integraban las bibliotecas. Para paliar la excesiva carga cuantitativa y el mecanicismo de las primeras evaluaciones del rendimiento, el autor adoptó como modelo conceptual y metodológico el estudio de Van House y Childers (1993). Partiendo de una visión de la biblioteca ya no como un sistema sino como un "constructo social", Calvert consideraba que era prioritario conocer la opinión de los distintos agentes para dar validez al sistema de evaluación de la biblioteca.

Además de la aproximación de Van House y sus colegas y seguidores, el avance hacia los nuevos sistemas de evaluación de la calidad orientada a la satisfacción de las expectativas de los usuarios se desarrolló en los años 90 y 2000 en el contexto de la corriente del "Total Quality Management" (TQM) o "Gestión de la Calidad Total30" (Cooper, 1996; O'Neil, 1994, Pacios Lozano, 2000). Al abrigo de esta corriente se desarrollaron distintos modelos de aseguramiento de la calidad total, entre los que se puede mencionar el Modelo de la European Foundation for Quality Management, también conocido como Modelo EFQM. Este modelo se popularizó en bibliotecas de todo el mundo (Düren, 2012; Stavridis y Tsimpoglou, 2012).

De igual modo, el conjunto de normas ISO 9000 (Organización Internacional de Normalización, 1987, 2000a, 2000b) se extendió como base para la evaluación y la certificación de los sistemas de calidad total de las organizaciones, y pronto se adoptó en bibliotecas (Düren, 2012; Klempin, 1997; Kostagiolas y Kitsiou, 2008; Luther, 2016; Pacios Lozano, 1995, 1997; Panday, 2014; Sardelli, 1999; Vonhof y Bertele, 2017). Al igual que en el Modelo EFQM, las ISO 9000 proponían un sistema para la gestión de la calidad orientada a la satisfacción del usuario o cliente.

Junto a los modelos de calidad, hay que destacar la iniciativa de un equipo de investigación de la Universidad de Texas que centró sus esfuerzos en introducir un cambio de perspectiva en la evaluación del rendimiento (Cook, Heath, Thompson y Thompson, 2001; Kyrillidou, 2002a, 2002b). El cambio de planteamiento consistió en

${ }^{30}$ Cooper (1996) definió la TQM como:

una filosofía de gestión orientada a las necesidades del usuario y un compromiso continuo por la mejora de la calidad. Un sistema centrado en los procesos tanto como en los productos, siendo aspectos clave de su metodología la opinión del usuario, la participación del personal y la medición continua de su éxito (pp. 92-93). 
poner al usuario en el centro de la gestión de los servicios, y en perseguir su satisfacción como objetivo prioritario. En este nuevo orden, se produjo una identificación entre el concepto del rendimiento y el nivel de satisfacción del usuario, es decir, un servicio bibliotecario alcanzaba un buen rendimiento si por sus características (disponibilidad, coste, rapidez, relevancia, etc.) contribuía a satisfacer las necesidades de los usuarios. A los datos estadísticos de inputs y outputs, se añadían nuevos datos cualitativos sobre la percepción del usuario o calidad percibida.

Por su parte, Cook y Heath (2001) se inspiraron en el modelo de evaluación de calidad SERVQUAL, desarrollado por Parasuraman, Zeithaml y Berry (1985) en el campo del marketing y la calidad de los servicios. Este modelo se fundamentaba sobre el principio de que:

la calidad del servicio es una función que expresa la distancia entre las expectativas y las percepciones (...) los clientes evalúan la calidad del servicio desde múltiples dimensiones (...) el conjunto de las evaluaciones dimensionales configura la imagen de la calidad global de la organización ${ }^{31}$ (Parasuraman, 2002, párr.5).

El modelo SERVQUAL establecía cinco dimensiones para la evaluación de los servicios:

1) Fiabilidad: capacidad de ofrecer un servicio de forma rigurosa y completa.

2) Seguridad: conocimiento y cortesía y capacidad para transmitir confianza y discreción.

3) Equipamientos: instalaciones, equipos, recursos materiales.

4) Empatía: adaptación a las necesidades del usuario concreto, atención individualizada, escucha.

5) Capacidad de respuesta: diligencia, actitud de ayuda al usuario.

A partir de estas cinco dimensiones, se detectaban los desajustes entre lo esperado y lo percibido sobre lo recibido, diferenciándose cinco tipos de brechas o deficiencias:

1) Discrepancia entre la expectativa del usuario y la percepción del gestor: el servicio no responde a lo que espera el usuario.

31 Traducido del original: "The notion that service quality is a function of the expectationsperceptions gap was reinforced by extensive qualitative research that my colleagues and I conducted in multiple sectors. This research also suggested that customers assess quality of service on multiple dimensions and that the dimensional assessments collectively shape the overall quality image of a service organization" (Parasuraman, 2002, párr. 5). 
2) Discrepancia entre la percepción del gestor y la organización y el diseño del servicio: el servicio está bien concebido, pero no está suficientemente organizado.

3) Discrepancia entre el diseño del servicio y su desempeño: aunque el servicio se ajusta a las expectativas de los usuarios y está correctamente diseñado, se desempeña de forma inadecuada o deficientemente.

4) Discrepancia entre desempeño del servicio y su visibilidad: el servicio se desempeña de forma adecuada pero no se comunica suficientemente.

5) Discrepancia entre el servicio esperado y el recibido: el usuario no conoce el servicio, no dispone de suficiente información.

En 2000, el mencionado equipo de investigación de la Universidad de Texas y otras diez instituciones académicas con el apoyo de la Association of Research Libraries (ARL), elaboraron una adaptación del modelo SERVQUAL al contexto de las bibliotecas universitarias. El resultado fue el desarrollo del modelo LibQUAL, que medía la satisfacción de los usuarios respecto de los servicios, y la brecha entre sus expectativas y sus percepciones, empleando un cuestionario sobre distintos aspectos clave de la calidad percibida, respecto a tres dimensiones:

1) El compromiso con el servicio.

2) El rigor y control de la información.

3) La dimensión espacial de la biblioteca.

El cuestionario extraía información sobre el nivel de servicio que el usuario desearía recibir, el nivel mínimo de servicio que consideraba aceptable y el nivel realmente observado o experimentado. En opinión de Parasuraman (2002), de todas las adaptaciones que tuvo el modelo SERVQUAL en diferentes ámbitos, el modelo LibQUAL fue la adaptación más rigurosa y sistemática. Desde el año 2000, el modelo se extendió rápidamente en bibliotecas universitarias y de investigación norteamericanas y del Reino Unido. Tomando como base el modelo, se desarrollaron nuevas herramientas y aplicaciones informáticas, como LibQUAL+, que permitía recabar la opinión de los usuarios de bibliotecas y su análisis en poco espacio de tiempo. La utilidad de estas herramientas se viene demostrando desde entonces en numerosos estudios de evaluación (Atkinson y Walton, 2017; Cook y Heath, 2001; Cook et al., 2001; Kyrillidou, Olshen, Heath, Bonnelly y Côte, 2005; Kyrillidou y Persson, 2006; Pourahmad, Neshat y Hasani, 2016; Thompson, Cook y Heath, 2003a, 2003b; Thompson, Cook y Kyrillidou, 2005).

La perspectiva del usuario sigue presente en los estudios evaluativos, bajo la nueva línea de evaluación de la experiencia del usuario en el uso de los distintos recursos de las bibliotecas, tanto físicos como virtuales (Appleton, 2018; Fleming-May et al., 2018). 
En el apartado siguiente se hace un repaso sobre la utilización de las herramientas de evaluación del rendimiento en los distintos tipos de bibliotecas, y su plasmación en artículos de revistas y otros estudios especializados. Al final del apartado se revisan los principales trabajos sobre evaluación del rendimiento bibliotecario publicados en España. Como se verá, fue un campo que suscitó un fuerte interés en los años 90 y 2000 , principalmente en el ámbito de las bibliotecas universitarias y públicas.

\subsubsection{Estudios de rendimiento y calidad aplicados a los distintos tipos de bibliotecas}

En las normas internacionales anteriormente mencionadas sobre evaluación bibliotecaria se recoge una clasificación de los distintos tipos de bibliotecas, atendiendo a las especificidades en su misión y funciones. Seguiremos esta clasificación para agrupar las distintas publicaciones sobre evaluación del rendimiento, según se refieran a bibliotecas universitarias, públicas, escolares, especializadas o nacionales ${ }^{32}$.

Un repaso de la literatura especializada permite observar que la mayor parte de los trabajos publicados sobre evaluación del rendimiento han centrado su atención sobre las bibliotecas públicas y las bibliotecas universitarias. Con respecto a las bibliotecas

32 En este trabajo adoptamos la clasificación y definiciones de los distintos tipos de bibliotecas que ofrece la norma UNE en ISO 2789 de Estadísticas Internacionales para Bibliotecas:

a) bibliotecas universitarias: bibliotecas cuya función principal es satisfacer las necesidades de información en el ámbito del aprendizaje y la investigación (bibliotecas de instituciones de enseñanza superior, bibliotecas generales de investigación).

b) bibliotecas públicas: bibliotecas de tipo general que satisfacen las necesidades de información del conjunto de la población de una comunidad local o regional, con un papel importante de la formación de tipo formal e individual, la alfabetización, el aprendizaje permanente, el desarrollo creativo personal y las actividades de ocio.

c) bibliotecas escolares: bibliotecas vinculadas a todos los tipos de escuelas por debajo de la enseñanza superior y cuya función principal es atender a los alumnos y profesores de estas escuelas.

d) bibliotecas especializadas: bibliotecas que abarcan una disciplina o campo concreto del conocimiento o un interés regional o local especial, o que principalmente atienden a una categoría concreta de usuarios. Además, las bibliotecas especializadas pueden estar patrocinadas por una organización para ponerla al servicio de sus propios objetivos laborales. Ejemplos de bibliotecas especializadas son las bibliotecas del sector industrial y comercial, bibliotecas de medios de comunicación, bibliotecas gubernamentales, bibliotecas de servicios sanitarios, o bibliotecas de instituciones y asociaciones profesionales y científicas.

e) bibliotecas nacionales: bibliotecas que son responsables de adquirir y conservar ejemplares de todos los documentos relevantes del país en el que están situadas, normalmente a través del depósito legal. (Asociación Española de Normalización, 2014, p. 26). 
públicas, la mayor parte de los estudios se centraron en sistemas bibliotecarios de países de cultura anglosajona ${ }^{33}$. Entre ellos, destacaremos los realizados en Queensland (Stephens, 1992); Nueva Zelanda (Calvert y Cullen, 1992, 1994); Escocia (Midwinter y McVicar, 1996); Irlanda (Robinson, 1998); Nueva Gales del Sur (Graham, 1998); Estados Unidos (Bertot, 2000; Closter, 2015; Van House y Childers, 1993, 1994); Canadá (Meunier, 2004); Reino Unido (Fuegi, 2004) y Sufdáfrica (De Jager y Nassimbeni, 2005).

En el área de los países nórdicos se pueden destacar las experiencias evaluativas en los sistemas de bibliotecas públicas de Suecia (Adrial et al., 2005; Ögland, 2010) y Noruega (Redse y Ra, 2011; Saxrud, 2015). Entre las experiencias desarrolladas en otras áreas geográficas, destacan los casos de Francia (Faurio e Illien, 2006; GirardBillon y Giappiconi 1997); Italia (Galluzzi y Solimine, 1999); Eslovaquia (Segesova, 2000) y Japón (Shimoyama, Nishiura, Naka, Tsuji y Itsumura, 2013). Como se puede ver, estas experiencias se desarrollaron en países con sistemas bibliotecarios desarrollados.

Al igual que sucedía con las bibliotecas públicas, la mayor parte de los estudios de evaluación del rendimiento en bibliotecas universitarias se realizaron en países anglosajones con sistemas universitarios desarrollados, como por ejemplo: la red de la Society of College, National and University Libraries (SCONUL) en Reino Unido (Barton, 1997, 1998; Winkworth, 1990); Estados Unidos (Hiller, Kyrillidou y Self, 2006; Hiller y Self, 2004; Passonneau, 2013; Richard, 1992; Shapiro, 1991); Nueva Zelanda (Cullen y Calvert, 1996), el Council of Australian University Librarians (CAUL) (Byrne, 1997) y el

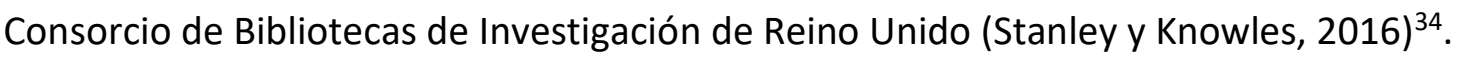

Entre los países del Norte de Europa destacaron los estudios sobre las bibliotecas universitarias de Dinamarca (Cotta-Schonberg y Line, 1994) y Finlandia (Saarti y Juntunen, 2013). Fuera de estas dos zonas geográficas principales, en los años 2000 se

\footnotetext{
${ }^{33}$ Un aspecto fundamental que contribuyó a la proliferación de los estudios en redes y sistemas bibliotecarios fue la experiencia previa de recopilación sistemática de datos estadísticos dentro de las redes bibliotecarias. Como ejemplo de ello, se puede mencionar el Statistics and Measurement Program, el modelo de centralización de datos estadísticos la Association of Research Libraries (ARL) (Kyrillidou, 2000; Stubbs, 1981) entre las bibliotecas universitarias de Estados Unidos y Canadá. Las series estadísticas de la ARL comenzaron en el año 1907, y en 1961 se empezaron a recoger con carácter anual. A partir de 1995, la ARL incluyó entre sus estadísticas una serie de nuevas medidas de rendimiento en forma de ratios sobre diferentes procesos internos y externos: circulación, referencia, préstamo interbibliotecario y suministro de documentos, sesiones de formación, etc.

34 El Research Libraries UK (RLUK) Consortium representa a las principales bibliotecas de investigación de Reino Unido e Irlanda, incluyendo más de veinte bibliotecas universitarias y las bibliotecas nacionales de Escocia, Gales y la British Library. En 2014, el RLUK desarrolló un conjunto de indicadores de calidad normalizados aplicables al conjunto de bibliotecas universitarias del país, con el fin de poder realizar estudios de benchmarking a nivel nacional.
} 
realizaron estudios de rendimiento en bibliotecas universitarias de Eslovenia (Ambrožič, 2000a, 2000b); Austria (Horvath, Bitzan, Gumpenberger, Kromp y Seissl, 2003); Polonia (Derfert-Wolf, Górski y Marcinek, 2004); Brasil (Das Graças Coletta y Rozenfeld, 2007); Portugal (Gaspar Pinto, 1994; Gaspar Pinto y Moscoso Castro, 2012; Melo, Pires y Taveira, 2008); Ghana (Badu, 2009); Kenia (Odera-Kwach y Ngulube, 2011); Taiwan (Wang y Liu, 2012) y Corea (Kim, Kwon, Yu y Choi, 2013).

Existen muy pocas publicaciones de evaluación de rendimiento en bibliotecas escolares. Se pueden citar los trabajos de Markless y Streatfield (2001) y Scott (2002) en Reino Unido y los de Zovko y Čelić-Tica (2012) en las bibliotecas de centros de educación primaria y secundaria de Croacia, donde la normativa bibliotecaria y educativa del país ordenaba la realización de este tipo de evaluaciones.

En el ámbito de las bibliotecas especializadas, las evaluaciones de rendimiento procuran mostrar la contribución de las bibliotecas a los objetivos de las organizaciones de las que dependen (McClure y Reifsnyder, 1984). Se pueden citar las evaluaciones realizadas en bibliotecas del ámbito de la salud (Briand et al., 2002; Dalton, 2012; Guimarães et al., 2007; Hewlett, 1998) y en bibliotecas que atienden a grupos específicos de usuarios, como el trabajo de Lithgow y Hepworth (1993) en bibliotecas de prisiones y el trabajo de Manžuch y Macevičiūtè (2016) en la Biblioteca para Ciegos en Lituania.

Existen muy pocas publicaciones académicas sobre evaluación del rendimiento en bibliotecas nacionales (Line, 2001; Poll, 2008c), y hasta fechas recientes la mayor parte de la información se encontraba en documentos no publicados. En la 69 Conferencia General de la IFLA, Ambrožič, Jakac-Bizjak y Mlekuš (2003) presentaron los resultados de un estudio sobre la situación de las bibliotecas nacionales europeas en cuanto a sus prácticas de gestión y evaluación ${ }^{35}$. Catorce de las bibliotecas nacionales europeas utilizaban indicadores de rendimiento, aunque solo ocho de ellas aplicaban indicadores normalizados.

Desde el ámbito de la normalización se dio respuesta a esta carencia con la publicación del Informe Técnico ISO/TR 28118 sobre indicadores de rendimiento para bibliotecas nacionales (Organización Internacional de Normalización, 2009). Desde la publicación de este Informe Técnico se ha avanzado en la introducción de mediciones de rendimiento en el ámbito de las bibliotecas patrimoniales, tal y como se refleja en los trabajos de Hashizume (2008) en Japón; La Mano González y Albelda Esteban (2009) en España; Redse y Ra (2011) en Noruega y Laitinen (2013) en Finlandia. En estos trabajos se mencionaba la importancia de contar con un modelo común para la evaluación comparativa de estas instituciones históricas que comparten una misma

${ }^{35}$ En el mismo marco internacional se anunció el lanzamiento de una encuesta entre treinta bibliotecas nacionales de la región de Asia y Oceanía (Baba y Shukor, 2003), aunque no se llegaron a publicar los resultados. 
misión de conservación del patrimonio, aunque estén enmarcadas en sistemas normativos diferentes y puedan divergir en cuanto a sus respectivos contextos socioeconómicos y culturales.

Para cerrar este apartado, haremos un repaso de los estudios de evaluación del rendimiento en España. En la bibliografía española no abundan las citas sobre evaluación en bibliotecas, siendo la fuente principal para su estudio la literatura gris en forma de memorias e informes de organismos e instituciones. Las primeras publicaciones académicas datan de los años 90 y se encuadran dentro de la corriente de la gestión de la calidad total (Caldera Morillo, Pirela Morillo y Ortega, 2011; Duarte Barrionuevo, 1995; La Mano González, 1998; Pinto Molina, 1998; Pinto Molina, Balagué Mola y Anglada i de Ferrer, 2007; Valls Pasoia y Casado, 1994), y la incorporación de las técnicas de la gestión pública y sus herramientas para la toma de decisiones (Bosch y Espelt, 1999; López Gijón y Vílchez Pardo, 1994; Morena de Diago, 2013; Vílchez Pardo, 1997).

Junto a los estudios que abordaron de una forma integral la evaluación de la biblioteca, otros estudios pusieron el foco en la evaluación del rendimiento de procesos, recursos o servicios específicos, como, por ejemplo: de los nuevos servicios electrónicos (Borrego Huerta y Urbano, 2005; Puente Lanzarote, Campo Hilario y Ruiz de Luzuriaga Peña, 2001); de la gestión de las colecciones (Massísimo i Sánchez de Boado, 2004; Pérez López, 2002); de los procesos técnicos (Cerezo López, Alonso Cervero y Gómez Pérez, 2002); de los medios sociales (González FernándezVillavicencio, Menéndez Novoa, Seoane García y San Millán Fernández, 2013) y de los servicios de referencia (González Fernández-Villavicencio, Cánovas Álvarez y Arahal Junco, 2014).

En bibliotecas universitarias españolas, las primeras experiencias se dieron en el marco de los procesos de evaluación que se desarrollaron desde 1996 dentro de los planes nacionales de evaluación de la calidad de las universidades, impulsados desde el Consejo de Coordinación Universitaria. Como señalaron Moscoso y Martínez del Valle (2009) al estudiar el caso español: "las bibliotecas han sido los primeros servicios universitarios que han contado con indicadores analizados de forma sistemática. $Y$ en ello la labor realizada por la Red de Bibliotecas Universitarias (REBIUN) ha sido fundamental” (p.173).

Entre las evaluaciones en bibliotecas universitarias, se pueden mencionar, por comunidades autónomas: Cataluña (Anglada i de Ferrer, 1999), Andalucía (Díaz, Barrionuevo, Martínez, Reche y Pérez, 2005), Murcia (Cobacho Gómez y Brugarolas Ros, 2006), Universidad Jaume I de Castellón (Falomir y Segarra, 2006), Universidad Complutense de Madrid (Gimeno Perelló, 2006; Simón de Blas, Arias Coello y Simón Martín, 2007), Universidad de Vigo (Marraud González, 2006). En todas ellas se combinó el enfoque cuantitativo con el punto de vista de los grupos de interés 
(Moscoso y Martínez del Valle, 2009) y la perspectiva del usuario (Játiva Miralles y Gallo León, 2006; López Gijón, Ávila Fernández, Pérez Gálvez y Herrera Viedma, 2010).

En paralelo a las evaluaciones se desarrollaron los primeros procesos de obtención de sellos de excelencia (Balagué Mola, 2007) mediante la introducción de los modelos de calidad reconocidos y las normas ISO 9000. En el caso de las bibliotecas universitarias de Andalucía (Celestino Angulo, 2006; Moreno Martínez y García Reche, 2006; Puy Moreno, 2000) y el Consorcio de Bibliotecas Universitarias de Cataluña (CBUC) (Anglada i de Ferrer, 1999; Balagué i Mola, 1999), trabajaron con sus propios modelos de evaluación.

En cuanto a las bibliotecas públicas españolas, las VII Jornadas sobre Bibliotecas Públicas celebradas en San Sebastián en 1995 (Asociación de Bibliotecarios y Documentalistas de Guipúzcoa, 1996) trataron de forma monográfica sobre la evaluación de los servicios de las bibliotecas, como herramienta para el cambio y la mejora de los sistemas bibliotecarios públicos (López Gijón, 1996; Vernis Domenech, 1996). Entre las experiencias concretas de evaluación del rendimiento se pueden mencionar los trabajos de la Biblioteca Pública de Valencia (Cortés Villalba y Gil Leyva, 2011), la Diputación de Barcelona (Omella Claparols, Permanyer Bastardas y Vilagrosa Alquézar, 2009) y las Bibliotecas Municipales de Cartagena (Belda González y Mercader Blanco, 2004).

Por su parte, la Biblioteca Nacional de España (BNE) empezó a trabajar con indicadores de rendimiento en 2008, y desde entonces ha publicado anualmente sus informes anuales de indicadores (Albelda Esteban, 2012). Asimismo, la BNE ha tenido desde entonces un papel activo en los proyectos internacionales de normalización de indicadores para bibliotecas (La Mano González y Albelda Esteban, 2009).

Por último, mencionaremos los escasos trabajos sobre experiencias de evaluación del rendimiento en bibliotecas escolares españolas (Faba Pérez, 2010; Ferrer y Moscoso Castro, 2011) y en bibliotecas especializadas (Gutiérrez, 2001; Malo de Molina Martin Montalvo y Quintana Martínez, 1995).

Recopilando todo lo visto hasta ahora, se puede observar una evolución en los estudios de evaluación del rendimiento, tanto en su objeto de interés, como en sus aspectos metodológicos. En cuanto al objeto de interés, la primitiva visión mecanicista y cuantitativa, orientada a la rendición de cuentas, fue dejando paso a nuevos trabajos, que, sin abandonar este tipo de información cuantitativa, desplazaban el foco de la evaluación desde la perspectiva gerencial de los primeros estudios, hasta una nueva perspectiva centrada en la calidad, cuyo centro era el usuario de los servicios. Desde esta nueva visión, era primordial conocer la calidad percibida por el usuario para poder satisfacer sus expectativas. 
A los estudios de evaluación de la calidad percibida les siguieron los estudios de evaluación del impacto, que se estudiarán en el siguiente apartado. Haciendo uso de metodologías cada vez más sofisticadas, estos trabajos introdujeron el análisis del valor social y económico de las bibliotecas, y su poder transformador en sus comunidades de usuarios y en la sociedad en general ${ }^{36}$.

Las evaluaciones de impacto se empezaron a producir en el contexto de las profundas transformaciones que vivieron las bibliotecas con la introducción de las nuevas tecnologías digitales, con el impacto de la crisis económica, y con el desarrollo de la nueva sociedad de la información y sus nuevas formas de comunicación interactiva en redes. Como veremos, los estudios de evaluación más recientes constituyen una aproximación a los nuevos roles que han ido asumiendo los distintos tipos de bibliotecas, y sirven no sólo para rendir cuentas, sino para reivindicar su valor en estos nuevos contextos sociales.

Atendiendo a los aspectos metodológicos, los estudios de evaluación bibliotecaria han ido ganando en complejidad, a medida que se exploraban nuevas metodologías para la obtención y el análisis de evidencias ${ }^{37}$. Por un lado, la visión cuantitativa se ha enfrentado al reto de medir la nueva realidad del mundo digital, cuyos límites a veces

\footnotetext{
${ }^{36}$ Entre los estudios de impacto, hay que destacar aquéllos en los que predomina la perspectiva económica. Como se verá más adelante, el objetivo de estos trabajos es cuantificar en términos monetarios el valor y los beneficios que reportan las bibliotecas a la sociedad.

${ }^{37}$ La investigación sobre nuevos métodos de obtención y análisis de evidencias de impacto se ha enriquecido con las aportaciones realizadas desde el movimiento conocido como "Biblioteconomía Basada en la Evidencia" o "Gestión Bibliotecaria Basada en la Evidencia" (Booth y Brice, 2004; Connor 2007; Kakirman Yildiz, 2012; Russell, 2008). Esta corriente profesional inspirada en el modelo de la medicina basada en la evidencia se ha desarrollado a partir de mediados de los años 90, primero en el ámbito de las bibliotecas especializadas en ciencias de la salud de Reino Unido, Canadá y Estados Unidos, y en la actualidad en todo tipo de bibliotecas en el ámbito internacional. Como advierten Booth y Brice (2004), dentro de esta corriente conviven los enfoques cuantitativitas y cualitativitas, sin que se considere la superioridad de uno sobre otro, ya que la cuestión fundamental es escoger la metodología más apropiada según el tipo de pregunta que se formule en la investigación. Estos planteamientos han influido de forma significativa en los estudios de evaluación, por su carácter empírico, su orientación pragmática y su apertura metodológica. Como señala Connor (2007), en esta corriente se sigue un proceso semejante al del método científico clásico, pero se diferencia principalmente de él en que su fin es de carácter eminentemente pragmático, pues está orientado a la toma de decisiones de gestión con base en información y evidencias. Como explica Kakirman Yildiz (2012), los seguidores de esta corriente tratan de superar la brecha entre la teoría y la práctica de la Biblioteconomía, siguiendo un proceso secuencial que, se inicia con la formulación de un problema o pregunta, continúa con la búsqueda y la selección crítica de respuestas entre la literatura profesional y otras fuentes en busca de evidencias, la selección de la metodología adecuada, la intervención o aplicación práctica a un caso concreto y la evaluación de los resultados obtenidos. La Biblioteconomía Basada en la Evidencia ha contribuido al desarrollo de estudios evaluativos en el ámbito de los servicios de información.
} 
escapaban al control de la propia biblioteca ${ }^{38}$. Por otro lado, como ya hemos visto, los estudios cuantitativos de evaluación del rendimiento fueron incorporando la perspectiva del usuario, abriéndose así paulatinamente a la visión cualitativa. Más aún, con la exploración de nuevas metodologías tomadas de las Ciencias Sociales para la obtención y el análisis de datos, como, por ejemplo, el retorno a la inversión o la valoración contingente - ambos tomados de la Economía - se han ampliado las posibilidades de evaluación de la visión cualitativa. En los estudios de evaluación más recientes es frecuente la integración de métodos con una doble visión cuantitativa y cualitativa.

Por último, cabe destacar la publicación de la norma ISO 16439 (Organización Internacional de Normalización, 2014b), que marcó un hito en la consolidación de los estudios de impacto bibliotecario, tanto por su contribución a la sistematización de los distintos métodos y procedimientos existentes, como por su aportación a la normalización terminológica en este ámbito. Retomamos esta norma en sucesivos capítulos de esta tesis como referente para construir nuestro marco conceptual y metodológico.

\footnotetext{
38 La investigación cuantitativa ha explorado la forma de obtener nuevos datos estadísticos e indicadores de rendimiento a medida que los recursos electrónicos y las nuevas tecnologías digitales se abrían paso junto a los servicios y recursos bibliotecarios tradicionales. Ejemplo de ello fueron los estándares de evaluación del rendimiento ISO 11620 (Organización Internacional de Normalización, 2008), que en su segunda edición incorporó la medición de servicios electrónicos, e ISO/TR14873 (Organización Internacional de Normalización, 2013b), donde se abordó la evaluación de la calidad en el archivado de la web. Con la introducción de los recursos electrónicos en las bibliotecas, las bibliotecas dependen en gran medida de los datos estadísticos suministrados por los agregadores y proveedores de servicios. Las bibliotecas han reaccionado ante la falta de normalización en la provisión de estos datos por parte de muchos de estos proveedores. Ejemplo de ello es la iniciativa COUNTER para la normalización de datos estadísticos de uso de recursos electrónicos (Shepherd, 2003).
} 


\section{CAPÍTULO 2. Estudios de evaluación del impacto en el ámbito de las bibliotecas}

\subsection{Contexto de los estudios sobre impacto bibliotecario}

Los actuales sistemas bibliotecarios de carácter público son instituciones que se han desarrollado al abrigo del Estado del bienestar en las sociedades desarrolladas. En el contexto de la crisis económica global de los últimos años y del desarrollo de la nueva sociedad del conocimiento, con sus nuevas formas de interacción en red, y una economía que se desarrolla sobre las nuevas tecnologías de la información y la comunicación, existe una presión creciente sobre las bibliotecas para que éstas muestren evidencias de su contribución en este nuevo entorno. Incluso, algunos autores han señalado que las bibliotecas se han visto de algún modo obligadas a realizar estudios sobre su impacto como una forma de "justificar su existencia" (McMenemy, 2007). Ya en los años 90 se realizaron algunos trabajos cualitativos cuyo propósito era evaluar la repercusión que había tenido el cierre de una determinada biblioteca sobre el conjunto de la comunidad de su área de influencia (Proctor, Usherwood y Sobczyk, 1996) o sobre grupos específicos de usuarios. Así, por ejemplo, el estudio de Reilly (1997) demostró que el cierre de las bibliotecas públicas de Sheffield (Reino Unido) en 1995, había tenido un impacto negativo sobre las oportunidades educativas y de integración de la juventud de la localidad.

Podemos decir que la evaluación del impacto es en nuestros días un área de interés estratégico en el ámbito bibliotecario (Madsen y Hurst, 2018). Los estudios sobre impacto se emplean en un doble sentido: como instrumento de evaluación y como instrumento para reivindicar el valor de las bibliotecas (Imholz y Arns, 2007; Seppänen y Laitinen, 2012; Wavell, Baxter, Johnson y Williams, 2002; Williams, Wavell, Baxter, MacLennan y Jobson, 2005).

Desde su experiencia, Markless y Streatfield (2007) advirtieron que existía un interés cada vez mayor por recoger evidencias de impacto debido a tres motivos principales: una cierta "obsesión" por la rendición de cuentas en las instituciones públicas, una preocupación creciente por el coste-beneficio y una aspiración por trabajar con decisiones fundamentadas sobre evidencias. Los autores recogieron las opiniones de una muestra de responsables de bibliotecas respecto a la creciente necesidad de obtener evidencias en su día a día. Estos fueron los principales argumentos que expresaron a favor de la evaluación del impacto (en orden de importancia decreciente): 
1) El interés por conocer la manera de mejorar los servicios.

2) La necesidad de responder ante la rendición de cuentas externa.

3) La necesidad de responder ante la rendición de cuentas interna.

4) La importancia de demostrar los resultados de la gestión.

5) La necesidad de obtener mayor reconocimiento entre los usuarios y en la sociedad en general.

6) Para obtener mayores recursos.

7) Por supervivencia, frente a amenazas de recortes presupuestarios o cierre de servicios.

Por su parte, las asociaciones de profesionales bibliotecarios han venido actuando como grandes impulsoras de estudios de impacto para reivindicar el valor de las bibliotecas y para defender su permanencia en un mundo sometido a constantes cambios. En este contexto, los distintos tipos de bibliotecas estarían capacitadas para jugar nuevos roles en beneficio de la sociedad: como soporte para la economía del conocimiento, como apoyo a la educación y como espacio para el fomento de la cohesión social. En la norma ISO 16439 sobre evaluación del impacto (Organización Internacional de Normalización, 2014b), se expresó de esta manera el contexto de creciente presión que han vivido y siguen viviendo las bibliotecas, en tanto que organizaciones sin ánimo de lucro, para mostrar evidencias de su valor en la sociedad:

Recientemente, ha habido una demanda creciente para las organizaciones sin ánimo de lucro para que prueben su valor para los individuos, para sus organizaciones y para la sociedad en general. Para las bibliotecas, este valor se ha aceptado tradicionalmente como algo evidente. Sin embargo, los usuarios cada vez son más independientes en sus búsquedas de información, y la información parece estar accesible en la web, de tal forma que los beneficios obtenidos por los servicios bibliotecarios son cuestionados no solamente por las instituciones financiadoras sino también por el público. Las bibliotecas han respondido a esta demanda y han desarrollado y probado métodos para identificar y probar sus beneficios a usuarios y a la sociedad ${ }^{39}$ (p. 13).

39 Traducido del original: "In recent years, there has been a growing demand for non-profit organizations to show proof of their value for individuals, for their parent organizations and for society. For libraries, such value has traditionally been accepted as self-evident. However, users are becoming increasingly independent in their information seeking practices, and information seems to be free on the web, so that the benefits gained from library services are questioned not only by funding institutions but also by the public. Libraries have responded to this demand and have developed and tested methods for identifying and proving their benefits to users and society" (Organización Internacional de Normalización, 2014b, p. 13). 
En efecto, el leitmotiv que se repite en buena parte de los estudios de impacto guarda relación con la defensa de los valores propios de las sociedades democráticas desarrolladas, como, por ejemplo, el acceso a la educación, la cohesión social y el acceso a la información. Se trata por tanto de demostrar por medio de evidencias, que las bibliotecas son instituciones necesarias y beneficiosas para la sociedad, y que contribuyen al sostenimiento de los valores democráticos ${ }^{40}$ y al desarrollo de la economía del conocimiento mediante el libre acceso a la información. Con estas palabras lo expresó Sipilä (2015) desde su posición como presidenta de la IFLA entre 2013 y 2015 :

Creo firmemente que las bibliotecas ejercen un impacto fundamental en la sociedad impulsando la igualdad de oportunidades y ofreciendo acceso igualitario al aprendizaje a lo largo de la vida y a la educación, la investigación y la innovación, la cultura y el ocio para toda construir comunidades y sociedades más fuertes (pp. 95-96).

En esta misma línea de reflexión sobre el valor de las bibliotecas, Brophy (2005, p. 45) distinguió tres grandes ámbitos de aplicación de los estudios de impacto: el ámbito de decisión de las políticas públicas, la gestión estratégica y la gestión operacional.

1) En el ámbito de decisión de las políticas públicas, los estudios sobre el impacto servirían para influir sobre los poderes públicos:

- Para impulsar a los gobiernos a incluir a las bibliotecas en las políticas de inclusión social y aprendizaje a lo largo de la vida.

- Para convencer a los gobiernos locales de la importancia de destinar una parte del presupuesto a las bibliotecas.

- Para persuadir a potenciales colaboradores (otras instituciones culturales, educativas y sociales, empresas, etc.) sobre los beneficios potenciales de colaborar con la biblioteca.

2) En la gestión estratégica:

- Para ayudar a identificar áreas de mejora e inversión.

- Para evaluar los resultados obtenidos tras el desarrollo de un programa o un plan determinado.

40 Desde la Asociación Americana de Bibliotecarios se defienden el bien público y la democracia como "valores esenciales" de las bibliotecas (American Library Association, 2004). Por otra parte, la Declaración de Lyon lanzada en el marco del Congreso Mundial de la IFLA proclamó que "el acceso a la información y las habilidades para utilizarla eficazmente son obligatorios para el desarrollo sostenible" (Federación Internacional de Asociaciones de Bibliotecarios y Bibliotecas, 2014). 
3) En la gestión operacional:

- Para ayudar a comprender en equilibrio entre inversión e impacto.

- Para ayudar a comprender las diferentes respuestas a las necesidades de los distintos grupos de usuarios.

- Para ofrecer datos comparativos con los que controlar el efecto de los cambios operativos introducidos en la gestión de los servicios.

Una vez esbozado el contexto en el que surgen y se desarrollan las evaluaciones de impacto, a continuación, se aborda la cuestión terminológica y conceptual que se plantea en este tipo de estudios. Como veremos, se trata de una cuestión compleja, debido a dos razones principales: por una parte, a la ausencia de modelos comunes, $y$, por otra parte, a que encontramos en la literatura profesional una variedad de trabajos, con aproximaciones evaluativas distintas, que son denominados bajo el término común de "estudios de impacto".

\subsection{Terminología y conceptos empleados en la evaluación del impacto en bibliotecas}

De la revisión de la literatura sobre impacto en bibliotecas se observa que existe cierta inconsistencia respecto a la terminología utilizada. Los autores anglosajones han utilizado indistintamente los términos "value", "outcome", "impact" y "benefit"41 42, y en nuestra lengua se han empleado como sinónimos los términos "valor", "beneficio" e "impacto", para denominar estudios con aproximaciones diversas. En opinión de Urquhart y Turner (2016, p. 17), se ha dado una "considerable confusión" en el empleo de esta terminología en la literatura profesional.

Saracevic y Kantor (1997a) profundizaron sobre la polisemia del concepto de "valor"- traducido del término inglés value - desde su sentido económico y filosófico primigenio, hasta su significado en el contexto de la sociedad del conocimiento o sociedad de la información posindustrial. En este nuevo contexto dominado por la tecnología y la economía del conocimiento, a los servicios de información se les

${ }^{41}$ Como señala Powell (2006, p. 106) no existe consenso entre los autores en el uso de los términos impact y outcome, y con frecuencia se emplean como sinónimos.

42 Es también frecuente encontrar la distinción entre beneficios intencionados (buscados mediante la puesta en marcha de programas bibliotecarios) y beneficios inesperados (los que se han producido, aunque de manera no intencionada), y entre beneficios directos o inmediatos e indirectos o a largo plazo (Markless y Streatfield, 2007). En los estudios de impacto económico suele emplearse el término "retorno" o "retorno a la inversión" que hace referencia a la expresión, en términos monetarios, del beneficio resultante de la inversión de recursos bibliotecarios. 
atribuiría un "valor de intercambio" y un "valor de uso". El valor de intercambio sería el precio de mercado de un bien o un servicio. Este concepto se correspondería con una visión económica restringida a los valores del mercado. En cuanto al valor de uso, se correspondería con una visión económica de corte utilitarista y se referiría a las dimensiones intrínsecas de los bienes: la demanda, la utilidad, el placer, la satisfacción, etc. Así lo resumían Saracevic y Kantor (1997a) ${ }^{43}$ :

el valor de una biblioteca y un servicio de información es una evaluación por parte de los usuarios (o sustitutos de éstos) de la calidad de la interacción que se produce con el servicio, y los beneficios resultantes de dicha interacción, puestos en relación con los motivos de usar ese servicio (p. 540)

Además, los autores establecieron una diferenciación entre el valor producido por los bienes tangibles (servicios, productos, y en general, todos aquellos bienes a los que se puede atribuir un valor monetario de mercado) y el valor producido por los bienes intangibles (aquellos bienes a los que no es posible atribuir un valor monetario, por ejemplo: conocimiento, tiempo, información, educación, calidad de vida, etc. $)^{44} 45$.

${ }^{43}$ Traducido del original: "The value of a library and information service is an assessment by users (or user surrogates) of the qualities of an interaction with the service and the worth or benefits of through these models, we now have answers how to approach the fundamental questions: What relations and the results of interaction, as related to the reasons for using the service" (Saracevic y Kantor, 1997a, p. 540).

44 El concepto de "Economía de los bienes intangibles" se acuñó para definir la tendencia a la desmaterialización en las transacciones de bienes y servicios que caracterizan la economía de la sociedad posindustrial. A la producción y transacciones de bienes tangibles que caracterizaron la época industrial le ha seguido un nuevo orden económico donde "el valor y la riqueza ya no es la producción de bienes materiales, sino la creación y manipulación de contenido desmaterializado" (Goldfinger, 1997, p. 191). La economía de los intangibles se caracteriza por tres tendencias principales: 1) La importancia del sector servicios sobre otros sectores productivos, 2) la globalización de la economía sobre el desarrollo de las nuevas tecnologías y 3) la importancia de la información y el conocimiento, junto al desarrollo de las nuevas tecnologías de la información y la comunicación. Como han señalado algunos autores, las fronteras de la economía de los intangibles son aún imprecisas (Koppius, 1999). Como señala Goldfinger (1997, p. 198), no solamente comprende los bienes relacionados con la información y el conocimiento, sino también bienes y actividades de ocio, juegos, deportes, etc.

${ }^{45}$ Saracevic y Kantor (1997a, 1997b) propusieron una aproximación evaluativa donde se distinguían seis áreas de impacto, que se correspondían con seis tipos de beneficios que obtenían los usuarios en su interacción con los recursos de las bibliotecas. Para cada una de las áreas de impacto se presentaba una escala que abarcaba distintos grados de impacto:

1) Beneficios de tipo cognitivo: la escala de impacto comprendía desde la ausencia de transmisión de conocimiento hasta la adquisición de conocimiento en su máximo grado de impacto.

2) Beneficios de tipo afectivo: la escala de impacto abarcaba desde la frustración hasta la satisfacción personal.

3) Satisfacción de expectativas: la escala de impacto abarcaba desde la insatisfacción del usuario hasta la satisfacción de sus expectativas. 
Como se verá más adelante, esta diferenciación entre bienes tangibles y bienes intangibles, que aparece ya expresada en este trabajo de 1997, es fundamental para la comprensión de los estudios de impacto aplicados al ámbito de las bibliotecas y de otras instituciones y bienes culturales, donde nos enfrentamos ante la dificultad de cuantificar el valor de los intangibles. Sobre este punto concreto se profundizará más adelante cuando tratemos sobre la evaluación del impacto económico.

En la misma línea, Rubin (2006) profundizó sobre el concepto de impacto, utilizando indistintamente los términos "outcome" e "impact". Para esta autora, los outcomes serían la expresión concreta del impacto, y formarían parte de la planificación y la evaluación de programas bibliotecarios orientados a producir cambios, o a cubrir determinadas necesidades de la comunidad de usuarios:

Los outcomes son los beneficios del usuario final, que demuestran la efectividad de un programa o servicio. La mayoría de estos beneficios son cambios en el comportamiento, habilidades, actitud, comportamiento o condición. Hay que decir que la persona podría haber alcanzado estos logros con o sin el contacto con la biblioteca. No obstante, la biblioteca aporta una gran contribución para su consecución. Los outcomes pueden considerarse también como los resultados clave o los logros alcanzados por el usuario. Dada esta definición de outcomes, su medición responde a la pregunta: ¿Qué diferencia supuso nuestro programa para todos aquellos que se beneficiaron del mismo? El impacto o outcome de nuestro programa se puede interpretar como los beneficios que experimenta el usuario (...). La medición de los outcomes es una aproximación orientada al usuario que se da en la planificación y la evaluación de servicios y programas que buscan cubrir necesidades específicas o producir determinados cambios en los usuarios. La medición de los outcomes - también conocida como evaluación basada en outcomes, evaluación de outcomes o evaluación basada en resultados - es un método para planificar y evaluar el impacto de un programa. Aunque la

4) Realización de tareas como resultado de la interacción con la biblioteca: la escala de impacto abarcaba desde la ausencia de aprendizaje por parte del usuario hasta el máximo grado de impacto, que se produce cuando el usuario se siente capaz de tomar decisiones informadas y descubrir recursos de información por sí mismo como resultado de su contacto con la biblioteca.

5) Efectos relacionados con el tiempo: la escala de impacto comprendía desde la necesidad del usuario de invertir su tiempo en conocer los recursos ofrecidos por la biblioteca, hasta obtener un ahorro de tiempo al poder acceder a esos recursos.

6) Aspectos económicos: la escala de impacto comprendía desde el coste que se produce cuando el servicio no está disponible o no ha sido satisfactorio para el usuario, hasta la obtención de un beneficio económico o retorno a la inversión, es decir, el valor monetario que revierte por cada euro que se han invertido en la biblioteca. 
medición de outcomes pueda resultar un término nuevo para muchos de nosotros, sin embargo, los outcomes son un concepto familiar. Son la intersección entre las necesidades de la comunidad, la finalidad del servicio y la respuesta del servicio bibliotecario (actividades) ${ }^{46}$ (pp. 2-3).

La autora diferenciaba entre outcomes o impactos a corto plazo, es decir, los beneficios visibles y medibles ya en el primer año de puesta en marcha de un programa; y los beneficios producidos en el largo plazo, es decir, aquellos cambios que no se harían visibles hasta al menos dos años desde el inicio del programa bibliotecario. Para Rubin, el alcance de la evaluación del impacto debía circunscribirse al contexto de un determinado programa bibliotecario previamente planificado y orientado a producir cambios concretos sobre determinados usuarios. Consistiría, por tanto, en evaluar los efectos producidos en los usuarios como resultado de su contacto con el programa bibliotecario. Las características definitorias de los outcomes o impactos serían las siguientes:

1) Suelen responder a una necesidad concreta de un grupo claramente definido.

2) Se dan cuando se persigue producir un impacto sobre la gente, no ofrecer un producto.

3) Se focaliza sobre los efectos y resultados, no sobre los procesos.

4) Se corresponden con programas que están diseñados para que los usuarios participen más de una vez a lo largo de un periodo de tiempo, de forma que el cambio pueda evidenciarse.

5) Contribuyen a lograr objetivos de mayor alcance dentro de la comunidad y forman parte de la misión de la biblioteca.

El término "impacto" se ha utilizado de forma común para designar estudios con planteamientos y aproximaciones muy diferentes. En este sentido, se podría decir que

\footnotetext{
${ }^{46}$ Traducido del original: "Outcomes are benefits to the end user that demonstrate the effectiveness of a program or service. Most of these benefits are changes in knowledge, skills, attitude, behaviour or condition. Note that these are accomplishments that the participant may or may not have experienced without the library program, but to which the library is a significant contributor. Outcomes can also be considered the key results or consequences sought by a user. Given these definitions of outcome, outcome measurement answers the question: "What difference did our program make to the participant?". The impact or outcome of our program can be seen in gains for the user (...). Outcome measurement is a user centred approach to the planning and assessment of programs or services that are provided to address user needs and designed to achieve change for the user. Outcome measurement - also known as outcome-based evaluation, outcome assessment, or results-based evaluation - is a method of planning for and measuring program impact. Although outcomes may be a new term for many of us, outcomes are familiar. They are the intersection of community needs, service goals, and library service responses (activities)" (Rubin, 2006, pp.2-3).
} 
estamos ante un término "paraguas", que se ha empleado con cierta inconsistencia en el ámbito de la evaluación bibliotecaria. En la literatura especializada se pueden encontrar trabajos donde se utiliza el término "impacto" como sinónimo de resultados de salida o "outputs". Estos resultados de salida, como el número de visitas a la biblioteca y el número de préstamos, que informan sobre los niveles de uso y de actividad de la biblioteca, se consideran como evidencias de impacto por algunos autores. La interpretación sería la siguiente: cuanto más altas fueran estas cifras de uso y actividad, mayor sería el impacto de la biblioteca sobre su entorno.

No obstante, para otros autores, los outputs no proporcionan por sí mismos evidencias de impacto. Siguiendo esta línea, la Association of College and Research Libraries $^{47}$ (ACRL) (1998) preparó un informe sobre evaluación del impacto en bibliotecas universitarias donde recomendó el empleo de outcomes para mostrar el impacto de las bibliotecas, siendo los outputs insuficientes para este fin:

Los outcomes, en nuestra opinión, son las maneras en las que los usuarios de las bibliotecas experimentan cambios como resultado del contacto con los recursos y programas de la biblioteca (...). Los outcomes importantes para una biblioteca universitaria incluyen las respuestas a preguntas como estas: ¿el resultado académico de los estudiantes ha mejorado por su contacto con la biblioteca?; ¿usando la biblioteca los estudiantes mejoran sus oportunidades de obtener una carrera exitosa?; ¿los estudiantes que frecuentan la biblioteca tienen mayores probabilidades de graduarse?; ¿el programa de formación bibliográfica de la biblioteca da como resultado una mayor alfabetización informacional de los estudiantes?; como resultado de la colaboración con el personal de la biblioteca, ¿es más probable que el profesorado considere la biblioteca como parte de su programa académico? (...). Es importante registrar los outputs de la biblioteca, pero es insuficiente para evaluar los outcomes (párr. 21-29) ${ }^{48}$.

${ }^{47}$ La ACRL es la mayor división de la American Library Association (ALA). En 1996, la ACRL creó un Grupo de Trabajo sobre Impacto Bibliotecario - la Task Force on Academic Library Outcomes Assessment - responsable de elaborar un estudio que sirviera para promover la evaluación del impacto en bibliotecas universitarias.

${ }^{48}$ Traducido del original: "Outcomes, as viewed by the Task Force are the ways in which library users are changed as a result of their contact with the library's resources and programs (...). The important outcomes of an academic library program involve the answers to questions like these: Is the academic performance of students improved through their contact with the library?; By using the library, do students improve their chances of having a successful career?; Are undergraduates who used the library more likely to succeed in graduate school?; Does the library's bibliographic instruction program result in a high level of "information literacy" among students?; As a result of collaboration with the library's staff, are faculty members more likely to view use of the library as an integral part of their courses?; Are students who use the library more likely to lead fuller and more satisfying lives? (...). It is important to track the library's outputs, but insufficient for assessing outcomes" (Association of College and Research Libraries, 1998, párr. 21-29). 
Con un planteamiento similar, Poll (2003) subrayó que "ni la calidad de los servicios bibliotecarios, ni la cantidad de su uso proporcionan evidencia del impacto sobre los usuarios $^{49 "}$ (p. 1). Abundando sobre la misma idea, Huysmans y Oomes (2013), en su estudio del impacto de las bibliotecas públicas de Holanda, indicaron que debía distinguirse entre los outputs (las salidas o productos resultantes de una actividad o servicio, expresados mediante datos cuantitativos) y los outcomes (los beneficios o impactos resultantes sobre la vida de las personas, los grupos y la sociedad en general, por ejemplo, cambios en actitudes, en conocimiento, en comportamiento, en habilidades, en la situación socioeconómica). Para estos autores, era imposible demostrar el impacto mediante outputs:

Durante mucho tiempo, las bibliotecas públicas han recopilado estadísticas sobre su rendimiento (...). Este tipo de cifras sirven para dibujar un mapa sobre la expansión del sector y para tener unas medidas muy rudimentarias sobre su impacto social. Sin embargo, si lo que se quiere es demostrar el valor de las bibliotecas públicas a determinados observadores, como los financiadores, estas mediciones son claramente insuficientes. No es lo mismo que un libro haya sido prestado que haya sido leído o consultado. Lo que nos gustaría saber es en qué medida la lectura de ese libro ha contribuido al conocimiento o a la visión del mundo del usuario. Aquí es donde se ve la distinción entre outputs y outcomes $^{50}$ (Huysmans y Oomes, 2013, p. 169).

Partiendo de esta diversidad terminológica y conceptual constatable en la literatura especializada, la publicación de la norma ISO 16439 sobre medición del impacto en bibliotecas significó un hito importante para los estudios de evaluación. En la norma se estableció un vocabulario común y se proporcionó un corpus de definiciones que podían aplicarse a cualquier tipo de biblioteca. En ella se definen los outputs como: "el producto de los procesos bibliotecarios ${ }^{51 "}$ (Organización Internacional de Normalización, 2014b, p. 8).

\footnotetext{
${ }^{49}$ Traducido del original: "neither the quality of library services nor the quantity of their use gives evidence as to the impact on users" (Poll, 2003, p. 1).

50 Traducido del original: "For long, public libraries have collected statistics on their performance (...). Numbers like these are valuable for mapping the sector's expansion and having crude measures of its societal impact. However, if one's aim is to demonstrate the public library's value to critical observers like subsidy providers, these measures quickly fall short. A book having been borrowed does not equal a book having been read or consulted. One would want to know what reading a book has contributed to a person's worldview or knowledge. Here, we touch upon the distinction between outputs and outcomes" (Huysmans y Oomes, 2013, p. 169).

51 Traducido del original: "output: products of library processes" (Organización Internacional de Normalización, 2014b, p. 8).
} 
El término value se define como "la importancia que los distintos grupos de interés (...) otorgan a la biblioteca, lo cual guarda relación con la percepción del beneficio real o potencial ${ }^{52 "}$ (Organización Internacional de Normalización, 2014b, p. 12).

La norma establece una distinción entre el término outcomes e impact: los outcomes son "los efectos directos de los outputs en relación con la planificación de la biblioteca, como, por ejemplo, número de usuarios, los niveles de satisfacción de los

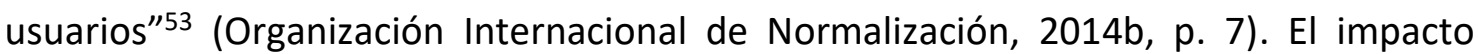
tiene que ver con las transformaciones producidas en individuos o grupos asociadas al uso de la biblioteca (Organización Internacional de Normalización, 2014b, p. 4). Esta diferencia de significado entre outcome e impact no es traducible al castellano, y en su lugar se emplea el término genérico "impacto".

Además de recoger definiciones de los conceptos principales, la norma diferenció distintas dimensiones o tipos de impacto (Organización Internacional de Normalización, 2014b, pp. 13-14):

- Según la inmediatez con la que se produzca el impacto: puede ser un impacto inmediato o a largo plazo.

- Según el alcance y fuerza del impacto: puede ser un impacto de largo alcance (si se produce una transformación sobre la vida de las personas) o de alcance limitado (cuando se producen cambios de menor importancia).

- Según el grado de planificación: se puede diferenciar entre impactos intencionados (planificados por la biblioteca) y no intencionados (no planificados previamente).

- Por el tipo de evidencias que se producen: se pueden distinguir entre impactos constatables por el usuario, e impactos potenciales, es decir, aquellos cuyas evidencias son más difíciles de obtener, como sucede cuando se trata de efectos de naturaleza intangible.

La elaboración de esta norma significó un importante esfuerzo de normalización, en un momento en el que empezaban a proliferar los estudios de impacto sin que se hubiera construido un marco teórico y práctico suficientemente estable. Como señala La Mano González (2014):

\footnotetext{
52 Traducido del original: "value: importance that stakeholders (...) attach to libraries and which is related to the perception of actual or potential benefit" (Organización Internacional de Normalización, 2014b, p. 12).

53 Traducido del original: "outcome: direct, pre-defined effect of the output related to goals and objectives of the library's planning (e.g. number of users, user satisfaction levels)" (Organización Internacional de Normalización, 2014b, p. 7).
} 
a pesar de esta proliferación y de la cada vez mayor complejidad y sofisticación que caracteriza este tipo de estudios, la revisión de los procedimientos y métodos utilizados en ellos, así como de la bibliografía sobre el tema, revela que se carece de una base teórica y práctica estable que sustente la evaluación del impacto bibliotecario y confiera la necesaria solidez a sus resultados (p. 163).

En la misma línea, así lo resumía Laitinen (2015):

Los inputs de la biblioteca intervienen en los procesos de los servicios, como resultado de los cuales se producen outputs y outcomes. Cada elemento afecta a los demás Para obtener el impacto buscado, se debe definir el número y la calidad de los outputs y outcomes. Los inputs deben adaptarse para producir los outputs y outcomes. La calidad es el "aceite" que hace que el proceso sea más efectivo. Del funcionamiento de la biblioteca pueden detectarse impactos positivos, tanto de valor social como económico (p. 323) ${ }^{54}$

En efecto, por todo lo visto hasta ahora en este apartado, se puede decir que una de las principales dificultades que debieron afrontar los primeros estudios sobre impacto, fue la ausencia de un marco conceptual suficientemente consolidado. Como se verá a continuación, los estudios sobre impacto realizados en los distintos tipos de bibliotecas fueron construyendo sus propios marcos conceptuales a medida que se publicaban nuevas investigaciones y estudios, y a menudo tomando como referentes distintos marcos teóricos ya establecidos en otros campos, como el Marketing (Urquhart, 2015) o la gestión de recursos (Urquhart y Tbaishat, 2016). En este sentido, la aportación de la norma ISO $16439^{55}$ sobre medición del impacto en bibliotecas (Organización Internacional de Normalización, 2014b) fue fundamental para la consolidación conceptual y metodológica en esta materia.

En el apartado siguiente volvemos a utilizar los contenidos de esta norma internacional para abordar los distintos enfoques metodológicos que presentan los estudios de impacto, atendiendo al tipo de aproximación (cualitativa-cuantitativa) y los distintos tipos de evidencias utilizadas.

\footnotetext{
54 Traducido del original: "Input to the library turns on the service processes as a result of which outputs and outcomes are created. Turning of any of the cogs affects all the others. To get the desired impact, one must define the number and quality of the needed outputs and outcomes. Inputs must be adapted to produce the needed outputs and outcomes. Quality is the "oil" that makes the processes more effective. Having the library operations positive impact, societal or monetary value may be detected" (Laitinen, 2015, p. 323).

55 En esta tesis adoptamos el concepto de impacto tal y como se concibe en la norma ISO 16439, es decir, como la transformación o cambio (tangible o intangible) que se produce en un individuo o en un grupo como resultado de su interacción o contacto con los servicios bibliotecarios.
} 


\subsection{Cuestiones metodológicas en la evaluación del impacto en bibliotecas}

En los estudios sobre evaluación del impacto bibliotecario se observa una gran diversidad en cuanto a la metodología y técnicas utilizadas. Con el fin de recoger y sistematizar las distintas opciones metodológicas, la norma ISO 16439 estableció una clasificación según el tipo de evidencias que se utilizaban en cada caso. Para ello se adoptó el criterio de Streatfield (2002), que distinguía entre "evidencia observada" y "evidencia solicitada", obedeciendo al tipo de procedimiento por el que se obtenían las evidencias. Junto a estas dos categorías, la norma estableció una tercera categoría para agrupar las metodologías y técnicas basadas en la "evidencia deducida". A continuación resumimos los distintos tipos de evidencias según la norma internacional (Organización Internacional de Normalización, 2014b, pp. 24-53):

1) La evidencia observada: es aquella que se obtiene mediante técnicas que recogen la observación del usuario o del evaluador en su experiencia de contacto de los servicios bibliotecarios. Bajo esta categoría se agrupan la observación, el análisis de registros, el autorregistro de usuarios, los análisis de citas y los resultados de test:

a) Observación: los distintos métodos de observación recogen información a partir del contacto directo del usuario o el evaluador con la biblioteca. Según el grado de estructuración de las observaciones, es decir, si se proporciona un esquema previo y codificado de elementos para la observación, puede tratarse de observación estructurada (con esquema de observación previo) o no estructurada (sin esquema de observación previo). Según el papel que desempeña el observador, puede tratarse de observación participante (si el observador participa en las actividades cotidianas del grupo que está siendo objeto de observación y realiza una observación desde dentro del grupo) o no participante (cuando el observador se sitúa en una posición externa al grupo objeto de observación). Según el conocimiento que tienen los sujetos observados, puede tratarse de una observación abierta (cuando los sujetos son conscientes de estar siendo observados) o discreta (cuando los sujetos no son conscientes de estar siendo observados).

b) Análisis de registros: consiste en extraer las evidencias a partir de la observación de registros informáticos de bases de datos y otros recursos electrónicos, páginas web, etc., a partir de los cuales se puede obtener información sobre los comportamientos de usuarios en su interacción con los servicios de la biblioteca. 
c) Autorregistro de los usuarios: son los usuarios quienes registran durante un periodo determinado sus experiencias en la interacción con los servicios bibliotecarios.

d) Análisis de citas: se deduce el impacto de los servicios de formación bibliotecaria sobre la competencia informacional de los usuarios.

e) Resultados de test: se obtiene información sobre el impacto de las actividades formativas organizadas por la biblioteca sobre los conocimientos, habilidades y competencias de los usuarios.

2) La evidencia solicitada: es aquella que se obtiene mediante métodos de recopilación de opinión e información proporcionada por los usuarios y no usuarios, sobre su experiencia valoración en relación con las bibliotecas. Bajo esta categoría se agrupan las encuestas de impacto, las entrevistas y grupos focales, la autoevaluación de los usuarios y la recogida de evidencias anecdóticas y narrativas personales:

a) Encuestas de impacto: es la técnica más utilizada en los estudios sobre impacto. En ellas se pregunta a los usuarios sobre su experiencia y valoración de las bibliotecas.

b) Entrevistas individuales o en grupo (grupos de discusión) sobre los beneficios que las personas obtienen de las bibliotecas. Según el grado de estructuración de las preguntas, es decir, si existe un cuestionario estandarizado con preguntas predeterminadas abiertas o cerradas, se puede diferenciar entre entrevistas estructuradas (con preguntas preestablecidas en un cuestionario), desestructuradas (no hay un cuestionario con preguntas estructuradas, sino un tema de discusión alrededor del cual el entrevistador plantea preguntas) o semiestructuradas (combina las dos opciones anteriores, incluyendo preguntas estructuradas pero dejando abierta la posibilidad de reformular las preguntas).

c) Autoevaluación de los usuarios: los usuarios registran su nivel de conocimientos, habilidades y competencias antes y después del contacto con los servicios y actividades de la biblioteca.

d) Recogida de evidencias anecdóticas y narrativas personales: consiste en el registro y análisis de narraciones, comentarios y anécdotas contadas por usuarios y por el personal alrededor de su experiencia con la biblioteca.

3) La evidencia deducida: es aquélla que se infiere a partir de los datos cuantitativos que arrojan las estadísticas bibliotecarias, indicadores de rendimiento y encuestas de satisfacción de usuarios. Bajo la categoría de evidencia deducida se agrupan la deducción a partir de estadísticas del uso de la biblioteca e indicadores de rendimiento y las encuestas de satisfacción: 
a) Deducción a partir de estadísticas del uso de la biblioteca: si se observa un aumento en la intensidad y frecuencia del uso de los servicios, se pueden establecer hipótesis sobre su efecto sobre las prácticas y las habilidades de los usuarios.

b) Deducción a partir de indicadores de rendimiento: consiste en analizar la evolución de los resultados de costes, eficiencia y calidad de los servicios. El análisis de las series temporales permite establecer hipótesis sobre si se produce algún efecto sobre los usuarios.

c) Encuestas de satisfacción: la evolución de los datos de satisfacción puede ser un indicio de un posible impacto sobre los usuarios.

Las primeras aproximaciones al estudio del impacto se realizaron aplicando técnicas de obtención de evidencias deducidas. No obstante, como ya hemos visto, no todos los autores aceptaron el uso de este tipo de evidencias, ya que, por sí mismas, no informaban sobre los beneficios o transformaciones que experimentaban las personas y las comunidades, sino que se limitaban a arrojar datos a partir de los cuales se podía intuir o deducir de una forma muy aproximada que podía darse un cierto impacto (Association of College and Research Libraries, 1998; Huysmans y Oomes, 2013; Poll, 2003).

Entre todas las técnicas de recopilación de datos cualitativos, la más utilizada en los estudios sobre impacto es la encuesta, que presenta la ventaja de que permite obtener una gran cantidad de datos en relativamente poco tiempo sobre poblaciones amplias (Liebst y Feinmark, 2016; Poll, 2014). Otras opciones como las entrevistas, los grupos focales y las narrativas personales (Calvert y Goulding, 2015) tienen la desventaja de que requieren mayores recursos y mucho más tiempo, aunque permiten ahondar en los razonamientos de los individuos.

La literatura especializada recomienda integrar la doble visión cuantitativa y cualitativa en la investigación en Información y Documentación (Frías y Borrego, 2004; Glazier, 1992, 2004; Madsen y Hurst, 2018; Suárez, 2010; Swanson y Rinehart, 2016; Wilson, 2016). La integración de métodos permite triangular las informaciones y arrojar luz sobre temas de investigación relativamente complejos y novedosos en el ámbito de las Ciencias Sociales.

Con el tiempo, los estudios de impacto han ido creciendo en complejidad metodológica, y han ido incorporando datos de evidencia observada y de evidencia solicitada, que proporcionan una visión más integral de la realidad. Por ejemplo, la literatura especializada ha dado cuenta del incremento en el uso de métodos etnográficos en bibliotecas universitarias, para obtener información sobre patrones de comportamiento de los usuarios, sobre percepción y evaluación de los espacios físicos 
y sobre la interacción de los diferentes grupos de usuarios con la biblioteca (Ramsden, 2016; Sharman, 2017).

En este apartado se han recogido los diferentes métodos utilizados para la obtención de evidencias del impacto, siguiendo la clasificación establecida en la norma ISO 16439 (Organización Internacional de Normalización, 2014b). Por su especificidad, hemos dejado fuera de este apartado las metodologías propias de los estudios sobre impacto económico, que serán abordados con detalle en el apartado siguiente.

\subsection{La evaluación del impacto económico}

\subsubsection{Aproximación al valor económico bibliotecas: marco conceptual}

El abordaje del impacto de las bibliotecas desde la Economía ha abierto la puerta a nuevos enfoques metodológicos. La evaluación del impacto económico persigue dos tipos de evidencias: desde una perspectiva micro, cuantificar la relación entre los costes de inversión y el beneficio de los programas, recursos y servicios que ofrece una biblioteca concreta (análisis coste-beneficio), y, desde una perspectiva más amplia, estimar la contribución económica de una biblioteca o un sistema bibliotecario a su entorno social, a nivel local, regional o nacional. En la norma ISO 16439 se define el impacto económico como:

El efecto que tiene una política, programa, proyecto, actividad o acontecimiento sobre la economía de un área determinada. Se suele medir en términos de cambios en crecimiento económico (resultado o valor añadido) y los cambios asociados en puestos de trabajo (empleo) y riqueza (sueldos). El análisis del impacto económico identifica el efecto directo e indirecto (multiplicador) de la inversión de la biblioteca sobre la economía, especialmente sobre la economía local ${ }^{56}$ (Organización Internacional de Normalización, 2014b, p. 63)

Lo que caracteriza a este tipo de estudios es, por una parte, la expresión del impacto o valor en términos monetarios, mediante procedimientos de cálculo específicos del campo de la Economía, y, por otra parte, la adopción de un marco

\footnotetext{
56 Traducido del original: "Economic impact is defined as the effect of a policy, programme, project, activity or event on the economy of a given area. It is usually measured in terms of changes in economic growth (output or value added) and associated changes in jobs (employment) and income (wages). Economic impact analysis identifies the direct and also the indirect (multiplier) effects of library expenditure on economies, especially on the local economy" (Organización Internacional de Normalización, 2014b, p. 63).
} 
teórico que proviene de la teoría económica y que caracteriza a los bienes culturales, y, en particular, a las instituciones bibliotecarias y los servicios de información como un tipo especial de bienes públicos ${ }^{57}$.

Sumsion, Hawkins y Morris (2003) explicaron que las bibliotecas funcionaban como bienes cuyos beneficios se extendían más allá del propio usuario individual hacia la sociedad en su conjunto. Según estos autores, las bibliotecas presentarían un "valor de mérito", es decir, que reportarían una serie de beneficios a la sociedad, como el avance educativo y cultural, la inclusión social, la igualdad de oportunidades y la creación de una ciudadanía informada. Además, existiría un coste de oportunidad que sintetizaría cuatro elementos: 1 ) las horas del usuario en la biblioteca, 2) el tiempo y otros costes de desplazamiento, 3) las desventajas posibles experimentadas por el usuario, 4) las probabilidades de éxito en satisfacer sus necesidades de información. De acuerdo con este concepto, el uso de la biblioteca se incrementaría hasta el nivel en el que el usuario esperara que sus beneficios excedieran a sus costes.

Por su parte, Matthews (2004, p. 132) identificó seis tipos de beneficios económicos que reportarían las bibliotecas públicas:

1) Beneficios directos sobre el individuo, por ejemplo: ahorro en compra de materiales culturales, servicios de información para inversores particulares, acceso a las tecnologías y a información sobre salud, servicios e información sobre empleo.

2) Beneficios directos sobre los negocios locales, por ejemplo, el acceso a información relevante para el desarrollo de los negocios.

\footnotetext{
${ }^{57}$ De acuerdo con la teoría económica, los bienes públicos son aquéllos que se caracterizan por dos rasgos principales: 1) su consumo es no rival, es decir, que al mismo tiempo que los consume un consumidor, puede aumentar el número de consumidores que pueden consumir el mismo bien, sin que se produzca una minoración en la cantidad consumida per cápita; y 2) su consumo es no excluyente, es decir, no es posible excluir a ningún individuo de consumir el bien público; en otras palabras, el bien público puede ser consumido sin permiso del oferente (Baumol, 2005, p. 276). Con referencia a los bienes culturales, Towse (Ed.) (2005) señaló que:
}

los bienes culturales tienen por naturaleza algunos de los componentes propios de los bienes públicos. Cuanto mayor sean sus beneficios externos y su carácter "público", mayor será la probabilidad de que el Estado intervenga en los mercados, bien sea para proveer los bienes culturales directamente, para subvencionarlos o para regular su producción o distribución. En segundo lugar, la demanda del consumidor no refleja el valor total de estos bienes, porque son bienes de experiencia y los gustos del total de los consumidores no están definitivamente formados, de manera que no es posible disponer de información completa respecto a los bienes culturales. Los problemas de información tienen como consecuencia el hecho de depender de la valoración de los expertos a la hora de juzgar la calidad de un bien (p. 22). 
3) Beneficios directos sobre la comunidad local, por ejemplo, la biblioteca contribuiría como empleadora, como compradora de recursos y como dinamizadora de las ventas de los negocios ubicados en su área de influencia.

4) Beneficios indirectos sobre el individuo, por ejemplo, la posible revalorización del valor residencial y comercial del área de influencia de la biblioteca.

5) Beneficios indirectos sobre los negocios locales, por ejemplo, la biblioteca podría contribuir a la formación, y, con ello, a la mejora de la competitividad de los profesionales de su área de influencia.

6) Beneficios indirectos sobre la comunidad local, por ejemplo, la biblioteca podría contribuir a la alfabetización y al desarrollo de competencias digitales entre los trabajadores de la comunidad local, lo cual redundaría en la dinamización del emprendimiento y la mejora de la calidad de vida de la comunidad.

Dentro de la teoría económica, la Economía de la Cultura ${ }^{58}$ ha provisto del marco conceptual necesario para abordar el impacto bibliotecario desde una visión económica. Desde este campo, Seaman (2005, pp. 404-405) explicó que los activos culturales podían producir tres tipos de impactos económicos:

1) El valor de consumo: incluyendo el valor recibido por los usuarios y por los no usuarios. Se considera que, incluso quienes no visitan ni son usuarios de las instituciones culturales, pueden percibir un valor de no consumo. Ello se refleja en su potencial disposición a pagar por el sostenimiento de estas instituciones y servicios. El valor de no consumo significa que el no usuario está dispuesto a pagar para mantener la opción de convertirse en usuario en un futuro, bien él mismo como usuario directo; bien por el prestigio indirecto que recibe por la existencia de ese bien cultural; por los beneficios que percibe sobre su calidad de vida por la mera existencia del bien, o por interés en legar el bien a sus herederos (valor de legado).

2) Aumentos de productividad y desarrollo económico a largo plazo asociados al activo cultural. Esto se refleja, por ejemplo, en la mejora de la economía local en el área de influencia de las instituciones culturales; y las ventajas de productividad que se generan por el valor educativo de los bienes culturales.

\footnotetext{
58 Como explica Towse (Ed.) (2005, pp. 19-20), el término pionero fue "Economía de las Artes". La Economía de la Cultura es la disciplina de la Economía que estudia la producción, distribución y consumo de los bienes y servicios culturales. Es un campo en expansión en el que estudian, entre otros asuntos relacionados con nuestro objeto de estudio: las políticas culturales y la financiación de la cultura, el impacto económico de la cultura, la aportación de los bienes culturales a la economía del bienestar, la economía de las instituciones, los bienes culturales, entre los cuales, los bienes patrimoniales y los bienes de información.
} 
3) Ganancias netas a corto plazo en la actividad económica medibles en términos de producción, renta y empleo. Se producen como consecuencia de los gastos que se producen por la propia existencia y actividad de un bien cultural determinado.

Desde la misma disciplina, Benhamou (2005) abordó el valor económico del patrimonio cultural, entendido como el conjunto de bienes y sus distintas dimensiones construidas socialmente (simbólica, histórica, de identidad nacional, social, etc.). Para Benhamou, se podía hablar de "bienes de patrimonio", como una categoría especial de bienes públicos con unas características propias: su condición de único, su durabilidad y carácter irreversible (por lo general, no pueden ser sustituidos por otro bien), su propiedad de bienes de mérito (redundan en beneficio de la sociedad) y su valor de legado (constituyen una herencia para las generaciones futuras). Aplicado a las bibliotecas, el concepto de "bienes de patrimonio" se ajustaría especialmente al caso de las bibliotecas nacionales.

Una vez introducido el marco conceptual que la Economía aporta al ámbito de la evaluación bibliotecaria, se repasan a continuación las principales metodologías utilizadas en los estudios de impacto económico.

\subsubsection{Metodologías de los estudios sobre el impacto económico}

Para introducir este apartado vamos a basarnos en lo expuesto por Missingham (2005) en su revisión bibliográfica sobre estudios sobre impacto económico del periodo 1999-2005. La autora vinculó el desarrollo de los estudios sobre impacto en bibliotecas con el desarrollo, desde la teoría de la evaluación, de "metodologías enfocadas a medir el valor de los programas y organizaciones que operan en la economía del conocimiento y contribuyen al capital social" (p. 142).

En su artículo, la autora distinguió tres etapas en los estudios sobre evaluación del impacto económico atendiendo a las metodologías utilizadas:

1) La primera etapa comprendía los estudios donde se evaluaba la eficiencia en la gestión de los recursos, aplicando los análisis de coste-eficiencia en los procesos y servicios de la biblioteca.

2) La segunda etapa se correspondía con los análisis coste-beneficio ${ }^{59}$ y el cálculo del retorno a la inversión ${ }^{60}$ (ROI) como metodología para demostrar la

${ }^{59}$ Matthews (2002, pp. 78-79) identificó cinco metodologías para la obtención del coste-beneficio: 1) Maximizar los beneficios de un coste determinado, por ejemplo, cuando la biblioteca tiene una cantidad determinada para gastar en un proyecto o actividad; 2) Minimizar los costes para un 
contribución de la biblioteca en términos monetarios. En esta etapa se desarrollaron herramientas en la web, como los calculadores de ROI, que realizaban de una forma simplificada este tipo de cálculos (Archives, Libraries and Museums Alliance UK, 2011).

3) La tercera etapa se correspondía con los estudios que estimaban el beneficio económico producido sobre el conjunto de los ciudadanos. En ellos se empleaba la metodología del retorno a la inversión, pero los costes y beneficios que se consideraban para calcular la ratio era mucho más complejos que en los estudios previos. Se tenían en cuenta tanto los beneficios tangibles como los intangibles, y a menudo era necesario recurrir a métodos alternativos, como la valoración contingente ${ }^{61}$, para estimar el coste $\mathrm{y}$ beneficio de recursos 0 servicios para los que no existían precios de mercado que pudieran servir de referencia.

Como observó Missingham, en los estudios más antiguos, el alcance del impacto económico se circunscribía al balance entre los costes y los resultados (outputs) de los servicios tradicionales de las bibliotecas (préstamo, suministro de documentos, reproducción de documentos, etc.). En contraste, en los estudios de impacto más recientes, se toman los servicios bibliotecarios en su conjunto y se evalúan de una forma global los impactos producidos sobre la sociedad a un nivel local, regional y nacional ${ }^{62}$.

determinado nivel de beneficios, por ejemplo, si la biblioteca conoce exactamente los beneficios que espera conseguir; 3) Maximizar la ratio de beneficios sobre costes, que se utiliza cuando hay varias alternativas de costes para varias alternativas de beneficios; 4) Maximizar los beneficios netos (el valor actual de los beneficios sobre el valor presente de los costes); 5) Maximizar el retorno a la inversión.

60 El análisis de retorno a la inversión (traducción del término anglosajón "Return of Investment", conocido también por sus siglas ROI) se expresa mediante una ratio que se obtiene calculando el cociente entre el valor monetario asignado a un recurso o servicio, y el coste en el que se ha incurrido para la provisión de ese recurso o servicio (Organización Internacional de Normalización, 2014b, p. 10).

${ }^{61}$ Como explicó Cuccia (2005) en términos económicos:

la valoración contingente es un método para estimar el valor que los individuos atribuyen a bienes no comerciables o a algunas características de bienes comerciables no reveladas por el mecanismo de mercado. Consiste básicamente en preguntar directamente a muestras seleccionadas de población, a partir de encuestas o entornos experimentales, cuál es su disponibilidad a pagar por incrementos cualitativos o cuantitativos de los bienes no comercializados, o cuál es su disponibilidad a aceptar disminuciones cualitativas y cuantitativas de bienes no comercializados. Ambas disponibilidades pueden ser utilizadas como medidas de la demanda individual del bien no comercializado. El objetivo principal de la valoración contingente es estimar la curva de la demanda de estos bienes y el área por debajo de la curva de la demanda, es decir, el excedente del consumidor (p. 781).

62 En el nivel local, las bibliotecas proporcionan apoyo a los negocios relacionados con sus abastecimientos, proveedores, y en general con los sectores de las industrias culturales. Por otra parte, 
Abundando en los aspectos metodológicos, hay que decir que la metodología del retorno a la inversión se ha popularizado en los estudios de impacto para evidenciar en términos monetarios el beneficio que obtiene la sociedad que invierte en sus bibliotecas (Taladriz Mas, 2013). Para el cálculo de los distintos costes y beneficios de los estudios de impacto, se suele recurrir a diferentes técnicas que se repasan a continuación:

1) Cálculo de costes de sustitución: se calculan los costes de los servicios y recursos de la biblioteca, tomando como referencia otros recursos o servicios similares que ya existen en el mercado. Es la técnica más sencilla, pero no siempre es posible, ya que no siempre existen en el mercado bienes o servicios asimilables a los de la biblioteca, pues lo que se trata de medir son beneficios intangibles. Para sortear esta dificultad, se emplean técnicas alternativas, como el cálculo de los costes de tiempo y las estimaciones de los usuarios.

2) Cálculo de costes de tiempo: esta técnica se fundamenta en que la decisión del usuario de pasar tiempo en la biblioteca implica una elección racional, donde invierte el valor de su tiempo. El cálculo de los costes tiene en cuenta tanto los costes de desplazamiento (incluidos los costes de alojamiento, en su caso) como los costes del tiempo que el usuario ha invertido en la biblioteca, calculados en función de los sueldos medios.

3) Estimación del usuario: mediante una encuesta, se pregunta a los usuarios sobre su valoración económica de los recursos y servicios que recibe de la biblioteca. Entre estos cálculos se suele estimar el excedente del consumidor, es decir, el valor monetario que el consumidor atribuye a un bien o servicio, aunque él no deba pagar de forma directa para obtenerlo. Es la diferencia entre el precio que el consumidor está dispuesto a pagar y lo que realmente paga por un bien o servicio. Junto al cálculo del excedente del consumidor, se emplea la metodología de la valoración contingente. Esta metodología económica parte del presupuesto tomado de la teoría económica de la elección racional del consumidor ${ }^{63}$ (Aabø y Audunson, 2002). Según este presupuesto, los individuos

la biblioteca funciona como un empleador, que contribuye a la creación de puestos de trabajo tanto en su plantilla como en los negocios de su entorno. Funciona, asimismo, como dinamizador de la economía local, siendo un punto de atracción para turistas y visitantes. En cuanto al impacto a nivel nacional, se producen beneficios sobre la formación y el empleo y sobre el crecimiento económico de los países.

${ }^{63}$ Guerrero et al. (2002) lo definen como:

Elección. Es uno de los conceptos clave del enfoque neoclásico de la Economía. Se supone que el hombre (en el sentido antropológico), dotado de necesidades ilimitadas, se enfrenta al problema de la escasez en cuanto compara con ellas sus recursos, que son siempre limitados. De esta comparación nace el problema de la elección, que obliga al hombre a utilizar los recursos adecuadamente para conseguir la eficiencia (p. 344). 
realizan elecciones racionales maximizando su beneficio. La metodología de la valoración contingente se construye sobre las preferencias de los consumidores, obtenidas mediante encuestas y entrevistas. En el ámbito que nos ocupa, se plantean al usuario dos cuestiones principales:

a) La disposición del usuario a pagar: se pregunta al usuario cuánto dinero estaría dispuesto a pagar por obtener un servicio del que aún no dispone.

b) La disposición del usuario a aceptar una compensación: se pregunta al usuario cuánto dinero cree que debería obtener si tuviera que ser compensado por la supresión de un servicio, por ejemplo, por cuánto dinero vendería su carné de usuario de la biblioteca.

De los dos tipos de preguntas, la que más se utiliza en los estudios en bibliotecas es la disposición para pagar, ya que con ella se suele alcanzar una tasa de respuestas mayor. La metodología de la valoración contingente permite estimar en términos monetarios el valor de los bienes intangibles, es decir, aquellos bienes para los que no es posible obtener un precio de mercado (Aab $\varnothing$ y Audunson, 2002; Aabø y Strand, 2004; Kim, 2011; Lee y Chung, 2012).

4) Estimación del no usuario: mediante una encuesta, se les pregunta a personas que no son usuarios de la biblioteca sobre su valoración. En estos casos se suele emplear la valoración contingente para obtener el valor del no-uso, es decir, el beneficio que se produce por la propia existencia de la biblioteca, que alcanza tanto a usuarios como a no usuarios. Esta opción es interesante, por ejemplo, en el caso de las bibliotecas nacionales, donde los encuestados, tanto usuarios como no usuarios de los servicios de la biblioteca, suelen apreciar el valor intrínseco de la biblioteca, por tratarse de una institución patrimonial, de carácter histórico y simbólico, que representa valores culturales colectivos. Existen múltiples ejemplos de la aplicación de la valoración contingente a estudios de impacto económico de bienes culturales del ámbito de la arqueología, las bellas artes, el patrimonio cultural, las instituciones y manifestaciones culturales (Noonan, 2003).

Si bien la valoración contingente presenta la ventaja de que permite estimar los valores del no uso y, los valores de los bienes intangibles para los que no existen precios de mercado, no obstante, algunos economistas, como Diamond y Hausman (1994), advirtieron sobre los puntos débiles de esta metodología. Para estos autores, las respuestas que daban los encuestados cuando se les preguntaba por su disposición a pagar o por su disposición a aceptar una compensación, no siempre eran fiables, y aconsejaban hacer un trabajo previo de elaboración de los cuestionarios para asegurar en lo posible la consistencia interna de las respuestas. $Y$ en su tesis doctoral sobre la aplicación de la valoración contingente a las bibliotecas públicas de Noruega, Aabø 
(2004) observó que con esta metodología no era posible estimar los impactos a largo plazo, como, por ejemplo, el beneficio de las bibliotecas públicas sobre la inclusión social.

\subsubsection{Limitaciones de los estudios sobre el impacto económico}

Si bien los estudios de visión economicista basados en el cálculo del retorno a la inversión se han popularizado entre los estudios de impacto, este tipo de análisis presentan ciertas limitaciones, tal y como señaló la consultora BOP Consulting en un estudio realizado en 2014 a instancias del Arts Council England (BOP Consulting, 2014, p. 49):

- Cobra demasiada importancia el resultado cuantitativo y las evidencias resultan demasiado abstractas. Se suelen echar en falta evidencias cotidianas que permitan una mejor comprensión de las conclusiones.

- La valoración económica resulta compleja de entender para los no economistas, se requiere cierto nivel de especialización para su realización y comprensión.

- Se evalúa el impacto económico a corto o medio plazo. Es necesario ofrecer un panorama más amplio sobre los beneficios que la sociedad obtiene de sus bibliotecas públicas.

Ante estas limitaciones, los expertos de BOP Consulting (2014) recomendaron el uso de nuevas aproximaciones desde disciplinas diferentes a la economía que sirvieran para enriquecer los estudios sobre evaluación del impacto bibliotecario con una visión global y multidimensional, poniendo el foco sobre las transformaciones sociales que producirían los sistemas bibliotecarios en cinco ámbitos principales: 1) Educación de niños y jóvenes y desarrollo personal, hábito lector y alfabetización; 2) Educación de adultos, adquisición de habilidades y empleabilidad; 3) Salud y calidad de vida (salud física y salud mental); 4) Apoyo a la cohesión de la comunidad; y 5) Inclusión digital.

Entre las alternativas metodológicas al ROI, otros autores han recomendado la metodología del retorno a la inversión social (SROI) ${ }^{64}$, que introduce toda una serie de

${ }^{64}$ De acuerdo con la definición de Luther (2008), se puede definir el retorno a la inversión social (SROI) como:

un concepto emergente diseñado para documentar los ahorros de costes sociales y medioambientales en los proyectos del sector público que garantizan la inversión continua. Se trata de cuantificar los beneficios sociales extendiendo el alcance del retorno a la inversión (ROI) al incluir factores que no se medían previamente (p.5). 
beneficios sociales y medioambientales en el análisis. EI SROI se ha utilizado para medir el impacto económico, social y medioambiental de los bienes altruistas e intangibles en el ámbito del conocido como "tercer sector", es decir, en organizaciones no lucrativas y de voluntariado. Sin embargo, no se ha explorado suficientemente en el ámbito que nos ocupa (Lamont, 2015).

Podemos citar como ejemplo de la preocupación sobre el impacto social el estudio de Fujiwara, Lawton y Mourato (2015) sobre las bibliotecas de Reino Unido. En él se preguntó a usuarios y no usuarios sobre la disposición a pagar vía impuestos para el sostenimiento de las bibliotecas públicas, resultando que los usuarios mostraron una disposición media para pagar 19,51 libras anuales de incremento vía impuestos; y los no usuarios, una disposición media para pagar 10,3 libras anuales. En esta investigación se desprendieron varias conclusiones de gran interés sociológico:

1) La disposición para pagar por el sostenimiento de las bibliotecas era mucho mayor entre los usuarios que valoraban la biblioteca como un espacio para socializarse.

2) La disposición para pagar por el sostenimiento de las bibliotecas se relacionaba positivamente con el nivel educativo, el grado de interés en la lectura y el nivel de ingresos.

3) Uno de los principales beneficios secundarios de las bibliotecas públicas se producía sobre el ámbito de la salud. Hacer uso frecuente de ellas repercutía en el bienestar, la calidad de vida y en último término, la salud de las personas. Como consecuencia de ello, se estimó que se producía una reducción en el gasto sanitario de 1,32 libras por persona al año, es decir, un coste medio anual de 27,5 millones de libras. La estimación de beneficios primarios y secundarios a nivel nacional se estimó en 748,1 millones de libras anuales.

Por su parte, Halpin, Rankin, Chapman y Walker (2015) reunieron un panel de expertos de Reino Unido con la finalidad de obtener los puntos de vista de los distintos grupos de interés sobre las áreas que debían ser evaluadas en los estudios de impacto. La investigación puso el acento sobre los beneficios sociales y educativos que se producían sobre la comunidad, como la provisión de un espacio seguro, accesible y gratuito, la atención a grupos con necesidades especiales y el libre acceso a la información. Los autores vincularon el papel de las bibliotecas públicas con los derechos humanos y con los Objetivos del Desarrollo del Milenio de las Naciones Unidas, especialmente en lo referente a la alfabetización, la erradicación de la pobreza y la extensión de la educación.

Los estudios más recientes suelen combinar la visión económica con la visión social, y en este sentido, las investigaciones en torno al impacto sobre el capital social en el 
ámbito de las bibliotecas públicas constituyen una línea de investigación interesante y prometedora que conjugan ambas perspectivas, como se verá más adelante.

En este apartado se han abordado las cuestiones conceptuales y metodológicas de los estudios sobre el impacto económico, ya que por su especificidad debían tratarse como un tipo especial de estudios sobre impacto. En el siguiente apartado se presentan los principales estudios sobre esta materia realizados en bibliotecas. Hemos considerado que resultaría relevante agrupar los distintos estudios teniendo en cuenta los distintos tipos de bibliotecas existentes, ya que, como se verá a continuación, las investigaciones presentan distinto enfoque dependiendo en gran medida del tipo de biblioteca. Cada tipo viene definido tanto por su misión como por su comunidad natural de usuarios. Ambos factores - la misión y los usuarios - son los ejes en torno a los cuales se articulan los trabajos de evaluación del impacto: por una parte, se analizan los beneficios y las transformaciones que se producen sobre los distintos perfiles de usuarios, en su interacción con la biblioteca, $y$, por otra parte, se analizan los beneficios que genera la biblioteca en el terreno social, a medida que asume nuevos roles en nuevos contextos, a la vez que desempeña sus funciones tradicionales.

\subsection{La evaluación del impacto en los distintos tipos de bibliotecas}

En este apartado se revisan los principales estudios de evaluación del impacto en bibliotecas publicados hasta la actualidad. Al igual que en el apartado dedicado a los estudios de evaluación del rendimiento, el contenido se organiza en varios subapartados, que se corresponden con las distintas tipologías de bibliotecas, incluyendo las universitarias, públicas, escolares, especializadas y nacionales. Hemos decidido organizar la información de esta forma porque, como se verá en los distintos ejemplos, el enfoque de los estudios depende en gran medida del tipo de biblioteca, siendo un factor importante si tienen o no una comunidad de usuarios predefinida con perfiles que les son propios.

Las bibliotecas universitarias cuentan con una comunidad de usuarios específica, que se corresponde con los miembros de la institución universitaria. Los estudios realizados en este tipo de bibliotecas suelen estar orientados a evaluar su impacto sobre el rendimiento académico del alumnado, y sobre la productividad científica de docentes e investigadores.

En el caso de las bibliotecas públicas, sí existe una comunidad de usuarios conocida, aunque no tan predefinida como en el caso de las universitarias, ya que sus usuarios pueden provenir no solo de su área geográfica de influencia, sino también de otras 
áreas. No obstante, los estudios sobre impacto en bibliotecas públicas suelen tener en cuenta los perfiles demográficos de la comunidad de su área de influencia y el enfoque predominante suele ser el análisis de los cambios que se producen en los distintos grupos poblacionales (por edad, sexo, estatus social, nivel de estudios, condición de inmigrante, etc.) por su contacto con los distintos programas y actividades planificados por la biblioteca.

En el caso de las bibliotecas escolares, existe una comunidad de usuarios conocida (por lo general, docentes, alumnado de los distintos cursos y personal de administración y servicios). Los estudios realizados en estas bibliotecas suelen estar orientados a evaluar su efecto sobre el rendimiento académico del alumnado y sobre su desarrollo formativo.

En el caso de las bibliotecas especializadas, también cuentan con una comunidad de usuarios delimitada (los miembros de la institución, empresa u organización de la que dependen). Los estudios realizados en este tipo de bibliotecas suelen orientarse a evaluar su contribución sobre los objetivos de la entidad superior. Así, por ejemplo, se estudia la contribución de los servicios de documentación de las empresas sobre la eficiencia de los trabajadores y sobre el rigor en la toma de decisiones. En el caso de las bibliotecas de centros hospitalarios, se estudia la contribución de la biblioteca sobre la calidad de los diagnósticos médicos y sobre su producción científica.

Por último, en el caso de las bibliotecas nacionales, no suele existir una comunidad predefinida de usuarios, ya que sus usuarios potenciales alcanzan a toda la ciudadanía. Los estudios realizados en bibliotecas nacionales suelen estar orientados a evaluar el impacto socioeconómico producido por la institución sobre el conjunto de la sociedad. Por otro lado, son instituciones que tienen un valor patrimonial intrínseco, y simbolizan la riqueza y la diversidad cultural de los países. Es frecuente el empleo de la metodología de la valoración contingente para recoger la opinión de usuarios reales y potenciales sobre los beneficios intangibles que se desprenden de su existencia y funcionamiento.

En los apartados siguientes se recoge una revisión bibliográfica de los estudios más relevantes de evaluación del impacto en bibliotecas. De acuerdo con lo expuesto anteriormente, los estudios se presentan organizados en cinco subapartados, cada uno de los cuales se corresponde con un tipo distinto de biblioteca: universitarias, públicas, escolares, especializadas y nacionales. Dentro de cada subapartado, aparecen en primer lugar los estudios de impacto de carácter general. Por su especificidad conceptual y metodológica, los estudios de impacto económico se recogen al final de cada subapartado. Por último, con el fin de ofrecer una visión de conjunto sobre la literatura especializada en nuestro país, hemos decidido recoger en un apartado distinto los estudios de impacto realizados hasta la fecha en bibliotecas españolas. 


\subsubsection{Estudios sobre el impacto de las bibliotecas universitarias}

Tradicionalmente, las bibliotecas universitarias han sido muy activas en la evaluación de su rendimiento, en la certificación de su calidad de acuerdo con modelos de calidad estandarizados (normas ISO 9000, modelo EFQM, etc.) y en el desarrollo de herramientas y técnicas de evaluación (Mehrjerdi, 2017; Oakleaf, 2010, 2018; Salisbury y Peasley, 2018; Savage, Piotrowski y Massengale, 2017; Town, 2018; Urquhart, 2018; Wallace, 2001).

Las bibliotecas universitarias fueron las primeras en cuantificar su impacto, tanto en términos de mejora de la productividad del profesorado y del rendimiento del alumnado (Blummer y Kenton, 2018; Griadhi, Suarni, Marhaeni y Sutajaya, 2018; Larsen, Wallace y Pankl, 2018; Nurse, Baker y Gambles, 2018; Saines et al., 2019), como en términos de beneficio económico sobre la sociedad.

Como señaló De Jager (2002), en los primeros trabajos donde se abordó el impacto de las bibliotecas universitarias, se utilizó un enfoque principalmente cuantitativo. En ellos se solían analizar correlaciones estadísticas entre dos variables que solían repetirse: por una parte, el número de préstamos que realizaba el alumnado en la biblioteca (variable independiente) y sus calificaciones académicas (variable dependiente) (Donovan, 1996; Okocha, 1994; Wells, 1995; Whitmire, 1998).

En 1998, el Grupo de Trabajo sobre Impacto Bibliotecario de la Association of College and Research Libraries (ACRL) elaboró un informe por el que se instaba a las bibliotecas universitarias a adoptar outcomes como medidas de evaluación de su impacto, argumentando que, hasta el momento, la mayor parte de los estudios de evaluación se habían fundamentado en datos de inputs, outputs e indicadores del rendimiento que resultaban insuficientes para servir como evidencias del impacto. De acuerdo con esta nueva aproximación evaluativa, la biblioteca universitaria debía interpretarse como un conjunto de servicios que producían beneficios sobre los miembros de la comunidad universitaria y sobre otros beneficiarios externos (empresas, otros organismos de investigación, etc.). La evaluación del impacto debía seguir tres pasos principales: en primer lugar, determinar los impactos esperados, teniendo en cuenta la misión y objetivos de la biblioteca; a continuación, establecer indicadores para obtener evidencias de los impactos producidos; $y$, finalmente, seleccionar los métodos más adecuados para obtener las evidencias.

El planteamiento de la ACRL presentaba dos principales novedades: por una parte, se exhortaba a las bibliotecas universitarias a mostrar su valor mediante datos de impacto, y, por otra parte, se adoptaba una perspectiva más global a la hora de evaluar las distintas dimensiones de este impacto, incluyendo los cambios que se 
producían en los conocimientos, habilidades y comportamientos del alumnado, como resultado de su interacción con las colecciones, servicios y programas de la biblioteca.

Entre 2001 y 2002, la Society of College, National and University Libraries (SCONUL), la Red Nacional de Bibliotecas Universitarias y de Investigación de Reino Unido, abordó esta materia en dos seminarios celebrados junto con la Library and Information Research Group (LIRG). En estos seminarios se instó a elaborar estudios longitudinales basados en evidencias científicas centradas en el comportamiento de los usuarios en relación con su uso de la biblioteca. Para poder realizar estas investigaciones, era preciso que las bibliotecas se familiarizaran con herramientas de evaluación estadística y con metodologías cualitativas (Fisher, 2003). Se puso en marcha el proyecto Impact Implementation Initiative, que aplicó una nueva metodología para medir el impacto de las bibliotecas universitarias de Reino Unido sobre el aprendizaje y la investigación (Payne y Conyers, 2005):

1) Selección de un área en la que la biblioteca buscara medir su impacto.

2) Articular objetivos para establecer lo que la biblioteca quería alcanzar en esa área determinada.

3) Desarrollar criterios para poder evaluar si se habían alcanzado los objetivos.

4) Crear indicadores de impacto.

5) Identificar qué evidencias debían obtenerse.

6) Seleccionar los métodos de evaluación apropiados para poder obtener esas evidencias.

Hasta entonces, las evaluaciones en Reino Unido se habían basado en medidas de rendimiento y de calidad percibida siguiendo el modelo LibQUAL. El foco de la evaluación se desplazaba a la contribución que las bibliotecas prestaban al ámbito del aprendizaje y la investigación, identificándose siete tipos de impactos (Payne y Conyers, 2005, p. 5):

1) Los beneficios generados sobre el estudio y la investigación por el repositorio institucional gestionado por la biblioteca.

2) Los beneficios generados sobre la investigación por el acceso a los recursos electrónicos desde la biblioteca.

3) Los beneficios generados sobre el aprendizaje por el desarrollo de cursos de formación informacional orientados a posgraduados.

4) Los beneficios generados sobre la investigación por la provisión de recursos especializados sobre las distintas disciplinas.

5) El impacto de las actividades de la biblioteca sobre la participación académica. 
6) Los beneficios generados sobre el aprendizaje y la investigación por la integración en un punto único de los sistemas de información y acceso a nuevas tecnologías.

7) Los beneficios generados sobre el aprendizaje gracias a los programas bibliotecarios de apoyo a estudiantes.

Por su parte, Weiner (2009), en su estudio sobre 247 universidades de Estados Unidos, demostró que existía una correlación estadísticamente significativa entre los resultados de las mediciones de rendimiento de las bibliotecas universitarias (el porcentaje de inversión de la universidad en su biblioteca, el promedio de asistentes a las actividades formativas, el volumen de transacciones del servicio de referencia y la proporción de personal bibliotecario profesional por biblioteca) y el nivel de prestigio alcanzado por la universidad en los rankings oficiales de prestigio institucional.

En su estudio sobre las bibliotecas americanas de la Association of Research Libraries (ARL), Emmons y Wilkinson (2011) identificaron como principales impactos, el promedio de permanencia del alumnado y el porcentaje de graduados. Mediante un modelo de regresión lineal múltiple, se demostró que, controlando las variables sociodemográficas (i.e., el estatus socioeconómico, el sexo, el origen étnico), se producía una correlación positiva estadísticamente significativa entre la ratio de personal bibliotecario por estudiante, el promedio de permanencia, y el porcentaje de egresados graduados.

En la misma línea de análisis de correlaciones, Wong y Webb (2011) elaboraron un estudio entre 2007 y 2009 en la Hong Kong Baptist University en el que demostraron que existía una correlación positiva entre la intensidad de uso de los servicios bibliotecarios y las calificaciones del alumnado.

Entre 2011 y 2012 se desarrollaron las dos primeras fases del Library Impact Data Project (LIDP), con ocho bibliotecas universitarias de Reino Unido. El proyecto buscaba probar la relación entre los datos de actividad de las bibliotecas y el nivel de estudios alcanzado por los estudiantes. Los resultados confirmaron que se daba una correlación positiva estadísticamente significativa entre las variables independientes "frecuencia de uso de los recursos electrónicos por estudiante" y "volumen de préstamos de libros por estudiante" y la variable dependiente "calificaciones académicas" (Stone, Pattern y Ramsden, 2011; Stone y Ramsden, 2013).

Por su parte, Creaser y Spezi (2012) abordaron el estudio del impacto de la biblioteca universitaria sobre el profesorado y la comunidad investigadora. A partir de una muestra de instituciones académicas de Reino Unido, Estados Unidos, Noruega y Suecia, demostraron que, con el incremento en las horas de atención del servicio de biblioteca se producía ahorro de tiempo y mejora en la calidad de los trabajos académicos. 
En un estudio posterior, Vance, Kirk y Gardner (2012) emplearon modelos de regresión para probar la influencia de la biblioteca de la Middle Tennessee State University sobre la permanencia y los resultados académicos del alumnado. Controlando las variables sociodemográficas y los resultados académicos previos, se producía una correlación estadísticamente significativa entre la asistencia a sesiones de formación de la biblioteca y la permanencia en la universidad en el alumnado de primer curso, aunque la influencia que se producía sobre los resultados académicos era mucho menor.

En la misma línea, Jantti y Cox (2013) probaron que en la Universidad de Wollongong (Nueva Gales del Sur) se daba una correlación estadísticamente significativa entre el uso de la biblioteca (medido con la variable "volumen de préstamos por estudiante") y la variable "resultados académicos". Por su parte, Jubb, Rowlands y Nicholas (2013), abordaron el impacto de las bibliotecas universitarias de Reino Unido (utilizando como variables los datos de inversión económica y los datos de número de descargas de los recursos electrónicos) sobre los resultados en investigación de la universidad. Como indicadores de impacto se utilizaron: el número de doctorados, premios, reconocimientos y financiaciones recibidas en forma de becas y contratos, número de artículos publicados y número de citas recibidas. Obviando las grandes diferencias que se producían debido al tamaño de las distintas instituciones, se observó que, por una parte, se producía una fuerte correlación positiva entre la inversión de la biblioteca en recursos electrónicos y el número de descargas. Por otra parte, se observó una correlación positiva entre el número de descargas y los resultados de la universidad en el ámbito de la investigación.

Por su parte, Rodríguez y Norberg (2014) estudiaron la influencia de las actividades formativas de la biblioteca del Barnard College (Nueva York) sobre el desarrollo del razonamiento empírico de los estudiantes. Se demostró la contribución del programa formativo de la biblioteca al desarrollo de destrezas como la exploración y análisis de datos, la redacción de textos, la construcción de gráficos y la elaboración de citas bibliográficas.

Eng y Stadler (2015) emplearon el análisis de regresión para comprobar si se producía alguna relación entre la inversión en la biblioteca universitaria y la permanencia del alumnado en la universidad. Aunque la hipótesis no se confirmó, sin embargo, sí se demostró que se producía una correlación significativa entre los datos de participación en cursos de formación impartidos por la biblioteca y los datos de permanencia en el segundo año de estudios. También se observó una fuerte correlación entre la participación en actividades de alfabetización informacional y el sentimiento de pertenencia del alumnado hacia la institución universitaria.

Como venimos observando, la mayor parte de os estudios de impacto en bibliotecas universitarias se fundamentan en el análisis estadístico de correlaciones 
entre variables, con una o más variables independientes (datos sobre recursos, servicios, colecciones, actividades de la biblioteca, frecuencia de uso de los servicios bibliotecarios) y una variable dependiente que se corresponde con un "outcome" o impacto (las calificaciones académicas, la puntuación de la universidad en los rankings de prestigio internacional, el número de doctorados egresados de la universidad, el número de publicaciones y de citas en revistas de impacto, la proporción de estudiantes que finalizan sus estudios, etc.). La principal dificultad consiste en aislar el impacto de la biblioteca de otros factores concurrentes.

Junto a las investigaciones cuantitativas, se pueden encontrar, aunque en menor cantidad, otras investigaciones que profundizan sobre el impacto percibido, utilizando técnicas cualitativas como narrativas personales, entrevistas en profundidad y grupos focales, que permiten extraer informaciones más matizadas sobre la experiencia de los usuarios y contextualizar los datos numéricos. Como ejemplo de este tipo de estudios, Nitecki y Abels (2013) identificaron cuatro ámbitos de impacto en bibliotecas universitarias de Estados Unidos:

1) Sobre la productividad de la comunidad investigadora.

2) Sobre el rendimiento del alumnado.

3) Sobre el ahorro de recursos (este beneficio se debía a que la biblioteca daba acceso a publicaciones científicas a toda la comunidad universitaria).

4) Estímulo para la curiosidad intelectual de toda la comunidad académica.

Siguiendo un planteamiento similar, Shreeve y Chelin (2014) emplearon entrevistas y grupos focales para obtener evidencias del impacto percibido por el alumnado de tres facultades de la Universidad West of England (Bristol). Se observó que, después de participar en actividades organizadas por la biblioteca universitaria, mejoraban la autoconfianza en su proceso de aprendizaje.

La exploración de nuevos indicadores de impacto es el objeto de nuevos trabajos evaluativos en bibliotecas universitarias. Thorpe, Lukes, Bever y He (2016) probaron que, en la Universidad de Kokomo (Indiana), el alumnado que más utilizaba la biblioteca obtenía mejores calificaciones, y alcanzaba mayores tasas de permanencia.

En la misma línea, Catalano y Phillips (2016) confirmaron la relación entre el nivel formación informacional proporcionado por las bibliotecas universitarias y los resultados académicos del alumnado, medidos con tres indicadores: la permanencia en la universidad, las calificaciones y la finalización de los estudios de graduación.

En los estudios cuantitativos más recientes se compara el nivel de impacto diferenciando entre los perfiles de usuarios y las diferentes disciplinas. En esta línea, Khan y Ahmed (2016) analizaron la relación entre el nivel de uso de los recursos electrónicos y la productividad alcanzada por estudiantes de cursos doctorado en el 
campo de las ingenierías. Reading (2016) demostró el impacto de un programa bibliotecario dirigido a estudiantes en situación de desventaja. Soria, Peterson, Fransen y Nackerud (2017) se centraron sobre el alumnado de los primeros cursos.

Por su parte, Montenegro et al. (2016) probaron que existía una correlación positiva significativa entre el número de sesiones a los recursos electrónicos y las calificaciones académicas. Observaron que en los cursos superiores aumentaban los datos de consultas a recursos electrónicos y descendían los datos de préstamos de obras impresas.

La literatura especializada está mostrando un interés cada vez mayor por el estudio de la biblioteca universitaria como espacio multifuncional para el aprendizaje. La evaluación de los espacios de la biblioteca (tanto físicos como virtuales) y su impacto sobre los resultados académicos y la experiencia de aprendizaje de los estudiantes es una línea de investigación que está arrojando resultados interesantes sobre la evolución de las bibliotecas universitarias (Andrews, Wright y Raskin, 2015; Baker et al., 2018; Behr y Hayward, 2016; Corrall, 2018; Fallin, 2016; Kim, 2016; Spencer y Watstein, 2017).

Las bibliotecas universitarias siguen siendo el principal campo de investigación en la evaluación del impacto. La bibliografía sigue dando cuenta de su interés por demostrar su influencia sobre el rendimiento de los estudiantes aportando evidencias cuantitativas (De Jager, Nassimbeni, Daniels y D’Angelo, 2018), cualitativas (Grieves, 2018; Grieves y Pritchard, 2018), y mediante la combinación de ambos tipos de evidencias (Głowacka, 2019). Al igual que sucede en las bibliotecas escolares, se ha documentado la importancia del personal bibliotecario profesional como factor de impacto sobre el rendimiento del alumnado (Cox, Gruber y Neuhaus 2019; Lance, Schwarz y Rodney, 2017).

En el siguiente apartado se recogen los estudios de evaluación del impacto económico en bibliotecas universitarias. Hemos considerado que este tipo de estudios requería una mención aparte dada la especificidad de su visión y metodología.

\subsubsection{Estudios sobre el impacto económico de las bibliotecas universitarias}

La evaluación del impacto económico en bibliotecas universitarias cuantifica en términos monetarios los beneficios generados por las bibliotecas sobre los distintos grupos de interés y en los distintos ámbitos de la actividad universitaria, incluyendo la enseñanza, la investigación, y el ámbito profesional y social. Como veremos a continuación, el retorno a la inversión ha sido hasta ahora la técnica más utilizada en este tipo de investigaciones. 
En el estudio pionero sobre el retorno a la inversión de la Biblioteca de la Universidad de Illinois en Urbana-Champaign (Kaufman y Watstein, 2008; Luther, 2008) se evaluó su contribución a la mejora en la productividad científica (medida en número de publicaciones), a la eficiencia investigadora (medida, entre otros indicadores, con el volumen de citas recibidas) y al aumento de proyectos de investigación de carácter interdisciplinar. Teniendo en cuenta estas variables, se estimó un retorno a la inversión de 4,38 dólares de beneficio por cada dólar invertido por la Universidad de Illinois en su biblioteca.

Con una perspectiva novedosa macroeconómica, el estudio de Kiviniemi, Laitinen y Saarti (2009) planteó la contribución de las bibliotecas universitarias finlandesas al crecimiento económico del país, evaluando la inversión en bibliotecas en el periodo 1977-2006 y el crecimiento del producto interior bruto nacional en esos mismos años.

En 2009 el Institute of Museum and Library Services (IMLS) de Washington D.C., financió el proyecto Lib-Value (Kingma y McClure, 2015; Mays, Tenopir y Kaufman, 2010; Tenopir, 2011, 2013), dirigido a la evaluación del retorno a la inversión en bibliotecas universitarias. El proyecto se desarrolló entre 2009 y 2011 en Estados Unidos (en las universidades de Tennessee, Illinois y Siracusa); en reino Unido (en las universidades de Cranfield, Dundee, East Anglia, Durham, Imperial College y Manchester) y Australia (en las universidades de Nueva Gales del Sur y Queensland).

A diferencia de los estudios previos, donde el ROI se expresaba con una cifra global que se calculaba integrando el conjunto de los servicios y recursos bibliotecarios, en el proyecto Lib-Value se quiso calcular, por separado, el ROI que reportaban las colecciones, los diferentes servicios y las instalaciones de las bibliotecas, a los distintos grupos de interés, y en cada una de las áreas funcionales de la universidad: 1) la investigación, 2) la enseñanza y el aprendizaje y 3) el ámbito profesional y social. Partiendo de este planteamiento novedoso, el proyecto abrió múltiples de posibilidades para calcular el ROI combinando los distintos tipos de recursos, los distintos grupos de interés y las diferentes áreas funcionales.

Como ya hemos dicho previamente, no existe un modelo común ni un marco conceptual único que pueda aplicarse en las evaluaciones. Los estudios suelen tomar como referencia las líneas estratégicas establecidas por las universidades a las que pertenecen, principalmente en relación con la enseñanza y la investigación. En este sentido, algunos autores han propuesto marcos conceptuales amplios y normalizados para medir el impacto en bibliotecas universitarias.

Para Town y Kyrillidou (2013), las evaluaciones de impacto realizadas hasta la fecha resultaban insuficientes, al situarse principalmente en el corto plazo, y al basarse principalmente en activos de tipo instrumental, como las colecciones, los servicios, las instalaciones y las actividades. Los autores sugerían que debía evaluarse también el impacto a largo plazo de los activos intangibles. Para ello establecieron un esquema 
de evaluación donde definieron cuatro dimensiones relacionadas con la generación del conocimiento:

1) Dimensión 1. El capital relacional: bajo este concepto se incluirían los beneficios obtenidos por la biblioteca como consecuencia de sus alianzas con otras organizaciones. Comprendería, entre otros aspectos, la posición competitiva de la institución y la capacidad para generar alianzas.

2) Dimensión 2. Capital bibliotecario: bajo este concepto se incluirían activos tangibles como las colecciones, servicios y espacios, e intangibles, como la capacidad organizativa o el capital humano.

3) Dimensión 3. Contribuciones de la biblioteca: bajo este concepto se incluirían las evidencias más directamente relacionadas con el impacto de la biblioteca sobre la investigación, el aprendizaje, la empleabilidad, el desarrollo profesional.

4) Dimensión 4. El impulso de la biblioteca: bajo este concepto se incluiría el potencial de la biblioteca para contribuir a los procesos de cambio e innovación.

En la misma línea, Corrall (2014) adoptó el marco conceptual de la teoría del capital intelectual (Brooking, 1996; Organización para la Cooperación y el Desarrollo Económicos, 2006; White, 2007a, 2007b, 2007c) para abordar la evaluación del impacto en bibliotecas universitarias. Según esta teoría, el capital intelectual se articulaba sobre tres pilares (Organización para la Cooperación y el Desarrollo Económicos, 2006, pp. 8-9):

1) El capital humano: el conocimiento y habilidades del personal, por ejemplo, la creatividad, la capacidad de trabajo, la flexibilidad, la motivación, la capacidad de aprender.

2) El capital relacional: las relaciones que establecen las organizaciones con sus grupos de interés, principalmente con los usuarios.

3) El capital estructural: el conocimiento que el personal aplica en el lugar de trabajo, por ejemplo, procedimientos, rutinas, uso de bases de datos y tecnologías de la información.

Para Corrall (2014, p. 27) la biblioteca universitaria contribuía a cada uno de esos tres pilares con activos de tres tipos:

1) Activos de la biblioteca relacionados con el capital humano:

- La experiencia del personal bibliotecario en el desarrollo de colecciones y en el trabajo con datos. 
- La experiencia del personal bibliotecario en el desarrollo y gestión de repositorios.

- La experiencia del personal bibliotecario en la gestión de servicios de información y referencia.

2) Activos de la biblioteca relacionados con el capital relacional:

- Las alianzas entre la biblioteca y el profesorado en la formación informacional.

- El trabajo conjunto de la biblioteca con otras unidades tecnológicas para el desarrollo de nuevos servicios digitales.

- Las redes de profesionales bibliotecarios que permiten compartir conocimiento.

3) Activos de la biblioteca relacionados con el capital estructural:

- Las estructuras organizativas de la biblioteca que favorecen la innovación y el desarrollo.

- Los sistemas y procedimientos con posibilidades de extensión o cambios.

- Las herramientas profesionales disponibles.

Para la recopilación de evidencias sobre estos activos intangibles, la autora recomendó el uso de los métodos cualitativos.

Por su parte, Ko, Shim y Pyo (2016) señalaron que era preciso seguir indagando sobre la influencia del perfil sociodemográfico de los entrevistados en su valoración de los distintos servicios de la biblioteca universitaria, con el fin de comprender y controlar el margen de subjetividad con el que se trabaja en este tipo de estudios.

Una vez revisados los principales trabajos de evaluación del impacto en bibliotecas universitarias, en el siguiente apartado se recogen los estudios más destacados realizados en bibliotecas públicas.

\subsubsection{Estudios sobre el impacto de las bibliotecas públicas}

Los estudios sobre impacto en bibliotecas públicas obedecen a tres planteamientos principales:

1) Estudios cuyo objetivo es obtener evidencias de los beneficios o cambios que se producen sobre una población concreta tras la realización de un programa o de la puesta en marcha de un servicio bibliotecario determinado. 
2) Estudios cuyo objetivo es obtener evidencias de los beneficios generales que se producen en los distintos ámbitos de la vida de los individuos, grupos y comunidades como consecuencia de su interacción con las bibliotecas públicas. Estos estudios revisten mayor complejidad que los anteriores, ya que, a priori, se desconocen los beneficios y se precisa de una primera aproximación prospectiva para identificarlos, antes de medir el alcance de su impacto. Dentro de este grupo de estudios, las investigaciones sobre el impacto traducido en forma de capital social han abierto una línea de investigación prometedora, donde la biblioteca pública funciona como espacio de socialización en beneficio de la comunidad ${ }^{65}$.

3) Estudios de impacto económico: traducen a valores monetarios los beneficios que obtiene una comunidad de usuarios o la sociedad en su conjunto de contar con un sistema de bibliotecas públicas.

En su investigación sobre las bibliotecas públicas de Pensilvania, McClure y Bertot (1998) emplearon diferentes métodos cuantitativos y cualitativos para identificar los beneficios que percibían los usuarios en su contacto con el sistema de bibliotecas públicas. A partir del análisis de una encuesta sobre más de 13.000 individuos, acompañada de entrevistas y grupos focales, se identificaron las siguientes áreas de impacto:

1) Impacto sobre los pequeños negocios.

2) Impacto sobre la alfabetización de niños y adultos.

3) Impacto sobre la educación y el desarrollo profesional.

4) Impacto sobre el acceso a la información en todo tipo de formatos.

5) Impacto sobre la salud de las personas y la calidad de vida.

6) Impacto sobre el conocimiento y los intereses culturales.

7) Impacto sobre la democracia: contribución a extender los valores democráticos.

8) Impacto sobre la carrera profesional (educación y trabajo): encontrar empleo, realizar determinadas tareas, desarrollar habilidades y destrezas útiles para el trabajo, encontrar oportunidades educativas, completar un determinado nivel

\footnotetext{
65 Los estudios de impacto sobre el capital social emplean el concepto sociológico de "tercer lugar" con el que de Oldenburg (1989) denominó a los espacios de socialización y de construcción de las comunidades democráticas. Baker y Evans (2011) sugirieron que "la biblioteca está cambiando hacia este modelo de Oldenburg" (p. 6), transformándose en nuevos espacios de aprendizaje. En la misma línea, para Reid (2012), la biblioteca era "el último espacio cívico"; y para Scott (2011) y Young (2012), la biblioteca reforzaba los valores democráticos y de compromiso con la comunidad.
} 
educativo, obtener un diploma, formación autodidacta en tiempo de ocio, desarrollo de la formación útil para el desempeño del trabajo.

En el estudio se analizaron los distintos tipos y niveles de impacto, de acuerdo con la variable "tipo de comunidad" (rural/urbana), y de acuerdo con el perfil sociodemográfico de los individuos (edad, sexo, etc.).

En su investigación sobre las bibliotecas públicas de Canadá, Fitch y Warner (1998) elaboraron un marco con los distintos beneficios que las bibliotecas aportaban a los distintos grupos de interés (usuarios, proveedores, negocios y sociedad en general), tal y como se enumera a continuación:

1) Aportación coste-efectividad para los proveedores de información.

2) Contribución al refuerzo de las economías locales.

3) Contribución al refuerzo de la economía del Estado del bienestar.

4) Contribución a la mejora del valor de mercado de la comunidad.

5) Atracción de la inversión económica.

6) Contribución a la creación de puestos de trabajo de alta cualificación relacionados con las nuevas tecnologías.

7) Contribución al refuerzo de la industria cultural.

8) Contribución al refuerzo de los valores de la sociedad democrática.

9) Contribución a la educación al aprendizaje a lo largo de la vida.

10) Ayuda en la toma de decisiones informadas.

11) Contribución a extender el acceso a las nuevas tecnologías de la información.

Se observó que el principal impacto se producía sobre el desarrollo de la economía local, debido a la gran capacidad de las bibliotecas de atraer al turismo ${ }^{66}$. Según sus autores, este estudio serviría para apoyar al sistema de bibliotecas públicas en su lucha por obtener recursos suficientes y proporcionaría argumentos para demostrar a los poderes públicos la importancia de mantener un sistema bibliotecario saludable en el contexto de los recortes presupuestarios.

En su manual sobre identificación y análisis del impacto en bibliotecas públicas, Durrance, Fisher y Hinton (2005, p. 16) plantearon la evaluación de los programas bibliotecarios diseñados para grupos con necesidades especiales. Según estos autores, los programas producían una serie de cambios sobre la vida de los individuos y grupos,

${ }^{66}$ Como señaló Benhamou (2005, p. 628), algunos cronistas destacan los efectos difusión (spillover) que los monumentos históricos generan a favor de las actividades locales y el turismo. 
y los estudios de impacto debían recoger evidencias de todos estos cambios, entre ellos:

- Cambios en la actitud de las personas.

- Mayor habilidad en el acceso a la información.

- Percepción personal (autoestima, autoconfianza, seguridad).

- Mayor conocimiento en el uso de las tecnologías.

- Mejora de las habilidades sociales y comunicativas.

- Aprendizaje, conocimiento, formación.

- Cambios de estatus (por la obtención de títulos formativos, promoción profesional, obtención de derechos de ciudadanía, etc.).

- Ahorro de costes (tiempo, dinero, energía, etc.).

Por su parte, el estudio de la Laser Foundation sobre el impacto social de las bibliotecas públicas de Reino Unido (PricewaterhouseCoopers LLP, 2005), presentó la novedad de vincular los beneficios resultantes de las políticas bibliotecarias con los objetivos prioritarios de las políticas sociales del gobierno en cuatro ámbitos: necesidades de la infancia, educación, sanidad y protección de las personas mayores. El estudio demostró los cambios experimentados por las personas que mantenían un contacto frecuente con los programas de actividades de las bibliotecas públicas:

- Cambios en los niveles de alfabetización y en las actitudes y comportamientos de los participantes en las actividades programadas en apoyo las familias. Estos cambios contribuían a las políticas sociales educativas y de apoyo a la infancia.

- Cambios en los niveles de competencia lectora y en las actitudes y comportamientos de los niños y jóvenes que participaban en programas de lectura programados en periodos vacacionales. Como en el caso anterior, estos cambios contribuían a las políticas sociales educativas y de apoyo a la infancia.

- Beneficios sobre los adultos que recibían apoyo de la biblioteca en sus necesidades de aprendizaje a lo largo de la vida. Estos cambios se podían observar tanto en su ámbito profesional (mayores probabilidades de promoción, obtención de diplomas) como personal (mejora de la autoconfianza, mejora de la calidad de vida, etc.).

- Beneficios sobre las personas que acudían a la biblioteca en busca de información relacionada con la salud. El acceso a este tipo de información desde las bibliotecas públicas influía sobre la percepción de la calidad de vida y el bienestar de las personas. 
- Beneficios sobre las personas mayores que accedían a los servicios bibliotecarios en las instalaciones de la biblioteca o a domicilio. El acceso a estos servicios influía sobre su calidad de vida.

En este estudio de amplio alcance, se demostró la contribución del sistema de bibliotecas públicas al conjunto de las políticas sociales impulsadas por el gobierno del Reino Unido.

Desde la Universidad de Washington se desarrolló el primer estudio a escala nacional sobre el impacto del acceso público y gratuito a Internet desde las bibliotecas públicas de Estados Unidos ${ }^{67}$ (Becker, Crandall y Fisher, 2009; Becker et al., 2010; Becker et al., 2011). EI U.S. IMPACT Public Library Study tenía como principales objetivos:

1) Conocer los distintos perfiles sociodemográficos de los usuarios de este tipo de servicios y los tipos de usos que podían observarse (acceso a Internet, acceso a programas de formación sobre nuevas tecnologías, utilización de ordenadores para acceder a distintos programas ofimáticos, etc.).

2) Construir indicadores de impacto para medir los beneficios sociales, económicos, profesionales e individuales que tendría para la vida de las personas y para su entorno familiar y social, el disfrute de estos servicios desde las bibliotecas públicas.

3) Establecer correlaciones entre los indicadores de impacto y distintas variables sociodemográficas.

4) Obtener información sobre posibles efectos negativos y sobre la ausencia de determinados servicios relacionados con las nuevas tecnologías.

\footnotetext{
${ }^{67}$ Desde 1994 se ha realizado en Estados Unidos un estudio longitudinal con datos sobre la introducción de las nuevas tecnologías en las bibliotecas públicas (Bertot et al., 2014; Bertot, Langa, Grimes, Sigler y Simmons, 2010; Bertot y McClure, 1998, 1999, 2002; Bertot, McClure y Fletcher, 1997; Bertot, McClure y Jaeger, 2004; Bertot, McClure, Jaeger y Ryan, 2006; Bertot, McClure, Wright, Jensen y Thomas, 2008, 2009; Bertot, McClure y Zweizig, 1996; Bertot, McDermott, Lincoln, Real y Peterson, 2012; Bertot, Real y Jaeger, 2016; Bertot, Real, Lee, McDermott y Jaeger, 2015; McClure, Bertot y Zweizig, 1994). Los Public Libraries and the Internet surveys, que desde 2006 pasaron a denominarse Public Library Funding \& Technology Access surveys, y desde 2013 se denominan Digital Inclusión surveys, recogen los datos de la encuesta anual sobre los servicios y recursos digitales en bibliotecas públicas a nivel nacional. Aunque no se puede decir que sean estudios de impacto propiamente dichos, en ellos se recogen datos estadísticos que evidencian la contribución de las bibliotecas públicas al cierre de la brecha digital y a la construcción de comunidades digitalmente inclusivas. Ejemplo de ello es el porcentaje de encuestados de distintos ámbitos geográficos (grandes ciudades, zonas rurales y barrios periféricos urbanos) a los que la biblioteca pública les había proporcionado acceso por videoconferencia a cursos de formación en línea, acceso a los nuevos servicios de la administración electrónica, o ayuda en la búsqueda de empleo.
} 
5) Ofrecer un marco conceptual básico para que las bibliotecas públicas del país pudieran evaluar estos servicios y utilizarlos como herramienta para la toma de decisiones y para informar a agentes financiadores, poderes públicos y a la ciudadanía en general.

Para la obtención de los datos se empleó una combinación de métodos cualitativos y cuantitativos:

1) Una encuesta telefónica a nivel nacional.

2) Una encuesta vía web distribuida en una muestra de bibliotecas públicas del país.

3) Un estudio pormenorizado de cuatro casos de bibliotecas públicas (Fayetteville Public Library de Arkansas; Enoch Pratt Free Library de Baltimore, Maryland; Marshalltown Public Library de lowa y Oakland Public Library en California) del que se obtuvo información sobre el comportamiento de los usuarios y sobre el contexto bibliotecario, mediante técnicas de observación y entrevistas.

EI U.S. IMPACT Public Library Study demostró la contribución de las bibliotecas públicas a la construcción y desarrollo de la infraestructura digital del país y al cierre de la brecha digital. Consecuentemente, se produciría impacto sobre la educación, el empleo, la salud, la calidad de vida, la integración social, la vida cívica y la economía doméstica de los ciudadanos.

Fuera del ámbito de los países anglosajones, destacó la investigación de Chiessi (2011) sobre las bibliotecas públicas de Italia. La finalidad del estudio era comprobar la validez de diferentes metodologías para registrar el valor percibido por los ciudadanos italianos respecto de sus bibliotecas públicas.

En su estudio sobre el impacto del sistema bibliotecario finlandés, Vakkari y Serola (2012) emplearon una encuesta a más de mil individuos para identificar y sistematizar los beneficios que estos individuos percibían de su contacto con el sistema de bibliotecas públicas. Se identificaron veinte beneficios distintos, agrupados en tres categorías principales:

1) Impacto sobre las actividades cotidianas:

a) Hogar,

b) cuidado de los hijos,

c) consumo,

d) salud,

e) relaciones sociales, 
f) viajes, ocio en general.

2) Impacto sobre intereses culturales:

1) lectura,

2) actividades culturales,

3) actividades recreativas,

4) deportes,

5) naturaleza,

6) participación en eventos.

3) Impacto sobre la carrera profesional (educación y trabajo):

a) encontrar empleo,

b) realizar determinadas tareas,

c) desarrollar habilidades y destrezas útiles para el trabajo,

d) encontrar oportunidades educativas,

e) completar un determinado nivel educativo,

f) obtener un diploma,

g) obtener formación autodidacta en tiempo de ocio,

h) desarrollo de la formación útil para el desempeño del trabajo.

Junto a los estudios donde se evalúa el impacto producido por una biblioteca o por un sistema bibliotecario sobre la población de un área geográfica, encontramos otros estudios en los que se evalúa el impacto a corto o medio plazo de un programa bibliotecario específico. Como ejemplo podemos tomar el trabajo de Rankin (2012), en el que se analizó el impacto del programa de lectura "National Year of Reading" desarrollado por las bibliotecas públicas de Yorkshire (Reino Unido). Como se resume en la Tabla 2, en este trabajo se utilizaron los Generic Social Outcomes (GSO ${ }^{68}$ ) del

68 En 2005, el Museums, Libraries and Archives Council (MLA) de Reino Unido financió un estudio para la elaboración de un banco de indicadores de impacto aplicables a museos, archivos y bibliotecas. El resultado fue un marco teórico conocido como "Generic Social Outcomes" (GSO), formado por tres áreas principales de impacto, subdivididas en categorías más específicas:

1) Comunidades más fuertes y seguras:

- $\quad$ Mejora del entendimiento y diálogo entre grupos.

- $\quad$ Apoyo a la diversidad e identidad cultural.

- $\quad$ Fortalecimiento de los lazos y relaciones familiares. 
Museums, Libraries and Archives Council (MLA) de Reino Unido como marco teórico para la clasificación de las evidencias de impacto. De acuerdo con este marco, los distintos efectos del programa de lectura se agruparon alrededor de tres ejes principales:

1) Eje 1: la contribución del programa a la creación de comunidades más fuertes y seguras.

2) Eje 2: la contribución del programa al fortalecimiento de la vida pública.

3) Eje 3: la contribución del programa a la salud y bienestar de los ciudadanos.

Tabla 2. Resumen de los outcomes identificados en el estudio de Rankin (2012, p. 12)

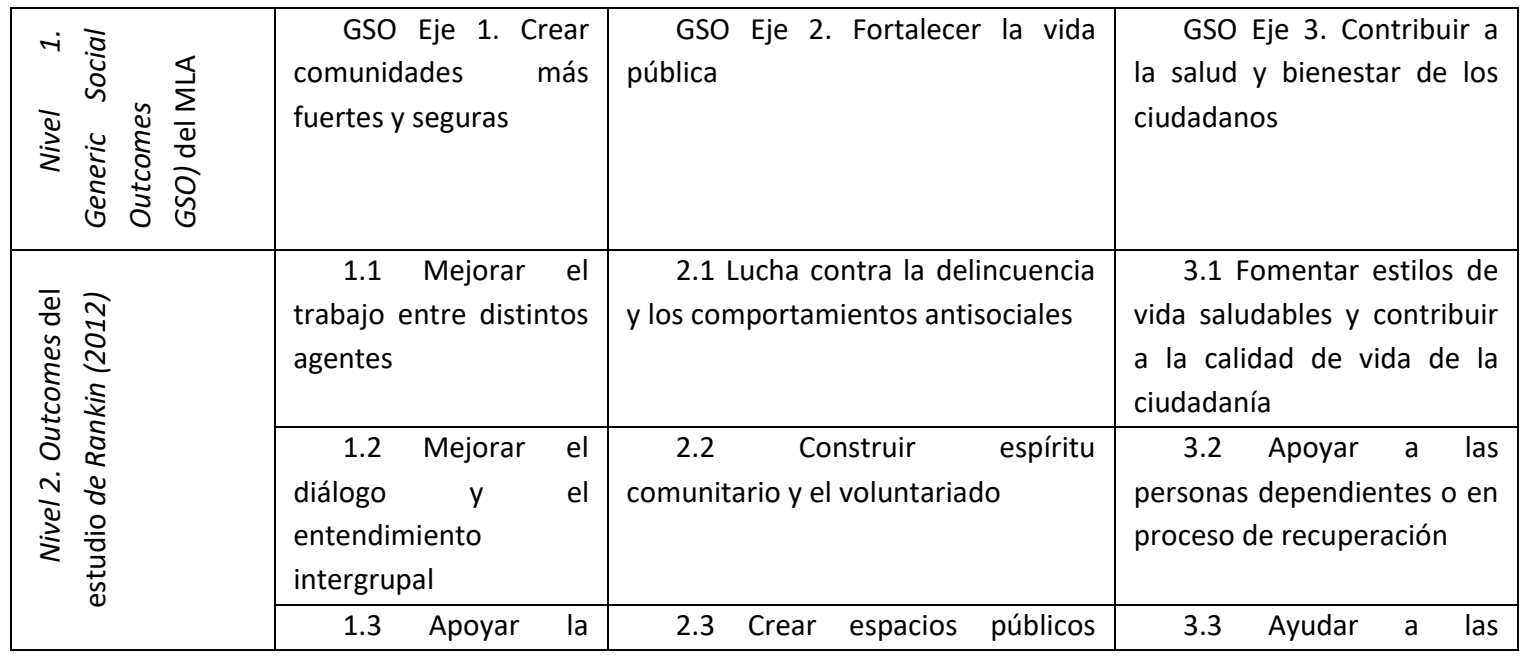

- Contribución a la prevención y reducción de delitos y de comportamientos antisociales.

2) Fortalecimiento de la vida pública:

- Refuerzo del compromiso cívico y social mediante la participación en las decisiones locales.

- $\quad$ Apoyo al voluntariado.

- Provisión de espacios públicos seguros e inclusivos.

- Empoderamiento de las comunidades.

- Mejora de la respuesta de los servicios a las necesidades de la comunidad.

3) Salud y bienestar:

- Contribución al bienestar físico y mental mediante la difusión de estilos de vida saludables.

- $\quad$ Apoyo en los procesos de recuperación y cuidado de enfermos.

- Apoyo a la independencia de las personas ancianas.

- Ayuda a niños y jóvenes a disfrutar de su vida y a contribuir positivamente con la comunidad. 


\begin{tabular}{|l|l|l|l|}
\hline & $\begin{array}{l}\text { diversidad cultural e } \\
\text { identitaria }\end{array}$ & seguros, inclusivos y confiables & $\begin{array}{l}\text { personas mayores a vivir de } \\
\text { manera independiente }\end{array}$ \\
\cline { 2 - 4 } & $\begin{array}{l}1.4 \text { Fortalecer los } \\
\text { lazos familiares }\end{array}$ & $\begin{array}{c}2.4 \text { Empoderamiento de la } \\
\text { sociedad mediante el conocimiento } \\
\text { de los derechos, beneficios y } \\
\text { servicios de la ciudadanía }\end{array}$ & $\begin{array}{l}\text { 3.4 Ayudar a los niños y } \\
\text { jóven a disfrutar de la vida } \\
\text { comunidad }\end{array}$ \\
\hline & $\begin{array}{l}2.5 \text { Mejorar la respuesta de los } \\
\text { servicios públicos a las necesidades } \\
\text { de la comunidad }\end{array}$ & \\
\hline
\end{tabular}

Entre las evaluaciones proyectos bibliotecarios específicos, destacan las realizadas en el marco de la Iniciativa Global Libraries $^{69}$ (Al et al., 2015; Paley et al., 2015; Streatfield, 2012; Streatfield et al., 2012; Streatfield et al., 2015). En ellas se mostraron evidencias de las transformaciones que se producían en las distintas comunidades después de introducir equipamientos informáticos y de dar acceso a las nuevas tecnologías desde las bibliotecas públicas locales. Para llevar a cabo las evaluaciones, se estableció un marco común en el que se definieron siete ejes o áreas de impacto con sus correspondientes indicadores (véase la Tabla 3).

Tabla 3. Áreas de impacto definidas en la evaluación de proyectos de la iniciativa Global Libraries acompañados de una selección de los indicadores asociados a cada área (Streatfield et al., 2015)

\begin{tabular}{|c|c|}
\hline Áreas de impacto & Indicadores asociados a cada área de impacto (selección) \\
\hline 1. Inclusión digital & $\begin{array}{l}\text { - Número de visitantes que han accedido a Internet por primera vez } \\
\text { desde la biblioteca pública. } \\
\text { - Número de visitantes que han aprendido nociones básicas de } \\
\text { informática como resultado de los servicios bibliotecarios. } \\
\text { - Número de visitantes que han ahorrado dinero como resultado de la } \\
\text { tecnología facilitada desde la biblioteca pública. } \\
\text { - Número de visitantes de grupos marginalizados que han } \\
\text { incrementado el uso de las tecnologías como resultado de los } \\
\text { servicios bibliotecarios. } \\
\text { Número de usuarios de Internet en la biblioteca pública, por edad y } \\
\text { sexo. }\end{array}$ \\
\hline 2. Cultura y ocio & $\begin{array}{l}\text { - Número de visitantes que están informados de las actividades } \\
\text { culturales de la comunidad gracias a que pueden acceder desde su } \\
\text { biblioteca pública a servicios como Facebook, Internet, etc. } \\
\text { - Número de visitantes que usan las tecnologías disponibles desde la }\end{array}$ \\
\hline
\end{tabular}

69 Bajo este nombre se han recogido proyectos financiados por la Fundación Bill y Melinda Gates, para la inclusión digital mediante la introducción de las tecnologías de la información en bibliotecas públicas en Estados Unidos y en comunidades en desarrollo de distintos países (Bulgaria, Botsuana, Polonia, Rumanía, Ucrania, Vietnam, Colombia, Indonesia, Sudáfrica, Turquía, Lituania, Chile, Méjico, Nepal, Bután, India, Guatemala, Honduras). 


\begin{tabular}{|c|c|}
\hline & $\begin{array}{l}\text { biblioteca pública para acceder a las noticias. } \\
\text { - Número de visitantes que se involucran en acciones para su } \\
\text { comunidad como resultado de los servicios que ofrece la biblioteca } \\
\text { pública (e.g., talleres, actividades realizadas en las instalaciones de la } \\
\text { biblioteca, o realizadas en remoto y a las que se accede desde la } \\
\text { biblioteca). }\end{array}$ \\
\hline 3. Educación & $\begin{array}{l}\text { - Número de visitantes que usan los servicios de la biblioteca pública } \\
\text { para participar en sesiones de formación informal. } \\
\text { - Número de estudiantes que usan los servicios de la biblioteca para } \\
\text { completar sus tareas escolares. } \\
\text { - Número de visitantes que leen gracias a las tecnologías disponibles } \\
\text { en la biblioteca pública. } \\
\text { Número de visitantes que se han cualificado para obtener un empleo } \\
\text { como resultado de oportunidades de formación educativa, o bien } \\
\text { orientadas a la búsqueda de empleo a las que han accedido desde la } \\
\text { biblioteca pública. } \\
\text { Número de estudiantes cuyo nivel de rendimiento ha mejorado } \\
\text { como resultado de los servicios proporcionados por la biblioteca } \\
\text { pública. }\end{array}$ \\
\hline 4. Comunicación & $\begin{array}{l}\text { - Número de visitantes que se comunican más con su familia y amigos } \\
\text { gracias a las tecnologías accesibles desde la biblioteca pública. }\end{array}$ \\
\hline 5. Desarrollo económico & $\begin{array}{l}\text { - Número de visitantes que usan las tecnologías disponibles en la } \\
\text { biblioteca pública para comunicarse con sus negocios. } \\
\text { - Número de visitantes que buscan información sobre temas de } \\
\text { agricultura en la biblioteca pública. } \\
\text { - Número de visitantes que compran o venden productos usando las } \\
\text { tecnologías accesibles desde la biblioteca pública. } \\
\text { - Número de visitantes que usan los servicios de la biblioteca pública } \\
\text { para redactar y enviar su CV. } \\
\text { Número de visitantes que usan los servicios de la biblioteca pública } \\
\text { para buscar ofertas de empleo. } \\
\text { Número de visitantes que encontraron un empleo después de usar } \\
\text { los servicios de la biblioteca pública especialmente diseñados para la } \\
\text { búsqueda de empleo (e.g., WIFI, Internet, ayuda y formación } \\
\text { impartida por personal de la biblioteca o por expertos externos, etc.) }\end{array}$ \\
\hline $\begin{array}{l}\text { 6. Salud física y mental, } \\
\text { apoyo a decisiones médicas }\end{array}$ & $\begin{array}{l}\text { - Número de visitantes que encuentran información sobre salud en la } \\
\text { biblioteca pública. } \\
\text { - Número de visitantes cuyas decisiones sobre salud se fundamentan } \\
\text { en información localizada desde la biblioteca pública. } \\
\text { - Número de visitantes cuya salud mejoró como resultado de la } \\
\text { información que encontraron en la biblioteca pública. }\end{array}$ \\
\hline 7. Administración pública & $\begin{array}{l}\text { - } \quad \text { Número de visitantes que buscan información sobre los servicios } \\
\text { públicos de la Administración desde la biblioteca pública. }\end{array}$ \\
\hline
\end{tabular}




\begin{tabular}{|c|c|c|}
\hline & - & $\begin{array}{l}\text { Número de visitantes que acceden a un servicio público haciendo } \\
\text { uso de las tecnologías disponibles en la biblioteca pública. } \\
\text { Número de visitantes que participan en procesos de participación } \\
\text { ciudadana a través de las tecnologías accesibles en la biblioteca } \\
\text { pública. } \\
\text { Número de visitantes que ahorran tiempo al usar las tecnologías } \\
\text { accesibles en la biblioteca pública. } \\
\text { Número de visitantes que reciben algún tipo de subsidio público } \\
\text { gracias a que pueden acceder a Internet desde la biblioteca pública. }\end{array}$ \\
\hline
\end{tabular}

Dentro de la iniciativa Global Libraries, en el año 2013 se llevó a cabo en la Unión Europea un estudio (Quick, Prior, Toombs, Taylor y Currenti, 2013) en el que se demostró que la ciudadanía percibía que las bibliotecas públicas contribuían a la inclusión digital en Europa. Entre los principales beneficios, se identificaron los siguientes: ahorro de tiempo (61\%), ahorro de dinero (50\%), desarrollo de intereses y aficiones (48\%), educación (47\%), comunicación con familia y amigos (43\%), acceso a información y servicios de la Administración (30 \%), acceso a recursos y habilidades necesarias para encontrar trabajo (28\%), mejora de las perspectivas de encontrar empleo o de emprender (26\%).

Entre las evaluaciones de programas bibliotecarios específicos, destacan los estudios de impacto de los programas de lectura, alfabetización y alfabetización informacional desarrollados por las bibliotecas públicas. Graham y Gagnon (2013) abordaron el efecto de los programas de alfabetización temprana sobre la estimulación en competencia lectora de niños y niñas entre 1 y 24 meses de vida. Aunque los resultados del estudio no fueron concluyentes, los autores señalaron el impacto de estos programas sobre la socialización temprana.

En la misma línea, el estudio de Dolman y Boyte-Hawryluk (2013) sobre el programa de lectura "Reading Buddies" de la Biblioteca Pública Grande Prairie en Alberta (Canadá), demostró que mejoraba la actitud de los participantes hacia la lectura. Además, se demostró que el nivel de lectura de los niños y niñas participantes lograba mantenerse durante los meses de verano, periodo en que solía producirse una merma en su competencia lectora, especialmente en los procedentes de entornos sociales más desfavorecidos ${ }^{70}$.

70 La literatura especializada ha documentado ampliamente el fenómeno denominado "summer reading setback", que consiste en la persistencia de pérdida de competencia lectora durante los periodos vacacionales en los niños y niñas provenientes de los entornos socioeconómicos más vulnerables. Como consecuencia de este fenómeno, se produciría una brecha (la literatura especializada lo denomina "summer learning gap" o "summer reading gap") entre el nivel de competencia lectora del alumnado proveniente de entornos socioeconómicos vulnerables y el proveniente de entornos socioeconómicos más favorecidos (Alexander, Entwisle y Olson, 2007; Allington et al., 2010; Cooper, Nye, Charlton, Lindsay y Greathouse, 1996; Heyns, 1978). 
En el contexto del sistema bibliotecario finlandés, Vakkari (2014) investigó sobre los beneficios que percibían los usuarios en su interacción con las bibliotecas públicas. Se identificaron tres tipos de beneficios: sobre las actividades de la vida cotidiana, sobre la carrera profesional y sobre las actividades culturales. La percepción de los beneficios variaba entre los distintos grupos sociales. Así, los adultos de mayor edad y con menos estudios percibieron un beneficio relativo mayor en sus actividades diarias, mientras que los más jóvenes y con mayor nivel educativo percibieron mayores beneficios relativos sobre la carrera profesional y las actividades educativas (Vakkari, 2014, p. 656).

Vakkari y sus colaboradores elaboraron un nuevo estudio comparativo tomando los casos de Finlandia, Holanda y Noruega, países con contexto similar y con sistemas bibliotecarios desarrollados (Vakkari, Aabø, Audunson, Huysmans y Oomes, 2014). La finalidad del estudio era comprobar si se daba alguna diferencia significativa en la percepción que tenían los ciudadanos de los distintos países sobre los beneficios que les reportaban sus sistemas de bibliotecas públicas. Se observó una diferencia importante entre los tres países, siendo Finlandia el país donde los ciudadanos identificaron una mayor variedad en cuanto a la tipología de beneficios.

Entre 2015 y 2016, Vakkari y sus colaboradores repitieron el mismo tipo de estudio en contextos tan diferentes como Corea del Sur y Estados Unidos (Sin y Vakkari, 2015; Vakkari et al., 2016). Se apreciaron bastantes diferencias en la percepción de los ciudadanos de los distintos países, tanto en lo concerniente a la tipología de los beneficios, como en lo concerniente al nivel de beneficio percibido. A partir de estos estudios comparativos, Vakkari y sus colaboradores dedujeron que el nivel de calidad de los servicios bibliotecarios funcionaba como un factor predictor de la percepción que los ciudadanos sobre el impacto de estos servicios. Es decir, que allí donde los sistemas bibliotecarios ofrecían servicios de mayor calidad, los ciudadanos percibían mayor impacto sobre sus vidas.

\subsubsection{Estudios sobre el impacto de la biblioteca pública en el marco conceptual del capital social}

Entre las evaluaciones realizadas en bibliotecas públicas, destaca un conjunto de investigaciones desarrolladas en Australia (Cox, 2000), los Países Nórdicos (Aabø y Audunson, 2012; Aab $\varnothing$, Audunson y Vårheim, 2010; Audunson, Vårheim, Aabø y Holm, 2007; Vårheim, 2009, 2011; Vårheim, Steinmo e Ide, 2008) y Canadá (Johnson, 2010, 2012, 2015; Johnson y Griffis, 2009, 2014b; Schrader y Brundin, 2012), que abordan el impacto de las bibliotecas en su dimensión de espacio físico generador "capital 
social ${ }^{71 \prime \prime}$. La hipótesis que se demuestra en estos estudios es la siguiente: las bibliotecas públicas, al posibilitar la interacción social, funcionan como espacios abiertos y seguros en los que se fomenta la socialización e integración de los individuos, la confianza mutua y la creación de redes, especialmente en comunidades urbanas multiculturales. En consecuencia, las bibliotecas contribuyen al fortalecimiento de la ciudadanía, a la cohesión social y al reforzamiento de los valores democráticos. Esta visión novedosa gira en torno al concepto de "capital social" tal y como la formuló Putnam (2000), sintetizando el significado que este concepto tenía dentro de la teoría sociológica:

Por analogía con los conceptos de capital físico y capital humano (...) la idea central de la teoría del capital social es que las redes sociales tienen valor. Igual que un destornillador (capital físico) o la educación escolar (capital humano), puede aumentar la productividad (individual y colectiva) también las relaciones sociales aumentan la productividad de los individuos y los grupos (...) El capital social se refiere a las conexiones entre individuos - las redes sociales y las normas de reciprocidad y confianza social que se desprenden de ellas. En ese sentido, el capital está íntimamente relacionado con lo que hemos denominado "virtud cívica". La diferencia es que el capital social llama la atención sobre el hecho de que la virtud cívica es más fuerte cuanto más inmersa está en una red de relaciones sociales recíprocas. Una sociedad de muchos individuos virtuosos pero aislados no es necesariamente rica en capital social ${ }^{72}$ (pp. 18 -19).

${ }^{71}$ Entre los teóricos que conceptualizaron la teoría del capital social destacó el sociólogo Pierre Bourdieu (1986). Para este autor, el capital social se definía como:

el conjunto de recursos reales o potenciales que se vinculan a la posesión de una red duradera de relaciones de conocimiento y reconocimiento mutuo - en otras palabras, siendo miembro de un grupo - más o menos institucionalizadas, que proveen a cada uno de los miembros el capital social (p. 21).

Mediante la pertenencia a grupos y redes y mediante los contactos sociales, los individuos compartirían recursos y obtendrían beneficios mutuamente. Por su parte, Putnam (2000) desarrollaría el concepto de capital social, aplicándolo al caso de Estados Unidos. El capital social se situaría en el ámbito de los valores y normas compartidos, la acción cívica y el compromiso colectivo, que contribuirían a crear confianza mutua y al reforzamiento de las democracias. Las comunidades con altos niveles de capital social obtendrían mejores resultados en indicadores sociales y económicos relacionados con la integración social, la democracia y la confianza en las instituciones. Asimismo, las comunidades con mayor capital social tendrían mayor resiliencia, es decir, mayor capacidad para superar de forma colectiva determinadas catástrofes sobrevenidas. Vårheim (2017) estudió el papel de las bibliotecas públicas en la potenciación de la resiliencia de las comunidades, siendo la resiliencia una de las dimensiones constitutivas del capital social.

72 Traducido del original: "By analogy with notions of physical capital and human capital (...) the core idea of social capital theory is that social networks have value. Just as a screwdriver (physical capital) or a college education (human capital) can increase productivity (both individual and collective), so too social contacts affect the productivity of individuals and groups (...) Social capital refers to connections 
Al mismo autor se debe la introducción de este concepto en el ámbito de la Biblioteconomía, en un encuentro de la American Library Association celebrado en 2002 en el que se abordó la misión central de la biblioteca pública. Tomando como modelo la Biblioteca Pública de Chicago, Putnam afirmó que la misión de la biblioteca pública no era otra que: "reflejar y servir a la diversidad de los habitantes de la ciudad, ayudándoles a descubrir los lazos y los intereses comunes que los unen" (Putnam, Feldstein y Cohen, 2003, p. 54).

Desde las investigaciones seminales de Putnam, se ha abierto una línea de investigación interdisciplinar donde se estudia el impacto de la biblioteca dentro del marco conceptual del capital social. Como se verá a continuación, estos estudios han proliferado en el ámbito de las bibliotecas públicas y en ellos se muestra su contribución en la creación de redes y vínculos sociales de confianza mutua entre personas. De acuerdo con la teoría del capital social, estos vínculos son la base para la creación de sociedades cohesionadas y de fuerte integración.

En su estudio pionero, Cox (2000) estudió la contribución a la construcción de capital social en diez bibliotecas públicas de zonas urbanas de Sidney y de zonas rurales de Nueva Gales del Sur. Los encuestados percibían la biblioteca como un "lugar seguro" donde se experimentaba un fuerte sentimiento de confianza recíproca entre las personas. Eran espacios propiciatorios para la generación de capital social:

Una característica única de la mayoría de las bibliotecas es la ausencia de sentido de exclusión, o del concepto del "otro". Es una percepción casi universal que las bibliotecas son lugares donde todo el mundo tiene derecho de acceso, cualesquiera que sean sus circunstancias o su origen. En la mayor parte de las bibliotecas, se ofrecen recursos para distintos grupos de la comunidad, y muchas ofrecen materiales en la lengua mayoritaria en esa comunidad. El hecho de que sean servicios públicos y gratuitos significa que nadie es rechazado, y que los usuarios sienten que tienen derecho a estar allí, creando un sentido de equidad y neutralizando cualquier sentido de marginalización o exclusión (pp. 8-9) ${ }^{73}$.

among individuals - social networks and the norms of reciprocity and trustworthiness that arise from them. In that sense, social capital is closely related to what some have called civic virtue. The difference is that "social capital" calls attention to the fact that civic virtue is more powerful when embedded in a dense network of reciprocal social relations. A society of many virtuous but isolated individuals is not necessarily rich in social capital" (Putnam, 2000, pp. 18 -19).

73 Traducido del original: "A unique feature of most libraries is the absence of a sense of exclusion, or a concept of "other". There is an almost universal perception that libraries are places where all people have a right of access, regardless of their circumstances or backgrounds. In most libraries, resources are provided specifically for different groups within the community, and many provide materials in the first languages prevalent in that community. The heritage of free use and the public ownership of libraries mean that nobody is turned away, and users feel that all others have a right to be there, creating a 
En Noruega, el proyecto "Public Arenas for Citizenship" (PLACE), desarrollado entre 2007 y 2012, abordó el papel de las bibliotecas en la construcción de capital social (Aabø y Audunson, 2012; Aabø et al., 2010; Audunson, 2016; Audunson et al., 2007; Vårheim, 2009, 2011; Vårheim et al., 2008). Entre 2006 y 2010 se realizaron dos encuestas en tres comunidades de Oslo y Troms $\varnothing$, en las que se indagó sobre las siguientes cuestiones:

1) ¿Hasta qué punto la biblioteca pública funciona como un lugar de encuentro social que previene el aislamiento social y favorece la comunicación, la promoción de la identidad local y cultural?

2) ¿Qué percepciones se pueden obtener del potencial de las bibliotecas para generar capital social?

3) ¿Funciona la biblioteca como un espacio de encuentro "de baja intensidad" ${ }^{74 " ? ~}$

4) ¿Existe una interrelación entre los espacios públicos y los espacios digitales?

5) ¿Se observan diferencias entre comunidades? ¿Qué variables sociodemográficas y culturales influirían (e.g., distribución de grupos de edad, proporción de minorías étnicas, tradiciones culturales locales, proporción de desempleados)?

El proyecto PLACE encontró evidencias de que las bibliotecas públicas funcionaban como lugar de encuentro e interrelación social:

1) Espacio para la comunicación interpersonal.

2) Lugar donde encontrar información sobre otros espacios públicos de la comunidad.

3) Espacio público para el debate de ideas.

4) Punto de información.

5) Espacio para actividades profesionales.

sense of equity and entitlement, and thereby neutralising any sense of marginalisation or exclusion" (Cox, 2000, pp. 8-9).

74 Los conceptos de espacios de encuentro de alta y baja intensidad fueron desarrollados por Audunson (2005) inspirándose en la dicotomía formulada por el sociólogo Goffman (1959) entre los conceptos front stage (espacios fuertemente estructurados mediante códigos, normas, etc., como el aula, el espacio de trabajo)-versus back-stage (espacios informales). Para Audunson, los espacios de encuentro de alta intensidad son espacios en los que las personas, al socializarse, asimilan y comparten los valores e intereses comunes del grupo al que pertenecen. Los lugares de baja intensidad son aquellos espacios donde las personas entran en contacto con otros grupos con valores e intereses diferentes. Para el autor, la biblioteca pública sería uno de estos espacios de baja intensidad. 
6) Espacio donde acceder al mundo digital.

El proyecto PLACE concluyó que, por todas estas evidencias, las bibliotecas públicas se constituirían como espacios de encuentro "de baja intensidad" y en ellos que se generarían valores comunitarios compartidos, confianza mutua, normas comunes y lazos y redes sociales. Como hemos visto, todos estos elementos conforman el concepto sociológico de "capital social".

A partir del desarrollo del proyecto PLACE han proliferado los estudios de impacto bibliotecario que han adoptado el marco conceptual del capital social. Entre ellos, se pueden mencionar varias investigaciones donde se demuestra la contribución de determinados programas bibliotecarios a la integración psicosocial de grupos con necesidades especiales. Veamos algunos ejemplos:

- Estudios sobre la contribución de la biblioteca pública en la integración de grupos de inmigrantes (Audunson, Essmat y Aabø, 2011; Johnston, 2016; Johnston y Audunson, 2019; Khoir, Du, Davison y Koronios, 2017; Pilerot, 2018), grupos étnicos minoritarios (Elbeshausen y Skov, 2004) y refugiados (Vårheim, 2014a).

- Estudios sobre el impacto de la biblioteca pública sobre el desarrollo psicosocial de jóvenes en riesgo de exclusión social (Williams y Edwards, 2011).

- Estudios sobre el impacto de los programas de grupos de lectura y conversación sobre la cohesión comunitaria y sobre el bienestar de sus miembros (Walwyn y Rowley, 2011).

- Estudios sobre el efecto de la biblioteca pública sobre la integración de personas en diferentes contextos geográficos: en los barrios de las grandes ciudades (Gong, Japzon y Chen, 2008); en comunidades rurales (Flaherty y Miller, 2016; Johnson y Griffis, 2014a, 2014b; Ntlotlang y Grand, 2016; Svendsen, 2013).

- Estudios sobre el impacto de los programas de enseñanza de la lengua de la comunidad sobre la confianza y la integración de estudiantes inmigrantes de primera generación (Vårheim, 2014b).

En esta misma línea, Miller (2014, p.324) emprendió un estudio comparativo entre las bibliotecas públicas de Edimburgo y Copenhague donde identificó las siguientes evidencias:

- Evidencias de la contribución de las bibliotecas públicas al desarrollo de la esfera pública, al ofrecer un espacio libre y neutral donde se realizan eventos de todo tipo. 
- Evidencias de la promoción de la cultura compartida y el refuerzo de los lazos comunitarios mediante encuentros formales e informales en los espacios de la biblioteca pública.

- Evidencias de la promoción de actividades e iniciativas comunitarias en sus instalaciones.

- Evidencias de la sensación de acogida entre los nuevos usuarios.

- Evidencias del fomento de los valores de equidad e integración: en la biblioteca pública todas las personas son tratadas igual, con independencia de sus diferencias por edad, origen o género.

- Evidencias de la mejora producida en la capacitación profesional de los miembros de la comunidad, gracias a las actividades formativas programadas.

Por todas estas evidencias, Miller concluyó que la biblioteca pública constituía un ejemplo de lo que el sociólogo Ray Oldenburg (1989) bautizó como "tercer lugar":

El tercer lugar es un término genérico que designa una gran variedad de lugares públicos en los que se produce el encuentro entre individuos de forma habitual, voluntaria, informal y deseada, más allá del ámbito privado del hogar y del lugar de trabajo (...) Así, el primer lugar es la casa: el más importante de todos. Es el primer entorno habitual y predecible para el niño y el que tendrá mayor influencia sobre su desarrollo. (...) El segundo lugar es el lugar de trabajo, que reduce al individuo a un papel únicamente productivo (...) Los terceros lugares son espacios neutrales y equiparan a todos los individuos en un mismo plano de igualdad social. En estos espacios, la conversación es la actividad principal y el principal medio para mostrar y apreciar la personalidad individual (...) Los lugares se caracterizan por tener una clientela habitual y buen humor, que contrasta con la seriedad con la que se desenvuelve la gente en otras esferas. Con unos elementos radicalmente diferentes a los del hogar, el tercer lugar es bastante similar a un buen hogar, por el descanso psicológico y el apoyo que proporciona ${ }^{75}$ (pp. 16-42).

\footnotetext{
75 Traducido del original: "The third place is a generic designation for a great variety of public places that host the regular, voluntary, informal, and happily anticipated gatherings of individuals beyond the realms of home and work. (...) Thus, the first place is the home-the most important place of all. It is the first regular and predictable environment of the growing child and the one that will have greater effect upon his or her development (...) The second place is the work setting, which reduces the individual to a single, productive role (...) Third places exist on neutral ground and serve to level their guests to a condition of social equality. Within these places, conversation is the primary activity and the major vehicle for the display and appreciation of human personality and individuality (...) The character for a place is determined most of all by its regular clientele and is marked by a playful mood, which contrasts with people's more serious involvement in other spheres. Though a radically different kind of setting
} 
En su artículo, Miller (2014) relacionó el concepto de "tercer lugar" con el marco conceptual de capital social. En este sentido, la biblioteca pública vendría a funcionar como un "tercer lugar"76.

En esta línea de valoración del espacio de la biblioteca pública en su doble vertiente física y virtual, algunos autores como Elmborg (2016) han destacado su papel en la formación informacional y como soporte para el aprendizaje a lo largo de la vida. En este sentido, se abre una línea de investigación para futuras investigaciones sobre su impacto sobre la vida de las personas y las comunidades.

\subsubsection{Estudios sobre el impacto económico de las bibliotecas públicas}

Uno de los principales objetivos de los estudios de impacto económico es demostrar que el gasto público destinado al sostenimiento de las bibliotecas es una buena inversión que se traduce en beneficios demostrables (Cram, 1995). Algunos estudios demuestran el impacto de las bibliotecas públicas sobre las economías locales. Vaughan (1997) y Vaughan, Tague-Sutcliffe y Tripp (1996) encuestaron a los pequeños empresarios locales de Ontario y demostraron que existía una correlación significativa entre el uso de los recursos de la biblioteca y la prosperidad de los negocios. Un 45 \% de los empresarios frecuentaban la biblioteca y el $31 \%$ mostraba confianza en la influencia positiva de estos servicios sobre su negocio.

Esta perspectiva ha sido ampliamente confirmada por estudios empíricos en los que se reconoce el papel dinamizador de los servicios bibliotecarios para negocios y empresas locales (Mehra, Bishop y Partee, 2017). La actividad de la biblioteca favorece la creación de negocios ( $y$, por tanto, empleos) en su área de influencia; dinamiza el sector editorial y librero, y el sector cultural y de servicios en general, además de ofrecer información especializada y otros servicios de valor añadido (acceso a Internet y otros recursos y servicios electrónicos y formativos) de interés para emprendedores y empresarios locales.

En el estudio de Holt y Elliott (1998) sobre la St. Louis Public Library, realizado entre 1995 y 1998, se utilizó por primera vez la metodología del análisis coste-beneficio aplicada a bibliotecas públicas, incluyendo el cálculo del excedente del consumidor -

from the home, the third place is remarkably similar to a good home the psychological comfort and support that it extends" Oldenburg (1989, pp. 16 - 42).

76 El uso concepto "tercer lugar" se ha extendido en la literatura especializada, en trabajos que abordan el estudio de la biblioteca como espacio seguro de socialización y de aprendizaje (Bruxvoort, 2016; Harris, 2007; Houghton, Foth y Miller, 2013; Kim, 2016; Lin, Pang y Luyt, 2015; Montgomery y Miller, 2011; Servet, 2010). 
fundamentado sobre la disposición a pagar del usuario - y el coste del tiempo del usuario. Se estimó que la biblioteca aportaba 67 millones de dólares de beneficio anuales.

El estudio realizado entre 2000 y 2001 acerca de las bibliotecas públicas de Florida fue pionero en la utilización de la metodología del retorno a la inversión para evaluar el impacto económico (Fraser, Nelson y McClure, 2002; McClure, Fraser, Nelson y Robbins, 2001). Se demostró que se producía un ROI de 6,27 dólares por cada dólar invertido en las bibliotecas públicas vía impuestos:

El objetivo del ROI es el siguiente: ¿usted (contribuyente) recibe más de lo que invierte? Es importante destacar que el ROI gobierna solo las decisiones racionales que hacemos. Matemáticamente el ROI puede representarse como la ratio entre los beneficios totales entre los costes totales (o los beneficios totales divididos por los costes totales). En términos contables, el ROI es la ratio entre el beneficio medio neto de una actividad, dividido por la inversión interna en esa actividad. Para las bibliotecas públicas, el ROI demuestra a los contribuyentes el valor de los servicios bibliotecarios y de información que la biblioteca proporciona comparado con su presupuesto anual ${ }^{77}$ (Fraser, Nelson y McClure, 2002, p.213).

Por su parte, MacEachern (2001) analizó la metodología del análisis coste-beneficio utilizada en los primeros estudios desarrollados en las bibliotecas públicas de Manakau, en la Biblioteca del Parlamento de Nueva Zelanda y en la Biblioteca de la Universidad de Canterbury. Los resultados del año 1999 mostraron que se había alcanzado un beneficio de al menos 18 millones de dólares neozelandeses.

En el estudio de Morris, Sumsion y Hawkins (2002) sobre las bibliotecas públicas de Reino Unido se evaluó el valor económico de la actividad del préstamo de documentos, comparando los costes del servicio con el valor percibido por los usuarios. El valor percibido variaba según las características sociodemográficas (edad, nivel de estudios, estatus, etc.) y según los intereses individuales. Se estimó que el servicio aportaba 815.000 libras anuales, y que esta cifra aumentaría con el incremento de los recursos electrónicos.

Como se ha visto anteriormente, la metodología de la valoración contingente ha tenido buena acogida en bibliotecas públicas como forma alternativa para estimar el

77 Traducido del original: "The focus of ROI is as follows: Did you (the taxpayer) receive more than you put in? It is important to note that ROI governs only the rational decisions we make. Mathematically, ROI can be represented as the ratio of Total Benefits to Total Costs (or Total Benefits divided by Total Costs). In accounting terms, ROI is the ratio of the average net income of an activity, divided by the internal investment in that activity. For public libraries, ROI demonstrates to taxpayers the value of the library services and information that the library delivers compared with the total annual budget" (Fraser, Nelson y McClure, 2002, p. 213). 
coste de recursos o servicios para los que no existen precios de mercado que puedan servir de referencia. Entre los primeros estudios donde se utilizó esta metodología, destacan los trabajos de Holt y Elliott (2003) en las bibliotecas públicas de Estados Unidos, y los estudios de Aabø (2005a, 2005b) en Noruega. La investigación de Aab $\varnothing$ (2005a, 2005b) demostró que más del 94 \% de la población noruega se consideraba con un cierto derecho de propiedad sobre la biblioteca local. La ratio coste beneficio resultante fue 1:4, y el valor medio atribuido por los ciudadanos a la biblioteca pública fue bastante elevado, entre 400 y 2000 coronas (siendo el gasto medio por hogar calculado en impuestos, equivalente a 420 coronas).

El estudio de Barron, Williams, Bajjaly, Arns y Wilson (2005) sobre el impacto económico de las bibliotecas públicas de Carolina del Sur calculó un ROI de 4,48 dólares por cada dólar invertido. Entre los beneficios económicos principales, se identificaron:

- Beneficios del uso de los servicios bibliotecarios orientados a los negocios: obtención de información comercial y económica relevante para los negocios locales.

- Beneficios del uso de los servicios bibliotecarios orientados a la búsqueda de empleo (sesiones de formación para desempleados, acceso a fuentes de información).

En el estudio sobre las bibliotecas públicas de Ohio (Levin, Driscoll y Fleeter, 2006) se estimaron los beneficios económicos directos en 283,6 millones de dólares, cerca de 3,81 dólares de beneficio por cada dólar invertido. En el mismo estudio se identificaron beneficios indirectos, aunque no se cuantificó su valor monetario. Entre estos beneficios indirectos, se mencionaban: la mejora en el nivel de alfabetización, la mejora de habilidades para la búsqueda de empleo, la promoción de la tolerancia, el fortalecimiento de los valores cívicos y la promoción del conocimiento y el desarrollo de una ciudadanía informada. Las bibliotecas públicas de Ohio volvieron a realizar un estudio de ROI en 2014 y el resultado fue 5,48 dólares de beneficio por cada dólar invertido (Howard Fleeter \& Associates, 2016). Por su parte, Majarrez, Cigna, Bajaj y Milam (2007) evaluaron el impacto de los programas de las bibliotecas públicas de Estados Unidos sobre el desarrollo local, identificando cuatro áreas de gran potencial:

1) Alfabetización temprana (favorece el éxito económico a largo plazo).

2) Formación en nuevas tecnologías (mejora la competitividad de los trabajadores locales).

3) Apoyo a pequeños empresarios mediante recursos de información (mejora su competitividad) y formación en nuevas tecnologías. 
4) Desarrollo del espacio urbano: las bibliotecas se implican en los planes de desarrollo de los barrios, favorecen las alianzas público-privadas.

En la misma línea, el estudio sobre las bibliotecas de Nueva Gales del Sur (Library Council of New South Wales, 2008) se centró en tres líneas de impacto: económico, social-cultural y medioambiental. Para el análisis económico se empleó la metodología de la valoración contingente, dando como resultado una disposición a pagar de 58,20 dólares anuales por usuario, cifra superior al gasto per cápita en 2004-2005, estimado en 42,73 dólares. En cuanto al ROI, se calculó que se generaban 4,24 dólares por cada dólar invertido en las bibliotecas públicas. Además, se concluyó que la actividad económica generada por las bibliotecas públicas en sus transacciones e intercambios de bienes y servicios producía un efecto dinamizador sobre la economía, estimado en 810,2 millones de dólares. En la Tabla 4 se resumen las áreas de impacto incluidas en este estudio, los beneficios asociados a cada área de impacto y los beneficios concretos percibidos por los encuestados.

Tabla 4. Resumen de la evaluación del impacto de Nueva Gales del Sur (Library Council of New South Wales, 2008)

\begin{tabular}{|l|l|l|}
\hline Áreas de impacto & Beneficios asociados a cada área & $\begin{array}{l}\text { Beneficios percibidos por los } \\
\text { encuestados }\end{array}$ \\
\hline Impacto sobre la economía & Beneficios sobre la economía & $\begin{array}{l}\text { Dinamización de la economía local } \\
\text { Apoyo a los buscadores de empleo } \\
\text { Apoyo a las pequeñas y medianas } \\
\text { empresas de la región }\end{array}$ \\
\hline Impacto cultural & $\begin{array}{l}\text { Beneficios sobre la cultura de la } \\
\text { comunidad }\end{array}$ & $\begin{array}{l}\text { Refuerzo de la diversidad sociocultural } \\
\text { Conservación de las culturas indígenas } \\
\text { Promoción de artistas locales }\end{array}$ \\
\hline Impacto social & $\begin{array}{l}\text { Contribución al bienestar social } \\
\text { Impacto medioambiental }\end{array}$ & $\begin{array}{l}\text { Dinamización e interacción social } \\
\text { Inclusión social }\end{array}$ \\
Promoción de la alfabetización \\
medioambiental
\end{tabular}


La investigación de McDougall, Saxena y Tate (2011) sobre la red de bibliotecas públicas de Victoria (Australia) abordó el valor económico de los beneficios sociales, medioambientales y el impacto sobre la economía local, empleando la metodología de la valoración contingente. Se estimó que las bibliotecas públicas aportaban 722 millones de dólares de beneficio y 120 millones de producto interior bruto; y su contribución a la generación de empleo alcanzó cerca de 4.430 empleos a tiempo completo.

El estudio socioeconómico sobre las bibliotecas públicas de Queensland (SGS Economics and Planning, 2012) siguió un esquema similar al utilizado en Nueva Gales del Sur y Victoria. En una primera fase del estudio, se identificó la contribución de las bibliotecas públicas al bienestar social de la región, a partir de estudios e informes preexistentes. Las principales áreas donde se observó la contribución de la biblioteca al desarrollo socioeconómico regional se relacionan a continuación:

- Dinamización social de la comunidad local.

- Ahorro en costes medioambientales.

- Contribución a la alfabetización (incluyendo la alfabetización digital).

- Apoyo a las instituciones educativas.

- Apoyo en la carrera profesional y académica.

- Contribución a la salud de la comunidad.

Ya en una segunda fase del mismo estudio, se empleó el análisis coste-beneficio y la valoración contingente para cuantificar en términos monetarios las contribuciones de las bibliotecas en las distintas áreas identificadas en la fase primera del estudio; y también se evaluó el impacto económico en términos de efecto dinamizador sobre la actividad económica local y sobre la creación de empleo. En una tercera fase, se elaboró una encuesta a hogares de Queensland en la que se preguntó sobre su disposición a pagar por el sostenimiento de las bibliotecas. Especialmente interesante fue la respuesta de los no usuarios, ya que éstos atribuyeron a las bibliotecas públicas tres tipos de valores:

1) El valor de opción: el no usuario sabe que puede hacer uso de la biblioteca en cualquier momento, y su supresión, significaría perder esta opción.

2) El valor patrimonial: los individuos valoran el mantenimiento de las bibliotecas para que las futuras generaciones puedan disfrutar de ellas.

3) El valor de la existencia: existe la percepción de que la biblioteca es beneficiosa para la comunidad, de manera que se está dispuesto a pagar por ella, aunque no se sea usuario. En el estudio se estimó que cada no usuario estaba dispuesto 
a pagar una media de 32 dólares al año (comparado con los 52 dólares de media que pagarían los usuarios).

Los resultados del análisis coste-beneficio de este estudio mostraron que, por cada dólar invertido, se obtenía un beneficio de hasta 4 dólares. Además, las bibliotecas públicas generaban 614 millones de beneficio en la región, 295 millones de producto interior bruto y 3.135 empleos a tiempo completo.

Por su parte, Stolarick y Silk (2013) realizaron un estudio sobre el impacto económico de la Biblioteca Pública de la Ciudad de Toronto. Junto al cálculo global del retorno a la inversión, que se estimó en 5,63 dólares por cada dólar invertido, se estimaron por separado el valor de los bienes tangibles directos e indirectos:

1) Beneficios tangibles directos, es decir, aquellos donde existiría un beneficiario identificable (persona u organización) que sería el receptor directo de los beneficios. Por ejemplo, se estimó que las salas de lectura y otros espacios de la Biblioteca Pública de la Ciudad de Toronto contribuían con 37,7 millones de dólares a la economía de la ciudad.

2) Beneficios tangibles indirectos, es decir, el efecto multiplicador que se generaría sobre la economía al producirse el beneficio directo. Por ejemplo, se estimó en 1,49 millones de dólares el beneficio económico directo producido por la página de empleo de la Biblioteca. A partir de esta estimación y teniendo en cuenta el efecto multiplicador, se estimó que se producía un beneficio indirecto de dos millones de dólares.

El estudio sobre el impacto del sistema de bibliotecas públicas de Australia ${ }^{78}$ (SGS Economics and Planning, 2013a) empleó las aproximaciones metodológicas ya probadas en los estudios previos de Victoria (McDougall et al., 2011) y Queensland (SGS Economics and Planning, 2012), aplicándolas a escala nacional. Las bibliotecas públicas australianas ofrecían un beneficio anual neto estimado de 1.970 millones de dólares. En cuanto al impacto dinamizador sobre la economía australiana, se estimó que las bibliotecas públicas repercutían en 3.000 millones de dólares anuales, 3.830 millones de valor añadido anual y contribuían a la creación de 30.950 empleos.

En 2015, la Danish Library Association avaló un estudio sobre el impacto económico de las bibliotecas públicas danesas (Jervelund, Kjøller-Hansen, Steen-Knudsen y

\footnotetext{
${ }^{78}$ Australia es junto con Estados Unidos el país que más estudios ha dedicado a la evaluación del impacto económico de sus bibliotecas públicas. En su revisión de los primeros estudios realizados aquel país, McCallum y Quinn (2004) destacaban el importante papel jugado por la Australian Library Association (ALIA) al solicitar al gobierno australiano el apoyo a su labor $y$ al comprometerse a presentar evidencias de su impacto para el país.
} 
Jørgensen, 2015). Entre las principales conclusiones del estudio, destacan las siguientes:

1) Contribución cultural y social (datos de valoración contingente a partir de una encuesta a usuarios y no usuarios de bibliotecas públicas): se estimó un valor de entre tres y cuatro mil millones de coronas danesas anuales.

2) La contribución sobre la educación: se estimó que las bibliotecas públicas contribuían en dos mil millones de coronas danesas anuales, considerando que su aportación a los niveles de lectura de niños y jóvenes favorecería la continuación y el acceso a estudios superiores, lo cual revertiría en mayor productividad y, por tanto, en el beneficio económico.

3) Contribución sobre los niveles de digitalización de la sociedad danesa: la aportación de las bibliotecas públicas a la inclusión digital se estimó en 150-200 millones de coronas danesas anuales.

En su investigación sobre el impacto económico de las bibliotecas públicas de Corea, Ko, Shim, Pyo, Chang y Chung (2012) calcularon el retorno a la inversión en 22 bibliotecas públicas, resultando una estimación global de 3,66. Los autores emplearon la técnica de la valoración contingente en una encuesta de alcance nacional. Una vez obtenido en ROI global, analizaron las diferencias en el ROI de las distintas bibliotecas según su tamaño, resultando ser las bibliotecas de tamaño mediano y pequeño las que alcanzaron un ROI mayor.

Por último, en su investigación sobre el impacto económico de las bibliotecas municipales de Praga, Hájek y Stejskal (2015) y Stejskal, Hájek y Rehak (2016), utilizaron también la técnica de la valoración contingente para preguntar a los usuarios su disposición a pagar por los servicios, y, a partir de ahí, calcular el ROI global (estimado en 2,55). La estimación del beneficio neto (beneficio bruto menos los costes) alcanzó 650.5 millones de coronas checas.

En el siguiente apartado se presentan los estudios más destacados de evaluación del impacto en bibliotecas escolares.

\subsubsection{Estudios sobre el impacto de las bibliotecas escolares}

En la mayor parte de los estudios sobre el impacto de las bibliotecas escolares se buscan evidencias de su contribución a los resultados académicos del alumnado en los distintos niveles educativos y en las distintas asignaturas del programa curricular. Algunos de estos trabajos son una respuesta desde las bibliotecas a las políticas educativas de los gobiernos, y en ellos se justifica la necesidad de incorporar a la 
biblioteca escolar dentro de los programas formativos (Williams, Wavell y Morrison, 2013). Como se verá a continuación, en buena parte de las investigaciones se reivindica la figura del bibliotecario escolar (y su colaboración con el profesorado) como factor clave para la mejora del rendimiento del alumnado (Hughes, 2014; Williams, Wavell y Coles, 2001). Encontramos dos grandes grupos de evaluaciones: por un lado, los estudios del impacto sobre resultados académicos, y por otro lado, los estudios del impacto sobre los procesos de aprendizaje y el desarrollo integral del alumnado.

\subsubsection{Estudios del impacto sobre los resultados académicos}

En un estudio temprano financiado por la U.S. Office of Education - Departamento de Educación estadounidense - Gaver (1961) analizó la correlación entre el perfil socioeconómico del alumnado, la cantidad y calidad de los recursos bibliotecarios disponibles y los resultados académicos alcanzados en la educación primaria. De este estudio se extrajeron cuatro hallazgos interesantes:

1) Se observó una correlación positiva entre el nivel educativo familiar y el interés por la lectura del alumnado.

2) Se dio una correlación positiva entre el estatus ocupacional familiar y la frecuencia en lectura de revistas por el alumnado.

3) Los mejores resultados académicos se daban en escuelas que disponían de biblioteca, y entre el alumnado de los últimos cursos de educación primaria.

4) Los mejores resultados académicos se producían en las escuelas que disponían de bibliotecas gestionadas por personal bibliotecario profesional.

El estudio de Gaver (1961) es un ejemplo aislado en su tiempo, pues para encontrar los primeros estudios de impacto de amplio alcance hay que esperar hasta 1993, cuando Keith Curry Lance y sus colegas del Library Research Service (Colorado) llevaron a cabo su investigación sobre las bibliotecas escolares del Estado de Colorado (Lance, Welborn y Hamilton-Pennell, 1993). Este estudio fue el primero de una larga serie de trabajos cuantitativos de similares características que se realizaron desde entonces en distintos estados de los Estados Unidos, conocidos como "Lance studies" (Lance, 2002).

El primero de los "Lance studies" se realizó a partir de una encuesta sobre una muestra de 221 escuelas de educación primaria y secundaria del Estado de Colorado, entre los años 1988-1989, donde se recopiló información sobre los recursos de sus bibliotecas escolares, entre los cuales: 
- El cómputo de horas de apertura semanal.

- El cómputo de horas semanales en las que la biblioteca estaba atendida por personal bibliotecario.

- El número de horas semanales dedicado por el personal a la identificación de materiales de refuerzo para el currículo escolar.

- El volumen de las colecciones por tipos de material.

- El número de ordenadores disponibles en la biblioteca escolar.

- El volumen de préstamos de una semana típica.

- El número de sesiones formativas en una semana típica.

Cada una de estas informaciones funcionaba como una variable explicativa dentro del estudio estadístico, y se analizaron las correlaciones entre cada una de estas variables y las calificaciones académicas obtenidas por el alumnado. Entre las principales conclusiones del estudio se pueden destacar las siguientes:

- Se demostró la relación entre la inversión en biblioteca escolar y las notas del alumnado. En las escuelas donde se destinaban más fondos a la biblioteca escolar, el alumnado obtenía mejores resultados en test de lectura.

- Se demostró que el tamaño de la plantilla de personal bibliotecario y el tamaño y variedad de las colecciones eran los dos factores que más influían sobre el rendimiento del alumnado.

- Se demostró que en las escuelas donde los bibliotecarios desempeñaban un papel formativo, el rendimiento del alumnado era superior. El papel formativo del bibliotecario escolar funcionaba como una variable predictora del nivel de rendimiento escolar.

El estudio de las bibliotecas escolares de Colorado sirvió de modelo replicable en posteriores estudios donde se utilizaron análisis estadísticos para demostrar el impacto de los programas de las bibliotecas escolares sobre los resultados académicos del alumnado (Achterman, 2008; Baumbach et al., 2003; Burgin, Bracy y Brown, 2003; Francis, Lance y Lietzau, 2010; Hall-Ellis y Berry, 1995; Haycock, 2011; Lance, HamiltonPennell y Rodney, 2000a, 2000b, 2000c, 2000d, 2002a, 2002b; Lance, Rodney y Hamilton-Pennell, 2005; Lance, Rodney y Russell, 2007; Lance, Rodney y Schwarz, 2010; Lance y Schwarz, 2012; Lance, Schwarz y Rodney, 2014; Quantitative Resources Llc., Miller, Want y Whitacre, 2003; Rodney, Lance y Hamilton-Pennell, 2002, 2003) ${ }^{79}$.

\footnotetext{
79 En 2004, la U.S. National Commission on Libraries and Information Science (NCLIS) - agencia independiente del Gobierno Federal que entre los años 1970 y 2008 cumplió el mandato legal de aconsejar al presidente y al Congreso de Estados Unidos sobre políticas bibliotecarias, siendo absorbida en 2008 por el Institute of Museum and Library Services (IMLS) - impulsó la elaboración del informe
} 
A la vista de estos trabajos de análisis cuantitativos, se evidenciaron cuatro principales conclusiones:

1) Existía una correlación positiva entre la participación del alumnado en los programas organizados por la biblioteca escolar y los resultados de los test oficiales. Por ejemplo, en su tercer estudio sobre el Estado de Colorado, Francis et al. (2010, pp. III-IV, 7-8) demostraron que, en las escuelas donde se producían mayor número de visitas a la biblioteca, entre un $67 \%$ y un $72 \%$ del alumnado alcanzaba el nivel de "proficient" o "advanced" en los test de lectura y un $10 \%$ alcanzaba un nivel insuficiente. Por el contrario, en las escuelas donde se producía menor número de visitas a la biblioteca, se reducía el porcentaje que alcanzaba nivel "proficient" o "advanced" (entre un $62 \%$ y un $67 \%$ del alumnado) y aumentaba el porcentaje de quienes obtenían un resultado insuficiente (entre un $12 \%$ y un $14 \%$ del alumnado).

2) Las escuelas en las que se producía una mayor inversión en la biblioteca escolar registraban mejores resultados académicos. Por ejemplo, en el estudio antes mencionado sobre el Estado de Colorado, Francis et al. (2010, p. III, 5-6) demostraron que, en las escuelas donde se destinaba mayor financiación para la biblioteca escolar, entre un $68 \%$ y un $72 \%$ del alumnado alcanzaba el nivel de "proficient" o "advanced" en los test de lectura y entre un $9 \%$ y un $10 \%$ obtenían un resultado insuficiente. Por el contrario, en las escuelas donde se destinaba menos financiación para la biblioteca escolar, se reducía el porcentaje que alcanzaba nivel "proficient" o "advanced" (entre un $62 \%$ y un $67 \%$ del alumnado) y aumentaba el porcentaje de quienes obtenían un resultado insuficiente (entre un $12 \%$ y un $14 \%$ del alumnado).

3) Asimismo, en las escuelas con colecciones bibliotecarias de revistas y vídeos más completas, entre un $67 \%$ y un $73 \%$ del alumnado alcanzaba el nivel de "proficient" o "advanced" en los test de lectura y entre un $9 \%$ y un $11 \%$ obtenía un resultado insuficiente. Por el contrario, en las escuelas donde había colecciones bibliotecarias de revistas y vídeos más precarias, se reducía el porcentaje de estudiantes que alcanzaban nivel "proficient" o "advanced" (entre un $61 \%$ y un $67 \%$ ) y se mantenía el porcentaje de quienes obtenían un resultado insuficiente (entre un $12 \%$ y un $14 \%$ del alumnado) (Francis et al., 2010, pp. IV-V, 9-10).

4) La colaboración entre el personal bibliotecario y el profesorado era un factor que influía positivamente sobre el rendimiento escolar del alumnado (Francis et al., 2010, pp. IV, V, 3, 7, 10).

\footnotetext{
"School Libraries Work!" (Scholastic Inc., 2004, 2006, 2008, 2016), para la recopilación y difusión de los estudios de impacto en bibliotecas escolares de Norteamérica. La responsable de sus actualizaciones es la editorial Scholastic, especializada en materiales educativos.
} 
5) Por último, se demostró que en las escuelas donde había bibliotecarios profesionales, el alumnado alcanzaba mejores resultados académicos en los test oficiales. Por ejemplo, en el mencionado tercer estudio sobre el Estado de Colorado de Francis et al. (2010, pp. II, 3-4), se demostró que las escuelas donde había bibliotecarios profesionales al frente de la biblioteca escolar, entre un 68 $\%$ y un $72 \%$ del alumnado alcanzaba el nivel de "proficient" o "advanced" en los test de lectura y entre un $9 \%$ y un $11 \%$ alcanzaba un nivel insuficiente. Por el contrario, en las escuelas donde no existía la figura del bibliotecario profesional, se reducía el porcentaje de estudiantes que alcanzaban nivel "proficient" o "advanced" (entre un $64 \%$ y un $68 \%$ ) y aumentaba el porcentaje de estudiantes que obtenían un resultado insuficiente (entre un $12 \%$ y un $13 \%$ ).

Cabe destacar la importancia que cobraba el bibliotecario profesional en estos estudios, demostrándose recurrentemente la correlación positiva entre el factor "tener bibliotecario profesional al frente de la biblioteca" y obtener buenos resultados en el rendimiento escolar del alumnado. A partir de este hallazgo, se ha abierto una línea de investigación que ha sido explorada por la literatura profesional (Coker, 2015; Dow, Lakin y Court, 2012; Jones y Zambone, 2008; Kaplan, 2010; Klinger y Shulha 2006; Lance y Hofschire, 2012; Nelson, 2010; Smalley, 2004; Todd, 2002), y ha servido de argumento para que las asociaciones bibliotecarias reivindiquen la profesionalización de la figura del bibliotecario escolar.

Por su parte, Krashen, Lee y McQuillan (2010, 2012) demostraron mediante un análisis multivariante que, controlando el efecto del factor "pobreza", el acceso a los libros en bibliotecas era un factor predictor de resultados en las evaluaciones de lectura. El alumnado con acceso a libros obtenía mejores resultados en las evaluaciones internacionales PIRLS y en las evaluaciones nacionales de Estados Unidos.

En la misma línea, el proyecto "Do school libraries make a difference?", en su fase piloto ya demostró que existía una correlación entre la dotación de recursos bibliotecarios y el desarrollo de competencias lectora e informacional en el alumnado de educación secundaria de Reino Unido (Gildersleeves, 2012).

Como acabamos de ver, en las primeras investigaciones en bibliotecas escolares predominó el análisis cuantitativo de datos basados en el análisis de correlaciones. Por lo general, estas correlaciones se construían con una variable dependiente (las calificaciones del alumnado) y una o varias variables independientes, consistentes en datos de inputs o outputs de la biblioteca escolar (cómputo de horas de apertura semanal, cómputo de horas semanales en las que la biblioteca estaba atendida por personal bibliotecario, número de horas semanales dedicado por el personal a la identificación de materiales de refuerzo para el currículo escolar, volumen de las colecciones por tipos de material, número de ordenadores disponibles en la biblioteca 
escolar, volumen de préstamos de una semana típica, número de sesiones formativas en una semana típica).

Veremos a continuación otros estudios en los que se incorporan metodologías cualitativas para obtener evidencias no solamente del impacto sobre las calificaciones académicas, sino también de las trasformaciones que se producían en el propio proceso de aprendizaje y en el desarrollo integral del alumnado por su contacto con la biblioteca.

\subsubsection{Estudios del impacto sobre el proceso de aprendizaje y el desarrollo integral del alumnado}

En estos estudios ya no se pone el foco sobre el rendimiento académico (medido mediante las calificaciones), sino sobre el proceso de aprendizaje en sí, y sobre el desarrollo integral del alumnado. La introducción de metodologías cualitativas propició esta nueva aproximación al impacto de las bibliotecas escolares sobre fenómenos complejos como la conducta, el comportamiento, la actitud ante el aprendizaje y la adquisición de las distintas habilidades cognitivas.

En su estudio sobre las bibliotecas escolares de Ohio, Todd y Kuhlthau (2005) aplicaron métodos cuantitativos y cualitativos para obtener evidencias sobre su influencia formativa y transformativa. Para establecer los indicadores de impacto, los autores adoptaron el marco teórico establecido por la American Library Association (1998, pp. 1-44) en sus Information Literacy Standards For Student Learning ${ }^{80}$. Adoptando este marco, el estudio abordó los beneficios de la biblioteca escolar sobre los procesos de aprendizaje informacional, tal y como se establecían en los estándares de la ALA. El estudio concluyó que la biblioteca escolar funcionaba como un agente dinámico que ayudaba al alumnado en sus procesos de aprendizaje, contribuyendo tanto a su desarrollo académico como personal. Se atribuía por tanto a la biblioteca

${ }^{80}$ Los Information Literacy Standards For Student Learning reúnen los contenidos y los procesos relacionados con la alfabetización informacional en el contexto escolar. Se estructuran en nueve estándares, según los cuales, el alumnado que tiene alfabetización informacional: 1) accede a la información de forma eficaz y eficiente; 2) evalúa la información de forma crítica y competente; y 3) usa la información de forma rigurosa y creativa. El alumnado que es capaz de aprender de forma autónoma, 4) tiene alfabetización informacional $y$, además, busca información relacionada con sus intereses personales; 5) y, además, aprecia la literatura y otras expresiones creativas de la información; 6) y, además, se esfuerza por encontrar información de calidad cuando busca y cuando él mismo genera información. El alumnado que contribuye positivamente en su entorno de aprendizaje y en la sociedad en general, 7) tiene alfabetización informacional y reconoce la importancia de la información para la sociedad democrática; 8) y tiene un comportamiento ético en todo lo relacionado con la información y las nuevas tecnologías; 9) y participa de forma efectiva en grupos para obtener y generar información. Cada uno de estos nueve estándares se acompaña de sus respectivos indicadores (en total se incluyen 21 indicadores) que permiten evaluar si se están alcanzando los distintos estándares. 
un papel dinamizador, funcionando como un lugar para la adquisición y generación de conocimiento.

Entre las evaluaciones de impacto de programas desarrollados por bibliotecas escolares, se pueden mencionar varios estudios de caso, como el trabajo de Klinger, Lee, Stephenson, Deluca y Luu (2009) en Ontario, el estudio de Smith (2001) en Texas, y el estudio de la misma autora en Wisconsin (Smith, 2006).

En el estudio sobre el impacto de las bibliotecas escolares del Estado de Nueva York (Small y Snyder, 2010; Small, Snyder y Parker, 2009), los autores tomaron como marco teórico los estándares establecidos por la Asociación Americana de Bibliotecarios de Bibliotecas Escolares ${ }^{81}$ (American Association of School Librarians, 2009). Se buscaron evidencias de la contribución de la biblioteca escolar a los cuatro estándares definidos por la AASL:

a) El proceso de la investigación y la adquisición de conocimiento.

b) El proceso por el cual el alumnado procesaría ese conocimiento para convertirlo en conclusiones y decisiones, transformándolo en conocimiento aplicado.

c) El proceso de compartir conocimiento con otros manteniendo unas pautas éticas.

d) La obtención de beneficios personales como crecimiento personal, motivación interés y habilidades para el aprendizaje, etc.

En el estudio se demostró la contribución de la biblioteca escolar sobre los distintos aspectos definidos por la AASL, destacando los beneficios sobre el comportamiento y las actitudes del alumnado respecto del proceso de aprendizaje, como, por ejemplo, tener mayor aprecio por la literatura, tener mayor curiosidad, alcanzar más confianza y autonomía en la búsqueda de información.

${ }^{81}$ La American Association of School Librarians publicó en 2009 sus Learning Standards, con el fin de incorporar dentro de su definición de "alfabetización informacional" a las nuevas formas de alfabetización, incluyendo la digital, visual, textual y tecnológica; y con el fin de servir de guía para construir los programas de las bibliotecas escolares dentro de su imbricación dentro del sistema educativo. El marco conceptual se fundamentaba sobre cuatro estándares principales: 1) El proceso de la investigación y la adquisición de conocimiento; 2) El proceso por el cual el alumnado procesaría ese conocimiento para convertirlo en conclusiones y decisiones, transformándolo en conocimiento aplicado; 3) El proceso de compartir conocimiento con otros manteniendo unas pautas éticas; y 4) La obtención de beneficios personales como crecimiento personal, motivación interés y habilidades para el aprendizaje, etc. Los programas de las bibliotecas escolares contribuirían a que el sistema educativo alcanzara estos estándares mediante programas y acciones orientadas al desarrollo de las habilidades cognitivas de los estudiantes, el refuerzo de su actitud respecto al aprendizaje, a la asunción de responsabilidades y en el aprendizaje de estrategias de autoevaluación (American Association of School Librarians, 2009, pp. 12-14). 
Por su parte, Fodale y Bates (2011) elaboraron un estudio tomando una muestra de estudiantes de entre 11 y 18 años de un área económicamente deprimida de Belfast. Para obtener la información, los autores recurrieron a entrevistas y cuestionarios dirigidos a profesorado y a las familias, y como marco teórico para la evaluación del impacto, emplearon los cinco "General Learning Objectives" 82 definidos en 2002 por el Learning Impact Research Project (LIRP) (Hooper-Greenhill, 2004) en Reino Unido. Los resultados del estudio confirmaron que la biblioteca escolar contribuía a reforzar los cinco objetivos del aprendizaje predefinidos en el marco teórico: con el uso de la biblioteca, el alumnado mejoraba su motivación por aprender, su autoestima y confianza personal, su actitud hacia la lectura y su proceso de alfabetización.

El impacto de la biblioteca escolar sobre la adquisición y desarrollo de la habilidad lectora despertó el interés de Huysmans, Kleijnen, Broekhof y Van Dalen (2013). En su investigación sobre el impacto de un programa de fomento de la lectura realizado en bibliotecas escolares holandesas en los años 2011-2012, los autores observaron que, el interés por la lectura y el nivel de competencia lectora de los escolares mejoraba en aquellas escuelas donde sí existía una biblioteca. Los autores recomendaron incorporar el programa de fomento de la lectura dentro del currículum académico para producir y consolidar este impacto positivo.

En su investigación sobre las bibliotecas escolares del Estado de Nueva York, SteflMabry y Radlick (2016) abordaron la dificultad de aislar estadísticamente el impacto producido por la biblioteca de otros factores concurrentes, como el origen socioeconómico familiar o su nivel educativo.

Fuera del ámbito anglosajón, recientemente se han desarrollado investigaciones sobre la contribución de las bibliotecas escolares nigerianas al desarrollo del sistema educativo (Baro y Eze, 2016; Busayo, 2018; Itsekor, Jegbefume y Oyebola, 2019), su impacto sobre el desarrollo socioeconómico del país (Chukwueke, Onuoha y Nnadozie, 2018; Danladi y Soko, 2018).

En el siguiente apartado se recogen los principales estudios de impacto en bibliotecas especializadas. Como se verá a continuación, la mayor parte de los trabajos circunscriben el alcance de su impacto al ámbito de las organizaciones de las que dependen las bibliotecas: empresas, centros de investigación, hospitales, etc.

\footnotetext{
82 En el Learning Impact Research Project (LIRP) desarrollado en 2002, se estableció un marco conceptual que se utilizarían desde entonces en las políticas educativas del Reino Unido. El marco estaba compuesto por cinco General Learning Outcomes (GLO): 1) Conocimiento y Comprensión, 2) Habilidades, 3) Actitudes y valores, 4) Disfrute, inspiración, creatividad, 5) Actividad, comportamiento y progreso.
} 


\subsubsection{Estudios de impacto en bibliotecas especializadas}

En el ámbito de las bibliotecas especializadas, los estudios de impacto analizan los beneficios que produce la biblioteca sobre la organización o institución a la que pertenece. Se suelen identificar tres aspectos (Matthews, 2002):

1) Contribución al éxito de las organizaciones: la información refuerza la toma de decisiones de valor estratégico y contribuye al cumplimiento de los objetivos corporativos. Ejemplo de ello es el estudio de Reynolds (2013) sobre el impacto percibido por el personal y directivos de la empresa Drivers Jonas Deloitte en relación con su servicio de información. El hecho de disponer información inmediata y actualizada repercutía en beneficios para la organización.

2) Contribución a la productividad de las organizaciones: la biblioteca ahorra tiempo a los miembros de la organización satisfaciendo sus necesidades de información (Chung, 2007; Greenshields, 1997). En su trabajo sobre los servicios bibliotecarios de la red de centros de investigación de Sudáfrica, el South African Council for Scientific and Industrial Research (CSIR), Botha, Erasmus y Van Deventer (2009) demostraron que las bibliotecas contribuían al ahorro de tiempo y al éxito en la labor investigadora.

3) Impacto económico: la biblioteca es un recurso económico de valor estratégico para la organización (Edgar,2004; Murray y Vilches, 2017).

Entre las evaluaciones en bibliotecas especializadas, hay que destacar las que se realizan en el ámbito de las bibliotecas de centros hospitalarios, como se puede ver en las revisiones bibliográficas de O'Connor (2002) y Marshall (2007). La mayor parte son estudios de impacto percibido, ya que suelen basarse en encuestas a profesionales de la salud para conocer la relevancia que tiene la biblioteca en su práctica profesional. La principal conclusión que se desprende es la importancia estratégica de los servicios de la biblioteca para la toma de decisiones médicas. Así lo demuestran los estudios de Marshall (1992) sobre los servicios hospitalarios de Rochester (Estado de Nueva York); el estudio de Burton (1995) en hospitales de Nueva Zelanda; el estudio de Urquhart y Hepworth (1995) sobre las bibliotecas del Sistema Nacional de Salud de Reino Unido; y el estudio a gran escala de Marshall et al. (2013) en 56 bibliotecas vinculadas a 118 hospitales de Estados Unidos y Canadá.

En otras investigaciones, se demuestra el impacto sobre el bienestar de los pacientes (Brettle, Maden y Payne, 2016; Cullen, 2004; Weightman y Williamson, 2005).

Otros estudios evalúan el retorno a la inversión de las bibliotecas de los centros hospitalarios. Un ejemplo de ello es el trabajo encargado por la Asociación Australiana 
de Bibliotecas (ALIA) a la consultora independiente SGS Economics and Planning (2013b), donde se demostró que, por cada dólar invertido, se producía un retorno de 9 dólares. Además, los profesionales de la sanidad percibían que la biblioteca añadía valor su práctica profesional: contribuía a mejorar los resultados de los estudios y exámenes; aportaba calidad a sus diagnósticos y reforzaba la investigación y la innovación.

Entre 2010 y 2016, el South Australian Health Library Service desarrolló una batería de indicadores para demostrar el impacto económico del servicio australiano de bibliotecas del sistema sanitario (Harris y Peterson, 2017). Se definieron cuatro áreas de impacto:

1. Apoyo en el cuidado a los pacientes.

2. Apoyo a la investigación basada en evidencias.

3. Apoyo a la toma de decisiones clínicas y a la formación.

4. Contribución al ahorro de costes en el sistema sanitario.

Por último, hay que decir que, aunque existe literatura sobre los servicios y recursos que las bibliotecas especializadas proporcionan a profesionales en las distintas ramas del saber (Howard, 2017), escasean los estudios de impacto fuera del ámbito de la empresa y del ámbito sanitario ya mencionados.

\subsubsection{Estudios de impacto en bibliotecas nacionales}

En el ámbito de las bibliotecas nacionales apenas existen trabajos publicados de evaluación del impacto.

Hunter y Hambelton (2011) abordaron la evaluación del impacto de la Biblioteca Nacional de Escocia sobre la generación de conocimiento. Para ello, elaboraron un análisis bibliométrico de todas aquellas publicaciones donde aparecía citada la biblioteca nacional.

Sin duda, la British Library ha sido pionera con la publicación de sus dos estudios de impacto: el primero de ellos, elaborado por la firma Spectrum Strategy Consultants and Indepen (2004), y el segundo, firmado por Tessler (2013). En ambos estudios se mostraron evidencias del impacto económico de la biblioteca nacional sobre la economía británica, haciendo uso de la metodología de la valoración contingente para la obtención de información. El estudio de 2004 concluyó que la British Library generaba un valor estimado de cerca de 4,4 veces el nivel de su inversión pública, es 
decir, que por cada libra que recibía de inversión anual, generaba 4,4 libras para la economía del país.

El estudio de 2013 profundizó en la valoración económica de los bienes intangibles con los que la biblioteca contribuía a la sociedad británica y a la sociedad global. Los usuarios valoraron las salas de lectura en 70 millones de libras anuales; su contribución a la educación superior se estimó en 5,4 millones de libras anuales; y la valoración percibida por el conjunto de los no usuarios alcanzó los 413 millones de libras anuales.

Aunque se ha estudiado el empleo de las redes sociales en bibliotecas nacionales (Medeiros y Oliveira Lucas, 2016), faltan estudios que aborden su impacto en la generación de redes y comunidades virtuales, tanto de usuarios reales como potenciales.

La reciente publicación de la norma ISO 21248:2019 (Organización Internacional de Normalización, 2019) es la iniciativa más novedosa en este campo. La norma proporciona un marco conceptual y metodológico necesario para la realización de futuras evaluaciones en bibliotecas nacionales.

\subsubsection{Estudios de impacto bibliotecario en España}

En España se han realizado tres estudios de impacto bibliotecario a gran escala hasta la fecha. El primero de ellos es el estudio realizado en la Red de Bibliotecas Municipales de la provincia de Barcelona (Luria Roig y Pintor González, 2013), promovido por la Diputación de Barcelona. En la primera parte del estudio se concluyó que los servicios de las bibliotecas municipales aportaban un ROI estimado de 2,25 euros de beneficio directo por cada euro invertido. En la segunda parte del estudio se abordó el cálculo del retorno social, o "capacidad para generar beneficios sociales tanto para el individuo como para la comunidad en general" (Pintor, 2013, p.48). Los autores abordaron las cinco dimensiones del impacto bibliotecario identificadas por Huysmans y Oomes (2013): cultural, social, educativo, económico y afectivo ${ }^{83 .}$

${ }^{83}$ Huysmans y Oomes (2013, p. 175) identificaron cinco áreas de impacto:

1) Impacto cultural: la biblioteca contribuía a la promoción de libros y literatura, al impulso de la industria editorial y de la escritura creativa, al apoyo de la cultura local, a la preservación y acceso al patrimonio cultural, al refuerzo del multiculturalismo y la diversidad.

2) Impacto social: la biblioteca contribuía a la promoción de la conexión entre personas y grupos, la participación y la inclusión, el capital social y la cohesión social, a reforzar el sentido de pertenencia a la comunidad, a promover el compromiso social y la participación de procesos democráticos. 
Si bien los resultados de esta segunda parte del estudio no son concluyentes, se identificaron dos ámbitos en torno a los cuales se articularía el impacto social: el individuo y la colectividad (Pintor, 2013, p.50):

- En el ámbito del individuo, las bibliotecas contribuirían al fomento del hábito lector, al acceso universal al conocimiento y a la lectura, a la inclusión social, a la inclusión de personas con discapacidad, a la inclusión de la diversidad cultural, a la inclusión laboral, a la alfabetización informacional y a la inclusión digital.

- En el ámbito de la comunidad, las bibliotecas contribuirían a la preservación y difusión de la memoria cultural local, al progreso cultural y artístico local, a la cohesión social, al capital social, a la revitalización del espacio público, al progreso económico local y a crear sociedades más y mejor informadas.

En segundo lugar, hay que mencionar el estudio realizado por la Federación Española de Sociedades de Archivística, Biblioteconomía, Documentación y Museística (Fesabid), promovido por el Consejo de Cooperación Bibliotecaria del Ministerio de Educación, Cultura y Deporte (Gómez Yáñez, 2014), sobre el del conjunto de bibliotecas públicas, universitarias y científicas españolas, más la Biblioteca Nacional de España. En este estudio se estimó que el retorno a la inversión del sistema bibliotecario español estaría entre un mínimo de 2,8 euros y un máximo de 3,83 euros por cada euro invertido. Calculado en precios de mercado, se estimó que las bibliotecas aportarían a la sociedad cerca de tres mil millones de euros anuales, considerando la aportación del conjunto de servicios bibliotecarios a las comunidades de investigación, profesionales, estudiantes y usuarios en general. Y considerando la

3) Impacto educativo: la biblioteca contribuía al desarrollo de habilidades informacionales, al aprendizaje a lo largo de la vida, a la adquisición de competencias ciudadanas, al desarrollo de la empatía, la argumentación, el pensamiento crítico, a la formación de decisiones fundamentadas, al conocimiento de los derechos civiles y de los servicios públicos, a la resolución de problemas y ayuda en la toma de decisiones relacionadas con la salud, los derechos del consumidor, al apoyo a la sociedad del conocimiento y la innovación.

4) Impacto económico: la biblioteca contribuía a la equidad en el acceso a los recursos, a la estimulación del emprendimiento, al ahorro de dinero y tiempo, a la gestión de finanzas personales, al apoyo a la carrera profesional y a los negocios locales, a la regeneración y revitalización de barrios, a la creación de empleo, a atraer el turismo, a atraer a nuevos habitantes hacia el área geográfica de influencia de la biblioteca, a fomentar de la actividad económica.

5) Impacto afectivo: la biblioteca contribuía al disfrute estético, a la satisfacción personal, la diversión, al cultivo de la creatividad, la imaginación, el desarrollo personal, la autorrealización, la autoconfianza. 
valoración realizada por los no usuarios de bibliotecas ${ }^{84}$, la aportación del sistema bibliotecario a la sociedad se estimó en 4.238 millones de euros anuales. Hay que decir que el estudio de Fesabid fue el primer análisis a nivel nacional sobre el sistema bibliotecario en España. Al abarcar bibliotecas de muy distintas tipologías, misión y funciones, resulta complejo poder de extraer a partir de él conclusiones válidas para el conjunto del sistema bibliotecario.

El tercero de los estudios españoles a gran escala fue el estudio del impacto socioeconómico de las bibliotecas de la Comunidad Foral de Navarra, promovido por el Consejo de Cooperación Bibliotecaria del Ministerio de Educación, Cultura y Deporte y el Gobierno de Navarra (Hernández Sánchez, 2016). En él se aplicó una metodología similar al estudio de Fesabid, pero a nivel local, extrayendo conclusiones sobre el retorno económico y social del sistema bibliotecario de la Comunidad Foral. Se estimó que, aplicando precios de referencia de mercado, los servicios bibliotecarios navarros aportaban un retorno a la inversión estimado de 3,49 euros por cada euro invertido. Considerando la disposición a pagar de usuarios y no usuarios, obtenida mediante la metodología de la valoración contingente, la estimación alcanzó los 4,66 euros de ROI por euro invertido. Este ROI se podía traducir en 44,1 millones de euros anuales de beneficio neto. Por último, en cuanto a la estimación del retorno a la inversión por tipos de bibliotecas, el ROI de las bibliotecas universitarias alcanzó los 4,14 euros por cada euro invertido, y el ROI de las bibliotecas públicas alcanzó los 3,06 euros por cada euro invertido.

Entre los estudios de impacto de programas bibliotecarios específicos, se puede destacar el trabajo de Gómez-Hernández, Hernández-Pedreño y Romero-Sánchez (2017) acerca de la repercusión del programa de servicios bibliotecarios de la Biblioteca Regional de Murcia orientado a usuarios en situación de vulnerabilidad social o exclusión digital.

Entre las bibliotecas universitarias, se puede destacar el trabajo de Fernández y Rubio (2013) en la Universidad Politécnica de Valencia. Los autores analizaron si existía alguna relación entre el presupuesto de la biblioteca y la productividad investigadora de la universidad. El análisis concluyó que en el periodo analizado (20012012) no se había producido una correlación estadísticamente significativa entre estas dos variables; no obstante, sí se observó una correlación fuerte entre el presupuesto para recursos electrónicos y la productividad investigadora.

En España las bibliotecas escolares han quedado fuera de los estudios de impacto realizados recientemente, ya mencionados en los párrafos anteriores. No obstante, contamos con información cuantitativa relativamente reciente sobre nuestras

\footnotetext{
${ }^{84}$ Para la obtención de la valoración de los no usuarios se recurrió a la metodología de la valoración contingente mediante encuestas a no usuarios de bibliotecas.
} 
bibliotecas escolares. La inclusión de la serie estadística sobre bibliotecas escolares dentro del Plan Estadístico Nacional nos permite tener una visión cuantitativa general sobre su situación desde $2010^{85}$. Entre los estudios que se han aproximado a esta materia, cabe destacar el trabajo de Marzal, Parra y Colmenero (2011) sobre la elaboración de un modelo de indicadores para evaluar el impacto de los programas de alfabetización informacional realizados en bibliotecas escolares con alumnado de educación reglada de primaria y segundaria. Los autores propusieron una batería de 28 indicadores agrupados en tres categorías: destrezas, habilidades y competencias.

Miret, Baró, Mañá, Vellosillo y Martín (2013) evaluaron la contribución de las bibliotecas escolares españolas al contexto educativo del periodo 2005 a 2011. El estudio documentó el papel activo de las bibliotecas escolares en tres ámbitos:

- En el desarrollo de la competencia en lectoescritura: acciones de promoción a la lectura, inversión en recursos para la lectura recreativa, y alianzas con bibliotecas públicas.

- En el desarrollo de competencias digitales: actividades de búsqueda de información e investigación documental.

- En el desarrollo de competencias en el uso de la información (búsqueda, selección, lectura crítica, etc.) utilizando las nuevas tecnologías.

En el mismo estudio se concluyó que en los centros privados y concertados predominaba la estrategia de formación del alumnado en competencias digitales y de investigación documental, mientras que en los centros públicos predominaba la estrategia de permitir el acceso de profesado y alumnado a la biblioteca en horas de clase y organizar actividades de animación a la lectura.

En España la elaboración de un estudio sobre el impacto en bibliotecas escolares es una cuestión pendiente. Retomaremos este último punto en los sucesivos capítulos de esta tesis, en la que profundizaremos en el estudio del impacto de las bibliotecas en el ámbito de la escuela, siendo éste el menos explorado en nuestro país (Albelda Esteban y La Mano González, 2017).

\footnotetext{
85 La estadística de Bibliotecas Escolares se recoge en el Plan Estadístico Nacional de los años 20132016 y en el Plan de los años 2017-2020. En su elaboración intervienen el ministerio y las consejerías o departamentos con competencia en materia de educación en todas las comunidades autónomas http://www.ine.es/ss/Satellite?L=es ES\&c=INEPlanEst C\&p=1254735995577\&pagename=INE\%2FINELa yout $\&$ charset $=u t f-8 \&$ cid $=1259935317768 \&$ submit $=\mid r$
} 


\section{Conclusiones de la primera parte}

La evaluación en bibliotecas ha sido tradicionalmente una práctica minoritaria, aunque han proliferado los estudios de evaluación del rendimiento y de evaluación del impacto al servicio de la toma de decisiones y la defensa del valor de las bibliotecas en la sociedad de la información. Una buena parte de los estudios de evaluación son impulsados y financiados por organismos e instituciones públicas, entidades normalizadoras, fundaciones y asociaciones profesionales de ámbito nacional e internacional.

$\checkmark$ Hasta fechas recientes, la evaluación en bibliotecas ha sido básicamente una evaluación del rendimiento. Se observa una evolución desde los primeros estudios de evaluación bibliotecaria basados en datos estadísticos de resultados e indicadores de rendimiento hasta las evaluaciones del impacto que utilizan información cuantitativa y cualitativa para identificar los beneficios que genera la biblioteca en la sociedad.

$\checkmark$ A pesar de los esfuerzos normalizadores recientes, el campo de la evaluación presenta una gran dispersión terminológica y metodológica. Los estudios recientes están incluyendo conceptos y metodologías prestadas de otras disciplinas de las Ciencias Sociales, como la Economía. Una de las principales dificultades metodológicas consiste en aislar el efecto de la biblioteca sobre otras variables que puedan concurrir en un mismo estudio.

$\checkmark$ La dimensión económica ha sido ampliamente utilizada en los estudios sobre impacto y ya se cuenta con una cierta tradición, sin embargo, es necesario seguir profundizando sobre el complejo problema de medir el valor de los bienes intangibles. Una de las técnicas más utilizadas es el retorno a la inversión, que traduce a términos monetarios el valor de las bibliotecas. La valoración contingente permite evaluar el valor de los bienes intangibles y obtener información sobre el beneficio percibido por los no usuarios. Siguiendo la sugerencia de Urquhart (2015), sería interesante probar la aplicación de marcos conceptuales tomados de la teoría del Marketing para analizar en profundidad el valor percibido por los usuarios expresado en los estudios cualitativos.

En el caso de las bibliotecas públicas, la visión excesivamente economicista está dejando paso a estudios donde se incluye una visión más preocupada por el papel social de las bibliotecas. Estos estudios evalúan los beneficios y cambios que se producen en los individuos, comunidades y sociedades, como resultado o en relación con las políticas, programas y proyectos bibliotecarios. En este sentido, como muestran Byrne (2018), y Kerslake y Kinnell (1998), el impacto social se suele relacionar con la inclusión social, la inclusión digital, el fortalecimiento de los 
valores democráticos de las comunidades. La literatura especializada ha reflejado abundantemente el papel de la biblioteca pública en la inclusión social, no obstante, faltan estudios que demuestren evidencias de su impacto sobre distintos grupos sociales y en diferentes contextos espaciotemporales.

Se observan distintos enfoques evaluativos en los distintos tipos de biblioteca (universitarias, públicas, escolares, especializadas y nacionales). El enfoque de los estudios depende en gran medida del tipo de biblioteca, siendo factores determinantes su misión y su comunidad de usuarios objetivo en cada caso.

Es necesario seguir elaborando estudios empíricos que permitan realizar evaluaciones longitudinales. A pesar de que la evaluación del impacto se ha popularizado en los últimos años, sin embargo, se necesita aún construir un corpus suficientemente amplio de trabajos empíricos que permita observar con cierta perspectiva la evolución de los datos de impacto en el tiempo y teniendo en cuenta los cambios que se producen en los entornos sociales. En este sentido, aunque exista un interés creciente sobre la evaluación del impacto y se elaboren estudios más o menos dispersos, no disponemos de suficiente información aún para poder contrastar la percepción que se tiene sobre el valor de los servicios bibliotecarios en los distintos entornos socioculturales, en sociedades con distintos grados de desarrollo, y en relación con distintos perfiles sociodemográficos.

El interés por el estudio de la biblioteca pública como espacio físico y virtual cuenta ya con un número considerable de citas bibliográficas en la literatura especializada. La mayor parte de los trabajos coinciden en que la biblioteca funciona como un "tercer lugar" que propicia la generación de capital social, especialmente en lo referente a la integración de grupos. No obstante, faltan estudios que aborden el impacto de los espacios de las bibliotecas sobre la experiencia de los individuos, en ámbitos como el aprendizaje a lo largo de la vida.

$\checkmark$ Al igual que sucede con las bibliotecas públicas, la bibliografía especializada está interesándose cada vez más por la dimensión espacial (física y virtual) de la biblioteca universitaria, concebida como espacio que propicia el aprendizaje. En este sentido, se abre una línea de investigación que estudia la configuración espacial y su repercusión sobre los resultados académicos y sobre los procesos de aprendizaje.

En el caso de las bibliotecas nacionales, predominan los estudios sobre su impacto económico, si bien no disponemos de suficiente investigación sobre su contribución a la generación de conocimiento y a distintas comunidades de usuarios, incluyendo usuarios reales y potenciales. La reciente publicación de la norma ISO 21248:2019 (Organización Internacional de Normalización, 2019) 
proporciona un marco conceptual y metodológico que puede ser utilizado en futuras evaluaciones sobre el valor intangible de este tipo especial de bibliotecas.

$\checkmark$ Con respecto a las bibliotecas especializadas, los estudios suelen mostrar su valor estratégico en pro de la consecución de los objetivos de las organizaciones y del incremento de la productividad de los profesionales. Se han realizado principalmente en bibliotecas de empresas, de centros de investigación, y en el ámbito de las bibliotecas de hospitales y centros de salud.

En el ámbito de las bibliotecas escolares, si bien su impacto sobre el rendimiento del alumnado ha sido estudiado en el contexto estadounidense, sin embargo, falta investigación sobre su impacto en otros sistemas educativos. En particular, en España las bibliotecas escolares han quedado fuera de los estudios sobre impacto bibliotecario realizados en los últimos años. No obstante, el interés por conocer los beneficios que puede reportar la inversión en un buen sistema de bibliotecas escolares es un tema que no pierde actualidad. Por su interés, y por tratarse de un campo de estudio no suficientemente explorado, hemos orientado los objetivos de esta tesis al estudio del impacto de la biblioteca en el ámbito escolar en España.

$\checkmark$ Por último, a lo largo de esta revisión bibliográfica, hemos dado cuenta de la importancia de la normalización en el campo de la evaluación bibliotecaria. En efecto, en el ámbito de la evaluación del impacto es la norma ISO 16439 la referencia más destacada en Biblioteconomía. Siendo así, la hemos adoptado como referente conceptual y terminológico, y hemos incorporado sus especificidades metodológicas en la segunda parte de esta tesis. 


\section{SEGUNDA PARTE. Desarrollo de la} investigación sobre el impacto de la biblioteca escolar desde una doble perspectiva: la aproximación cuantitativa y cualitativa

De acuerdo con el planteamiento de integración de métodos que se recoge en el capítulo introductorio de esta tesis, en los capítulos 3 y 4 se complementan sendas perspectivas cuantitativa y cualitativa. Con la primera hemos alcanzado un conocimiento general del problema y se han obtenido las primeras evidencias, y con la segunda hemos profundizado sobre esos primeros resultados y sobre las relaciones que se establecen entre las variables cuantitativas. La suma de las dos perspectivas produce una imagen de conjunto que nos acerca a una mayor comprensión de los procesos complejos que se producen en el ámbito educativo.

\section{CAPÍTULO 3. La perspectiva cuantitativa: el análisis del impacto de las bibliotecas escolares a partir de los estudios PIRLS y PISA}

\subsection{Introducción}

En este capítulo abordamos la cuestión del impacto de la biblioteca escolar, como recurso del sistema educativo, sobre el rendimiento académico del alumnado de educación primaria y secundaria en España. Profundizamos así en el impacto educativo, que es una de las dimensiones del impacto bibliotecario según la literatura especializada (Huysmans y Oomes, 2013; Organización Internacional de Normalización, 2014b ${ }^{86}$ ).

\footnotetext{
${ }^{86}$ La norma ISO 16439 dedica un epígrafe a la posibilidad de realizar evaluaciones de impacto en bibliotecas tomando como variables los resultados del alumnado en test normalizados. La norma establece que, aunque este tipo de estudios no están pensados para medir de manera específica el
} 
Nos aproximarnos al problema de investigación con un enfoque metodológico cuantitativo que se sostiene sobre asociaciones entre variables, siendo la variable dependiente el resultado obtenido por el alumnado en las pruebas internacionales de competencia lectora. Entre las variables independientes, incluimos la existencia (sí /no) de biblioteca en el centro educativo; la intensidad de uso de la biblioteca por el alumnado; el acceso a diferentes recursos bibliotecarios, como el préstamo de libros impresos y electrónicos y la colección bibliográfica.

Dentro del marco de esta tesis, con esta primera aproximación cuantitativa obtenemos información para abordar el primero de los objetivos de esta investigación: identificar y analizar cambios en habilidades y competencias que se producen como resultado o guardan relación con el uso de la biblioteca escolar. En particular, analizamos la contribución de la biblioteca escolar al rendimiento del alumnado en competencia lectora y cómo influyen los distintos recursos de la biblioteca escolar sobre este rendimiento. Con ello respondemos a las preguntas de investigación 1 y 2 :

1. ¿Tiene alguna influencia el hecho de tener biblioteca en el centro educativo sobre el rendimiento académico en competencia lectora? Y en caso afirmativo, ¿sobre qué dimensiones competenciales se observa este impacto?

- comprender e interpretar textos literarios e informativos

- ser competentes en obtener e inferir información a partir de la lectura

- ser capaces de interpretar, integrar y evaluar críticamente la información obtenida en el entorno papel y en el entorno digital y con los distintos tipos de material y soportes bibliográficos

2. ¿Cómo influyen los distintos recursos, actividades o prácticas vinculadas a la biblioteca sobre el desarrollo de la competencia lectora?

Para el análisis se han utilizado los conjuntos de datos de la evaluación internacional PIRLS 2016 sobre rendimiento en competencia lectora del alumnado de cuarto curso de educación primaria en España. El análisis estadístico de los datos PIRLS 2016 se ha complementado con un segundo análisis de los conjuntos de datos del estudio PISA 2009 sobre rendimiento en competencia lectora del alumnado de educación secundaria en España.

En ambos casos se ha utilizado el individuo (alumno/a) como unidad de análisis:

- La muestra española para PIRLS 2016 incluye 14.595 individuos de 629 centros educativos de las distintas comunidades autónomas, representando una

impacto de los programas y servicios bibliotecarios, no obstante, sí evalúan las competencias informacionales, que sí pueden servir como indicadores del impacto de los programas de formación desarrollados por la biblioteca (Organización Internacional de Normalización, 2014b, p.77). 
población de cerca de 457.000 estudiantes de educación primaria de nueve años de edad.

- La muestra española para PISA 2009 incluye cerca de 26.000 individuos de 910 centros educativos, representando una población de cerca de 387.000 estudiantes de educación secundaria de quince años de edad.

Al trabajar con estos conjuntos de datos, hemos asumido por lo tanto una serie de condicionantes en nuestro análisis:

- Hemos trabajado con conjuntos de datos que fueron concebidos para evaluar el rendimiento del alumnado, y que permiten analizar el peso relativo de los distintos factores socioeconómicos, educativos y culturales, sobre ese rendimiento. En esta investigación nos hemos propuesto evaluar el impacto del factor "biblioteca escolar" sobre este rendimiento.

- Como indicador de rendimiento académico se ha utilizado un dato cuantitativo: la puntuación media ${ }^{87}$ en competencia lectora obtenida por el alumnado en sendos estudios internacionales.

- Hay que tener en cuenta que solamente se han analizado datos del rendimiento en competencia lectora ${ }^{88}$. Si bien el ámbito de la lectoescritura parece el área

\footnotetext{
87 Asumimos que en las evaluaciones internacionales PIRLS y PISA, los promedios globales de los resultados académicos están calculados según el procedimiento de los "valores plausibles", con el fin de reducir sesgos (Foy et al., 2018; Organización para la Cooperación y el Desarrollo Económicos, 2012). Así se justifica en el informe español del último estudio PIRLS:

El estudio PIRLS utiliza la teoría de respuesta al ítem (TRI) para asignar las puntuaciones a los alumnos. Este modelo expresa el nivel de rendimiento en una escala común a la empleada para estimar la dificultad de las preguntas de la prueba. Para cada alumno se obtiene la distribución a posteriori de la destreza medida, de la que se extraen cinco valores aleatorios, denominados valores plausibles. Por ello la puntuación asignada a cada alumno no se expresa mediante un único valor (estimador puntual, como por ejemplo la media). Este procedimiento reduce el sesgo de la varianza de los estimadores obtenidos (Wu, M., 2005 y 2010). Las bases de datos de PIRLS incluyen una ponderación para que los estimadores obtenidos puedan ser aplicados a la población completa de alumnos de cada país (Instituto Nacional de Evaluación Educativa, 2017, p.27).
}

Por todo ello hemos debido seguir las indicaciones para el trabajo con valores plausibles tal y como se especifican en los informes técnicos de PIRLS 2016 y PISA 2009. Se ha utilizado el programa IEA IDB Analyzer, que incorpora en su módulo de análisis la opción específica de trabajo con valores plausibles.

${ }^{88}$ Adoptamos el concepto de competencia lectora que se recoge en el marco conceptual de los estudios PIRLS y PISA. En PIRLS 2016, se establece que:

Reading literacy is the ability to understand and use those written language forms required by society and/or valued by the individual. Readers can construct meaning from texts in a variety of forms. They read to learn, to participate in communities of readers in school and everyday life, and for enjoyment (Mullis y Martin, 2015, p. 12). 
de impacto natural de la biblioteca, no obstante, también cabe preguntarse por el impacto de la biblioteca sobre otras competencias del alumnado, tanto curriculares como no curriculares, que han quedado fuera de este análisis cuantitativo.

- El alcance de nuestro análisis ha estado condicionado por las variables que hemos podido obtener de los conjuntos de datos PIRLS 2016 y PISA 2009. Ha sido necesario realizar una revisión sistemática de estos conjuntos de datos para identificar todas aquellas variables donde se menciona la biblioteca escolar ${ }^{89}$, como se muestra en la Tabla 5 y en la Tabla 44. Por tanto, el alcance de este análisis ha quedado circunscrito a un número limitado de variables que han resultado de la explotación de los conjuntos de datos PIRLS y PISA. Con estos datos solo hemos podido responder a las preguntas 1 y 2 de la investigación, que plantean el impacto de la biblioteca escolar y sus recursos sobre la competencia lectora del alumnado. Hemos aceptado esta limitación debido a que se ha trabajado con datos cuya obtención cae fuera de nuestro control.

- Tanto los datos PIRLS como los datos PISA se encuentran disponibles de manera abierta para la investigación. No obstante, ha sido preciso solicitar a la Asociación Internacional para la Evaluación del Rendimiento Educativo, IEA, los

En PISA 2009, se define como:

The PISA 2009 definition of reading adds engagement in reading as an integral part of reading literacy: Reading literacy is understanding, using, reflecting on and engaging with written texts, in order to achieve one's goals, to develop one's knowledge and potential, and to participate in society (Organización para la Cooperación y el Desarrollo Económicos, 2009, p. 23).

En estas definiciones, la competencia lectora se aproxima al concepto de "alfabetización informacional” tal y como lo conciben Cuevas Cerveró y Marzal García Quismondo (2007): “la capacidad para el acceso, valoración y uso competente de la información" (p. 63).

${ }^{89}$ La norma ISO 16439 advierte de que, cuando la evaluación del impacto de una biblioteca se enmarca dentro de una evaluación más general en la que se evalúa una organización superior, se observa que

por lo general, la biblioteca suele jugar un papel menor dentro de la evaluación general. En estos casos, se suele preguntar principalmente sobre la percepción de la eficacia de la biblioteca y su valor en general, y solo ocasionalmente se pregunta sobre su impacto sobre los individuos, aunque los resultados pueden ser útiles para identificar posibles impactos y para comparar el impacto y el valor de la biblioteca con otros servicios de la institución (Organización Internacional de Normalización, 2014b, p.75).

[Traducido del original: "Usually, the library plays only a minor role in such broader assessment. The questions ask predominantly for an appreciation of the library's effectiveness and general value, only occasionally for its impact on individuals, but the findings can be useful for identifying possible impacts and comparing library impact and value with that of other institutional services"]. 
correspondientes permisos para reutilización, reproducción o traducción de sus propios materiales, incluyendo los conjuntos de datos, el software específico, los cuestionarios de evaluación utilizados en el estudio PIRLS 2016 y el material bibliográfico publicado por esta entidad.

- En cuanto al tratamiento de los datos, los procedimientos de análisis y su interpretación, ha sido preciso seguir las indicaciones y procedimientos establecidos por la IEA y por la OCDE en los respectivos documentos técnicos de PIRLS 2016 (Foy et al., 2018) y PISA 2009 (Organización para la Cooperación y el Desarrollo Económicos, 2012). Asimismo, ha sido preciso aprender el manejo y la sintaxis del software específico de la IEA para realizar la extracción, fusión, tratamiento y análisis estadístico de los conjuntos de datos: el programa International Database Analyzer (Versión 4.0) junto con el programa comercial IBM SPSS Statistics for Windows (Versión 22.0).

Una vez advertidos los elementos condicionantes de trabajar con los conjuntos de datos, hemos procedido a su análisis. En los siguientes apartados se detalla un primer análisis cuantitativo sobre el efecto de la biblioteca escolar sobre la competencia lectora del alumnado español de educación primaria con los datos PIRLS 2016. Seguidamente se ha realizado un segundo análisis con los conjuntos de datos del estudio PISA 2009. Con este segundo análisis se ha ampliado el alcance de la investigación cuantitativa introduciendo información sobre el efecto de la biblioteca escolar sobre el alumnado de educación secundaria.

\subsection{Análisis en el ámbito de la educación primaria}

\subsubsection{Las bibliotecas en el estudio PIRLS 2016}

Los estudios PIRLS evalúan con una periodicidad quinquenal el rendimiento en competencia lectora del alumnado de cuarto curso de educación primaria en cerca de cincuenta países, entre ellos, España. En esta investigación hemos recogido los datos de la última de las evaluaciones PIRLS en la que ha participado nuestro país, que corresponde al año 2016.

Junto a la prueba de evaluación de la competencia lectora, PIRLS recaba información sobre la actitud y hábitos de lectura del propio alumnado y de su contexto familiar y educativo. Para recabar estos datos, PIRLS emplea cuatro cuestionarios: uno con preguntas para el alumnado, uno dirigido al profesorado, otro 
cuestionario para las familias, y un último cuestionario dirigido a responsables de los centros educativos.

En sus sucesivas ediciones desde 2001 se incluyen preguntas sobre la biblioteca escolar en los cuestionarios dirigidos al alumnado, al profesorado y a responsables de los centros educativos, tal y como se resume en la Tabla 5. En la tabla se pueden observar las distintas preguntas en las que se hace alusión a las bibliotecas. En las columnas primera y segunda se especifica la edición del estudio PIRLS y el cuestionario en el que se incluye cada pregunta. En la columna tercera se registra el número con el que se identifica cada pregunta dentro del cuestionario, y en la columna cuarta se registra el código de la variable a la que corresponde cada pregunta, para su identificación dentro de los ficheros de los conjuntos de datos.

Tabla 5. Presencia de las bibliotecas en el estudio PIRLS $2016^{90}$

\begin{tabular}{|c|c|c|c|c|}
\hline PIRLS & Questionnaire & $\begin{array}{l}\text { Question } \\
\text { number }\end{array}$ & Variable & Question \\
\hline $\begin{array}{l}\text { PIRLS } \\
2016\end{array}$ & $\begin{array}{l}\text { Student } \\
\text { Questionnaire }\end{array}$ & SQR-03 & ASBR03 & $\begin{array}{l}\text { How often do you borrow } \\
\text { books (including ebooks) from } \\
\text { your <school or local library>? } \\
\text { - At least once a week } \\
\text { - } \text { Once or twice a month } \\
\text { - A few times a year } \\
\text { - Never or almost never }\end{array}$ \\
\hline $\begin{array}{l}\text { PIRLS } \\
2016\end{array}$ & $\begin{array}{l}\text { School } \\
\text { Questionnaire }\end{array}$ & ScQ-09 & ACBG09 & $\begin{array}{l}\text { Does your school have a } \\
\text { school library? } \\
\text { - Yes } \\
\text { - No }\end{array}$ \\
\hline $\begin{array}{l}\text { PIRLS } \\
2016\end{array}$ & $\begin{array}{l}\text { School } \\
\text { Questionnaire }\end{array}$ & ScQ-09A & ACBG09A & $\begin{array}{l}\text { Approximately how many } \\
\text { books (print) with different titles } \\
\text { does your school library have } \\
\text { (exclude magazines and } \\
\text { periodicals)? }\end{array}$ \\
\hline
\end{tabular}

${ }^{90}$ Esta tabla recoge la versión internacional de los cuestionarios PIRLS 2016. Fuente: International Association for the Evaluation of Educational Achievement (2018). PIRLS 2016 User Guide for the International Database. Supplement1, International version of the PIRLS 2016 Context Questionnaires. https://timssandpirls.bc.edu/pirls2016/international-database/downloads/P16_UG_Supplement1.pdf 


\begin{tabular}{|c|c|c|c|c|}
\hline & & & & $\begin{array}{ll}\text { - } & 250 \text { or fewer } \\
\text { - } & 251-500 \\
\text { - } & 501-2,000 \\
\text { - } & 2,001-5,000 \\
\text { - } & 5,001-10,000 \\
\text { - } & \text { more than } 10,000\end{array}$ \\
\hline $\begin{array}{l}\text { PIRLS } \\
2016\end{array}$ & $\begin{array}{l}\text { School } \\
\text { Questionnaire }\end{array}$ & ScQ-09B & ACBG09B & $\begin{array}{l}\text { Approximately how many } \\
\text { titles of magazines and other } \\
\text { periodicals (print) does your } \\
\text { school library have? } \\
\text { - } 0 \\
\text { - } 1-5 \\
\text { - } 6-10 \\
\text { - } 11-30 \\
\text { - } 31 \text { or more }\end{array}$ \\
\hline $\begin{array}{l}\text { PIRLS } \\
2016\end{array}$ & $\begin{array}{l}\text { School } \\
\text { Questionnaire }\end{array}$ & ScQ-09C & ACBG09C & $\begin{array}{l}\text { Can students borrow print } \\
\text { materials from the library to take } \\
\text { home? } \\
\text { - Yes } \\
\text { - No }\end{array}$ \\
\hline $\begin{array}{l}\text { PIRLS } \\
2016\end{array}$ & $\begin{array}{l}\text { School } \\
\text { Questionnaire }\end{array}$ & ScQ-10 & ACBG10 & $\begin{array}{l}\text { Does the school provide } \\
\text { access to digital books? } \\
\text { - Yes } \\
\text { - No }\end{array}$ \\
\hline $\begin{array}{l}\text { PIRLS } \\
2016\end{array}$ & $\begin{array}{l}\text { School } \\
\text { Questionnaire }\end{array}$ & $\mathrm{ScQ}-12 \mathrm{Bc}$ & ACBG12BC & $\begin{array}{l}\text { How much is your school's } \\
\text { capacity to provide instruction } \\
\text { affected by a shortage or } \\
\text { inadequacy of the following? } \\
\text { Resources for Reading } \\
\text { Instruction: Library resources } \\
\text { books, ebooks, magazines, etc.) } \\
\text { - Not at all } \\
\text { - A little }\end{array}$ \\
\hline
\end{tabular}




\begin{tabular}{|c|c|c|c|c|}
\hline & & & & $\begin{array}{l}\text { - } \text { Some } \\
\text { - } \text { A lot }\end{array}$ \\
\hline $\begin{array}{l}\text { PIRLS } \\
2016\end{array}$ & $\begin{array}{l}\text { Teacher } \\
\text { Questionnaire }\end{array}$ & TQR-15A & ATBR15A & $\begin{array}{l}\text { Do you have a library or } \\
\text { reading corner in your } \\
\text { classroom? } \\
\text { - Yes } \\
\text { - No }\end{array}$ \\
\hline $\begin{array}{l}\text { PIRLS } \\
2016\end{array}$ & $\begin{array}{l}\text { Teacher } \\
\text { Questionnaire }\end{array}$ & TQR-15B & ATBR15B & $\begin{array}{l}\text { About how many books are in } \\
\text { your classroom library? } \\
\text { - } 0-25 \\
\text { - } 26-50 \\
\text { - } 51-100 \\
\text { - more than } 100\end{array}$ \\
\hline $\begin{array}{l}\text { PIRLS } \\
2016\end{array}$ & $\begin{array}{l}\text { Teacher } \\
\text { Questionnaire }\end{array}$ & TQR-15C & ATBR15C & $\begin{array}{l}\text { About how many magazines } \\
\text { with different titles are in your } \\
\text { classroom library? } \\
\text { - } 0 \\
\text { - } 1-2 \\
\text { - } 3-5 \\
\text { - } \text { more than } 5\end{array}$ \\
\hline $\begin{array}{l}\text { PIRLS } \\
2016\end{array}$ & $\begin{array}{l}\text { Teacher } \\
\text { Questionnaire }\end{array}$ & TQR-15D & ATBR15D & $\begin{array}{l}\text { How often do you give the } \\
\text { students in your class time to use } \\
\text { the classroom library or reading } \\
\text { corner? } \\
\text { - Every day or almost every } \\
\text { day } \\
\text { - Once or twice a week } \\
\text { - Once or twice a month } \\
\text { - Never or almost never }\end{array}$ \\
\hline $\begin{array}{l}\text { PIRLS } \\
2016\end{array}$ & $\begin{array}{l}\text { Teacher } \\
\text { Questionnaire }\end{array}$ & TQR-15E & ATBR15E & $\begin{array}{l}\text { Can the students borrow } \\
\text { books from the classroom library } \\
\text { or reading corner to take home? } \\
\text { - Yes } \\
\text { - No }\end{array}$ \\
\hline
\end{tabular}




\begin{tabular}{|l|l|l|l|l|}
\hline $\begin{array}{l}\text { PIRLS } \\
2016\end{array}$ & $\begin{array}{l}\text { Teacher } \\
\text { Questionnaire }\end{array}$ & TQR-16 & ATBR16 & $\begin{array}{l}\text { How often do you take or } \\
\text { send the students to a library } \\
\text { other than your classroom } \\
\text { library? }\end{array}$ \\
& $\begin{array}{l}\text { - At least once or twice a week } \\
\text { Once or twice a month } \\
\text { - A few times a year } \\
\text { - Never or almost never }\end{array}$ \\
\hline
\end{tabular}

El trabajo con los conjuntos de datos PIRLS 2016 ha comenzado con la descarga de los ficheros y del programa IEA IDB Analyzer ${ }^{91}$ desde la página web de la IEA. A continuación se han seleccionado los datos referidos a España y se ha realizado la fusión de los distintos ficheros de datos utilizando el módulo específico del programa. Tanto para la correcta fusión de los archivos como para su interpretación se han seguido los procedimientos establecidos en la documentación técnica específica de la IEA (Foy et al., 2018). Así, se ha realizado por una parte la fusión de los ficheros de datos de alumnado y profesorado, y por otra parte, los ficheros de datos de alumnado y centro educativo. En ambos casos, la unidad de análisis y de interpretación es el individuo (alumno/a), tal y como se indica en Foy et al. (2018, pp. 11-12).

Una vez realizada la selección y extracción de datos referidos a España, se ha procedido a identificar las variables necesarias para realizar los análisis. A continuación nos detenemos en cada una de ellas.

\subsubsection{Selección de variables para el análisis cuantitativo con los datos PIRLS 2016}

\subsubsection{Variable dependiente: rendimiento del alumnado en competencia lectora general y en cuatro dimensiones de esta competencia}

Nuestro análisis de basa en una variable dependiente numérica y varias variables explicativas de tipo categórico. La variable dependiente es la puntuación media obtenida por el alumnado español en la prueba de competencia lectora de la evaluación internacional PIRLS 2016.

\footnotetext{
${ }^{91}$ Los conjuntos de datos y el programa IEA IDB Analyzer están disponibles para su descarga en la página web de la IEA (https://timssandpirls.bc.edu/pirls2016/)
} 
Como se observa en la Tabla 6, el alumnado español alcanzó en la prueba de competencia lectora general un valor de 527,74 puntos $^{92}$ con una desviación típica de 65,06 (siendo la media de los países de la OCDE = 540 y la media de los países de la $U E=539)$.

Tabla 6. PIRLS 2016. Puntuación media obtenida por el alumnado español en la prueba de competencia lectora general

Average for ASRREAO by IDCNIRY

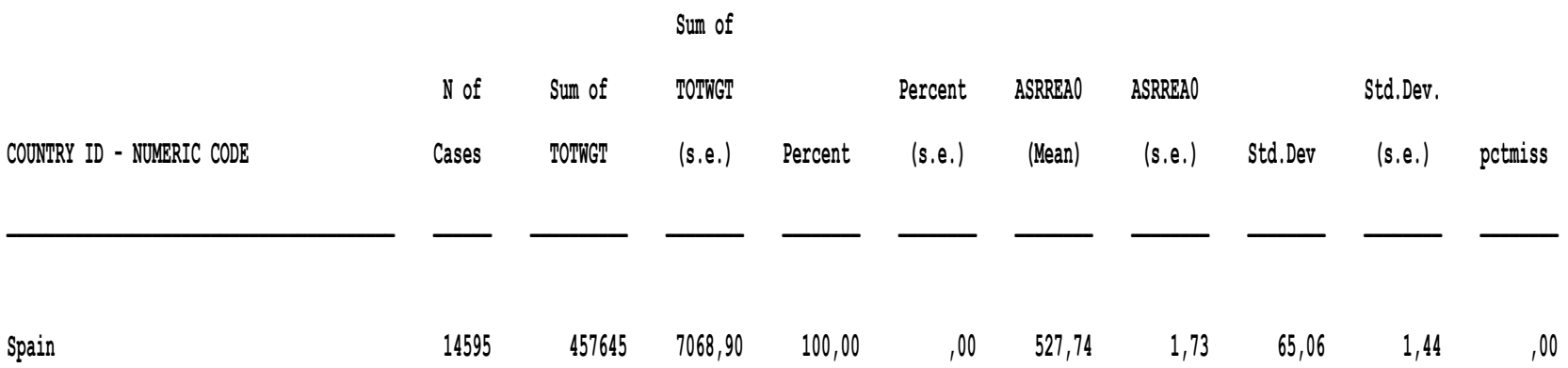

Como se observa en la Tabla 7, además de la evaluación de la competencia lectora general, en PIRLS 2016 se evalúan cuatro dimensiones de la competencia lectora ${ }^{93}$, atendiendo por una parte a los propósitos de la lectura y, por otra parte, según los procesos de comprensión que intervienen en la lectura (Instituto Nacional de Evaluación Educativa, 2017, pp.15-19).

A. Según los propósitos de la lectura, se evalúan las siguientes dimensiones:

1. Tener una experiencia literaria: se refiere a la vivencia de la lectura cuando el lector accede a textos de expresión literaria.

92 En PIRLS se establecen cuatro niveles de rendimiento: nivel bajo (de 400 a 475 puntos); nivel intermedio (de 475 a 550 puntos); nivel alto (de 550 a 625 puntos) y nivel avanzado (625 puntos o más) (Foy et al., 2018, p. 63).

93 Tal y como se define en el marco teórico del estudio PIRLS, la definición aceptada para la comprensión lectora es la siguiente:

La comprensión lectora es la habilidad para comprender y utilizar las formas lingüísticas requeridas y/o valoradas por el individuo. Los lectores son capaces de construir significado a partir de una variedad de textos. Leen para aprender, para participar en las comunidades de lectores del ámbito escolar y de la vida cotidiana, y para su disfrute personal (Instituto Nacional de Evaluación Educativa, 2017, p.14). 
2. Adquirir y usar la información: se refiere a la experiencia del lector que accede a textos de valor principalmente informativo (textos científicos, históricos, sociales, etc.). El lector se enfrenta a la dificultad de obtener información contenida en documentos con estructura y formatos diferentes, incluyendo diferentes tipos de texto, gráficas, tablas, índices, resúmenes, etc.

B. Según los procesos de comprensión que intervienen en la lectura, se evalúan las siguientes dimensiones de la competencia lectora:

1. Obtener información y extraer inferencias directas: estos procesos incluyen, entre otros, la identificación de información relevante, buscar ideas específicas, buscar definiciones, identificar contextos espaciotemporales, hallar la idea principal expresada en el texto, inferir secuencias de acontecimientos y argumentos, inferir generalizaciones explícitas en los textos.

2. Interpretar, integrar y evaluar: estos procesos incluyen, entre otros, identificar el mensaje o tema principal de un texto, comparar y contrastar información del texto, extrapolar ideas del texto al mundo real, emitir juicios críticos sobre la claridad y la verosimilitud del texto, y sobre el punto de vista del autor.

Tabla 7. Escalas de rendimiento en la competencia lectora establecidas en PIRLS 2016 (Foy et al., 2018, p. 62)

\begin{tabular}{|l|l|}
\hline Reading & Overall Reading (REA) \\
\hline \multirow{2}{*}{ Purposes for reading } & 1. Reading for literary experience (LIT) \\
\cline { 2 - 2 } & 2. Reading to acquire and use information (INF) \\
\hline \multirow{2}{*}{ Processes of comprehension } & 3. Retrieving and Straightforward Inferencing (RSI) \\
\cline { 2 - 2 } & 4. Interpreting, Integrating, and Evaluating (IIE) \\
\hline
\end{tabular}

En la Tabla 8 se recopilan las puntuaciones obtenidas por el alumnado de educación primaria español en cada una de las cuatro dimensiones mencionadas. En nuestro análisis hemos utilizado en primer lugar los resultados en competencia lectora general como variable dependiente. Seguidamente se ha repetido el análisis usando como variable dependiente los resultados alcanzados en cada una de las cuatro dimensiones de la competencia lectora en particular, para analizar el efecto del factor biblioteca escolar sobre cada una de ellas.

Tabla 8. PIRLS 2016. Puntuación media obtenida por el alumnado español en la prueba de competencia lectora. Resultados obtenidos en la competencia lectora general y en cuatro dimensiones según el propósito de la lectura y según los procesos de comprensión que intervienen en la lectura

\begin{tabular}{|l|l|c|}
\hline $\begin{array}{l}\text { Competencia lectora } \\
\text { general }\end{array}$ & propósitos de la lectura & $\begin{array}{c}\text { procesos de comprensión que } \\
\text { intervienen en la lectura }\end{array}$ \\
\hline
\end{tabular}




\begin{tabular}{|l|l|l|l|l|}
\hline & $\begin{array}{l}1 . \quad \text { Tener una } \\
\text { experiencia } \\
\text { literaria }\end{array}$ & $\begin{array}{l}\text { 2. Adquirir y usar } \\
\text { la información. }\end{array}$ & $\begin{array}{l}\text { 3. Obtener } \\
\text { información e } \\
\text { inferencias } \\
\text { directas }\end{array}$ & $\begin{array}{l}4 . \\
\text { integrar y evaluar }\end{array}$ \\
\hline $\begin{array}{l}\text { puntuación media }= \\
527,74 \\
\text { Desv.típ. }=65,06\end{array}$ & $\begin{array}{l}\text { puntuación media } \\
=530 \\
\text { Desv.típ. }=70,09\end{array}$ & $\begin{array}{l}\text { puntuación media } \\
=526,60 \\
\text { Desv.típ. }=65,51\end{array}$ & $\begin{array}{l}\text { puntuación media } \\
=526,46 \\
\text { Desv.típ. }=64,75\end{array}$ & $\begin{array}{l}\text { puntuación media } \\
=529,10 \\
\text { Desv.típ. }=66,41\end{array}$ \\
\hline
\end{tabular}

La varianza del dato de puntuación en competencia lectora es un problema multidimensional ${ }^{94}$. Entre los distintos factores que explican esta varianza, en esta investigación nos hemos centrado en el posible impacto de la biblioteca escolar, para lo cual se ha comprobado la influencia de los siguientes factores (variables explicativas).

\subsubsection{Variable explicativa 1: el centro educativo dispone de biblioteca escolar (sí/no)}

En PIRLS 2016 se preguntó al alumnado si su escuela disponía o no de biblioteca. En España, el 96,11 \% del alumnado de educación primaria respondió que sí disponía de biblioteca en su centro educativo ${ }^{95}$. A partir de esta variable dicotómica hemos

94 Entre los factores asociados al rendimiento en competencia lectora del alumnado español, PIRLS 2016 destacó la diferencia por sexos (las niñas superaban en 11 puntos a los niños. Esta diferencia aumentaba cuando los niños alcanzaban los 15 años de edad, como se observa en las pruebas PISA). En cuanto al entorno social y económico, se estimó que un $12,2 \%$ de la variabilidad en el rendimiento del alumnado de educación primaria podía atribuirse a estos factores, entre los que se incluye el nivel de estudios del padre y la madre (se daba una diferencia de 51 puntos entre el alumnado procedente de familias con estudios superiores y el alumnado procedente de familias con estudios básicos); la ocupación del padre y de la madre (se daba una diferencia de 57 puntos entre las puntuaciones medias del alumnado procedente de familias con empleos cualificados y del alumnado procedente de familias con empleos sin especialización o no remunerados). En cuanto al entorno educativo, destacó el factor énfasis del centro en el éxito académico del alumnado, traduciéndose en una ventaja de 41 puntos para el alumnado cuyo centro destacaba por este aspecto. En cuanto a la actitud del alumnado respecto de la escuela y su entorno educativo y cultural familiar, destacaron los factores: gusto del alumnado por la lectura (el alumnado al que le gustaba leer aventajaba en 22 puntos al que no tenía esta afición); seguridad del alumnado respecto de la lectura (el alumnado que se sentía seguro respecto de su capacidad en lectura aventajaba en 71 puntos al que no sentía esta seguridad); sentido de pertenencia al centro (el alumnado con alto sentido de pertenencia aventajaba 21 puntos al alumnado que no tenía este vínculo); gusto del padre y la madre por la lectura (el alumnado procedente de familias lectoras aventajaba en 33 puntos al alumnado procedente de familias no lectoras); número de libros en casa (cuanto mayor era el número de libros en el hogar, mayor rendimiento alcanzaba el alumnado, hasta 62 puntos de diferencia entre alumnado con más de 200 libros y el alumnado con menos de 10 libros en el hogar) (Instituto Nacional de Evaluación Educativa, 2017).

95 Las estadísticas sobre bibliotecas escolares del Ministerio de Educación, Cultura y Deporte para el curso 2015-2016 muestran que: 
contrastado las medias en competencia lectora de dos grupos de alumnado: aquéllos que disponen de biblioteca integrada en su centro educativo y los que carecen de este recurso en su centro.

\subsubsection{Variable explicativa 2: intensidad con la que el alumnado hace uso de la biblioteca}

En el estudio PIRLS 2016 se preguntó al alumnado con qué frecuencia visitaba la biblioteca para tomar libros en préstamo, dando varias opciones de respuesta según una escala Likert. Como se muestra en la Tabla 9, un 23,85 \% respondió que no lo hacía nunca o casi nunca; un 14,13 \% algunas veces al año; un 24,09 \% que lo hacía con una frecuencia mensual, y un $37,93 \%$ contestó que lo hacía semanalmente.

Para realizar nuestro análisis hemos convertido la variable en dicotómica distinguiendo dos grupos: por una parte, el alumnado que acude a la biblioteca al menos algunas veces al año (englobamos aquí los que acuden alguna vez, bien sea con una periodicidad semanal, mensual o varias veces a lo largo del año), y, por otra parte, el alumnado que no acude a la biblioteca nunca o casi nunca. Con esta variable dicotómica hemos contrastado las medias en competencia lectora de ambos grupos. La frecuencia del préstamo de materiales bibliográficos es un indicador que proporciona información sobre la intensidad de uso de la biblioteca, al ser una de las motivaciones ${ }^{96}$ principales por las que el alumnado visita la biblioteca.

- El 86,4 \% de los centros públicos de educación primaria y educación especial tienen una biblioteca de centro en funcionamiento. El 5,6 \% de los centros tiene una biblioteca circunstancialmente cerrada y en el $8,1 \%$ no hay biblioteca.

- Con respecto a los centros privados, la estadística no diferencia entre centros por niveles de enseñanza. Tomando el conjunto de los centros privados de educación primaria y secundaria, el $82,9 \%$ de los centros tiene una biblioteca de centro en funcionamiento; el 7,6 \% de los centros tiene una biblioteca circunstancialmente cerrada y en el 9,5 \% no hay biblioteca.

- En los centros en los que no hay biblioteca, suele ser frecuente que este servicio se cubra parcialmente por bibliotecas de departamento o de aula o mediante acuerdos con bibliotecas públicas.

- En el 88,1 \% de los centros públicos de educación primaria y educación especial existe un proyecto integrado de biblioteca. Dentro del conjunto de los centros privados de educación primaria y secundaria, un 68,9\% cuenta con un proyecto integrado de biblioteca.

96 Los datos más recientes con relación a los usos de la biblioteca escolar son los que recogen las estadísticas sobre bibliotecas escolares del Ministerio de Educación, Cultura y Deporte para el curso 2015-2016. Resumimos a continuación los más relevantes:

- El préstamo de libros sigue siendo una de las principales actividades de las bibliotecas escolares, incluyendo préstamos directos o transmisiones por tiempo limitado de libros electrónicos u otros documentos digitales de la colección. Solo el 9,4 \% de los centros públicos de educación 
Tabla 9. PIRLS 2016. Frecuencia con la que el alumnado español toma libros en préstamo de su biblioteca escolar

Percentages by (IDCNTRY ASBR03)

\begin{tabular}{|c|c|c|c|c|c|c|}
\hline COUNTRY ID - NUNERIC CODE & $\begin{array}{l}\text { READ \HOW OFTEN BORROW } \\
\text { BOOKS SCHOOL LIBRA }\end{array}$ & $\begin{array}{l}\mathrm{N} \text { of } \\
\text { Cases }\end{array}$ & $\begin{array}{l}\text { Sum of } \\
\text { TOTNGT }\end{array}$ & $\begin{array}{l}\text { Sum of } \\
\text { TOTWGT } \\
\text { (s.e.) }\end{array}$ & Percent & $\begin{array}{r}\text { Percent } \\
\text { (s.e.) }\end{array}$ \\
\hline \multirow[t]{4}{*}{ Spain } & At least once a week & 5464 & 171317 & 6610,41 & 37,93 & 1,31 \\
\hline & Once or twice a month & 3321 & 108809 & 3201,53 & 24,09 &, 63 \\
\hline & A few times a year & 2102 & 63817 & 2538,80 & 14,13 &, 56 \\
\hline & Never or almost never & 3557 & 107712 & 4456,74 & 23,85 &, 86 \\
\hline
\end{tabular}

\subsubsection{Variable explicativa 3: el alumnado tiene acceso al préstamo de materiales bibliográficos impresos (sí/no)}

Como se observa en la Tabla 10, los resultados de PIRLS 2016 muestran que el $87,06 \%$ del alumnado español de educación primaria estudia en escuelas donde existe préstamo domiciliario de materiales bibliográficos impresos, frente a un 12,94 $\%$ cuyas escuelas no proporcionan este servicio.

primaria y educación especial registraron cero préstamos, y el 52 \% de los centros registró 500 o más préstamos.

- Entre los centros privados de educación primaria y secundaria, el 20,3 \% registró cero préstamos y el $22,5 \%$ registró 500 o más préstamos.

- Con relación a la organización de otro tipo de actividades, en los centros públicos de educación primaria y educación especial se registran las siguientes: actividades de fomento de la lectura (93,9\% de los centros); actividades culturales y encuentros literarios (58,3\% de los centros); de enseñanza y aprendizaje para apoyar el desarrollo del currículo (69,6 \% de los centros); formación de usuarios (40,5\% de los centros); conferencias y seminarios $(17,1 \%$ de los centros); actividades relacionadas con el tratamiento de la información y competencia digital ( $28,1 \%$ de los centros); actividades con la participación de las familias ( $41,5 \%$ de los centros); actividades específicas de atención a la diversidad (20,9 \% de los centros) y otro tipo de actividades (36,2 \% de los centros).

Con relación a la organización de otro tipo de actividades, en los centros privados de educación primaria y secundaria se registran las siguientes: actividades de fomento de la lectura ( $78 \%$ de los centros); de enseñanza y aprendizaje para apoyar el desarrollo del currículo (52,7 \% de los centros); actividades culturales y encuentros literarios (38,9\% de los centros); formación de usuarios ( $24,2 \%$ de los centros); actividades con la participación de las familias (23\% de los centros); actividades relacionadas con el tratamiento de la información y competencia digital (22,9 \% de los centros); actividades específicas de atención a la diversidad ( $22,1 \%$ de los centros); conferencias y seminarios (19 $\%$ de los centros); y otro tipo de actividades (30,1 \% de los centros). 
Con esta variable dicotómica hemos contrastado las medias de competencia lectora de dos grupos de alumnado: el que tiene acceso a este recurso bibliotecario tradicional y el que no tiene acceso a este recurso desde su escuela.

Tabla 10. PIRLS 2016. Alumnado español con y sin acceso al préstamo domiciliario de materiales bibliográficos impresos de su biblioteca escolar

Percentages by (IDCNTRY ACBG09C)

\begin{tabular}{|c|c|c|c|c|c|c|}
\hline COONTRY ID - NONERIC CODE & $\begin{array}{l}\text { GEN } \backslash \text { BORROW MATERIAL FROM } \\
\text { LIBRARY }\end{array}$ & $\begin{array}{l}\mathrm{N} \text { of } \\
\text { Cases }\end{array}$ & $\begin{array}{l}\text { Sum of } \\
\text { TOTWGI }\end{array}$ & $\begin{array}{l}\text { Sum of } \\
\text { TOTWGT } \\
\text { (s.e.) }\end{array}$ & Percent & $\begin{array}{r}\text { Percent } \\
\text { (s.e.) }\end{array}$ \\
\hline \multirow[t]{2}{*}{ Spain } & Yes & 11965 & 362699 & 10854,16 & 87,06 & 1,97 \\
\hline & No & 1621 & 53927 & 8652,54 & 12,94 & 1,97 \\
\hline
\end{tabular}

\subsubsection{Variable explicativa 4: el alumnado tiene acceso a libros electrónicos desde su centro educativo}

Como se ve en la Tabla 11, los resultados de PIRLS 2016 muestran que el 37,47 \% del alumnado español de educación primaria estudia en escuelas que proporcionan acceso a libros electrónicos, frente a un 62,53 \% cuyas escuelas no proporcionan este acceso $^{97}$.

Con esta variable dicotómica hemos contrastado las medias en competencia lectora de dos grupos de alumnado: el que tiene acceso a este recurso y el que no tiene acceso a este recurso desde su escuela.

97 Según la estadística española de bibliotecas escolares, en los centros públicos de educación primaria y educación especial, el 8,9\% dispone de libros electrónicos o e-book; el 9,3\% tiene suscripciones a publicaciones electrónicas; el 54,8 \% tiene audiovisuales en soporte digital; el 7,7 \% tiene documentos ACNEE digitales, y el $12,2 \%$ dispone de otros documentos digitales.

Con relación a los centros privados de educación primaria y secundaria, el $4 \%$ dispone de libros electrónicos o e-book; el 11,5\% tiene suscripciones a publicaciones electrónicas; el 37,8 \% tiene audiovisuales en soporte digital; el 12,5 \% tiene documentos ACNEE digitales, y el $17 \%$ dispone de otros documentos digitales. 
Tabla 11. PIRLS 2016. Alumnado español con y sin acceso a libros electrónicos desde sus centros educativos

Percentages by (IDCNTRY ACBG10)

\begin{tabular}{|c|c|c|c|c|c|c|}
\hline COUNTRY ID - NUMERIC CODE & $\begin{array}{l}\text { GEN } \backslash \text { ACCESS TO } \\
\text { DIGITAL BOOKS }\end{array}$ & $\begin{array}{l}\mathrm{N} \text { of } \\
\text { Cases }\end{array}$ & $\begin{array}{l}\text { Sum of } \\
\text { TOTWGT }\end{array}$ & $\begin{array}{l}\text { Sum of } \\
\text { TOTWGT } \\
\text { (s.e.) }\end{array}$ & Percent & $\begin{array}{r}\text { Percent } \\
\text { (s.e.) }\end{array}$ \\
\hline \multirow[t]{2}{*}{ Spain } & Yes & 5997 & 166707 & 11132,92 & 37,47 & 2,57 \\
\hline & No & 8148 & 278177 & 13823,05 & 62.53 & 2,57 \\
\hline
\end{tabular}

\subsubsection{Variable explicativa 5: tamaño de la colección}

La variable se sustenta sobre el indicador "número de títulos de libros disponibles en la biblioteca escolar98". Como se ve en la Tabla 12 , el $16,70 \%$ del alumnado de educación primaria estudia en centros cuya biblioteca tiene una colección bibliográfica de más de 5.000 títulos; el 66,69 \% en centros cuya biblioteca tiene entre 501 y 5.000 títulos; y el 12,57 \% del alumnado estudia en centros cuya biblioteca cuenta con 500 títulos o menos.

Con esta variable dicotómica hemos contrastado las medias en competencia lectora de dos grupos de alumnado: el que tiene acceso a bibliotecas con colecciones bibliográficas amplias y el que o bien carece de biblioteca o bien tiene acceso a colecciones de escasos recursos bibliográficos.

En esta misma línea, con respecto a la dotación de recursos en la biblioteca escolar, tal y como se muestra en la Tabla 13 , el $21,61 \%$ del alumnado estudia en centros cuyos responsables opinan que la capacidad docente del centro se ve afectada algo o bastante por una situación de escasez de la biblioteca escolar o por ser inadecuados sus recursos. El 78,39 \% del alumnado pertenece a centros cuyos responsables consideran que apenas se ve afectada la capacidad docente del centro por la precariedad de su biblioteca.

\footnotetext{
98 Según la estadística española de bibliotecas escolares, en los centros públicos de educación primaria y educación especial, el $47,4 \%$ de las bibliotecas escolares tiene entre 50 y 100 metros cuadrados de superficie, y solo el 8,2 \% supera estas dimensiones. En el 70,7 \% de los centros, las colecciones de la biblioteca tienen 2.000 o más ejemplares. Y en el $70 \%$ de los centros hay al menos un ordenador disponible para su uso en la biblioteca.

Con relación a los centros privados de educación primaria y secundaria, el 40,8 \% de las bibliotecas escolares tiene entre 50 y 100 metros cuadrados de superficie, y solo el $21,3 \%$ supera estas dimensiones. En el $52 \%$ de los centros, las colecciones de la biblioteca tienen 2.000 o más ejemplares. Y en el $72,8 \%$ de los centros hay al menos un ordenador disponible para su uso en la biblioteca.
} 
En esta misma línea, en PIRLS 2016, se demostró que no verse afectado por la escasez de recursos de lectura en el centro educativo era un factor que influía positivamente sobre la resiliencia del alumnado (Instituto Nacional de Evaluación Educativa, 2017, p. 125).

Tabla 12. PIRLS 2016. Resultados sobre el tamaño de la colección de la biblioteca en los centros educativos españoles

Percentages by (IDCNTRY ACDG09)

\begin{tabular}{|c|c|c|c|c|c|c|}
\hline COUNTRY ID - NUMERIC CODE & SIZE OF SCHOOL LIBRARY & $\begin{array}{l}\mathrm{N} \text { of } \\
\text { Cases }\end{array}$ & $\begin{array}{l}\text { Sum of } \\
\text { TOTWGT }\end{array}$ & $\begin{array}{l}\text { Sum of } \\
\text { TOTWGT } \\
\text { (s.e.) }\end{array}$ & Percent & $\begin{array}{r}\text { Percent } \\
\text { (s.e.) }\end{array}$ \\
\hline \multirow[t]{4}{*}{ Spain } & More than 5,000 Book Titles & 2884 & 72656 & 9231,00 & 16,70 & 2,07 \\
\hline & 501-5,000 Book Titles & 9084 & 290176 & 13445,62 & 66,69 & 2,85 \\
\hline & 500 Book Titles or Fewer & 1601 & 54694 & 8560,60 & 12,57 & 1,94 \\
\hline & No School Library & 407 & 17604 & 5915,54 & 4,05 & 1,35 \\
\hline
\end{tabular}

Tabla 13. PIRLS 2016. Opinión de responsables de los centros educativos respecto de si la capacidad docente de su escuela se ve afectada por una situación de escasez de la biblioteca escolar o por ser inadecuados sus recursos. Salida de ordenador utilizando el programa IEA IDB Analyzer-SPSS

Percentages by (IDCNTRY ACBG12BCDUMMY)

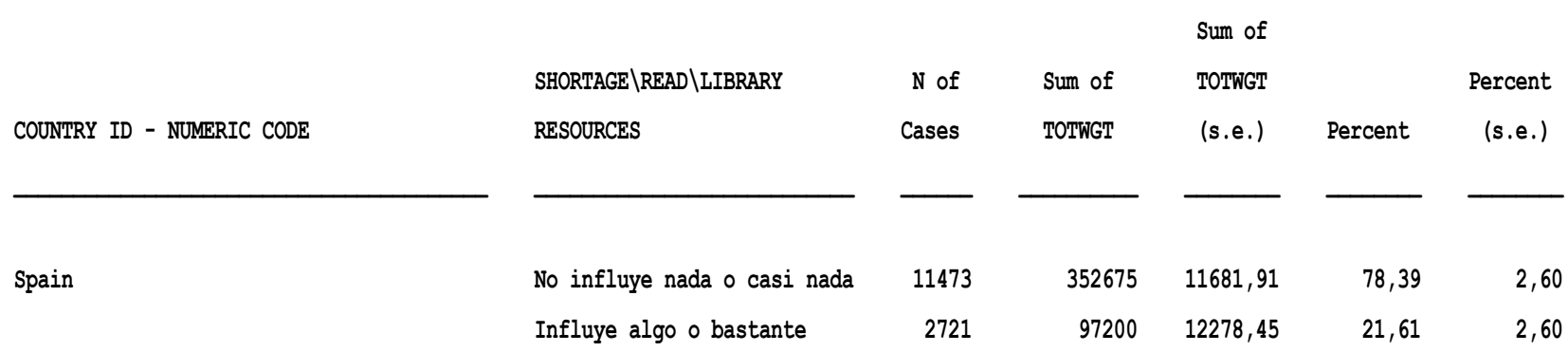

\subsubsection{Hipótesis y procedimiento de análisis}

Una vez definidas la variable dependiente y las variables explicativas disponibles en los conjuntos de datos PIRLS 2016, hemos corroborado que con estas variables se podía responder a las preguntas 1 y 2 de la investigación: 
1. ¿Tiene alguna influencia el hecho de tener biblioteca en el centro educativo sobre el rendimiento académico en competencia lectora? $Y$ en caso afirmativo, ¿sobre qué dimensiones competenciales se observa este impacto?

- comprender e interpretar textos literarios e informativos

- ser competentes en obtener e inferir información a partir de la lectura

- ser capaces de interpretar, integrar y evaluar críticamente la información obtenida en el entorno papel y en el entorno digital y con los distintos tipos de material y soportes bibliográficos

2. ¿Cómo influyen los distintos recursos, actividades o prácticas vinculadas a la biblioteca sobre el desarrollo de la competencia lectora?

Para responder a estas preguntas se han puesto a prueba las siguientes hipótesis:

Hipótesis 1 (H1). El alumnado que dispone de una biblioteca integrada en su centro educativo obtiene mejores resultados académicos en competencia lectora, si se compara con el alumnado que no dispone de biblioteca escolar.

Hipótesis 2 (H2). El alumnado que más utiliza la biblioteca escolar obtiene mejores resultados académicos en competencia lectora, comparado con el alumnado que no tiene este hábito.

Hipótesis 3 (H3). El alumnado que tiene acceso a préstamo de materiales bibliográficos impresos en su escuela obtiene mejores resultados académicos en competencia lectora, comparado con el alumnado que no dispone de este recurso.

Hipótesis 4 (H4). El alumnado que tiene acceso a libros electrónicos en su escuela obtiene mejores resultados académicos en competencia lectora, comparado con el alumnado que no dispone de este recurso.

Hipótesis 5 (H5). El alumnado con acceso a colecciones bibliográficas amplias y de calidad demuestra mayor competencia lectora, comparado con el alumnado que carece de biblioteca o que accede a una colección con escasos recursos.

Estas hipótesis son coherentes con el marco teórico y conceptual de la evaluación bibliotecaria expuesto en el capítulo 2 de esta tesis y con la revisión bibliográfica que sustenta este marco teórico.

Una vez formuladas las cinco hipótesis, a continuación, se ha procedido a su comprobación, para verificar su validez en función del nivel de significación estadística. Para cada hipótesis, se ha comparado la competencia lectora de dos grupos: por un lado, la que alcanza el alumnado que tiene biblioteca escolar, la utiliza de forma frecuente y accede a determinados recursos bibliotecarios desde su escuela, $y$, por otro lado, la competencia lectora del alumnado que no tiene biblioteca escolar, el que apenas hace uso de ella, y el que tiene acceso a escasos recursos bibliotecarios desde su escuela. 
En las hipótesis $\mathrm{H} 1$ a $\mathrm{H} 5$ se ha trabajado con una variable dependiente numérica y una variable independiente dicotómica. Como prueba de decisión estadística, se ha utilizado una prueba de contraste de hipótesis con comparación de medias para muestras independientes de la misma población. Se han comparado las medias de los resultados obtenidos por los dos grupos objeto de comparación, tomando como prueba de contraste el valor $\mathrm{t}^{99}$, con un valor crítico $\mathrm{t}=1,96$, trabajando con un nivel de confianza del $95 \%$ y un nivel de significación 0,05, por ser lo más aceptado en el ámbito de las ciencias sociales (Camarero, Almazán, Arribas, Mañas y Vallejos, 2010; Moore, 2009; Morales Vallejo, 2008; Tejedor y Etxeberria, 2006; Vilà Baños y Bisquerra Alzina, 2016).

En los apartados siguientes exponemos los resultados del análisis una vez contrastadas las distintas hipótesis.

\subsubsection{Resultados}

A continuación, se analiza la influencia de cada una de las variables explicativas sobre la variable dependiente. Contrastamos así las hipótesis de las que partimos, para verificar su validez en función del nivel de significación estadística:

\subsubsection{Comprobación de la H1. El alumnado que dispone de una biblioteca integrada en su centro educativo obtiene mejores resultados académicos en competencia lectora, si se compara con el alumnado que no dispone de biblioteca escolar}

Como se puede observar en la Tabla 14, si se comparan los resultados (medias) en competencia lectora (general) teniendo en cuenta la variable "tener biblioteca en el centro educativo (si/no)", se observa que el resultado es 528,42 (error estándar = 1,77 ) para alumnado con biblioteca escolar y 504,70 (error estándar $=8,11$ ) para alumnado sin biblioteca escolar. Esta diferencia de 23,71 es estadísticamente significativa al $95 \%$ de nivel de confianza $(t>1,96)$.

\footnotetext{
99 Hemos optado por esta prueba paramétrica asumiendo que trabajamos con muestras grandes normalmente distribuidas.
} 
Tabla 14. PIRLS 2016. Comparación de resultados medios en competencia lectora (general) del alumnado español, introduciendo la variable "el alumnado tiene biblioteca en su centro educativo". Salida de ordenador utilizando el programa IEA IDB Analyzer - SPSS

Average fOr ASRREA by IDCNRYY ACBCO9

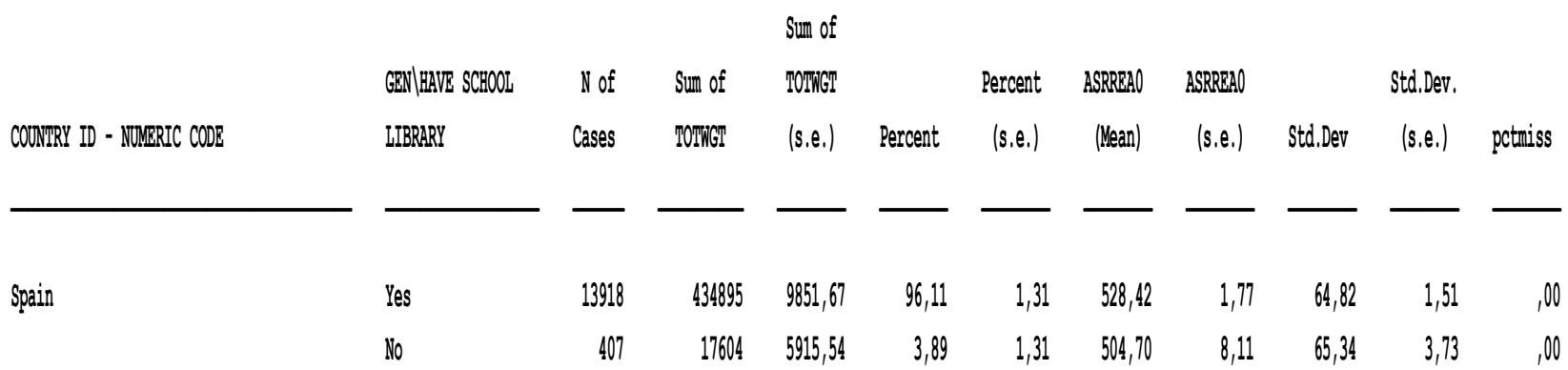

Regression Coefficients

\begin{tabular}{|c|c|c|c|c|c|c|c|}
\hline IDCNTRY & Variable & $\begin{array}{l}\text { Regression } \\
\text { Coefficient }\end{array}$ & $\begin{array}{c}\text { Regression } \\
\text { Coefficient } \\
\text { (s.e.) }\end{array}$ & $\begin{array}{c}\text { Regression } \\
\text { Coefficient } \\
\text { (t-value) }\end{array}$ & $\begin{array}{l}\text { Stndrdzd. } \\
\text { Coefficient }\end{array}$ & $\begin{array}{l}\text { Stndrdzd. } \\
\text { Coefficient } \\
\text { (s.e.) }\end{array}$ & $\begin{array}{l}\text { Stndrdzd. } \\
\text { Coefficient } \\
\text { (t-value) }\end{array}$ \\
\hline \multirow[t]{2}{*}{ Spain } & (CONSTANT) & 528,42 & 1,77 & 299,29 & . & . & . \\
\hline & ACBG09 D2 & $-23,71$ & 8,41 & $-2,82$ &,- 07 &, 03 & $-2,28$ \\
\hline
\end{tabular}

Si repetimos el mismo análisis tomando como variable dependiente el resultado en competencia lectora referido a la dimensión "Tener una experiencia literaria", observamos que el alumnado con biblioteca escolar obtiene una puntuación media notablemente superior de 530,72 (error estándar $=1,90$ ) y el alumnado sin biblioteca escolar obtiene una puntuación media de 505,89 (error estándar $=8,30$ ). Como se observa en la Tabla 15, esta diferencia de 24,83 es estadísticamente significativa al 95 $\%$ de nivel de confianza. 
Tabla 15. PIRLS 2016. Comparación de resultados medios en competencia lectora (atendiendo a la dimensión: Tener una experiencia literaria) del alumnado español, introduciendo la variable "el alumnado tiene biblioteca en su centro educativo". Salida de ordenador utilizando el programa IEA IDB Analyzer-SPSS

Average for ASRUIIO by IDCVMRY ACBBO9

\begin{tabular}{|c|c|c|c|c|c|c|c|c|c|c|c|}
\hline \multirow[b]{3}{*}{ COONRRY ID - NONERIC CODE } & \multirow{3}{*}{ 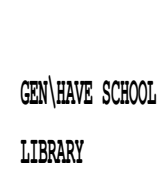 } & \multirow{3}{*}{$\begin{array}{l}\text { Nof } \\
\text { Cases }\end{array}$} & \multirow{3}{*}{$\begin{array}{l}\text { Sum of } \\
\text { MOOMGE? }\end{array}$} & \multicolumn{2}{|l|}{ Sum of } & \multirow[b]{2}{*}{ Percent } & \multirow[b]{2}{*}{ ASRIITO } & \multirow[b]{2}{*}{ ASRLIMO } & \multirow{2}{*}{\multicolumn{2}{|c|}{ Std. Dev. }} & \multirow[b]{3}{*}{ petriss } \\
\hline & & & & MOTNG! & & & & & & & \\
\hline & & & & $(s . e)$. & Percent & (s.e. $)$ & (Mean) & $(s . e)$. & Std. Dev & (s.e.) & \\
\hline \multirow[t]{2}{*}{ Spain } & Yes & 13918 & 438895 & 9851,67 & 96,11 & 1,31 & 530,72 & 1,90 & 69,87 & 1,78 &, 00 \\
\hline & 110 & 407 & 17604 & 5915,54 & 3,89 & 1,31 & 505,89 & 8,30 & 70,49 & 3,68 &, 00 \\
\hline
\end{tabular}

Regression Coefficients

\begin{tabular}{|c|c|c|c|c|c|c|c|}
\hline IDCNTRY & Variable & $\begin{array}{l}\text { Regression } \\
\text { Coefficient }\end{array}$ & $\begin{array}{c}\text { Regression } \\
\text { Coefficient } \\
\text { (s.e.) }\end{array}$ & $\begin{array}{c}\text { Regression } \\
\text { Coefficient } \\
\text { (t-value) }\end{array}$ & $\begin{array}{l}\text { Stndrdzd. } \\
\text { Coefficient }\end{array}$ & $\begin{array}{l}\text { Stndrdzd. } \\
\text { Coefficient } \\
\text { (s.e.) }\end{array}$ & $\begin{array}{c}\text { Stndrdzd. } \\
\text { Coefficient } \\
\text { (t-value) }\end{array}$ \\
\hline \multirow[t]{2}{*}{ Spain } & (CONSTANT) & 530,72 & 1,90 & 279,53 & . & . & \\
\hline & ACBG09 D2 & $-24,83$ & 8,62 & $-2,88$ &,- 07 &, 03 & -2, \\
\hline
\end{tabular}

Como se observa en la Tabla 16, si repetimos el mismo análisis tomando como variable dependiente el resultado en competencia lectora referido a la dimensión "Adquirir y usar la información", observamos que el alumnado con biblioteca escolar obtiene una puntuación media notablemente superior de 527,44 (error estándar = 1,56) y el alumnado sin biblioteca escolar obtiene una puntuación media de 499,77 (error estándar $=10,10$ ). Esta diferencia de 27,67 es estadísticamente significativa al $95 \%$ de nivel de confianza. 
Tabla 16. PIRLS 2016. Comparación de resultados medios en competencia lectora (atendiendo a la dimensión: Adquirir y usar la información) del alumnado español, introduciendo la variable "el alumnado tiene biblioteca en su centro educativo". Salida de ordenador utilizando el programa IEA IDB Analyzer-SPSS

Average for ASRINP by IDONRY ACBCO9

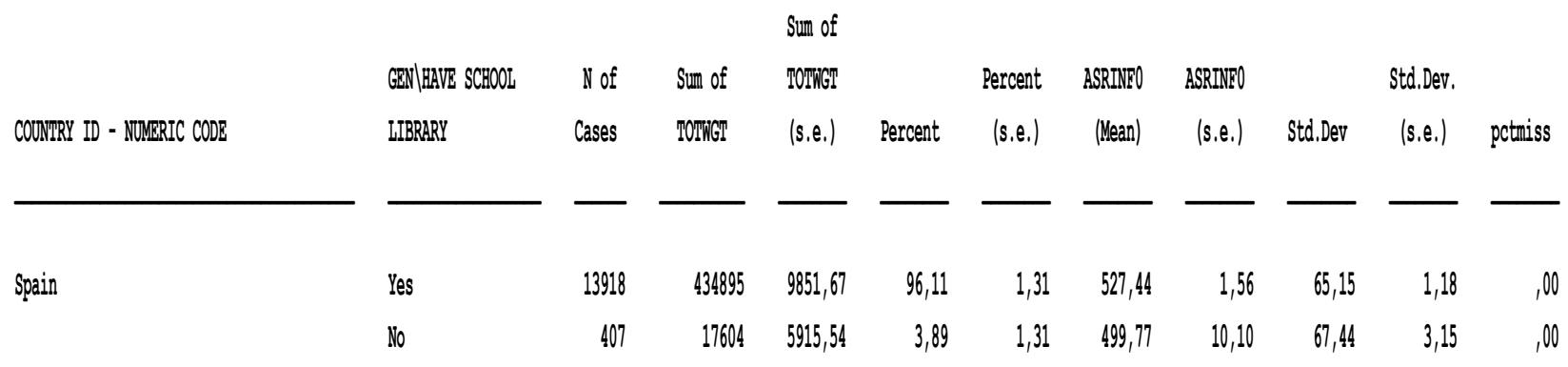

Regression Coefficients

\begin{tabular}{|c|c|c|c|c|c|c|c|}
\hline IDCNTRY & Variable & $\begin{array}{l}\text { Regression } \\
\text { Coefficient }\end{array}$ & $\begin{array}{c}\text { Regression } \\
\text { Coefficient } \\
\text { (s.e.) }\end{array}$ & $\begin{array}{c}\text { Regression } \\
\text { Coefficient } \\
\text { (t-value) }\end{array}$ & $\begin{array}{l}\text { Stndrdzd. } \\
\text { Coefficient }\end{array}$ & $\begin{array}{l}\text { Stndrdzd. } \\
\text { Coefficient } \\
\text { (s.e.) }\end{array}$ & $\begin{array}{c}\text { Stndrdzd. } \\
\text { Coefficient } \\
\text { (t-value) }\end{array}$ \\
\hline \multirow[t]{2}{*}{ Spain } & (CONSTANT) & 527,44 & 1,56 & 338,07 & . & . & \\
\hline & ACBG09_D2 & $-27,67$ & 10,23 & $-2,71$ &,- 08 &, 04 & $-2,23$ \\
\hline
\end{tabular}

Como se observa en la Tabla 17, si repetimos el mismo análisis tomando como variable dependiente el resultado en competencia lectora referido a la dimensión "Obtener información e inferencias directas", observamos que el alumnado con biblioteca escolar obtiene una puntuación media de 527,08 (error estándar $=1,68$ ) y el alumnado sin biblioteca escolar obtiene una puntuación media de 504,90 (error estándar $=8,70)$. Esta diferencia de 22,18 es estadísticamente significativa al $95 \%$ de nivel de confianza. 
Tabla 17. PIRLS 2016. Comparación de resultados medios en competencia lectora (atendiendo a la dimensión: Obtener información e inferencias directas) del alumnado español, introduciendo la variable "el alumnado tiene biblioteca en su centro educativo". Salida de ordenador utilizando el programa IEA IDB Analyzer-SPSS

Average for ASRRSTO by IDCNTRY ACBGO9

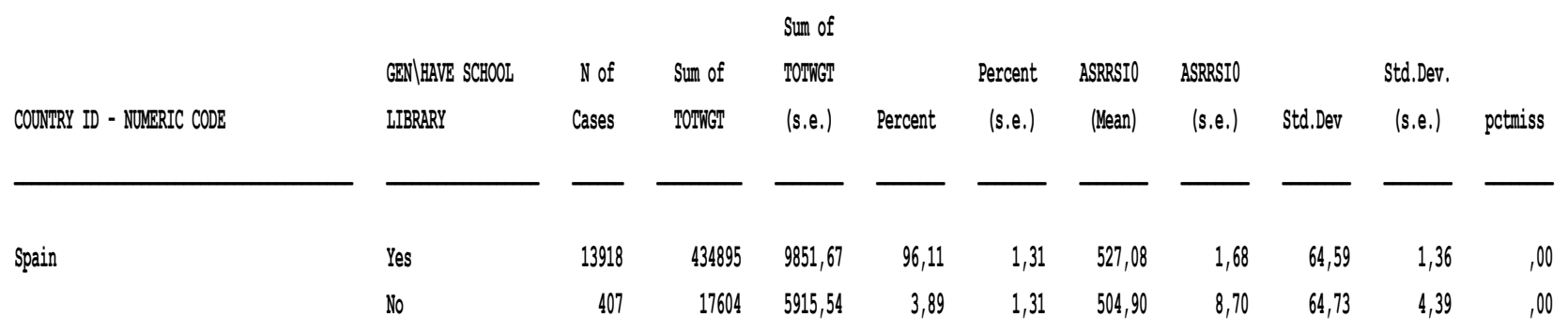

Regression Coefficients

\begin{tabular}{|c|c|c|c|c|c|c|c|}
\hline IDCNTRY & Variable & $\begin{array}{l}\text { Regression } \\
\text { Coefficient }\end{array}$ & $\begin{array}{l}\text { Regression } \\
\text { Coefficient } \\
\text { (s.e.) }\end{array}$ & $\begin{array}{l}\text { Regression } \\
\text { Coefficient } \\
\text { (t-value) }\end{array}$ & $\begin{array}{l}\text { Stndrdzd. } \\
\text { Coefficient }\end{array}$ & $\begin{array}{l}\text { Stndrdzd. } \\
\text { Coefficient } \\
\text { (s.e.) }\end{array}$ & $\begin{array}{l}\text { Stndrdzd. } \\
\text { Coefficient } \\
\text { (t-value) }\end{array}$ \\
\hline \multirow[t]{2}{*}{ Spain } & (CONSTANT) & 527,08 & 1,68 & 312,93 & . & & . \\
\hline & ACBGO9 D2 & $-22,18$ & 8,86 & $-2,50$ &,- 07 & ,03 & $-2,11$ \\
\hline
\end{tabular}

Por último, como se observa en la Tabla 18, si repetimos el mismo análisis tomando como variable dependiente el resultado en competencia lectora referido a la dimensión "Interpretar, integrar y evaluar", observamos que el alumnado con biblioteca escolar obtiene una puntuación media de 529,74 (error estándar $=1,76$ ) y el alumnado sin biblioteca escolar obtiene una puntuación media de 507,09 (error estándar $=7,35$ ). Esta diferencia de 22,65 es estadísticamente significativa al $95 \%$ de nivel de confianza. 
Tabla 18. PIRLS 2016. Comparación de resultados medios en competencia lectora (atendiendo a la dimensión: Interpretar, integrar y evaluar) del alumnado español, introduciendo la variable "el alumnado tiene biblioteca en su centro educativo". Salida de ordenador utilizando el programa IEA IDB Analyzer-SPSS

Average for ASRIIZO by IDCNRPY ACBBOS

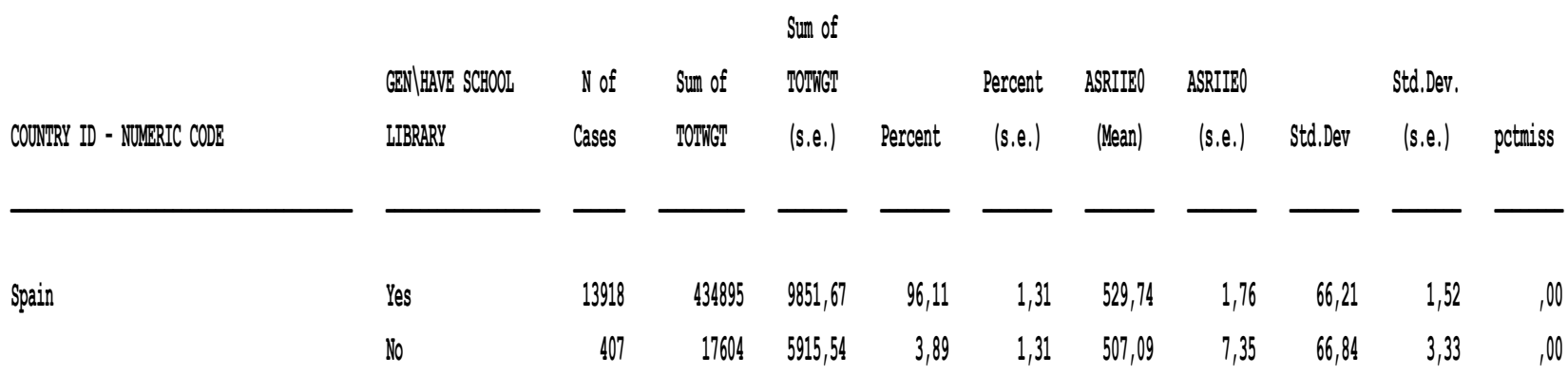

Regression Coefficients

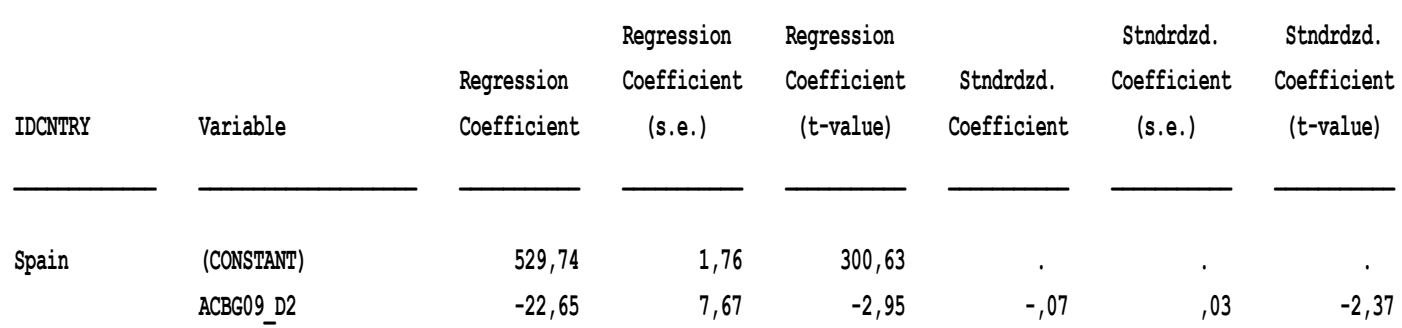

Resumimos en la Tabla 19 las puntuaciones medias obtenidas por el alumnado en las distintas dimensiones de la competencia lectora, diferenciando los grupos de alumnado con y sin biblioteca. Observamos que, tanto en los resultados de competencia lectora general como en los resultados obtenidos para las cuatro dimensiones de esta competencia, existe una notable ventaja, estadísticamente significativa a un $95 \%$ de nivel de confianza, para el grupo de alumnado con biblioteca, en comparación con el alumnado sin biblioteca. La diferencia mayor se produce cuando se consideran los propósitos de la lectura, fundamentalmente en la dimensión "Adquirir y usar la información", donde la diferencia media entre los dos grupos alcanza un valor de 27,67.

Tabla 19. Puntuaciones medias obtenidas por el alumnado en las distintas dimensiones de la competencia lectora, diferenciando los grupos de alumnado con y sin biblioteca

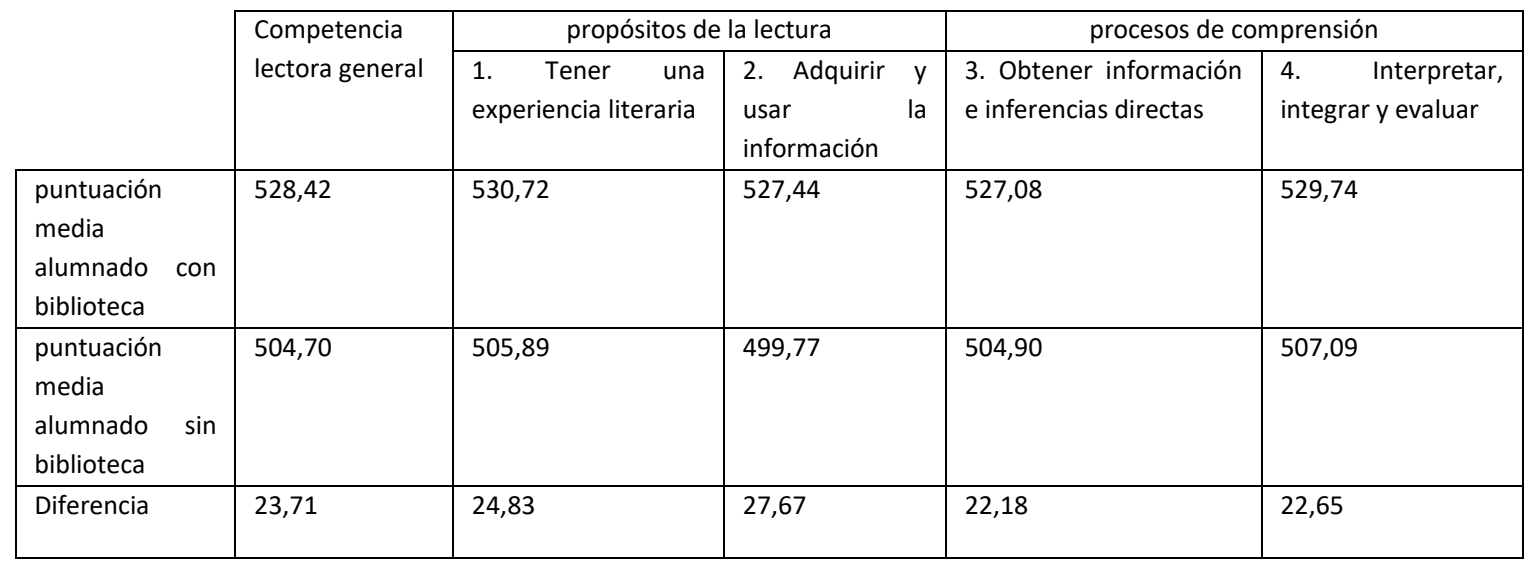




\begin{tabular}{|l|l|l|l|l|l|}
\hline $\begin{array}{l}\text { Significación } \\
\mathrm{t}>1,96\end{array}$ & Sí Sí & Sí & Sí & Sí \\
\hline
\end{tabular}

\subsubsection{Comprobación de la H2. El alumnado que más utiliza la biblioteca escolar obtiene mejores resultados académicos en competencia lectora, comparado con el alumnado que no tiene este hábito}

Como se puede observar en la Tabla 20, si se comparan los resultados (medias) en competencia lectora teniendo en cuenta la variable "intensidad de uso de la biblioteca escolar", se observa que el resultado es 528,68 (error estándar $=1,74$ ), ligeramente superior para el alumnado que acude a la biblioteca al menos varias veces al año para tomar libros en préstamo. El resultado es ligeramente inferior $(528,11$, error estándar $=2,49$ ) para el alumnado que no acude a la biblioteca nunca o casi nunca. No obstante, esta diferencia de 0,57 no es estadísticamente significativa a un $95 \%$ de nivel de confianza.

Tabla 20. PIRLS 2016. Comparación de resultados medios en competencia lectora del alumnado español, introduciendo la variable "frecuencia con la que el alumnado acude a su biblioteca escolar para tomar libros en préstamo". Salida de ordenador utilizando el programa IEA IDB Analyzer - SPSS

Average for ASRREAO by IDCNRRY ASBRO3 _DOMMY

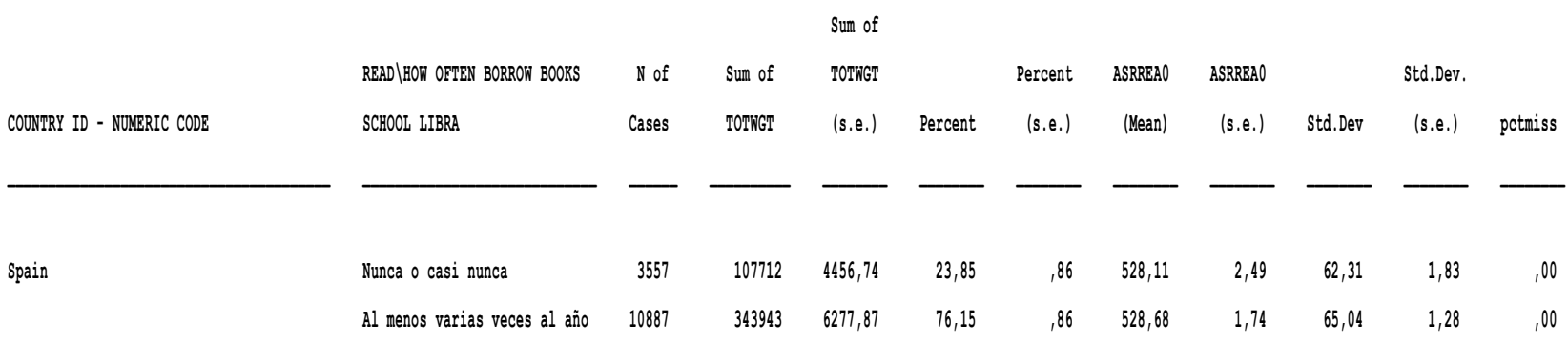

Regression Coefficients

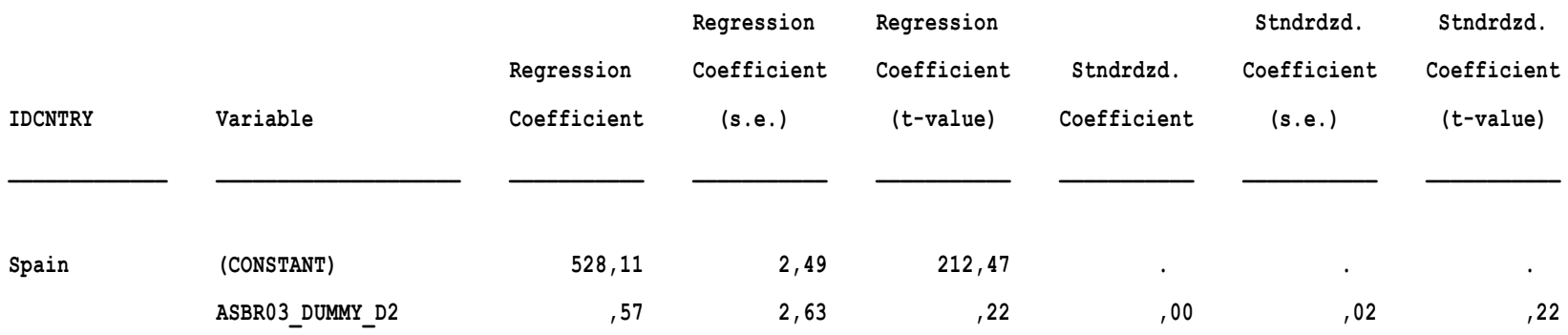


Como se observa en la Tabla 21, si repetimos el mismo análisis tomando como variable dependiente el resultado en competencia lectora referido a la dimensión "Tener una experiencia literaria", observamos que el alumnado que acude a la biblioteca al menos varias veces al año para tomar libros en préstamo obtiene una puntuación media ligeramente inferior $(530,77$, error estándar $=1,94)$, comparado con el alumnado que no acude nunca o casi nunca (puntuación media $=531,25$, error estándar $=2,68$ ). Esta diferencia de 0,48 no es estadísticamente significativa al $95 \%$ de nivel de confianza.

El resultado no se ajusta a lo esperado, ya que aparentemente obtiene mejores resultados el alumnado que menos frecuenta la biblioteca para tomar libros en préstamo. No obstante, no son resultados concluyentes. Como hemos visto, no se cumple la significación estadística a un $95 \%$ de nivel de confianza. Por otro lado, si bien el préstamo de materiales es una de las razones principales por las que el alumnado acude a la biblioteca, no obstante, puede que éste no sea un buen indicador para medir el nivel de uso de la biblioteca. Con los datos PIRLS 2016 no hemos obtenido suficiente información sobre los distintos motivos por los que el alumnado de educación primaria acude a la biblioteca y sobre el efecto que tiene sobre su aprendizaje cada uno de esos usos. Estos puntos que han quedado sin respuesta se han retomado en el análisis cualitativo. 
Tabla 21. PIRLS 2016. Comparación de resultados medios en competencia lectora (dimensión: Tener una experiencia literaria) del alumnado español, introduciendo la variable "frecuencia con la que el alumnado acude a su biblioteca para tomar libros en préstamo". Salida de ordenador utilizando el programa IEA IDB Analyzer - SPSS

Average for ASRLITO by IDCNRRY ASBRO3 DOWMY

\begin{tabular}{|c|c|c|c|c|c|c|c|c|c|c|c|}
\hline & & & & Sum of & & & & & & & \\
\hline & RRAD|HON ORTEN BORRON BOOKS & Nof & Sum of & TOING! & & Percent & ASRLITO & ASRLITO & & Std. Dev. & \\
\hline COONRRY ID - NONERIC CODE & SCHOOL LIBRA & Cases & TOMNG! & (s.e.) & Percent & (s.e.) & (Mean) & (s.e.) & Std. Dev & (s.e.) & petmiss \\
\hline Spain & Nunca $o$ casi nunca & 3557 & 107712 & 4456,74 & 23,85 &, 86 & 531,25 & 2,68 & 67,38 & 1,67 &, 00 \\
\hline & Al menos varias veces al año & 10887 & 343943 & 6277,87 & 76,15 &, 86 & 530,77 & 1,94 & 69,91 & 1,56 & 00 \\
\hline
\end{tabular}

Regression Coefficients

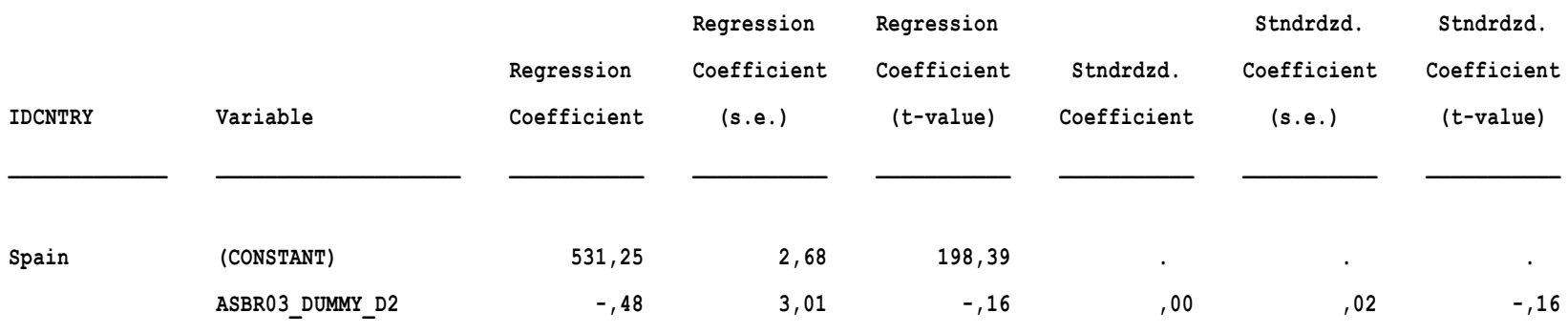

Como se ve en la Tabla 22, si repetimos el mismo análisis tomando como variable dependiente el resultado en competencia lectora referido a la dimensión "Adquirir y usar la información", observamos que el alumnado que acude a la biblioteca al menos varias veces al año para tomar libros en préstamo obtiene una puntuación media superior $(528,42$, error estándar $=1,66)$, comparado con el alumnado que no acude nunca o casi nunca (puntuación media 524,06, error estándar $=2,84$ ). Esta diferencia de 4,36 no es estadísticamente significativa al $95 \%$ de nivel de confianza. 
Tabla 22. PIRLS 2016. Comparación de resultados medios en competencia lectora (dimensión: Adquirir y usar la información) del alumnado español, introduciendo la variable "frecuencia con la que el alumnado acude a su biblioteca para tomar libros en préstamo". Salida de ordenador utilizando el programa IEA IDB Analyzer - SPSS

Average for ASRINIP by IDCNRRY ASBRO3 DoWMY

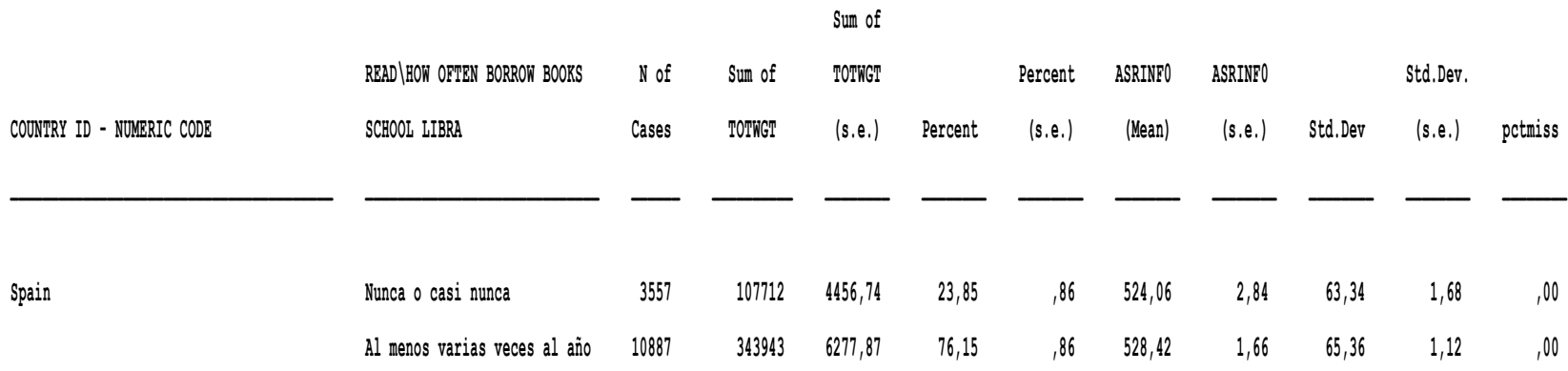

Regression Coefficients

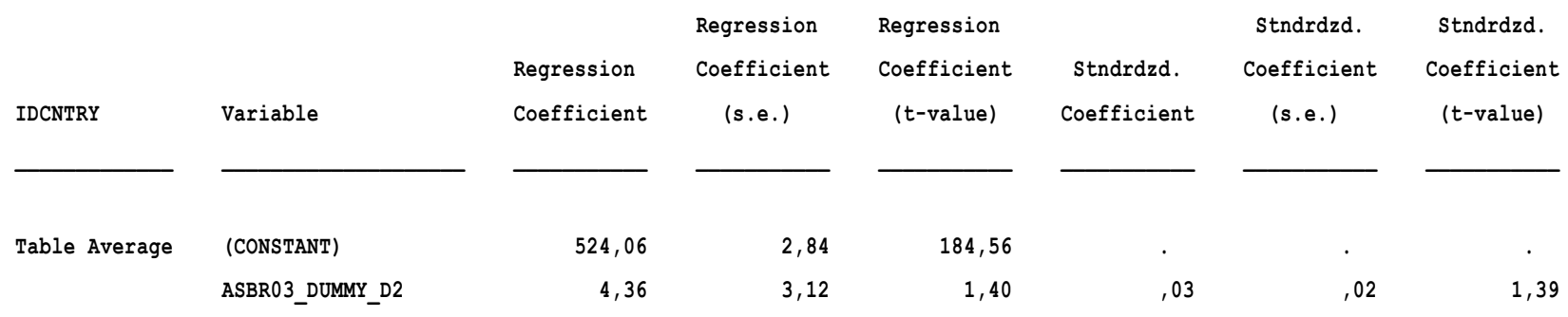

Como se observa en la Tabla 23, si repetimos el mismo análisis tomando como variable dependiente el resultado en competencia lectora referido a la dimensión "Obtener información e inferencias directas", observamos que el alumnado que acude a la biblioteca al menos varias veces al año para tomar libros en préstamo obtiene una puntuación media superior $(527,68$, error estándar $=1,80)$, comparado con el alumnado que no acude nunca o casi nunca (puntuación media 525,92, error estándar $=2,49)$. Esta diferencia de 1,77 no es estadísticamente significativa al $95 \%$ de nivel de confianza. 
Tabla 23. PIRLS 2016. Comparación de resultados medios en competencia lectora (dimensión: Obtener información e inferencias directas) del alumnado español, introduciendo la variable "frecuencia con la que el alumnado acude a su biblioteca para tomar libros en préstamo". Salida de ordenador utilizando el programa IEA IDB Analyzer - SPSS

Average for ASRRSIO by IDCNRRY ASBRO3 DOWMY

\begin{tabular}{|c|c|c|c|c|c|c|c|c|c|c|c|}
\hline & & & & Sum of & & & & & & & \\
\hline & READ \HON ORTEN BORRON BOOKS & $N$ of & Sum of & TONAGI & & Percent & ASRRSIO & ASRRSIO & & Std. Dev. & \\
\hline COONRRY ID - NONERIC CODE & SCHOOL LIBRA & Cases & TONMG & (s.e.) & Percent & (s.e.) & (Mean) & (s.e.) & Std. Dev & (s.e.) & pctmiss \\
\hline Spain & Nunca o casi nunca & 3557 & 107712 & 4456,74 & 23,85 &, 86 & 525,92 & 2,49 & 61,93 & 1,92 &, 00 \\
\hline & Al menos varias veces al año & 10887 & 343943 & 6277,87 & 76,15 &, 86 & 527,68 & 1,80 & 64,73 & 1,20 &, 00 \\
\hline
\end{tabular}

Regression Coefficients

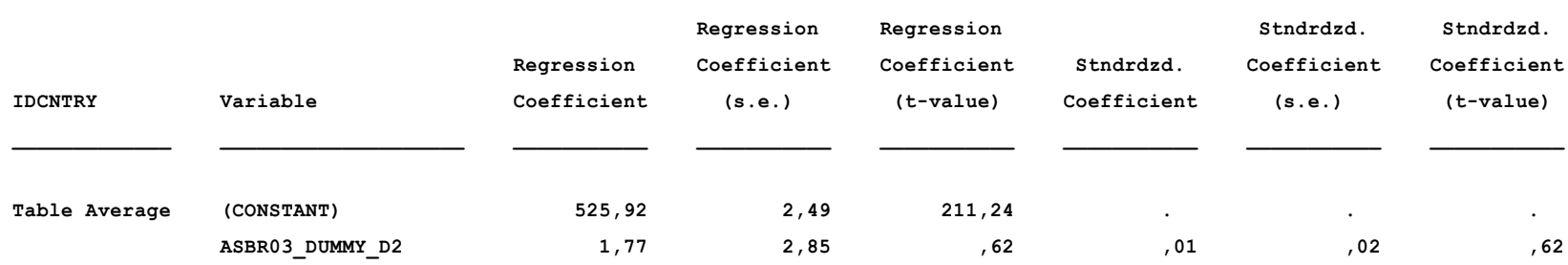

Como se ve en la Tabla 24, si repetimos el mismo análisis tomando como variable dependiente el resultado en competencia lectora referido a la dimensión "Interpretar, integrar y evaluar", observamos que el alumnado que acude a la biblioteca al menos varias veces al año para tomar libros en préstamo obtiene una puntuación media superior $(530,43$, error estándar $=1,79)$, comparado con el alumnado que no acude nunca o casi nunca (puntuación media 528,34, error estándar $=2,38$ ). Esta diferencia de 2,09 no es estadísticamente significativa al $95 \%$ de nivel de confianza. 
Tabla 24. PIRLS 2016. Comparación de resultados medios en competencia lectora (dimensión: Interpretar, integrar y evaluar) del alumnado español, introduciendo la variable "frecuencia con la que el alumnado acude a su biblioteca para tomar libros en préstamo". Salida de ordenador utilizando el programa IEA IDB Analyzer - SPSS

Average for ASRIIEO by IDCNRRY ASBRO3 DOWMY

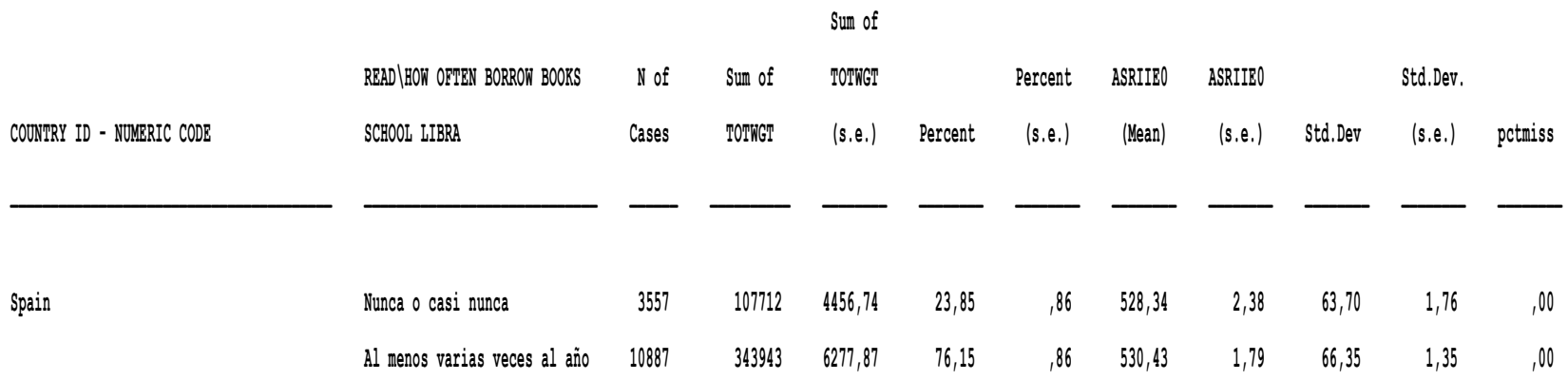

Regression Coefficients

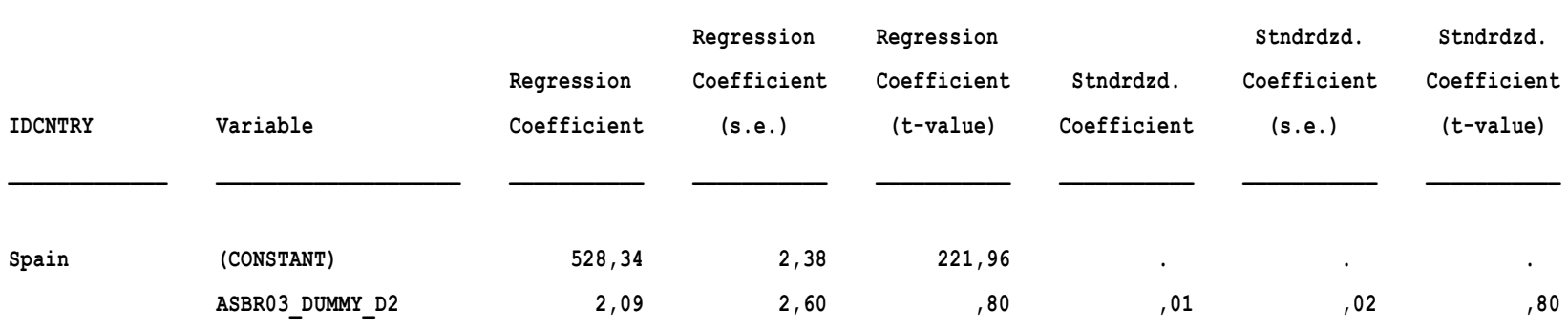

Resumimos en la Tabla 25 las puntuaciones medias obtenidas por el alumnado en las distintas dimensiones de la competencia lectora, diferenciando los grupos de alumnado según su nivel de uso de la biblioteca para tomar libros en préstamo.

Observamos que se produce una ventaja para el alumnado que más frecuenta la biblioteca para tomar libros en préstamo en los resultados de competencia lectora general, y en los resultados obtenidos para tres de las cuatro dimensiones de esta competencia, exceptuando la de tener una experiencia literaria. La diferencia mayor se produce cuando se consideran los propósitos de la lectura, fundamentalmente en la dimensión "Adquirir y usar la información", donde la diferencia media entre el alumnado que frecuenta la biblioteca y aquel que no acude nunca o casi nunca alcanza un 4,36 . No obstante, los resultados no son estadísticamente significativos a un $95 \%$ de nivel de confianza. Ha sido preciso contrastar estos resultados preliminares a la luz del posterior estudio cualitativo, para indagar sobre los distintos motivos por los que el alumnado acude a la biblioteca y para conocer su efecto sobre su formación competencial. 
Tabla 25. Puntuaciones medias obtenidas por el alumnado en las distintas dimensiones de la competencia lectora, diferenciando los grupos de alumnado según su nivel de uso de la biblioteca para tomar libros en préstamo

\begin{tabular}{|c|c|c|c|c|c|}
\hline & \multirow{2}{*}{$\begin{array}{l}\text { Competencia } \\
\text { lectora } \\
\text { general }\end{array}$} & \multicolumn{2}{|c|}{ propósitos de la lectura } & \multicolumn{2}{|c|}{ procesos de comprensión } \\
\hline & & $\begin{array}{l}\text { 1. Tener una } \\
\text { experiencia } \\
\text { literaria }\end{array}$ & $\begin{array}{l}\text { 2. Adquirir y } \\
\text { usar la } \\
\text { información }\end{array}$ & $\begin{array}{l}\text { 3. Obtener } \\
\text { información e } \\
\text { inferencias } \\
\text { directas }\end{array}$ & $\begin{array}{l}4 . \\
\text { Interpretar, } \\
\text { integrar y } \\
\text { evaluar }\end{array}$ \\
\hline $\begin{array}{l}\text { puntuación media } \\
\text { alumnado que frecuenta la } \\
\text { biblioteca al menos varias } \\
\text { veces al año para tomar } \\
\text { libros en préstamo }\end{array}$ & 528,68 & 530,77 & 528,42 & 527,68 & 530,43 \\
\hline $\begin{array}{l}\text { puntuación } \\
\text { alumnado que no } \\
\text { frecuenta la biblioteca } \\
\text { nunca o casi nunca }\end{array}$ & 528,11 & 531,25 & 524,06 & 525,92 & 528,34 \\
\hline Diferencia & 0,57 & 0,48 & 4,36 & 1,77 & 2,09 \\
\hline $\begin{array}{l}\text { Significación } \\
t>1,96\end{array}$ & No & No & No & No & No \\
\hline
\end{tabular}

\subsubsection{Comprobación de la H3. El alumnado que tiene acceso a préstamo de materiales bibliográficos impresos en su escuela obtiene mejores resultados académicos en competencia lectora, comparado con el alumnado que no dispone de este recurso}

Como se puede observar en la Tabla 26, si se comparan los resultados (medias) en competencia lectora teniendo en cuenta la variable "el alumnado tiene acceso a préstamo de materiales bibliográficos impresos", se observa que, el resultado es superior $(528,93$, error estándar $=2,03)$ para el alumnado con préstamo domiciliario de materiales bibliográficos, comparado con el alumnado que carece de este servicio en su escuela. Éstos alcanzan un resultado de 527,78 (error estándar $=4,34$ ). No obstante, esta diferencia de 1,15 no es estadísticamente significativa al $95 \%$ de nivel de confianza. 
Tabla 26. PIRLS 2016. Comparación de resultados medios en competencia lectora del alumnado español, introduciendo la variable "el alumnado tiene acceso a préstamo de materiales bibliográficos impresos". Salida de ordenador utilizando el programa IEA IDB Analyzer-SPSS

Average for ASRRER by IDCMRY ACBOQSC

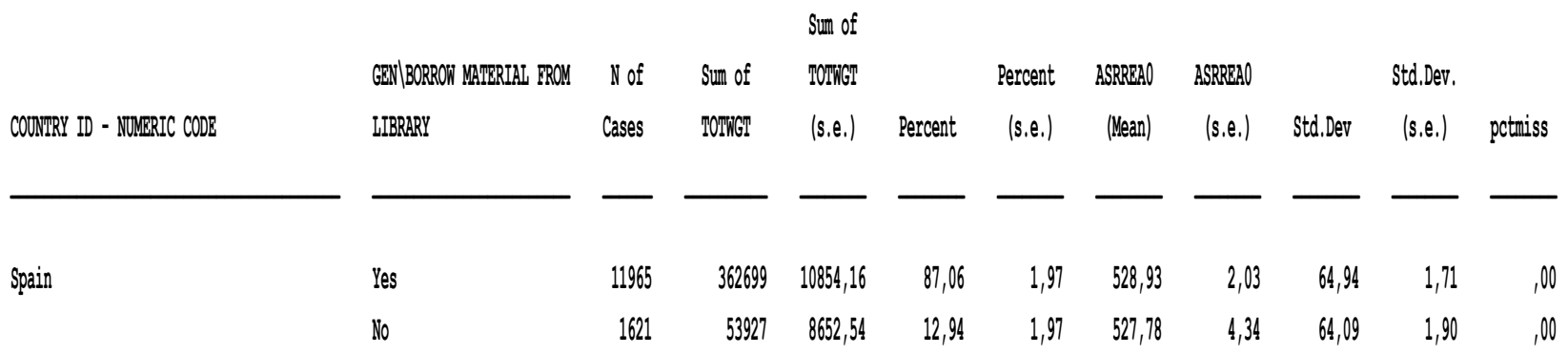

Regression Coefficients

\begin{tabular}{|c|c|c|c|c|c|c|c|}
\hline IDCNTRY & Variable & $\begin{array}{l}\text { Regression } \\
\text { Coefficient }\end{array}$ & $\begin{array}{c}\text { Regression } \\
\text { Coefficient } \\
\text { (s.e.) }\end{array}$ & $\begin{array}{l}\text { Regression } \\
\text { Coefficient } \\
\text { (t-value) }\end{array}$ & $\begin{array}{l}\text { Stndrdzd. } \\
\text { Coefficient }\end{array}$ & $\begin{array}{l}\text { Stndrdzd. } \\
\text { Coefficient } \\
\text { (s.e.) }\end{array}$ & $\begin{array}{l}\text { Stndrdzd. } \\
\text { Coefficient } \\
\text { (t-value) }\end{array}$ \\
\hline \multirow[t]{2}{*}{ Spain } & (CONSTANT) & 528,93 & 2,03 & 260,93 & . & . & . \\
\hline & ACBG09C_D2 & $-1,15$ & 5,24 &,- 22 &,- 01 &, 03 &,- 22 \\
\hline
\end{tabular}

Como se ve en la Tabla 27, si repetimos el mismo análisis tomando como variable dependiente el resultado en competencia lectora referido a la dimensión "Tener una experiencia literaria", observamos que el alumnado que tiene acceso a préstamo de materiales bibliográficos impresos obtiene una puntuación media ligeramente superior $(531,25$, error estándar $=2,23)$, comparado con el alumnado que no lo tiene (puntuación media $=531,09$, error estándar $=4,72$ ).

Esta diferencia de 0,15 no es estadísticamente significativa al $95 \%$ de nivel de confianza. 
Tabla 27. PIRLS 2016. Comparación de resultados medios en competencia lectora (dimensión: Tener una experiencia literaria) del alumnado español, introduciendo la variable "el alumnado tiene acceso a préstamo de materiales bibliográficos impresos". Salida de ordenador utilizando el programa IEA IDB Analyzer - SPSS

Average for ASRLITO by IDOMrRY aCBCOSC

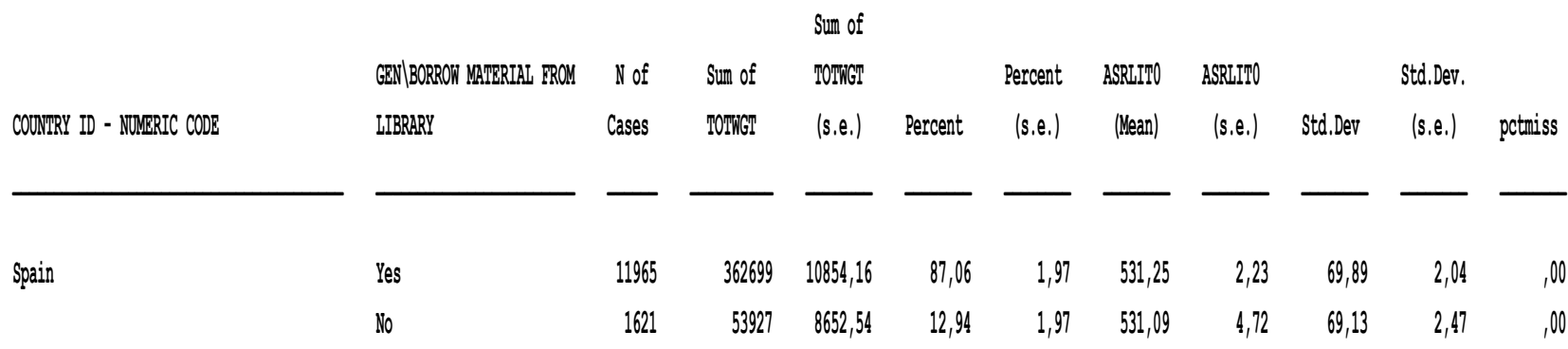

Regression Coefficients

\begin{tabular}{|c|c|c|c|c|c|c|c|}
\hline IDCNTRY & Variable & $\begin{array}{l}\text { Regression } \\
\text { Coefficient }\end{array}$ & $\begin{array}{c}\text { Regression } \\
\text { Coefficient } \\
\text { (s.e.) }\end{array}$ & $\begin{array}{c}\text { Regression } \\
\text { Coefficient } \\
\text { (t-value) }\end{array}$ & $\begin{array}{l}\text { Stndrdzd. } \\
\text { Coefficient }\end{array}$ & $\begin{array}{c}\text { Stndrdzd. } \\
\text { Coefficient } \\
\text { (s.e.) }\end{array}$ & $\begin{array}{l}\text { Stndrdzd. } \\
\text { Coefficient } \\
\text { (t-value) }\end{array}$ \\
\hline \multirow[t]{2}{*}{ Spain } & (CONSTANT) & 531,25 & 2,23 & 237,72 & & & \\
\hline & ACBG09CD2 &,- 15 & 5,87 &,- 03 &, 00 &, 03 &,- 03 \\
\hline
\end{tabular}

Como se ve en la Tabla 28, si repetimos el mismo análisis tomando como variable dependiente el resultado en competencia lectora referido a la dimensión "Adquirir y usar la información", observamos que el alumnado que tiene acceso a préstamo de materiales bibliográficos impresos obtiene una puntuación media ligeramente superior $(528,01$, error estándar $=1,88)$, comparado con el alumnado que no lo tiene (puntuación media $=526,79$, error estándar $=4,68$ ). Esta diferencia de 1,22 no es estadísticamente significativa al $95 \%$ de nivel de confianza. 
Tabla 28. PIRLS 2016. Comparación de resultados medios en competencia lectora (dimensión: Adquirir y usar la información) del alumnado español, introduciendo la variable "el alumnado tiene acceso a préstamo de materiales bibliográficos impresos". Salida de ordenador utilizando el programa IEA IDB Analyzer - SPSS

Average for ASRNIPO by IDOMRRY aCBCOOC

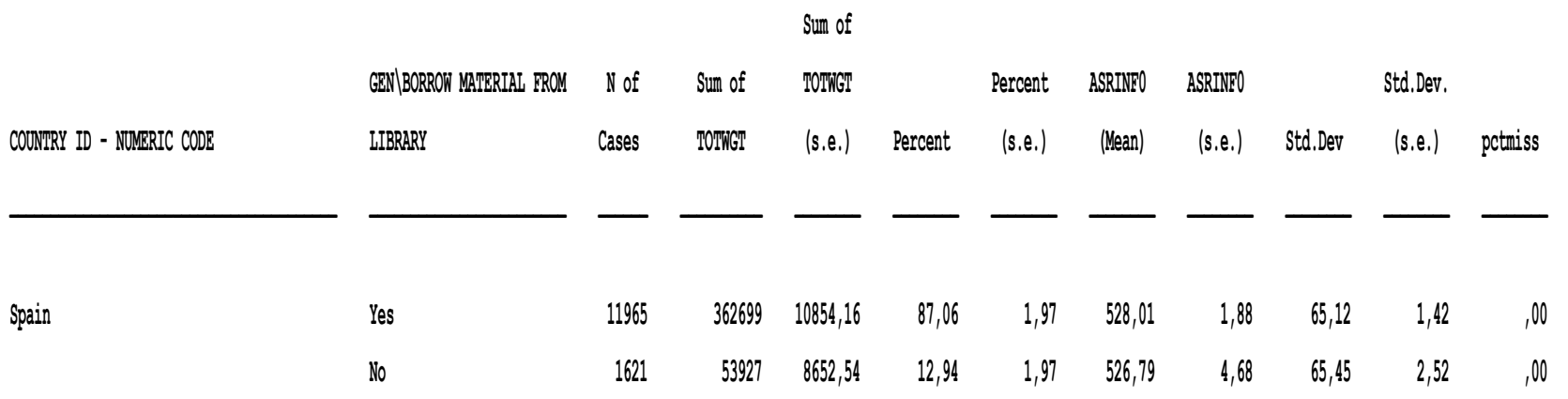

Regression Coefficients

\begin{tabular}{|c|c|c|c|c|c|c|c|}
\hline IDCNTRY & Variable & $\begin{array}{l}\text { Regression } \\
\text { Coefficient }\end{array}$ & $\begin{array}{c}\text { Regression } \\
\text { Coefficient } \\
\text { (s.e.) }\end{array}$ & $\begin{array}{c}\text { Regression } \\
\text { Coefficient } \\
\text { (t-value) }\end{array}$ & $\begin{array}{l}\text { Stndrdzd. } \\
\text { Coefficient }\end{array}$ & $\begin{array}{c}\text { Stndrdzd. } \\
\text { Coefficient } \\
\text { (s.e.) }\end{array}$ & $\begin{array}{l}\text { Stndrdzd. } \\
\text { Coefficient } \\
\text { (t-value) }\end{array}$ \\
\hline \multirow[t]{2}{*}{ Spain } & (CONSTANT) & 528,01 & 1,88 & 280,36 & & . & . \\
\hline & ACBG09C_D2 & $-1,22$ & 5,50 &,- 22 &,- 01 &, 03 &,- 22 \\
\hline
\end{tabular}

Como se ve en la Tabla 29, si repetimos el mismo análisis tomando como variable dependiente el resultado en competencia lectora referido a la dimensión "Obtener información e inferencias directas", observamos que el alumnado que tiene acceso a préstamo de materiales bibliográficos impresos obtiene una puntuación media ligeramente superior $(527,54$, error estándar $=1,99)$, comparado con el alumnado que no lo tiene (puntuación media $=526,72$, error estándar $=4,14$ ). Esta diferencia de 0,82 no es estadísticamente significativa al $95 \%$ de nivel de confianza. 
Tabla 29. PIRLS 2016. Comparación de resultados medios en competencia lectora (dimensión: Obtener información e inferencias directas) del alumnado español, introduciendo la variable "el alumnado tiene acceso a préstamo de materiales bibliográficos impresos". Salida de ordenador utilizando el programa IEA IDB Analyzer - SPSS

Average for ASRRSI by IDCNRY ACBOOOC

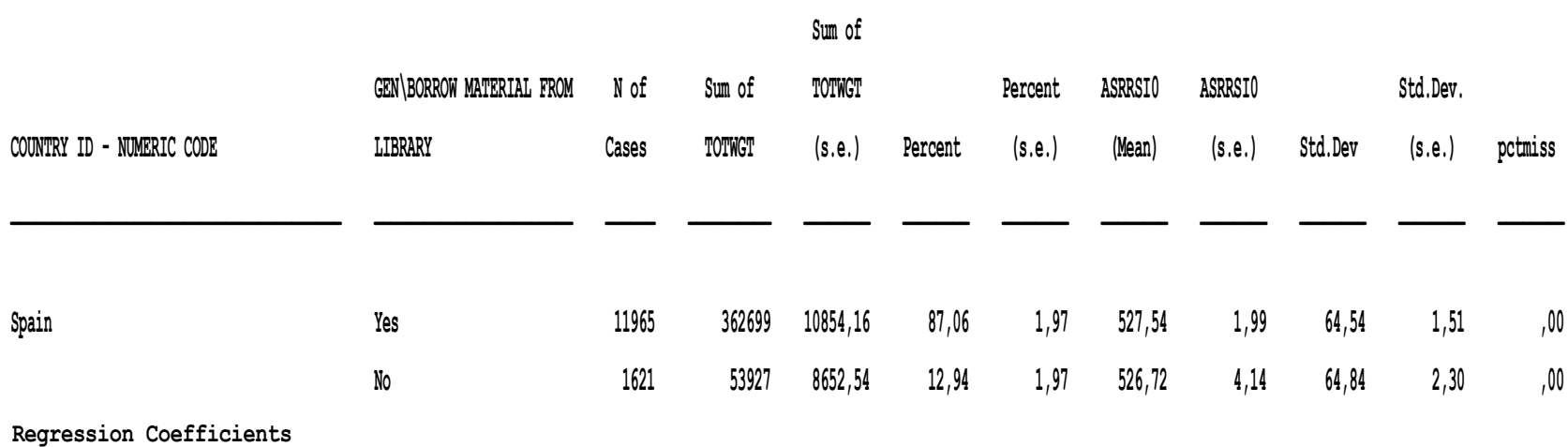

\begin{tabular}{|c|c|c|c|c|c|c|c|}
\hline IDCNTRY & Variable & $\begin{array}{l}\text { Regression } \\
\text { Coefficient }\end{array}$ & $\begin{array}{c}\text { Regression } \\
\text { Coefficient } \\
\text { (s.e.) }\end{array}$ & $\begin{array}{l}\text { Regression } \\
\text { Coefficient } \\
\text { (t-value) }\end{array}$ & $\begin{array}{l}\text { Stndrdzd. } \\
\text { Coefficient }\end{array}$ & $\begin{array}{l}\text { Stndrdzd. } \\
\text { Coefficient } \\
\text { (s.e.) }\end{array}$ & $\begin{array}{l}\text { Stndrdzd. } \\
\text { Coefficient } \\
\text { (t-value) }\end{array}$ \\
\hline \multirow[t]{2}{*}{ Spain } & (CONSTANT) & 527,54 & 1,99 & 264,80 & & & . \\
\hline & ACBG09C D2 &,- 82 & 5,07 &,- 16 &, 00 & ,03 &,- 16 \\
\hline
\end{tabular}

Como se ve en la Tabla 30, si repetimos el mismo análisis tomando como variable dependiente el resultado en competencia lectora referido a la dimensión "Interpretar, integrar y evaluar", observamos que el alumnado que tiene acceso a préstamo de materiales bibliográficos impresos obtiene una puntuación media ligeramente superior $(530,25$, error estándar $=2,08)$, comparado con el alumnado que no lo tiene (puntuación media $=529,18$, error estándar $=4,53$ ).

Esta diferencia de 1,07 no es estadísticamente significativa al $95 \%$ de nivel de confianza. 
Tabla 30. PIRLS 2016. Comparación de resultados medios en competencia lectora (dimensión: Interpretar, integrar y evaluar) del alumnado español, introduciendo la variable "el alumnado tiene acceso a préstamo de materiales bibliográficos impresos". Salida de ordenador utilizando el programa IEA IDB Analyzer - SPSS

Average for ASRIIEO by IDCNRRY ACBCOIC

\begin{tabular}{|c|c|c|c|c|c|c|c|c|c|c|c|}
\hline & & & & Sum of & & & & & & & \\
\hline & GEN BORRON MAMERIAL $\mathbb{R O O M}$ & Nof & Sum of & TOMNG! & & Percent & ASRIIEO & ASRIIEO & & Std. Dev. & \\
\hline COONIRY ID - NONERIC CODE & LIBRRRY & Cases & TOTKG! & (s.e.) & Percent & (s.e.) & (Mean) & (s.e.) & Std.Dev & (s.e.) & pctmiss \\
\hline Spain & Yes & 11965 & 362699 & 10854,16 & 87,06 & 1,97 & 530,25 & 2,08 & 66,30 & 1,72 & \\
\hline & No & 1621 & 53927 & 8652,54 & 12,94 & 1,97 & 529,18 & 4,53 & 65,89 & 2,35 & \\
\hline
\end{tabular}

Regression Coefficients

\begin{tabular}{|c|c|c|c|c|c|c|c|}
\hline IDCNTRY & Variable & $\begin{array}{l}\text { Regression } \\
\text { Coefficient }\end{array}$ & $\begin{array}{c}\text { Regression } \\
\text { Coefficient } \\
\text { (s.e.) }\end{array}$ & $\begin{array}{c}\text { Regression } \\
\text { Coefficient } \\
\text { (t-value) }\end{array}$ & $\begin{array}{l}\text { Stndrdzd. } \\
\text { Coefficient }\end{array}$ & $\begin{array}{l}\text { Stndrdzd. } \\
\text { Coefficient } \\
\text { (s.e.) }\end{array}$ & $\begin{array}{l}\text { Stndrdzd. } \\
\text { Coefficient } \\
\text { (t-value) }\end{array}$ \\
\hline \multirow[t]{2}{*}{ Spain } & (CONSTANT) & 530,25 & 2,08 & 254,35 & . & . & $\cdot$ \\
\hline & ACBG09C_D2 & $-1,07$ & 5,44 &,- 20 &,- 01 &, 03 &,- 20 \\
\hline
\end{tabular}

Resumimos en la Tabla 31 las puntuaciones medias obtenidas por el alumnado en las distintas dimensiones de la competencia lectora, diferenciando los grupos de alumnado que tiene o no acceso a préstamo de materiales bibliográficos impresos.

Observamos que, tanto en los resultados de competencia lectora general como en los resultados obtenidos para las cuatro dimensiones de esta competencia, existe una ligera ventaja para el grupo de alumnado con acceso a préstamo de materiales bibliográficos impresos, en comparación con el alumnado que no lo tiene. La diferencia mayor se produce cuando se consideran los propósitos de la lectura, fundamentalmente en la dimensión "Adquirir y usar la información", donde la diferencia media entre los dos grupos alcanza un 1,22. No obstante los resultados no son estadísticamente significativos a un $95 \%$ de nivel de confianza. Ha sido preciso contrastar estos resultados preliminares a la luz de la información cualitativa, para conocer mejor el efecto que tiene el préstamo de materiales bibliográficos sobre el alumnado dentro de las dinámicas de uso de la biblioteca. 
Tabla 31. Puntuaciones medias obtenidas por el alumnado en las distintas dimensiones de la competencia lectora, diferenciando los grupos de alumnado que tiene o no acceso a préstamo de materiales bibliográficos impresos

\begin{tabular}{|c|c|c|c|c|c|}
\hline & \multirow{2}{*}{$\begin{array}{l}\text { Competencia } \\
\text { lectora } \\
\text { general }\end{array}$} & \multicolumn{2}{|c|}{ propósitos de la lectura } & \multicolumn{2}{|c|}{ procesos de comprensión } \\
\hline & & $\begin{array}{l}\text { 1. Tener una } \\
\text { experiencia } \\
\text { literaria }\end{array}$ & $\begin{array}{l}\text { 2. Adquirir y } \\
\text { usar la } \\
\text { información. }\end{array}$ & $\begin{array}{l}3 . \quad \text { Obtener } \\
\text { información e } \\
\text { inferencias } \\
\text { directas } \\
\end{array}$ & $\begin{array}{l}\text { 4. Interpretar, } \\
\text { integrar y } \\
\text { evaluar }\end{array}$ \\
\hline $\begin{array}{l}\text { puntuación } \\
\text { alumnado que sí tienen } \\
\text { acceso a préstamo de } \\
\text { materiales bibliográficos } \\
\text { impresos }\end{array}$ & 528,93 & 531,25 & 528,01 & 527,54 & 530,25 \\
\hline $\begin{array}{l}\text { puntuación media } \\
\text { alumnado que no tienen } \\
\text { acceso a préstamo de } \\
\text { materiales bibliográficos } \\
\text { impresos }\end{array}$ & 527,78 & 531,09 & 526,79 & 526,72 & 529,18 \\
\hline Diferencia & 1,15 & 0,15 & 1,22 & 0,82 & 1,07 \\
\hline $\begin{array}{l}\text { Significación } \\
t>1,96\end{array}$ & No & No & No & No & No \\
\hline
\end{tabular}

\subsubsection{Comprobación de la H4. El alumnado que tiene acceso a libros electrónicos en su escuela obtiene mejores resultados académicos en competencia lectora, comparado con el alumnado que no dispone de este recurso}

Como se puede observar en la Tabla 32, si se comparan los resultados (medias) en competencia lectora teniendo en cuenta esta variable, se ve que el resultado es 535,33 (error estándar $=1,85$ ) para el alumnado con acceso a libros electrónicos en la escuela y 522,50 (error estándar $=2,45$ ) para el alumnado sin acceso. Esta diferencia de 12,83 es estadísticamente significativa al $95 \%$ de nivel de confianza. 
Tabla 32. PIRLS 2016. Comparación de resultados medios en competencia lectora del alumnado español, introduciendo la variable "la escuela proporciona acceso a libros electrónicos" en el análisis de comparación de medias. Salida de ordenador utilizando el programa IEA IDB Analyzer - SPSS

Average for ASRREAO by IDCNIRY ACBGIO

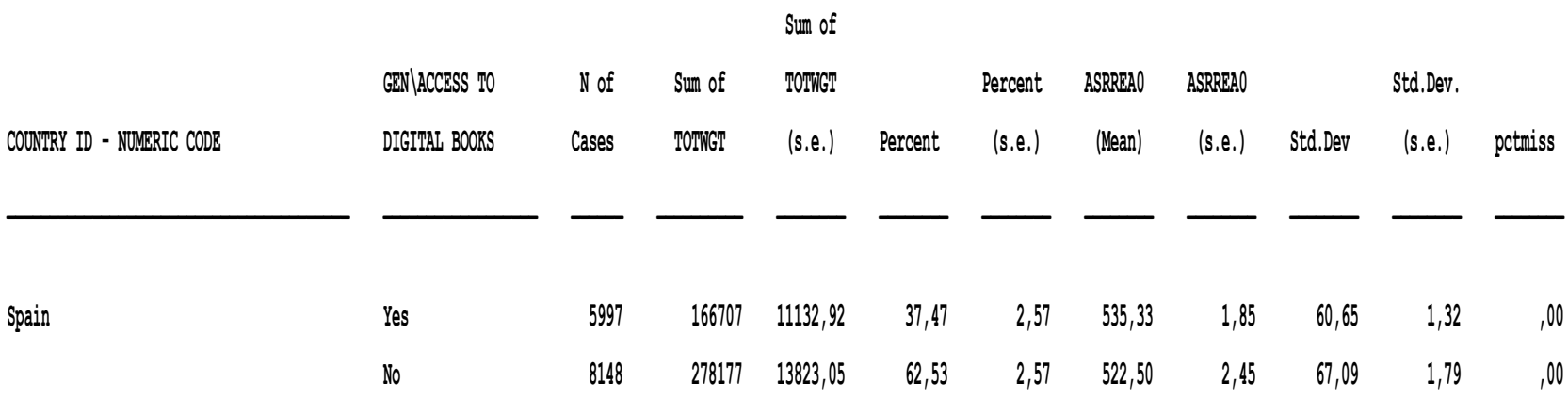

Regression Coefficients

\begin{tabular}{|c|c|c|c|c|c|c|c|}
\hline IDCNTRY & Variable & $\begin{array}{l}\text { Regression } \\
\text { Coefficient }\end{array}$ & $\begin{array}{c}\text { Regression } \\
\text { Coefficient } \\
\text { (s.e.) }\end{array}$ & $\begin{array}{c}\text { Regression } \\
\text { Coefficient } \\
\text { (t-value) }\end{array}$ & $\begin{array}{l}\text { Stndrdzd. } \\
\text { Coefficient }\end{array}$ & $\begin{array}{c}\text { Stndrdzd. } \\
\text { Coefficient } \\
\text { (s.e.) }\end{array}$ & $\begin{array}{l}\text { Stndrdzd. } \\
\text { Coefficient } \\
\text { (t-value) }\end{array}$ \\
\hline \multirow[t]{2}{*}{ Spain } & (CONSTANT) & 535,33 & 1,85 & 288,66 & . & . & \\
\hline & ACBG10 D2 & $-12,83$ & 3,08 & $-4,16$ &,- 10 &, 02 & $-4,34$ \\
\hline
\end{tabular}

Como se ve en la Tabla 33, si repetimos el mismo análisis tomando como variable dependiente el resultado en competencia lectora referido a la dimensión "Tener una experiencia literaria", observamos que el alumnado que tiene acceso a libros electrónicos desde su escuela obtiene una puntuación media superior $(537,49$, error estándar $=1,97$ ), comparado con el alumnado que no tiene este acceso (puntuación media $=524,76$, error estándar $=2,68)$.

Esta diferencia de 12,73 sí es estadísticamente significativa al $95 \%$ de nivel de confianza. 
Tabla 33. PIRLS 2016. Comparación de resultados medios en competencia lectora (dimensión: Tener una experiencia literaria) del alumnado español, introduciendo la variable "el alumnado tiene acceso a libros electrónicos". Salida de ordenador utilizando el programa IEA IDB Analyzer - SPSS

Average for ASRIITO by IDCNRYY ACBC10

\begin{tabular}{|c|c|c|c|c|c|c|c|c|c|c|c|}
\hline & & & & Sum of & & & & & & & \\
\hline & GENVICCCESS 10 & Nof & Sum of & MOMNG! & & Percent & ASRLITO & ASRLITO & & Std. Dev. & \\
\hline COONRRY ID - NONRRIC CODE & DIGITAL BOOKS & Cases & IOMNG! & (s.e.) & Percent & $($ s.e. $)$ & (Mean) & (s.e.) & Std.Dev & (s.e.) & pctmiss \\
\hline Spain & Yes & 5997 & 166707 & 11132,92 & 37,47 & 2,57 & 537,49 & 1,97 & 65,81 & 1,22 &, 00 \\
\hline & 110 & 8148 & 278177 & 13823,05 & 62,53 & 2,57 & 524,76 & 2,68 & 72,08 & 2,27 & 00 \\
\hline
\end{tabular}

Regression Coefficients

\begin{tabular}{|c|c|c|c|c|c|c|c|}
\hline IDCNTRY & Variable & $\begin{array}{l}\text { Regression } \\
\text { Coefficient }\end{array}$ & $\begin{array}{c}\text { Regression } \\
\text { Coefficient } \\
\text { (s.e.) }\end{array}$ & $\begin{array}{c}\text { Regression } \\
\text { Coefficient } \\
\text { (t-value) }\end{array}$ & $\begin{array}{l}\text { Stndrdzd. } \\
\text { Coefficient }\end{array}$ & $\begin{array}{c}\text { Stndrdzd. } \\
\text { Coefficient } \\
\text { (s.e.) }\end{array}$ & $\begin{array}{l}\text { Stndrdzd. } \\
\text { Coefficient } \\
\text { (t-value) }\end{array}$ \\
\hline \multirow[t]{2}{*}{ Spain } & (CONSTANT) & 537,49 & 1,97 & 272,50 & . & & \\
\hline & ACBG10_D2 & $-12,73$ & 3,38 & $-3,76$ &,- 09 &, 02 & $-3,96$ \\
\hline
\end{tabular}

Como se ve en la Tabla 34, si repetimos el mismo análisis tomando como variable dependiente el resultado en competencia lectora referido a la dimensión "Adquirir y usar la información", observamos que el alumnado que tiene acceso a libros electrónicos desde su escuela obtiene una puntuación media superior $(534,43$, error estándar $=1,84$ ), comparado con el alumnado que no tiene este acceso (puntuación media $=521,31$, error estándar $=2,28$ ).

Esta diferencia de 13,11 sí es estadísticamente significativa al $95 \%$ de nivel de confianza. 
Tabla 34. PIRLS 2016. Comparación de resultados medios en competencia lectora (dimensión: Adquirir y usar la información) del alumnado español, introduciendo la variable "el alumnado tiene acceso a libros electrónicos". Salida de ordenador utilizando el programa IEA IDB Analyzer - SPSS

Average for ASRNINO by IDCWRRY ACBGIO

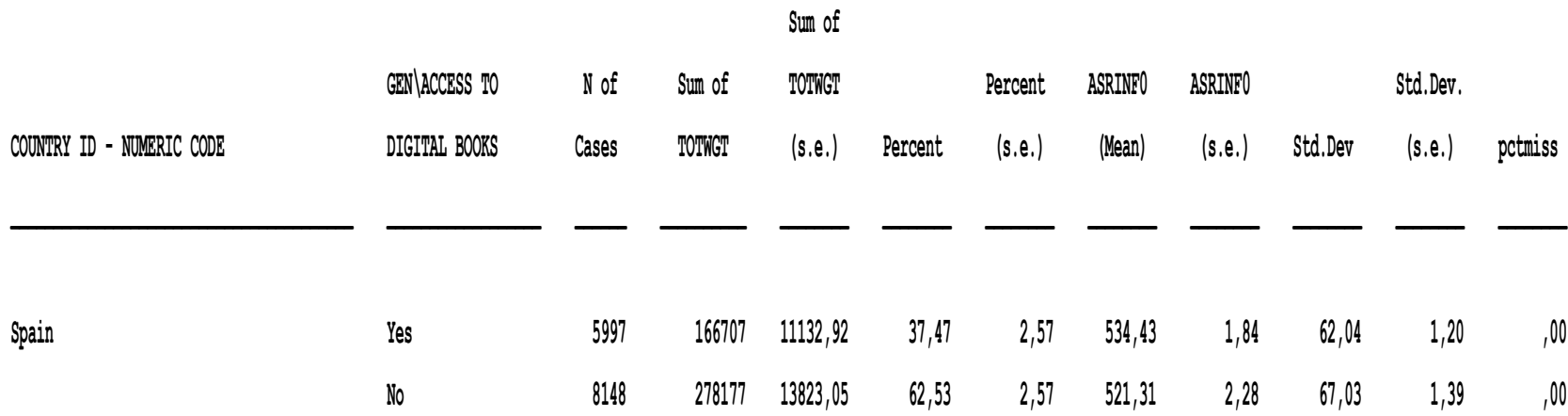

Regression Coefficients

\begin{tabular}{|c|c|c|c|c|c|c|c|}
\hline IDCNTRY & Variable & $\begin{array}{l}\text { Regression } \\
\text { Coefficient }\end{array}$ & $\begin{array}{c}\text { Regression } \\
\text { Coefficient } \\
\text { (s.e.) }\end{array}$ & $\begin{array}{c}\text { Regression } \\
\text { Coefficient } \\
\text { (t-value) }\end{array}$ & $\begin{array}{l}\text { Stndrdzd. } \\
\text { Coefficient }\end{array}$ & $\begin{array}{l}\text { Stndrdzd. } \\
\text { Coefficient } \\
\text { (s.e.) }\end{array}$ & $\begin{array}{l}\text { Stndrdzd. } \\
\text { Coefficient } \\
\text { (t-value) }\end{array}$ \\
\hline \multirow[t]{2}{*}{ Spain } & (CONSTANT) & 534,43 & 1,84 & 289,81 & . & . & . \\
\hline & ACBG10 D2 & $-13,11$ & 3,07 & $-4,27$ &,- 10 &, 02 & $-4,42$ \\
\hline
\end{tabular}

Como se ve en la Tabla 35, si repetimos el mismo análisis tomando como variable dependiente el resultado en competencia lectora referido a la dimensión "Obtener información e inferencias directas", observamos que el alumnado que tiene acceso a libros electrónicos desde su escuela obtiene una puntuación media superior $(533,11$, error estándar $=1,90)$, comparado con el alumnado que no tiene este acceso (puntuación media $=521,82$, error estándar $=2,42$ ).

Esta diferencia de 11,28 sí es estadísticamente significativa al $95 \%$ de nivel de confianza. 
Tabla 35. PIRLS 2016. Comparación de resultados medios en competencia lectora (dimensión: Obtener información e inferencias directas) del alumnado español introduciendo la variable "el alumnado tiene acceso a libros electrónicos". Salida de ordenador utilizando el programa IEA IDB Analyzer - SPSS

Average for ASRRSI by IDCMRRY ACBGIO

\begin{tabular}{|c|c|c|c|c|c|c|c|c|c|c|c|}
\hline & GEN|ACCESS IO & Nof & Sum of & MOMG! & & Percent & ASRRSIO & ASRRSIO & & Std. Dev. & \\
\hline COONRYY ID - NONERTC CODE & DIGITAL BOOKS & Cases & TOMNG! & (s.e.) & Percent & (s.e.) & (Mean) & (s.e.) & Std. Dev & (s.e.) & petmiss \\
\hline \multirow[t]{2}{*}{ Spain } & Yes & 5997 & 166707 & 11132,92 & 37,47 & 2,57 & 533,11 & 1,90 & 60,83 & 1,30 & , \\
\hline & 110 & 8148 & 278177 & 13823,05 & 62,53 & 2,57 & 521,82 & 2,42 & 66,71 & 1,73 & 00 \\
\hline
\end{tabular}

Regression Coefficients

\begin{tabular}{|c|c|c|c|c|c|c|c|}
\hline IDCNTRY & Variable & $\begin{array}{l}\text { Regression } \\
\text { Coefficient }\end{array}$ & $\begin{array}{c}\text { Regression } \\
\text { Coefficient } \\
\text { (s.e.) }\end{array}$ & $\begin{array}{c}\text { Regression } \\
\text { Coefficient } \\
\text { (t-value) }\end{array}$ & $\begin{array}{l}\text { Stndrdzd. } \\
\text { Coefficient }\end{array}$ & $\begin{array}{l}\text { Stndrdzd. } \\
\text { Coefficient } \\
\text { (s.e.) }\end{array}$ & $\begin{array}{l}\text { Stndrdzd. } \\
\text { Coefficient } \\
\text { (t-value) }\end{array}$ \\
\hline \multirow[t]{2}{*}{ Spain } & (CONSTANT) & 533,11 & 1,90 & 280,96 & . & . & r \\
\hline & ACBG10_D2 & $-11,28$ & 3,17 & $-3,56$ &,- 08 &, 02 & $-3,69$ \\
\hline
\end{tabular}

Como se ve en la Tabla 36, si repetimos el mismo análisis tomando como variable dependiente el resultado en competencia lectora referido a la dimensión "Interpretar, integrar y evaluar", observamos que el alumnado que tiene acceso a libros electrónicos desde su escuela obtiene una puntuación media superior $(536,82$, error estándar $=1,97$ ), comparado con el alumnado que no tiene este acceso (puntuación media $=523,89$, error estándar $=2,47$ ).

Esta diferencia de 12,93 sí es estadísticamente significativa al $95 \%$ de nivel de confianza. 
Tabla 36. PIRLS 2016. Comparación de resultados medios en competencia lectora (dimensión: Interpretar, integrar y evaluar) del alumnado español, introduciendo la variable "el alumnado tiene acceso a libros electrónicos". Salida de ordenador utilizando el programa IEA IDB Analyzer - SPSS

\section{Averaage for ASPIIDO by IDCWNPY ACBGIO}

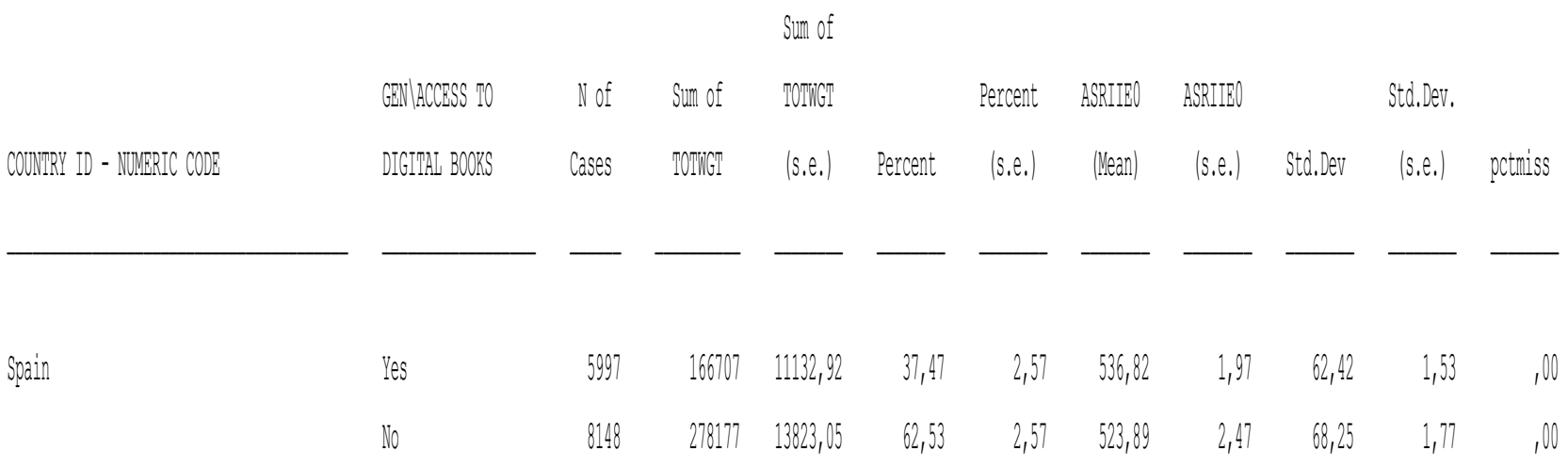

Regression Coefficients

\begin{tabular}{|c|c|c|c|c|c|c|c|}
\hline IDCNTRY & Variable & $\begin{array}{l}\text { Regression } \\
\text { Coefficient }\end{array}$ & $\begin{array}{l}\text { Regression } \\
\text { Coefficient } \\
\text { (s.e.) }\end{array}$ & $\begin{array}{c}\text { Regression } \\
\text { Coefficient } \\
\text { (t-value) }\end{array}$ & $\begin{array}{l}\text { Stndrdzd. } \\
\text { Coefficient }\end{array}$ & $\begin{array}{c}\text { Stndrdzd. } \\
\text { Coefficient } \\
\text { (s.e.) }\end{array}$ & $\begin{array}{c}\text { Stndrdzd. } \\
\text { Coefficient } \\
\text { (t-value) }\end{array}$ \\
\hline \multirow[t]{2}{*}{ Spain } & (CONSTANT) & 536,82 & 1,97 & 272,80 & . & . & . \\
\hline & ACBG10_D2 & $-12,93$ & 3,29 & $-3,93$ &,- 09 &, 02 & $-4,10$ \\
\hline
\end{tabular}

Resumimos en la Tabla 37 las puntuaciones medias obtenidas por el alumnado en las distintas dimensiones de la competencia lectora, diferenciando los grupos de alumnado con y sin acceso a libros electrónicos desde su escuela.

Observamos que, tanto en los resultados de competencia lectora general como en los resultados obtenidos para las cuatro dimensiones de esta competencia, existe una ventaja, estadísticamente significativa a un $95 \%$ de nivel de confianza, para el grupo de alumnado con acceso a libros electrónicos, en comparación con el alumnado sin este acceso. La diferencia mayor se produce cuando se consideran los propósitos de la lectura, fundamentalmente en la dimensión "Adquirir y usar la información", donde la diferencia media entre los dos grupos alcanza un 13,11. 
Tabla 37. Puntuaciones medias obtenidas por el alumnado en las distintas dimensiones de la competencia lectora, diferenciando los grupos de alumnado con y sin acceso a libros electrónicos desde su centro educativo

\begin{tabular}{|c|c|c|c|c|c|}
\hline & \multirow{2}{*}{$\begin{array}{l}\text { Competencia } \\
\text { lectora } \\
\text { general }\end{array}$} & \multicolumn{2}{|c|}{ propósitos de la lectura } & \multicolumn{2}{|c|}{ procesos de comprensión } \\
\hline & & $\begin{array}{l}\text { 1. Tener una } \\
\text { experiencia } \\
\text { literaria }\end{array}$ & $\begin{array}{l}\text { 2. Adquirir y } \\
\text { usar la } \\
\text { información }\end{array}$ & $\begin{array}{l}\text { 3. Obtener } \\
\text { información e } \\
\text { inferencias } \\
\text { directas }\end{array}$ & $\begin{array}{l}\text { 4. Interpretar, } \\
\text { integrar y } \\
\text { evaluar }\end{array}$ \\
\hline $\begin{array}{lr}\text { puntuación } & \text { media } \\
\text { alumnado que sí tienen } \\
\text { acceso a libros } \\
\text { electrónicos desde su } \\
\text { escuela }\end{array}$ & 535,33 & 537,49 & 534,43 & 533,11 & 536,82 \\
\hline $\begin{array}{lr}\text { puntuación } & \text { media } \\
\text { alumnado que no tienen } \\
\text { acceso a libros } \\
\text { electrónicos desde su } \\
\text { escuela }\end{array}$ & 522,50 & 524,76 & 521,31 & 521,82 & 523,89 \\
\hline Diferencia & 12,83 & 12,73 & 13,11 & 11,28 & 12,93 \\
\hline $\begin{array}{l}\text { Significación } \\
t>1,96\end{array}$ & Sí & Sí & Sí & Sí & Sí \\
\hline
\end{tabular}

\subsubsection{Comprobación de la H5. El alumnado con acceso a colecciones bibliográficas amplias y de calidad demuestra mayor competencia lectora, comparado con el alumnado que carece de este recurso o que accede a una colección más precaria}

Como se observa en la Tabla 38, el resultado en competencia lectora del alumnado mejora si aumenta el tamaño de la biblioteca, medido por número de libros que componen su colección.

Los resultados del alumnado alcanzan un valor medio de 525,06 (error estándar $=$ 1,80 ) en el caso de alumnado con bibliotecas de un tamaño hasta 5.000 títulos, y alcanzan un valor medio de 540,33 (error estándar $=3,03$ ) en el caso del alumnado con acceso a bibliotecas de más de 5.000 títulos.

Esta diferencia de 15,26 es estadísticamente significativa al $95 \%$ de nivel de confianza.

Como se puede observar, la comprensión lectora mejora a medida que aumenta el tamaño de la colección bibliográfica. Los resultados varían desde 504,70 puntos en alumnado sin biblioteca; 517,64 puntos en alumnado con bibliotecas hasta 500 títulos; 
527,70 puntos en alumnado con bibliotecas que tienen entre 501 y 5.000 títulos; y 540,33 puntos en alumnado con bibliotecas con más de 5.000 títulos.

Tabla 38. PIRLS 2016. Comparación de resultados medios en competencia lectora (general) del alumnado español, introduciendo la variable "tamaño de la colección bibliográfica" en el análisis de comparación de medias. Salida de ordenador utilizando el programa IEA IDB Analyzer-SPSS

Average for ASRREA by IDCNRY ACOCOODDMWY

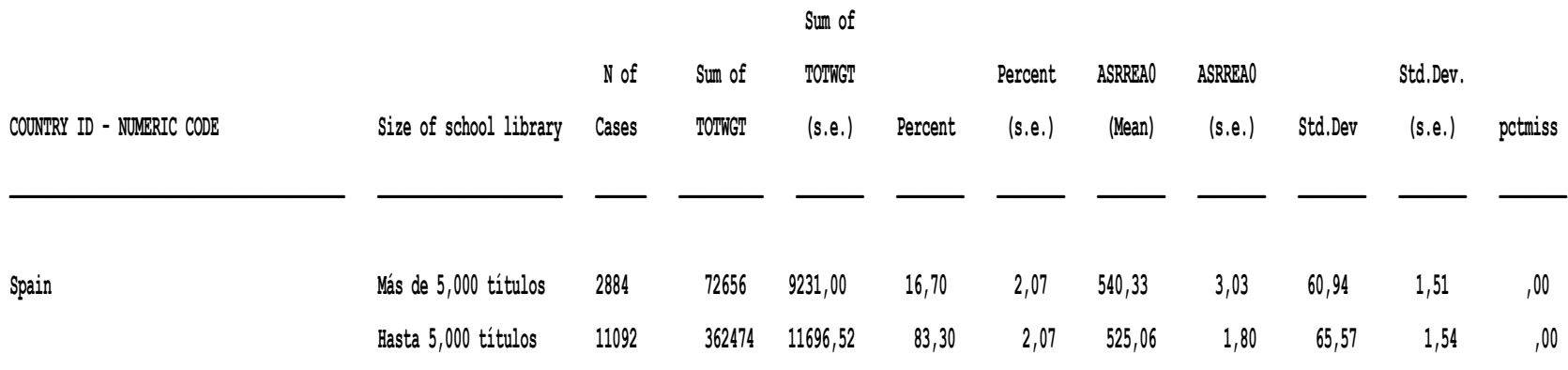

Regression Coefficients

\begin{tabular}{|c|c|c|c|c|c|c|c|}
\hline IDCNTRY & Variable & $\begin{array}{l}\text { Regression } \\
\text { Coefficient }\end{array}$ & $\begin{array}{l}\text { Regression } \\
\text { Coefficient } \\
\text { (s.e.) }\end{array}$ & $\begin{array}{c}\text { Regression } \\
\text { Coefficient } \\
\text { (t-value) }\end{array}$ & $\begin{array}{l}\text { Stndrdzd. } \\
\text { Coefficient }\end{array}$ & $\begin{array}{c}\text { Stndrdzd. } \\
\text { Coefficient } \\
\text { (s.e.) }\end{array}$ & $\begin{array}{c}\text { Stndrdzd. } \\
\text { Coefficient } \\
\text { (t-value) }\end{array}$ \\
\hline \multirow[t]{2}{*}{ Spain } & (CONSTANT) & 540,33 & 3,03 & 178,27 & . & . & $\cdot$ \\
\hline & ACDG09DUMMY_D2 & $-15,26$ & 3,36 & $-4,55$ &,- 09 &, 02 & $-4,41$ \\
\hline
\end{tabular}

Average for ASRRBA by IDONRY ACDOCO

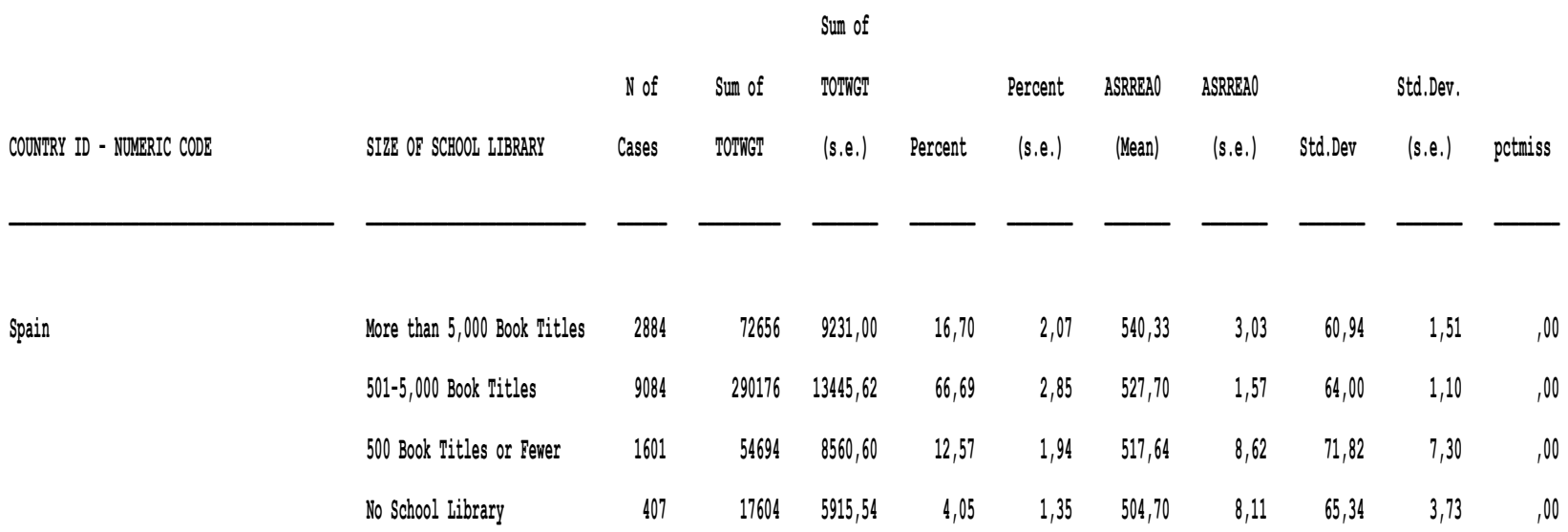

Como se ve en la Tabla 39, si repetimos el mismo análisis tomando como variable dependiente el resultado en competencia lectora referido a la dimensión "Tener una experiencia literaria", observamos que los resultados del alumnado alcanzan un valor 
medio de 527,65 (error estándar $=1,95$ ) en el caso de alumnado con bibliotecas de un tamaño hasta 5.000 títulos, y alcanzan un valor medio de 541,78 (error estándar $=3,07$ ) en el caso del alumnado con acceso a bibliotecas de más de 5.000 títulos. Esta diferencia de 14,12 es estadísticamente significativa al $95 \%$ de nivel de confianza.

Tabla 39. PIRLS 2016. Comparación de resultados medios en competencia lectora del alumnado español (dimensión: Tener una experiencia literaria), introduciendo la variable "tamaño de la colección bibliográfica" en el análisis de comparación de medias. Salida de ordenador utilizando el programa IEA IDB Analyzer-SPSS

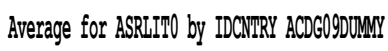

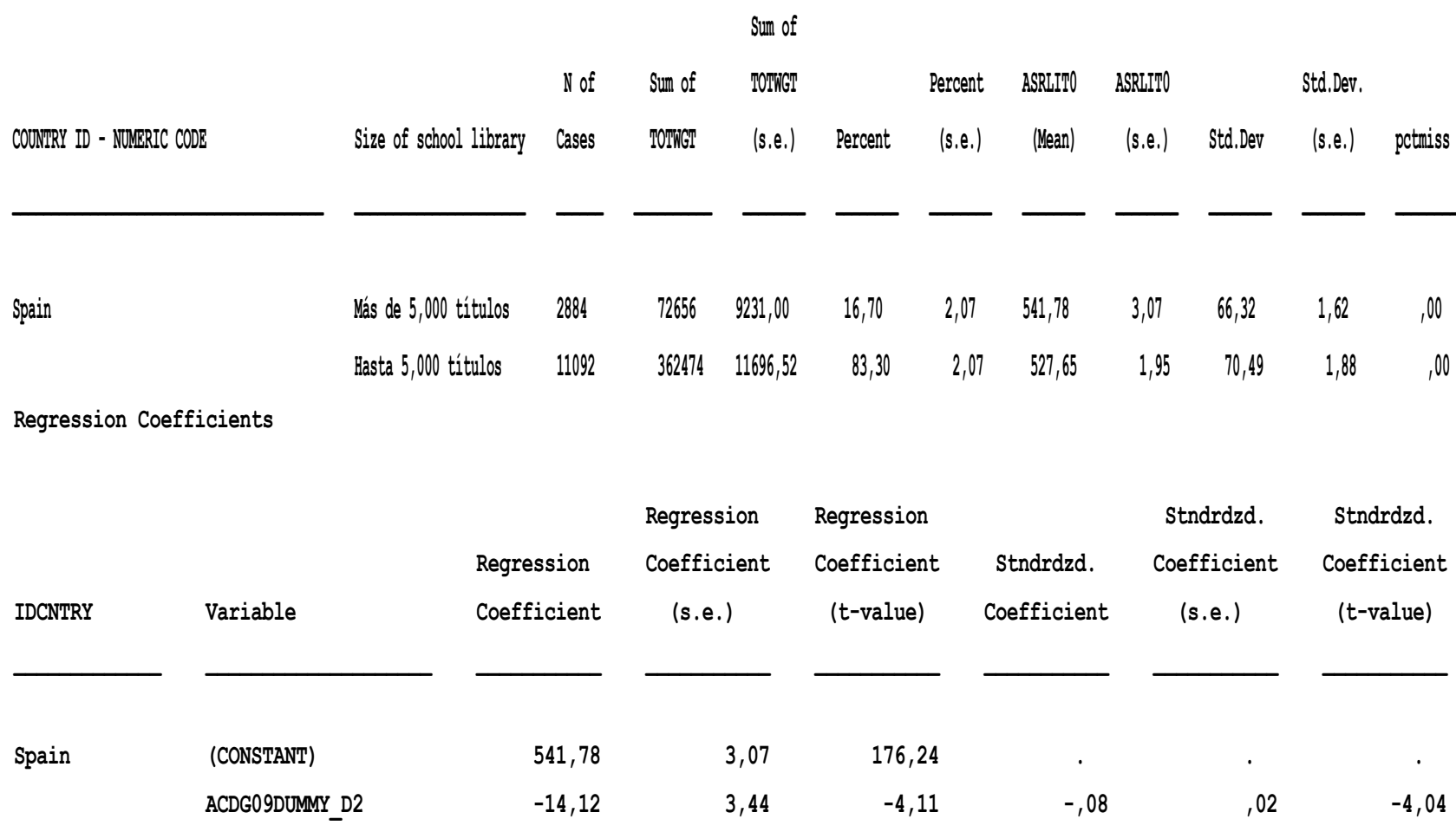

Como se ve en la Tabla 40, si repetimos el mismo análisis tomando como variable dependiente el resultado en competencia lectora referido a la dimensión "Adquirir y usar la información", observamos que los resultados del alumnado alcanzan un valor medio de 523,77 (error estándar $=1,68$ ) en el caso de alumnado con bibliotecas de un tamaño hasta 5.000 títulos, y alcanzan un valor medio de 540,16 (error estándar = 3,07 ) en el caso del alumnado con acceso a bibliotecas de más de 5.000 títulos. Esta diferencia de 16,39 es estadísticamente significativa al $95 \%$ de nivel de confianza. 
Tabla 40. PIRLS 2016. Comparación de resultados medios en competencia lectora (dimensión: Adquirir y usar la información) del alumnado español, introduciendo la variable "tamaño de la colección bibliográfica" en el análisis de comparación de medias. Salida de ordenador utilizando el programa IEA IDB Analyzer-SPSS

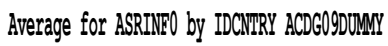

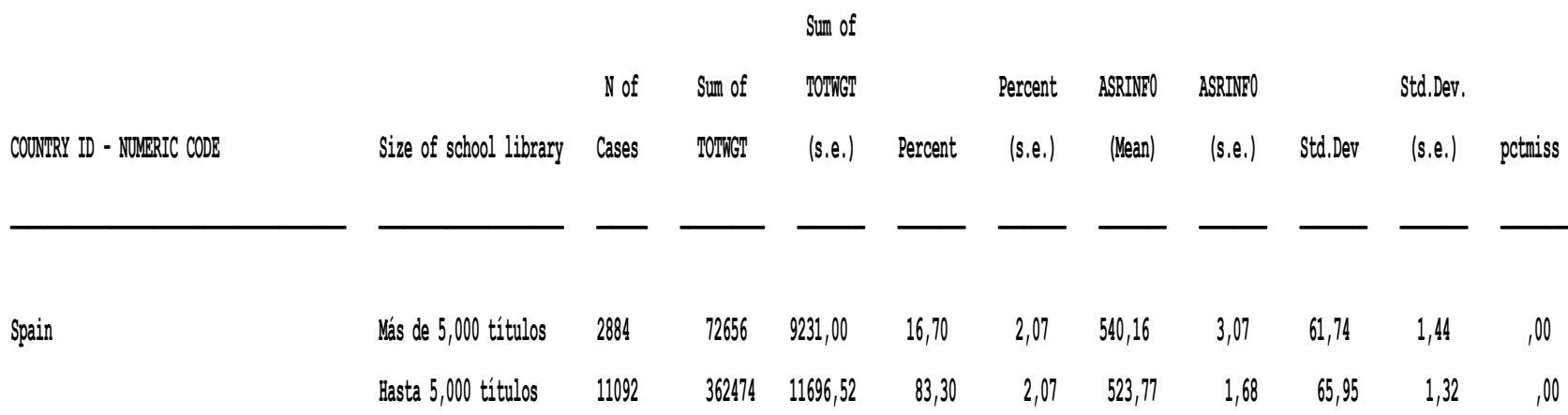

Regression Coefficients

\begin{tabular}{|c|c|c|c|c|c|c|c|}
\hline IDCNTRY & Variable & $\begin{array}{l}\text { Regression } \\
\text { Coefficient }\end{array}$ & $\begin{array}{c}\text { Regression } \\
\text { Coefficient } \\
\text { (s.e.) }\end{array}$ & $\begin{array}{c}\text { Regression } \\
\text { Coefficient } \\
\text { (t-value) }\end{array}$ & $\begin{array}{l}\text { Stndrdzd. } \\
\text { Coefficient }\end{array}$ & $\begin{array}{c}\text { Stndrdzd. } \\
\text { Coefficient } \\
\text { (s.e.) }\end{array}$ & $\begin{array}{l}\text { Stndrdzd. } \\
\text { Coefficient } \\
\text { (t-value) }\end{array}$ \\
\hline \multirow[t]{2}{*}{ Spain } & (CONSTANT) & 540,16 & 3,07 & 176,18 & ${ }^{\circ}$ & & . \\
\hline & ACDG09DUMMY D2 & $-16,39$ & 3,23 & $-5,07$ &,- 09 &, 02 & $-4,87$ \\
\hline
\end{tabular}

Como se ve en la Tabla 41, si repetimos el mismo análisis tomando como variable dependiente el resultado en competencia lectora referido a la dimensión "Obtener información e inferencias directas", observamos que los resultados del alumnado alcanzan un valor medio de 523,94 (error estándar $=1,78$ ) en el caso de alumnado con bibliotecas de un tamaño hasta 5.000 títulos, y alcanzan un valor medio de 538,30 (error estándar $=3,01$ ) en el caso del alumnado con acceso a bibliotecas de más de 5.000 títulos. Esta diferencia de 14,36 es estadísticamente significativa al $95 \%$ de nivel de confianza. 
Tabla 41. PIRLS 2016. Comparación de resultados medios en competencia lectora (dimensión: Obtener información e inferencias directas) del alumnado español, introduciendo la variable "tamaño de la colección bibliográfica" en el análisis de comparación de medias. Salida de ordenador utilizando el programa IEA IDB Analyzer - SPSS

Average for ASRRSIO by IDCNRPY ACOCOODOMYY

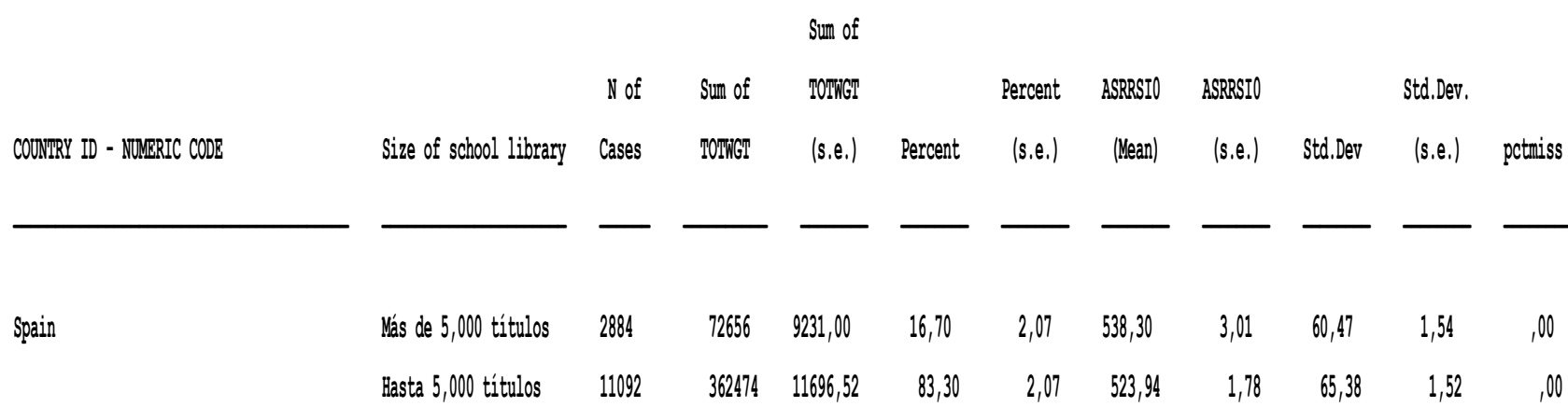

Regression Coefficients

\begin{tabular}{|c|c|c|c|c|c|c|c|}
\hline IDCNTRY & Variable & $\begin{array}{l}\text { Regression } \\
\text { Coefficient }\end{array}$ & $\begin{array}{c}\text { Regression } \\
\text { Coefficient } \\
\text { (s.e.) }\end{array}$ & $\begin{array}{c}\text { Regression } \\
\text { Coefficient } \\
\text { (t-value) }\end{array}$ & $\begin{array}{l}\text { Stndrdzd. } \\
\text { Coefficient }\end{array}$ & $\begin{array}{l}\text { Stndrdzd. } \\
\text { Coefficient } \\
\text { (s.e.) }\end{array}$ & $\begin{array}{l}\text { Stndrdzd. } \\
\text { Coefficient } \\
\text { (t-value) }\end{array}$ \\
\hline \multirow[t]{2}{*}{ Spain } & (CONSTANT) & 538,30 & 3,01 & 178,74 & . & . & \\
\hline & ACDG09DUMMY_D2 & $-14,36$ & 3,29 & $-4,37$ &,- 08 &, 02 & $-4,20$ \\
\hline
\end{tabular}

Como se ve en la Tabla 42, si repetimos el mismo análisis tomando como variable dependiente el resultado en competencia lectora referido a la dimensión "Interpretar, integrar y evaluar", observamos que los resultados del alumnado alcanzan un valor medio de 526,49 (error estándar $=1,78$ ) en el caso de alumnado con bibliotecas de un tamaño hasta 5.000 títulos, y alcanzan un valor medio de 541,46 (error estándar = 3,32 ) en el caso del alumnado con acceso a bibliotecas de más de 5.000 títulos. Esta diferencia de 14,96 es estadísticamente significativa al $95 \%$ de nivel de confianza. 
Tabla 42. PIRLS 2016. Comparación de resultados medios en competencia lectora (dimensión: Interpretar, integrar y evaluar) del alumnado español, introduciendo la variable "tamaño de la colección bibliográfica" en el análisis de comparación de medias. Salida de ordenador utilizando el programa IEA IDB Analyzer-SPSS

Average for ASRIIZO by IDCNRYY ACDGO9DOMYY

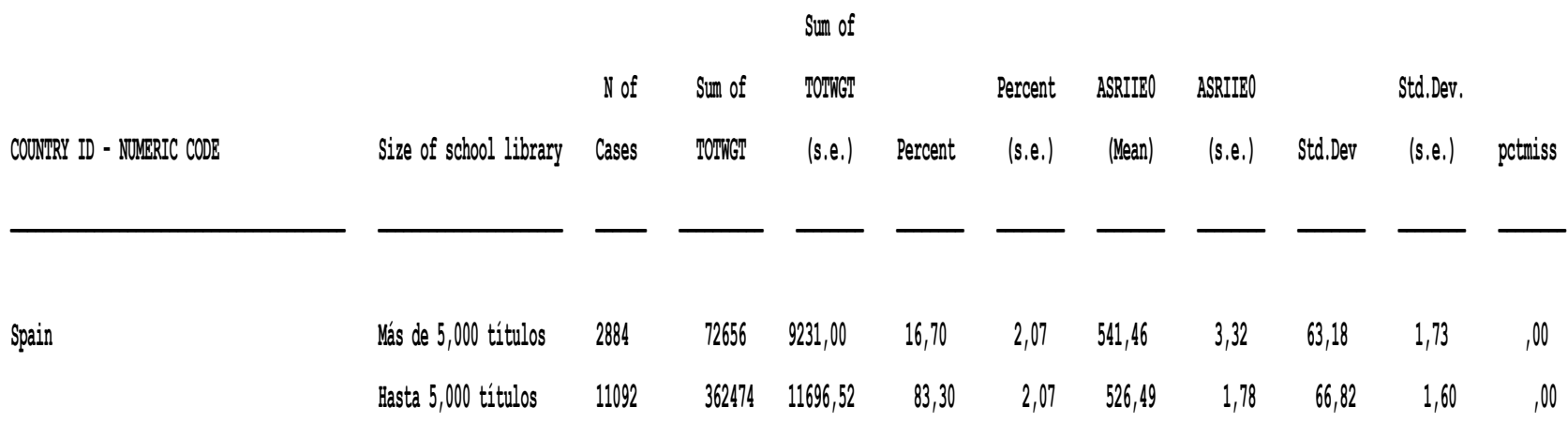

Regression Coefficients

\begin{tabular}{|c|c|c|c|c|c|c|c|}
\hline IDCNTRY & Variable & $\begin{array}{l}\text { Regression } \\
\text { Coefficient }\end{array}$ & $\begin{array}{c}\text { Regression } \\
\text { Coefficient } \\
\text { (s.e.) }\end{array}$ & $\begin{array}{c}\text { Regression } \\
\text { Coefficient } \\
\text { (t-value) }\end{array}$ & $\begin{array}{l}\text { Stndrdzd. } \\
\text { Coefficient }\end{array}$ & $\begin{array}{l}\text { Stndrdzd. } \\
\text { Coefficient } \\
\text { (s.e.) }\end{array}$ & $\begin{array}{l}\text { Stndrdzd. } \\
\text { Coefficient } \\
\text { (t-value) }\end{array}$ \\
\hline \multirow[t]{2}{*}{ Spain } & (CONSTANT) & 541,46 & 3,32 & 163,31 & $\cdot$ & & . \\
\hline & ACDGOgDUMMY_D2 & $-14,96$ & 3,47 & $-4,31$ &,- 08 & ,02 & $-4,17$ \\
\hline
\end{tabular}

Resumimos en la Tabla 43 las puntuaciones medias obtenidas por el alumnado en las distintas dimensiones de la competencia lectora, diferenciando los grupos de alumnado según tengan acceso a bibliotecas dotadas de colecciones de más de 5.000 títulos o de un tamaño hasta 5.000 títulos.

Observamos que, tanto en los resultados de competencia lectora general como en los resultados obtenidos para las cuatro dimensiones de esta competencia, existe una ventaja, estadísticamente significativa a un $95 \%$ de nivel de confianza, para el grupo de alumnado con acceso a bibliotecas dotadas de colecciones más grandes (más de 5.000 títulos), en comparación con el alumnado que tiene acceso a bibliotecas con colecciones pequeñas (hasta 5.000 títulos). La diferencia mayor se produce en la dimensión "Adquirir y usar la información", donde la diferencia media entre los dos grupos alcanza un 16,39. 
Tabla 43. Puntuaciones medias obtenidas por el alumnado en las distintas dimensiones de la competencia lectora, diferenciando los grupos de alumnado según tengan acceso a bibliotecas dotadas de colecciones de más de 5.000 títulos o de tamaño hasta 5.000 títulos

\begin{tabular}{|c|c|c|c|c|c|}
\hline & \multirow{2}{*}{$\begin{array}{l}\text { Competencia } \\
\text { lectora } \\
\text { general }\end{array}$} & \multicolumn{2}{|c|}{ propósitos de la lectura } & \multicolumn{2}{|c|}{ procesos de comprensión } \\
\hline & & $\begin{array}{l}\text { 1. Tener una } \\
\text { experiencia } \\
\text { literaria }\end{array}$ & $\begin{array}{l}\text { 2. Adquirir y } \\
\text { usar la } \\
\text { información. }\end{array}$ & $\begin{array}{l}3 . \quad \text { Obtener } \\
\text { información e } \\
\text { inferencias } \\
\text { directas } \\
\end{array}$ & $\begin{array}{l}4 . \\
\text { Interpretar, } \\
\text { integrar y } \\
\text { evaluar }\end{array}$ \\
\hline $\begin{array}{l}\text { puntuación } \\
\text { alumnado que tienen } \\
\text { acceso a bibliotecas } \\
\text { dotadas de colecciones de } \\
\text { más de } 5.000 \text { títulos }\end{array}$ & 540,33 & 541,78 & 540,16 & 538,30 & 541,46 \\
\hline $\begin{array}{l}\text { puntuación } \\
\text { alumnado que tienen } \\
\text { acceso a bibliotecas } \\
\text { dotadas de colecciones de } \\
\text { tamaño hasta } 5.000 \text { títulos }\end{array}$ & 525,06 & 527,65 & 523,77 & 523,94 & 526,49 \\
\hline Diferencia & 15,26 & 14,12 & 16,39 & 14,36 & 14,96 \\
\hline $\begin{array}{l}\text { Significación } \\
t>1,96\end{array}$ & Sí & Sí & Sí & Sí & Sí \\
\hline
\end{tabular}




\subsection{Análisis en el ámbito de la educación secundaria}

\subsubsection{Las bibliotecas en el estudio PISA 2009}

Los estudios PISA evalúan a nivel internacional y con una periodicidad trienal el rendimiento del alumnado de quince años en competencias clave de su desarrollo formativo, y, en cada edición, analizan en profundidad una de estas competencias. En su edición de 2009 PISA dio prioridad a la competencia lectora ${ }^{100}$.

Junto a la prueba de evaluación competencial que realiza el alumnado, PISA recaba información sobre el contexto socioeconómico, cultural y educativo del alumnado por medio de cuatro cuestionarios ${ }^{101}$ : el cuestionario del alumnado, el de su entorno familiar, el del profesorado y el de responsables de los centros educativos.

Como se puede ver en la Tabla 44, en los diferentes cuestionarios que se emplearon en PISA 2009, se incluyó una sección específica dedicada a las bibliotecas, donde se preguntó al alumnado si su centro educativo tenía o no biblioteca, sobre la frecuencia con la que la visitaban y los distintos usos que hacían de ella. En la tabla se pueden observar las distintas preguntas en las que se hace alusión a las bibliotecas. En las columnas primera y segunda se especifican la edición del estudio PISA y el cuestionario en el que se incluye cada pregunta; en la tercera columna, se registra el código con el que se puede identificar cada pregunta dentro del cuestionario. Este mismo código sirve para identificar la variable correspondiente dentro de los ficheros

100 En las ediciones posteriores PISA 2012 y 2015 se dio prioridad a las competencias en matemáticas y ciencias. En estas ediciones no se incluyó una batería de preguntas específica sobre bibliotecas como sí se hizo en 2009.

101 PISA 2009 incluye cuatro cuestionarios: alumnado, profesorado, entorno familiar y responsables de centros educativos (Organización para la Cooperación y el Desarrollo Económicos, 2012). Estos cuatro cuestionarios se corresponden con cuatro archivos que contienen los respectivos conjuntos de datos:

- Student performance and questionnaire data file (filename: INT_STQ09_DEC11)

- Teacher questionnaire data file (filename: INT_SCQ09_Dec11)

- Home questionnaire data file (filename: INT_PAR09_DEC11

- School questionnaire data file (filename: INT_SCQ09_Dec11)

Estos conjuntos de datos están disponibles en la página web de la OCDE (http://www.oecd.org/pisa/data/pisa2009database-downloadabledata) 
de los conjuntos de datos. En la última columna se recogen las preguntas propiamente dichas.

Tabla 44. Presencia de las bibliotecas en el estudio PISA $2009^{102}$

\begin{tabular}{|c|c|c|c|}
\hline Estudio & Cuestionario & $\begin{array}{l}\text { Código de } \\
\text { pregunta }\end{array}$ & Pregunta \\
\hline $\begin{array}{l}\text { PISA } \\
2009\end{array}$ & $\begin{array}{l}\text { Student } \\
\text { questionnaire }\end{array}$ & ST24Q07 & $\begin{array}{l}\text { How much do you agree or disagree with these } \\
\text { statements about reading? ... } \\
\text { g) I enjoy going to a bookstore or a library } \\
\text { (Strongly disagree / Disagree / Agree / Strongly } \\
\text { agree) }\end{array}$ \\
\hline $\begin{array}{l}\text { PISA } \\
2009\end{array}$ & $\begin{array}{l}\text { Student } \\
\text { questionnaire }\end{array}$ & $\begin{array}{l}\text { ST39Q01- } \\
\text { Q07 }\end{array}$ & $\begin{array}{l}\text { How often do you visit a library for the } \\
\text { following activities? } \\
\text { (Never / A few times a year / About once a } \\
\text { month / Several times a month / Several times a } \\
\text { week) } \\
\text { a) Borrow books to read for pleasure } \\
\text { b) Borrow books for school work } \\
\text { c)Work on homework, course assignments or } \\
\text { research papers } \\
\text { d) Read magazines or newspapers } \\
\text { e) Read books for fun } \\
\text { f) Learn about things that are not course- } \\
\text { related, such as sports, hobbies, people or music } \\
\text { g) Use the Internet }\end{array}$ \\
\hline $\begin{array}{l}\text { PISA } \\
2009\end{array}$ & $\begin{array}{l}\text { Student } \\
\text { questionnaire }\end{array}$ & ST40Q01 & $\begin{array}{l}\text { Does your school have a <school library>? } \\
\text { (Yes/No) }\end{array}$ \\
\hline $\begin{array}{l}\text { PISA } \\
2009\end{array}$ & $\begin{array}{l}\text { Parent } \\
\text { questionnaire }\end{array}$ & PA06Q04 & $\begin{array}{l}\text { How much do you agree or disagree with these } \\
\text { statements about reading? ... } \\
\text { d) I enjoy going to a bookstore or a library } \\
\text { (Strongly disagree / Disagree / Agree / Strongly } \\
\text { agree) }\end{array}$ \\
\hline PISA & Parent & PA08Q06 & How often do you or someone else in your \\
\hline
\end{tabular}

102 Esta tabla recoge la versión internacional de los cuestionarios del estudio PISA 2009, disponibles en: http://www.oecd.org/pisa/data/pisa2009database-downloadabledata.htm 


\begin{tabular}{|c|c|c|c|}
\hline 2009 & questionnaire & & $\begin{array}{l}\text { home do the following things with your child?... } \\
\text { f) Go to a bookstore or library with your child } \\
\text { (Never or hardly ever /Once or twice a month } \\
\text { /Once or twice a week / Every day or almost every } \\
\text { day) }\end{array}$ \\
\hline $\begin{array}{l}\text { PISA } \\
2009\end{array}$ & $\begin{array}{l}\text { Parent } \\
\text { questionnaire }\end{array}$ & PA15Q05 & $\begin{array}{l}\text { The last <academic year>, have you } \\
\text { participated in any of the following school-related } \\
\text { activities? ... } \\
\text { e) Volunteer in the school library or media } \\
\text { centre (Yes/No) }\end{array}$ \\
\hline $\begin{array}{l}\text { PISA } \\
2009\end{array}$ & $\begin{array}{l}\text { School } \\
\text { questionnaire }\end{array}$ & SC11Q05 & $\begin{array}{l}\text { Is your school's capacity to provide instruction } \\
\text { hindered by any of the following issues? ... } \\
\text { e) A lack of library staff } \\
\text { (Not at all /Very little /To some extent/ A lot) }\end{array}$ \\
\hline $\begin{array}{l}\text { PISA } \\
2009\end{array}$ & $\begin{array}{l}\text { School } \\
\text { questionnaire }\end{array}$ & SC11Q12 & $\begin{array}{l}\text { Is your school's capacity to provide instruction } \\
\text { hindered by any of the following issues? ... } \\
\text { I) Shortage or inadequacy of library materials } \\
\text { (Not at all /Very little /To some extent/ A lot) }\end{array}$ \\
\hline $\begin{array}{l}\text { PISA } \\
2009\end{array}$ & $\begin{array}{l}\text { School } \\
\text { questionnaire }\end{array}$ & SC13Q12 & $\begin{array}{l}\text { This academic year, which of the following } \\
\text { activities does your school offer to students in the } \\
<\text { national modal grade for } 15 \text {-years-olds >? ... } \\
\text { l) Collaboration with local libraries (Yes/No) }\end{array}$ \\
\hline
\end{tabular}

El trabajo con los conjuntos de datos PISA 2009 ha comenzado con la descarga de los ficheros que se encuentran disponibles en la página web de la OCDE ${ }^{103}$. Posteriormente se ha realizado la extracción de datos correspondientes a España, seleccionando en los ficheros la variable "país" y el código 724 que identifica a España.

Para un correcto tratamiento de los archivos y su análisis e interpretación, se han seguido los procedimientos establecidos en la documentación técnica específica de la OCDE (Organización para la Cooperación y el Desarrollo Económicos, 2012, pp. 396402). Para la realización de los análisis se ha utilizado el programa IEA IDB Analyzer descargable desde la página web de la IEA.

\footnotetext{
${ }^{103}$ Los datos se encuentran disponibles en: http://www.oecd.org/pisa/data/
} 
A continuación se ha procedido a identificar las variables disponibles para realizar los posteriores análisis. Nos detenemos en cada una de ellas.

\subsubsection{Selección de variables para el análisis cuantitativo con los datos PISA 2009}

\subsubsection{Variable dependiente: rendimiento del alumnado en competencia lectora general}

Nuestro análisis se ha basado en una variable dependiente numérica y varias variables explicativas, todas ellas de tipo cualitativo y dicotómicas, salvo la variable 2 , que es numérica como se verá a continuación.

La variable dependiente es la puntuación media obtenida por el alumnado español en la prueba de competencia lectora de la evaluación internacional PISA 2009. Como se muestra en la Tabla 45, el alumnado español alcanzó 481 puntos $^{104}$ (siendo la media de los países de la OCDE =493) con una desviación típica de 87,51.

Tabla 45. PISA 2009. Puntuación media obtenida por el alumnado español en la prueba de competencia lectora

Average for PVREAD by CNT

Sum of

Country code $\quad N$ of Sum of $\quad$ of

3-character Sum of W FSTU

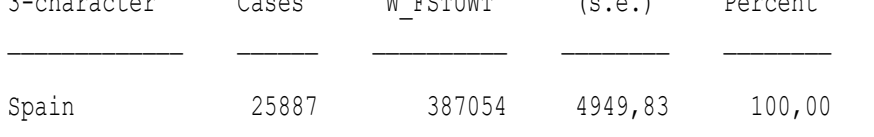

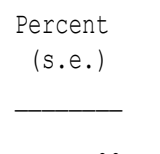

, 00

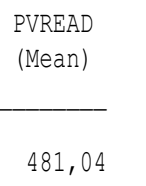

PVREA

(s.e.) Std.Dev

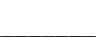

2,02
Std. Dev.

(s.e.)

87,51

Del mismo modo que sucedía con el alumnado de educación primaria, la varianza del dato de puntuación en competencia lectora del alumnado de educación secundaria es un problema multidimensional ${ }^{105}$. Entre los factores que explican esta

${ }^{104}$ En PISA 2009 se establecieron seis niveles de rendimiento: Nivel 6: más de 698,32. Nivel 5 mayor que 625,61 y menor o igual que 698,32 . Nivel 4 : mayor que 552,89 y menor o igual que 625,61 . Nivel 3 : mayor que 480,18 y menor o igual que 552,89 . Nivel 2 : mayor que 407,47 y menor o igual que 480,18. Nivel 1a mayor que 334,75 y menor o igual que 407,47 . Nivel 1 b 262,04 y menor o igual que 334,75 (Organización para la Cooperación y el Desarrollo Económicos, 2012, p. 266).

105 Entre los factores asociados al rendimiento en competencia lectora del alumnado español, PISA 2009 destacó los siguientes: sexo (las chicas alcanzaron 29 puntos más que los chicos); condición de inmigrante (el alumnado nativo alcanzó 56 puntos de ventaja sobre el inmigrante); ocupación y nivel de estudios del padre y de la madre (se registró una diferencia de 60 puntos entre el alumnado procedente de familias con ocupaciones de alta cualificación y el procedente de familias con ocupaciones de baja 
varianza, en este análisis nos hemos centrado en el posible efecto de la biblioteca escolar, probando la influencia de los siguientes factores (variables explicativas) sobre el rendimiento del alumnado:

\subsubsection{Variable explicativa 1: el centro educativo tiene biblioteca escolar (sí/no)}

En PISA 2009 se preguntó al alumnado si su escuela disponía o no de biblioteca. En España, el 95,57 \% respondió que sí disponía de biblioteca en su centro educativo ${ }^{106}$. A partir de esta variable dicotómica hemos contrastado las medias en competencia lectora de dos grupos de alumnado: aquéllos que disponen de biblioteca integrada en su centro educativo y los que carecen de este recurso en su centro.

cualificación; y una diferencia de 100 puntos entre el alumnado procedente de familias con estudios superiores y el procedente de familias con estudios básicos) (Instituto de Evaluación, 2010).

Entre los factores que guardaban relación con la competencia lectora en PISA 2015 se confirmaron diferencias significativas por sexo en todos los países (20 puntos más a favor de las chicas en España); por condición de inmigrante (40 puntos de ventaja los nativos españoles respecto de los inmigrantes); por el nivel de estudios del padre y de la madre (siendo éste el factor asociado que más correlaciona con los resultados del alumnado de educación secundaria tanto en España como en el resto de los países evaluados); tener conexión a Internet en casa (el $8 \%$ del alumnado que no tiene ordenador coincide con el que alcanza peores resultados en su rendimiento), y el número de libros en el hogar (supera en 112 puntos en lectura el alumnado que dice tener más de 200 libros en casa) (Instituto Nacional de Evaluación Educativa, 2016).

${ }^{106}$ Las estadísticas oficiales sobre bibliotecas escolares para el curso 2015-2016 muestran que:

- $\quad$ El 92,3 \% de los centros públicos de educación secundaria y formación profesional tienen una biblioteca de centro en funcionamiento. El 3,7 \% de los centros tiene una biblioteca circunstancialmente cerrada y en el 3,9\% no hay biblioteca.

- Con respecto a los centros privados, la estadística no diferencia entre centros por niveles de enseñanza. Tomando el conjunto de los centros privados de educación primaria y secundaria, el $82,9 \%$ de los centros tiene una biblioteca de centro en funcionamiento; el 7,6 \% de los centros tiene una biblioteca circunstancialmente cerrada y en el 9,5 \% no hay biblioteca.

- En los centros en los que no hay biblioteca, suele ser frecuente que este servicio se cubra parcialmente por bibliotecas de departamento o de aula o mediante acuerdos con bibliotecas públicas.

- $\quad$ En el 83,5 \% de los centros públicos de educación secundaria y formación profesional existe un proyecto integrado de biblioteca. Dentro del conjunto de los centros privados de educación primaria y secundaria, un $68,9 \%$ cuenta con un proyecto integrado de biblioteca. 


\subsubsection{Variable explicativa 2: intensidad con la que el alumnado hace uso de la biblioteca}

En PISA 2009, esta variable se corresponde con un valor que sintetiza los valores alcanzados por siete indicadores ${ }^{107}: 1$. La frecuencia con la que el alumnado toma en préstamo libros (para lectura por ocio) de su biblioteca; 2 . La frecuencia con la que el alumnado toma en préstamo libros (para estudio) de su biblioteca; 3. La frecuencia con la que visita la biblioteca para hacer deberes; 4. La frecuencia con la que visita la biblioteca para leer revistas o periódicos; 5 . La frecuencia con la que visita la biblioteca para leer por diversión; 6. La frecuencia con la que visita la biblioteca para aprender sobre materias no lectivas (aficiones, pasatiempos, etc.); 7. La frecuencia con la que visita la biblioteca para usar Internet. Con esta variable numérica hemos analizado si existe alguna asociación entre los factores intensidad de uso de la biblioteca escolar y nivel de competencia lectora alcanzada por el alumnado.

España alcanzó un valor medio de -0,29, con una desviación típica de 1,04, en la variable nivel de uso de las bibliotecas. Este valor queda bastante por debajo de la media del conjunto de los países participantes en PISA 2009, que alcanzó el valor de 0,41 , con una desviación típica de 1,04 , y siendo los valores mínimo $-1,85$ y máximo 3,99 .

Las variables explicativas 3 a 9 que se presentan a continuación, aportan información sobre la frecuencia con la que el alumnado español hace uso de su biblioteca escolar, diferenciando por los distintos recursos que utiliza o según la motivación que le lleva a acudir a su biblioteca.

\subsubsection{Variable explicativa 3: frecuencia con la que el alumnado acude a la biblioteca para tomar en préstamo libros para leer por ocio}

Como se observa en la Tabla 46, un $84,8 \%$ del alumnado dijo que no acudía nunca o casi nunca (algunas veces al año) a la biblioteca para tomar libros en préstamo para leer por ocio. Sólo un 9,6 \% lo hacía una vez al mes y un 5,6 \% lo hacía varias veces a la semana o al mes. Para trabajar con esta variable la hemos convertido en dicotómica, diferenciando por un lado el alumnado que alcanza una frecuencia de al menos, varias veces al año, mensual o semanalmente, y, por otro lado, los que no toman nunca

\footnotetext{
107 El estudio PISA 2009 sintetiza la información recogida en estos siete parámetros bajo la variable numérica "LIBUSE", con la que se mide la frecuencia con la que el alumnado utiliza la biblioteca escolar y sus recursos (Organización para la Cooperación y el Desarrollo Económicos, 2012, pp. 299-300).
} 
libros en préstamo para leer por ocio. Posteriormente se han contrastado las medias en competencia lectora de ambos grupos.

Tabla 46. PISA 2009. Frecuencia con la que el alumnado español acude a la biblioteca para tomar libros en préstamo para leer por placer

\begin{tabular}{|ll|r|r|r|r|}
\hline & & Frecuencia & Porcentaje & Porcentaje válido & Porcentaje acumulado \\
\hline Válido & Never & 229454 & 59,3 & 60,1 & 60,1 \\
& A few times a year & 94490 & 24,4 & 24,7 & 84,8 \\
& About once a month & 36560 & 9,4 & 9,6 & 94,4 \\
& Several times a month & 17185 & 4,4 & 4,5 & 98,9 \\
& Several times a week & 4120 & 1,1 & 1,1 & 100,0 \\
& Total & 381809 & 98,6 & 100,0 & \\
Perdidos & 1541 &, 4 & & \\
& N/A & 3704 & 1,0 & & \\
& Miss & 5245 & 1,4 & & \\
& Total & 387054 & 100,0 & & \\
Total & & & & & \\
& & & & & \\
\end{tabular}

\subsubsection{Variable explicativa 4: frecuencia con la que el alumnado acude a la biblioteca para tomar en préstamo libros para hacer trabajos de clase}

Como se observa en la Tabla 47, un 77,9 \% del alumnado dijo que no acudía nunca o casi nunca (algunas veces al año) a la biblioteca para tomar en préstamo libros de estudio (manuales, etc.) para hacer trabajos de clase. Sólo un 14 \% lo hacía una vez al mes y un $8,1 \%$ lo hacía varias veces a la semana o al mes.

Para trabajar con esta variable la hemos convertido en dicotómica, diferenciando por un lado el alumnado que alcanza una frecuencia de al menos, varias veces al año, mensual o semanalmente, $y$, por otro lado, el que no toma nunca libros en préstamo para hacer trabajos de clase. Posteriormente se han contrastado las medias en competencia lectora de ambos grupos.

Tabla 47. PISA 2009. Frecuencia con la que el alumnado español acude a la biblioteca para tomar libros en préstamo para hacer trabajos de clase

\begin{tabular}{|l|r|r|r|r|}
\hline & Frecuencia & Porcentaje & Porcentaje válido & $\begin{array}{r}\text { Porcentaje } \\
\text { acumulado }\end{array}$ \\
\hline Válido Never & 181569 & 46,9 & 47,6 & 47,6 \\
\hline
\end{tabular}




\begin{tabular}{|c|c|c|c|c|c|}
\hline & A few times a year & 115474 & 29,8 & 30.3 & 779 \\
\hline & About once a month & 53543 & 13,8 & 14,0 & 91,9 \\
\hline & Several times a month & 26336 & 6,8 & 6,9 & 98,8 \\
\hline & Several times a week & 4504 & 1,2 & 1,2 & 100,0 \\
\hline & Total & 381427 & 98,5 & 100,0 & \\
\hline Perdidos & N/A & 1541 & , 4 & & \\
\hline & Miss & 4087 & 1,1 & & \\
\hline & Total & 5628 & 1,5 & & \\
\hline Total & & 387054 & 100,0 & & \\
\hline
\end{tabular}

\subsubsection{Variable explicativa 5: frecuencia con la que el alumnado acude a la biblioteca para realizar trabajos o investigaciones}

Según muestra la Tabla 48, un 69,4 \% del alumnado dijo que no acudía nunca o casi nunca (algunas veces al año) a la biblioteca para hacer deberes o investigaciones para la clase. Sólo un 13,2 \% lo hacía una vez al mes y un 17,5 \% lo hacía varias veces a la semana o al mes.

Para trabajar con esta variable la hemos convertido en dicotómica, diferenciando por un lado el alumnado que acude a la biblioteca para realizar trabajos o investigaciones con una frecuencia de al menos, varias veces al año, mensual o semanalmente, $y$, por otro lado, el que no lo hace nunca. Posteriormente se han contrastado las medias en competencia lectora de ambos grupos.

Tabla 48. PISA 2009. Frecuencia con la que el alumnado español acude a la biblioteca para realizar trabajos o investigaciones

\begin{tabular}{|ll|l|l|l|l|}
\hline & Frecuencia & Porcentaje & Porcentaje válido & $\begin{array}{l}\text { Porcentaje } \\
\text { acumulado }\end{array}$ \\
\hline Válido & Never & 179547 & 46,4 & 47,1 & 47,1 \\
& A few times a year & 84883 & 21,9 & 22,3 & 69,4 \\
About once a month & 50360 & 13,0 & 13,2 & 82,6 \\
Several times a month & 43280 & 11,2 & 11,4 & 93,9
\end{tabular}




\begin{tabular}{|ll|l|l|l|l|}
\hline & Several times a week & 23154 & 6,0 & 6,1 & 100,0 \\
& Total & 381224 & 98,5 & 100,0 & \\
& Nerdidos & 1541 &, 4 & & \\
& Miss & 4289 & 1,1 & & \\
& Total & 5830 & 1,5 & & \\
\hline
\end{tabular}

\subsubsection{Variable explicativa 6: frecuencia con la que el alumnado acude a la biblioteca para leer periódicos o revistas}

Como se observa en la Tabla 49, un 81,8 \% del alumnado dijo que no acudía nunca o casi nunca (algunas veces al año) a la biblioteca para leer revistas o periódicos. Sólo un $7,1 \%$ lo hacía una vez al mes y un 11,1 \% lo hacía varias veces a la semana o al mes. Para trabajar con esta variable la hemos convertido en dicotómica, diferenciando por un lado el alumnado que acude a la biblioteca para leer periódicos o revistas con una frecuencia de al menos, varias veces al año, mensual o semanalmente, $y$, por otro lado, el que no lo hace nunca. Posteriormente se han contrastado las medias en competencia lectora de ambos grupos.

Tabla 49. PISA 2009. Frecuencia con la que el alumnado español acude a la biblioteca para leer revistas o periódicos

\begin{tabular}{|c|c|c|c|c|c|}
\hline & & Frecuencia & Porcentaje & Porcentaje válido & $\begin{array}{l}\text { Porcentaje } \\
\text { acumulado }\end{array}$ \\
\hline \multirow[t]{6}{*}{ Válido } & Never & 263764 & 68,1 & 69,3 & 69,3 \\
\hline & A few times a year & 47436 & 12,3 & 12,5 & 81,8 \\
\hline & About once a month & 26842 & 6,9 & 7,1 & 88,8 \\
\hline & Several times a month & 25275 & 6,5 & 6,6 & 95,5 \\
\hline & Several times a week & 17172 & 4,4 & 4,5 & 100,0 \\
\hline & Total & 380489 & 98,3 & 100,0 & \\
\hline \multirow[t]{2}{*}{ Perdidos } & N/A & 1541 & 4 & & \\
\hline & Miss & 5024 & 1,3 & & \\
\hline
\end{tabular}




\begin{tabular}{|l|r|r|r|} 
& 6565 & 1,7 & \\
Total & 387054 & 100,0 & \\
\hline
\end{tabular}

\subsubsection{Variable explicativa 7: frecuencia con la que el alumnado acude a la biblioteca para leer por ocio}

Como se ve en la Tabla 50, un $82,5 \%$ del alumnado dijo que no acudía nunca o casi nunca (algunas veces al año) a la biblioteca para leer por diversión. Sólo un 8,2 \% lo hacía una vez al mes y un 9,4 \% lo hacía varias veces a la semana o al mes. Para trabajar con esta variable la hemos convertido en dicotómica, diferenciando por un lado el alumnado que acude a la biblioteca para leer por ocio con una frecuencia de al menos, varias veces al año, mensual o semanalmente, $y$, por otro lado, el que no lo hace nunca. Posteriormente se han contrastado las medias en competencia lectora de ambos grupos.

Tabla 50. PISA 2009. Frecuencia con la que el alumnado español acude a la biblioteca para leer libros por ocio o diversión

\begin{tabular}{|c|c|c|c|c|c|}
\hline & & Frecuencia & Porcentaje & Porcentaje válido & $\begin{array}{l}\text { Porcentaje } \\
\text { acumulado }\end{array}$ \\
\hline \multirow[t]{6}{*}{ Válido } & Never & 249794 & 64,5 & 65,8 & 65,8 \\
\hline & A few times a year & 63300 & 16,4 & 16,7 & 82,4 \\
\hline & About once a month & 31069 & 8,0 & 8,2 & 90,6 \\
\hline & Several times a month & 23938 & 6,2 & 6,3 & 96,9 \\
\hline & Several times a week & 11737 & 3,0 & 3,1 & 100,0 \\
\hline & Total & 379837 & 98,1 & 100,0 & \\
\hline \multirow[t]{3}{*}{ Perdidos } & N/A & 1541 & 4 & & \\
\hline & Miss & 5676 & 1,5 & & \\
\hline & Total & 7217 & 1,9 & & \\
\hline Total & & 387054 & 100,0 & & \\
\hline
\end{tabular}




\subsubsection{Variable explicativa 8: frecuencia con la que el alumnado acude a la biblioteca para informarse sobre contenidos nuevos que no se explican en clase, como deportes, aficiones o música}

Como se ve en la Tabla 51, un 77,7 \% del alumnado dijo que no acudía nunca o casi nunca (algunas veces al año) a la biblioteca para aprender sobre materias no lectivas (aficiones, pasatiempos, etc.). Sólo un 7,9 \% lo hacía una vez al mes y un 14,4 \% lo hacía varias veces a la semana o al mes. Para trabajar con esta variable la hemos convertido en dicotómica, diferenciando por un lado el alumnado que acude a la biblioteca para informarse sobre contenidos nuevos que no se explican en clase con una frecuencia de al menos, varias veces al año, mensual o semanalmente, $y$, por otro lado, el que no lo hace nunca. Posteriormente se han contrastado las medias en competencia lectora de ambos grupos.

Tabla 51. PISA 2009. Frecuencia con la que el alumnado español acude a la biblioteca para informarse sobre materias que no se explican en clase

\begin{tabular}{|c|c|c|c|c|c|}
\hline & & Frecuencia & Porcentaje & Porcentaje válido & $\begin{array}{l}\text { Porcentaje } \\
\text { acumulado }\end{array}$ \\
\hline \multirow[t]{6}{*}{ Válido } & Never & 234275 & 60,5 & 61,6 & 61,6 \\
\hline & A few times a year & 61413 & 15,9 & 16,1 & 77,7 \\
\hline & About once a month & 30215 & 7,8 & 7,9 & 85,6 \\
\hline & Several times a month & 29743 & 7,7 & 7,8 & 93,4 \\
\hline & Several times a week & 24957 & 6,4 & 6,6 & 100,0 \\
\hline & Total & 380603 & 98,3 & 100,0 & \\
\hline \multirow[t]{3}{*}{ Perdidos } & N/A & 1541 & 4 & & \\
\hline & Miss & 4910 & 1,3 & & \\
\hline & Total & 6452 & 1,7 & & \\
\hline Total & & 387054 & 100,0 & & \\
\hline
\end{tabular}




\subsubsection{Variable explicativa 9: frecuencia con la que el alumnado acude a la biblioteca para usar Internet}

Como se observa en la Tabla 52, un 69,2 \% del alumnado dijo que no acudía nunca o casi nunca (algunas veces al año) a la biblioteca para hacer uso de Internet. Sólo un 6,7 \% lo hacía una vez al mes y un 24,2 \% lo hacía varias veces a la semana o al mes. Hay que decir que, entre todos los motivos para visitar la biblioteca, éste es el más frecuente, seguido de hacer tareas escolares ${ }^{108}$.

Para trabajar con esta variable la hemos convertido en dicotómica, diferenciando por un lado el alumnado que acude a la biblioteca para usar Internet con una frecuencia de al menos, varias veces al año, mensual o semanalmente, y, por otro lado, el que no lo hace nunca. Posteriormente se han contrastado las medias en competencia lectora de ambos grupos.

108 Los datos más recientes con relación a los usos de la biblioteca escolar en educación secundaria son los que recogen las estadísticas sobre bibliotecas escolares del Ministerio de Educación para el curso 2015-2016. Resumimos a continuación los más relevantes:

- El préstamo de libros sigue siendo una de las principales actividades de las bibliotecas escolares, incluyendo préstamos directos o transmisiones por tiempo limitado de libros electrónicos u otros documentos digitales de la colección. Solo el 5,8 \% de los centros públicos de educación secundaria y formación profesional registraron cero préstamos, y el 26,2 \% de los centros registró 500 o más préstamos.

- Entre los centros privados de educación primaria y secundaria, el 20,3 \% registró cero préstamos y el 22,5\% registró 500 o más préstamos.

- Con relación a la organización de otro tipo de actividades, en los centros públicos de educación secundaria y formación profesional se registran las siguientes: actividades de fomento de la lectura (86,3\% de los centros); actividades culturales y encuentros literarios $(64,7 \%$ de los centros); de enseñanza y aprendizaje para apoyar el desarrollo del currículo (60 \% de los centros); formación de usuarios (45,5 \% de los centros); conferencias y seminarios (34 \% de los centros); actividades relacionadas con el tratamiento de la información y competencia digital (31 \% de los centros); actividades con la participación de las familias (23,7 \% de los centros); actividades específicas de atención a la diversidad (20,8 \% de los centros) y otro tipo de actividades (39,3\% de los centros).

- Con relación a la organización de otro tipo de actividades, en los centros privados de educación primaria y secundaria se registran las siguientes: actividades de fomento de la lectura (78 \% de los centros); de enseñanza y aprendizaje para apoyar el desarrollo del currículo (52,7 \% de los centros); actividades culturales y encuentros literarios (38,9\% de los centros); formación de usuarios (24,2 \% de los centros); actividades con la participación de las familias (23\% de los centros); actividades relacionadas con el tratamiento de la información y competencia digital (22,9 \% de los centros); actividades específicas de atención a la diversidad $(22,1 \%$ de los centros); conferencias y seminarios (19\% de los centros); y otro tipo de actividades (30,1 \% de los centros). 
Tabla 52. PISA 2009. Frecuencia con la que el alumnado español acude a la biblioteca para usar Internet

\begin{tabular}{|ll|r|r|r|r|}
\hline & Frecuencia & Porcentaje & Porcentaje válido & $\begin{array}{r}\text { Porcentaje } \\
\text { acumulado }\end{array}$ \\
\hline Válido $\quad$ Never & 211596 & 54,7 & 55,6 & 55,6 \\
& A few times a year & 51618 & 13,3 & 13,6 & 69,1 \\
& About once a month & 25574 & 6,6 & 6,7 & 75,8 \\
& Several times a month & 33616 & 8,7 & 8,8 & 84,6 \\
& Several times a week & 58477 & 15,1 & 15,4 & 100,0 \\
& Total & 380881 & 98,4 & 100,0 & \\
Perdidos $\quad$ N/A & 1541 &, 4 & & \\
& Miss & 4632 & 1,2 & & \\
& Total & 6173 & 1,6 & & \\
\hline
\end{tabular}

\subsubsection{Variable explicativa 10: actitud (positiva/negativa) del alumnado hacia las bibliotecas}

En PISA 2009 se preguntó al alumnado si disfrutaba o no cuando visitaba una biblioteca o una librería, dando varias opciones de respuesta según una escala Likert. Para el análisis hemos procedido a convertir esta variable en dicotómica, agrupando por un lado el alumnado que dice estar de acuerdo o muy de acuerdo con esta afirmación, y, por otro lado, el alumnado que dice estar en desacuerdo o muy en desacuerdo. Como se observa en la Tabla 53, sólo el 30,4 \% del alumnado reconoció que disfrutaba de la experiencia de visitar bibliotecas o librerías.

Con esta variable dicotómica hemos contrastado las medias en competencia lectora de dos grupos de alumnado: el que tiene una actitud positiva hacia las bibliotecas y el que no tiene esta actitud positiva.

Tabla 53. PISA 2009. Opinión del alumnado español sobre si disfruta cuando va a una biblioteca o a una librería 


\begin{tabular}{|ll|r|r|r|r|}
\hline Válido & $\begin{array}{l}\text { En desacuerdo o muy } \\
\text { en desacuerdo } \\
\text { De acuerdo o muy de } \\
\text { acuerdo } \\
\text { Total }\end{array}$ & 116291 & 30,0 & 69,7 & 69,6 \\
Perdidos & 382013 & 98,7 & 100,0 & 100,0 \\
Sistema & 5041 & 1,3 & \\
\hline
\end{tabular}

\subsubsection{Hipótesis y procedimiento de análisis}

Una vez explicadas las variables disponibles en los conjuntos de datos para su posterior análisis, hemos comprobado que con estas variables podíamos responder parcialmente a las preguntas 1 y 2 de la investigación:

En primer lugar, se ha respondido a la cuestión sobre si tiene alguna influencia el hecho de tener biblioteca en el centro educativo sobre el rendimiento académico en competencia lectora del alumnado. No obstante, con los ficheros de datos disponibles, no se ha podido evaluar este efecto diferenciando entre diferentes dimensiones de la competencia lectora general.

En segundo lugar, con estas variables se ha respondido a la pregunta 2, sobre cómo influyen los distintos recursos, actividades o prácticas vinculadas a la biblioteca sobre el desarrollo de la competencia lectora. Asimismo, se ha obtenido información sobre la relación entre tener una actitud positiva respecto a la biblioteca y el nivel alcanzado en competencia lectora.

A partir de las variables disponibles, y ligadas a las preguntas de investigación 1 y 2 , se han probado las siguientes hipótesis:

Hipótesis 1 (H1). El alumnado que dispone de una biblioteca integrada en su centro educativo obtiene mejores resultados académicos en competencia lectora, si se compara con el alumnado que no dispone de biblioteca escolar.

Hipótesis 2 (H2). El alumnado que más utiliza la biblioteca escolar obtiene mejores resultados académicos en competencia lectora, comparado con el alumnado que no tiene este hábito.

Hipótesis 3 (H3). El alumnado que acude a la biblioteca para tomar en préstamo libros para leer por ocio obtiene mejores resultados académicos en competencia lectora, si se compara con el alumnado que no tiene este hábito. 
Hipótesis 4 (H4). El alumnado que acude a la biblioteca para tomar en préstamo libros para hacer trabajos de clase obtiene mejores resultados académicos en competencia lectora, si se compara con el alumnado que no tiene este hábito.

Hipótesis 5 (H5). El alumnado que acude a la biblioteca para realizar trabajos o investigaciones obtiene mejores resultados académicos en competencia lectora, si se compara con el alumnado que no tiene este hábito.

Hipótesis 6 (H6). El alumnado que acude a la biblioteca para leer periódicos o revistas obtiene mejores resultados académicos en competencia lectora, si se compara con el alumnado que no tiene este hábito.

Hipótesis 7 (H7). El alumnado que acude a la biblioteca para leer por ocio obtiene mejores resultados académicos en competencia lectora, si se compara con el alumnado que no tiene este hábito.

Hipótesis 8 (H8). El alumnado que acude a la biblioteca para informarse sobre contenidos nuevos que no se explican en clase, como deportes, aficiones o música obtiene mejores resultados académicos en competencia lectora, si se compara con el alumnado que no tiene este hábito.

Hipótesis 9 (H9). El alumnado que acude a la biblioteca para usar Internet obtiene mejores resultados académicos en competencia lectora, si se compara con el alumnado que no tiene este hábito

Hipótesis 10 (H10). El alumnado que tiene una actitud más positiva hacia las bibliotecas obtiene mejores resultados académicos en competencia lectora, comparado con el alumnado que tiene una actitud menos positiva respecto de las bibliotecas.

Para el análisis se han realizado las siguientes pruebas estadísticas:

En las hipótesis $\mathrm{H} 1, \mathrm{H} 3, \mathrm{H} 4, \mathrm{H} 5, \mathrm{H} 6, \mathrm{H} 7, \mathrm{H} 8, \mathrm{H} 9$ y $\mathrm{H} 10$ se ha trabajado con una variable dependiente numérica y una variable independiente dicotómica. Como prueba estadística se ha utilizado una prueba de contraste de hipótesis con comparación de medias para muestras independientes de la misma población. Se han comparado las medias de los resultados obtenidos por los dos grupos objeto de comparación en cada caso, tomando como prueba de contraste el valor $\mathrm{t}$, con un valor crítico $t=1,96$, trabajando con un nivel de confianza del $95 \%$ y un nivel de significación 0,05 .

En la hipótesis $2 \mathrm{H} 2$ se ha trabajado con dos variables numéricas. Como prueba estadística se ha utilizado el coeficiente de correlación $r$ de Pearson para interpretar la asociación entre las dos variables, y, a partir de este coeficiente, se ha calculado el coeficiente de determinación para evaluar la proporción de varianza que comparten ambas variables. 


\subsubsection{Resultados}

A continuación, se ha analizado la influencia de cada una de las variables explicativas sobre la variable dependiente. Se han contrastado así las hipótesis de las que partimos, para verificar su validez en función del nivel de significación estadística:

\subsubsection{Comprobación de la H1. El alumnado que dispone de biblioteca integrada en su centro educativo obtiene mejores resultados académicos en competencia lectora, si se compara con el alumnado que no dispone de biblioteca escolar}

Como se muestra en la Tabla 54, el resultado fue notablemente superior para el alumnado con biblioteca, que alcanzó una puntuación media de 485,06 (error estándar 1,98), mientras que el alumnado sin biblioteca alcanzó una puntuación media de 472,11 (error estándar 5,28).

El test de significación muestra que esta diferencia de 12,95 es estadísticamente significativa con un nivel de confianza del $95 \%$ ( $t>1,96)$.

Tabla 54. PISA 2009. Comparación de resultados medios en competencia lectora del alumnado español, introduciendo la variable "el alumnado tiene biblioteca en su centro educativo". Salida de ordenador utilizando el programa IEA IDB Analyzer - SPSS

Average for PVREAD by CNT ST40001

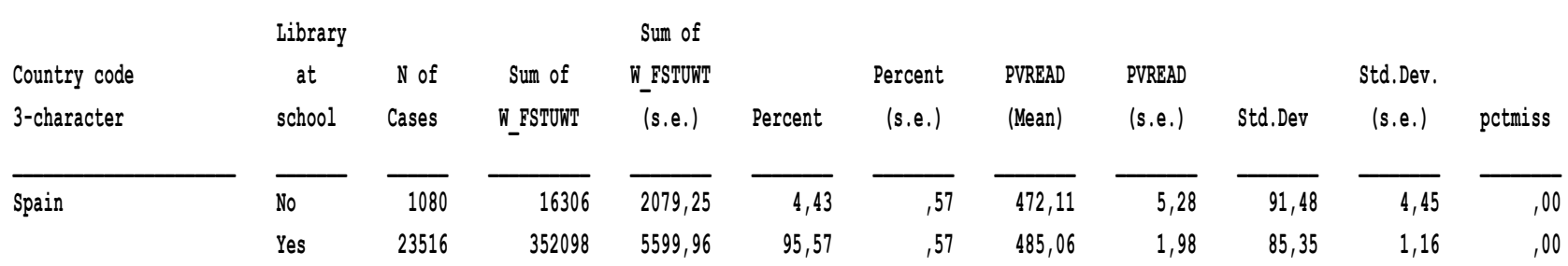

Regression Coefficients

\begin{tabular}{|c|c|c|c|c|c|c|c|}
\hline CNT & Variable & $\begin{array}{l}\text { Regression } \\
\text { Coefficient }\end{array}$ & $\begin{array}{c}\text { Regression } \\
\text { Coefficient } \\
\text { (s.e.) }\end{array}$ & $\begin{array}{l}\text { Regression } \\
\text { Coefficient } \\
\text { (t-value) }\end{array}$ & $\begin{array}{l}\text { Stndrdzd. } \\
\text { Coefficient }\end{array}$ & $\begin{array}{l}\text { Stndrdzd. } \\
\text { Coefficient } \\
\text { (s.e.) }\end{array}$ & $\begin{array}{l}\text { Stndrdzd. } \\
\text { Coefficient } \\
\text { (t-value) }\end{array}$ \\
\hline \multirow[t]{2}{*}{ Spain } & (CONSTANT) & 472,11 & 5,28 & 89,36 & . & . & . \\
\hline & $\mathrm{ST} 40 \mathrm{Q} 01 \mathrm{D} 2$ & 12,95 & 4,98 & 2,60 &, 03 & , 01 & 2,78 \\
\hline
\end{tabular}




\subsubsection{Comprobación de la H2. El alumnado que más utiliza la biblioteca escolar obtiene mejores resultados académicos en competencia lectora, comparado con el alumnado que no tiene este hábito}

Para la comprobación de esta hipótesis se ha realizado un análisis de correlación entre dos variables numéricas: el resultado medio en competencia lectora y la variable "frecuencia de uso de la biblioteca - LIBUSE". Como se muestra en la Tabla 55, se produce una asociación estadísticamente significativa $[z=0,09 \sqrt{N}-1=14,51]$ y muy débil entre las dos variables $(r=-0,09)$. Como señala Morales Vallejo (2008, p. 148), cuando se trabaja con muestras grandes como es el caso, se suelen encontrar correlaciones estadísticamente significativas pero muy pequeñas. Aquí, al trabajar con una variable que, en palabras de Morales Vallejo (2008) no es "pura", sino que integra varios parámetros, es probable que, como señala el autor, se dé un caso de correlación “contaminada por otras variables que no tenemos en cuenta”(p. 148).

El coeficiente de determinación $r_{x, y}{ }^{2}=0,0081$, por lo que se concluye que solamente un $0,81 \%$ del rendimiento en competencia lectora está asociado a la frecuencia de uso de la biblioteca escolar.

Por otra parte, el sentido negativo de la asociación indicaría un impacto negativo de hacer uso de la biblioteca, es decir: cuanto más uso de haría de ella, peores resultados se observarían. No hemos sabido explicar este resultado, por lo que se hace necesario profundizar sobre los diferentes usos que hace el alumnado de la biblioteca y evaluar cuál es su impacto. A continuación, en las hipótesis H3 a H9 se ha comprobado el efecto que tienen diferentes usos que hace el alumnado de la biblioteca escolar sobre su rendimiento en competencia lectora.

Tabla 55. PISA 2009. Correlación entre la variable del resultado medio en competencia lectora del alumnado español y la variable "frecuencia de uso de la biblioteca". Salida de ordenador utilizando el programa IEA IDB Analyzer-SPSS

Correlation Coefficients

PAGE 1

\begin{tabular}{|c|c|c|c|c|c|}
\hline CNT & variable & $\begin{array}{l}\text { Correlation } \\
\text { with LIBUSE }\end{array}$ & $\begin{array}{c}\text { Correlation } \\
\text { with LIBUSE } \\
\text { (s.e.) }\end{array}$ & $\begin{array}{c}\text { Correlation } \\
\text { with } \\
\text { PV_READ }\end{array}$ & $\begin{array}{c}\text { Correlation } \\
\text { with } \\
\text { PV_READ } \\
\text { (s.e.) }\end{array}$ \\
\hline Spain & $\begin{array}{l}\text { LIBUSE } \\
\text { PV_READ }\end{array}$ & $\begin{array}{l}1,00 \\
-, 09\end{array}$ & $\begin{array}{l}, 00 \\
, 02\end{array}$ & $\begin{array}{l}-, 09 \\
1,00\end{array}$ & $\begin{array}{l}, 02 \\
, 00\end{array}$ \\
\hline
\end{tabular}




\subsubsection{Comprobación de la H3. El alumnado que acude a la biblioteca para tomar en préstamo libros para leer por ocio obtiene mejores resultados académicos en competencia lectora, si se compara con el alumnado que no tiene este hábito.}

Como se puede observar en la Tabla 56, si se comparan los resultados (medias) en competencia lectora teniendo en cuenta la variable "el alumnado acude a la biblioteca para tomar en préstamo libros para leer por ocio", se observa que, el resultado es notablemente superior $(496,70$, error estándar $=2,00$ ) para el alumnado que sí tiene este hábito, comparado con el alumnado que no lo tiene. Éstos alcanzan un resultado de 472,82 (error estándar $=2,53$ ). La diferencia entre ambos grupos de alumnado alcanza un valor medio de 23,88 , y sí es estadísticamente significativa al $95 \%$ de nivel de confianza.

Tabla 56. PISA 2009. Comparación de resultados medios en competencia lectora del alumnado español, introduciendo la variable "el alumnado acude a la biblioteca para tomar en préstamo libros para leer por ocio". Salida de ordenador utilizando el programa IEA IDB Analyzer-SPSS

Average for PVRRAD by CNI ST39001 DOMMY

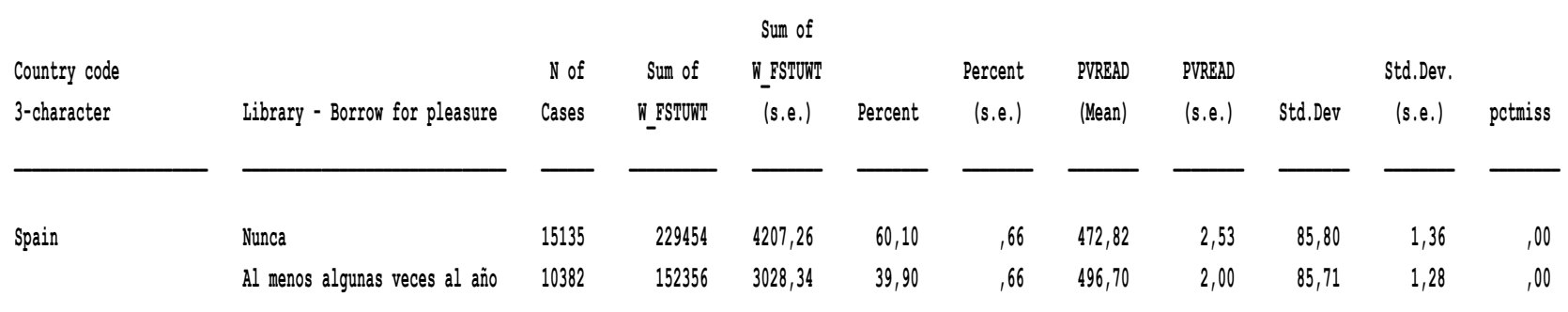

Regression Coefficients

\begin{tabular}{|c|c|c|c|c|c|c|c|}
\hline CNT & Variable & $\begin{array}{l}\text { Regression } \\
\text { Coefficient }\end{array}$ & $\begin{array}{c}\text { Regression } \\
\text { Coefficient } \\
\text { (s.e.) }\end{array}$ & $\begin{array}{l}\text { Regression } \\
\text { Coefficient } \\
\text { (t-value) }\end{array}$ & $\begin{array}{l}\text { Stndrdzd. } \\
\text { Coefficient }\end{array}$ & $\begin{array}{c}\text { Stndrdzd. } \\
\text { Coefficient } \\
\text { (s.e.) }\end{array}$ & $\begin{array}{l}\text { Stndrdzd. } \\
\text { Coefficient } \\
\text { (t-value) }\end{array}$ \\
\hline \multirow[t]{2}{*}{ Spain } & (CONSTANT) & 472,82 & 2,53 & 186,87 & . & . & . \\
\hline & ST39Q01_DUMMY_D2 & 23,88 & 2,44 & 9,77 &, 14 &, 01 & 10,41 \\
\hline
\end{tabular}




\subsubsection{Comprobación de la H4. El alumnado que acude a la biblioteca para tomar en préstamo libros para hacer trabajos de clase obtiene mejores resultados académicos en competencia lectora, si se compara con el alumnado que no tiene este hábito.}

Como se puede observar en la Tabla 57, si se comparan los resultados (medias) en competencia lectora teniendo en cuenta la variable "el alumnado acude a la biblioteca para tomar en préstamo libros para hacer trabajos de clase", se observa que, el resultado es notablemente superior $(486,51$, error estándar $=1,86)$ para el alumnado que sí tiene este hábito, comparado con el alumnado que no lo tiene. Éstos alcanzan un resultado de 478,04 (error estándar $=2,99$ ). La diferencia entre ambos grupos de alumnado alcanza un valor medio de 8,47 , y sí es estadísticamente significativa al $95 \%$ de nivel de confianza.

Tabla 57. PISA 2009. Comparación de resultados medios en competencia lectora del alumnado español, introduciendo la variable "el alumnado acude a la biblioteca para tomar en préstamo libros para hacer trabajos de clase". Salida de ordenador utilizando el programa IEA IDB Analyzer-SPSS

Average for PrRRAD by CVI ST33902 DowMYY

\begin{tabular}{|c|c|c|c|c|c|c|c|c|c|c|c|}
\hline \multirow{3}{*}{$\begin{array}{l}\text { Country code } \\
\text { 3-character }\end{array}$} & \multirow{3}{*}{ Library - Borron for work } & \multicolumn{5}{|c|}{ Sum of } & \multirow{3}{*}{$\begin{array}{l}\text { PVREBD } \\
\text { (Mean) }\end{array}$} & \multirow{3}{*}{$\begin{array}{l}\text { PVRRAD } \\
\text { (s.e.) }\end{array}$} & \multirow{3}{*}{\multicolumn{2}{|c|}{$\begin{array}{cc} & \text { Std. Dev. } \\
\text { Std. Dev } & \text { (s.e.) }\end{array}$}} & \multirow[b]{3}{*}{ petriss } \\
\hline & & $\mathbb{N}$ of & Sun of & NESTOWT? & & Percent & & & & & \\
\hline & & & & (s.e.) & Percent & (s.e.) & & & & & \\
\hline \multirow[t]{2}{*}{ Spain } & Nunca & 12233 & 181569 & 3888,89 & 47,60 &, 82 & 478,04 & 2,99 & 88,33 & 1,75 &, 00 \\
\hline & Al menos algunas veces al año & 13260 & 199858 & 4191,54 & 52,40 &, 82 & 486,51 & 1,86 & 84,59 & 1,07 &, 00 \\
\hline
\end{tabular}

Regression Coefficients

\begin{tabular}{|c|c|c|c|c|c|c|c|}
\hline $\mathrm{CNT}$ & Variable & $\begin{array}{l}\text { Regression } \\
\text { Coefficient }\end{array}$ & $\begin{array}{l}\text { Regression } \\
\text { Coefficient } \\
\text { (s.e.) }\end{array}$ & $\begin{array}{l}\text { Regression } \\
\text { Coefficient } \\
\text { ( } t \text {-value) }\end{array}$ & $\begin{array}{l}\text { Stndrdzd. } \\
\text { Coefficient }\end{array}$ & $\begin{array}{l}\text { Stndrdzd. } \\
\text { Coefficient } \\
\text { (s.e.) }\end{array}$ & $\begin{array}{l}\text { Stndrdzd. } \\
\text { Coefficient } \\
\text { (t-value) }\end{array}$ \\
\hline \multirow[t]{2}{*}{ Spain } & (CONSTANT) & 478,04 & 2,99 & 159,74 & . & . & . \\
\hline & ST39Q02_DOMMY_D2 & 8,47 & 2,86 & 2,96 &, 05 &, 02 & 3,02 \\
\hline
\end{tabular}




\subsubsection{Comprobación de la H5. El alumnado que acude a la biblioteca para realizar trabajos o investigaciones obtiene mejores resultados académicos en competencia lectora, si se compara con el alumnado que no tiene este hábito.}

Como se puede observar en la Tabla 58, si se comparan los resultados (medias) en competencia lectora teniendo en cuenta la variable "el alumnado acude a la biblioteca para realizar trabajos o investigaciones", se observa que, el resultado es superior $(483,66$, error estándar $=2,67)$ para el alumnado que no tiene este hábito, comparado con el alumnado que sí lo tiene. Éstos alcanzan un resultado de 481,43 (error estándar $=1,92$ ). La diferencia entre ambos grupos de alumnado alcanza un valor medio de 2,23, aunque no es estadísticamente significativa al $95 \%$ de nivel de confianza.

Tabla 58. PISA 2009. Comparación de resultados medios en competencia lectora del alumnado español, introduciendo la variable "el alumnado acude a la biblioteca para realizar trabajos o investigaciones". Salida de ordenador utilizando el programa IEA IDB Analyzer-SPSS

Average for PVREAD by CNI ST39Q03 _oUMMY

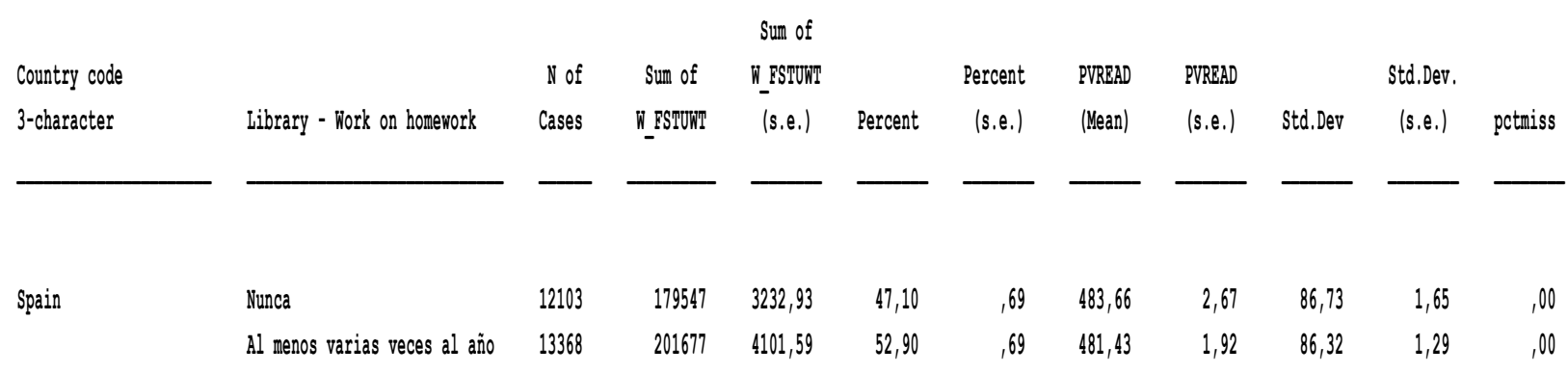

Regression Coefficients

\begin{tabular}{|c|c|c|c|c|c|c|c|}
\hline CNT & Variable & $\begin{array}{l}\text { Regression } \\
\text { Coefficient }\end{array}$ & $\begin{array}{c}\text { Regression } \\
\text { Coefficient } \\
\text { (s.e.) }\end{array}$ & $\begin{array}{c}\text { Regression } \\
\text { Coefficient } \\
\text { (t-value) }\end{array}$ & $\begin{array}{l}\text { Stndrdzd. } \\
\text { Coefficient }\end{array}$ & $\begin{array}{c}\text { Stndrdzd. } \\
\text { Coefficient } \\
\text { (s.e.) }\end{array}$ & $\begin{array}{l}\text { Stndrdzd. } \\
\text { Coefficient } \\
\text { (t-value) }\end{array}$ \\
\hline \multirow[t]{2}{*}{ Spain } & (CONSTANT) & 483,66 & 2,67 & 181,48 & . & & . \\
\hline & ST39003 DUMMY D2 & $-2,23$ & 2,26 &,- 99 &,- 01 &, 01 &,- 98 \\
\hline
\end{tabular}




\subsubsection{Comprobación de la H6. El alumnado que acude a la biblioteca para leer periódicos o revistas obtiene mejores resultados académicos en competencia lectora, si se compara con el alumnado que no tiene este hábito.}

Como se puede observar en la Tabla 59, si se comparan los resultados (medias) en competencia lectora teniendo en cuenta la variable "el alumnado acude a la biblioteca para leer periódicos o revistas", se observa que, el resultado es notablemente superior $(493,92$, error estándar $=2,04)$ para el alumnado que no tiene este hábito, comparado con el alumnado que sí lo tiene. Éstos alcanzan un resultado de 457,11 (error estándar $=2,60)$. La diferencia entre ambos grupos de alumnado alcanza un valor medio de 36,81, y sí es estadísticamente significativa al $95 \%$ de nivel de confianza.

Tabla 59. PISA 2009. Comparación de resultados medios en competencia lectora del alumnado español, introduciendo la variable "el alumnado acude a la biblioteca para leer periódicos o revistas". Salida de ordenador utilizando el programa IEA IDB Analyzer - SPSS

Average for PVREAD by CNT ST39004 DOMMY

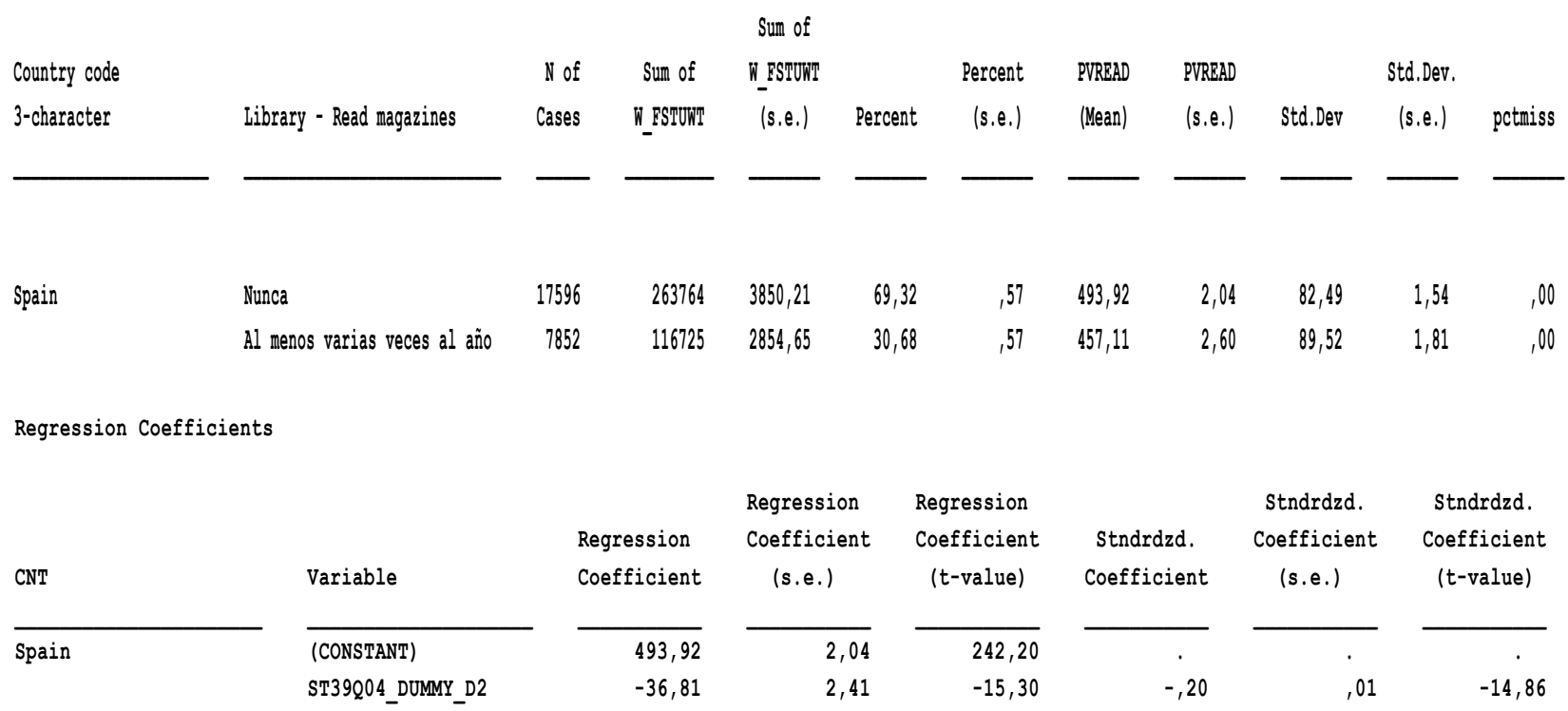




\subsubsection{Comprobación de la H7. El alumnado que acude a la biblioteca para leer por ocio obtiene mejores resultados académicos en competencia lectora, si se compara con el alumnado que no tiene este hábito.}

Como se puede observar en la Tabla 60, si se comparan los resultados (medias) en competencia lectora teniendo en cuenta la variable "el alumnado acude a la biblioteca para leer por ocio", se observa que, el resultado es ligeramente superior $(483,01$, error estándar $=2,27$ ) para el alumnado que no tiene este hábito, comparado con el alumnado que sí lo tiene. Éstos alcanzan un resultado de 482,09 (error estándar = $2,19)$. La diferencia entre ambos grupos de alumnado alcanza un valor medio de 0,92 , y no es estadísticamente significativa al $95 \%$ de nivel de confianza.

Tabla 60. PISA 2009. Comparación de resultados medios en competencia lectora del alumnado español, introduciendo la variable "el alumnado acude a la biblioteca para leer por ocio". Salida de ordenador utilizando el programa IEA IDB Analyzer-SPSS

Average for PVREAD by CNT ST39005 DOMMY

\begin{tabular}{|c|c|c|c|c|c|c|c|c|c|c|c|}
\hline \multirow{2}{*}{\multicolumn{2}{|c|}{ Country code }} & \multirow{3}{*}{$\begin{array}{l}N \text { of } \\
\text { Cases }\end{array}$} & \multicolumn{3}{|c|}{ Sum of } & \multirow[b]{2}{*}{ Percent } & \multirow{2}{*}{ PVREAD } & \multirow[b]{2}{*}{ PVREAD } & \multirow{2}{*}{\multicolumn{2}{|c|}{ Std.Dev. }} & \\
\hline & & & Sum of & W ESTUNI & & & & & & & \multirow[b]{2}{*}{ pctmiss } \\
\hline 3-character & Library - Read for fun & & WE_STUNI & (s.e.) & Percent & (s.e.) & (Mean) & (s.e.) & Std. Dev & (s.e.) & \\
\hline \multirow[t]{2}{*}{ Spain } & Nunca & 16642 & 249794 & 4124,76 & 65,76 &, 60 & 483,01 & 2,27 & 84,66 & 1,39 &, 00 \\
\hline & Al menos algunas veces al año & 8754 & 130043 & 2822,91 & 34,24 &, 60 & 482,09 & 2,19 & 89,48 & 1,57 &, 00 \\
\hline
\end{tabular}

Regression Coefficients

\begin{tabular}{|c|c|c|c|c|c|c|c|}
\hline CNT & Variable & $\begin{array}{l}\text { Regression } \\
\text { Coefficient }\end{array}$ & $\begin{array}{c}\text { Regression } \\
\text { Coefficient } \\
\text { (s.e.) }\end{array}$ & $\begin{array}{c}\text { Regression } \\
\text { Coefficient } \\
\text { (t-value) }\end{array}$ & $\begin{array}{l}\text { Stndrdzd. } \\
\text { Coefficient }\end{array}$ & $\begin{array}{c}\text { Stndrdzd. } \\
\text { Coefficient } \\
\text { (s.e.) }\end{array}$ & $\begin{array}{c}\text { Stndrdzd. } \\
\text { Coefficient } \\
\text { (t-value) }\end{array}$ \\
\hline \multirow[t]{2}{*}{ Spain } & (CONSTANT) & 483,01 & 2,27 & 213,12 & . & . & \\
\hline & ST39Q05_DUMMY_D2 &,- 92 & 2,13 &,- 43 &,- 01 &, 01 &,- 43 \\
\hline
\end{tabular}




\subsubsection{Comprobación de la H8. El alumnado que acude a}

la biblioteca para informarse sobre contenidos nuevos que no se explican en clase, como deportes, aficiones o música, obtiene mejores resultados académicos en competencia lectora, si se compara con el alumnado que no tiene este hábito.

Como se puede observar en la Tabla 61, si se comparan los resultados (medias) en competencia lectora teniendo en cuenta la variable "el alumnado acude a la biblioteca para informarse sobre contenidos nuevos", se observa que, el resultado es superior $(491,40$, error estándar $=2,36)$ para el alumnado que no tiene este hábito, comparado con el alumnado que sí lo tiene. Éstos alcanzan un resultado de 468,31 (error estándar $=2,12$ ). La diferencia entre ambos grupos de alumnado alcanza un valor medio de 23,10 , y sí es estadísticamente significativa al $95 \%$ de nivel de confianza.

Tabla 61. PISA 2009. Comparación de resultados medios en competencia lectora del alumnado español, introduciendo la variable "el alumnado acude a la biblioteca para informarse sobre contenidos nuevos que no se explican en clase". Salida de ordenador utilizando el programa IEA IDB Analyzer - SPSS

Average for PVREAD by CNI ST39006 _DUMYY

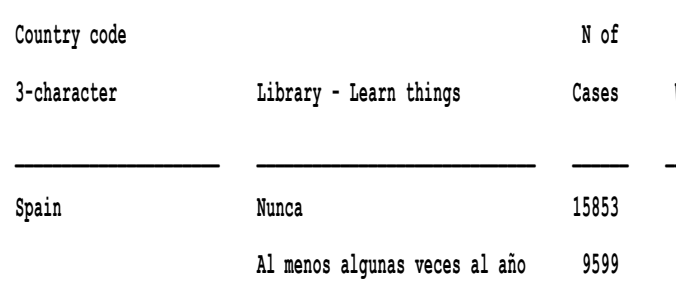

Sum of

Regression Coefficients

\begin{tabular}{|c|c|c|c|c|c|c|c|}
\hline $\mathrm{CNT}$ & Variable & $\begin{array}{l}\text { Regression } \\
\text { Coefficient }\end{array}$ & $\begin{array}{c}\text { Regression } \\
\text { Coefficient } \\
\text { (s.e.) }\end{array}$ & $\begin{array}{c}\text { Regression } \\
\text { Coefficient } \\
\text { (t-value) }\end{array}$ & $\begin{array}{l}\text { Stndrdzd. } \\
\text { Coefficient }\end{array}$ & $\begin{array}{l}\text { Stndrdzd. } \\
\text { Coefficient } \\
\text { (s.e.) }\end{array}$ & $\begin{array}{l}\text { Stndrdzd. } \\
\text { Coefficient } \\
\text { (t-value) }\end{array}$ \\
\hline \multirow[t]{2}{*}{ Spain } & (CONSTANT) & 491,40 & 2,36 & 207,96 & . & . & \\
\hline & ST39Q06 DUMMY D2 & $-23,10$ & 2,29 & $-10,10$ &,- 13 &, 01 & $-9,80$ \\
\hline
\end{tabular}




\subsubsection{Comprobación de la H9. El alumnado que acude a la biblioteca para usar Internet obtiene mejores resultados académicos en competencia lectora, si se compara con el alumnado que no tiene este hábito}

Como se puede observar en la Tabla 62, si se comparan los resultados (medias) en competencia lectora teniendo en cuenta la variable "el alumnado acude a la biblioteca para usar Internet", se observa que, el resultado es notablemente superior $(497,87$, error estándar $=2,01$ ) para el alumnado que no tiene este hábito, comparado con el alumnado que sí lo tiene. Éstos alcanzan un resultado de 463,47 (error estándar = $2,60)$. La diferencia entre ambos grupos de alumnado alcanza un valor medio de 34,40 , y sí es estadísticamente significativa al $95 \%$ de nivel de confianza.

Tabla 62. PISA 2009. Comparación de resultados medios en competencia lectora del alumnado español, introduciendo la variable "el alumnado acude a la biblioteca para usar Internet". Salida de ordenador utilizando el programa IEA IDB Analyzer-SPSS

Average for PRRRAD by CNI ST39007__ovMMY

\begin{tabular}{|c|c|c|c|c|c|c|c|c|c|c|c|}
\hline Country code & & $N$ of & Sum of & NESSUVII & & Percent & PVRRAD & PVREAD & & Std.Dev. & \\
\hline 3-character & Library - Use internet & Cases & W_ESSUVII & (s.e.) & Percent & (s.e.) & (Mean) & (s.e.) & Std. Dev & (s.e.) & petmiss \\
\hline \multirow[t]{2}{*}{ Spain } & Nunca & 14302 & 211596 & 4193,78 & 55,55 &, 79 & 497,87 & 2,01 & 82,68 & 1,68 &, 00 \\
\hline & A1 menos algunas veces & 11149 & 169285 & 3671,28 & 44,45 &, 79 & 463,47 & 2,60 & 87,27 & 1,26 &, 00 \\
\hline
\end{tabular}

Regression Coefficients

\begin{tabular}{|c|c|c|c|c|c|c|c|}
\hline $\mathrm{CNT}$ & Variable & $\begin{array}{l}\text { Regression } \\
\text { Coefficient }\end{array}$ & $\begin{array}{c}\text { Regression } \\
\text { Coefficient } \\
\text { (s.e.) }\end{array}$ & $\begin{array}{c}\text { Regression } \\
\text { Coefficient } \\
\text { (t-value) }\end{array}$ & $\begin{array}{l}\text { Stndrdzd. } \\
\text { Coefficient }\end{array}$ & $\begin{array}{l}\text { Stndrdzd. } \\
\text { Coefficient } \\
\text { (s.e.) }\end{array}$ & $\begin{array}{l}\text { Stndrdzd. } \\
\text { Coefficient } \\
\text { (t-value) }\end{array}$ \\
\hline \multirow[t]{2}{*}{ Spain } & (CONSTANT) & 497,87 & 2,01 & 247,56 & . & . & . \\
\hline & ST39007_DUMMY_D2 & $-34,40$ & 2,40 & $-14,34$ &,- 20 &, 01 & $-14,47$ \\
\hline
\end{tabular}




\subsubsection{Comprobación de la H10. El alumnado que tiene una actitud más positiva hacia las bibliotecas obtiene mejores resultados académicos en competencia lectora, comparado con el alumnado que tiene una actitud menos positiva respecto de las bibliotecas}

Como se muestra en la Tabla 63, el resultado fue notablemente superior, alcanzando una puntuación media de 509,50 (error estándar 2,24) para el alumnado que disfruta yendo a la biblioteca. El resultado fue 470,34 (error estándar 2,21) para el alumnado que no disfruta yendo a la biblioteca. Observamos que el alumnado que tiene una actitud positiva hacia la biblioteca tiene una ventaja de 39,16 puntos de media de rendimiento en competencia lectora, comparado con el alumnado que carece de esta actitud positiva hacia la biblioteca.

El test de significación muestra que esta diferencia es estadísticamente significativa con un nivel de confianza del $95 \%$ ( $\mathrm{t}>1,96)$.

Tabla 63. PISA 2009. Comparación de resultados medios en competencia lectora del alumnado español, introduciendo la variable "el alumnado tiene una actitud positiva hacia la biblioteca (si/no)". Salida de ordenador utilizando el programa IEA IDB Analyzer - SPSS

Average for PVREAD by CNI ST24Q07 _oUMY

Country code

3-character

Spain
Read Atti tude - Enjoy library

In desacuerdo 0 muy en desacuerdo

De acuerdo o muy de acuerdo

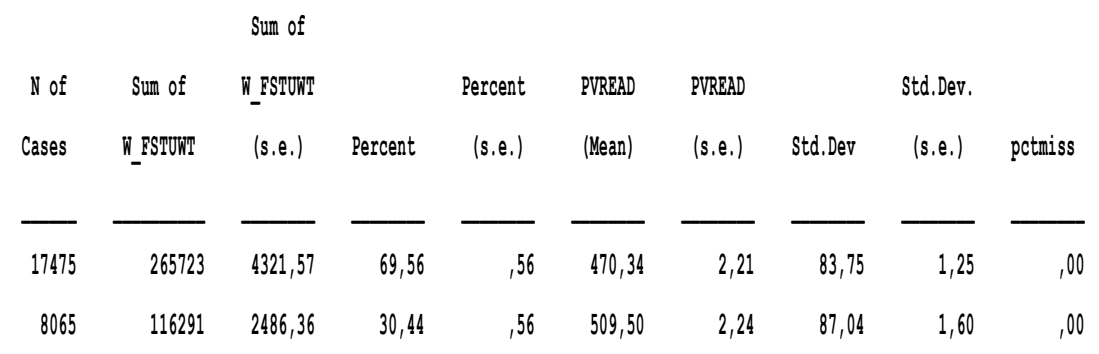

Regression Coefficients

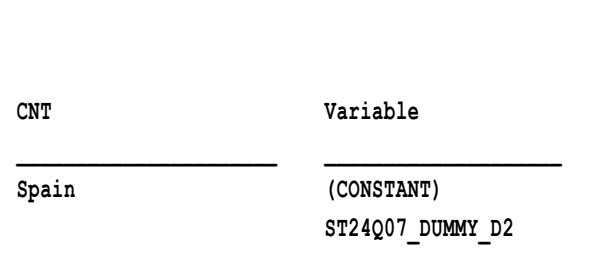

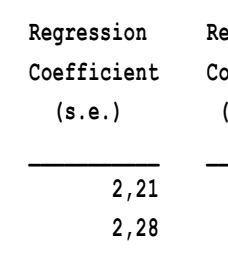

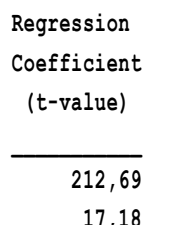

17,18

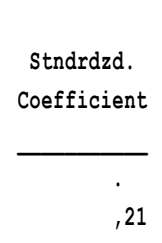

Stndrdzd. Coefficient (s.e.)

Stndrdzd. Coefficient ( $t$-value) 


\subsection{Conclusiones de la aproximación cuantitativa}

A partir de los análisis estadísticos realizados con los datos de los estudios PIRLS 2016 y PISA 2009 hemos extraído una serie de conclusiones preliminares acerca del primero de los objetivos de la investigación: identificar y analizar cambios en habilidades y competencias que se producen en el alumnado asociados al uso de la biblioteca escolar. En particular, se ha analizado la contribución de la biblioteca escolar al rendimiento del alumnado en competencia lectora (en respuesta a la pregunta de investigación número 1), y cómo influyen distintos recursos de la biblioteca sobre este rendimiento (en respuesta a la pregunta de investigación número 2). A continuación se recogen las conclusiones de los análisis, en primer lugar los correspondientes al ámbito de la educación primaria y posteriormente los correspondientes al ámbito de la educación secundaria.

En el ámbito de la educación primaria, los análisis han arrojado las siguientes conclusiones:

$\checkmark$ Se confirma que existe relación entre el rendimiento en competencia lectora del alumnado de educación primaria y el factor disponer de biblioteca escolar en el centro educativo. El alumnado con biblioteca escolar alcanza un rendimiento superior en competencia lectora (una ventaja media de 23,71 ) comparado con el que alcanza el alumnado sin biblioteca ${ }^{109}$. La relación entre rendimiento competencial y disponer de biblioteca se confirma en las cuatro dimensiones de la competencia lectora evaluadas. En todas ellas, el alumnado con biblioteca alcanza valores medios de rendimiento significativamente superiores:

- La diferencia mayor se produce en la dimensión "Adquirir y usar la información", donde la diferencia media entre los dos grupos de alumnado alcanza un 27,67 .

- Respecto a la dimensión "Tener una experiencia literaria", la diferencia entre los dos grupos de alumnado alcanza un 24,83 .

- Respecto a la dimensión "Interpretar, integrar y evaluar", la diferencia entre los dos grupos de alumnado alcanza un 22,65.

\footnotetext{
${ }^{109}$ En un análisis similar con datos de PIRLS 2011 (Albelda Esteban y La Mano González, 2017) se observó que, si bien se daba una diferencia media de 4,65 entre los resultados de los dos grupos de alumnado con y sin biblioteca, este resultado no era estadísticamente significativo. La repetición del análisis con datos de 2016 nos permite corroborar que, en efecto, el alumnado con biblioteca alcanza un rendimiento significativamente distinto al alumnado sin biblioteca escolar.
} 
- Respecto a la dimensión "Obtener información e inferencias directas", la diferencia entre los dos grupos de alumnado alcanza un 22,18.

En cuanto a la intensidad de uso de la biblioteca por el alumnado, no se confirma que exista una relación entre el rendimiento en competencia lectora y el factor frecuencia con la que se visita la biblioteca para tomar libros en préstamo ${ }^{110}$. Si bien se produce una ligera ventaja media de 0,57 en el grupo de alumnado que frecuenta la biblioteca al menos varias veces al año, esta diferencia no alcanza una significación estadística al $95 \%$ de nivel de confianza.

Tampoco se puede confirmar la relación entre el nivel de uso de la biblioteca y el rendimiento en las diferentes dimensiones de la competencia lectora. Se observa una ventaja para el alumnado que más usa la biblioteca en las dimensiones "Adquirir y usar la información", (diferencia media de 4,36); "Interpretar, integrar y evaluar" (diferencia media de 2,09) y "Obtener información e inferencias directas" (diferencia media de 1,77), pero estas diferencias no son significativas al $95 \%$ de nivel de confianza. Respecto a la dimensión "Tener una experiencia literaria", se produce un resultado inesperado, ya que el rendimiento medio del alumnado que menos frecuenta la biblioteca es superior al que sí la frecuenta, con una ligera diferencia media de 0,48 . No obstante, este resultado tampoco es estadísticamente significativo, por lo que tampoco podemos confirmar la relación entre intensidad de uso de la biblioteca y rendimiento competencial.

En cuanto a la influencia de los diferentes recursos bibliotecarios sobre el rendimiento del alumnado, se confirma que el recurso bibliotecario que más contribuye a este rendimiento es tener acceso a una colección bibliográfica amplia. En efecto, el alumnado con acceso a bibliotecas con colecciones bibliográficas mejor dotadas alcanza mejor rendimiento en competencia lectora, con una ventaja media significativa de 15,26 , comparado con el alumnado que accede a bibliotecas con colecciones bibliográficas más precarias. Se observa que a medida que aumenta el tamaño de la colección, mejora el rendimiento del alumnado. De igual modo, se confirma que el tamaño de la colección es el factor bibliotecario que más influye sobre el rendimiento del alumnado en cada una de las cuatro dimensiones de la competencia lectora evaluadas. Los resultados son estadísticamente significativos en todos los casos:

\footnotetext{
${ }^{110}$ A pesar de que no se ha observado en el análisis la suficiente significación estadística, hay que considerar la relevancia del préstamo libros dentro de las rutinas con las que el alumnado se relaciona con su biblioteca. En un reciente estudio con datos de PIRLS 2011, Huang et al. (2019) demostraron que los resultados de comprensión lectora del alumnado de Hong Kong estaban asociados a la frecuencia con la que acudían a la biblioteca para tomar libros en préstamo y al tamaño de la colección de la biblioteca escolar.
} 
- La mayor diferencia se produce en la dimensión "Adquirir y usar la información", donde el alumnado con acceso a colecciones amplias alcanza una ventaja media de 16,39, comparado con el que tiene acceso a colecciones precarias.

- Respecto a la dimensión "Interpretar, integrar y evaluar", la diferencia entre los dos grupos de alumnado alcanza un 14,96.

- Respecto a la dimensión "Obtener información e inferencias directas", la diferencia entre los dos grupos de alumnado alcanza un 14,36.

- Respecto a la dimensión "Tener una experiencia literaria", la diferencia entre los dos grupos de alumnado alcanza un 14,12.

En cuanto al acceso al préstamo de materiales bibliográficos impresos, no se confirma que exista relación entre este factor y el rendimiento en competencia lectora. Aunque el alumnado con acceso a este recurso alcanza una ligera ventaja en su rendimiento general (diferencia media de 1,15), esta diferencia no es estadísticamente significativa. Tampoco se confirma la relación entre este factor y las cuatro dimensiones competenciales evaluadas. En todas ellas el alumnado con acceso a préstamo de impresos alcanza una ligera ventaja, si bien ésta no es estadísticamente significativa.

Se confirma que el acceso a libros electrónicos desde la escuela es un factor relacionado con el rendimiento en competencia lectora. El alumnado que accede a este recurso alcanza mejores resultados en la competencia general (una ventaja media significativa de 12,83 ). Asimismo, se confirma la relación entre este factor y el rendimiento del alumnado en las cuatro dimensiones competenciales evaluadas, alcanzándose resultados estadísticamente significativos en todos los casos:

- La mayor diferencia se produce en la dimensión "Adquirir y usar la información", donde el alumnado con acceso a libros electrónicos alcanza una ventaja media de 13,11.

- Respecto a la dimensión "Interpretar, integrar y evaluar", la diferencia entre los dos grupos de alumnado alcanza un 12,93.

- Respecto a la dimensión "Tener una experiencia literaria", la diferencia entre los dos grupos de alumnado alcanza un 12,73.

- Respecto a la dimensión "Obtener información e inferencias directas", la diferencia entre los dos grupos de alumnado alcanza un 11,28.

En la misma línea, en el ámbito de la educación secundaria, en PISA 2009 se confirma que: "los jóvenes que toman parte en una gran variedad de actividades de lectura digital obtienen en general un rendimiento más elevado que los que 
apenas se dedican a este tipo de actividades"(Instituto de Evaluación, 2010, p. 127).

$\checkmark \quad$ A la vista de los análisis, si consideramos globalmente el impacto de las bibliotecas sobre el rendimiento del alumnado de educación primaria, podemos concluir que se confirma que la existencia de biblioteca escolar es un factor que contribuye al rendimiento en competencia lectora. En cuanto al uso y acceso a los distintos recursos bibliotecarios, se demuestra que los factores tener acceso a una colección bibliográfica amplia y tener acceso a libros electrónicos, influyen positivamente sobre ese rendimiento competencial.

$\checkmark$ De todos los factores que se han considerado en el análisis, se confirma que, en primer lugar, la existencia de la biblioteca en su conjunto, y en segundo lugar, tener acceso a una colección bibliográfica amplia, son los factores que mayor impacto tienen sobre la competencia lectora general y sobre las cuatro dimensiones competenciales evaluadas en el alumnado de educación primaria.

Se confirma que la mayor contribución del factor biblioteca escolar se produce sobre la dimensión "Adquirir y usar la información" en todos los análisis realizados. En segundo lugar de importancia está la dimensión "Interpretar, integrar y evaluar", y en tercer lugar de importancia se observa el efecto de la biblioteca sobre las dimensiones "Tener una experiencia literaria" y "Obtener información e inferencias directas".

En el ámbito de la educación secundaria se han extraído las siguientes conclusiones:

$\checkmark$ Se confirma que existe relación entre el rendimiento en competencia lectora general y el factor tener biblioteca escolar. El alumnado con biblioteca escolar alcanza una ventaja media estadísticamente significativa de 12,95.

$\checkmark$ No se puede confirmar que exista relación entre la intensidad de uso de la biblioteca y el rendimiento competencial del alumnado. Se da una asociación muy débil entre las dos variables. No obstante, si se analiza por separado la influencia de los distintos usos y recursos bibliotecarios sobre el rendimiento del alumnado, se puede confirmar la influencia positiva del préstamo de libros para leer por ocio y del préstamo de libros para hacer trabajos de clase.

Se confirma la influencia negativa de determinados factores como acudir a la biblioteca para leer periódicos o revistas, para informarse sobre contenidos nuevos que no se explican en clase o para usar Internet. No sabemos dar respuesta a estos resultados, si bien, es importante tener en cuenta lo siguiente: 
- Respecto del factor leer periódicos o revistas en la biblioteca, hay que decir que, en PISA 2009 se confirmó que lo importante no es que el alumnado lea un determinado tipo de material, sino que acceda a una variedad de materiales de lectura:

Normalmente, cuanto más versátil sea el lector, mejor nivel de rendimiento conseguirá, aunque algunos tipos de material se asocian más sólidamente que otros con el rendimiento. Los resultados de PISA muestran, como se ha señalado, que lo importante en este índice no es el leer un determinado género o material de lectura, sino la variedad de materiales que se lean (Instituto de Evaluación, 2010, p. 126).

- Respecto del factor consultar Internet en la biblioteca, aunque su efecto sobre la competencia lectora ha resultado negativo en nuestro análisis, sin embargo hay que decir que el acceso a Internet desde la biblioteca sigue siendo un recurso necesario para garantizar la equidad del sistema educativo. En PISA 2015 se confirmó que el 8 \% del alumnado español no tenía ordenador y que el $5 \%$ no tenía Internet en casa. Este alumnado coincidía con el que alcanzaba peores resultados en su rendimiento (Instituto Nacional de Evaluación Educativa, 2016, pp. 124-125). En esta misma línea, Warschauer, Knobel y Stone (2004) demostraron que la brecha digital actúa como un factor de desigualdad y que el sistema escolar puede funcionar como nivelador social proporcionando un acceso igualitario al alumnado a las nuevas tecnologías de la información. Por su parte, Asselin y Doiron (2008) destacaron el papel de la biblioteca escolar en el aprendizaje de competencias digitales necesarias para el nuevo contexto educativo de entorno digital.

No se puede confirmar que exista relación entre el rendimiento del alumnado y los factores acudir a la biblioteca para hacer deberes de clase o investigaciones; o acudir a la biblioteca para leer por ocio ${ }^{111}$.

Se confirma que la actitud del alumnado respecto de su biblioteca escolar influye sobre su rendimiento académico: el alumnado con una actitud positiva hacia las bibliotecas obtiene una ventaja media estadísticamente significativa de 39,16 comparado con el alumnado que no muestra esta actitud positiva al acudir a las bibliotecas. Resulta interesante observar que de entre todos los factores

111 Aunque el factor ir a la biblioteca para leer por ocio no parece contribuir al rendimiento competencial, hay que decir que en PISA 2009 se confirmó la correlación entre tener motivación y entender la lectura como una actividad placentera y el rendimiento en competencia lectora (eliminando el factor biblioteca) (Instituto de Evaluación, 2010). 
analizados éste es el que mayor impacto tiene sobre el rendimiento competencial del alumnado de educación secundaria. En la misma línea, en PISA 2009 se confirmó el impacto del factor motivación del alumnado sobre el rendimiento en competencia lectora:

El rendimiento en lectura de los alumnos españoles aumenta a medida que se incrementa el tiempo dedicado a la misma por diversión. (...) Leer por placer y rendimiento son, pues, factores positivamente asociados. El bajo rendimiento en comprensión lectora en los alumnos que dicen no leer por diversión parece aconsejar la difusión de medidas de fomento de la lectura, pero animar a los alumnos a leer más horas no significa necesariamente que mejoren su comprensión lectora. Existe un umbral que indica que la diferencia estriba en que lean diariamente por diversión, no en la cantidad "bruta" de tiempo que pasan leyendo (Instituto de Evaluación, 2010, p. 126).

Con la explotación de los datos PISA 2009 hemos obtenido información complementaria acerca de la contribución de la biblioteca escolar sobre la competencia lectora del alumnado que ha superado la etapa primaria. En este punto hay que decir que, en cualquier comparación que se realice entre estos datos y los correspondientes al estudio PIRLS se debe tener en cuenta la posible influencia de la variable edad, dada la diversidad de usos y costumbres lectoras asociadas a las distintas franjas de edad ${ }^{112}$.

Por último, han quedado fuera del análisis cuantitativo cinco puntos sobre los que los datos utilizados no proporcionan información. Estos puntos se exponen a continuación:

1) En primer lugar, el efecto del bibliotecario escolar sobre el rendimiento del alumnado ha sido ampliamente documentado por la literatura especializada (American Association of School Librarians, 2014; Johnston y Green, 2018; Lonsdale, 2003). Según la estadística española de bibliotecas escolares en el $51 \%$ de centros públicos y en el $39 \%$ de los centros privados, se ocupan de la coordinación de la biblioteca personas con formación específica en tareas bibliotecarias. PISA 2009 y PIRLS 2016 no incluyen información sobre el perfil del profesorado bibliotecario. Es por ello que, en futuros análisis se recomienda introducir este factor como variable explicativa del impacto de la biblioteca sobre el rendimiento del alumnado.

112 En este sentido, Yubero Jiménez y Larrañaga Rubio (2010) explicaron que

Aunque en los primeros años de Primaria los niños se suelen volcar con la lectura, normalmente compartida, es en los últimos años de la niñez cuando las decisiones en relación con la lectura se hacen más personales y guardan estrecha relación con la distribución del tiempo libre (p.17). 
2) En segundo lugar, una vez corroborada la influencia de la biblioteca sobre el rendimiento del alumnado, en futuros análisis se deberá analizar el impacto de las bibliotecas que siguen el modelo CREA (Centros de Recursos para la Educación y el Aprendizaje) (Cuevas Cerveró y Marzal García Quismondo, 2007; Lozano, 2014), en comparación con las bibliotecas que responden al modelo tradicional de biblioteca escolar de centro y de aula113.

3) En tercer lugar, futuros análisis deberán considerar el grado de inclusión de la biblioteca en el proyecto educativo del centro y su influencia sobre el rendimiento del alumnado. Como observaremos en el capítulo 4, la presencia de la biblioteca escolar en los documentos oficiales de los centros educativos es un indicador del valor que éstos le otorgan dentro del sistema educativo ${ }^{114}$.

4) En cuarto lugar, hemos podido mostrar que una actitud positiva del alumnado de educación secundaria hacia la biblioteca es un factor que influye positivamente sobre su rendimiento académico. Se recomienda replicar el análisis con alumnado de educación primaria, e indagar sobre los beneficios que obtiene el alumnado que muestra una mayor motivación respecto a la biblioteca.

5) En quinto lugar, en este análisis hemos evaluado el impacto sobre la competencia lectora. Futuros análisis deberán evaluar el impacto sobre otras competencias

113 En su estudio con alumnado chileno de cuarto grado de educación primaria, Valdés (2013) observó que

hay un significativo mayor uso en el colegio en el cual la biblioteca está considerada como un CRA (Centro de Recursos para el Aprendizaje), donde hay mayor variedad de volúmenes, variedad de actividades ofrecidas y visitas periódicas para realizar actividades coordinadas con el profesor dentro de ella (p. 84).

Por su parte, Serna, Rodríguez y Etxaniz (2017), en su estudio con escolares de Vizcaya, observaron que

No podemos afirmar que los hábitos lectores (...) estén condicionados a la existencia de la biblioteca escolar. No obstante, nuestros datos sí indican una relación entre los hábitos lectores y el valor que le dan a la lectura los escolares con el hecho de que las bibliotecas tengan protagonismo educativo y un alto grado de dinamización en promoción de la lectura (p. 32).

${ }^{114}$ Según la estadística española de bibliotecas escolares en el $47,8 \%$ de los centros públicos y en el $31 \%$ de los privados, existe una asignación específica para la biblioteca del presupuesto global del centro. Y sobre el reflejo del proyecto de la biblioteca escolar dentro de la documentación administrativa de los centros: en el $86,8 \%$ de los centros públicos y en el $68,9 \%$ de los privados, la biblioteca está dentro del proyecto integrado del centro; en el $62 \%$ de los centros públicos y en el 40,6 $\%$ de los privados, la biblioteca forma parte del proyecto educativo de centro; en el $64,5 \%$ de los centros públicos y en el $42,3 \%$ de los privados, la biblioteca forma parte del programa general anual; en el $58,5 \%$ de los centros públicos y en el $36,7 \%$ de los privados, la biblioteca está presente en la memoria anual de actividades. 
curriculares, como el cálculo, la expresión artística o las competencias sociales y cívicas.

Por último, consideramos que sería de gran interés introducir en los cuestionarios de futuras evaluaciones internacionales nuevas preguntas que ayuden a afinar nuestro conocimiento sobre el papel actual de la biblioteca escolar. En efecto, en futuros estudios PIRLS y PISA sería relevante preguntar sobre la actual dimensión formativa de este recurso educativo imprescindible en el nuevo contexto digital.

Una vez realizada la primera aproximación cuantitativa, y siguiendo el planteamiento metodológico de la integración de métodos, en el capítulo cuarto se desarrolla la investigación cualitativa. Con la introducción de la perspectiva cualitativa hemos acercado el foco hacia el lugar donde se producen los fenómenos con el fin de alcanzar una comprensión integral de los mismos. 


\section{CAPÍTULO 4. La perspectiva cualitativa: el caso de la biblioteca escolar del CEIP "Virrey Morcillo" Albacete) (Villarrobledo,}

\subsection{Introducción}

En el capítulo anterior se ha abordado la cuestión del impacto de la biblioteca escolar desde un enfoque cuantitativo, empleando el análisis estadístico de conjuntos de datos extraídos de fuentes externas como estrategia metodológica.

Se ha analizado la contribución de la biblioteca escolar al rendimiento del alumnado en competencia lectora (en respuesta a la pregunta de investigación número 1), y cómo influyen distintos recursos de la biblioteca sobre este rendimiento (en respuesta a la pregunta de investigación número 2). Recordemos que ambas preguntas corresponden al objetivo 1a) de esta tesis: Identificar y analizar cambios en habilidades y competencias que se producen como resultado o guardan relación con el uso de la biblioteca escolar (véase la Tabla 1).

Hasta ahora hemos podido confirmar que, en el ámbito de la educación primaria, el alumnado con biblioteca, con acceso a una colección bibliográfica amplia y con acceso a libros electrónicos supera en rendimiento en competencia lectora al alumnado que no dispone de estos recursos. Y en el ámbito de la educación secundaria, el alumnado con biblioteca, con acceso al préstamo de libros y con una actitud positiva hacia la biblioteca alcanza un mayor rendimiento en competencia lectora. Sin embargo, aún no hemos sabido explicar cómo y por qué se produce este impacto, y han quedado algunas preguntas de investigación por responder, acerca de la contribución de la biblioteca escolar a la institución de la que depende y a su entorno social.

Por un lado, como ya se advirtió en el apartado metodológico, trabajar con datos extraídos de fuentes externas implica asumir una serie de limitaciones. Dado que la obtención de estos datos queda fuera del control del investigador, éste no siempre encuentra en los conjuntos de datos disponibles toda la información que necesita para responder a las preguntas de investigación planteadas. En nuestro caso, con los conjuntos de datos PIRLS y PISA hemos encontrado información para responder a las preguntas de investigación 1 y 2 . 
Por otro lado, como se ha expuesto en el apartado 3.4, en algunos análisis estadísticos realizados no se han obtenido resultados estadísticamente significativos. En estos casos no hemos podido aceptar las hipótesis planteadas con el suficiente nivel de confianza (n.c. $=95 \%$ ).

Hemos concluido por tanto que el análisis cuantitativo resulta ser algo reduccionista para los propósitos de esta investigación, ya que se escapa información relevante para comprender procesos, conductas y experiencias subjetivas que se producen en los individuos como consecuencia, o en relación con el uso de la biblioteca.

Para una comprensión global del alcance del problema, más allá de la frecuencia de uso de la biblioteca, es preciso profundizar sobre cómo usa el alumnado los distintos recursos bibliotecarios, y cómo contribuyen éstos a su rendimiento. Y más allá del impacto que se produce sobre el rendimiento en competencias básicas (medibles mediante calificaciones numéricas), nos interesa conocer el efecto que se produce sobre los procesos del aprendizaje del alumnado a medio y largo plazo, y sobre otros aspectos de carácter intangible no medibles mediante puntuaciones académicas, como cambios en actitudes y comportamientos, y efectos sobre el bienestar individual.

El capítulo 4 complementa la visión del capítulo 3, abordando el objeto de investigación desde una perspectiva cualitativa a partir de datos correspondientes a un estudio de caso de una biblioteca escolar de un centro español de educación primaria. Con estos datos se han obtenido resultados con los que responder a las preguntas 1 a 11 de la investigación. Al contrario de lo que sucedía en el capítulo 3, el hecho de trabajar en esta fase de la investigación con datos extraídos por nosotros mismos nos ha permitido tener un mayor control sobre su obtención, alcance y significado. Además, con el empleo de técnicas de tipo cualitativo como la entrevista hemos podido indagar sobre determinados contenidos que han surgido en el transcurso de la investigación.

En el capítulo que nos ocupa nos hemos aproximado a las preguntas de investigación desde un enfoque metodológico de tipo naturalista, buscando la comprensión de los fenómenos desde dentro del contexto en el que éstos se producen. Inicialmente se pensó en un planteamiento metodológico que consistía en solicitar información a una muestra de centros educativos con biblioteca escolar, con representación de las distintas comunidades y ciudades autónomas españolas. Al profesorado bibliotecario de estos centros se le invitó a mantener una entrevista a distancia, o a contestar un cuestionario de preguntas sobre su valoración de la biblioteca escolar. Como no se obtuvieron suficientes repuestas favorables para participar en la investigación, decidimos entonces reconducir el planteamiento metodológico inicial y centrarnos en un estudio de caso. 
Así pues, la investigación ha consistido en la realización de un estudio de caso de una biblioteca escolar que se integra en una red cooperativa de bibliotecas escolares. La estrategia ha consistido en registrar el impacto bibliotecario tal y como es percibido de manera subjetiva por el profesorado. El estudio de caso ${ }^{115}$ es un enfoque apropiado para esta investigación, ya que permite registrar evidencias desde dentro del contexto educativo e indagar sobre cómo y por qué se produce el impacto bibliotecario en ese contexto.

Antes de cerrar este apartado, hay que mencionar las cuestiones éticas que hemos tenido presentes en todo momento en el desarrollo de la investigación. Para ello nos hemos guiado por las recomendaciones recogidas en la bibliografía sobre investigación cualitativa, y las hemos adaptado al contexto educativo (Christians, 2005; Flick, 2009; Kvale, 2011; Simons, 2011; Stake, 1998). Hemos seguido las siguientes directrices éticas:

- Consentimiento informado: se ha informado a todos los participantes sobre el propósito y contexto de la investigación, de manera que el proceso sea lo más transparente posible. Se ha respetado en todo momento el carácter voluntario de la participación en la investigación.

- Respeto a la confidencialidad de los participantes: en el texto de esta tesis se han recogido los datos identificativos de los centros educativos, pues son datos públicos tomados de las páginas web de los propios centros. Se han evitado los nombres propios de los participantes, tanto en la transcripción de las opiniones y respuestas, como en su posterior análisis.

${ }^{115}$ Como señala Tójar Hurtado (2006, pp.113-114), existe cierto debate entre los autores a la hora de considerar el estudio de caso como un método o como un objeto de estudio. Simons (2011) establece la siguiente definición:

Un estudio de caso es una investigación exhaustiva y desde múltiples perspectivas de la complejidad y unicidad de un determinado proyecto, política, institución, programa o sistema en un contexto "real". Se basa en la investigación, integra diferentes métodos y se guía por las pruebas. La finalidad principal es generar una comprensión exhaustiva de un tema determinado (por ejemplo, en una tesis), un programa, una política, una institución, o un sistema, para generar conocimientos y/o formar el desarrollo de políticas, la práctica profesional y la acción civil o de la comunidad (p. 42).

La autora añade que, dentro de los tipos de estudios de casos existentes, el estudio de caso instrumental es aquel que "se escoge para estudiar un tema o una pregunta de la investigación determinadas de otros ámbitos, es decir, el caso se elige para conseguir entender otra cosa" (Simons, 2011, p. 42). En esta tesis recurrimos a un estudio de caso como estrategia metodológica para obtener datos cualitativos que nos permitan responder a nuestras preguntas de investigación. Estamos pues en el supuesto del estudio de caso instrumental. 
- Respeto a la opinión de los participantes: se ha respetado la libertad para expresar cualquier tipo de opinión, así como el derecho a no responder a todas las preguntas planteadas.

- Fidelidad a la literalidad de los datos: se ha respetado la integridad de la información aportada por los participantes, no se ha omitido ni transformado el contenido original.

- Consideración hacia el tiempo de los participantes: se ha procurado que los participantes no invirtieran más tiempo del necesario en colaborar con la investigación.

Por último, como señala Kvale (2011, pp. 48-58), nos hemos planteado la cuestión moral que supone construir conocimiento a partir de la voz de los otros expresada en contextos naturales. Ciertamente, en el transcurso de la investigación se ha producido un vínculo entre la investigadora y los entrevistados, y la investigación ha prosperado en gran medida gracias a la implicación y compromiso de ambas partes respecto del tema de investigación. En este sentido queremos poner en valor la generosidad de los participantes, al darnos acceso a su entorno cotidiano, convertido en nuestro campo de estudio, y al brindarnos su colaboración desinteresada.

Asimismo, somos conscientes de que las conclusiones de esta investigación pueden contribuir a poner en valor el trabajo que se realiza desde los centros educativos con las bibliotecas escolares. En este sentido, hemos asumido el compromiso de compartir los resultados de esta investigación con los centros participantes.

A continuación, se expone el desarrollo de la investigación cualitativa. Como señala Tójar Hurtado (2006) "el diseño cualitativo es emergente (...) va desarrollándose a partir de los datos que se van obteniendo" (p. 159). En los apartados siguientes se detallan los sucesivos pasos de la investigación, desde el diseño de partida hasta su conclusión. Se explican la estrategia de muestreo cualitativo y los criterios utilizados para la selección del caso de estudio; y la fase de trabajo con los datos cualitativos. Se exponen las estrategias y técnicas utilizadas para la obtención de las evidencias, y se concluye el capítulo con el análisis e interpretación de los datos obtenidos a la luz de las preguntas de investigación planteadas ${ }^{116}$.

\footnotetext{
${ }^{116}$ En este apartado se recogen contenidos que han sido parcialmente publicados por la autora de esta tesis (Albelda Esteban, 2019a, 2019b).
} 


\subsection{Primeros pasos de la investigación cualitativa}

\subsubsection{Elaboración de una muestra de centros educativos con biblioteca escolar}

Los primeros pasos de la investigación cualitativa han consistido en elaborar una muestra de centros educativos españoles con biblioteca escolar. Para ello hemos seguido la lógica del muestreo cualitativo (Flick, 2014). De acuerdo con esta lógica, hemos buscado la necesaria objetividad del procedimiento de muestreo con el fin de garantizar la representatividad ${ }^{117}$ de la muestra y de los datos resultantes. Para ello hemos aplicado el principio de heterogeneidad (Valles, 2014), procurando que los casos seleccionados sean representativos de las variables que entran en juego en nuestro problema de investigación. Por otro lado, se han tenido en cuenta las limitaciones ${ }^{118}$ de medios y tiempo disponibles, cuestiones determinantes en las decisiones muestrales que se toman en toda investigación cualitativa (Flick, 2009, p. 132; Kvale, 2011, p. 71; Valles, 2014, p. 77).

Siguiendo estas premisas, hemos predefinido los siguientes criterios de selección de centros educativos para la muestra:

Criterio 1. Ámbito geográfico: teniendo en cuenta que en nuestro país las competencias educativas están transferidas a las comunidades autónomas, y que por tanto las bibliotecas escolares dependen en última instancia de ellas, no se puede obviar la variable geográfica. Por este motivo hemos decidido incluir en la muestra una representación de bibliotecas escolares de las diecisiete comunidades autónomas, más Ceuta y Melilla. La opción de limitar la muestra a centros de una única comunidad autónoma se ha descartado, ya que esta limitación geográfica podría producir cierto sesgo en los datos.

Criterio 2. Nivel de enseñanza y titularidad: en la muestra se han incluido centros de educación secundaria y de infantil y primaria, de titularidad pública y privada o concertada.

117 Como señala Valles (2014): “el muestreo cualitativo no pretende la representación estadística, sino la representación tipológica, socioestructural correspondiente a los objetos de estudio" (p.77).

118 La investigación se realiza en el marco de una tesis doctoral, por lo que su audiencia en primer lugar es la comunidad académica. Esta circunstancia también condiciona la limitación de medios y tiempo disponibles para la realización de la investigación. Para salvar esta cuestión práctica se ha recurrido a estrategias como combinar las entrevistas presenciales con la solicitud de información a distancia. 
Criterio 3. Características socioeconómicas y demográficas del entorno: en la medida de lo posible se ha procurado que hubiera representación de centros educativos con entornos socioeconómicos diversos, incluyendo municipios rurales y urbanos con diferentes niveles de renta y distintas características demográficas. Para obtener esta información se ha consultado información estadística ${ }^{119}$ de cada uno de los municipios y/o distritos en los que se ubica cada uno de los centros educativos. Con la incorporación de estas variables al muestreo hemos pretendido que los datos resultantes sean lo suficientemente diversos como para asegurar su representatividad.

Criterio 4. Criterio de intensidad ${ }^{120}$ : hemos escogido centros educativos donde se han encontrado evidencias de una mayor implicación del centro con su biblioteca escolar. Hemos descartado por tanto aquellos casos donde podía haber indicios de que la biblioteca escolar jugaba un papel secundario o marginal. Para ello, dentro de cada una de las comunidades autónomas se han seleccionado centros educativos que cumplían al menos una de las siguientes condiciones:

a) Condición 1: La biblioteca del centro educativo ha recibido algún premio o reconocimiento durante la última década. Para nuestra investigación era importante que, en lo posible, las bibliotecas seleccionadas contaran con cierta trayectoria y estuvieran en condiciones de proporcionar evidencias de su impacto sobre la comunidad educativa con cierta perspectiva temporal.

b) Condición 2: La biblioteca aparece en la página web del centro educativo de forma destacada, o incluso tiene web o blog propio, o bien aparece mencionada en la documentación oficial del centro educativo (memoria, proyecto educativo

${ }^{119}$ Se han consultado las Estadísticas Territoriales del Instituto Nacional de Estadística, incluyendo los indicadores demográficos y de población, económicos y sociales (http://www.ine.es/FichasWeb/RegComunidades.do) (véase el Anexo 9).

Para grandes ciudades como Madrid y Sevilla se han consultado la información estadística referida a los barrios, disponible en los portales de información estadística municipales (www.madrid.es/estadistica $\quad$ https://www.sevilla.org/servicios/servicio-de-estadisticaempadronamiento).

120 Patton (2002) define el criterio de intensidad aplicado al muestreo cualitativo, como:

seleccionar casos ricos en información donde el fenómeno de nuestro interés se manifiesta de forma intensa aunque no extrema (...) e implica un trabajo exploratorio por parte del investigador para determinar la naturaleza de la variación de la situación que se estudia y para elaborar la muestra de ejemplos donde el fenómeno estudiado se muestra con intensidad (p. 234).

[Traducido del original: "An intensity sample consists of information-rich cases that manifest the phenomenon of interest intensely (but not extremely (...). The researcher or evaluator must do some exploratory work to determine the nature of the variation in the situation under study, then sample intense examples of the phenomenon of interest"] (Patton, 2002, p. 234). 
de centro, plan de lectura, normativa interna, etc.). Hemos interpretado que la presencia de la biblioteca de manera destacada en la web o en la documentación oficial de los centros es un indicador del peso relativo que se le otorga dentro de la comunidad educativa.

De acuerdo con las decisiones de muestreo establecidas en el apartado anterior, se ha procedido a la búsqueda y localización de centros educativos con biblioteca escolar en cada una de las comunidades autónomas. Como resultado de esta búsqueda hemos encontrado lo siguiente:

- Comunidades con una red de bibliotecas escolares constituida con su propio portal web: Andalucía, Aragón, Castilla y León, Cataluña, Extremadura, Galicia, Comunidad de Madrid, Castilla-La Mancha.

- Comunidades sin red de bibliotecas escolares, o, que, en caso de haberla, no dispone aún de un portal web común. En estos casos se ha procedido a buscar la información sobre bibliotecas escolares en las páginas web de las respectivas consejerías de educación: Asturias, Baleares, Canarias, Cantabria, Comunidad Valenciana, Murcia, Navarra, País Vasco, La Rioja, Ceuta y Melilla.

Hemos partido del universo de centros educativos censados en España con biblioteca escolar ${ }^{121}$. Para verificar la primera condición de selección, hemos consultado la información disponible en la web del Ministerio de Educación y Formación Profesional ${ }^{122}$ sobre los premios concedidos a bibliotecas escolares entre los años 2009-2011. Se ha consultado la ficha informativa de los ochenta y dos centros premiados en esos años, y a continuación, se ha consultado la página web de cada centro, para comprobar si se cumplía la segunda condición de selección.

121 Según las estadísticas sobre las enseñanzas no universitarias del Ministerio de Educación y Formación Profesional para el curso 2016-2017, en España la educación infantil de primer ciclo es impartida en 9.952 centros; el segundo ciclo en 14.125 centros; la educación primaria se imparte en 13.863 centros y la educación secundaria obligatoria se imparte en 7.381 centros (http://estadisticas.mecd.gob.es/EducaJaxiPx/Tabla.htm?path=/Educacion/Centros/Centrosyunid/RD20 16-2017/Res//I0/\&file=RDRS02.px\&type=pcaxis\&L=0).

Según las estadísticas de bibliotecas escolares para el curso $2015-2016$, el 86,9 \% de los centros educativos tienen una biblioteca de centro en funcionamiento. El 5,6\% de los centros tiene una biblioteca circunstancialmente cerrada y en el 7,5 \% no hay biblioteca. En los centros en los que no hay biblioteca, suele ser frecuente que este servicio se cubra parcialmente por bibliotecas de departamento o de aula o mediante acuerdos con bibliotecas públicas (http://www.educacionyfp.gob.es/servicios-alciudadano-mecd/estadisticas/educacion/no-universitaria/centros/bibliotecas-escolares/20152016.html).

${ }^{122}$ https://www.mecd.gob.es/servicios-al-ciudadano-mecd/catalogo/educacion/centrosdocentes/premios.html 
Como resultado de estas comprobaciones se han seleccionado diecinueve centros, uno por cada comunidad autónoma más Ceuta y Melilla. En la Tabla 64 se recoge el listado completo. En trece centros se cumplen las dos condiciones de selección, es decir, sus bibliotecas han recibido algún premio o reconocimiento durante la última década; y la biblioteca ocupa un lugar destacado en su web o en su documentación oficial. Prácticamente en todos se cumple esta segunda condición, e incluso la biblioteca cuenta con su propio blog y tiene elaborada una normativa propia.

Diecisiete de los centros seleccionados son de titularidad pública, y dos son concertados. Diez son centros de educación secundaria y nueve son centros de educación infantil y primaria.

Se han consultado los datos estadísticos del INE para verificar que la muestra incluye centros educativos ubicados en entornos socioeconómicos y demográficos de características diversas.

Como se ha dicho al inicio de este capítulo, nuestro propósito al tener en cuenta estas variables era que los datos resultantes fueran lo más diversos y representativos posibles, si bien no hemos empleado criterios de muestreo y representatividad estadística sino criterios de muestreo y representatividad cualitativa. 
Tabla 64. Muestra de centros educativos españoles con biblioteca escolar

\begin{tabular}{|c|c|c|c|c|c|}
\hline 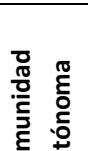 & Centro & $\begin{array}{ll}\text { Nivel de } \\
\text { docencia }\end{array}$ & Titularidad & $\begin{array}{l}\text { Condición } 1 \\
\text { La biblioteca ha recibido algún premio o } \\
\text { reconocimiento durante la última década }\end{array}$ & $\begin{array}{l}\text { Condición } 2 \\
\text { La biblioteca ocupa un lugar destacado en la web o en la documentación administrativa del } \\
\text { centro educativo }\end{array}$ \\
\hline$\frac{\frac{\pi}{3}}{\frac{\pi}{\frac{\pi}{0}}}$ & $\begin{array}{l}\text { CEIP } \text { Andalucía } \\
\text { (Sevilla) }\end{array}$ & 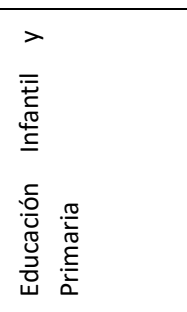 & Público & Premio Nacional Bibliotecas Escolares 2011 & 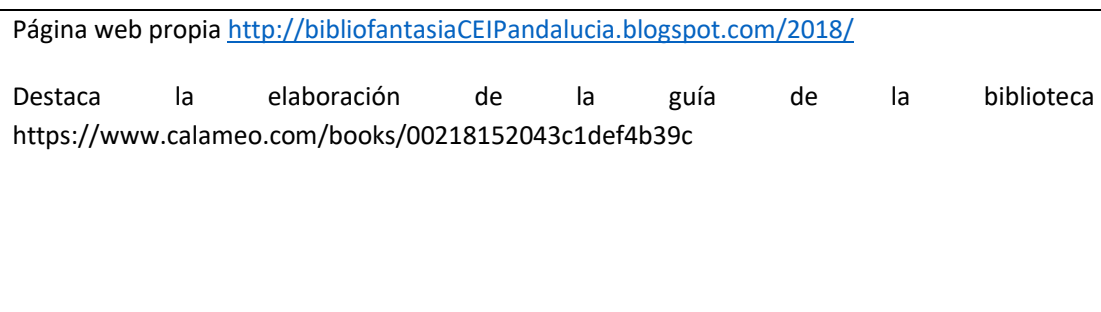 \\
\hline 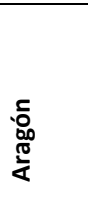 & $\begin{array}{lr}\text { Colegio } & \text { Salesiano } \\
\text { Santo } & \text { Domingo } \\
\text { Savio } & \text { (Monzón, } \\
\text { Huesca) } & \end{array}$ & 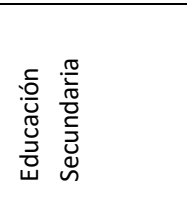 & Concertado & Premio Nacional Bibliotecas Escolares 2010 & No tiene web propia \\
\hline 营 & $\begin{array}{ll}\text { IES } & \text { Jerónimo } \\
\text { González (Langreo, } \\
\text { Asturias) }\end{array}$ & 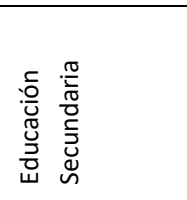 & Público & Premio Nacional Bibliotecas Escolares 2011 & Presencia en la web como proyecto del centro \\
\hline 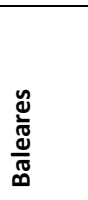 & $\begin{array}{lr}\text { CEIP } & \text { Badies } \\
\text { (Llucmajor, } & \text { Illes } \\
\text { Balears) } & \end{array}$ & 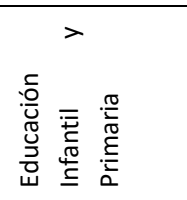 & Público & Premio Nacional Bibliotecas Escolares 2011 & $\begin{array}{l}\text { Blog propio } \\
\text { http://cpbadiesbiblioteca.blogspot.com/ } \\
\text { Aparece como proyecto de centro dentro de la Memoria }\end{array}$ \\
\hline 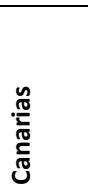 & $\begin{array}{l}\text { IES Gran Tarajal } \\
\text { (Tuineje, } \\
\text { Fuerteventura) }\end{array}$ & 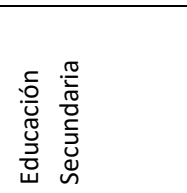 & Público & $\begin{array}{l}\text { No tiene premio. Escogida al azar entre los } \\
\text { centros educativos de la Comunidad Autónoma }\end{array}$ & Presencia en la web \\
\hline
\end{tabular}




\begin{tabular}{|c|c|c|c|c|c|}
\hline 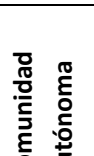 & Centro & $\begin{array}{ll}\text { Nivel de } \\
\text { docencia }\end{array}$ & Titularidad & $\begin{array}{l}\text { Condición } 1 \\
\text { La biblioteca ha recibido algún premio o } \\
\text { reconocimiento durante la última década }\end{array}$ & $\begin{array}{l}\text { Condición } 2 \\
\text { La biblioteca ocupa un lugar destacado en la web o en la documentación administrativa del } \\
\text { centro educativo }\end{array}$ \\
\hline 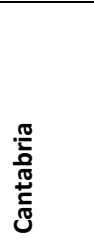 & $\begin{array}{l}\text { CEIP Gerardo Diego } \\
\text { (Los Corrales de } \\
\text { Buelna, Cantabria) }\end{array}$ & 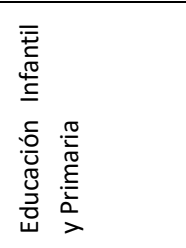 & Público & $\begin{array}{l}\text { Premio Buenas Prácticas Lectoras } 2014 \\
\text { concedido por el Gobierno de Cantabria } \\
\text { Sello de "Buena Práctica Iberoamericana" } \\
\text { concedido por el Portal Leer.es del Ministerio de } \\
\text { Educación. }\end{array}$ & $\begin{array}{l}\text { Presencia en la web, blog propio } \\
\text { http://bibliotecagerardodiegocorrales.blogspot.com }\end{array}$ \\
\hline 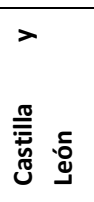 & $\begin{array}{l}\text { IES San Leonardo } \\
\text { (San Leonardo de } \\
\text { Yagüe, Soria) }\end{array}$ & 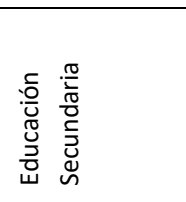 & Público & Premio Nacional Bibliotecas Escolares 2011 & $\begin{array}{l}\text { Presencia en la web con programa propio con sus propios objetivos alineados a los del centro } \\
\text { educativo } \\
\text { http://iessanleonardo.centros.educa.jcyl.es/sitio/upload/img/EXTRACTOS.swf }\end{array}$ \\
\hline 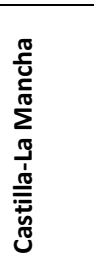 & $\begin{array}{l}\text { CEIP } \quad \text { Virrey } \\
\text { Morcillo } \\
\text { (Villarrobledo, } \\
\text { Albacete) }\end{array}$ & 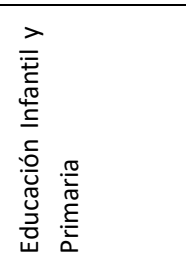 & Público & Premio Nacional Bibliotecas Escolares 2009 & $\begin{array}{l}\text { Presencia en la web. } \\
\text { Tiene web y blog propio } \\
\text { http://duendes-libronylibreta.blogspot.com/ }\end{array}$ \\
\hline$\frac{\pi}{\frac{\pi}{5}}$ & $\begin{array}{l}\text { La Salle (Figueres, } \\
\text { Girona) }\end{array}$ & 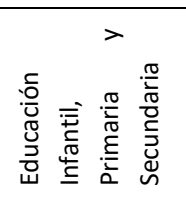 & Concertado & Premio Nacional Bibliotecas Escolares 2011 & Presencia en la web. Forma parte del programa de innovación del centro \\
\hline 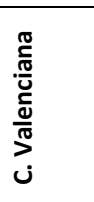 & $\begin{array}{lr}\text { IES } & \text { Francisco } \\
\text { Figueras } & \text { Pacheco } \\
\text { (Alicante) } & \end{array}$ & 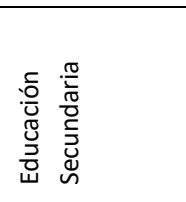 & Público & Premio Nacional Bibliotecas Escolares 2010 & Presencia en la web. Creada a la vez que el centro en 1972 \\
\hline 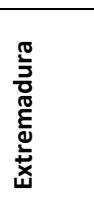 & $\begin{array}{lr}\text { CEIP } & \text { Francisco } \\
\text { Valdés } & \text { (Don } \\
\text { Benito, Badajoz) }\end{array}$ & 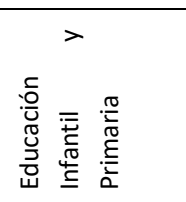 & Público & Premio Nacional Bibliotecas Escolares 2011 & $\begin{array}{l}\text { Presencia en la web blog propio } \\
\text { http://bibliovaldes.blogspot.com/ }\end{array}$ \\
\hline
\end{tabular}




\begin{tabular}{|c|c|c|c|c|c|}
\hline 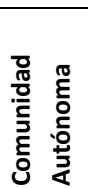 & Centro & $\begin{array}{ll}\text { Nivel de } \\
\text { docencia }\end{array}$ & Titularidad & $\begin{array}{l}\text { Condición } 1 \\
\text { La biblioteca ha recibido algún premio o } \\
\text { reconocimiento durante la última década }\end{array}$ & $\begin{array}{l}\text { Condición } 2 \\
\text { La biblioteca ocupa un lugar destacado en la web o en la documentación administrativa del } \\
\text { centro educativo }\end{array}$ \\
\hline 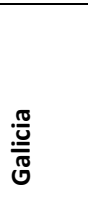 & $\begin{array}{l}\text { CEIP Condesa de } \\
\text { Fenosa (O Barco de } \\
\text { Valdeorras, } \\
\text { Ourense) }\end{array}$ & 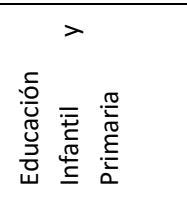 & Público & Premio Nacional Bibliotecas Escolares 2011 & $\begin{array}{l}\text { Presencia en la web } \\
\text { Especial atención a contenidos audiovisuales } \\
\text { http://www.edu.xunta.es/biblioteca/blog/?q=node/1129 }\end{array}$ \\
\hline 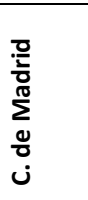 & $\begin{array}{l}\text { CEIP Doctor Severo } \\
\text { Ochoa (Madrid) }\end{array}$ & 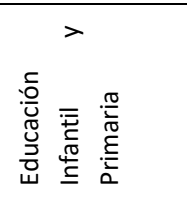 & Público & $\begin{array}{l}\text { No tiene premio } \\
\text { Escogido al azar entre las bibliotecas de la } \\
\text { Comunidad }\end{array}$ & $\begin{array}{l}\text { Blog propio } \\
\underline{\text { http://bibliosevero.blogspot.com/ }}\end{array}$ \\
\hline 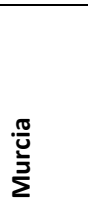 & $\begin{array}{l}\text { IES Infante Don } \\
\text { Juan Manuel } \\
\text { (Murcia) }\end{array}$ & 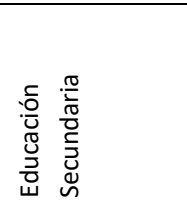 & Público & Premio Nacional Bibliotecas Escolares 2010 & Presencia en la web \\
\hline 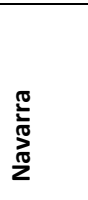 & $\begin{array}{l}\text { IES Navarro } \\
\text { Villoslada } \\
\text { (Pamplona, } \\
\text { Navarra) }\end{array}$ & 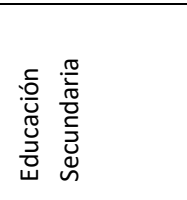 & Público & $\begin{array}{l}\text { No tiene premio } \\
\text { Escogido al azar entre las bibliotecas de la } \\
\text { Comunidad Foral }\end{array}$ & Presencia en la web \\
\hline 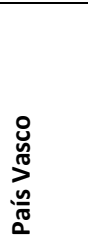 & $\begin{array}{l}\text { Bizarain ikastola } \\
\text { (Beraun, } \\
\text { Errenteria) }\end{array}$ & 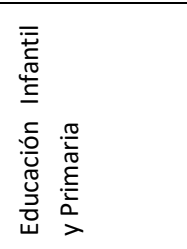 & Público & $\begin{array}{l}\text { No tiene premio } \\
\text { Escogido al azar dentro del blog BEGEL, del } \\
\text { profesorado de las bibliotecas escolares de } \\
\text { Guipúzcoa } \\
\text { http://eskolaliburutegiakgip.blogspot.com/ }\end{array}$ & Presencia en la web \\
\hline 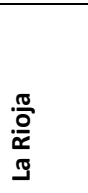 & $\begin{array}{l}\text { IES Batalla de } \\
\text { Clavijo (Logroño, La } \\
\text { Rioja) }\end{array}$ & 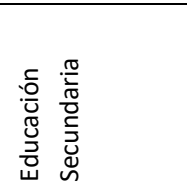 & Público & Premio Nacional Bibliotecas Escolares 2009 & Presencia en la web \\
\hline
\end{tabular}




\begin{tabular}{|c|c|c|c|c|c|}
\hline 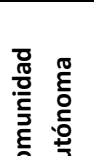 & Centro & $\begin{array}{l}\text { Nivel de } \\
\text { docencia }\end{array}$ & Titularidad & $\begin{array}{l}\text { Condición } 1 \\
\text { La biblioteca ha recibido algún premio o } \\
\text { reconocimiento durante la última década }\end{array}$ & $\begin{array}{l}\text { Condición } 2 \\
\text { La biblioteca ocupa un lugar destacado en la web o en la documentación administrativa del } \\
\text { centro educativo }\end{array}$ \\
\hline ũ & $\begin{array}{l}\text { IES Clara } \\
\text { Campoamor } \\
\text { (Ceuta) }\end{array}$ & 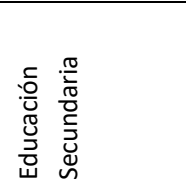 & Público & $\begin{array}{l}\text { No tiene premio. } \\
\text { Se ha escogido al azar entre los centros } \\
\text { educativos de Ceuta }\end{array}$ & $\begin{array}{l}\text { Tiene blog propio } \\
\text { http://grupolectorclaracampoamor.blogspot.com/ }\end{array}$ \\
\hline 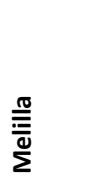 & $\begin{array}{l}\text { IES } \\
\text { (Melilla) }\end{array}$ & 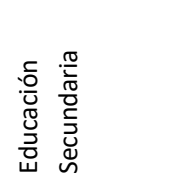 & Público & Premio Nacional Bibliotecas Escolares 2011 & $\begin{array}{l}\text { Presencia en la web } \\
\text { https://www.iesrusadir.es/web/211-bibliorusadir-1 }\end{array}$ \\
\hline
\end{tabular}




\subsubsection{Toma de contacto y respuesta de los centros educativos}

Una vez elaborada la muestra de centros, el paso siguiente ha consistido en contactar con cada uno de ellos con el fin de invitarles a participar en la investigación. A los responsables de cada uno de los diecinueve centros educativos seleccionados se les ha enviado, tanto por correo ordinario como por correo electrónico, la siguiente documentación (véase el Anexo 1):

- Una carta de presentación firmada por la directora de la tesis, avalando la investigación en curso y solicitando la colaboración del centro.

- Una carta firmada por la investigadora, donde se presentaban los objetivos de la investigación. En esta carta se invitaba al profesorado responsable de la biblioteca escolar a responder a un cuestionario de preguntas sobre su percepción acerca del papel de la biblioteca, para mantener posteriormente una entrevista con la investigadora. En la Tabla 65 se recoge el cuestionario de preguntas. Como se puede observar, siguiendo la recomendación de Kvale (2011, p.87), todas ellas están vinculadas a los objetivos y preguntas de investigación.

Con la finalidad de asegurarnos el mayor número posible de respuestas, hemos ofrecido a los centros la posibilidad de elegir el canal comunicación, bien concertando una fecha para una entrevista telefónica o mediante videoconferencia, o bien sustituyendo la entrevista a distancia por el envío del cuestionario cumplimentado a vuelta de correo. Por otra parte, hemos mostrado en todo momento una actitud facilitadora y flexible hacia los potenciales participantes, ofreciéndoles la posibilidad de contactar sobre cualquier cuestión y de adaptarnos al calendario y a otras necesidades de sus centros.

Aún a riesgo de recibir un bajo porcentaje de respuestas, en esta fase de la investigación hemos preferido que las preguntas del cuestionario sean de respuestas abiertas. Nuestra intención ha sido que el profesorado pueda expresar con sus propias palabras y con la menor mediación posible sus percepciones sobre la contribución de la biblioteca escolar.

Como resultado de esta fase de contacto con los diecinueve centros, se han recibido cinco respuestas, de las cuales tres han sido favorables a colaborar con la investigación. Un centro educativo de Galicia y uno de Cantabria han enviado el 
cuestionario cumplimentado (véase el Anexo 2) y un tercer centro de Castilla-La Mancha nos ha ofrecido la posibilidad de realizar la investigación sobre el terreno ${ }^{123}$.

También se han recibido respuestas de dos centros del País Vasco y Cataluña, manifestando su imposibilidad de participar por diferentes motivos. En el primero de los casos, el motivo expresado ha sido la falta de personal al frente de la biblioteca. En el segundo caso, se nos ha informado de que actualmente la biblioteca no está en funcionamiento.

Teniendo presente que una investigación cualitativa es siempre un proceso de naturaleza emergente, y que está sometida a probables imprevistos y reajustes, hemos mantenido desde el principio un diseño flexible, que pudiera reformularse $y$ adaptarse sin dificultad a las necesidades que fueran surgiendo en el transcurso de la propia investigación. El número de respuestas recibidas ha sido muy bajo, por lo que ha habido que abandonar la idea inicial de realizar la investigación sobre una muestra de bibliotecas que incluyera una representación de todas las comunidades autónomas españolas. Hemos decidido entonces centrar la investigación en un caso particular de biblioteca escolar. Como se explica en el apartado siguiente, hemos realizado la selección del caso de entre los tres centros que en la fase preliminar se habían ofrecido a colaborar con la investigación.

${ }^{123}$ Se trata del CEIP Condesa de Fenosa (O Barco de Valdeorras, Orense), el CEIP Gerardo Diego (Los Corrales de Buelna, Cantabria), y el CEIP Virrey Morcillo (Villarrobledo, Albacete). 
Tabla 65. Cuestionario de preguntas empleado en la investigación cualitativa

\begin{tabular}{|c|c|c|c|}
\hline & & Preguntas de investigación & Cuestionario de preguntas \\
\hline 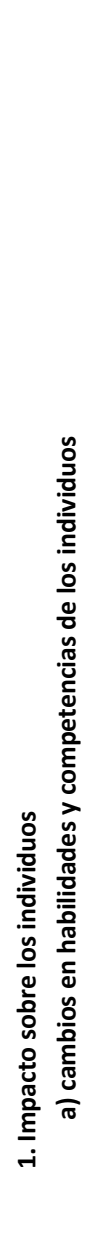 & & $\begin{array}{l}\text { ¿Tiene alguna influencia el hecho de } \\
\text { tener biblioteca en el centro educativo } \\
\text { sobre el rendimiento académico en } \\
\text { competencia lectora? y en caso } \\
\text { afirmativo, ¿sobre qué dimensiones } \\
\text { competenciales se observa este } \\
\text { impacto? } \\
\text { - } \quad \text { literarios e informativos } \\
\text { ser competentes en obtener e } \\
\text { inferir información a partir de la } \\
\text { lectura } \\
\text { ser capaces de interpretar, } \\
\text { integrar y evaluar críticamente la } \\
\text { información obtenida en el } \\
\text { entorno papel y en el entorno } \\
\text { digital y con los distintos tipos de } \\
\text { material y soportes bibliográficos } \\
\text { ¿Cómo influyen los distintos recursos, } \\
\text { actividades o prácticas vinculadas a la } \\
\text { biblioteca sobre el desarrollo de la } \\
\text { competencia lectora? } \\
\text { profesorado? }\end{array}$ & $\begin{array}{c}\text { - ¿Cree que ayuda de alguna forma la biblioteca de su centro a } \\
\text { mejorar las competencias del alumnado en lectoescritura? } \\
\text { En caso afirmativo, ¿en qué aspectos se puede } \\
\text { apreciar esta contribución tanto en el entorno } \\
\text { papel como en el entorno digital? ¿con qué tipos } \\
\text { de textos? } \\
\text { En caso negativo, ¿qué cree que se necesitaría } \\
\text { cambiar para aprovechar mejor el recurso de la } \\
\text { biblioteca escolar? } \\
\text { ¿Qué recursos de la biblioteca cree que son clave } \\
\text { actualmente para la adquisición y desarrollo de las } \\
\text { competencias del alumnado: el préstamo de libros } \\
\text { impresos y electrónicos, la colección bibliográfica, } \\
\text { el propio espacio físico de la biblioteca, las } \\
\text { actividades formativas y lúdicas que organiza la } \\
\text { biblioteca? } \\
\text { E }\end{array}$ \\
\hline
\end{tabular}




\begin{tabular}{|c|c|c|}
\hline 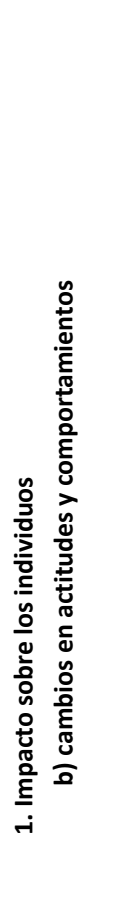 & $\begin{array}{l}\text { 4. ¿En qué medida frecuentar la } \\
\text { biblioteca escolar produce cambios en } \\
\text { actitudes y comportamientos en el } \\
\text { alumnado? } \\
\text { 5. ¿En qué medida frecuentar la } \\
\text { biblioteca escolar produce cambios en } \\
\text { actitudes y comportamientos en el } \\
\text { profesorado? }\end{array}$ & $\begin{array}{l}\text { _ } \begin{array}{l}\text { ¿Observa alguna diferencia destacable en el comportamiento } \\
\text { del alumnado que más visita la biblioteca? }\end{array} \\
\text { _ } \quad \text { ¿Qué perfil de alumnado es el que más ha interiorizado el } \\
\text { uso de la biblioteca dentro de su rutina académica diaria? } \\
\text { - ¿Cree que la biblioteca puede ayudar al alumnado a ser más } \\
\text { autónomo en sus búsquedas y en el manejo de la } \\
\text { información? } \\
\text { - ¿Cree que les estimula en su motivación por aprender? } \\
\text { - ¿Cambian sus hábitos de lectura y sus preferencias en cuanto } \\
\text { al tipo de lectura y gusto literario como resultado de acudir a } \\
\text { la biblioteca? } \\
\text { ¿Se interesan por nuevas áreas de conocimiento después de } \\
\text { visitar la biblioteca? } \\
\text { ¿En qué medida puede la biblioteca ayudar a interiorizar } \\
\text { valores? ¿qué valores destacaría? } \\
\text { ¿En qué medida cree que el uso de la biblioteca escolar } \\
\text { puede producir cambios en actitudes y comportamientos en } \\
\text { el profesorado? }\end{array}$ \\
\hline 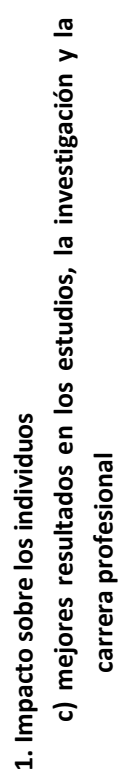 & $\begin{array}{l}\text { 6. ¿Contribuye la biblioteca escolar a } \\
\text { mejorar el rendimiento académico del } \\
\text { alumnado a medio y largo plazo? } \\
\text { 7. ¿Contribuye la biblioteca escolar a } \\
\text { mejorar el rendimiento y la carrera } \\
\text { profesional del profesorado a medio y } \\
\text { largo plazo? }\end{array}$ & 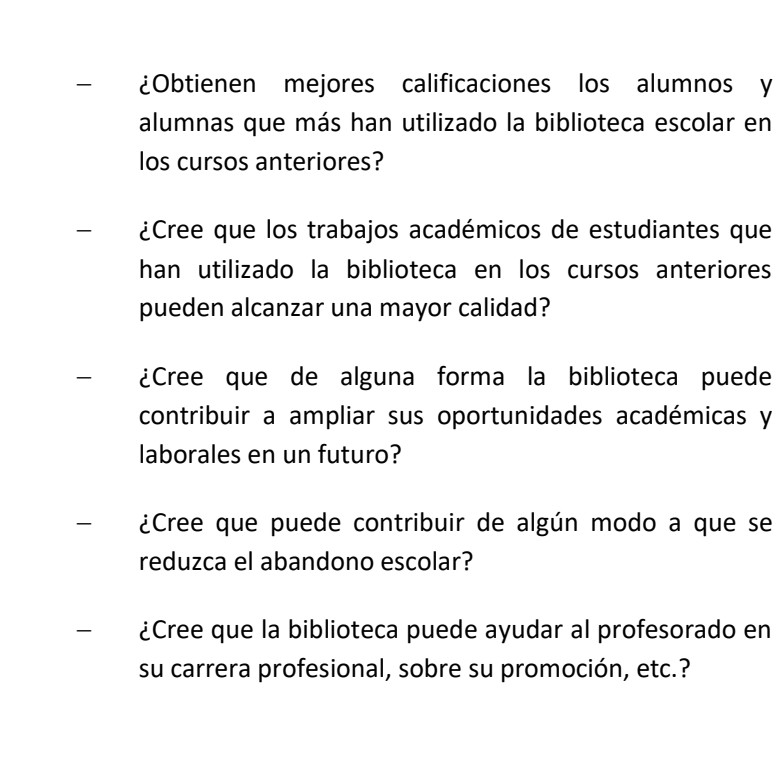 \\
\hline
\end{tabular}




\begin{tabular}{|c|c|c|}
\hline 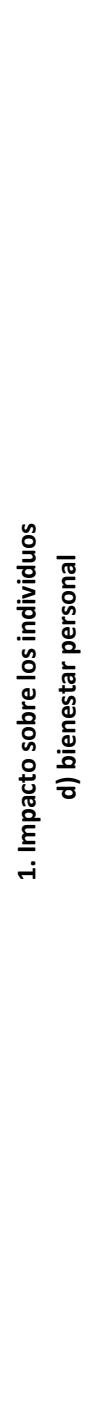 & $\begin{array}{l}\text { 8. ¿Qué beneficios reporta la biblioteca } \\
\text { escolar como lugar físico? } \\
\text { - ¿cómo es percibido este } \\
\text { espacio físico por el } \\
\text { alumnado? } \\
\text { - ¿cómo es percibido el } \\
\text { espacio físico por el } \\
\text { profesorado? }\end{array}$ & 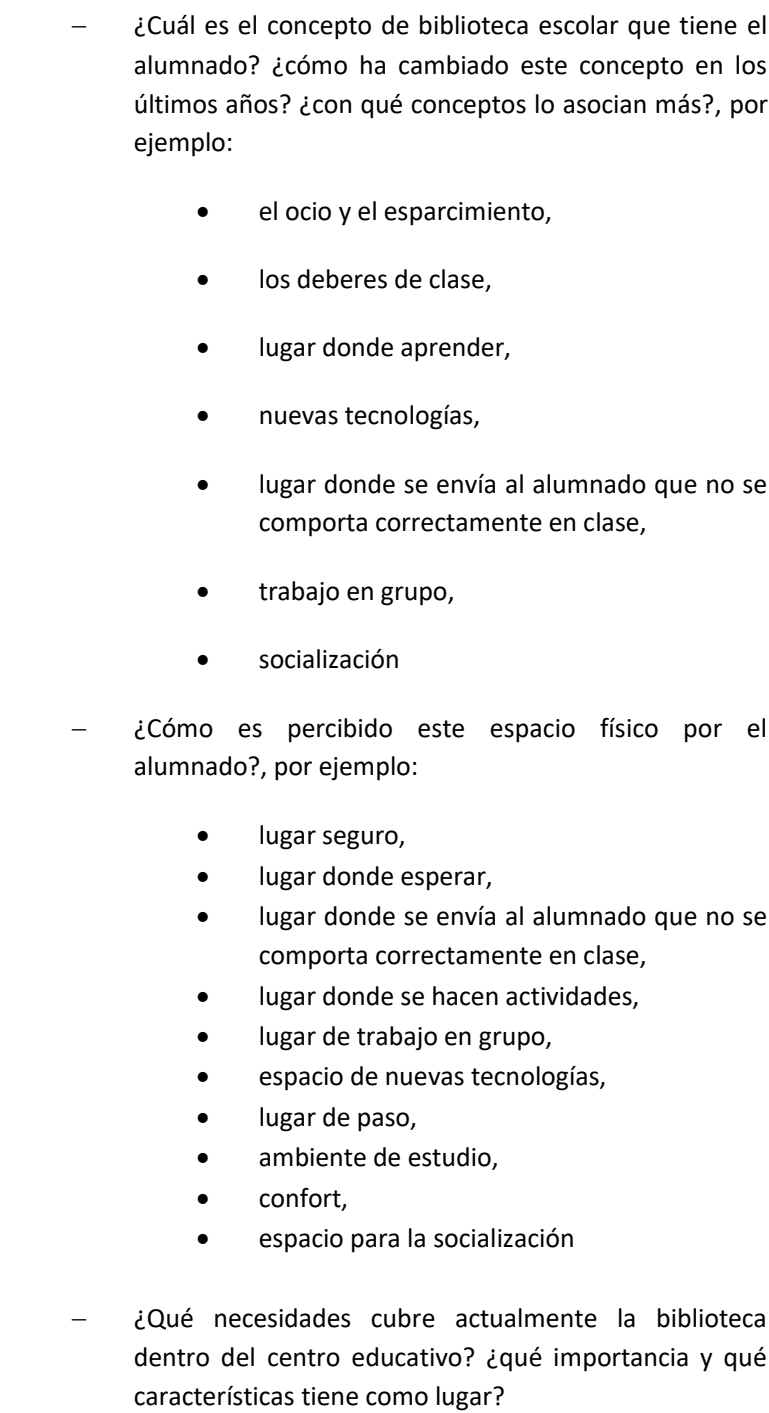 \\
\hline 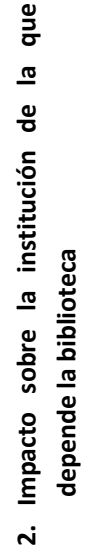 & $\begin{array}{l}\text { 9. ¿Contribuye la biblioteca a los fines del } \\
\text { centro educativo? Y, en caso } \\
\text { afirmativo, ¿sobre qué aspectos se } \\
\text { observa esta contribución? }\end{array}$ & $\begin{array}{l}-\quad \text { ¿Contribuye a mejorar el prestigio del centro educativo? } \\
\text { - } \quad \text { ¿lnfluye en la elección del centro por parte de las familias? } \\
\text { - } \quad \text { ¿Se asocia a la calidad de la enseñanza del centro? } \\
-\quad \text { ¿Contribuye a darle visibilidad? } \\
\text { - } \quad \text { ¿Contribuye a establecer alianzas con otras instituciones? } \\
-\quad \text { ¿Contribuye a la obtención de premios, reconocimientos y } \\
\quad \text { financiación externa? }\end{array}$ \\
\hline
\end{tabular}




\begin{tabular}{|c|c|c|c|}
\hline 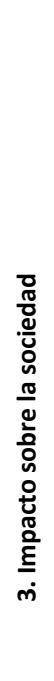 & $\begin{array}{l}\text { 10. ¿Contribuye la biblioteca a fomentar } \\
\text { determinados valores sociales en la } \\
\text { escuela? } \\
\text { 11. ¿Contribuye la biblioteca a mejorar el } \\
\text { entorno social en el que se ubica el } \\
\text { centro educativo? }\end{array}$ & - & $\begin{array}{l}\text { ¿Contribuye la biblioteca a fomentar valores?, por } \\
\text { ejemplo: } \\
\text { - } \quad \text { el sentido de pertenencia, } \\
\text { - } \quad \text { el sentido del bien común que hay que cuidar y } \\
\text { compartir, } \\
\text { - la cohesión, } \\
\text { - la preservación del patrimonio cultural, } \\
\text { la equidad, } \\
\text { el respeto a la diversidad, } \\
\text { ¿Contribuye la biblioteca a compensar las posibles } \\
\text { deficiencias del entorno en el que se emplaza el centro } \\
\text { educativo? (carencia de infraestructuras en el barrio, } \\
\text { riesgos psicosociales, etc.) }\end{array}$ \\
\hline
\end{tabular}

\subsubsection{Selección y presentación del caso de estudio}

A la vista de las tres respuestas positivas recibidas de los centros de Galicia, Cantabria y Castilla-La Mancha, hemos evaluado las tres opciones a la luz de los criterios de preselección. Hemos revisado de nuevo la información contenida en las páginas web de los tres centros y sus documentos oficiales, con el fin de seleccionar nuestro caso de estudio:

1) El CEIP Condesa de Fenosa (O Barco de Valdeorras, Orense) recibió el Premio Nacional Bibliotecas Escolares en 2011 y su biblioteca está integrada dentro de la red de bibliotecas escolares de Galicia. La biblioteca tiene una fuerte presencia en la web y en la documentación oficial del centro educativo. Entre otros aspectos destacables, el centro implementa los distintos programas impulsados desde el Gobierno Autonómico, como el Programa de Bibliotecas Inclusivas, o el Plan de Mejora de Bibliotecas (PLAMBE). ${ }^{124}$

2) El CEIP Gerardo Diego (Los Corrales de Buelna, Cantabria), obtuvo el primer Premio Buenas Prácticas Lectoras 2014 concedido por el Gobierno de Cantabria por su propuesta didáctica "Un año en la Biblioteca de Amelia" y el Sello "Buena Práctica Iberoamericana" concedido el Ministerio de Educación dentro de la iniciativa Leer.es para el fomento de la lectura. Destaca especialmente por los contenidos y esmerado diseño de su blog, donde se recoge permanentemente

124 Para completar la información sobre la Red de Bibliotecas Escolares de Galicia véase la web de la Consellería de Educación, Universidade e Formación Profesional de la Xunta de Galicia: http://www.edu.xunta.es/biblioteca/blog/ 
información sobre sus actividades dentro de la comunidad educativa ${ }^{125}$. No obstante, no hemos encontrado en la web del centro documentos oficiales donde poder evaluar la presencia de la biblioteca.

3) El CEIP Virrey Morcillo ${ }^{126}$ (Villarrobledo, Albacete) obtuvo en 2009 el Premio Nacional de Buenas Prácticas para la Dinamización e Innovación de las Bibliotecas de los Centros Escolares concedido por el Ministerio de Educación. Su primer Plan de Lectura y Biblioteca se remonta al año 2005 y desde entonces ha venido desarrollando y evaluando año tras año sucesivos planes de lectura y biblioteca hasta la actualidad. Cuenta con blog propio actualizado y una importante presencia en redes sociales ${ }^{127}$. Tras la consulta de los documentos oficiales del centro se concluye que la biblioteca ocupa un lugar muy destacado en la vida del CEIP.

Una vez evaluados los tres casos, se ha seleccionado el CEIP Virrey Morcillo (Villarrobledo, Albacete) por tres motivos principales:

1) La disposición a colaborar de los responsables del centro educativo, que han dado todo tipo de facilidades para que pudiéramos realizar la investigación sobre el terreno, incluso brindándose a participar en las entrevistas. Consideramos que contar con el respaldo de la dirección del centro era fundamental para obtener el permiso de acceso necesario para la realización de una investigación de este tipo.

2) El caso responde a los criterios de representatividad e intensidad informativa (Patton, 2002), tras haber comprobado la fuerte presencia de la biblioteca escolar en las dinámicas educativas y su trayectoria consolidada de trabajo con buenas prácticas bibliotecarias y planes de lectura. Se puede decir que se trata de un caso de éxito, donde se manifiesta con intensidad el impacto de la biblioteca escolar sobre la comunidad educativa.

3) Un tercer criterio de oportunidad: el centro se integra dentro de una red cooperativa de bibliotecas escolares ${ }^{128}$ de intensa actividad y larga trayectoria,

125 Se puede consultar el blog de la biblioteca del CEIP Gerardo Diego en la siguiente dirección: http://bibliotecagerardodiegocorrales.blogspot.com/

126 Se puede consultar toda la información del blog en la dirección: http://duendeslibronylibreta.blogspot.com/

${ }^{127}$ La permanente actualización de contenidos en el blog de la biblioteca, así como en sus cuentas de Facebook, ISSUU, Youtube, Scoopit y Pinterest, es un indicador de su alto nivel de integración dentro de la comunidad escolar y con otros agentes externos del ámbito educativo.

128 La red cooperativa aglutina cerca de 50 centros educativos de la provincia de Albacete y trabaja activamente desde 2010. El profesorado responsable de las bibliotecas conforma el Grupo Cooperativo Bibliotecas Escolares en Red (BERED) de la provincia de Albacete (https://bibliotecasescolaresenredalbacete.blogspot.com/). EI CEIP Virrey Morcillo actualmente coordina esta red cooperativa. 
muy comprometida con la puesta en valor de las bibliotecas escolares, y consciente de la necesidad de investigación en este ámbito. Se nos ha abierto pues la posibilidad de complementar y contrastar la información del CEIP Virrey Morcillo con la de otros centros de esta red. Este punto es importante, pues ha contribuido a la validación de los datos y a dar mayor solidez a su interpretación.

Respecto de las respuestas enviadas por los responsables de las bibliotecas del CEIP Condesa de Fenosa (O Barco de Valdeorras, Orense) y del CEIP Gerardo Diego (Los Corrales de Buelna, Cantabria), hemos decidido incluirlas en el análisis cualitativo, pues también han contribuido a la triangulación de la información resultante de nuestro caso de estudio. Las informaciones proporcionadas por ambos centros educativos se recogen en el Anexo 2. Su análisis se recoge en el apartado 4.3.1

\subsubsection{El caso de estudio: la biblioteca del CEIP Virrey Morcillo (Villarrobledo, Albacete)}

\subsection{El entorno del CEIP: el municipio de Villarrobledo y el Grupo Cooperativo Bibliotecas Escolares en Red (BERED)}

EI CEIP objeto de nuestro estudio de caso se emplaza en el municipio de Villarrobledo, situado en el noroeste de la provincia de Albacete y a cerca de $90 \mathrm{~km}$. de la ciudad de Albacete, dentro de la Comunidad Autónoma de Castilla-La Mancha.

Según datos del INE, este municipio registró una población total de 25.241 habitantes en 2018. El CEIP está situado en la calle Estación número 31, en la zona sur de Villarrobledo, a poca distancia de la estación de tren y cerca de instituciones como el Ayuntamiento, sito en la Plaza de Ramón y Cajal, la Iglesia de San Blas, el Centro de Servicios Sociales Virrey Morcillo, el Museo - Biblioteca Municipal, y la Casa de la Cultura.

Entre las actividades culturales de la localidad destaca el Plan Municipal de Lectura y Escritura (http://bibliotecas.villarrobledo.com/plan-lector) desarrollado por sus bibliotecas públicas en colaboración con los centros educativos del municipio. La biblioteca del CEIP Virrey Morcillo mantiene una relación de colaboración con su entorno sociocultural próximo, en el contexto de este Plan Municipal de Lectura. Esta colaboración se traduce en multitud de actividades de fomento de la lectura y actividades formativas que se desarrollan a lo largo del curso escolar y en los que participan el CEIP y las bibliotecas públicas de la localidad.

El centro forma parte del Grupo Cooperativo Bibliotecas Escolares en Red (BERED), una red cooperativa de bibliotecas escolares que aglutina cerca de 50 centros educativos de Castilla-La Mancha, en su mayor parte de la Provincia de Albacete. Esta 
red cooperativa trabaja activamente desde el curso 2010-2011, cuando un grupo de docentes comprometidos con el fomento de la lectura decidieron unirse para impulsar acciones de promoción de la lectura desde sus bibliotecas escolares.

Desde su constitución en el curso 2010-2011, este grupo de docentes bibliotecarios se ha venido reuniendo con una periodicidad mensual en los diferentes centros de la red, para compartir experiencia y conocimientos, desarrollar acciones formativas, hacer intercambios de lotes de libros, y hacer seguimiento de las líneas de trabajo que ellos mismos establecen con carácter anual. Estas líneas giran en torno a ocho objetivos. Los recogemos a continuación tal y como aparecen descritos en su blog (https://bibliotecasescolaresenredalbacete.blogspot.com/):

1) Configurar un grupo abierto y estable de docentes interesados en fomentar la lectura y las bibliotecas escolares en sus centros de referencia, facilitando el trabajo individual o de los equipos o comisiones de biblioteca respectivas mediante el trabajo cooperativo, la selección, producción y e intercambio de materiales, recursos y propuestas.

2) Potenciar la configuración de las bibliotecas escolares como agente de dinamización de nuestros centros educativos, un centro de recursos para el aprendizaje y la investigación para la comunidad escolar que genere procesos de aprendizaje y mejora de la escuela.

3) Mejorar la formación de los docentes implicados en la creación, gestión y dinamización de las bibliotecas escolares.

4) Analizar y diseñar propuestas compartidas que faciliten su extrapolación a los distintos centros coordinados fomentando el trabajo de la lectura y la escritura, la educación literaria, el fomento de la lectura, la educación documental y la alfabetización en información.

5) Compartir documentos, archivos, e inquietudes relacionados con la lectura y las bibliotecas escolares para facilitar la labor como responsables de los planes de lectura, escritura, investigación y bibliotecas de nuestros centros.

6) Necesidad de un trabajo sistemático, riguroso y con una base formativa adecuada. Por eso consideramos importante la formación y el diseño de proyectos anuales coordinados.

7) Compaginar el acompañamiento presencial regular con el uso de herramientas digitales con el fin de equilibrar los beneficios y dificultades de los enfoques existentes (presencial y online) en los procesos de trabajo colectivo.

8) Potenciar vías y actuaciones de coordinación con otros agentes implicados en el fomento de la lectura especialmente las bibliotecas públicas, creando redes de cooperación entre bibliotecas escolares y otras entidades.

En cuanto a la organización de la red cooperativa, desde 2016 cuenta con un equipo base encargado de coordinar las iniciativas del grupo. En el momento de la 
elaboración de esta tesis, este equipo ha estado encabezado por el responsable de coordinar la biblioteca del CEIP Virrey Morcillo.

Desde su constitución, el Grupo BERED ha funcionado como un grupo abierto, y cada año integra a nuevos miembros. En el momento de realización de esta tesis, estaba constituido por cuarenta y ocho profesores y profesoras de centros educativos de la Comunidad de Castilla-La Mancha, en su gran mayoría de la provincia de Albacete, incluyendo treinta y ocho centros de educación infantil y primaria (CEIPs), cinco institutos de educación secundaria (IESs) y cinco centros rurales agrupados (CRAs).

El Grupo BERED cuenta con su propio blog y su logo, y desarrolla una presencia activa en redes sociales a través de diferentes plataformas: Facebook (https://www.facebook.com/bibliotecasescolaresenredalbacete), Twitter (https://twitter.com/bibliotecasab).

En abril de 2014 recibieron el sello Buenas Prácticas Iberoamericanas de Leer.es otorgado por el Ministerio de Educación. Y en 2019, fueron galardonados con el Premio Día de la Enseñanza de Castilla-La Mancha, otorgado por la Consejería de Educación, Cultura y Deportes de la Junta de Comunidades de Castilla-La Mancha.

\subsection{EI CEIP Virrey Morcillo}

EI CEIP Virrey Morcillo es un centro de titularidad pública dependiente de la Junta de Comunidades de Castilla-La Mancha, a través de su Consejería de Educación, Cultura y Deporte. En el curso 2018-2019, el centro ha escolarizado a 450 alumnos y alumnas distribuidos en 6 unidades de educación infantil y 14 unidades de educación primaria. La ratio de estudiantes por grupo está en torno a 23-25 individuos y la mayoría procede de barrios cercanos al centro educativo.

El edificio se construyó entre 1988 y 1989 y consta de dos plantas. En la planta superior se encuentra la biblioteca. Además de las aulas y los despachos de dirección, secretaría, jefatura de estudios y AMPA, el centro alberga una sala para docentes, una sala multiusos, un comedor, un gimnasio, un aula de música, un aula multimedia dotada de recursos informáticos, y un patio de recreo que incluye una zona destinada al alumnado de los cursos de educación infantil y una zona para alumnado de los cursos de primaria dotada de equipamiento deportivo. El centro cuenta con equipamiento informático en todas sus aulas: ordenadores con acceso a Internet, proyector con pantalla, y pizarras digitales. El profesorado dispone de ordenadores portátiles, y los diferentes despachos disponen de ordenadores para los trabajos administrativos. También hay equipos reproductores de sonido de uso común. 
El equipo docente se compone de seis profesores y profesoras de educación infantil, catorce de educación primaria, tres de lengua inglesa, dos de educación física, uno de música, uno de pedagogía terapéutica y un orientador.

Respecto del alumnado, por lo general, alcanza unos buenos resultados académicos y tiene hábito de estudio, no registrándose ningún caso de absentismo escolar. Es interesante destacar que ha aumentado el alumnado procedente de otras nacionalidades, para los cuales el centro realiza distintas actuaciones con vistas a su plena integración. La mayoría del alumnado proviene de familias con situación socioeconómica media. La formación de padres y madres es de nivel medio y destaca su participación, interés y motivación por la formación de los hijos e hijas escolarizados en el centro.

Tal y como se refleja en la documentación del CEIP, (Colegio de Educación Infantil y Primaria Virrey Morcillo, 2009, pp. 8-10) los principios educativos y valores del centro son: el pluralismo ideológico y valores democráticos (marco de tolerancia, respeto al a libertad y convicciones personales, diálogo, respeto mutuo, colaboración y solidaridad, respeto y defensa del medioambiente, paz y no violencia, espíritu crítico, responsabilidad y participación); principios metodológicos (metodologías activas, atención a la diversidad, promoción de la autonomía del alumnado, uso de nuevas tecnologías y cooperación); modelo de centro (integrado con toda la comunidad educativa, participativo, abierto a la diversidad y al entorno, donde se potencia la convivencia).

Para lograr alcanzar este modelo de centro, el CEIP ha establecido para el curso 2018-2019 unos objetivos educativos y de aprendizaje, unos objetivos de ámbito institucional y administrativo, y objetivos vinculados al ámbito humano y de la convivencia. Para su consecución, se han establecido unas normas de convivencia, organización y funcionamiento, y se han desarrollado una programación didáctica y unos planes institucionales de respuesta a la diversidad del alumnado, entre los cuales se encuentra el Plan de Lectura, Escritura, Información y Biblioteca.

\subsection{La biblioteca del CEIP y el Plan de Lectura}

El Plan de Lectura, Escritura, Información y Biblioteca, es uno de los planes específicos principales del centro y se menciona de forma destacada en su documentación oficial (Colegio de Educación Infantil y Primaria Virrey Morcillo, 2009, 2017, 2018a, 2018b, 2018c, 2018d, 2018e). El primer Plan de Lectura se remonta al año 2005 y desde entonces se aprueba, se desarrolla y se evalúa con carácter anual, con la implicación de todos los miembros de la comunidad educativa (profesorado, equipo directivo, equipo de biblioteca, AMPA, autoridades educativas). 
El último Plan, aprobado para el curso 2018-2019, marca dos ejes principales de actuación:

1) El fomento de la lectura, la escritura y la educación literaria.

2) Leer para aprender e informarse.

Al amparo de estos dos ejes principales, se establecen seis líneas de trabajo alrededor de las cuales se desarrollan los objetivos del Plan:

1) Diseño, gestión y organización de la biblioteca escolar y del Plan de Lectura, Escritura, Información y Biblioteca.

2) Desarrollo curricular y fomento de la capacidad para informarse e investigar:

a. Formación de usuarios: conocer la biblioteca y aprender a usarla.

b. Competencia informacional y digital: los proyectos escolares de investigación documental.

c. Apoyo de la biblioteca a programas, proyectos, áreas y aulas.

3) Competencia lingüística y literaria, el fomento de la lectura y la escritura.

4) Implicación e interacción con la comunidad educativa y con el entorno para configurar la biblioteca como agente de dinamización cultural y compensador de necesidades.

5) Recursos y su gestión.

6) Difusión, supervisión y evaluación de la biblioteca escolar y del Plan de Lectura, Escritura, Información y Biblioteca (Colegio de Educación Infantil y Primaria Virrey Morcillo, 2018c, p.3).

La biblioteca del CEIP cuenta para su organización con un equipo de biblioteca formado por cinco docentes: un coordinador del Plan de Lectura, Escritura, Información y Biblioteca, una representante de educación infantil, y tres representantes de educación primaria, dos de las cuales imparten lengua inglesa. Además de este equipo de docentes, la biblioteca cuenta con la colaboración de un grupo de alumnos y alumnas de 5 ㅇ y 60 de educación primaria. Son los conocidos como ayudantes de biblioteca, y sus funciones se recogen en el reglamento de la biblioteca escolar. Se encargan de mantener la sala de lectura y consulta debidamente ordenada, colaboran en el préstamo de materiales, orientan a sus compañeros y compañeras de clase en sus búsquedas dentro de la colección bibliográfica, y desarrollan sesiones de animación para otros cursos. 
En el Plan se establece que "todos los maestros del claustro son profesores de lectura y su implicación constante asegura la integración curricular del Plan en todas las áreas y en todo tipo de contenido. Gracias a esto se desarrolla la competencia lectora" (Colegio de Educación Infantil y Primaria Virrey Morcillo, 2018c, p. 2).

Por último, se contempla en el Plan la creación de una comisión de biblioteca constituida por familias voluntarias.

La biblioteca se sitúa en la planta superior del edificio, en un lugar cercano a las aulas. El espacio cuenta con 88 metros cuadrados y en él se han diseñado varias áreas diferenciadas ${ }^{129}$ :

- La zona de gestión, con un ordenador para el préstamo de materiales y otras tareas bibliotecarias.

- La zona de acceso y difusión, ubicada junto a la entrada.

- La zona dedicada a la ficción, que incluye un espacio para la lectura relajada, materiales para nuevos lectores de 3 a 6 años, narrativa para lectores de 6 a 9 años, narrativa para lectores de 9 a 12 años, poesía, teatro, inglés y cómics para lectores de 6 a 9 años, y para lectores de 9 a 12 años, estanterías de libros de formato álbum, un mueble para actividades con títeres.

- La zona de información organizada según los números de la Clasificación Decimal Universal (CDU).

- Estanterías con materiales de interés para familias.

- La zona multimedia, que incluye un cañón, pizarra digital y ordenadores con acceso a Internet.

- Una zona central con puestos de lectura a disposición del alumnado.

El centro obtuvo en 2009 el Premio Nacional de Buenas Prácticas para la Dinamización e Innovación de las Bibliotecas de los Centros Escolares concedido por el Ministerio de Educación por la implicación de la biblioteca en el desarrollo del Plan de Lectura. Con estas palabras relataban los responsables de este centro los inicios del Plan de Lectura y la creación de la biblioteca, en su presentación a la convocatoria de 2009 del mencionado Premio Nacional:

129 Puede consultarse un plano de la biblioteca en la siguiente dirección: https://issuu.com/imanuelgarrido/docs/plano be ceipvirreymorcillo?embed cta=read more\&embed context=embed\&embed domain=duendeslibronylibreta.blogspot.com\&embed id=6250987\%252F2017116 
El origen de nuestro PLEB se remonta a la primera convocatoria que hizo la Consejería de Educación de Castilla-La Mancha para promover los proyectos de innovación sobre el Plan de Lectura y Uso de Bibliotecas. Nos remontamos con ello al año 2005. Por aquel entonces, la biblioteca ya estaba en el espacio específico para ello y lo primero que nos propusimos fue hacer de ella un lugar agradable. Así que, gracias a unos cuantos maestros y maestras de nuestro centro, genios del dibujo y el pincel, se pintaron las paredes con imágenes atractivas, llenas de color y relacionadas con personajes de cuentos. Así, tenemos un enorme dragón que escupe fuego, una Caperucita que se escapa de un castillo, una simpática abuela que lee cuentos, o un Gulliver gigante rodeado de "traviesos" liliputienses. Hicimos traslados de armarios, para que fueran todos iguales, y destinamos una zona a los más pequeños para cuentacuentos. La acondicionamos con un suelo cálido, con el fin de que pudieran sentarse a leer allí, y se delimitó con algunos expositores en los que los alumnos tienen a su alcance sus libros preferidos. De la misma manera, se han diferenciado la zona del bibliotecario, la de lectura para alumnos (con cinco mesas amplias) y una zona de entrada en la que se han dispuesto expositores y una mesa que utilizamos para recomendar libros y presentarlos de manera atractiva mediante objetos, carteles y decorados. Las estanterías se han organizado de manera vertical (cuatro o cinco estanterías completas para cada ciclo y una sección para familias y maestros) en siete zonas diferenciadas y señalizadas con atractivos carteles, con el mismo código de color que la sección infantil de la Biblioteca Municipal, asegurándonos un alto nivel de autonomía de los alumnos en ambas instalaciones (Ministerio de Educación, 2010, pp. 135-137).

Como se verá en los apartados siguientes, la documentación oficial refleja que la biblioteca escolar juega un papel muy destacado en la vida de este centro. Es un recurso que contribuye a la consecución de los objetivos del CEIP, tanto los objetivos vinculados a procesos de enseñanza y aprendizaje de competencias básicas, como los objetivos vinculados al desarrollo de la convivencia en la comunidad educativa, y los objetivos de cooperación con otros agentes del contexto educativo y social de la localidad.

La biblioteca cuenta con un blog (http://duendes-libronylibreta.blogspot.com.es) y un logo propio, y es muy activa en redes sociales. Actualmente está presente en las plataformas: Symbaloo (http://www.symbaloo.com/home/mix/bibliotecavirrey), Facebook (https://www.facebook.com/biblioteca.ceipvirreymorcillo), Youtube (https://www.youtube.com/user/bibliotecavirrey),

Pinterest (http://www.pinterest.com/bibliovirrey/), Issuu (http://issuu.com/biblioteca.virrey) y Slideshare (http://www.slideshare.net/bibliotecavirrey).

Retomando nuestras preguntas de investigación, podemos decir que el caso seleccionado es idóneo para registrar evidencias del efecto de la biblioteca escolar 
sobre los individuos, sus habilidades y comportamientos, sobre la institución de la que depende y sus objetivos educativos, y sobre el contexto social inmediato. En el apartado siguiente se aborda la fase de trabajo con los datos cualitativos: las estrategias y técnicas empleadas para su obtención, su análisis y posterior interpretación.

\subsection{Trabajo con los datos cualitativos}

\subsubsection{Estrategias y técnicas para la obtención de los datos y su análisis}

Para documentar el impacto de las bibliotecas hemos optado por un diseño de investigación orientado a la obtención de evidencias solicitadas ${ }^{130}$ a distintos agentes relacionados con el problema de investigación, combinado con el análisis de materiales documentales.

En la decisión de trabajar con evidencias solicitadas hemos sopesado la dificultad que entraña acceder a los potenciales informantes y conseguir su colaboración voluntaria para asegurarnos un nivel de respuestas suficiente para el análisis ${ }^{131}$. Ciertamente esta dificultad es menor cuando se decide trabajar con evidencias observadas ${ }^{132}$, donde el investigador registra con sus propias palabras aquello que

130 La norma ISO 16439 sobre evaluación del impacto en bibliotecas (Organización Internacional de Normalización, 2014b), define el conjunto de técnicas de obtención de evidencias solicitadas como:

Los métodos agrupados bajo "evidencia solicitada" emplean varias técnicas de preguntas a usuarios y no usuarios sobre su experiencia y estimación de los beneficios de la biblioteca. Los métodos comprenden preguntas escritas (encuestas), preguntas orales (entrevistas, grupos focales) y autoevaluación de usuarios (p. 28).

[Traducido del original: "The methods grouped under "solicited evidence" employ various techniques of questioning users and non-users about their experience and estimation of library benefits. The methods comprise written questioning (surveys), oral questioning (interviews, focus groups), and self-assessment of users" (p.28)].

${ }^{131}$ Esta decisión siempre implica cierto riesgo, ya que el progreso de la investigación depende en gran medida del nivel de respuesta que obtengamos en esta fase.

132 La norma ISO 16439 sobre evaluación del impacto en bibliotecas (Organización Internacional de Normalización, 2014b), define el conjunto de técnicas de obtención de evidencias observadas como:

Los métodos agrupados bajo "evidencia observada" emplean la observación del comportamiento del usuario en su contacto con los servicios bibliotecarios, incluyendo la observación directa de los investigadores, y la observación realizada con dispositivos como grabación en vídeo o análisis log. Se incluye la observación a uno mismo, es decir, cuando los usuarios registran sus avances en el aprendizaje. Se incluye el análisis de citas, en el sentido 
observa de manera más o menos autónoma; o con evidencias deducidas ${ }^{133}$, donde el investigador infiere el impacto producido a partir de datos estadísticos previos. Sin embargo, hemos descartado estas opciones por varios motivos. En primer lugar, hemos descartado trabajar con evidencias deducidas, ya que nuestro planteamiento para esta parte de la tesis ha sido trabajar con datos cualitativos de tipo verbal, para complementar a la inicial aproximación cuantitativa. En segundo lugar, hemos descartado trabajar con evidencias observadas, pues hemos querido capturar el impacto de la biblioteca tal y como es percibido y expresado por quienes consideramos que están en mejor disposición para hablar de ello debido a su experiencia.

Entre todos los miembros de la comunidad educativa, hemos seleccionado al profesorado más estrechamente vinculado a la biblioteca, bien por tener alguna responsabilidad en su organización o bien por ser usuarios asiduos. En esta decisión hemos aplicado el principio de pertinencia ${ }^{134}$ (Tójar Hurtado, 2006, p. 187), considerando que, el profesorado, por su conocimiento y experiencia, está en disposición de proporcionar una información más completa sobre nuestro tema de investigación.

Hay que decir que, en el transcurso de la investigación, se realizó una breve entrevista a un grupo de madres del CEIP Virrey Morcillo, en la que expresaron su percepción sobre los beneficios de contar con una biblioteca escolar para la educación de sus hijos e hijas. No obstante, hemos descartado estos contenidos de nuestro

de identificar los cambios que se producen en el manejo de las citas después del contacto con la biblioteca. Otra perspectiva se centra en los test utilizados para identificar la mejora en las habilidades y competencias después del contacto con la biblioteca, especialmente después de recibir formación informacional (p. 46).

[Traducido del original: "The methods grouped under "observed evidence" employ observation of user behaviour during contact with library services, including direct observation by researchers as well as observation by technical devices, e.g. via video-recording or log analysis. Self-observation, that is users' self-recording of their learning developments, is included. Citation analysis in the sense of identifying changes in citation behaviour after library contact is included. Another perspective focuses on tests, used for identifying an increase of skills and competences in users after library contact, especially after information literacy training" (p. 46)].

133 La norma ISO 16439 sobre evaluación del impacto en bibliotecas (Organización Internacional de Normalización, 2014b), define el conjunto de técnicas de obtención de evidencias deducidas como: "Ios datos que las bibliotecas recogen regularmente para sus estadísticas anuales, las evaluaciones que realizan mediante las mediciones de rendimiento y las encuestas de satisfacción de usuarios pueden utilizarse para identificar el impacto potencial" (p.24). [Traducido del original: "data that libraries collect regularly for their annual statistics or that they assess via performance measurement and user satisfaction surveys can be used for identifying potential impact" (p. 24)].

134 Como señala Tójar Hurtado (2006), "La pertinencia se refiere a la elección de las personas que mejor y más información pueden generar sobre la investigación” (p. 187). 
análisis y hemos preferido poner el foco sobre el impacto percibido por el profesorado aplicando el mismo criterio de pertinencia.

Por el mismo motivo hemos descartado una dinámica de debate alrededor de la biblioteca que realizamos en una clase de alumnos y alumnas de 5o curso de educación primaria. En este caso, además, hemos tenido presente que, como señala Shenton (2011), la realización de investigaciones cualitativas con menores de edad precisa de una metodología específica, lo cual queda fuera del alcance de esta investigación. Estos contenidos descartados del análisis se recogen en el Anexo 7.

Por otro lado, de acuerdo con el criterio de economía (Valles, 2014), hemos aplicado el principio de punto de saturación teórica ${ }^{135}$, según el cual no se ha establecido a priori un número mínimo de participantes, sino que la cantidad ha venido marcada por las necesidades específicas de la investigación.

En los apartados siguientes se explican las técnicas empleadas para obtener la información. Se han combinado varias técnicas de evidencia solicitada junto con un análisis documental. La utilización de diferentes técnicas obedece a dos motivos principales: por una parte, sirve para la triangulación de los datos, lo que contribuye a dar robustez a su interpretación. Por otra parte, se ensayan varias propuestas metodológicas para el análisis del impacto recogidas en la norma ISO 16439, lo que contribuye a la validación del texto normativo.

En los subapartados 4.3.1.1 a 4.3.1.6 se abordan las cinco técnicas utilizadas:

1) Cuestionario de respuestas abiertas respondido por el CEIP Condesa de Fenosa (O Barco de Valdeorras, Orense) y el CEIP Gerardo Diego (Los Corrales de Buelna, Cantabria).

2) Análisis de documentos oficiales de centros educativos integrados en el Grupo Cooperativo Bibliotecas Escolares en Red - BERED de la provincia de Albacete.

3) Encuesta dirigida al profesorado que integra el Grupo Cooperativo Bibliotecas Escolares en Red - BERED.

4) Análisis de documentos oficiales y noticias del blog del CEIP Virrey Morcillo.

5) Entrevistas a la dirección del CEIP Virrey Morcillo y al coordinador de su biblioteca y del Grupo Cooperativo Bibliotecas Escolares en Red - BERED.

135 Valles (2014) explica que: “El llamado punto de saturación teórica se alcanza cuando la información recogida resulta sobrada en relación con los objetivos de la investigación. Esto es, nuevas entrevistas (o, en su caso, nuevas observaciones o documentos) no añaden nada relevante a lo conocido" (p. 77). Sobre el mismo problema, Kvale (2011) aclara que: "El número necesario de sujetos depende del propósito del estudio (...), podrían realizarse nuevas entrevistas hasta alcanzar un punto de saturación en que más entrevistas produjeran poco conocimiento nuevo" (p. 70). 
6) Grupo de discusión con profesorado del CEIP Virrey Morcillo.

En cada uno de los subapartados se define la técnica de obtención de datos a la luz de la bibliografía consultada; se explican los motivos de su utilización en esta investigación, se describe su diseño, y se analizan los datos obtenidos. Como ya se expuso en el apartado metodológico de esta tesis, para realizar el análisis de los datos cualitativos se ha seguido un procedimiento en fases consecutivas (Massot Lafon, Dorio Alcaraz y Sabariego Puig, 2016, pp. 350-352; Simons, 2011, pp. 168-172; Tójar Hurtado, 2006, pp. 287-323):

1) Fase 1. Reducción de la información mediante la separación de las unidades de contenido relevante: se han subrayado aquellos fragmentos de los materiales cualitativos que son relevantes para responder a las preguntas de investigación.

2) Fase 2. Categorización de las unidades de contenido: se ha procedido a categorizar o etiquetar los fragmentos seleccionados según los temas clave de la investigación.

3) Fase 3. Síntesis y verificación de los contenidos: se han comprobado los términos, expresiones y conceptos repetidos, y se han buscado posibles patrones y relaciones entre las unidades de contenido.

4) Fase 4. Interpretación de los datos a la luz de las preguntas de investigación. Esta fase corresponde al apartado 4.3.2.

Se ha utilizado el programa especializado para análisis cualitativo ATLAS.ti (Versión $8)^{136}$. Se han integrado los contenidos en esta herramienta informática, y a continuación se han marcado y categorizado los fragmentos de texto relevantes para responder a las preguntas de investigación. En el procedimiento de categorización se ha seguido una estrategia de tipo mixto "inductiva-deductiva":

a) Por un lado, las categorías se han construido a partir de los contenidos analizados, y, por tanto, la información "emerge" de los datos cualitativos primarios. Las categorías sintetizan el contenido de los fragmentos seleccionados mediante palabras o cadenas de palabras.

b) Por otro lado, si bien no hemos aplicado en la categorización un esquema de descriptores preestablecido, sí hemos tenido presente las preguntas de investigación (véase la Tabla 1) como marco conceptual de referencia para construir las categorías y para establecer vínculos entre contenidos relacionados a nivel conceptual. En la Tabla 66 se recogen los descriptores

136 En ATLAS.ti (versión 8) los contenidos objeto de análisis se denominan "documentos primarios"; los fragmentos de texto que seleccionamos y marcamos se denominan "citas", y los términos que empleamos para realizar el etiquetado de los fragmentos reciben el nombre de "códigos". 
utilizados para categorizar los contenidos cualitativos, agrupados según su vinculación a las diferentes preguntas de investigación. 
Tabla 66. Descriptores utilizados para categorizar los contenidos cualitativos, agrupados según su vinculación a las diferentes preguntas de investigación

\begin{tabular}{|c|c|c|}
\hline & Preguntas de investigación & $\begin{array}{l}\text { Descriptores utilizados para categorizar } \\
\text { los contenidos cualitativos }\end{array}$ \\
\hline 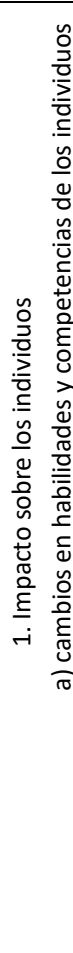 & $\begin{array}{l}\text { 4. ¿Tiene alguna influencia el hecho de tener biblioteca } \\
\text { en el centro educativo sobre el rendimiento académico en } \\
\text { competencia lectora? Y en caso afirmativo, ¿sobre qué } \\
\text { dimensiones competenciales se observa este impacto? } \\
\text { - comprender e interpretar textos literarios e } \\
\text { informativos } \\
\text { - ser competentes en obtener e inferir información a } \\
\text { partir de la lectura } \\
\text { críticamente la información obtenida en el entorno papel y } \\
\text { en el entorno digital y con los distintos tipos de material y } \\
\text { soportes bibliográficos } \\
\text { p. ¿Cómo influyen los distintos recursos, actividades o } \\
\text { competencia lectora? } \\
\text { 6. ¿En qué medida se producen cambios en habilidades } \\
\text { y competencias en el profesorado? }\end{array}$ & $\begin{array}{ll}\text { - } & \text { Aprendizaje autónomo } \\
\text { - } & \text { Aprender a usar Internet de manera } \\
\text { - } & \text { Celectiva } \\
\text { - } & \text { Competencia digital } \\
\text { - } & \text { Competencia lectora general } \\
\text { - } & \text { Competencias comunicativas y } \\
\text { - } & \text { Compüísticas } \\
\text { - } & \text { Debate de ideas con el alumnado } \\
\text { - } & \text { Desarrollo de la imaginación } \\
\text { - } & \text { Desarrollo del pensamiento crítico y } \\
\text { - } & \text { la reflexión } \\
\text { - } & \text { literarios } \\
\text { - } & \text { Actividades con familias } \\
\text { - } & \text { Actividades de fomento de la lectura } \\
\text { - } & \text { Biblioteca como lugar } \\
\text { - } & \text { Biblioteca digital y tradicional } \\
\text { - } & \text { Colección bibliográfica rica y variada } \\
\text { - } & \text { Lectura en familia } \\
\text { - } & \text { Lectura en silencio } \\
\text { - } & \text { Lectura en voz alta } \\
\text { - } & \text { Préstamo de de } \\
\text { bibliográficos }\end{array}$ \\
\hline 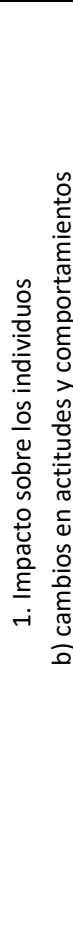 & $\begin{array}{l}\text { 6. ¿En qué medida frecuentar la biblioteca escolar } \\
\text { produce cambios en actitudes y comportamientos en el } \\
\text { alumnado? } \\
\text { 7. ¿En qué medida frecuentar la biblioteca escolar } \\
\text { produce cambios en actitudes y comportamientos en el } \\
\text { profesorado? }\end{array}$ & 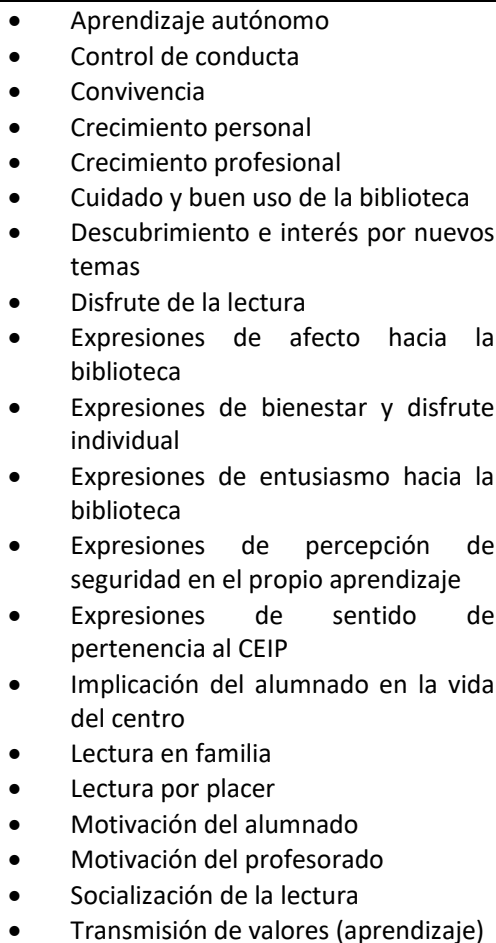 \\
\hline
\end{tabular}




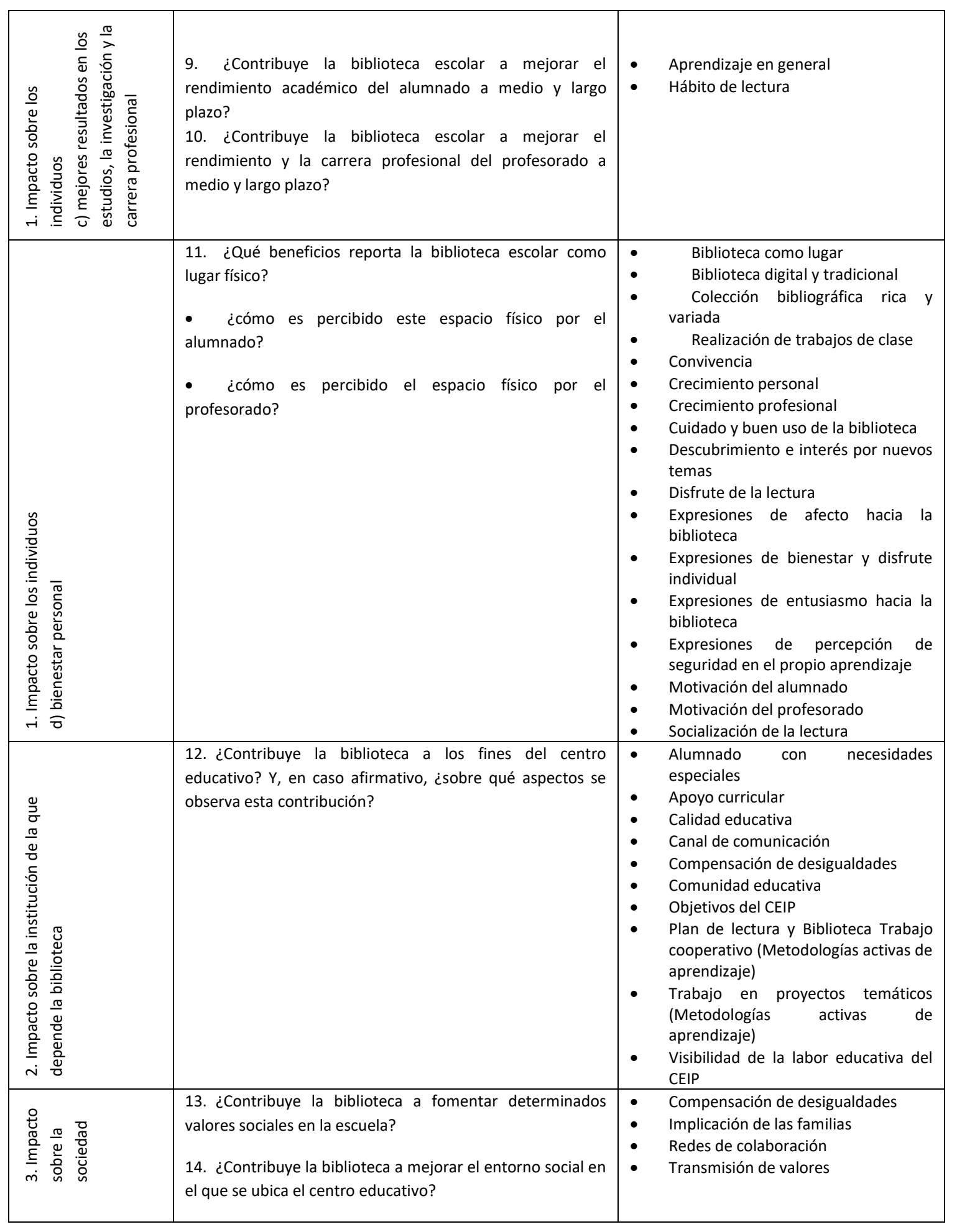

Veamos en los subapartados siguientes la aplicación de las distintas técnicas de obtención de información. 


\subsubsection{Respuestas enviadas por el profesorado responsable de las bibliotecas del CEIP Condesa de Fenosa (O Barco de Valdeorras, Orense) y del CEIP Gerardo Diego (Los Corrales de Buelna, Cantabria)}

Como ya se adelantó en el apartado 4.2.3, en este subapartado, se analiza la información proporcionada por el profesorado responsable de las bibliotecas del CEIP Condesa de Fenosa (O Barco de Valdeorras, Orense) y del CEIP Gerardo Diego (Los Corrales de Buelna, Cantabria), en respuesta al cuestionario que les enviamos, junto a otros diecisiete centros educativos españoles (véase el apartado 4.2).

El cuestionario de preguntas utilizado se recoge en la Tabla 65 y en él se indaga sobre su percepción de la contribución de la biblioteca escolar siguiendo el esquema de preguntas de investigación preestablecidas. Las respuestas proporcionadas por ambos centros educativos se recogen en el Anexo 2.

Hemos decidido incorporar este material cualitativo a nuestro análisis con vistas a la triangulación de la información resultante de nuestro caso de estudio. De este modo hemos podido contrastar la información proporcionada por nuestro CEIP con la de estos dos centros educativos pertenecientes a otras comunidades autónomas.

El contenido de las respuestas se ha analizado con ayuda del programa ATLAS.ti y siguiendo el procedimiento en fases consecutivas expuesto en el apartado 4.3.1. En la Tabla 67 se recogen los descriptores que hemos utilizado en el análisis de las informaciones proporcionadas por sendos centros educativos de Cantabria y Galicia. Junto a cada descriptor se ha registrado la frecuencia con la que se ha empleado cada uno en la fase de categorización de contenidos. Se han destacado en azul los descriptores que han alcanzado una frecuencia mayor que 1 sumando los resultados de los dos conjuntos de datos. A partir de este primer análisis, hemos observado que desde los centros educativos se han enfatizado los siguientes aspectos respecto de sus bibliotecas escolares:

- Adquisición y desarrollo de competencias: se destaca la incidencia de la biblioteca sobre competencias básicas y sobre la competencia lectora general del alumnado, en especial sobre sobre la competencia informacional, seguida de las competencias comunicativas y lingüísticas y la competencia digital. También se destaca su incidencia sobre la formación del profesorado.

- Incidencia de los recursos y actividades bibliotecarias sobre la formación del alumnado: se ponen en valor las actividades de fomento de la lectura, el espacio físico de la biblioteca, tener una colección bibliográfica amplia y variada y practicar la lectura en silencio. 
- Actitudes y comportamiento: se destaca el efecto de la biblioteca sobre la motivación del alumnado y del profesorado, sobre la interiorización de valores, sobre la socialización de la lectura y sobre el sentido de pertenencia al CEIP.

- Efecto sobre la institución: se destaca la importancia de la biblioteca en el refuerzo de la comunidad educativa en su conjunto, su papel en el desarrollo curricular, en la implantación de metodologías de aprendizaje proactivo, su contribución a la mejora de la calidad educativa y a dar visibilidad a la labor educativa del CEIP. Se resalta también su contribución a la convivencia dentro del CEIP.

- Efecto sobre el entorno social: se destaca la participación de la biblioteca escolar en redes de colaboración y su papel facilitador en la implicación de las familias en la vida del CEIP.

Tabla 67. Análisis de las informaciones proporcionadas por los centros educativos CEIP Gerardo Diego (Los Corrales de Buelna, Cantabria) y CEIP Condesa de Fenosa (O Barco de Valdeorras, Ourense). Categorización de los datos primarios empleando el programa ATLAS.ti

\begin{tabular}{|c|c|c|}
\hline \multirow[b]{2}{*}{$\begin{array}{l}\text { Descriptores utilizados en el análisis para la categorización de } \\
\text { los contenidos }\end{array}$} & \multicolumn{2}{|c|}{$\begin{array}{l}\text { Número de veces que se emplean los descriptores en el } \\
\text { análisis de contenidos }\end{array}$} \\
\hline & $\begin{array}{l}\text { Información proporcionada } \\
\text { por el CEIP Gerardo Diego (Los } \\
\text { Corrales de Buelna, } \\
\text { Cantabria) }\end{array}$ & $\begin{array}{l}\text { Información proporcionada por } \\
\text { el CEIP Condesa de Fenosa (O } \\
\text { Barco de Valdeorras, Ourense) }\end{array}$ \\
\hline Actividades con familias & 1 & \\
\hline Actividades de fomento de la lectura & 5 & 1 \\
\hline Alumnado con necesidades especiales & & 1 \\
\hline Apoyo curricular & 2 & \\
\hline Aprendizaje en general & 1 & \\
\hline Aprendizaje autónomo & 1 & \\
\hline Biblioteca como lugar & 1 & 2 \\
\hline Biblioteca digital y tradicional & 1 & \\
\hline Calidad educativa & 1 & 1 \\
\hline Canal de comunicación & 1 & \\
\hline Colección bibliográfica rica y variada & 1 & 1 \\
\hline Compensación de desigualdades & & 1 \\
\hline Competencia digital & & 2 \\
\hline Competencia informacional & & 4 \\
\hline Competencia lectora general & 2 & 3 \\
\hline Competencias comunicativas y lingüísticas & 2 & \\
\hline Competencias sociales & 1 & \\
\hline Comunidad educativa & 5 & 1 \\
\hline Control de conducta & 1 & \\
\hline Convivencia & 4 & 1 \\
\hline Crecimiento personal & 1 & \\
\hline Cuidado y buen uso de la biblioteca & & 1 \\
\hline Expresiones de afecto hacia la biblioteca & & 1 \\
\hline Expresiones de sentido de pertenencia al CEIP & 4 & 1 \\
\hline Formación del profesorado & 1 & 3 \\
\hline Hábito de la lectura & 1 & \\
\hline Implicación de las familias & 3 & \\
\hline
\end{tabular}




\begin{tabular}{|l|c|c|}
\hline Lectura en silencio & & 2 \\
\hline Lectura en voz alta & 5 & 1 \\
\hline Motivación del alumnado & 7 & 3 \\
\hline Motivación del profesorado & 3 & 2 \\
\hline Redes de colaboración & 2 & 2 \\
\hline Refuerzo de competencias básicas & 3 & 1 \\
\hline Socialización de la lectura & 5 & 3 \\
\hline Trabajo cooperativo (Metodologías activas de aprendizaje) & 3 & 1 \\
\hline $\begin{array}{l}\text { Trabajo en proyectos temáticos (Metodologías activas de } \\
\text { aprendizaje) }\end{array}$ & & \\
\hline Transmisión de valores & 4 & 1 \\
\hline Visibilidad de la labor educativa del CEIP & 2 & \\
\hline
\end{tabular}

\subsubsection{Análisis de documentos oficiales de centros educativos integrados en el Grupo Cooperativo Bibliotecas Escolares en Red - BERED de la provincia de Albacete}

Creemos como Simons (2011) que el análisis de los documentos sirve para "dar mayor profundidad al caso" (p. 97). En esta investigación hemos decidido utilizar esta metodología con la finalidad de contextualizar nuestro caso de estudio. Antes de adentrarnos en él, hemos aplicado el análisis documental a otros centros educativos de la red cooperativa de bibliotecas escolares BERED, con el fin de evaluar a qué fines sirve la biblioteca escolar en estos centros. Los resultados se han empleado en la posterior triangulación de conclusiones.

El procedimiento de trabajo ha consistido en realizar una búsqueda de los documentos oficiales disponibles en las páginas web de los cuarenta y ocho centros educativos de la red en los que aparecía mencionada la biblioteca escolar. Como resultado de esta búsqueda, se han seleccionado treinta y tres documentos de quince centros diferentes, incluyendo memorias, planes de lectura y biblioteca, normas de convivencia, propuestas curriculares, programaciones anuales y proyectos educativos de centro (véase el listado en la Tabla 68). Los documentos originales se adjuntan en el Anexo 3.

Tabla 68. Relación de documentos oficiales de centros educativos del Grupo Cooperativo $B E R E D$ seleccionados para la realización de análisis documental

\begin{tabular}{|l|l|}
\hline Centros Educativos & Documentos seleccionados \\
\hline $\begin{array}{l}\text { Biblioteca escolar del CEIP Ana } \\
\text { Soto (Albacete). }\end{array}$ & $\begin{array}{l}\text { Plan de Trabajo Comisión de Biblioteca Escolar y Plan de Lectura } \\
\text { Normas de la Biblioteca } \\
\text { http://www.colegioanasoto.es/para-alumnos-as/nuestra-biblioteca/ }\end{array}$ \\
\hline $\begin{array}{l}\text { Biblioteca escolar del CEIP } \\
\text { Benjamín Palencia (Albacete). }\end{array}$ & $\begin{array}{l}\text { Plan General de Actuaciones } \\
\text { http://ceip-benjaminpalenciaalbacete.centros.castillalamancha.es/ }\end{array}$ \\
\hline $\begin{array}{l}\text { Biblioteca escolar del CEIP } \\
\text { Cristóbal Valera (Albacete). }\end{array}$ & $\begin{array}{l}\text { Normas de Convivencia, Organización y Funcionamiento } \\
\text { Programación General Anual }\end{array}$ \\
\hline
\end{tabular}




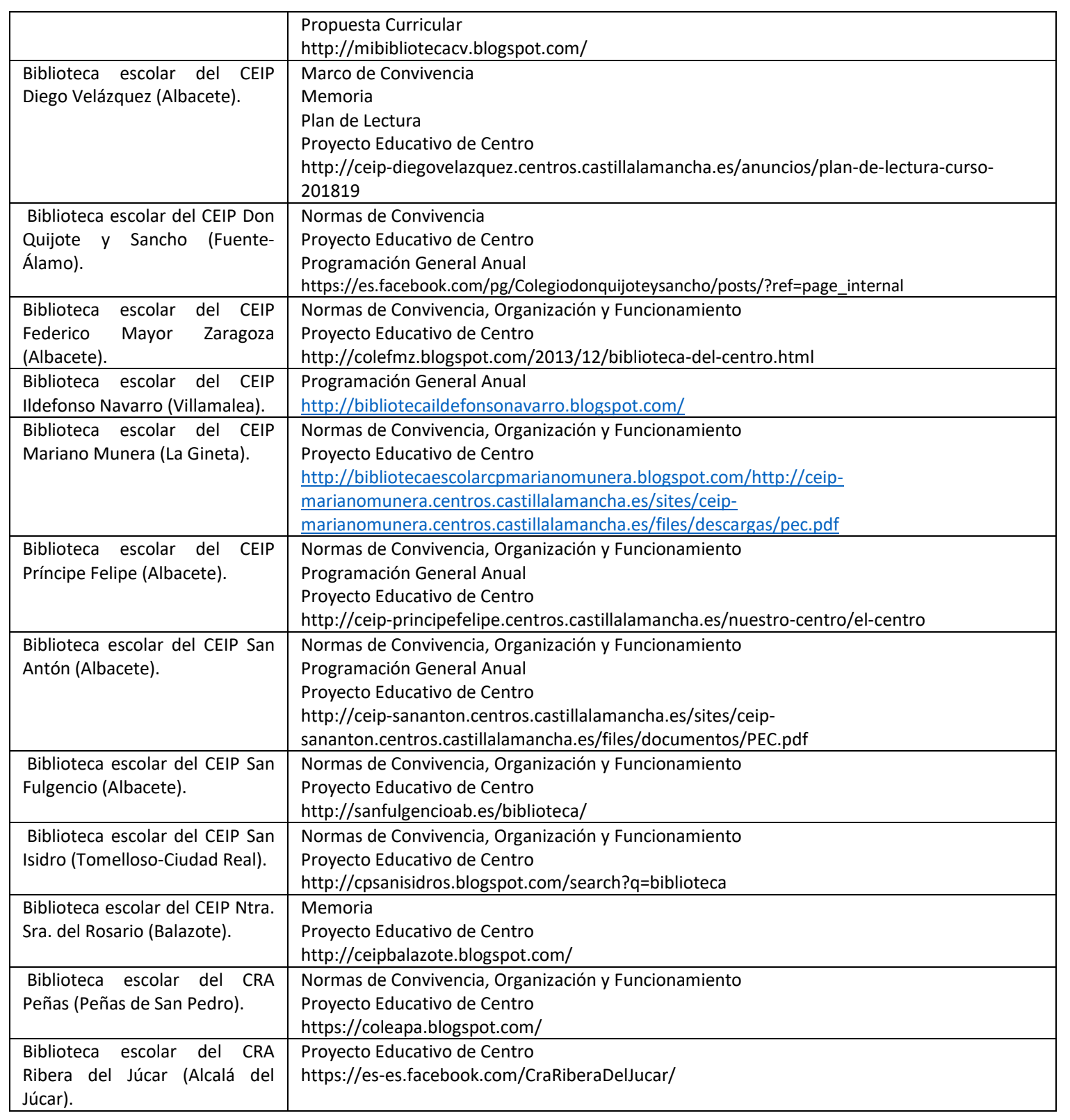

Una vez realizada esta búsqueda, hemos procedido a realizar su análisis con ayuda del programa ATLAS.ti y siguiendo el procedimiento en fases consecutivas expuesto en el apartado 4.3.1. En la Tabla 69 se recogen los descriptores que hemos utilizado en el análisis de los documentos. Junto a cada descriptor se ha registrado la frecuencia con la que se ha empleado cada uno en la fase de categorización de contenidos. Se han destacado en azul los descriptores que han alcanzado una frecuencia mayor que 1. A partir de este primer análisis, hemos observado que en la documentación consultada de los centros educativos de la red cooperativa se enfatizan los siguientes aspectos respecto de sus bibliotecas escolares:

- Adquisición y desarrollo de competencias: se destaca la incidencia de la biblioteca sobre la competencia lectora general, y sobre competencias más específicas como la informacional, las habilidades comunicativas y lingüísticas, 
la competencia digital, la experiencia literaria, el desarrollo del pensamiento crítico y la creatividad del alumnado. También se destaca su incidencia sobre la formación del profesorado.

- Incidencia de los recursos y actividades bibliotecarias sobre la formación del alumnado: en primer lugar, se ponen en valor las actividades de fomento de la lectura, la colección bibliográfica rica y variada y su préstamo, y el espacio de la biblioteca. En segundo lugar de importancia, se resaltan las actividades con familias, la práctica de la lectura en silencio y en voz alta.

- Actitudes y comportamiento: se destaca el efecto de la biblioteca sobre la motivación de alumnado y profesorado, sobre la socialización de la lectura entre el alumnado, y la inculcación del disfrute de la lectura. También se observa su papel facilitador en el control de conductas y en la inculcación de comportamientos cívicos, como el cuidado y respeto por los bienes compartidos.

- Efecto de la biblioteca a medio y largo plazo: se percibe su beneficio sobre el aprendizaje en general y en el refuerzo del aprendizaje autónomo.

- Efecto sobre la institución: se destaca la importancia de la biblioteca para la consecución de los objetivos de los centros educativos, para el desarrollo curricular, las dinámicas de trabajo cooperativo y en proyectos, y para reforzar la comunidad educativa funcionando como canal de comunicación.

- Efecto sobre el entorno social: se destaca la participación de la biblioteca escolar en redes de colaboración y su papel facilitador en la implicación de las familias en la vida del CEIP.

Tabla 69. Análisis de documentos oficiales de centros educativos integrados en el Grupo Cooperativo Bibliotecas Escolares en Red - BERED de la provincia de Albacete. Categorización de los datos primarios empleando el programa ATLAS.ti

\begin{tabular}{|l|c|}
\hline $\begin{array}{l}\text { Descriptores utilizados en el análisis para la categorización de } \\
\text { los contenidos }\end{array}$ & $\begin{array}{c}\text { Número de veces que se emplean los descriptores en el análisis } \\
\text { de contenidos }\end{array}$ \\
\hline Actividades con familias & 5 \\
\hline Actividades de fomento de la lectura & 14 \\
\hline Apoyo curricular & 11 \\
\hline Aprendizaje en general & 7 \\
\hline Aprendizaje autónomo & 1 \\
\hline Biblioteca como lugar & 11 \\
\hline Biblioteca digital y tradicional & 2 \\
\hline Calidad educativa & 1 \\
\hline Canal de comunicación & 2 \\
\hline Colección bibliográfica rica y variada & 14 \\
\hline Competencia digital & 4 \\
\hline Competencia informacional & 7 \\
\hline Competencia lectora general & 10 \\
\hline
\end{tabular}




\begin{tabular}{|c|c|}
\hline Competencias comunicativas y lingüísticas & 7 \\
\hline Comunidad educativa & 6 \\
\hline Control de conducta & 9 \\
\hline Convivencia & 1 \\
\hline Cuidado y buen uso de la biblioteca & 10 \\
\hline Desarrollo de la imaginación y la creatividad & 2 \\
\hline Desarrollo del pensamiento crítico y la reflexión & 4 \\
\hline Disfrute de la lectura & 8 \\
\hline Experiencia y conocimientos literarios & 3 \\
\hline Expresiones de sentido de pertenencia al CEIP & 1 \\
\hline Formación del profesorado & 7 \\
\hline Implicación de las familias & 7 \\
\hline Implicación del alumnado en la vida del centro & 1 \\
\hline Lectura en silencio & 2 \\
\hline Lectura en voz alta & 4 \\
\hline Lectura por placer & 4 \\
\hline Motivación del alumnado & 14 \\
\hline Motivación del profesorado & 12 \\
\hline Objetivos del CEIP & 35 \\
\hline Plan de lectura y Biblioteca & 23 \\
\hline Préstamo de materiales bibliográficos & 12 \\
\hline Redes de colaboración & 14 \\
\hline Refuerzo de competencias básicas & 2 \\
\hline Socialización de la lectura & 10 \\
\hline Trabajo cooperativo (Metodologías activas de aprendizaje) & 4 \\
\hline $\begin{array}{l}\text { Trabajo en proyectos temáticos (Metodologías activas de } \\
\text { aprendizaje) }\end{array}$ & 4 \\
\hline Visibilidad de la labor educativa del CEIP & 1 \\
\hline
\end{tabular}

\subsubsection{Encuesta dirigida al profesorado que integra el Grupo Cooperativo Bibliotecas Escolares en Red - BERED de la provincia de Albacete}

Esta encuesta ha seguido el modelo de "encuestas de impacto ${ }^{137 ", ~ t a l ~ y ~ c o m o ~ l a s ~}$ denomina la norma ISO 16439. Su finalidad ha sido doble: por un lado, registrar la percepción de los docentes sobre la contribución de la biblioteca escolar a la adquisición y desarrollo de las cuatro dimensiones de la competencia lectora ya observadas en el análisis de los datos PIRLS 2016 (1. Tener una experiencia literaria; 2. Adquirir y usar la información; 3. Obtener información e inferencias directas; 4.

137 La norma ISO 16439 sobre evaluación del impacto en bibliotecas (Organización Internacional de Normalización, 2014b), define la encuesta de impacto como:

Las encuestas de impacto (...) añaden una nueva dimensión: preguntan sobre los efectos especialmente efectos beneficiosos - del contacto con la biblioteca. Se pude preguntar por: influencias que los usuarios han experimentado individualmente; influencias que ellos piensan que tienen las bibliotecas (p. 28).

[Traducido del original: "Impact surveys (...) add a new dimension: they ask about the effects especially beneficial effects - of library contact. The impact survey can ask for: influences that users experienced individually; influences that they think libraries normally have" (p.28)]. 
Interpretar, integrar y evaluar), y por otro lado, registrar su percepción sobre el grado de contribución de los distintos recursos bibliotecarios a estas competencias.

El contenido íntegro de la encuesta y sus resultados se pueden consultar en el Anexo 4 de esta tesis. La encuesta se compone de veintiuna preguntas organizadas en tres bloques:

1) Comprensión de textos literarios e informativos en distintos soportes

2) Localización, obtención y elaboración de información

3) Recursos y actividades de la biblioteca escolar

Todas las preguntas son de respuesta obligatoria y cerrada entre un número limitado de opciones:

- una pregunta de alternativa simple si/no

- una pregunta de opción múltiple para escoger entre tres alternativas

- nueve preguntas para elegir una opción dentro de una escala de acuerdo de cero a cinco

- diez preguntas para elegir una opción dentro de una escala de importancia de cero a diez

La encuesta se ha diseñado y se ha distribuido en forma de formulario en línea utilizando la herramienta "Google Forms". Sus destinatarios han sido cuarenta y ocho profesores y profesoras de centros de educación primaria y secundaria del Grupo Cooperativo Bibliotecas Escolares en Red - BERED. Hemos contado con la ayuda del coordinador de la BERED para la distribución del formulario a través de una lista de distribución. Se han recibido cuarenta y siete respuestas, el 98 \% de los encuestados.

Las Tablas 70 y 71 recogen los resultados de la encuesta. El $98 \%$ de los encuestados han respondido que están de acuerdo con que su biblioteca escolar sirve de ayuda para mejorar los resultados del alumnado en competencia lectora. Solo se ha recibido una respuesta en sentido negativo.

Con relación a la competencia lectora con textos literarios, la mayoría de encuestados han confirmado la influencia positiva de la biblioteca escolar sobre los siguientes aspectos:

- El 84,7 \% está de acuerdo o muy de acuerdo con que la biblioteca contribuye a que el alumnado aprenda a diferenciar los distintos géneros literarios (poesía, teatro, narrativa, etc.).

- El 80,5 \% está de acuerdo o muy de acuerdo con que la biblioteca contribuye a que el alumnado aprenda a enfrentarse a textos literarios que tienen cierta dificultad. Solo un encuestado está en desacuerdo con esta afirmación, y ocho 
no se declaran ni muy de acuerdo ni en desacuerdo.

Con relación a la competencia lectora con textos informativos:

- El 76,1 \% está de acuerdo o muy de acuerdo con que la biblioteca contribuye a que el alumnado aprenda a enfrentarse a textos científicos, históricos, geográficos, sociales, etc. y a diferenciar las distintas formas de presentar la información (texto, tablas, gráficos, resúmenes, etc.). El 4,3\% (2 respuestas) está en desacuerdo con esta afirmación, y el 19,6 \% (9 respuestas) no se han manifestado ni muy de acuerdo ni en desacuerdo.

Con relación a la competencia en localización y obtención de información e inferencias directas, y a interpretarla, integrarla y evaluarla:

- El 87 \% está de acuerdo o muy de acuerdo con que la biblioteca contribuye a que el alumnado aprenda a buscar y a obtener información en fuentes de diferente formato (diccionarios, enciclopedias, manuales, la web, etc.). El $11 \%$ (5 respuestas) está en desacuerdo con esta afirmación.

- El 91,3 \% está de acuerdo o muy de acuerdo con que la biblioteca contribuye a que el alumnado aprenda a identificar los contenidos con los que más disfruta y aquéllos que más despiertan su interés.

- El 73,9 \% está de acuerdo o muy de acuerdo con que la biblioteca contribuye a que el alumnado aprenda a seleccionar de una manera crítica las fuentes más adecuadas para obtener la información que necesita. El 6,5 \% (3 respuestas) está en desacuerdo con esta afirmación y el 19,6 \% (9 respuestas) no se manifiesta ni muy de acuerdo ni en desacuerdo).

- El 65,2 \% está de acuerdo o muy de acuerdo con que la biblioteca contribuye a que el alumnado aprenda a discriminar la información relevante en los textos donde busca. El 8,7 \% (4 respuestas) está en desacuerdo con esta afirmación. En esta pregunta ha habido un número destacable de encuestados (el 26,1 \%, 12 respuestas) que no se han declarado ni muy de acuerdo ni en desacuerdo.

- El 67,4 \% está de acuerdo o muy de acuerdo con que la biblioteca contribuye a que el alumnado aprenda a extraer conclusiones a partir de lo que lee y sabe resumirlas. El 4,3\% (2 respuestas) está en desacuerdo con esta afirmación. Igual que en el caso anterior, en esta pregunta ha habido un número destacable de encuestados (el 28,3\%, 13 respuestas) que no se han declarado ni muy de acuerdo ni en desacuerdo.

- El 80,5 \% está de acuerdo o muy de acuerdo con que la biblioteca contribuye a que el alumnado aprenda a expresar en público la información que ha localizado o el libro que ha leído. El 4,3 \% (2 respuestas) está en desacuerdo con esta afirmación. 
Respecto de los recursos (incluyendo servicios y actividades) de la biblioteca escolar y su influencia sobre la competencia lectora, todos ellos han alcanzado una valoración alta: de los diez recursos, ocho han alcanzado una puntuación media de 80 más puntos en una escala de cero a diez.

El recurso más valorado por el profesorado es la colección bibliográfica (ha recibido una puntuación media de 9,07), cuando ésta es amplia, actualizada y adaptada a las distintas edades y ciclos formativos. El hecho de contar con una amplia oferta de los distintos géneros literarios (poesía, teatro, narrativa, etc.) recibe también una valoración alta (puntuación media de 8,72 ).

En segundo lugar de importancia, está el hecho de que la biblioteca esté integrada dentro del proyecto formativo del centro y su vinculación expresa con el plan de lectura (puntuación media de 8,91). Le sigue en tercer lugar de importancia el espacio físico de la biblioteca, cuando está adaptado y abierto a la comunidad escolar (puntuación media de 8,8).

El profesorado considera que es importante adquirir una formación bibliotecaria. Esta formación alcanza una valoración media de 8,52 puntos.

Entre las actividades organizadas por la biblioteca, la más valorada es la lectura con familias (puntuación media de 8,28), seguida de las actividades de alfabetización informacional (puntuación media de 8,22), la lectura en silencio (puntuación media de 8,09 ), la lectura en voz alta de textos (puntuación media 7,91) y el acceso a Internet y a nuevas tecnologías, que es el recurso menos valorado, alcanzando una puntuación media de 7,76.

Si se observa en conjunto, los recursos más valorados son los recursos materiales, (incluyendo la colección y el espacio), junto con que la biblioteca esté presente en el proyecto educativo y la formación del profesorado. Por debajo de ellos están las distintas actividades organizadas por la biblioteca. 
Tabla 70. Resultados de la encuesta realizada a los representantes del Grupo Cooperativo Bibliotecas Escolares en Red - BERED (provincia de Albacete) sobre su percepción de la contribución de la biblioteca escolar en el ámbito de la competencia lectora del alumnado (datos: valoración en una escala de 0 a 5 donde 0 es "muy en desacuerdo" y 5 es "muy de acuerdo")

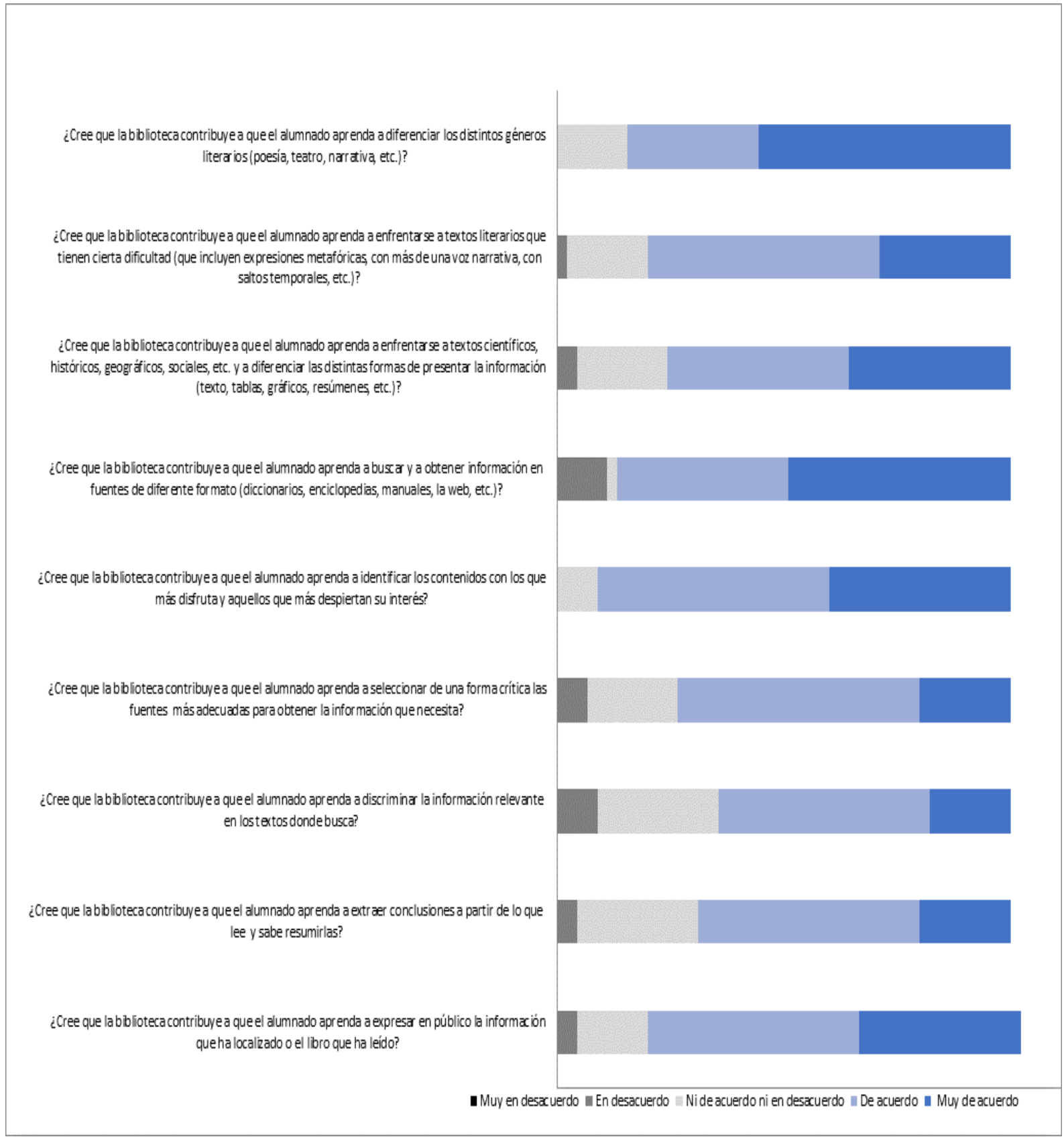


Tabla 71. Resultados de la encuesta realizada a los representantes del Grupo Cooperativo Bibliotecas Escolares en Red - BERED Valoración de la incidencia de los distintos recursos bibliotecarios sobre la competencia lectora del alumnado (dato: puntuación media en una escala de 0 a 10)

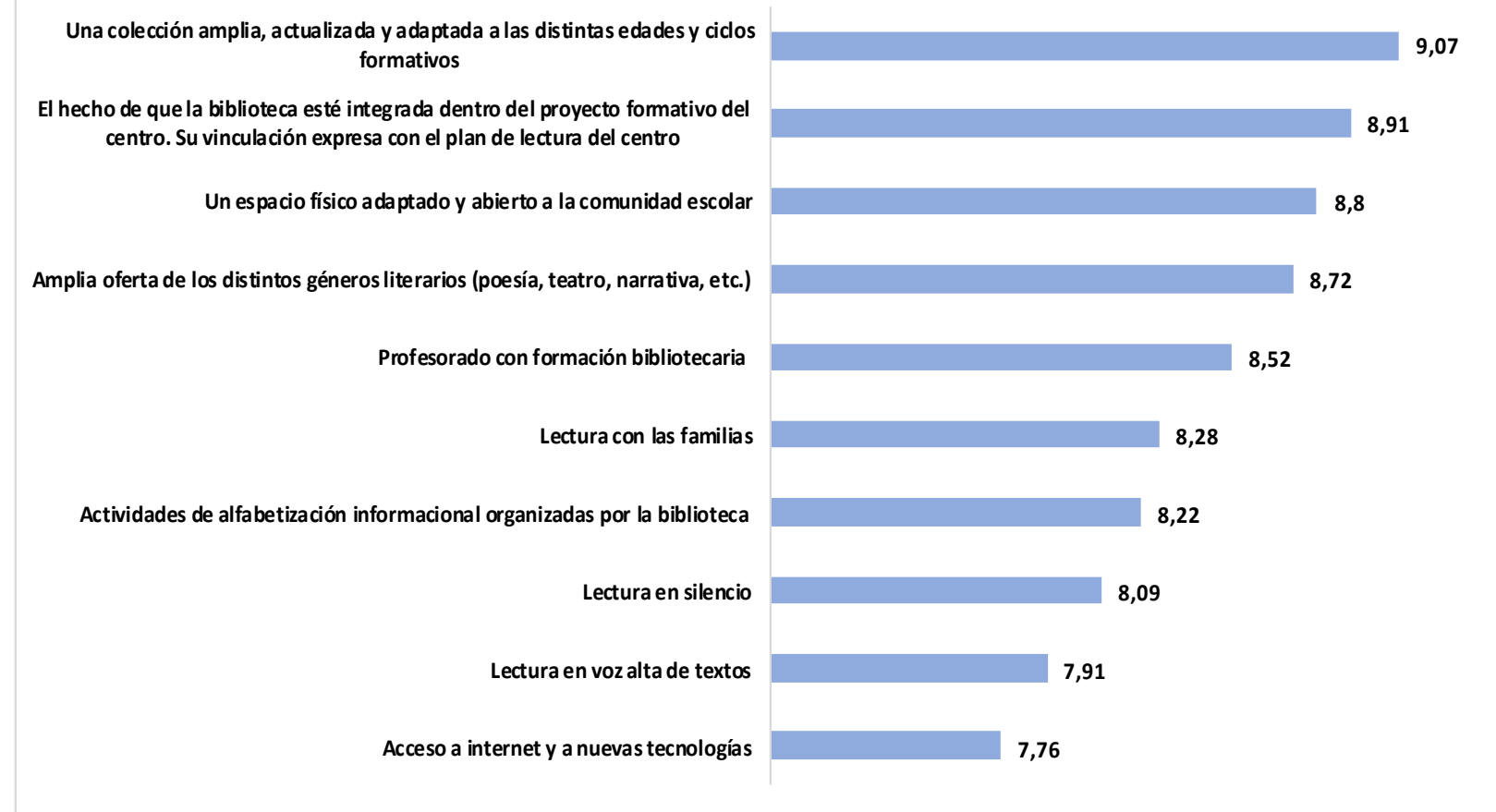

\subsubsection{Análisis de documentos oficiales y noticias del blog del CEIP Virrey Morcillo}

Como ya se ha apuntado en el subapartado 4.3.1.2, siguiendo a Simons (2011), hemos empleado la metodología del análisis documental con la finalidad de comprender mejor el contexto educativo en el que se encuadra el CEIP Virrey Morcillo y evaluar a qué fines sirve la biblioteca escolar dentro de la institución educativa según se desprende de estos documentos.

El procedimiento de trabajo ha consistido en realizar una búsqueda de los documentos disponibles en la web del CEIP. Una vez realizada esta búsqueda, hemos procedido a clasificarlos según su tipología. Hemos encontrado dos grandes grupos de documentos de interés para la investigación:

1) Documentos de carácter oficial. Se han seleccionado aquéllos en los que se menciona expresamente la biblioteca:

- La última Memoria publicada correspondiente al año 2017-2018.

- Las Normas de Convivencia, Organización y Funcionamiento aprobadas en el curso 2009/2010 y actualizadas en el año 2018. 
- El Plan de Lectura, Escritura, Información y Biblioteca Escolar correspondiente al curso 2018-2019. También se han consultado los planes publicados en sus sucesivas ediciones desde 2011, acompañados de sus respectivas memorias de seguimiento ${ }^{138}$.

- La Programación Anual de Actuaciones del Equipo de Orientación y Apoyo correspondiente al curso 2018-2019.

- La Programación General Anual correspondiente al curso 2018-2019.

- La Propuesta Curricular aprobada en el año 2017.

- El Proyecto Educativo de Centro aprobado en el curso 2009/2010.

Los documentos originales se recogen en el Anexo 5.

2) Noticias publicadas dentro del blog de la biblioteca del CEIP, cuya autoría corresponde al profesorado responsable de la biblioteca. El alcance cronológico de las noticias abarca desde el año 2010 hasta junio de 2019, y en ellas se combinan el texto con el vídeo, ilustraciones y fotografías. Se han seleccionado aquellas noticias cuyo contenido informativo guarda alguna relación con las preguntas de investigación. Se han eliminado los nombres propios y se han suprimido aquellas fotografías y vídeos que no añaden contenido informativo nuevo. Las noticias seleccionadas se pueden agrupar en los siguientes bloques temáticos: inauguración de la biblioteca; actividades con familias; actividades con las bibliotecas municipales de Villarrobledo; actividades con y sobre autores e ilustradores; actividades en torno a valores universales; actividades de formación de usuarios; participación del alumnado en la organización y mantenimiento de la biblioteca; celebraciones; certámenes de poesía; noticias sobre la colección bibliográfica; premios y reconocimientos.

La recopilación de noticias analizadas se recoge en el Anexo 6.

Los documentos se han analizado con ayuda del programa ATLAS.ti y siguiendo el procedimiento en fases consecutivas expuesto en el apartado 4.3.1. En la Tabla 72 se recogen los descriptores que hemos utilizado en el análisis de los documentos oficiales y las noticias del blog del CEIP. Junto a cada descriptor se ha registrado la frecuencia con la que se ha empleado cada uno en la fase de categorización de contenidos. Se han destacado en azul los descriptores que han alcanzado una frecuencia mayor que 1. A partir de este primer análisis, hemos observado que en la documentación

\footnotetext{
138 Las ediciones del Plan de Lectura y Biblioteca desde 2011 se encuentran disponibles para su consulta en línea en el blog del CEIP Virrey Morcillo (http://duendeslibronylibreta.blogspot.com/search/label/PLEIB).
} 
consultada se desprenden los siguientes aspectos respecto de la biblioteca escolar del CEIP:

- Adquisición y desarrollo de competencias: se destaca la incidencia de la biblioteca sobre la competencia lectora general, y sobre competencias más específicas, como la competencia informacional, la experiencia literaria, la competencia digital, el desarrollo de la creatividad y el pensamiento crítico, y en menor medida, sobre las habilidades sociales del alumnado. También se aprecia la incidencia sobre la formación del profesorado.

- Incidencia de los recursos y actividades bibliotecarias sobre la formación del alumnado: se destaca la incidencia de tener una colección bibliográfica amplia y variada, el préstamo de materiales, el espacio físico de la biblioteca. Entre las actividades, se destacan las de fomento de la lectura, las actividades con familias, y la lectura en voz alta.

- Actitudes y comportamiento: se destaca la contribución de la biblioteca a la motivación del alumnado y del profesorado, la socialización de la lectura y el aprendizaje de su disfrute, sobre el refuerzo del sentido de pertenencia al CEIP y en el aprendizaje de valores y comportamientos cívicos, como el cuidado y buen uso de los recursos comunes.

- Efecto de la biblioteca a medio y largo plazo, en particular sobre el aprendizaje en general y sobre la autonomía del alumnado en el proceso de aprendizaje, y sobre la formación de futuros lectores.

- Efecto sobre la institución: destaca la importancia de la biblioteca para la consecución de los objetivos del CEIP, para la implantación de metodologías de aprendizaje proactivo, su utilidad para el apoyo curricular, y en la compensación de desigualdades, incluyendo las actuaciones diseñadas para el alumnado con necesidades especiales. Asimismo, funciona como canal de comunicación y como indicador de calidad educativa.

- Efecto sobre el entorno social: se destaca la participación de la biblioteca escolar en redes de colaboración, en la transmisión de valores y su papel facilitador en la implicación de las familias en la vida del CEIP.

Tabla 72. Análisis de documentos oficiales y noticias del blog del CEIP Virrey Morcillo. Categorización de los datos primarios empleando el programa ATLAS.ti

\begin{tabular}{|l|c|l|}
\hline \multicolumn{1}{|c|}{$\begin{array}{l}\text { Descriptores utilizados en el análisis para la } \\
\text { categorización de los contenidos }\end{array}$} & Número de veces que se emplean los descriptores en el análisis de contenidos \\
\cline { 2 - 3 } & $\begin{array}{l}\text { Documentos oficiales del CEIP Virrey } \\
\text { Morcillo }\end{array}$ & $\begin{array}{l}\text { Noticias publicadas en el blog de } \\
\text { la biblioteca del CEIP Virrey } \\
\text { Morcillo }\end{array}$ \\
\hline Actividades con familias & 12 & 8 \\
\hline Actividades de fomento de la lectura & 26 & 20 \\
\hline
\end{tabular}




\begin{tabular}{|c|c|c|}
\hline Alumnado con necesidades especiales & 3 & \\
\hline Apoyo curricular & 15 & \\
\hline Aprender a usar Internet de manera selectiva & 4 & 6 \\
\hline Aprendizaje en general & 7 & 1 \\
\hline Aprendizaje autónomo & 8 & 2 \\
\hline Biblioteca como lugar & 7 & 12 \\
\hline Biblioteca digital y tradicional & 5 & 5 \\
\hline Calidad educativa & & 3 \\
\hline Canal de comunicación & 4 & 12 \\
\hline Colección bibliográfica rica y variada & 15 & 25 \\
\hline Compensación de desigualdades & 5 & \\
\hline Competencia digital & 13 & 2 \\
\hline Competencia informacional & 18 & 1 \\
\hline Competencia lectora general & 27 & \\
\hline Competencias comunicativas y lingüísticas & 8 & 6 \\
\hline Competencias sociales & 2 & \\
\hline Comunidad educativa & 17 & 10 \\
\hline Control de conducta & 6 & \\
\hline Convivencia & 8 & 6 \\
\hline Crecimiento personal & 1 & 1 \\
\hline Crecimiento profesional & & 1 \\
\hline Cuidado y buen uso de la biblioteca & 12 & 3 \\
\hline Debate de ideas con el alumnado & 5 & 4 \\
\hline Desarrollo de la imaginación y la creatividad & & 7 \\
\hline Desarrollo del pensamiento crítico y la reflexión & 6 & 2 \\
\hline Disfrute de la lectura & & 21 \\
\hline Experiencia y conocimientos literarios & 7 & 17 \\
\hline Expresiones de afecto hacia la biblioteca & & 13 \\
\hline Expresiones de entusiasmo hacia la biblioteca & & 38 \\
\hline Expresiones de sentido de pertenencia al CEIP & & 13 \\
\hline Formación del profesorado & 6 & \\
\hline Hábito de la lectura & 3 & \\
\hline Implicación de las familias & 9 & 16 \\
\hline Implicación del alumnado en la vida del centro & 7 & 4 \\
\hline Lectura en voz alta & & 11 \\
\hline Lectura por placer & 5 & 6 \\
\hline Motivación del alumnado & 12 & 50 \\
\hline Motivación del profesorado & 9 & 52 \\
\hline Objetivos del CEIP & 64 & \\
\hline Plan de lectura y Biblioteca & 44 & 15 \\
\hline Préstamo de materiales bibliográficos & 10 & 11 \\
\hline Realización de trabajos de clase & 1 & \\
\hline Redes de colaboración & 15 & 6 \\
\hline Refuerzo de competencias básicas & 3 & \\
\hline Socialización de la lectura & 14 & 37 \\
\hline $\begin{array}{l}\text { Trabajo cooperativo (Metodologías activas de } \\
\text { aprendizaje) }\end{array}$ & 11 & 3 \\
\hline $\begin{array}{l}\text { Trabajo en proyectos temáticos (Metodologías } \\
\text { activas de aprendizaje) }\end{array}$ & 13 & 17 \\
\hline Transmisión de valores & 3 & 10 \\
\hline Visibilidad de la labor educativa del CEIP & & 3 \\
\hline
\end{tabular}




\subsubsection{Entrevistas a la dirección del CEIP Virrey Morcillo y al coordinador de su biblioteca y del Grupo Cooperativo Bibliotecas Escolares en Red - BERED}

En las entrevistas a la directora del CEIP Virrey Morcillo y al coordinador de su biblioteca (que es a su vez coordinador del Grupo Cooperativo Bibliotecas Escolares en Red, BERED), se ha seguido el modelo de entrevista semiestructurada. La entrevista se ha apoyado sobre un guion de preguntas predefinidas, pero con la posibilidad de incorporar cuestiones nuevas que pudieran surgir en el transcurso de la conversación, y de reformular preguntas para motivar a los entrevistados. ${ }^{139}$

En ambos casos se ha tratado de entrevistas presenciales realizadas de manera individual. Como señala Flick $(2009$, p. 266) el contacto cara a cara ofrece al investigador la posibilidad de interpretar elementos de la comunicación no verbal, como las pausas, las variaciones de voz y el lenguaje corporal y gestual.

Respecto al perfil de los dos entrevistados, corresponde al tipo de entrevistas a expertos $^{140}$ (Flick, 2009). Ambos cuentan con una larga trayectoria de trabajo con la biblioteca del centro, lo cual se traduce en un amplio bagaje de conocimiento y experiencia de gran interés para nuestro tema de investigación. Con la entrevista a la responsable del centro se ha introducido la perspectiva del equipo directivo y de la comunidad educativa en su conjunto, con sus objetivos y su visión más a medio y largo plazo. Todo ello, sumado a una larga experiencia docente y a un profundo conocimiento e implicación en el proyecto de la biblioteca del CEIP desde sus inicios. Su aportación a esta investigación ha sido muy valiosa pues sitúa a la biblioteca escolar en el centro de la misión educativa con una perspectiva temporal amplia.

Por otro lado, con la entrevista al coordinador de la biblioteca escolar y del Grupo Cooperativo $B E R E D$, se ha introducido la perspectiva de trabajo en equipo dentro y fuera del centro educativo; el conocimiento del potencial educativo de los distintos recursos de la biblioteca escolar, y su valor para tejer relaciones de convivencia dentro de la comunidad educativa y para crear redes de cooperación en torno a la escuela.

139 Como señala Kvale (2011), la investigación con entrevistas responde a una concepción epistemológica posmoderna, según la cual, el conocimiento tiene una "naturaleza conversacional, narrativa, lingüística, contextual e interrelacional" (p. 46), y se construye gracias a la interacción entre el entrevistador y los entrevistados.

140 Atendiendo al perfil de los entrevistados, Flick (2009, pp.165-169) menciona la modalidad de "entrevistas a expertos", que se realizan no solo a especialistas en una determinada disciplina sino también a determinados miembros de las organizaciones que pueden aportar su bagaje o experiencia profesional. 
El objetivo de estas entrevistas ha sido obtener una información matizada y con cierta perspectiva temporal sobre nuestro objeto de investigación. Si bien nos hemos apoyado en nuestro guion de preguntas (véase la Tabla 65), dado el rico bagaje de conocimiento de ambos entrevistados, en esta ocasión hemos preferido dejarles mucha más libertad para elaborar sus propias observaciones.

Las transcripciones de las entrevistas se recogen en el Anexo 7.

El contenido resultante de las dos entrevistas se ha analizado con ayuda del programa ATLAS.ti y siguiendo el procedimiento en fases consecutivas expuesto en el apartado 4.3.1. En la Tabla 73 se recogen los descriptores que hemos utilizado en el análisis. Junto a cada descriptor se ha registrado la frecuencia con la que se ha empleado cada uno en la fase de categorización de contenidos. Se han destacado en azul los descriptores que han alcanzado una frecuencia mayor que 1. A partir de este primer análisis, hemos observado que en las entrevistas se enfatizan los siguientes aspectos respecto de la biblioteca escolar del CEIP:

- Adquisición y desarrollo de competencias: se ha destacado la incidencia de la biblioteca sobre la competencia lectora, y en particular sobre la competencia informacional, la experiencia literaria, y competencias afines como las habilidades comunicativas y lingüísticas, el desarrollo del pensamiento crítico y las competencias sociales del alumnado.

- Incidencia de los recursos y actividades bibliotecarias sobre la formación del alumnado: entre los recursos, se destaca tener una colección bibliográfica amplia y variada y el espacio físico de la biblioteca. Entre las actividades, la lectura en silencio y en voz alta, y las actividades de fomento de la lectura.

- Actitudes y comportamiento: se destaca el efecto de la biblioteca sobre la motivación del alumnado y del profesorado, sobre el sentido de pertenencia e implicación del alumnado en el CEIP, sobre el aprendizaje de valores y normas de convivencia. Se destaca también el papel de la biblioteca en la socialización de la lectura y en la adquisición del hábito lector y su disfrute.

- Se manifiesta el efecto de la biblioteca sobre el bienestar individual de alumnado y profesorado. Son abundantes las expresiones positivas en relación con acudir a la biblioteca.

- Se menciona el beneficio que puede proporcionar la biblioteca a medio y largo plazo sobre el aprendizaje y en la formación de futuros lectores.

- Efecto sobre la institución: se destaca la incidencia de la biblioteca en el refuerzo de la comunidad educativa en su conjunto, su papel en el apoyo curricular, incluyendo su contribución al equilibrio de desigualdades entre el alumnado, y a la implantación de metodologías de aprendizaje proactivo. 
También se percibe su contribución a dar visibilidad a la labor docente y a la mejora de la calidad educativa.

- Efecto sobre el entorno social: se destaca el papel de la biblioteca en el establecimiento de redes de colaboración, en la transmisión de valores y en propiciar la implicación de las familias.

Tabla 73. Análisis de entrevistas con la dirección del CEIP Virrey Morcillo y con el coordinador de su biblioteca. Categorización de los datos primarios empleando el programa ATLAS.ti

\begin{tabular}{|c|c|}
\hline $\begin{array}{l}\text { Descriptores utilizados en el análisis para la } \\
\text { categorización de los contenidos }\end{array}$ & $\begin{array}{l}\text { Número de veces que se emplean los descriptores en el análisis de } \\
\text { contenidos }\end{array}$ \\
\hline Actividades con familias & 1 \\
\hline Actividades de fomento de la lectura & 2 \\
\hline Apoyo curricular & 3 \\
\hline Aprender a usar Internet de manera selectiva & 1 \\
\hline Aprendizaje en general & 2 \\
\hline Aprendizaje autónomo & 2 \\
\hline Biblioteca como lugar & 3 \\
\hline Calidad educativa & 3 \\
\hline Colección bibliográfica rica y variada & 4 \\
\hline Compensación de desigualdades & 2 \\
\hline Competencia digital & 1 \\
\hline Competencia informacional & 5 \\
\hline Competencia lectora general & 3 \\
\hline Competencias comunicativas y lingüísticas & 4 \\
\hline Competencias sociales & 2 \\
\hline Comunidad educativa & 7 \\
\hline Control de conducta & 2 \\
\hline Convivencia & 4 \\
\hline Debate de ideas con el alumnado & 2 \\
\hline Desarrollo de la imaginación y la creatividad & 1 \\
\hline Desarrollo del pensamiento crítico y la reflexión & 5 \\
\hline Descubrimiento e interés por nuevos temas & 3 \\
\hline Disfrute de la lectura & 5 \\
\hline Experiencia y conocimientos literarios & 2 \\
\hline Expresiones de afecto hacia la biblioteca & 5 \\
\hline Expresiones de bienestar y disfrute individual & 7 \\
\hline Expresiones de entusiasmo hacia la biblioteca & 1 \\
\hline Expresiones de sentido de pertenencia al CEIP & 8 \\
\hline Formación del profesorado & 1 \\
\hline Hábito de la lectura & 7 \\
\hline Implicación de las familias & 7 \\
\hline Implicación del alumnado en la vida del centro & 2 \\
\hline Lectura en familia & 1 \\
\hline Lectura en silencio & 3 \\
\hline Lectura en voz alta & 2 \\
\hline Lectura por placer & 2 \\
\hline Motivación del alumnado & 18 \\
\hline Motivación del profesorado & 10 \\
\hline Plan de lectura y Biblioteca & 5 \\
\hline Préstamo de materiales bibliográficos & 1 \\
\hline Redes de colaboración & 3 \\
\hline Socialización de la lectura & 4 \\
\hline Trabajo cooperativo (Metodologías activas de & 5 \\
\hline
\end{tabular}




\begin{tabular}{|l|l|}
\hline aprendizaje) & \\
\hline $\begin{array}{l}\text { Trabajo en proyectos temáticos (Metodologías activas de } \\
\text { aprendizaje) }\end{array}$ & 2 \\
\hline Transmisión de valores & 4 \\
\hline Visibilidad de la labor educativa del CEIP & 2 \\
\hline
\end{tabular}

\subsubsection{Grupo de discusión con profesorado del CEIP Virrey Morcillo}

Como dice Gutiérrez Brito (2014), el grupo de discusión convierte al investigador en un moderador y lo sitúa ante una doble tarea:

A) Crear una situación grupal artificial donde los integrantes se manifiesten y hablen libremente, y de la manera más natural y espontánea.

B) Mantener al grupo en una situación de trabajo e interés particular que se deriva del tema investigado y de los objetivos de la investigación (p. 43).

El grupo de discusión o grupo focal se presenta en la norma ISO 16439 como un tipo especial de entrevista que se realiza con varias personas y en el cual se trabaja sobre dos temas principales: la opinión de los participantes sobre el valor de la biblioteca y los beneficios que ellos han obtenido al utilizarla (Organización Internacional de Normalización, 2014b, pp. 41-42).

Hemos optado por aplicar la dinámica del grupo de discusión o grupo focal a nuestro caso para plantear un debate acerca de nuestro objeto de investigación. De ese debate se han obtenido evidencias del impacto de la biblioteca escolar, tal y como es percibido por el profesorado.

De entre el equipo docente que conforma el CEIP, hemos seleccionado para participar en el grupo a cinco profesores y profesoras directamente vinculados a la biblioteca escolar, por participar en su organización y por ser usuarios habituales de la misma. En el grupo han estado representados docentes de los distintos niveles educativos impartidos en el CEIP: una representante de educación infantil, tres representantes de educación primaria (dos de las cuales imparten lengua inglesa) y el coordinador del Plan de Lectura, Escritura, Información y Biblioteca.

Esta técnica de grupo presenta la ventaja de que, al abrir el debate, se propicia la pluralidad de apreciaciones sobre los temas planteados. Nuestro rol como investigadora ha consistido en conducir y animar la discusión, estimulando la 
intervención de todos los participantes ${ }^{141}$ y procurando que no hubiera una opinión dominante que pudiera producir cierto sesgo en los datos.

Hemos utilizado un diseño semiestructurado, combinando el guion de preguntas ineludibles ligadas a las preguntas de investigación con la suficiente flexibilidad para incorporar temas no previstos inicialmente.

Para conducir el debate, nos hemos apoyado en el mismo cuestionario de preguntas que hemos empleado para las entrevistas a la directora y al coordinador de biblioteca, y que se recoge en la Tabla 65.

Las transcripciones de las notas tomadas a lo largo del desarrollo del grupo de discusión se recogen en el Anexo 8.

El contenido resultante del grupo de discusión se ha analizado con ayuda del programa ATLAS.ti y siguiendo el procedimiento en fases consecutivas expuesto en el apartado 4.3.1. En la Tabla 74 se recogen los descriptores que hemos utilizado en el análisis. Junto a cada descriptor se ha registrado la frecuencia con la que se ha empleado cada uno en la fase de categorización de contenidos. Se han destacado en azul los descriptores que han alcanzado una frecuencia mayor que 1. A partir de este primer análisis, hemos observado que en el grupo de discusión se enfatizan los siguientes aspectos respecto de la biblioteca escolar del CEIP:

- Adquisición y desarrollo de competencias: se destaca la incidencia de la biblioteca sobre la competencia lectora general y en particular sobre la competencia informacional y digital, en las habilidades comunicativas y lingüísticas, y el desarrollo del pensamiento crítico en el alumnado. También se ha destacado la repercusión sobre la formación del profesorado.

- Incidencia de los recursos y actividades bibliotecarias sobre la formación del alumnado: se pone de relevancia tener una colección bibliográfica amplia y variada, el espacio físico de la biblioteca y el préstamo de materiales, tanto tradicionales como en soporte digital. Entre las actividades, se destacan las de fomento de la lectura, las actividades con familias, y la lectura en voz alta.

- Actitudes y comportamiento: se ha destacado el efecto de la biblioteca sobre la motivación del alumnado y del profesorado, sobre la socialización y el disfrute de la lectura, la adquisición del hábito lector y el cultivo de la lectura

141 Simons (2011) habla de un modelo democrático de relación entre el investigador y los participantes:

Realizar estudios de caso siguiendo esta tradición supone implicarse con los interesados durante todo el proceso, documentar sus opiniones y juicios, negociar con ellos el significado y las interpretaciones, usar unos métodos y un lenguaje que sean accesibles, y comunicarse con un público y unos beneficiarios que están más allá del caso (p. 61). 
en familia, sobre aprendizaje de las normas de conducta y convivencia y valores, y sobre el sentido de pertenencia al CEIP. También se observa su incidencia sobre la autonomía y la seguridad del alumnado en su proceso de aprendizaje, incluyendo el descubrimiento de nuevos temas de su interés. Abundan las expresiones positivas hacia la biblioteca, en relación con todas estas cuestiones.

- El efecto de la biblioteca a medio y largo plazo sobre la adquisición del hábito lector y el aprendizaje autónomo.

- Efecto sobre la institución: se destaca el valor de la biblioteca para la implantación de metodologías de aprendizaje proactivo, para el apoyo curricular, y el fortalecimiento de la comunidad educativa, incluyendo su papel como canal de comunicación.

- Efecto sobre el entorno social: se destaca el papel de la biblioteca escolar en el establecimiento de redes de colaboración, en propiciar la implicación de las familias y la transmisión de valores.

Tabla 74. Análisis de grupo de discusión con profesorado del CEIP Virrey Morcillo. Categorización de los datos primarios empleando el programa ATLAS.ti

\begin{tabular}{|c|c|}
\hline $\begin{array}{l}\text { Descriptores utilizados en el análisis para la } \\
\text { categorización de los contenidos }\end{array}$ & Número de veces que se emplean los descriptores en el análisis de contenidos \\
\hline Actividades con familias & 2 \\
\hline Actividades de fomento de la lectura & 3 \\
\hline Apoyo curricular & 2 \\
\hline Aprender a usar Internet de manera selectiva & 4 \\
\hline Aprendizaje en general & 6 \\
\hline Aprendizaje autónomo & 9 \\
\hline Biblioteca como lugar & 9 \\
\hline Biblioteca digital y tradicional & 2 \\
\hline Canal de comunicación & 2 \\
\hline Colección bibliográfica rica y variada & 18 \\
\hline Competencia digital & 4 \\
\hline Competencia informacional & 11 \\
\hline Competencia lectora general & 6 \\
\hline Competencias comunicativas y lingüísticas & 2 \\
\hline Competencias sociales & 1 \\
\hline Comunidad educativa & 5 \\
\hline Control de conducta & 4 \\
\hline Convivencia & 4 \\
\hline Cuidado y buen uso de la biblioteca & 3 \\
\hline Debate de ideas con el alumnado & 1 \\
\hline Desarrollo del pensamiento crítico y la reflexión & 4 \\
\hline Descubrimiento e interés por nuevos temas & 5 \\
\hline Disfrute de la lectura & 8 \\
\hline Experiencia y conocimientos literarios & 1 \\
\hline Expresiones de afecto hacia la biblioteca & 2 \\
\hline Expresiones de bienestar y disfrute individual & 6 \\
\hline Expresiones de entusiasmo hacia la biblioteca & 4 \\
\hline Expresiones de percepción de seguridad en el & 3 \\
\hline
\end{tabular}




\begin{tabular}{|c|c|}
\hline propio aprendizaje & \\
\hline Expresiones de sentido de pertenencia al CEIP & 7 \\
\hline Formación del profesorado & 3 \\
\hline Hábito de la lectura & 8 \\
\hline Implicación de las familias & 5 \\
\hline Implicación del alumnado en la vida del centro & 1 \\
\hline Lectura en familia & 3 \\
\hline Lectura en silencio & 1 \\
\hline Lectura en voz alta & 2 \\
\hline Lectura por placer & 2 \\
\hline Motivación del alumnado & 29 \\
\hline Motivación del profesorado & 15 \\
\hline Plan de lectura y Biblioteca & 5 \\
\hline Préstamo de materiales bibliográficos & 7 \\
\hline Redes de colaboración & 4 \\
\hline Socialización de la lectura & 9 \\
\hline $\begin{array}{l}\text { Trabajo cooperativo (Metodologías activas de } \\
\text { aprendizaje) }\end{array}$ & 3 \\
\hline $\begin{array}{l}\text { Trabajo en proyectos temáticos (Metodologías } \\
\text { activas de aprendizaje) }\end{array}$ & 7 \\
\hline Transmisión de valores & 5 \\
\hline Visibilidad de la labor educativa del CEIP & 1 \\
\hline
\end{tabular}

Antes de cerrar este apartado, diremos que los contenidos analizados se pueden agrupar en tres conjuntos, según se trate de informaciones contextuales o de informaciones referidas al interior del CEIP objeto de estudio:

1) Información procedente de otros centros de educación españoles: la información proporcionada por el CEIP Gerardo Diego (Los Corrales de Buelna, Cantabria) y por el CEIP Condesa de Fenosa (O Barco de Valdeorras, Ourense).

2) Información correspondiente al entorno del CEIP Virrey Morcillo: documentos oficiales de centros educativos de la red cooperativa BERED.

3) Información obtenida en el propio CEIP Virrey Morcillo: documentos oficiales, noticias publicadas en el blog de su biblioteca, entrevistas a la directora y al coordinador de la biblioteca, y grupo de discusión con profesorado del CEIP.

Como resumen de los subapartados 4.3.1.1. a 4.3.1.6, se recogen en la Tabla 75 los descriptores utilizados para categorizar los contenidos cualitativos analizados. Junto a cada descriptor se ha registrado la frecuencia con la que se ha empleado cada descriptor en cada uno de los materiales analizados. En la última columna se ha contabilizado el número de veces que se ha utilizado cada descriptor en el conjunto de los contenidos analizados. Hemos marcado en color azul los valores que se encuentran por encima del valor de la mediana $(M e=23,5)$. 
Atendiendo a la frecuencia con la que aparece cada categoría, hemos observado los siguientes aspectos que en conjunto se ponen en relieve respecto del efecto de la biblioteca escolar:

- Adquisición y desarrollo de competencias: se destaca la incidencia de la biblioteca sobre la competencia lectora general y en particular sobre la competencia informacional, seguidas por orden de frecuencia, la experiencia literaria, las habilidades comunicativas y lingüísticas, la competencia digital, y en menor medida sobre el desarrollo del pensamiento crítico en el alumnado, y sobre la formación del profesorado.

- Incidencia de los recursos y actividades bibliotecarias sobre la formación del alumnado: en todos los materiales analizados se pone de relevancia tener una colección bibliográfica amplia y variada, la organización de actividades de fomento de la lectura y contar con un espacio adecuado para la biblioteca. Estos tres recursos son los que más veces se citan, seguidos del préstamo de materiales y las actividades con familias.

- Actitudes y comportamiento: aparece de manera muy destacada el efecto de la biblioteca sobre la motivación del alumnado y del profesorado. Estos aspectos están mencionados en todos los materiales analizados, junto con la socialización de la lectura. También se destaca la incidencia de la biblioteca sobre el aprendizaje del disfrute de la lectura, sobre la interiorización de normas y valores y sobre el sentido de pertenencia respecto del CEIP.

- Efectos a medio y largo plazo: se destaca el efecto de la biblioteca sobre el proceso de aprendizaje en general y sobre la adquisición del hábito lector.

- Efecto sobre la institución: en todos los materiales analizados se destaca el valor de la biblioteca para el refuerzo de la comunidad educativa y para la implantación de metodologías de aprendizaje proactivo. Se destaca su contribución en la consecución de los objetivos de los centros, propiciando lazos de convivencia y siendo una herramienta de utilidad para el refuerzo curricular.

- Efecto sobre el entorno social: en todos los materiales analizados se destaca el papel de la biblioteca escolar en el establecimiento de redes de colaboración externa. También se destaca su importancia para la transmisión de valores y para propiciar la implicación de las familias en la vida de los centros educativos. 
Tabla 75. Categorización de contenidos extraídos del material cualitativo. Datos obtenidos utilizando los datos primarios y el programa ATLAS.ti

\begin{tabular}{|c|c|c|c|c|c|c|c|c|}
\hline \multirow[t]{2}{*}{$\begin{array}{l}\text { Descriptores utilizados en el análisis para la } \\
\text { categorización de los contenidos }\end{array}$} & \multicolumn{8}{|c|}{$\begin{array}{l}\text { Número de veces que se emplean los descriptores en el análisis } \\
\qquad \text { de contenidos }\end{array}$} \\
\hline & 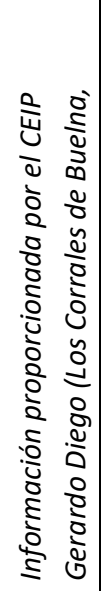 & 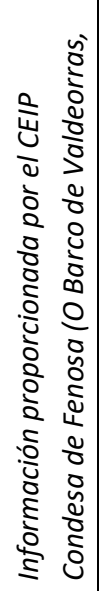 & 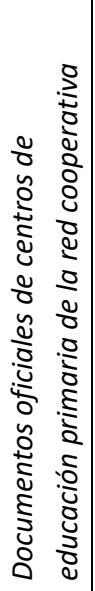 & 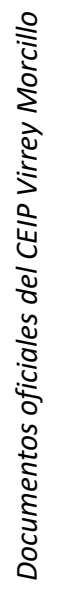 & 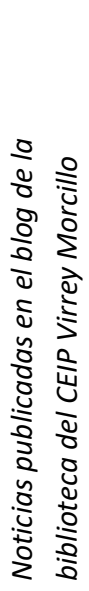 & 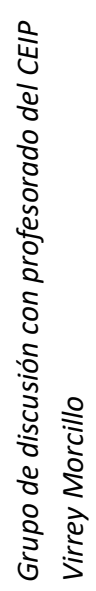 & 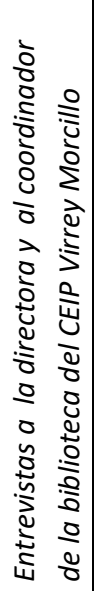 & 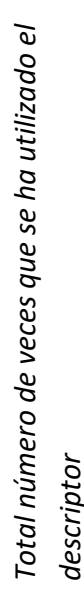 \\
\hline Actividades con familias & 1 & & 5 & 12 & 8 & 2 & 1 & 29 \\
\hline Actividades de fomento de la lectura & 5 & 1 & 14 & 26 & 20 & 3 & 2 & 71 \\
\hline Alumnado con necesidades especiales & & 1 & & 3 & & & & 4 \\
\hline Apoyo curricular & 2 & & 11 & 15 & & 2 & 3 & 33 \\
\hline Aprender a usar Internet de manera selectiva & & & & 4 & 6 & 4 & 1 & 15 \\
\hline Aprendizaje en general & 1 & & 7 & 7 & 1 & 6 & 2 & 24 \\
\hline Aprendizaje autónomo & 1 & & 1 & 8 & 2 & 9 & 2 & 23 \\
\hline Biblioteca como lugar & 1 & 2 & 11 & 7 & 12 & 9 & 3 & 45 \\
\hline Biblioteca digital y tradicional & 1 & & 2 & 5 & 5 & 2 & & 15 \\
\hline Calidad educativa & 1 & 1 & 1 & & 3 & & 3 & 9 \\
\hline Canal de comunicación & 1 & & 2 & 4 & 12 & 2 & & 21 \\
\hline Colección bibliográfica rica y variada & 1 & 1 & 14 & 15 & 25 & 18 & 4 & 78 \\
\hline Compensación de desigualdades & & 1 & & 5 & & & 2 & 8 \\
\hline Competencia digital & & 2 & 4 & 13 & 2 & 4 & 1 & 26 \\
\hline Competencia informacional & & 4 & 7 & 18 & 1 & 11 & 5 & 46 \\
\hline Competencia lectora general & 2 & 3 & 10 & 27 & & 6 & 3 & 51 \\
\hline Competencias comunicativas y lingüísticas & 2 & & 7 & 8 & 6 & 2 & 4 & 29 \\
\hline Competencias sociales & 1 & & & 2 & & 1 & 2 & 6 \\
\hline Comunidad educativa & 5 & 1 & 6 & 17 & 10 & 5 & 7 & 51 \\
\hline Control de conducta & 1 & & 9 & 6 & & 4 & 2 & 22 \\
\hline Convivencia & 4 & 1 & 1 & 8 & 6 & 4 & 4 & 28 \\
\hline Crecimiento personal & 1 & & & 1 & 1 & & & 3 \\
\hline Crecimiento profesional & & & & & 1 & & & 1 \\
\hline Cuidado y buen uso de la biblioteca & & 1 & 10 & 12 & 3 & 3 & & 29 \\
\hline Debate de ideas con el alumnado & & & & 5 & 4 & 1 & 2 & 12 \\
\hline Desarrollo de la imaginación y la creatividad & & & 2 & & 7 & & 1 & 10 \\
\hline Desarrollo del pensamiento crítico y la reflexión & & & 4 & 6 & 2 & 4 & 5 & 21 \\
\hline Descubrimiento e interés por nuevos temas & & & & & & 5 & 3 & 8 \\
\hline Disfrute de la lectura & & & 8 & & 21 & 8 & 5 & 42 \\
\hline Experiencia y conocimientos literarios & & & 3 & 7 & 17 & 1 & 2 & 30 \\
\hline Expresiones de afecto hacia la biblioteca & & 1 & & & 13 & 2 & 5 & 21 \\
\hline Expresiones de bienestar y disfrute individual & & & & & & 6 & 7 & 13 \\
\hline Expresiones de entusiasmo hacia la biblioteca & & & & & 38 & 4 & 1 & 43 \\
\hline Expresiones de percepción de seguridad en el & & & & & & 3 & & 3 \\
\hline
\end{tabular}




\begin{tabular}{|c|c|c|c|c|c|c|c|c|}
\hline propio aprendizaje & & & & & & & & \\
\hline Expresiones de sentido de pertenencia al CEIP & 4 & 1 & 1 & & 13 & 7 & 8 & 34 \\
\hline Formación del profesorado & 1 & 3 & 7 & 6 & & 3 & 1 & 21 \\
\hline Hábito de la lectura & 1 & & & 3 & & 8 & 7 & 19 \\
\hline Implicación de las familias & 3 & & 7 & 9 & 16 & 5 & 7 & 47 \\
\hline Implicación del alumnado en la vida del centro & & & 1 & 7 & 4 & 1 & 2 & 15 \\
\hline Lectura en familia & & & & & & 3 & 1 & 4 \\
\hline Lectura en silencio & & 2 & 2 & & & 1 & 3 & 8 \\
\hline Lectura en voz alta & & 1 & 4 & & 11 & 2 & 2 & 20 \\
\hline Lectura por placer & & & 4 & 5 & 6 & 2 & 2 & 19 \\
\hline Motivación del alumnado & 5 & 3 & 14 & 12 & 50 & 29 & 18 & 131 \\
\hline Motivación del profesorado & 7 & 2 & 12 & 9 & 52 & 15 & 10 & 107 \\
\hline Objetivos del CEIP & & & 35 & 64 & & & & 99 \\
\hline Plan de lectura y Biblioteca & & & 23 & 44 & 15 & 5 & 5 & 92 \\
\hline Préstamo de materiales bibliográficos & & & 12 & 10 & 11 & 7 & 1 & 41 \\
\hline Realización de trabajos de clase & & & & 1 & & & & 1 \\
\hline Redes de colaboración & 3 & 1 & 14 & 15 & 6 & 4 & 3 & 46 \\
\hline Refuerzo de competencias básicas & 2 & & 2 & 3 & & & & 7 \\
\hline Socialización de la lectura & 3 & 2 & 10 & 14 & 37 & 9 & 4 & 79 \\
\hline $\begin{array}{l}\text { Trabajo cooperativo (Metodologías activas de } \\
\text { aprendizaje) }\end{array}$ & 5 & 1 & 4 & 11 & 3 & 3 & 5 & 32 \\
\hline $\begin{array}{l}\text { Trabajo en proyectos temáticos (Metodologías } \\
\text { activas de aprendizaje) }\end{array}$ & 3 & 3 & 4 & 13 & 17 & 7 & 2 & 49 \\
\hline Transmisión de valores & 4 & 1 & & 3 & 10 & 5 & 4 & 27 \\
\hline Visibilidad de la labor educativa del CEIP & 2 & 1 & 1 & & 3 & 1 & 2 & 10 \\
\hline
\end{tabular}

Una vez realizado este primer análisis de los datos cualitativos, en el siguiente apartado se aborda su interpretación a la luz de las preguntas de investigación planteadas.

\subsubsection{Interpretación de los datos cualitativos}

En este apartado se aborda la fase 4 del análisis de datos cualitativos, una vez realizada la selección, categorización y análisis previo de los contenidos relevantes para la investigación (fases 1, 2 y 3 del análisis). Se ha realizado una interpretación de conjunto de la información cualitativa obtenida mediante las diferentes técnicas explicadas en los subapartados 4.3.1.1. a 4.3.1.6.

Para ello se ha procedido a la relectura en profundidad de los contenidos, y se han buscado relaciones entre las categorías extraídas. Como herramienta de ayuda para la búsqueda de relaciones y patrones entre conceptos se ha empleado una tabla de coocurrencias (Tabla 76), que recoge los casos en los que dos categorías aparecen en la misma cita o fragmento analizado. En la tabla se han destacado en color azul los casos de coocurrencias que se producen con una frecuencia superior a la media. 


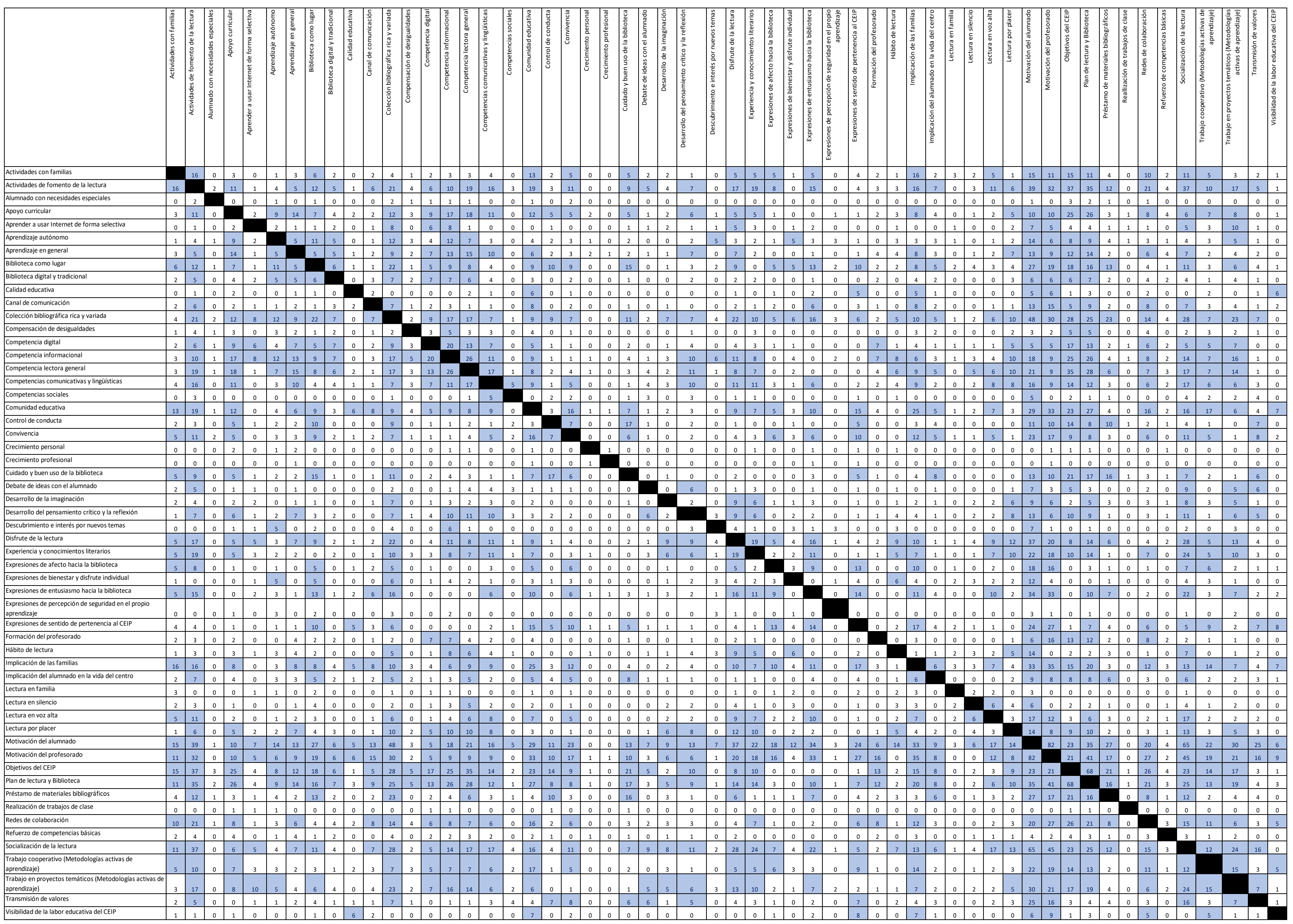


Como resultado de todos los análisis anteriores, en los siguientes subapartados se exponen las interpretaciones de los datos cualitativos en respuesta a las preguntas de investigación.

\subsubsection{Influencia de la biblioteca sobre las habilidades y competencias individuales}

\subsection{Influencia sobre la competencia lectora del alumnado}

Desde el contexto educativo se percibe que la biblioteca escolar contribuye a mejorar la competencia lectora del alumnado de la mano del plan de lectura. El efecto se produce sobre la competencia lectora general y sobre las distintas dimensiones de esta competencia (tener una experiencia literaria; adquirir y usar la información; obtener información e inferencias directas; e interpretar, integrar y evaluar). Los docentes perciben que:

$\checkmark$ El alumnado toma conciencia de sus gustos literarios y descubre géneros como la poesía y el teatro. Con el descubrimiento de los géneros literarios, aprenden a enfrentarse a recursos literarios de cierta complejidad, como los recursos metafóricos. También aprenden a identificar las obras de un mismo autor o de una misma temática.

$\checkmark$ Con la implantación del plan de lectura se construye una colección bibliográfica rica y variada y se organizan actividades de fomento de la lectura que propician la experiencia literaria del alumnado. De este modo desarrollan su sensibilidad literaria más allá de la afición por las populares sagas de ficción infantil y juvenil, a la vez que potencian la creatividad, el pensamiento crítico y las competencias comunicativas y lingüísticas.

$\checkmark$ La presencia de títulos de contenido informativo en la colección contribuye a desarrollar la competencia informacional del alumnado, siempre que su cobertura temática sea amplia y adaptada a las necesidades graduales, y se imparta formación sobre su utilización.

$\checkmark$ El alumnado que experimenta seguridad y autonomía en el manejo de la colección mejora sus búsquedas documentales, aprende a seleccionar las fuentes adecuadas y a localizar la información relevante en todo tipo de soportes, analógicos y digitales, y formatos (texto, tablas, gráficos, índices, etc.). La experiencia de acceder libremente, con autonomía y confianza, a un espacio de conocimiento organizado como es la biblioteca, es estimulante para el alumnado, y éste suele repetir la experiencia. Aprenden de esta forma a 
familiarizarse con las fuentes de información y a hacer un uso competente de ellas, tanto en el entorno papel como en el digital.

$\checkmark$ La competencia informacional se ve potenciada cuando, dentro del marco del plan de lectura del centro, se trabaja por tareas y proyectos donde el alumnado necesita de la biblioteca para localizar información en sus investigaciones documentales. Aprenden a contar con este recurso que les proporciona seguridad en la resolución de sus tareas de clase y gracias al cual descubren nuevas materias de su interés.

$\checkmark$ Desde la biblioteca se refuerza la competencia digital del alumnado proporcionándole formación para la realización de estrategias de búsqueda eficaces en Internet y para la aplicación de criterios de fiabilidad en el uso de la información, todo ello ligado a la realización de proyectos temáticos programados en el plan de lectura.

$\checkmark$ La biblioteca ayuda a desarrollar la capacidad crítica del alumnado, tanto en su decisión de qué libros leer, como en su reflexión sobre los contenidos, tanto de ficción como informativos ${ }^{142}$. Junto a la capacidad crítica desarrollan las habilidades comunicativas y lingüísticas. Son capaces de debatir y argumentar en torno a una lectura concreta, aprenden a diferenciar las ideas principales $y$ secundarias, a resumir los contenidos y exponerlos en público, y a discriminar la información útil para sus tareas.

$\checkmark$ De entre las cuatro dimensiones de la competencia lectora consideradas, la que se menciona de manera más recurrente en los datos cualitativos es la competencia informacional, en cuanto a su vinculación con los objetivos del CEIP y con el desarrollo del plan de lectura, y en relación con los procesos de aprendizaje y con el refuerzo del resto de competencias básicas. Cabe destacar que la competencia informacional se menciona en relación con los objetivos que persiguen la compensación de desigualdades en el ámbito de los centros educativos.

\subsection{Influencia de los distintos recursos, actividades o prácticas vinculadas a la biblioteca sobre el desarrollo de la competencia lectora del alumnado}

Con relación a la contribución de los diferentes recursos bibliotecarios sobre el rendimiento del alumnado, los docentes perciben que, para alcanzar su mayor potencial, la biblioteca debe evolucionar desde el modelo básico de colección

142 La literatura reciente confirma la importancia de la biblioteca escolar para el desarrollo del pensamiento crítico desde edades tempranas (Lewis, 2019; McPherson, 2008). 
organizada de libros hacia el modelo de centro de recursos tradicionales y digitales al servicio de la lectura, el aprendizaje y la información.

$\checkmark$ El recurso más valorado por los docentes es la colección bibliográfica. Se percibe que una colección amplia, actualizada y adaptada a las distintas edades y ciclos formativos, y con amplia oferta de los distintos géneros literarios en los distintos soportes produce un efecto positivo sobre el proceso de aprendizaje, sobre la competencia lectora y las cuatro dimensiones consideradas (en especial sobre la competencia informacional), así como sobre el desarrollo del pensamiento crítico y la creatividad, las competencias digitales, comunicativas y lingüísticas.

$\checkmark$ La colección bibliográfica aparece mencionada con frecuencia en los datos cualitativos en relación con la adquisición del hábito lector y el disfrute de la lectura, y junto a expresiones positivas y de afecto donde se manifiesta el sentido de pertenencia al CEIP y la motivación del alumnado y del profesorado.

$\checkmark$ Se percibe un mayor beneficio sobre el alumnado que accede a una biblioteca de centro donde se integran las colecciones de todos los niveles formativos, en comparación con aquél que solo accede a un lote de libros en el aula. El beneficio es mayor si el alumnado puede escoger entre un abanico amplio de títulos a su alcance.

$\checkmark$ Junto al número de títulos disponibles se considera clave que estén representados todos los niveles curriculares y que estén cubiertas las distintas necesidades especiales ${ }^{143}$ (distintos tamaños de letra, libros de lectura fácil, libros en braille, etc.); que convivan textos de géneros literarios variados y textos de contenido informativo, en soportes analógicos y digitales.

$\checkmark$ La organización temática de la colección debe ser sencilla y comprensible para el alumnado. Las actividades formativas orientadas a explicar la organización lógica de la colección (por materias, niveles, etc.) contribuyen a incrementar su uso.

$\checkmark$ La libertad de acceso a la colección y el préstamo de materiales bibliográficos son imprescindibles para que el alumnado se familiarice con los recursos de la biblioteca y haga un uso provechoso de ellos. El préstamo de libros sigue siendo una práctica fundamental en el aprendizaje de la dinámica de la biblioteca, en la adquisición del hábito lector y en la socialización de la lectura. Ayuda a que el alumnado interiorice normas de comportamiento y se involucre en la comunidad educativa. Los docentes perciben que el préstamo de materiales motiva al alumnado a acudir a la biblioteca si se plantea como una actividad lúdica, donde

${ }^{143}$ En la misma línea, Agee (2019) ha destacado la importancia de que la colección bibliográfica esté adaptada a todas las necesidades para garantizar la igualdad de acceso. Para la autora, esto se traduce en una igualdad de oportunidades de mejora en los resultados académicos de todo el alumnado. 
ellos pueden seleccionar libremente lo que desean leer, y cuando se relaciona con actividades y tareas programadas en el plan de lectura.

Después de la colección bibliográfica, la biblioteca en tanto que lugar se percibe como un recurso que ayuda al alumnado a reforzar su autonomía en sus procesos de aprendizaje. Es un espacio para la socialización de la lectura, y donde se refuerza esta competencia. El beneficio que aporta contar con este espacio abierto a toda la comunidad educativa es mayor si su diseño, mobiliario y distribución espacial son acogedores, funcionales y adaptados ${ }^{144}$, y si la organización lógica de colecciones y recursos es comprensible para el alumnado.

$\checkmark$ Las actividades de fomento de la lectura vinculadas a tareas y proyectos planificados en el plan de lectura, en combinación con el uso de la colección y el espacio físico de la biblioteca, contribuyen al aprendizaje en general, a reforzar la competencia lectora en las cuatro dimensiones evaluadas, y en especial la experiencia y conocimiento literarios, y las competencias comunicativas y lingüísticas.

Las actividades con familias contempladas en el plan de lectura contribuyen a reforzar la experiencia literaria del alumnado y a propiciar el gusto por leer. Se observa que estas actividades fortalecen el vínculo del alumnado respecto de sus centros educativos.

$\checkmark$ La práctica de la lectura en silencio y la lectura en voz alta en la biblioteca y en el aula refuerzan la competencia lectora general. La lectura en voz alta además refuerza las competencias comunicativas y lingüísticas y la experiencia literaria.

$\checkmark$ Por último, si bien la formación en el uso de las tecnologías de la información y el conocimiento se contempla como uno de los objetivos educativos básicos de los centros educativos, hay que decir que, el acceso a Internet desde la biblioteca es el recurso menos crítico en opinión de los docentes, debido en gran medida a que parte del alumnado ya accede a Internet desde dispositivos propios. Para los

\footnotetext{
${ }^{144}$ En la misma línea, Stewart (2018) mostró a partir de un estudio de caso que la biblioteca escolar se percibía como un espacio funcional cuyo diseño y recursos contribuyen positivamente al desarrollo cognitivo y social del alumnado. Por su parte, Baker y Alexander (2018) mostraron que, en el espacio de la biblioteca, el alumnado descubre nuevas áreas de interés, aprende a respetarse y a cuidar los recursos comunes, aprende nuevos roles, gana confianza al mostrar sus trabajos a los demás, y en general, refuerza competencias relacionadas con la socialización y el aprendizaje autónomo. Para Robertson (2019), la adaptación del espacio de la biblioteca a las nuevas necesidades curriculares es una estrategia que contribuye al aprendizaje a largo plazo. Según este autor, el espacio debe ser funcional y versátil, para que se puedan realizar en él proyectos y actividades en torno a las colecciones bibliográficas.
} 
docentes, lo que realmente marca la diferencia es contar con actividades de formación informacional sobre el uso de Internet de manera selectiva ${ }^{145}$.

\subsection{Influencia sobre habilidades y competencias en el profesorado}

Los docentes perciben que la biblioteca es un recurso que les ayuda a mejorar sus habilidades y competencias, especialmente en el ámbito de las competencias informacionales y en el uso de las nuevas tecnologías de la información, la educación y el aprendizaje. Les ayuda a implantar y potenciar metodologías de enseñanza de tipo participativo y proactivo, y a reforzar el enriquecimiento curricular del alumnado, de acuerdo con los objetivos y planes del centro educativo.

Los datos corroboran las conclusiones de los estudios anglosajones acerca del efecto beneficioso del profesorado con conocimientos bibliotecarios ${ }^{146}$ sobre el rendimiento del alumnado. Los docentes perciben que este efecto se potencia si el profesorado accede a una formación específica bibliotecaria y cuando en el centro educativo hay docentes de los diferentes ciclos formativos que están involucrados en las dinámicas de la biblioteca:

$\checkmark$ El profesorado bibliotecario contribuye al aprendizaje autónomo del alumnado, le guía y orienta en la utilización competente de los recursos bibliotecarios, según sus intereses y necesidades. El beneficio sobre su aprendizaje autónomo es mayor cuando se trabaja por tareas y proyectos para los cuales el alumnado debe buscar información tanto impresa como en Internet, y donde la biblioteca es un recurso ineludible. Se puede decir que la biblioteca es una herramienta que contribuye a transformar el modelo tradicional de estudio con libros de texto y ejercicios en un modelo de aprendizaje proactivo basado en tareas $y$ proyectos.

$\checkmark$ El profesorado cree que es importante incluir la formación bibliotecaria ${ }^{147}$ básica dentro de los planes de formación docente, con el apoyo de las autoridades educativas y de las bibliotecas públicas.

145 Una investigación reciente muestra cómo desde la biblioteca escolar se puede enseñar al alumnado de educación secundaria a usar Internet con criterios selectivos y a ser críticos ante las noticias falsas (Martha et al., 2019).

146 Robledo Ramón, Fidalgo Redondo y Méndez del Río (2019) han subrayado el rol de los docentes en la transmisión de la competencia lectora, y la eficacia de las metodologías de interacción en torno a la lectura desarrolladas en el aula.

147 Según la estadística española de bibliotecas escolares en el $51 \%$ de centros públicos y en el $39 \%$ de los centros privados, la biblioteca es coordinada por personas con formación específica bibliotecaria. 
La participación en redes de cooperación con otros centros educativos y con entidades culturales locales contribuye a la adquisición de esta formación bibliotecaria básica por parte de los docentes.

\subsubsection{Influencia de la biblioteca sobre cambios en actitudes y comportamiento individuales}

\subsection{Influencia sobre actitudes y comportamientos del alumnado}

La biblioteca escolar contribuye a producir cambios de carácter intangible observables en las actitudes y en el comportamiento del alumnado. Los docentes aprecian este tipo de cambios en el proceso formativo del alumnado que frecuenta la biblioteca escolar desde edades tempranas:

$\checkmark$ El alumnado con formación temprana en el uso de la biblioteca interioriza el hábito de ir a la biblioteca como una rutina de carácter lúdico ${ }^{148}$, equiparable a ir al recreo. El mayor cambio se produce cuando aprenden a moverse autónomamente dentro del espacio de la biblioteca, accediendo a todos los recursos disponibles, no solo los adaptados a su nivel educativo. Se observa que el alumnado que frecuenta la biblioteca experimenta mayor autonomía y seguridad en el aprendizaje general ${ }^{149}$. Desde las edades más tempranas perciben la biblioteca como un recurso de ayuda y como un espacio de conocimiento por donde saben moverse con soltura. Aprenden a recurrir a la biblioteca cuando sienten que necesitan localizar algún tipo de información

148 Yubero Jiménez y Larrañaga Rubio (2010) subrayaron la importancia de que el niño asocie la lectura a actividades placenteras:

la consideración de la lectura por su valor instrumental aleja al niño de leer como actividad placentera y la delega al tiempo que le dedica en el colegio y al estudio, lo que no facilita el desarrollo del hábito lector (...) El acercamiento a la lectura no suele producirse de forma espontánea y, por este motivo, se debe construir un contexto que facilite el encuentro (p. 16).

Los autores incidieron en que en la adquisición del hábito lector es fundamental que el niño crezca en un contexto en el "que se valore leer y que se descubra el gusto por la lectura", como es el contexto familiar. En esta misma línea, consideramos que la biblioteca escolar es un contexto facilitador de la motivación por leer, asociada a actividades lúdicas y al fomento de modelos de comportamiento lector.

149 García Crespo, Galián, Fernández Alonso y Muñiz (2019) han destacado la importancia de que el alumnado de educación primaria adquiera confianza en la lectura como estrategia para potenciar su resiliencia:

los esfuerzos para mejorar la resiliencia del alumnado deben ir dirigidos al desarrollo de programas destinados a aumentar la confianza en la lectura, así como potenciar tareas en competencias lectoras previas al acceso a primaria ya que favorecerán la compensación de una situación de desventaja social, económica y cultural en cuanto a los resultados académicos se refiere (pp. 89-90). 
tanto para resolver las tareas de clase como para resolver situaciones de su vida cotidiana.

$\checkmark$ Se observa que el alumnado mejora su motivación ${ }^{150}$ por aprender y se interesa por nuevas áreas de conocimiento después de visitar la biblioteca. También aprenden a acudir a la biblioteca cada vez que descubren un nuevo tema de interés en su vida cotidiana.

$\checkmark$ Se observa que el alumnado que se acostumbra a compartir los recursos y espacios de la biblioteca colaborando en tareas y proyectos refuerza su sentido de pertenencia al centro educativo. Quienes más se implican en el cuidado y las rutinas de la biblioteca aprenden a participar y a implicarse en la vida del centro, más allá de su asistencia a las clases. Se crea un vínculo afectivo entre el alumnado y el centro donde se sienten parte activa. En los datos cualitativos se observa que coinciden las expresiones de sentido de pertenencia al CEIP con expresiones positivas y de afecto hacia la biblioteca escolar.

$\checkmark$ La combinación de actividades de lectura con familias ${ }^{151}$ y el sistema de trabajo cooperativo y por proyectos alrededor de la colección bibliográfica es una fórmula que ayuda a incentivar la motivación del alumnado en su proceso de aprendizaje, y favorece la implicación de las familias en este proceso. Se observa que las actividades de lectura con familias organizadas desde la biblioteca escolar contribuyen a fomentar el hábito de la lectura en el contexto del hogar. Se propician los vínculos familiares alrededor de la lectura y el aprendizaje.

$\checkmark$ Las actividades que involucran al alumnado en el cuidado de las colecciones y del espacio de la biblioteca ayudan a que el alumnado interiorice valores como compartir y cuidar los recursos y los espacios comunes, respetando las reglas y normas de conducta. Con estas las dinámicas bibliotecarias aprenden a asumir

150 Logan, Medford y Hughes (2011) mostraron que la motivación intrínseca del alumnado (incluyendo el deseo de aprender cosas nuevas, el interés por trabajar en tareas complejas y su nivel de implicación) es un factor que contribuye a la mejora del rendimiento en competencia lectora entre el grupo de estudiantes con peores resultados en las evaluaciones de lectura. En esta línea, consideramos que la biblioteca escolar, como favorecedora de la motivación del alumnado, juega un papel importante como nivelador de desigualdades.

151 Como señaló Pensiero (2011), la participación de las familias en actividades de lectura y otras actividades de estimulación cognitiva como la visita a la biblioteca, refuerza la capacidad lectora en edades tempranas. La literatura ha demostrado que el hábito de la lectura en voz alta realizada por padres y madres tiene un efecto beneficioso sobre la capacidad lingüística de la persona en edades de 3 a 5 años (Klein, Biedinger y Becker, 2014). Por su parte, Flecha y Buslon (2016, p. 139) mostraron que la participación de las familias en actividades extraescolares como la lectura compartida contribuía al rendimiento académico del alumnado. Algunas de estas actividades se desarrollaban en el espacio de la biblioteca escolar. 
derechos y deberes como usuarios de servicios y bienes compartidos, y se fortalece el sentido de pertenencia al centro educativo.

$\checkmark$ Las actividades programadas en el plan de lectura pueden ayudar al aprendizaje de valores universales como la solidaridad y el respeto entre las personas, y a luchar desde el aula contra problemas sociales como el acoso escolar o los estereotipos sexistas.

$\checkmark$ Se observa que la participación en tareas de debate en torno a lecturas contribuye a que el alumnado aprenda a expresar sus opiniones respetando las de los demás.

$\checkmark$ La lectura en voz alta y el préstamo regular de libros impresos y electrónicos contribuyen a la socialización de la lectura y a reforzar la comunicación y las relaciones interpersonales entre estudiantes. Por ejemplo, se observa que éstos se recomiendan libros entre sí de acuerdo con sus experiencias de lectura.

Por último, hay que destacar que, en opinión de los docentes, no existe un perfil específico de alumnado que frecuenta la biblioteca. Se puede decir que se ha superado el estereotipo tradicional según el cual el alumnado que acudía a la biblioteca era el más estudioso o el más aplicado en sus tareas escolares. Se comprueba que, en la actualidad, la biblioteca funciona como un recurso integrador que puede beneficiar a todo el alumnado, según sus gustos, intereses y necesidades.

\subsection{Influencia sobre actitudes y comportamientos del profesorado}

En el material cualitativo se menciona de manera muy destacada la motivación del alumnado y el profesorado en relación con su experiencia con la biblioteca escolar. Abundan las expresiones de sentido de pertenencia, disfrute y afecto por la biblioteca, en relación con la organización de actividades de fomento de la lectura, la construcción y cuidado de la colección y del espacio bibliotecario, y con la implicación del alumnado y sus familias en el CEIP.

La biblioteca contribuye a reforzar la formación del profesorado y a dar mayor visibilidad a su labor docente, lo cual influye positivamente sobre su motivación e implicación ${ }^{152}$ en los objetivos y planes del CEIP.

152 Soulen y Wine (2018) han mostrado que los responsables de las bibliotecas escolares suelen ayudar en los procesos de acogida, integración y apoyo de los maestros noveles en sus primeros años de experiencia docente, lo cual redunda directamente en su resiliencia, e indirectamente en la mejora de los resultados académicos del alumnado. 


\subsubsection{Influencia de la biblioteca sobre la formación académica a medio y largo plazo y sobre la carrera profesional del alumnado y del profesorado}

El material cualitativo no aporta suficiente información para responder a estas cuestiones, ya que no siempre es posible seguir la trayectoria académica y profesional del antiguo alumnado y de los docentes desde los centros educativos. No obstante, el profesorado percibe que el paso por la biblioteca escolar en los cursos de educación primaria favorece la adquisición del hábito de la lectura y el refuerzo de competencias que contribuyen a la formación a medio y largo plazo, y al aprendizaje para toda la vida. Se subraya la importancia de continuar fomentando el uso de las bibliotecas entre el alumnado una vez que pasa a la educación secundaria, para que consolide esta base inicial y amplíe sus oportunidades académicas futuras ${ }^{153}$.

Respecto a la carrera profesional de los docentes, no hay constancia sobre la influencia de la biblioteca sobre la carrera profesional, más allá del beneficio sobre su formación informacional y digital, y sobre su motivación y satisfacción personal.

\subsubsection{Influencia de la biblioteca (en particular, la biblioteca como lugar) sobre el bienestar individual}

En el material cualitativo abundan las expresiones de satisfacción en relación con el hábito de la lectura y con el uso de la colección bibliográfica dentro el espacio físico de la biblioteca escolar. Aparece asociado a los conceptos de autonomía, seguridad, confianza, esparcimiento, bien común que se cuida y comparte, convivencia, lugar de ayuda donde encontrar información para los proyectos y tareas, espacio para actividades.

El alumnado vincula la biblioteca al trabajo de clase, pero también al recreo y al cultivo de las aficiones individuales. Es donde descubren nuevos temas de interés, y donde pueden leer libremente de acuerdo con sus gustos. Todo ello contribuye a su formación como futuros lectores. También es un espacio donde se convive, se comparten recursos y se practican actividades en torno a la lectura. Todo ello

153 Kraaykamp (2003) demostró que los niños que en su infancia habían sido miembros de una biblioteca, de adultos tenían mayor interés por las bibliotecas y los libros. En la misma línea, Baker y Alexander (2018) destacaron que en la biblioteca escolar se refuerzan competencias clave para el futuro académico y profesional del alumnado, por ejemplo: habilidades cognitivas como el pensamiento crítico, la resolución de problemas y toma de decisiones, la creatividad, comunicación y habilidades interpersonales, colaboración y liderazgo, y aspectos intrapersonales como la motivación, la ética y la responsabilidad. También es interesante añadir que la literatura avala el impacto positivo de las habilidades básicas de lectoescritura y cálculo sobre la empleabilidad (Mclntosh y Vignoles, 2001). 
contribuye a su socialización y al aprendizaje de las normas básicas de convivencia desde edades tempranas ${ }^{154}$.

Se puede decir que el alumnado crea un vínculo afectivo positivo con este lugar especial que les proporciona seguridad y disfrute. Los docentes opinan que la biblioteca debe ser un espacio donde gusta ir y donde gusta estar, y es a través de ese gusto como la persona se forma como lectora desde edades tempranas. La lectura en silencio en el espacio de la biblioteca es una actividad que contribuye a que el alumnado asimile el hábito de la lectura como una experiencia personal y desarrolle su sensibilidad literaria. Aprende así la importancia de poder contar con un tiempo propio para leer y disfrutar de la experiencia lectora.

\subsubsection{Influencia de la biblioteca sobre la institución de la que depende y en su entorno social próximo}

Del análisis del material cualitativo se desprende que una biblioteca escolar que está plenamente integrada en su centro educativo funciona como un recurso transversal que produce efectos positivos sobre el centro del que depende, contribuyendo a que se cumplan sus fines y objetivos, en torno a tres ejes principales:

1) Apoya los objetivos de enseñanza y aprendizaje, incluyendo el refuerzo curricular y la implantación de nuevas metodologías de trabajo y aprendizaje con el uso de las nuevas tecnologías:

$\checkmark$ Ayuda a afianzar y a avanzar en el uso de metodologías activas de trabajo cooperativo y el aprendizaje basado en proyectos. Tal y como se refleja en la Propuesta Curricular del CEIP Virrey Morcillo, la biblioteca se percibe como un "recurso de apoyo al currículo de todos los niveles escolarizados, áreas y materias" (Colegio de Educación Infantil y Primaria Virrey Morcillo, 2017, p. 37).

$\checkmark$ Contribuye a introducir y consolidar el uso de las nuevas tecnologías en los procesos de aprendizaje y enseñanza con un manejo competente y crítico de los recursos de información disponibles tanto en papel como en soporte digital. Contribuye a afianzar la competencia digital de los docentes.

2) Refuerza la cohesión entre los miembros de la comunidad educativa en torno a los objetivos y proyectos comunes, potenciando valores comunitarios y de convivencia, y actuando como un compensador de desigualdades:

154 La literatura ha mostrado el papel de la biblioteca escolar para la convivencia y la inclusión de las personas (Clyde, 2003; Odasso, 2007). En la misma línea, Moorefield-Lang y Kitzie (2018) mostraron que la biblioteca escolar se percibe como un "lugar seguro" que inspira confianza y bienestar, y donde jóvenes LGTB se sienten seguros e incluidos. 
Funciona como un canal de comunicación para toda la comunidad educativa a través de su blog y sus redes sociales. Esto contribuye a la cohesión entre familias, alumnado, docentes y equipo directivo de los centros. Tal y como se dice en la Propuesta Curricular del CEIP Virrey Morcillo, la biblioteca se percibe como "un espacio de encuentros abiertos, presenciales y virtuales de apoyo al aprendizaje y a la enseñanza, en conexión con las redes bibliotecarias y el entorno" (Colegio de Educación Infantil y Primaria Virrey Morcillo, 2017, p. 39).

$\checkmark$ Contribuye a incentivar la motivación del alumnado por aprender y por participar en las iniciativas del centro educativo.

$\checkmark$ Contribuye a la participación de las familias en las dinámicas educativas, y con ello a reforzar el sentido de pertenencia del alumnado respecto del centro educativo.

$\checkmark$ Contribuye a potenciar los valores comunitarios y de convivencia recogidos en la propuesta curricular del centro: respeto a las personas, cosas y normas, tolerancia en el debate de ideas, y sentido del bien común que hay que cuidar y compartir.

$\checkmark$ En la misma línea, los docentes valoran que la biblioteca escolar ayuda a compensar las diferencias socioeconómicas y educativas de partida del alumnado y sus familias ${ }^{155}$, siendo la equidad uno de los valores inspiradores de los objetivos de los centros educativos. Desde la biblioteca se garantiza el acceso equitativo a todos los recursos bibliotecarios y se proporciona la formación necesaria para el uso competente de los mismos. Los docentes perciben que el Plan de lectura y la biblioteca funcionan como un "compensador de necesidades" (Colegio de Educación Infantil y Primaria Virrey Morcillo, 2018c, p. 3).

$\checkmark$ El hecho de contar con una biblioteca de calidad contribuye a mejorar el prestigio del centro educativo y se asocia la calidad de la biblioteca con la calidad de la enseñanza que ofrece el centro. Contribuye a dar visibilidad al proyecto educativo y sus objetivos ante las autoridades educativas y ante la sociedad en su conjunto, traduciéndose esta visibilidad en la obtención de reconocimientos y premios.

3) Contribuye a establecer redes de cooperación:

\footnotetext{
155 Incidiendo en la misma idea, destacamos el trabajo de (Marzoli y Papa (2019) con alumnado italiano de educación primaria. Los autores demostraron que, el alumnado procedente de escuelas con bibliotecas mejor equipadas y con un mejor funcionamiento alcanzaba mejores resultados en las evaluaciones de lengua italiana y matemáticas, observándose mayores diferencias en el caso de escuelas que registraban un índice de estatus socioeconómico y cultural (ESCS) medio-bajo.
} 
$\checkmark$ Favorece las alianzas con otros agentes del ámbito cultural y educativo del entorno geográfico próximo, incluidas las bibliotecas públicas de la localidad y otras bibliotecas de centros escolares de la misma provincia con quienes se comparten recursos y conocimiento.

$\checkmark$ Contribuye a crear redes de colaboración dentro y fuera del centro educativo, como planes de lectura municipales y regionales y redes de bibliotecas de centros escolares. La participación del profesorado en estas redes ayuda a reforzar su motivación, su formación profesional, a potenciar su sentido de pertenencia y su implicación en los objetivos educativos, dando visibilidad a su labor docente.

$\checkmark$ Propicia la implicación de las familias en la educación de los hijos y en las necesidades y proyectos de los centros educativos. 


\section{CONCLUSIONES}

1) El objetivo principal de esta tesis ha sido profundizar sobre la dimensión educativa del impacto bibliotecario en el contexto de las bibliotecas escolares españolas. La tesis se enmarca en el campo de la investigación sobre evaluación de bibliotecas, adoptando la norma ISO 16439 como marco conceptual y como guía metodológica.

Siguiendo este referente conceptual, hemos partido de la definición de impacto como "la transformación o cambio que se produce en un individuo o en un grupo como resultado del contacto con servicios bibliotecarios. El cambio puede ser tangible o intangible" (Organización Internacional de Normalización, 2014b, p. 4).

Seguidamente, hemos explorado los tres niveles de impacto mencionados en la norma internacional: 1) impacto sobre los individuos, 2) impacto sobre la comunidad o institución de la que depende la biblioteca y 3) impacto sobre el conjunto de la sociedad. Las preguntas de investigación se corresponden con cada uno de estos tres niveles.

Con una doble visión cuantitativa y cualitativa, hemos obtenido evidencias de la contribución de la biblioteca escolar sobre el alumnado y el profesorado (individuos), sobre el centro educativo (institución / comunidad de la que depende) y sobre su entorno social (sociedad).

c) Efectos sobre los individuos

Desde ambas visiones se demuestra el efecto positivo de la biblioteca escolar sobre las habilidades y competencias individuales, en particular sobre el rendimiento y habilidades en competencia lectora. El alumnado con biblioteca escolar alcanza mejores resultados en las evaluaciones internacionales de lectura en educación primaria y secundaria. Asimismo, la biblioteca contribuye al desarrollo de cuatro dimensiones de la competencia lectora: adquirir y usar la información; tener una experiencia literaria; obtener información e inferencias directas, e interpretar, integrar y evaluar. Tanto en la investigación cuantitativa como en la cualitativa, se constata que la principal contribución de la biblioteca escolar se produce sobre la lectura en su dimensión de competencia informacional.

El alumnado que aprovecha los recursos de la biblioteca escolar adquiere y desarrolla su destreza en la búsqueda y selección de información, y en la extracción de conclusiones pertinentes. Aprende a desenvolverse con textos literarios e informativos en distintos soportes, en su doble experiencia de lectura por ocio y 
para la resolución de tareas para las que necesita realizar búsquedas documentales. Al mismo tiempo, se potencia su capacidad crítica y sus habilidades comunicativas.

En cuanto al profesorado, la biblioteca escolar contribuye a reforzar su integración en la vida de los centros educativos, y a potenciar sus habilidades docentes, especialmente en el ámbito de las competencias informacionales y en el uso de las nuevas tecnologías de la información, la educación y el aprendizaje.

Más allá de la frecuencia con la que el alumnado visita la biblioteca, es clave que tenga acceso a una variedad de actividades planificadas, y a recursos coordinados e impulsados desde la biblioteca del centro educativo y con el apoyo de un plan de lectura.

Entre los recursos bibliotecarios disponibles, se confirma la importancia de tener una colección bibliográfica amplia y de calidad, y de planificar actividades formativas orientadas a su correcto uso por parte del alumnado y el profesorado. El préstamo regular de ejemplares contribuye a reforzar el hábito lector y el uso de la biblioteca como una rutina más entre las actividades escolares.

Entre las actividades programadas, la lectura en voz alta, y con familias contribuyen a crear un vínculo afectivo del alumnado con la biblioteca, que favorece la práctica de la lectura tanto individual como en el hogar. Las actividades de fomento de la lectura vinculadas a tareas y proyectos, en combinación con el uso de la colección y del espacio físico de la biblioteca, benefician al alumnado en sus procesos de aprendizaje.

Los datos corroboran las conclusiones de los estudios anglosajones acerca del impacto del profesorado bibliotecario sobre el rendimiento del alumnado. Se produce un mayor efecto si el profesorado tiene una formación específica bibliotecaria y cuando en el centro educativo hay docentes de los diferentes ciclos formativos que están involucrados en las dinámicas de la biblioteca.

Por otro lado, se demuestra que la biblioteca contribuye a que se produzcan cambios observables en actitudes y comportamientos del alumnado. Los datos evidencian que contribuye a mejorar determinados aspectos intangibles de su proceso formativo, como la motivación por aprender, el aprendizaje autónomo, el sentido de pertenencia al centro educativo, la socialización de la lectura y el cultivo del hábito lector en soledad y en el entorno familiar.

El alumnado que frecuenta la biblioteca experimenta mayor autonomía y seguridad en sus aprendizajes. Desde edades tempranas perciben la biblioteca como un recurso de ayuda y como un espacio seguro de conocimiento por donde saben moverse con seguridad y confianza. Con el aprendizaje de las normas de la biblioteca aprenden a respetar los bienes compartidos e interiorizan valores y normas de conducta y convivencia. 
El efecto beneficioso sobre el bienestar del alumnado se ve reforzado cuando éste experimenta disfrute y confianza al utilizar los recursos y al participar en las actividades de la biblioteca. Para ello es clave que perciban su experiencia en la biblioteca como una actividad satisfactoria y no como una obligación.

Respecto del profesorado, se observa que su implicación en los planes de lectura y biblioteca incide positivamente sobre su motivación en general.

No hemos obtenido suficientes evidencias sobre los efectos de usar la biblioteca escolar sobre la formación del alumnado en el largo plazo, incluyendo la continuidad en los estudios superiores y la carrera profesional. La norma internacional advierte de la dificultad de evidenciar los efectos a largo plazo sobre los individuos, ya que no siempre es posible hacer un seguimiento de las personas para poder dar cuenta de estas evidencias con una perspectiva temporal amplia. En opinión de los docentes, sí se puede afirmar que la biblioteca escolar contribuye a crear una base sólida para la formación de futuros lectores y aprendices a lo largo de la vida, lo cual favorecería indirectamente a sus oportunidades académicas y laborales futuras. No obstante, se precisa investigación con diseños longitudinales de panel para corroborar estos extremos.

\section{d) Efectos sobre la institución / comunidad educativa}

Los datos confirman la contribución de la biblioteca a los fines y objetivos del centro educativo al que pertenece en tres ejes: 1 ) apoya los objetivos de enseñanza y aprendizaje, incluyendo el refuerzo curricular y la implantación de nuevas metodologías de trabajo y aprendizaje con el uso de las nuevas tecnologías; 2) refuerza la cohesión entre los miembros de la comunidad educativa en torno a los objetivos y proyectos comunes, potenciando valores comunitarios y de convivencia y actuando como un compensador de desigualdades; y 3) contribuye a establecer redes de cooperación con entidades externas, como redes bibliotecas escolares e instituciones educativas y culturales de la localidad. En este sentido, podemos concluir que la biblioteca es un recurso vertebrador e integrador que refuerza y cohesiona la comunidad educativa en torno a objetivos comunes docentes y de convivencia.

\section{e) Efectos sobre la sociedad}

Con relación a la contribución de la biblioteca al entorno social, hay que decir que no hemos obtenido suficientes evidencias, aparte de su colaboración con otras entidades educativas y culturales en redes de cooperación, y de su papel de refuerzo del entorno social más próximo propiciando la implicación de las familias en la comunidad educativa y la transmisión de valores entre todos los miembros de esta comunidad. 
Como se vio en el capítulo de revisión bibliográfica, la literatura ha indagado sobre el poder transformador, dinamizador y compensador de necesidades de la biblioteca pública respecto de su entorno social (Al, Dogan, Soydal y Taskin, 2019; Failla, 2017). En la misma línea, es preciso profundizar sobre la contribución de la biblioteca escolar a la creación de tejido social a través de las alianzas que establece con su comunidad próxima. Para ello es necesario recabar el impacto percibido no solo por los docentes sino también por las familias, y por distintos agentes sociales, educativos y culturales del entorno, incluidas las bibliotecas públicas y otros centros educativos.

2) Hay que decir que una de las principales limitaciones de esta tesis es la falta de ejemplos de estudios semejantes realizados en España con los que poder comparar los resultados. Como ya se ha visto, existen abundantes estudios que demuestran los beneficios de contar con un programa robusto de bibliotecas escolares, si bien éstos se circunscriben a países de cultura anglosajona.

En efecto, una de las principales conclusiones de esta tesis es constatar la necesidad de hacer investigación comparativa acerca del impacto de las bibliotecas escolares en comunidades con diferentes características poblacionales y socioculturales. En el caso de España, se precisa investigación comparativa entre los distintos sistemas educativos autonómicos.

Por otra parte, y con la misma finalidad comparativa, se recomienda introducir preguntas sobre la experiencia con la biblioteca escolar en los cuestionarios de futuras evaluaciones internacionales PIRLS, PISA y TIMSS.

3) Corroboramos la utilidad de aplicar el marco conceptual que proporciona la norma ISO 16439 para abordar nuevas investigaciones en el campo de la evaluación del impacto educativo, tanto para el conjunto de España como para estudios a nivel autonómico o local. Las ventajas de usar como referente una norma internacional son varias. Por un lado, al emplear un mismo marco conceptual y terminológico se allana el camino para la comparación entre casos extraídos de distintos contextos geográficos y culturales. Por otro lado, la utilización de este marco conceptual permite al investigador desarrollar una evaluación en profundidad de las diferentes dimensiones del impacto, sin descuidar cuestiones importantes como la dimensión temporal, el alcance, la intencionalidad, los elementos tangibles e intangibles.

De igual modo, la norma proporciona una guía exhaustiva de las distintas opciones metodológicas que se abren al investigador que aborda un estudio sobre el impacto, recogiendo las particularidades que deben tenerse en cuenta al entrar en el ámbito bibliotecario. 
4) Abundando en la cuestión metodológica, se confirma que es adecuado utilizar la complementación de métodos con una doble visión cuantitativa y cualitativa para abordar un problema complejo y multidimensional como el que nos ocupa. La doble aproximación nos ha permitido corroborar los resultados y afianzar las conclusiones empleando por una parte datos cuantitativos secundarios del conjunto de España y, por otra parte, datos cualitativos primarios extraídos de un estudio de caso.

La integración de las dos visiones nos ha permitido contrastar los resultados de la primera aproximación cuantitativa, y salvar las limitaciones que presenta el análisis estadístico cuando se aplica a la realidad multidimensional y dinámica del campo educativo.

La visión estadística se ha complementado con un segundo abordaje de tipo naturalista, orientado a registrar el impacto percibido. Como señalan Cook y Reichardt (1986), al emplear una perspectiva naturalista obtenemos una visión integral de la realidad, para una mejor comprensión de los procesos y realidades dinámicas del contexto educativo que nos ocupa.

En cuanto a la utilización del estudio de caso como estrategia metodológica, hemos comprobado que es un enfoque apropiado para realizar una evaluación del impacto en bibliotecas escolares. Por una parte, permite registrar con exhaustividad las diferentes perspectivas del problema de investigación, capturando la subjetividad de los diferentes receptores del impacto. Por otra parte, el estudio de caso es una estrategia flexible que permite utilizar diferentes técnicas para obtener las evidencias desde dentro del contexto que se estudia, en nuestro caso, el contexto educativo. En esta investigación hemos integrado técnicas de obtención de evidencias solicitadas (encuesta, entrevistas, grupo de discusión) junto al análisis de documentos.

5) Al emplear el estudio de caso nos planteamos la cuestión compleja de si es posible realizar una generalización de resultados a partir de un caso particular. Como señala Flick (2009, p. 407), este problema se plantea en toda investigación cualitativa.

Por una parte, hemos procurado fundamentar la selección del caso sobre criterios de representatividad e intensidad informativa (Patton, 2002), con el objeto de lograr una mayor objetividad y de asegurar la máxima representatividad de los datos resultantes. Siguiendo a Valles (2014), hemos aplicado el criterio de economía y el principio de punto de saturación teórica, de acuerdo con el cual, en un determinado momento de la investigación puede suceder que nuevas evidencias no añadan información relevante.

Para asegurarnos de la validez de los resultados, hemos contrastado los datos obtenidos en el CEIP Virrey Morcillo con información obtenida de otras bibliotecas 
escolares de la red cooperativa donde se integra este centro, y con datos proporcionados por sendas bibliotecas escolares de Galicia y Cantabria.

Con todo ello, consideramos que nuestros resultados alcanzan un nivel de objetividad y representatividad suficiente. El caso estudiado arroja luz sobre los efectos que puede producir una biblioteca escolar en funcionamiento y plenamente integrada en la vida de un centro educativo sobre las personas y sobre la comunidad educativa en su conjunto. Esta tesis por tanto contribuye a construir el marco teórico sobre la evaluación del impacto educativo de las bibliotecas tomando como punto de partida el marco proporcionado por la mencionada norma internacional.

6) Como se advierte en la norma internacional, la evaluación del impacto entraña la dificultad de cuantificar su naturaleza intangible. En esta investigación hemos encontrado dos tipos de evidencias de impacto: por una parte, las que pueden cuantificarse mediante puntuaciones, como es el caso del rendimiento del alumnado en competencias básicas. Por otra parte, aquellas evidencias que son de naturaleza más intangible y para cuyo registro se precisan metodologías cualitativas. Es el caso, por ejemplo, de las evidencias del impacto sobre las actitudes y comportamiento. Para éstas últimas hemos utilizado la perspectiva de impacto subjetivo tal y como lo perciben los docentes.

Asumimos por tanto que una parte de los resultados de nuestra investigación se fundamentan sobre el impacto percibido, y por tanto, sobre datos cualitativos con un componente subjetivo. Esto no resta validez a los resultados, más bien al contrario, como señala la propia norma internacional: "Los métodos cualitativos aportan textura y significado a los datos cuantitativos y ayudan a identificar los impactos de la biblioteca. Utilizadas conjuntamente, son herramientas potentes para el análisis y la comprensión de la interacción del usuario con la biblioteca" (Organización Internacional de Normalización, 2014b, p.54).

7) Tal y como advierte la norma internacional, nos hemos encontrado con la dificultad de aislar la influencia de la biblioteca de otros factores concurrentes, como, por ejemplo, el entorno familiar y social del alumnado, el acceso a otros recursos educativos dentro y fuera del centro educativo, y la propia actitud subjetiva del alumnado respecto de su proceso de aprendizaje.

La investigación socioeducativa ha explicado la influencia de los diferentes factores contextuales socioeconómicos, educativos y culturales, sobre el rendimiento académico y sobre el proceso de aprendizaje general. Como apunta Duru-Bellat (2010), la mayoría de los trabajos se pueden agrupar en torno a dos grandes grupos de 
variables explicativas externas que actúan como factores de desigualdad ${ }^{156}$. Por una parte se encuentran las investigaciones que ponen el foco sobre el origen socioeconómico y la disponibilidad de recursos en el entorno familiar (Bernardi y Cebolla, 2014; Durham, Farkas, Hammer, Tomblin y Catts, 2007; Fergusson, Horwood y Boden, 2008; Guadalupe, y Villanueva, 2013; Marks, 2005; Martínez García, 2010; Schubert y Becker, 2010; Siddiqi, Subramanian, Berkman, Hertzman y Kawachi, 2007); y el capital educativo y cultural de padre y madre, incluyendo aspectos como su nivel educativo (Martins y Veiga, 2010), sus hábitos culturales (De Graaf, De Graaf y Kraaykamp, 2000; Donohue, 2008; Kraaykamp, 2003), la condición de inmigrante de primera o segunda generación (Hillmert, 2013; Pereira, Santos Rego y Lorenzo Moledo, 2013; Verwiebe y Riederer, 2013) y las diferencias entre los entornos urbanos y rurales (Donoso Díaz, Arias Rojas, Gajardo Poblete y Frites Camilla, 2013).

Por otra parte, se encuentran las investigaciones que se centran en el sistema escolar, su configuración y recursos (Ferrer, Valiente González y Castel, 2010; Kotte, Lietz y López, 2005; Müller y Karle, 1993), incluyendo aspectos como la titularidad de los centros educativos (Calero Martínez y Escardíbul Ferrá, 2007) y el nivel de desempeño del profesorado (Keslin, 2014; Lorga, 2014).

El efecto de la biblioteca escolar es uno más entre los posibles factores explicativos, y sigue abierto el debate sobre este problema complejo y multidimensional. Si bien no se puede deducir una relación causa-efecto entre usar la biblioteca escolar y generar cambios en el desarrollo formativo del alumnado, sí podemos decir que, el factor biblioteca escolar contribuye a reforzar otros factores del contexto familiar y educativo que sí se ha demostrado que correlacionan significativamente con un mejor rendimiento académico, por ejemplo, la sensación de seguridad en el aprendizaje y la lectura, el cultivo de la lectura en el ámbito familiar y el sentido de pertenencia al centro educativo (Instituto Nacional de Evaluación Educativa, 2017):

En esta tesis hemos comprobado que el alumnado que utiliza la biblioteca ve reforzada su seguridad y su capacidad de aprender autónomamente. En la misma línea, los resultados de PIRLS 2016 evidencian que: "La diferencia entre las puntaciones medias de los estudiantes muy seguros en lectura y las de aquellos poco seguros es muy grande (...) En España esa diferencia llega a los 71 puntos" (Instituto Nacional de Evaluación Educativa, 2017, p.91). Asimismo, la seguridad en la lectura es un factor que, cuando alcanza valores altos, tiene un impacto positivo sobre la resiliencia del alumnado (Instituto Nacional de Evaluación Educativa, 2017, p.125).

${ }^{156}$ Como telón de fondo de todos estos estudios se plantea el debate clásico sobre si la escuela y sus recursos favorecen la movilidad y la transformación social, o si por el contrario, contribuyen a la reproducción social de la desigualdad (Carabaña, 2016; Coleman et al., 1966; Martín-Lagos López, 2018). 
Hemos comprobado que actividades programadas por la biblioteca como la lectura en silencio y con familias favorecen la práctica de la lectura tanto individual como en el hogar, y la implicación de las familias en los procesos formativos. La literatura ha demostrado que la influencia del entorno familiar y la transmisión de los hábitos de lectura del padre y la madre predisponen a un mayor desarrollo de la capacidad lectora (Notten y Kraaykamp, 2010; Serpell, Sonnenschein, Baker y Ganapathy, 2002). Los resultados de PIRLS 2016 evidencian que:

A mayor gusto por la lectura de los alumnos, mejores son sus resultados. Esta relación también se da entre el gusto por la lectura de los padres y el rendimiento de los alumnos (...) En España, la diferencia de puntuaciones medias estimadas entre los alumnos a los que no les gusta leer frente a los que les gusta mucho leer es de 22 puntos a favor de estos últimos (...), la diferencia de rendimiento de los alumnos a cuyos padres no les gusta leer frente a los alumnos a cuyos padres les gusta mucho leer es de 33 puntos a favor de estos últimos (...) Cuanto mayor es el número de libros en el domicilio familiar, más alta es la puntuación media obtenida en comprensión lectora. En España, tener más de 200 libros frente a tener menos de 10 supone una diferencia de 62 puntos en comprensión lectora (Instituto Nacional de Evaluación Educativa, 2017, pp.93-95, 129).

En el ámbito de la educación secundaria en los sucesivos estudios PISA desde 2000 hasta 2015 se corrobora la relación positiva significativa entre el número de libros en el hogar y rendimiento del alumnado en lectura. En 2015 en España el alumnado que dice tener más de 200 libros en casa supera al resto del alumnado en 112 puntos en lectura. (Instituto Nacional de Evaluación Educativa (2016, pp.122123). En la misma línea, a partir de una investigación en 27 países, Evans, Kelley, Sikora, y Treiman (2010) demostraron que quienes crecían en hogares con libros alcanzaban una media de tres años más de escolarización, con independencia del estatus socioeconómico familiar.

También hemos comprobado que se produce un vínculo afectivo entre el alumnado y la biblioteca, y ello ayuda a reforzar su sentimiento de pertenencia al centro educativo. En esta misma línea, los resultados de PIRLS 2016 evidencian que:

aquellos estudiantes que manifiestan un alto sentido de pertenencia al centro en el que cursan sus estudios obtienen mejor rendimiento que los que no tienen este sentimiento (...). La diferencia de rendimiento medio estimado entre los alumnos españoles con sentido de pertenencia alto y aquellos con sentido de pertenencia bajo es de 21 puntos (Instituto Nacional de Evaluación Educativa, 2017, p.89). 
8) Antes de cerrar este apartado, destacamos algunos puntos que han quedado fuera de esta tesis y sobre los que es necesario volver en futuras investigaciones sobre el impacto de las bibliotecas escolares:

$\checkmark$ En esta tesis hemos registrado evidencias del efecto de la biblioteca sobre la competencia lectora y sobre distintas dimensiones de esta competencia. Del mismo modo, es posible evaluar el efecto sobre otras competencias curriculares, como el cálculo, la expresión artística o las competencias sociales y cívicas.

$\checkmark$ Si bien en la investigación cuantitativa hemos abordado la contribución de la biblioteca escolar en el ámbito de la educación primaria y secundaria, en la investigación cualitativa nos hemos centrado en el contexto de la educación primaria. Las conclusiones de esta investigación se circunscriben a este ámbito, por lo que, en futuras investigaciones, será preciso realizar estudios comparativos entre los diferentes niveles educativos.

$\checkmark$ En esta investigación se ha registrado el impacto percibido por los docentes. En futuras investigaciones cualitativas se deberá ampliar el perfil de los participantes, con el fin de investigar el impacto percibido por otros agentes del ámbito educativo, como los padres y madres, los responsables de los centros educativos y el propio alumnado.

$\checkmark$ Como ya hemos señalado previamente, es preciso profundizar sobre la contribución de la biblioteca escolar a la creación de tejido social a través de las alianzas que establece con su entorno. Basándose en el concepto de capital social (Putnam, 2000), algunos autores como Dufur, Parcel y Troutman (2013) han señalado que con la participación de las familias en actividades extracurriculares se favorecen las alianzas entre los miembros de la comunidad educativa. En esta misma línea, nuevas investigaciones sobre la contribución de la biblioteca escolar en el marco conceptual del capital social aportarán luz sobre su impacto sobre el entorno próximo en el que se integra el centro educativo.

Las bibliotecas escolares evolucionan de un modo desigual hacia el modelo CREA (Centros de Recursos para la Educación y el Aprendizaje). Cabe preguntarse por el impacto de este tipo de biblioteca en comparación con los modelos tradicionales de biblioteca escolar de centro y biblioteca de aula.

9) Por último, queda añadir que, como señala la bibliografía (Kvale, 2011; Tójar Hurtado, 2006), la decisión de emprender un proyecto de investigación revela siempre una postura ética de partida en el investigador, desde el momento de la elección del objeto de estudio. 
En nuestro caso, partimos del convencimiento de que era necesario aportar conocimiento sobre el valor de la biblioteca escolar, habiendo quedado ésta fuera de los últimos estudios de impacto bibliotecario realizados en nuestro país.

Una reciente encuesta lanzada por la Comisión Europea (Comisión Europea, 2017) confirmaba la percepción de la ciudadanía acerca del valor de la biblioteca escolar para el fomento de la lectura y el uso competente de la información; para el desarrollo de las competencias necesarias en el actual contexto digital; para fomentar el aprendizaje a lo largo de la vida, incluyendo el aprendizaje informal; como recurso para reforzar el rendimiento académico, la implicación educativa de las familias y para promocionar valores como la inclusión y la equidad. Con nuestro trabajo queremos contribuir a reivindicar el papel de la biblioteca escolar como recurso funcional del sistema educativo, mostrando evidencias de su aportación transversal a los distintos elementos del sistema, incluyendo el alumnado y sus familias, los docentes y comunidad educativa en su conjunto, los centros educativos y su entorno social.

Finalmente, hemos querido dar visibilidad a la labor de los docentes - bibliotecarios de nuestro sistema educativo, y a iniciativas como el Grupo Bibliotecas Escolares en Red - BERED de la provincia Albacete, que trabajan con ilusión y sin descanso para aprovechar al máximo el potencial educativo y transformador de sus respectivas bibliotecas escolares. Sirva por tanto esta tesis como contribución a la creación de conocimiento en este campo, en pro del binomio inseparable de la educación y las bibliotecas. 


\section{BIBLIOGRAFÍA}

Aabø, S. (2004). The value of public libraries: a methodological discussion and empirical study applying the contingent valuation method (Tesis doctoral, Universidad de Oslo). Recuperado de https://www.duo.uio.no/bitstream/handle/10852/27223/avhandlingaabo.pdf?sequence=1\&isAllowed=y

Aabø, S. (2005a). Are public libraries worth their price? a contingent valuation study of Norwegian public libraries. New Library World, 106(11/12), 487-495.

Aabø, S. (2005b). Valuing the benefits of public libraries. Information Economics and Policy, 17, 175-198.

Aabø, S. y Audunson, R. (2002). Rational choice and valuation of public libraries: can economic models for evaluating non-market goods be applied to public libraries? Journal of Librarianship and Information Science, 34(1), 5-15.

Aabø, S. y Audunson, R. (2012). Use of library space and the library as a place. Library \& Information Science Research, 34(2), 138-149.

Aabø, S., Audunson, R. y Vårheim, A. (2010). How do public libraries function as meeting places? Library \& Information Science Research, 32(1), 16-26.

Aabø, S. y Strand, J. (2004). Public library valuation, non-use values and altruistic motivations. Library \& Information Science Research, 26, 351-372.

Achterman, D. (2008). Haves, halves, and have-nots: school libraries and student achievement in California (Tesis doctoral, Universidad de North Texas). Recuperado de http://digital.library.unt.edu/ark:/67531/metadc9800/

Adrial, C., Edgren, J., Nilsson, J. y Mânsby, S. (2005). Together we shape better libraries: the Swedish quality handbook project. IFLA Journal, 31(2), 188-193.

Agee, S. (2019). Equal access + equal opportunity = success for all learners. Knowledge Quest, 48(2), 24-29.

Al, U., Andrade Blanco, P., Chiranov, M., Cruz Silva, L.M., Devetakova, L.N., Dewata, Y., ... Tkachuk, Y. (2015). Global Libraries impact planning and assessment progress. Performance Measurement and Metrics, 16(2), 109-131.

Al, U., Dogan, G., Soydal, I. y Taskin, Z. (2019). Libraries as learning environments: the example of "Libraries for Everyone". Library Management, 40(1/2), 74-87.

Albelda Esteban, B. (2012). Evaluación de servicios bibliotecarios: experiencias recientes en la Biblioteca Nacional de España. Boletín de la ANABAD, 62(4), 321334.

Albelda Esteban, B. (2014). El enfoque cuantitativo: la evaluación mediante estadísticas e indicadores. En Nuevos instrumentos para la evaluación de bibliotecas: la normativa internacional ISO (pp. 23-83). Madrid: AENOR.

Albelda Esteban, B. (2019a). Bibliotecas escolares: su contribución a los objetivos de los centros educativos: resultados preliminares de un estudio de caso. En Actas del 
II Encuentro de Doctorandos/as e Investigadores/as Noveles de AIDIPE (pp. 182188). Asociación Interuniversitaria de Investigación en Pedagogía. Recuperado de https://aidipe2019.aidipe.org/actas/

Albelda Esteban, B. (2019b). Contribución de las bibliotecas escolares a la adquisición de competencias en comprensión lectora en educación primaria en España: una aproximación a partir de los datos del estudio PIRLS 2016. Revista de Educación, 384, 11-39. doi: 10.4438/1988-592X-RE-2019-384-408

Albelda Esteban, B. y La Mano González, M. de. (2017). Libraries contribution to the acquisition of reading literacy at primary and secondary school in Spain: an approach based on international assessment studies. En J.M. Dodero, M.S. Ibarra Sáiz e I. Ruiz Rube (Eds.), 5th International Conference Technological Ecosystems for Enhancing Multiculturality Proceedings (art. 102). New York: ACM. doi: $10.1145 / 3144826.3145449$

Alexander, K.L. Entwisle D.R. y Olson L.S. (2007). Lasting consequences of the summer learning gap. American Sociological Review, 72(2), 167-180.

Allington, R.L., McGill-Franzen, A., Camilli, G., Williams, L., Graff, J., Zeig, J., ... Nowak, R. (2010). Addressing summer reading setback among economically disadvantaged elementary students. Reading Psychology, 31, 411-427.

Álvarez Méndez, J.M. (1986). Investigación cuantitativa / Investigación cualitativa: ¿una falsa disyuntiva? En T.D. Cook y CH.S. Reichardt (Eds.), Métodos cualitativos y cuantitativos en investigación evaluativa (pp. 9-23). Madrid: Morata.

Alvira Martín, F. (1983). Perspectiva cualitativa-perspectiva cuantitativa en la metodología sociológica. Revista Española de Investigaciones Sociológicas, 22, 53-75.

Ambrožič, M. (2000a). Library performance measurement: the case of academic libraries (Part 1). Knjiznica, 44(3), 101-135.

Ambrožič, M. (2000b). Library performance measurement: the case of academic libraries (Part 2). Knjiznica, 44(4), 65-98.

Ambrožič, M., Jakac-Bizjak, V. y Mlekuš, H. (agosto, 2003). Performance evaluation in European national libraries: state-of-the-art. Comunicación presentada en World Library and Information Congress: 69th IFLA General Conference and Council, Berlín. Recuperado de http://webdoc.sub.gwdg.de/ebook/aw/2003/ifla/vortraege/iv/ifla69/papers/02 4e-Ambrozic_Jakac-Bizjak_Mlekus.pdf

American Association of School Librarians. (2009). Standards for the 21st-century learner in action. Chicago: ALA.

American Association of School Librarians. (2014). Causality: school libraries and student success (CLASS): white paper. Washington, D.C.: Institute of Museum and Library Services. Recuperado de http://www.ala.org/aasl/sites/ala.org.aasl/files/content/researchandstatistics/C LASSWhitePaperFINAL.pdf 
American Library Association. (1998). Information power: building partnerships for learning. Chicago, IL: American Library Association.

American Library Association. (2004). Core Values of Librarianship. Recuperado de http://www.ala.org/advocacy/intfreedom/statementspols/corevalues

American Psychological Association. (2010). Publication manual of the American Psychological Association (6th ed.). Washington, DC: APA.

Andrews, C., Wright, S.E. y Raskin, H. (2015). Library learning spaces: investigating libraries and investing in student feedback. Journal of Library Administration, 56(6), 647-672.

Anglada i de Ferrer, L.M. (1999). La elaboración de una guía para la evaluación de los servicios bibliotecarios de las universidades de Cataluña. En Les biblioteques i els centres de documentació al segle XXI: peça clau de la societat de la información: 7 Jornades Catalanes de Documentació (pp. 31-37). Barcelona: Col·legi Oficial de Bibliotecaris-Documentalistes de Catalunya.

Anguera Argilaga, M.T. (1986). La investigación cualitativa. Educar, 10, 23-50.

Appleton, L. (2018). Qualitative methods for engaging students in performance measurement. Information and Learning Science, 119(1/2), 64-76. doi: 10.1108/ILS-09-2017-0093

Archives, Libraries and Museums Alliance UK. (2011). Impact toolkit for archives and museums ALMA-UK. Recuperado de https://almauk.org/workingtogether/our activity/economic-impacts/research-into-economic-impacts/

Asociación de Bibliotecarios y Documentalistas de Guipúzcoa. (1996). Evaluación de los servicios bibliotecarios: VII Jornadas sobre Bibliotecas Públicas, 1,2,3 de junio de 1995, San Sebastián. Donostia: Asociación de Bibliotecarios y Documentalistas de Guipúzcoa.

Asociación Española de Normalización. (2014). UNE-ISO 2789:2014, Información y documentación. Estadísticas internacionales de bibliotecas. Madrid: AENOR.

Asselin, M. y Doiron, R. (2008). Towards a transformative pedagogy for school libraries 2.0. School Libraries Worldwide, 14(2), 1-18.

Association of College and Research Libraries. (1998). Task Force on Academic Library Outcomes Assessment Report. Chicago: ALA. Recuperado de http://www.ala.org/acrl/publications/whitepapers/taskforceacademic

Atkinson, J. y Walton, G. (2017). Establishing quality in university libraries: role of external frameworks. New Review of Academic Librarianship, 23(1), 1-5.

ATLAS.ti (Versión 8) [Programa de ordenador]. Berlin: ATLAS.ti Scientific Software Development $\mathrm{GmbH}$.

Audunson, R. (2005). The public library as a meeting-place in a multicultural and digital context: the necessity of low-intensive meeting-places. Journal of Documentation, 61(3), 429-441.

Audunson, R. (2016). The library and quality of life. Scandinavian Library Quarterly, $49(1 / 2), 1-7$. 
Audunson, R., Essmat, S. y Aabø, S. (2011). Public libraries: a meeting place for immigrant women? Library \& Information Science Research, 33(3), 220-227.

Audunson, R., Vårheim, A., Aab $\varnothing$, S. y Holm, E.D. (2007). Public libraries, social capital and low intensive meeting places. Information Research, 12(4). Recuperado de http://www.informationr.net/ir/12-4/colis/colis20.html

Baba, D. y Shukor, R. (agosto, 2003). Performance indicators for national libraries in Asia/Oceania: preliminary proposals based on a survey of Asia/Oceania libraries. Comunicación presentada en World Library and Information Congress: 69th IFLA General Conference and Council, Berlin. Recuperado de http://webdoc.sub.gwdg.de/ebook/aw/2003/ifla/vortraege/iv/ifla69/papers/02 5e-Baba_Shukor.pdf

Badu, E.E. (2009). Performance measurement in academic libraries in Ghana. Ghana Library Journal, 21(1-2). doi: 10.4314/glj.v21i1-2.69494

Baker, D. y Evans, W. (2011). Libraries, society and social responsibility. En D. Baker y W. Evans (Eds.), Libraries and society: role, responsibility and future in an age of change (pp. 1-16). Oxford: Chandos Publishing.

Baker, N., Furlong, K., Consiglio, D., Holbert, G.L., Milberg, C., Reynolds, K. y Wilson, J. (2018). Demonstrating the value of "library as place" with the MISO Survey. Performance Measurement and Metrics, 19(2), 111-120. doi: 10.1108/PMM-012018-0004

Baker, S.F. y Alexander, B. (2018). A major making undertaking: a new librarian transforms a middle school library into a makerspace aligned to high school career endorsements. Knowledge Quest, 46(5), 64-69.

Baker, S.L. y Lancaster, F.W. (1991). Measurement and evaluation of library services (2nd ed.). Arlington, VA.: Information Resources Press.

Balagué i Mola, N. (1999). El desarrollo de un sistema de calidad basado en la norma ISO 9002 en el servicio de bibliotecas de la Universidad Autónoma de Barcelona. En Les biblioteques i els centres de documentació al segle XXI: peça clau de la societat de la información: 7 Jornades Catalanes de Documentació (pp. 49-56). Barcelona: Col-legi Oficial de Bibliotecaris-Documentalistes de Catalunya.

Balagué Mola, N. (2007). Consolidando la calidad en las bibliotecas universitarias: evaluaciones, sellos, diplomas y certificaciones. El Profesional de la Información, 16(4), 338-343.

Baro, E.E. y Eze, M.E. (2016). Enhancing quality learning: the impact of school library services to students in Nigeria. School Libraries Worldwide, 22(1), 8-19.

Barron, D.D., Williams, R.V., Bajjaly, S., Arns, J. y Wilson, S. (2005). The economic impact of public libraries on South Carolina. Columbia: University of South Carolina. Recuperado de http://www.libsci.sc.edu/sceis/home.htm

Barton, J. (1997). Performance indicators for university libraries. SCONUL Newsletter, 11, 8-9. 
Barton, J. (1998). The recommendations of the Cranfield project on performance indicators for academic libraries. SCONUL Newsletter, 14, 15-17.

Baumbach, D., Lee, J., Hart, T., Lance, K.C., Rodney, M., Wane, M. y Zhang, Y. (2003). Making the grade: the status of school library media centers in the Sunshine State and how they contribute to student achievement. Salt Lake City, UT: Hi Willow Research and Pub.

Baumol, W.J. (2005). La economía del bienestar aplicada. En R. Towse (Ed.), Manual de economía de la cultura (pp. 271-288). Madrid: Fundación Autor.

Baumol, W.J. y Marcus, M. (1973). Economics of academic libraries. Washington, DC: American Council on Education.

Becker, S., Crandall, M.D. y Fisher, K.E. (2009). Communicating the impact of free access to computers and the Internet in public libraries: a mixed methods approach to developing outcome indicators. Public Library Quarterly, 28(2), 109119.

Becker, S., Crandall, M.D., Fisher, K.E., Blakewood, R., Kinney, B. y Russell-Sauvé, C. (2011). Opportunity for all: how library policies and practices impact public Internet access. Washington, D.C.: Institute of Museum and Library Services. Recuperado de https://www.imls.gov/assets/1/AssetManager/OppForAll2.pdf

Becker, S., Crandall, M.D., Fisher, K.E., Kinney, B., Landry, C. y Rocha, A. (2010). Opportunity for all: how the American public benefits from Internet access at U.S. libraries. Washington, D.C.: Institute of Museum and Library Services. Recuperado de https://www.imls.gov/assets/1/AssetManager/OpportunityForAll.pdf

Behr, M.D. y Hayward, J.L. (2016). Evolution or integration: what is the current state of library services for distance learners? Journal of Library \& Information Services in distance learning, 10(3-4), 88-100.

Belda González, C. y Mercader Blanco, M.J. (2004). Evaluación de las bibliotecas municipales de Cartagena: primer paso hacia la calidad. Boletín de la ANABAD, 54(1-2), 551-557.

Benhamou, F. (2005). El patrimonio. En R. Towse (Ed.), Manual de economía de la cultura (pp. 625-637). Madrid: Fundación Autor.

Berghaus-Sprengel, A. (2001). The comparison of library operations as an instrument of performance measurement in public libraries. Bibliothek Forschung und Praxis, 25(2), 143-191.

Bericat, E. (1998). La integración de los métodos cualitativo y cuantitativo en la investigación social: significado y medida. Barcelona: Ariel.

Bernardi, F. y Cebolla, H. (2014). Clase social de origen y rendimiento escolar como predictores de las trayectorias educativas. Revista Española de Investigaciones Sociológicas, 146, 3-22. 
Bertot, J.C. (2000). Developing national network statistics and performance measures for US public libraries: issues, findings and recommendations. Performance Measurement and Metrics, 1(1), 15-42.

Bertot, J.C. (2001). Library network statistics and performance measures: approaches and issues. Liber Quarterly, 11(3), 224-243.

Bertot, J.C., Dalton, P., McClure, C.R. y Shim, W. (2003). Assessing networked services: an update. SCONUL Newsletter, 29, 27-34.

Bertot, J.C., Jaeger, P.T., Lee, J., Dubbels, K., McDermott, A.J. y Real, B. (2014). 2013 Digital inclusion survey: survey findings and results. College Park, MD: University of Maryland College Park. Recuperado de http://ipac.umd.edu/

Bertot, J.C., Langa, L.A., Grimes, J.M, Sigler, K. y Simmons, S.M. (2010). 2009-2010 Public library funding and technology access survey: survey findings and results. College Park, MD: University of Maryland College Park. Recuperado de http://plinternetsurvey.org/sites/default/files/publications/2010 plftas.pdf

Bertot, J.C. y McClure, C.R. (1998). Moving toward more effective public Internet access: the 1998 national survey of public library outlet Internet connectivity. Washington: National Commission on Libraries and Information Science. Recuperado de http://plinternetsurvey.org/sites/default/files/publications/1998_plinternet.pdf

Bertot, J.C. y McClure, C.R. (1999). Public libraries and the Internet 2000: summary findings and data tables. Washington: National Commission on Libraries and Information Science. Recuperado de http://plinternetsurvey.org/sites/default/files/publications/2000_plinternet.pdf

Bertot, J.C. y McClure, C.R. (2002). Public libraries and the Internet 2002: Internet connectivity and networked services. Florida: Florida State University. Recuperado de http://plinternetsurvey.org/sites/default/files/publications/2002_plinternet.pdf

Bertot, J.C., McClure C.R. y Fletcher, P.D. (1997). The 1997 national survey of public libraries and the Internet: progress and issues. Washington: National Commission on Libraries and Information Science. Recuperado de http://plinternetsurvey.org/sites/default/files/publications/1997_plinternet.pdf

Bertot, J.C., McClure, C.R. y Jaeger, P.T. (2004). Public libraries and the Internet 2004: survey results and findings. Florida: Florida State University. Recuperado de http://plinternetsurvey.org/sites/default/files/publications/2004_plinternet.pdf

Bertot, J.C., McClure C.R., Jaeger, P.T. y Ryan, J. (2006). Public libraries and the Internet 2006: study results and findings. Florida: Florida State University. Recuperado de http://plinternetsurvey.org/sites/default/files/publications/2006 plinternet.pdf

Bertot, J.C., McClure C.R., Wright, C.B., Jensen, E. y Thomas, S. (2008). Public libraries and the Internet 2008: study results and findings. Florida: Florida State University. Recuperado de http://plinternetsurvey.org/sites/default/files/publications/2008_plinternet.pdf 
Bertot, J.C., McClure C.R., Wright, C.B., Jensen, E. y Thomas, S. (2009). Public libraries and the Internet 2009: study results and findings. Florida: Florida State University. Recuperado

de http://plinternetsurvey.org/sites/default/files/publications/2009_plinternet.pdf

Bertot, J.C., McClure C.R. y Zweizig, D.L. (1996). The 1996 national survey of public libraries and the Internet: progress and issues. Washington: National Commission on Libraries and Information Science. Recuperado de http://plinternetsurvey.org/sites/default/files/publications/1996_plinternet.pdf

Bertot, J.C., McDermott, A., Lincoln, R., Real, B. y Peterson, K. (2012). 2011-2012 Public library funding \& technology access survey: survey findings \& report. College Park, MD: University of Maryland College Park. Recuperado de http://www.plinternetsurvey.org

Bertot, J.C., Real, B. y Jaeger, P.T. (2016). Public libraries building digital inclusive communities: data and findings from the 2013 digital inclusion survey. The Library Quarterly, 86(3), 270-289.

Bertot, J.C., Real, B., Lee, J., McDermott, A.J. y Jaeger, P.T. (2015). 2014 Digital inclusion survey: findings and results. College Park, MD: Information Policy \& Access Center, University of Maryland College Park. Recuperado de http://digitalinclusion.umd.edu/

Bloor, I.G. (1991). Performance indicators and decision support systems for libraries: a practical application of keys to success. London: British Library Research and Development Department.

Blummer, B. y Kenton, J.M. (2018). Academic libraries and student learning outcomes. Performance Measurement and Metrics, 19(1), 75-87. doi: 10.1108/PMM-112017-0053

Bommer, M.R., Chorba, R.W. y Grattidge, W. (1979). Performance assessment model for academic libraries. Journal of the American Society for Information Science, 30(1), 93-99.

Booth, A. y Brice, A. (Eds.). (2004). Evidence-based practice for information professionals: a handbook. London: Facet.

Bop Consulting. (2014). Evidence review of the economic contribution of libraries. Manchester: Arts Council England. Recuperado de http://www.artscouncil.org.uk/sites/default/files/downloadfile/Evidence review economic contribution libraries 2014.pdf

Borrego Huerta, A. y Urbano, C. (2005). Estadísticas e indicadores de rendimiento de colecciones y servicios bibliotecarios de carácter electrónico: estudio de caso de las revistas electrónicas. El Profesional de la Información, 14(1), 30-38.

Bosch, M. y Espelt, C. (1999). Factores involucrados en el proceso de toma de decisiones en bibliotecas de tamaño medio y pequeño: resultados del proyecto DECIMA. Revista Española de Documentación Científica, 22(1), 9-22. 
Botha, E., Erasmus, R. y Van Deventer, M. (2009). Evaluating the impact of a special library and information service. Journal of Librarianship and Information Science, 41(2), 108-123.

Bourdieu, P. (1986). The forms of capital. En J. G. Richardson (Ed.), Handbook of theory and research for the Sociology of Education (pp. 241-258). Westport: Greenwood Press.

Brettle, A., Maden, M. y Payne, C. (2016). The impact of clinical librarian services on patients and health care organisations. Health Information and Libraries Journal, 33(2), 100-120.

Briand, B., Buffeteau, A., Cudelou, J., Drouet, C., Mangeot, A., Paillard, M. y Regnault, M. (2002). Indicateurs de performance des services documentaires: I' experience d'un groupe de professionnels de l' information. Documentaliste, 39(1-2), 26-33

Brooking, A. (1996). Intellectual capital. London: International Thomson Business Press.

Brophy, P. (2005). The development of a model for assessing the level of impact of information and library services. Library \& Information Research, 29(93), 43-49.

Bruxvoort, D. (2016). Library as third place: a strategic framework. SCONUL Focus, 68, 13-14. Recuperado de https://www.sconul.ac.uk/page/sconul-focus

Bryman, A. (1984). The debate about quantitative and qualitative research: a question of method or epistemology? The British Journal of Sociology, 35(1), 75-92.

Burgin, R., Bracy, P.B. y Brown, K. (2003). An essential connection: how quality school library media programs improve student achievement in North Carolina. Greensboro, NC: RB Software \& Consulting. Recuperado de http://www.rburgin.com/NCschools2003/NCSchoolStudy.pdf

Burton, J.E. (1995). The impact of medical libraries and literature on patient care in New Zealand. Bulletin of the Medical Library Association, 83(4), 425-430.

Busayo, I. O. (2018). Access use and benefits of the school library: a case study of deeper life high school, Ado-Ekiti. The School Librarian, 66(4), 210-213.

Byrne, A. (1997). CAUL's interest in performance measurement. Australian Academic and Research Libraries, 28(4), 252-258.

Byrne, A. (2018). Democracy and libraries: symbol or symbiosis? Library Management, 39(5), 284-294.

Caldera Morillo, E., Pirela Morillo, J. y Ortega, E. (2011). Dimensiones para el estudio de la calidad de servicios en bibliotecas universitarias. Documentación de las Ciencias de la Información, 34, 333-347. Recuperado de http://revistas.ucm.es/index.php/DCIN/article/view/36462/35310

Calenge, B. (1999). Les indicateurs de performance. Bulletin des Bibliothèques de France, 44(5), 95-96.

Calero Martínez, J. y Escardíbul Ferrá, J.O. (2007). Evaluación de servicios educativos: el rendimiento de los centros públicos y privados medido en PISA 2003. Documents de Treball IEB, 7. 
Calvert, P. (1994). Library effectiveness: the search for a social context. Journal of Librarianship and Information Science, 26(1), 15-21.

Calvert, P. y Cullen, R. (1992). Performance measurement in New Zealand public libraries: a research project. Australasian Public Libraries and Information Services, 5(1), 3-12.

Calvert, P. y Cullen, R. (1994). Further dimensions of public library effectiveness, II: the second stage of the New Zealand study. Library \& Information Science Research, 16(2), 87-104.

Calvert, P. y Goulding, A. (2015). Narratives and stories that capture the library's worth: a qualitative approach to measuring value and impact in New Zealand's libraries. Performance Measurement and Metrics, 16(3), 276-288.

Camarero, L., Almazán, A., Arribas, J.M., Mañas, B. y Vallejos, A.F. (2010). Estadística para la investigación social. Madrid: Ibergarceta.

Carabaña, J. (2016). El Informe Coleman, 50 años después. RASE. 9(1), 9-21.

Carbone, P. (1995). The Committee Draft of International Standard ISO CD 11620 on Library Performance Indicators. IFLA Journal, 21(4), 274-277.

Carbone, P. (1998). Évaluer la performance des bibliothèques: une nouvelle norme. Bulletin des Bibliothèques de France, 43(6), 40-45.

Catalano, A. y Phillips, S.R. (2016). Information literacy and retention: a case study of the value of the library. Evidence Based Library and Information Practice, 11(4), 2-13.

Celestino Angulo, S. (2006). El proceso de evaluación de la calidad en la Biblioteca de la Universidad de Sevilla. Boletín de la ANABAD, 56(1), 141-154.

Cerezo López, E.M., Alonso Cervero, B. y Gómez Pérez, A.M. (2002). Evaluación de la calidad en la automatización de bibliotecas. El Profesional de la Información, 11(2), 141-146.

Chiessi, S. (2011). What are libraries worth? a way to assess the impact of Italian public libraries on users' lives and society. The Hague: IFLA.

Childers, T. y Van House, N.A. (1989). Dimensions of public library effectiveness. Library and Information Science Research, 11(3), 273-301.

Christians, C.G. (2005). Ethics and politics in qualitative research. En N.K. Denzin e Y.S. Lincoln (Eds.), The Sage handbook of qualitative research (pp. 139-164). Thousand Oaks, Calif: Sage Publications.

Chukwueke, C., Onuoha, J. y Nnadozie, C.O. (2018). Effect of library services on the educational development of secondary school students in Abia State: a study of Igbere secondary school Igbere. Library Philosophy and Practice, 1847. Recuperado de http://digitalcommons.unl.edu/libphilprac/1847/

Chung, H.-K. (2007). Measuring the economic value of special libraries. The Bottom Line: Managing Library Finances, 20(1), 30-44.

Clarke, Z. (2001). EQUINOX Project: summary of results. Library and Information Research News, 25(79), 39-41. 
Closter, M. (2015). Public library evaluation: a retrospective on the evolution of measurement systems. Public Library Quarterly, 34(2), 107-123.

Clyde, L.A. (agosto, 2003). School libraries and social responsibility: support for special groups and issues: the case of homosexuality. Comunicación presentada en World Library and Information Congress: 69th IFLA General Conference and Council, Berlín. Recuperado de https://archive.ifla.org/IV/ifla69/papers/192eClyde.pdf

Cobacho Gómez, L. y Brugarolas Ros, C. M. (2006). La implantación del sistema de gestión de la calidad en la biblioteca de la universidad de Murcia (2002/2006). Boletín de la ANABAD, 56(1), 121-140.

Coker, E. (2015). Certified teacher-librarians, library quality and student achievement in Washington state public schools. Seattle: Washington Library Media Association. Recuperado de https://fopsl.files.wordpress.com/2012/01/certified-teacherlibrarians-library-quality-and-student-achievement-in-washington-state-publicschools.pdf

Colegio de Educación Infantil y Primaria Virrey Morcillo. (2009). Proyecto Educativo de Centro 2009-2010. Recuperado de http://CEIPvirreymorcillo.centros.castillalamancha.es/educacion/documentos

Colegio de Educación Infantil y Primaria Virrey Morcillo. (2017). Propuesta Curricular. Recuperado de http://CEIPvirreymorcillo.centros.castillalamancha.es/educacion/documentos

Colegio de Educación Infantil y Primaria Virrey Morcillo. (2018a). Memoria 2017-2018. Recuperado de http://CEIPvirreymorcillo.centros.castillalamancha.es/educacion/documentos

Colegio de Educación Infantil y Primaria Virrey Morcillo. (2018b). Normas de Convivencia, Organización y Funcionamiento 2009-2010, actualización 2018. Recuperado de http://CEIPvirreymorcillo.centros.castillalamancha.es/educacion/documentos

Colegio de Educación Infantil y Primaria Virrey Morcillo. (2018c). Plan de Lectura, Escritura, Información y Biblioteca. Curso 2018-2019. Recuperado de http://CEIP-virreymorcillo.centros.castillalamancha.es/educacion/documentos

Colegio de Educación Infantil y Primaria Virrey Morcillo. (2018d). Programación Anual de Actuaciones del Equipo de Orientación y Apoyo 2018-2019. Recuperado de http://CEIP-virreymorcillo.centros.castillalamancha.es/educacion/documentos

Colegio de Educación Infantil y Primaria Virrey Morcillo. (2018e). Programación General Anual 2018-2019. Recuperado de http://CEIPvirreymorcillo.centros.castillalamancha.es/educacion/documentos

Coleman, J. S., Campbell, E. Q., Hobson, C. J., McParttland, J., Mood, A. M., Weinfeld, F. D. y York, R. L. (1966). Equality of educational opportunity. Washington: U.S. Department of Health, Education and Welfare. 
Comisión Europea. (7 diciembre, 2017). Poll on school libraries: results [Mensaje en un blog]. https://www.schooleducationgateway.eu/en/pub/viewpoints/polls/poll-onschool-libraries-.htm

Connor, E. (Ed.). (2007). Evidence-based librarianship: case studies and active learning exercises. Oxford: Chandos.

Cook, C. y Heath, F. (2001). Users' perceptions of library service quality: a LibQUAL+ qualitative study. Library Trends, 49(4), 548-584.

Cook, C., Heath, F., Thompson, B. y Thompson, R.L. (2001). LibQUAL+: service quality assessment in research libraries. IFLA Journal, 4, 264-268.

Cook, T.D. y Reichardt, CH.S. (1986). Hacia una superación del enfrentamiento entre los métodos cualitativos y cuantitativos en investigación evaluativa. En T.D. Cook y CH.S. Reichardt (Eds.), Métodos cualitativos y cuantitativos en investigación evaluativa (pp. 25-58). Madrid: Morata.

Cooper, H., Nye, B., Charlton, K., Lindsay, J. y Greathouse, S. (1996). The effects of summer vacation on achievement test scores: a narrative and meta-analytic review. Review of Educational Research, 66(3), 227-268.

Cooper, M. (1996). The use of Total Quality Management (TQM) in libraries and information services in Australia and overseas. The Australian Library Journal, 45(2), 92-101.

Corrall, S. (2014). Library service capital: The case for measuring and managing intangible assets. Libraries in the Digital Age (LIDA) Proceedings, 13, 21-32. Recuperado

de http://ozk.unizd.hr/proceedings/index.php/lida/article/view/169/141

Corrall, S. (2018). Library space assessment methods: perspectives of new information professionals. Information and Learning Science, 119(1/2), 39-63.

Cortés Villalba, C. y Gil Leyva, I. (2011). Evaluación de la biblioteca pública de Valencia mediante la técnica encadenada de grupos de discusión y encuesta. Revista General de Información y Documentación, 21, 335-362. doi: 10.5209/rev_RGID.2011.v21.38027

Cotta-Schonberg, M. y Line, M.B. (1994). Evaluation of academic libraries: with special reference to the Copenhagen Business School Library. Journal of Librarianship and Information Science, 26(2), 55-69.

Cottrill, J., Letelier, F., Blanco, P.A., García, H., Chiranov, M., Tkachuk, Y., ... Triyono. (2015). From impact to advocacy: working together toward public library sustainability. Performance Measurement and Metrics, 16(2), 159-176.

Cox, A., Gruber, A. M. y Neuhaus, C. (2019). Complexities of demonstrating library value: an exploratory study of research consultations. Portal: Libraries and the Academy, 19(4), 577-590. 
Cox, E. (2000). A safe place to go: libraries and social capital. Sydney: University of Technology. Recuperado de https://www.sl.nsw.gov.au/sites/default/files/safe_place.pdf

Cram, J. (1995). Moving from cost centre to profitable investment: managing the perception of a library's worth. Australasian Public Libraries and Information Services, 8(3), 107-113.

Creaser, C. (2001). Performance measurement and benchmarking for school's library services. Journal of Librarianship and Information Science, 33(3), 126-132.

Creaser, C. (2018). Assessing the impact of libraries - the role of ISO 16439. Information and Learning Science, 119(1/2), 87-93. doi: 10.1108/ILS-05-2017-0037

Creaser, C. y Spezi, V. (2012). Working together: evolving value for academic libraries. Loughborough: LISU, Loughborough University. Recuperado de https://dspace.lboro.ac.uk/2134/13476

Cuccia, T. (2005). La valoración contingente. En R. Towse (Ed.), Manual de economía de la cultura (pp. 781-801). Madrid: Fundación Autor.

Cuevas Cerveró, A. y Marzal García Quismondo, M.A. (2007). La competencia lectora como modelo de alfabetización en información. Anales de Documentación, 10, 49-70. Recuperado de http://revistas.um.es/analesdoc/article/view/1082/1132

Cullen, R. (2004). Evaluating digital libraries in the health sector. Part 2: measuring impacts and outcomes. Health Information and Libraries Journal, 21(1), 3-13.

Cullen, R. y Calvert, P. (1995). Stakeholder perceptions of university library effectiveness. The Journal of Academic Librarianship, 21(6), 438-448.

Cullen, R. y Calvert, P. (1996). New Zealand university libraries effectiveness project: dimensions and concepts of organizational effectiveness. Library \& Information Science Research, 18(2), 99-119.

Dalton, M. (2012). Key performance indicators in Irish hospital libraries: developing outcome-based metrics to support advocacy and service delivery. Evidence Based Library and Information Practice, 7(4), 82-95.

Danladi, D. R. y Soko, Y. R. (2018). The role of school libraries in promoting reading culture among secondary school students: a case study of Federal Government College, Jos. Library Philosophy and Practice, 2058. Recuperado de http://digitalcommons.unl.edu/libphilprac/2058/

Das Graças Coletta, T. y Rozenfeld, H. (2007). Indicadores de desempenho para bibliotecas universitárias: definições e aplicações sob o ponto de vista da literatura. Perspectivas em Ciência da Informação, 12(3), 129-141.

De Graaf, N.D., De Graaf, P.M. y Kraaykamp, G. (2000). Parental cultural capital and educational attainment in the Netherlands: a refinement of the cultural capital perspective. Sociology of Education, 73(2), 92-111.

De Jager, K. (2002). Successful students: does the library make a difference? Performance Measurement and Metrics, 3(3), 140-144. 
De Jager, K. y Nassimbeni, M. (2005). Towards measuring the performance of public libraries in South Africa. South African Journal of Libraries and Information Science, 71(1), 39-50.

De Jager, K., Nassimbeni, M., Daniels, W. y D'Angelo, A. (2018). The use of academic libraries in turbulent times: student library behavior and academic performance at the University of Cape Town. Performance Measurement and Metrics, 19(1), 40-52. doi: 10.1108/PMM-09-2017-0037

De Miguel, M. (1988). Paradigmas de la investigación educativa española. En Aspectos metodológicos de la investigación educativa (pp. 60-77). Madrid: Narcea.

De Prospo, E.R., Altman, E. y Beasley, K.E. (1973). Performance measures for public libraries. Chicago: Public Library Association.

Derfert-Wolf, L., Górski, M. y Marcinek, M. (2004). Management based on reliable comparative data. Library statistics and performance indicators. A common project of Polish research libraries. Comunicación presentada en International Association of Scientific and Technological University Libraries, IATUL Annual Conference, West Lafayette, Indiana. Recuperado de http://docs.lib.purdue.edu/iatul/2004/papers/2/

Diamond, P.A. y Hausman, J.A. (1994). Contingent valuation: is some number better than no number? Journal of Economic Perspectives, 8(4), 45-64.

Díaz, C., Barrionuevo, M., Martínez, J., Reche, G. y Pérez, A. (agosto, 2005). Excellence and quality in Andalusia university library system. Comunicación presentada en 71st IFLA General Conference and Council, Oslo. Recuperado de http://archive.ifla.org/IV/ifla71/papers/091e-Diaz.pdf

Dolman, H. y Boyte-Hawryluk, S. (2013). Impact of the Reading Buddies Program on reading level and attitude towards reading. Evidence Based Library and Information Practice, 8(1), 35-46.

Donohue, K. (2008). Children's early reading: how parents' beliefs about literacy learning and their own school experiences relate to the literacy support they provide for their children. New York: New York University.

Donoso Díaz, S., Arias Rojas, O., Gajardo Poblete, C. y Frites Camilla, C. (2013) Inequidades invisibles en la educación chilena: brechas entre estudiantes urbanos y rurales en la prueba PISA de lectura 2009. Educaçao \& Sociedade, 34(125), 1203-1227.

Donovan, J.M. (1996). Do libraries deserve tenure? Casting an anthropological eye on role definition within the law school. Law Library Journal, 88(3), 382-401.

Dow, M.J., Lakin, J.M. y Court, S.C. (2012). School librarian staffing levels and student achievement as represented in 2006-2009 Kansas Annual Yearly Progress data. School Library Research, 15, 1-15.

Duarte Barrionuevo, M. (1995). Indicadores como instrumento de evaluación de los servicios bibliotecarios: 1. aspectos metodológicos. Boletín de la ANABAD, 45(1), 95-106. 
Dufur, M.J., Parcel, T.L. y Troutman, K.P. (2013). Does capital at home matter more than capital at school? Social capital effects on academic achievement. Research in Social Stratification and Mobility, 31, 1-21.

Düren, P. (2012). Total Quality Management in academic libraries: best practices. Qualitative and Quantitative Methods in Libraries, 1, 43-50. Recuperado de http://www.qqml.net/papers/July_Issue/5QQML_Journal_2012_Duren_1_4350.pdf

Durham, R. E., Farkas, G., Hammer, C.S., Tomblin, J.B. y Catts, H.W. (2007). Kindergarten oral language skill: a key variable in the intergenerational transmission of socioeconomic status. Research in Social Stratification and Mobility, 25, 294-305.

Durrance, J.C., Fisher, K.E. y Hinton, M.B. (2005). How libraries and librarians help: a guide to identifying user-centred outcomes. Chicago: American Library Association.

Duru-Bellat, M. (2010). Las desigualdades educativas en Europa: una cuestión de actualidad. Revista Española de Educación Comparada, 16, 105-130.

Edgar, W. (2004). Corporate library impact, Part I: a theoretical approach. The Library Quarterly, 74(2), 122-151.

Elbeshausen, H. y Skov, P. (2004). Public libraries in a multicultural space: a case study of integration processes in local communities. New Library World, 105(3/4), 131-141.

Ellis, M. (1998). Benchmarking public libraries: comparisons in context. Australasian Public Libraries and Information Services, 11(2), 56-60.

Elmborg, J. (2016). Tending the garden of learning: lifelong learning as core library value. Library Trends, 64(3), 533-555.

Emmons, M. y Wilkinson, F.C. (2011). The academic library impact on student persistence. College \& Research Libraries, 72(2), 128-149.

Eng, S. y Stadler, D. (2015). Linking library to student retention: a statistical analysis. Evidence Based Library and Information Practice, 10(3), 50-63.

Erasimus, E. y Bauer, B. (2006). BIX: Beteiligung von sechs osterreichischen Universitatsbibliotheken am Bibliotheksindex. Mitteilungen der Vereinigung Osterreichischer Bibliothekarinnen und Bibliothekare, 59(3), 9-20.

Evans, M.D.R., Kelley, J., Sikora, J. y Treiman, D.J. (2010). Family scholarly culture and educational success: books and schooling in 27 nations. Research in Social Stratification and Mobility, 28, 171-197.

Faba Pérez, C. (2010). Indicadores de calidad tradicionales y webmétricos para la evaluación de bibliotecas escolares. Boletín de la ANABAD, 60(2), 85-97.

Failla, L. (2017). Du livre à la ville: la bibliothèque comme espace public. Genève: MétisPresses.

Fallin, L. (2016). Beyond books: the concept of the academic library as learning space. New Library World, 117(5/6), 308-320. 
Falomir, V. y Segarra, J.R. (2006). El Sistema de Gestión de Calidad (Norma ISO 9001:2000) en la Biblioteca de la Universitat Jaume I de Castellón. Boletín de la ANABAD, 56(1), 75-87.

Faurio, D. e Illien, G. (2006). Organiser, gérer, évaluer son activité. Bulletin des Bibliothèques de France, 51(6), 94-95.

Federación Internacional de Asociaciones de Bibliotecarios y Bibliotecas. (2010). Library Statistics Manifesto. Recuperado de http://www.ifla.org/files/statistics-andevaluation/publications/library-statistics-manifesto-en.pdf

Federación Internacional de Asociaciones de Bibliotecarios y Bibliotecas. (2014). Declaración de Lyon. Recuperado de http://www.lyondeclaration.org/

Fergusson, D.M., Horwood, L.J. y Boden, J.M. (2008). The transmission of social inequality: examination of the linkages between family socioeconomic status in childhood and educational achievement in young adulthood. Research in Social Stratification and Mobility, 26, 277-295.

Fernández, S. y Rubio, F. (2013). ¿El dinero importa? Relación entre el presupuesto de la biblioteca y la productividad investigadora de la Universitat Politècnica de València. Revista Española de Documentación Científica, 36(4), 1-11.

Ferrer, F., Valiente González, O. y Castel, J.L. (2010) Los resultados PISA-2006 desde la perspectiva de las desigualdades educativas: la comparación entre comunidades autónomas en España. Revista Española de Pedagogía, 68(245), 23-48.

Ferrer, L. M. y Moscoso Castro, P. (2011). La biblioteca escolar vista por sus usuarios: el caso de la biblioteca del CEIP Isabel la Católica (Colmenar Viejo, Madrid). Revista General de Información y Documentación, 21, 79-98. Recuperado de http://revistas.ucm.es/index.php/RGID/article/download/79-98/36608

Fisher, B. (2003). Do libraries aid learning? Approaches and methods for measuring impact: a report of the LIRG/SCONUL seminar 9-10 December 2002, Scarborough. Library and Information Research, 27(85), 22-25.

Fitch, L. y Warner, J. (1998). Dividends: the value of public libraries in Canada. The Bottom Line, 11(4), 158-179.

Flaherty, M.G. y Miller, D. (2016). Rural public libraries as community change agents: opportunities for health promotion. Journal of Education for Library and Information Science, 57(2), 143-150.

Flecha, R. y Buslon, N. (2016). 50 años después del Informe Coleman. Las actuaciones educativas de éxito sí mejoran los resultados académicos. International Journal of Sociology of Education, 5(2), 127-143. doi: 10.17583/rise.2016.2087

Fleming-May, R., Mays, R., Walker, T., Forrester, A., Tenopir, C., Bilal, D. y Allard, S. (2018). Experience assessment: designing an innovative curriculum for assessment and UX professionals. Performance Measurement and Metrics, 19(1), 30-39. doi: 10.1108/PMM-09-2017-0036

Flick, U. (2009). An introduction to qualitative research (4th ed.). London: Sage Publications. 
Flick, U. (2014). El diseño de investigación cualitativa. Madrid: Morata.

Fodale, F. y Bates, J. (2011). What is the impact of the school library on pupils' personal development? a case study of a secondary school in Northern Ireland. School Libraries Worldwide, 17(2), 99-113.

Foy, P. (Ed.), Aldrich, C.E.A., Fishbein, B.G., Köhler, H., Kowolik, K., Liu, J., ... Yin, L. (2018). PIRLS 2016 user guide for the international database. Chestnut Hill, MA: TIMSS \& PIRLS International Study Center, Lynch School of Education, Boston College, International Association for the Evaluation of Educational Achievement. Recuperado

de https://timssandpirls.bc.edu/pirls2016/international-database/index.html

Francis, B.H., Lance, K.C. y Lietzau, Z. (2010). School librarians continue to help students achieve standards: the third Colorado study. Denver, CO: Colorado State Library, Library Research Service. Recuperado de https://www.Irs.org/documents/closer look/CO3 2010 Closer Look Report.p $\underline{\mathrm{df}}$

Fraser, B.T., Nelson, T.W. y McClure, C.R. (2002). Describing the economic impacts and benefits of Florida public libraries: findings and methodological applications for future work. Library \& Information Science Research, 24, 211-233.

Frías, J. A. y Borrego, A. (2004). Más allá de la cantidad: la incorporación de los métodos cualitativos a la investigación en Información y Documentación. En J. A. Frías y A. B. Ríos Hilario (Eds.), Metodologías de investigación en Información y Documentación (pp. 193-211). Salamanca: Ediciones Universidad de Salamanca.

Fuegi, D. (agosto, 2004). Recent developments in the application of statistics, standards and performance indicators in public libraries in England. Comunicación presentada en World Library and Information Congress: 70th IFLA General Conference and Council, Buenos Aires. Recuperado de http://archive.ifla.org/IV/ifla70/papers/120e-Fuegi.pdf

Fujiwara, D., Lawton, R. y Mourato, S. (2015). The health and wellbeing benefits of public libraries: full report. Manchester: Arts Council England. Recuperado de http://www.artscouncil.org.uk/sites/default/files/downloadfile/The\%20health\%20and\%20wellbeing\%20benefits\%20of\%20public\%20librari es.pdf

Galluzzi, A. y Solimine, G. (1999). Le biblioteche pubbliche italiane negli anni novanta: dalle misure agli idicatori e dagli indicatori ai dati. Bollettino AIB, 39(4), 455-468. Recuperado de http://bollettino.aib.it/article/view/8454/7547

García Crespo, F. J., Galián, B., Fernández Alonso, R. y Muñiz, J. (2019). Resiliencia educativa en comprensión lectora: factores determinantes en PIRLS-Europa. Revista de Educación, 384, 71-96.

Garrod, P. y Kinnell, M. (1996). Performance measurement, benchmarking and the UK library and information services sector. Libri, 46(3), 141-148. 
Gaspar Pinto, L. (1994). Indicadores de performance para as bibliotecas da Rede Nacional de Leitura Publica. Cadernos BAD, 3, 147-157. Recuperado de http://www.bad.pt/publicacoes/index.php/cadernos/index

Gaspar Pinto, L. y Moscoso Castro, P. (2012). Quatro décadas de investigação e práticas de avaliação do desempenho de bibliotecas em Portugal: uma abordagem metaavaliativa. Actas do Congresso Nacional de Bibliotecários, Arquivistas e Documentalistas, $11 . \quad$ Recuperado de http://www.bad.pt/publicacoes/index.php/congressosbad/issue/archive

Gaver, M.V. (1961). Effectiveness of centralized library service in elementary schools (phase I). The Library Quarterly, 31(3), 245-256.

Getz, M. (1980). Public libraries: an economic view. Baltimore, MD: Johns Hopkins University Press.

Gildersleeves, L. (2012). Do school libraries make a difference? Some considerations on investigating school library impact in the United Kingdom. Library Management, 33(6/7), 403-413.

Gimeno Perelló, J. (2006). Evaluación de la calidad en la biblioteca de la Universidad Complutense. Boletín de la ANABAD, 56(1), 89-119.

Girard-Billon, A. y Giappiconi, T. (1997). L'evaluation dans les bibliothèques publiques Francaises. Bulletin des Bibliothèques de France, 43(1), 78-84.

Glazier, J. D. (1992). Qualitative research methodologies for Library and Information Science: an introduction. En J. D. Glazier y R. R. Powell (Eds.), Qualitative research in information management (pp. 1-13). Englewood, CO: Libraries Unlimited.

Glazier, J. D. (2004). Qualitative, and nonqualitative research methodologies: thesis, antithesis, or synthesis? En J. A. Frías y A. B. Ríos Hilario (Eds.), Metodologías de investigación en Información y Documentación (pp. 177-192). Salamanca: Ediciones Universidad de Salamanca.

Głowacka, E. (2019). Research on the impact of academic libraries - areas, methods, indicators. Library Management, 40(8), 583-592.

Goffmann, E. (1959). The Presentation of Self in Everyday Life. Garden City, N.Y.: Doubleday.

Goldfinger, C. (1997). Intangible economy and its implications for statistics and statisticians. International Statistical Review, 65(2), 191-220.

Gómez-Hernández, J.A., Hernández-Pedreño, M. y Romero-Sánchez, E. (2017). Social and digital empowerment of vulnerable library users of the Murcia Regional Library, Spain. El profesional de la información, 26(1), 20-32.

Gómez Yáñez, J.A. (2014). El valor económico y social de los servicios de información: bibliotecas. Estudio Fesabid. Madrid: Fesabid. Recuperado de http://www.fesabid.org/sites/default/files/repositorio/fesabid-valoreconomico-social-servicios-informacion-bibliotecas.pdf 
Gong, H, Japzon, A.C. y Chen, C. (2008). Public libraries and social capital in three New York City neighbourhoods. Tijdschrift voor economische en sociale geografie, 99(1), 65-83.

González Fernández-Villavicencio, N., Cánovas Álvarez, E. y Arahal Junco, C. (2014). Evaluación del servicio de referencia de una biblioteca universitaria: Biblioteca de la Universidad de Sevilla. Revista Española de Documentación Científica, 37(2), e45. doi: 10.3989/redc.2014.2.1072

González Fernández-Villavicencio, N., Menéndez Novoa, J.L., Seoane García, C. y San Millán Fernández, M.E. (2013). Revisión y propuesta de indicadores (KPI) de la Biblioteca en los medios sociales. Revista Española de Documentación Científica, 36(1), e005. doi: 10.3989/redc.2013.1.919

Goodall, D.L. (1988). Performance measurement: a historical perspective. Journal of Librarianship and Information Science, 20(2), 128-144.

Graham, J. (1998). Le management de la qualité totale a la bibliothèque d'État de Nouvelle-Galles du Sud. Bulletin des Bibliothèques de France, 43(1), 57-64.

Graham, S. y Gagnon, A. (2013). A quasi-experimental evaluation of an early literacy program at the Regina Public Library. The Canadian Journal of Information and Library Science, 37(2), 103-121.

Greene, J.C., Caracelli, V.J. y Graham, W.F. (1989). Toward a conceptual framework for mixed-method evaluation designs. Educational Evaluation and Policy Analysis, 11(3), 255-274.

Greenshields, S. (1997). The value of libraries and professional librarians to Australian companies: an annotated bibliography. The Australian Library Journal, 46(2), 161-170.

Griadhi, M.H.W., Suarni, N. K., Marhaeni, A. N. y Sutajaya, I. M. (2018). The effect of library services quality towards achievement motivation and learning achievement of Undiksha students on Bali-Indonesia. Library Philosophy and Practice, 1822. Recuperado de http://digitalcommons.unl.edu/libphilprac/1822/

Grieves, K. (2018). Generating bespoke value and impact evidence to inform a thought leadership approach to service engagement at The University of Sunderland. Performance Measurement and Metrics, 19(1), 53-65. doi: 10.1108/PMM-092017-0041

Grieves, K. y Pritchard, O. (2018). Articulating value and impact through outcomecentered service delivery: the student and learning support experience at the University of Sunderland. Performance Measurement and Metrics, 19(1), 2-11. doi: 10.1108/PMM-08-2017-0034

Guadalupe, C. y Villanueva, A. (2013). PISA 2009/2000 in Latin America: re-reading changes in student achievement and its relationship with social conditions. Apuntes, 72, 157-192.

Guerrero, D. (Coord.), Anula Castells, C., Berzosa, C., Bilbao, A., Díaz Calleja, E., León E. de y Soto, F. (2002). Manual de economía política. Madrid: Síntesis. 
Guimarães, M., Lins, E., Rodrigues, J., Lamarão, C., Santos, M., Da Silva, V. y Da Silva, D. (2007). Indicadores de desempenho de bibliotecas no campo da saúde: relato de estudo piloto na Fiocruz. Perspectivas em Ciencia da Informacao, 12(1), 8496.

Gutiérrez, I. (2001). Evaluación de los servicios del centro bibliográfico y cultural de la ONCE: propuestas y alternativas. Revista General de Información y Documentación, 11(1), 133-164.

Gutiérrez Brito, J. (2014). Dinámica del grupo de discusión. Madrid: CIS.

Hájek, P. y Stejskal, J. (2015). Modelling public library value using the contingent valuation method: the case of the Municipal Library of Prague. Journal of Librarianship and Information Science, 47(1), 43-55.

Hall-Ellis, S.D. y Berry, M.A. (1995). School library media centres and academic achievement in South Texas. Texas Library Journal, 71(2), 94-97.

Halpin, E., Rankin, C., Chapman, E.L. y Walker, C. (2015). Measuring the value of public libraries in the digital age: what the power people need to know. Journal of Librarianship and Information Science, 47(1), 30-42.

Hamburg, M., Cohen, J., Montgomery, K.L., Williams, J.G., Bulik, S., Flynn, R.R., ... Mansfield, U. (1974). Library planning and decision-making systems. Cambridge, MA: MIT Press.

Hannabuss, S. (1987). The concept of performance: a semantic review. Aslib Proceedings, 39(5), 149-158.

Harris, C. (2007). Libraries with lattes: the new third place. APLIS, 20(4), 145-152.

Harris L. y Peterson, M. (2017). The economic value and clinical impact of the South Australian Health Library Service 2011-2016: a case study in organizational performance and survival. Business Information Review, 34(1), 18-24. doi: $10.1177 / 0266382117692451$

Hashizume, A. (agosto, 2008). Utilization of indicators in the National Diet Library (NDL): efforts for activity evaluation. Comunicación presentada en World Library and Information Congress: 74th IFLA General Conference and Council, Québec. Recuperado de http://archive.ifla.org/IV/ifla74/papers/160-Hashizume-en.pdf

Haycock, K. (2011). Connecting British Columbia (Canada) school libraries and student achievement: a comparison of higher and lower performing schools with similar overall funding. School Libraries Worldwide, 17(1), 37-50.

Hernández Sánchez, H. (2016). Estudio de impacto socioeconómico de las bibliotecas en la Comunidad Foral de Navarra. Pamplona: Gobierno de Navarra. Recuperado de $\quad$ http://www.elvalordelasbibliotecas.es/wpcontent/uploads/2016/04/info elvalor 1604.pdf

Hewlett, J. (1998). Performance indicators in NHS libraries. Health libraries review, 15(4), 245-253.

Heyns, B. (1978). Summer learning and the effects of schooling. New York: Academic Press. 
Hiller, S., Kyrillidou, M. y Self, J. (2006). Assessment in North American research libraries: a preliminary report card. Performance Measurement and Metrics, 7(2), $100-106$.

Hiller, S. y Self, J. (2004). From measurement to management: using data wisely for planning and decision-making. Library Trends, 53(1), 129-155.

Hillmert, S. (2013). Links between immigration and social inequality in education: a comparison among five European countries. Research in Social Stratification and Mobility, 32, 7-23.

Hindle, A. y Raper, D. (1976). The economics of information. Annual Review of Information Science and Technology, 11, 28-54.

Holt, G.E. y Elliott, D. (1998). Proving your library's worth: a test case. Library Journal, 123(18), 42-44.

Holt, G.E. y Elliott, D. (2003). Measuring outcomes: applying cost-benefit analysis to middle-sized and smaller public libraries. Library Trends, 51(3), 424-440.

Hood, C. (1991). A public management for all seasons? Public Administration, 69, 3-19.

Hooper-Greenhill, E. (2004). Measuring learning outcomes in museums, archives and libraries: The Learning Impact Research Project (LIRP). International Journal of Heritage Studies, 10(2), 151-174.

Horvath, R., Bitzan, K., Gumpenberger, C., Kromp, B. y Seissl, M. (2003). Leistungsmessung in Rot-Weiß-Rot: Erfahrungen and wissenschaftlichen Bibliotheken in Österreich. Bibliotheksdienst, 37(2), 180-187.

Houghton, K., Foth, M. y Miller, E. (2013). The continuing relevance of the library as a third place for users and non-users of IT: the case of Canada Bay. Australian Library Journal, 62(1), 27-39.

Howard, H. (2017). Landing the job: how special libraries can support career research introduction. Public Services Quarterly, 13(1), 55-59.

Howard Fleeter \& Associates. (2016). The return on investment of Ohio's public libraries, a comparison with other States. Recuperado de http://olc.org/wpcontent/uploads/documents/post-id 2060/2016/04/Ohio-Public-Libraries-ROIReport.pdf

Huang, H., Tse, S-k, Chu, S.K-W., Xiao, X-y., Lam, J.W-y., Ng, R.H-W. y Hui, S-Y. (2019). The correlation between out-of-school and in-school reading resources with primary school students' reading attainment. Information Research, 24(3), 834. Recuperado de http://www.informationr.net/ir/24-3/paper834.html

Hughes, H. (2014). School libraries, teacher-librarians and student outcomes: presenting and using the evidence. School Libraries Worldwide, 20(1), 29-50.

Hunter, D. y Hambelton, P. (2011). A bibliometric approach to evaluating the impact of national libraries. Library and Information Research, 35(111), 3-19.

Huysmans, F., Kleijnen, E., Broekhof K. y Van Dalen, T. (2013). The library at school: effects on reading attitude and reading frequency. Performance Measurement and Metrics, 14(2), 142-156. 
Huysmans, F. y Oomes, M. (2013). Measuring the public library's societal value: a methodological research program. IFLA Journal, 39(2), 168-177.

IBM SPSS Statistics for Windows (Versión 22.0) [Programa de ordenador]. Armonk, NY: IBM Corporation.

Imholz, S. y Arns, J.W. (2007). Worth their weight: an assessment of the evolving field of library evaluation. New York: Americans for Libraries Council. Recuperado de http://www.ala.org/research/sites/ala.org.research/files/content/librarystats/w orththeirweight.pdf

Instituto de Evaluación (2010). PISA 2009, Programa para la Evaluación Internacional de los Alumnos, OCDE, Informe español. Madrid: Ministerio de Educación. Recuperado de http://www.educacionyfp.gob.es/inee/evaluacionesinternacionales/pisa/pisa-200-2009.html

Instituto Nacional de Evaluación Educativa (2016). PISA 2015, Programa para la Evaluación Internacional de los Alumnos Informe Español. Madrid: Ministerio de Educación Cultura y Deporte. Recuperado de http://www.educacionyfp.gob.es/inee/evaluaciones-internacionales/pisa/pisa2015.html

Instituto Nacional de Evaluación Educativa. (2017). PIRLS 2016, estudio internacional de progreso en comprensión lectora, informe español. Madrid: Ministerio de Educación, Cultura y Deporte. Recuperado de https://www.mecd.gob.es/inee/dam/jcr:64541373-26c2-4e0f-b66c79168c44bbec/PIRLS\%202016\%20INFORME\%20NACIONAL_ONLINE_20dic.pdf International Association for the Evaluation of Educational Achievement. (2018). PIRLS 2016 User Guide for the International Database. Supplement1, International version of the PIRLS 2016 Context Questionnaires. Chestnut Hill, MA: TIMSS \& PIRLS International Study Center, Lynch School of Education, Boston College. Recuperado de https://timssandpirls.bc.edu/pirls2016/internationaldatabase/downloads/P16 UG Supplement1.pdf

International Database Analyzer (Versión 4.0) [Programa de ordenador]. Hamburg: IEA. Itsekor, V., Jegbefume, M. C. y Oyebola, O. J. (2019). The role of librarians in the implementation of the national policy of education. Library Philosophy and Practice, 2123. http://digitalcommons.unl.edu/libphilprac/2123/

Jantti, M. y Cox, B. (2013). Measuring the value of library resources and student academic performance through relational datasets. Evidence Based Library and Information Practice, 8(2), 163-171.

Játiva Miralles, M.V. y Gallo León, J.P. (2006). LibQUAL+: evaluación de calidad de servicios desde la perspectiva del usuario. Boletín de la ANABAD, 56(1), 53-74.

Jervelund, C., Kjøller-Hansen, A.O., Steen-Knudsen, J. y Jørgensen, J. (2015). The economic value of public libraries. Copenhagen: Think Tank Libraries of the Future. Recuperado de http://fremtidensbiblioteker.dk/wp/wpcontent/uploads/2014/07/Samle final opslag UK.pdf 
Johnson, C.A. (2010). Do public libraries contribute to social capital? a preliminary investigation into the relationship. Library \& Information Science Research, 32(2), 147-155.

Johnson, C.A. (2012). How do public libraries create social capital? an analysis of interactions between library staff and patrons. Library \& Information Science Research, 34(1), 52-62.

Johnson, C.A. (2015). Social capital and library and information science research: definitional chaos or coherent research enterprise? Information Research, 20(4), 35-49.

Johnson, C.A. y Griffis, M.R. (2009). A place where everybody knows your name? investigating the relationship between public libraries and social capital. Canadian Journal of Information \& Library Sciences, 33(3/4), 159-191.

Johnson, C.A. y Griffis, M.R. (2014a). The effect of library use on the social capital of rural communities. Journal of Librarianship and Information Science, 46(3), 179190.

Johnson, C.A. y Griffis, M.R. (2014b). Social capital and inclusion in rural public libraries: a qualitative approach. Journal of Librarianship and Information Science, 46(2), 96-109.

Johnston, J. (2016). Conversation-based programming and newcomer integration: a case study of the Språkhörnan program at Malmö City Library. Library \& Information Science Research, 38(1), 10-17.

Johnston, J. y Audunson R. (2019). Supporting immigrants' political integration through discussion and debate in public libraries. Journal of librarianship and information science, 51(1), 228-242.

Johnston, M.P. y Green, L.S. (2018). Still polishing the diamond: school library research over the last decade. School Library Research, 21. Recuperado de http://www.ala.org/aasl/slr/volume21/johnston-green

Jones, J.B. y Zambone, A.M. (2008). The power of the media specialist to improve academic achievement and strengthen at-risk students. Columbus, $\mathrm{OH}$ : Linworth Books.

Jouguelet, S. (2008). Evaluating and measuring the role of university libraries. Bulletin des Bibliothèques de France, 53(3), 22-28.

Jubb, M., Rowlands, I. y Nicholas, D. (2013). Value of libraries: relationships between provision, usage, and research outcomes. Evidence Based Library and Information Practice, 8(2), 139-152.

Kakirman Yildiz, A. (2012). A review of secondary literature on Evidence Based Library Management. Qualitative and Quantitative Methods in Libraries, 1, 63-72. Recuperado de http://www.qqml.net/papers/July_Issue/7QQML_Journal_2012_KakirmanYildiz_1_63-72.pdf 
Kaplan, A.G. (2010). School library impact studies and school library media programs in the United States. School Libraries Worldwide, 16(2), 55-63.

Kaplan, R.S. y Norton, D.P. (1996). The Balanced Scorecard: translating strategy into action. Boston, MA: Harvard Business School Press.

Kaufman, P. y Watstein, S.B. (2008). Library value (return on investment, ROI) and the challenge of placing a value on public services. Reference Services Review, 36(3), 226-231.

Kerslake, E. y Kinnell, M. (1998). Reviewing the literature on public libraries and social inclusion. Libri, 48, 1-12.

Keslin, H.K. (2014). Programme for International Student Assessment (PISA) Reading competencies: a study of the factors in academic reading. Anthropologist, 18(1), 171-182.

Khan, A. y Ahmed, S. (2016). The impact of digital library resources' usage on research productivity: a study among engineering students in Pakistan. Pakistan Journal of Information Management \& Libraries, 17, 174-183.

Khoir, S., Du, J.T., Davison, R.M. y Koronios, A. (2017). Contributing to social capital: an investigation of Asian immigrants' use of public library services. Library \& Information Science Research, 39, 34-45.

Kim, G. (2011). A critical review of valuation studies to identify frameworks in library services. Library \& Information Science Research, 33, 112-119.

Kim, G., Kwon, N., Yu, S. y Choi, Y. (2013). An integrated analysis of quantitative and qualitative data for identifying factors in information services: a working paper. Qualitative and Quantitative Methods in Libraries, 4, 393-402. Recuperado de http://www.qqml.net/papers/December 2013 Issue/246QQML Journal 2013 Kim etal 4393 402.pdf

Kim, J.A. (2016). Dimension of user perception of academic library as place. The Journal of Academic Librarianship, 42, 509-514.

Kingma, B. y McClure, K. (2015). Lib-Value: values, outcomes, and return on investment of academic libraries, Phase III: ROI of the Syracuse University Library. College \& Research Libraries, 76(1), 63-80.

Kiviniemi, V., Laitinen, M. y Saarti, J. (2009). Are libraries worth investing in? Finnish university libraries and their effect on the national economy. Liber Quarterly, 19(1), 54-61.

Klein, O., Biedinger, N. y Becker, B. (2014). The effect of reading aloud daily: differential effects of reading to native-born German and Turkish-origin immigrant children. Research in Social Stratification and Mobility, 38, 43-56.

Klempin, H. (1997). Performance et demarche qualité dans les bibliothèques publiques de la Republique Fédérale d'Allemagne. Bulletin des Bibliothèques de France, 43(1), 65-71.

Klinger, D.A., Lee, E.A., Stephenson, G., Deluca, C. y Luu, K. (2009). Exemplary School Libraries in Ontario. Toronto: Ontario Library Association. Recuperado de 
http://www.peopleforeducation.ca/wp-content/uploads/2011/12/ExemplarySchool-Libraries-in-Ontario.pdf

Klinger, D.A. y Shulha, L. (2006). School libraries \& student achievement in Ontario. Toronto: Ontario Library Association. Recuperado de http://www.peopleforeducation.ca/wp-content/uploads/2011/07/SchoolLibraries-2006.pdf

Klug, P. (2000). BIX-The Library Index, or: why less is often more. Performance Measurement \& Metrics, 1(2), 129-134.

Ko, Y.M., Shim, W. y Pyo, S.-H. (2016). Factors affecting users' assessment of the economic value of university library services. Journal of Librarianship and Information Science, 48(3), 223-235.

Ko, Y.M., Shim, W., Pyo, S-H., Chang, J.S. y Chung, H. K. (2012). An economic valuation study of public libraries in Korea. Library \& Information Science Research, 34(2), 117-124.

Koppius, O. (1999). Dimensions of intangible goods. Comunicación presentada en 32nd Annual Hawaii International Conference on System Sciences, Maui. doi: 10.1109/HICSS.1999.772916

Kostagiolas, P.A. y Kitsiou, M.B. (2008). Issues and perceptions for ISO 9000 implementation in Greek academic libraries. Library Management, 29(6/7), 583599.

Kotte, D., Lietz, P. y López, M. (2005). Factors influencing reading achievement in Germany and Spain: evidence from PISA 2000. International Education Journal, 6(1), 113-124.

Kraaykamp, G. (2003). Literary socialization and reading preferences: effects of parents, the library and the school. Poetics, 31, 235-257.

Krashen, S., Lee, S. y McQuillan, J. (2010). An analysis of the PIRLS (2006) data: can the school library reduce the effect of poverty on reading achievement? CSLA Journal, 34, 26-28. Recuperado de http://csla.net/wpcontent/uploads/2012/09/10 springjournal.pdf

Krashen, S., Lee, S. y McQuillan, J. (2012). Is the library important? multivariate studies at the national and international level. Journal of Language \& Literacy Education, 8(1), 26-38.

Kvale, S. (2011). Las entrevistas en investigación cualitativa. Madrid: Morata.

Kyrillidou, M. (2000). Research library trends: ARL Statistics. Journal of Academic Librarianship, 26(6), 427-436.

Kyrillidou, M. (2002a). From input and output measures to quality and outcome measures, or, from the user in the life of the library to the library in the life of the user. Journal of Academic Librarianship, 28(1), 42-46.

Kyrillidou, M. (2002b). An overview of performance measures in higher education and libraries. Journal of Library Administration, 35(4), 7-18. 
Kyrillidou, M. y Cook, C. (2008). The evolution of measurement and evaluation of libraries: a perspective from the Association of Research Libraries. Library Trends, 55(4), 888-909.

Kyrillidou, M., Olshen, T., Heath, F., Bonnelly, C. y Côte, J. (2005). La mise en œuvre interculturelle de LibQUAL+: le cas du français. Bulletin des Bibliothèques de France, 50(5), 48-55.

Kyrillidou, M. y Persson, A.C. (2006). The new library user in Sweden: a LibQUAL+ study at Lund University. Performance Measurement and Metrics, 7(2), 45-53.

La Mano González, M. de (1998). Propuesta de un sistema de evaluación para bibliotecas universitarias. Revista Española de Documentación Científica, 21(2), 174-197.

La Mano González, M. de (2014). Métodos y técnicas para evaluar el impacto de los servicios bibliotecarios: la norma internacional ISO 16439. En Nuevos instrumentos para la evaluación de bibliotecas: la normativa internacional ISO (pp. 163-210). Madrid: AENOR.

La Mano González, M. de y Albelda Esteban, B. (2009). Evaluación de bibliotecas nacionales: elaboración de una normativa internacional y su aplicación en la Biblioteca Nacional de España. El Profesional de la Información, 18(6), 660-668.

La Mano González, M. de (Coord.), Albelda Esteban, B., Pérez Morillo, M. y Romero Garuz, S. (2014). Nuevos instrumentos para la evaluación de bibliotecas: Ia normativa internacional ISO. Madrid: AENOR.

La Mano González, M. de y Creaser, C. (2016). The impact of the Balanced Scorecard in libraries: from performance measurement to strategic management. Journal of Librarianship and Information Science, 48(2), 191-208.

Laitinen, M. (2013). Library statistics with confidence: facts from figures with no fear. Qualitative and Quantitative Methods in Libraries, 4, 459-467. Recuperado de http://www.qqml.net/papers/December_2013_Issue/2412QQML_Journal_2013 _Laitinen_4_459_467.pdf

Laitinen, M. (2015). The challenge of showing economic impact of library. Qualitative and Quantitative Methods in Libraries, 4, 321-330. Recuperado de http://www.qqml.net/papers/June 2015 Issue/428QQML Journal 2015 Laitin en 321-330.pdf

Laitinen, M. y Saarti, J. (2014). Evidence based service change: remodelling the academic libraries for the post-digital era. Qualitative and Quantitative Methods in Libraries, 3, 611-618. Recuperado de http://www.qqml.net/papers/September_2014_Issue/335QQML_Journal_2014 _LaitinnenandSaarti_Sept_611-618.pdf

Lamont, M. (2015). Using economic data to demonstrate the value of the library. Qualitative and Quantitative Methods in Libraries, 4, 69-75. Recuperado de http://www.qqml.net/papers/March 2015 Issue/418QQML Journal 2015 La mont 69-75.pdf 
Lancaster, F.W. (1988). If you want to evaluate your library . . . Champaign, IL: University of Illinois.

Lancaster, F.W. (1993). If you want to evaluate your library . . . (2 ${ }^{\text {nd }}$ ed. $)$. Champaign, IL: University of Illinois.

Lancaster, F.W. y Joncich, M. J. (1977). The Measurement and Evaluation of Library Services. Arlington, VA: Information Resources Press.

Lance, K.C. (2002). How school librarians leave no child behind: the impact of school library media programs on the academic achievement of U.S. public school students. School Libraries in Canada, 22(2), 3-6.

Lance, K.C., Hamilton-Pennell, C. y Rodney, M.J. (2000a). Information Empowered: the school librarian as an agent of academic achievement in Alaska schools. Juneau: Alaska State Library.

Lance, K.C., Hamilton-Pennell, C. y Rodney, M.J. (2000b). Measuring up to standards: the impact of school library programs \& information literacy in Pennsylvania schools. Greensburg, Penn.: Pennsylvania Citizens for Better Libraries.

Lance, K.C., Hamilton-Pennell, C. y Rodney, M.J. (2000c). How school librarians help kids achieve standards: the second Colorado study. San Jose, California: Hi Willow Research and Publishing.

Lance, K.C., Hamilton-Pennell, C. y Rodney, M.J. (2000d). Good schools have school librarians: Oregon school librarians collaborate to improve academic achievement. Portland: Oregon Educational Media Association.

Lance, K.C., Hamilton-Pennell, C. y Rodney, M.J. (2002a). How school libraries improve outcomes for children: The New Mexico study. Santa Fe: New Mexico State Library.

Lance, K.C., Hamilton-Pennell, C. y Rodney, M.J. (2002b). Make the connection: quality school library media programs impact academic achievement in lowa. Bettendorf, IA: Mississippi Bend Area Education Agency. Recuperado de http://www.iowaaeaonline.org/pages/uploaded_files/Make\%20The\%20Connec tion.pdf

Lance, K.C. y Hofschire, L. (2012). Change in school librarian staffing linked with change in CSAP reading performance, 2005 to 2011. Denver, CO: Colorado State Library, Library Research Service. Recuperado de http://www.Irs.org/documents/closer look/CO4 2012 Closer Look Report.pdf

Lance, K.C., Rodney, M. J. y Hamilton-Pennell, C. (2005). Powerful libraries make powerful learners: the Illinois study. Canton, Illinois: Illinois School Library Media Association http://www.is/ma.org/lllinoisStudy.htm

Lance, K.C., Rodney, M.J. y Russell, B. (2007). How students, teachers, and principals benefit from strong school libraries: the Indiana study. Recuperado de http://c.ymcdn.com/sites/www.ilfonline.org/resource/resmgr/aisle/executivesu mmary.pdf 
Lance, K.C., Rodney, M.J. y Schwarz, B. (2010). Idaho school library impact study 2009: how Idaho school librarians, teachers, and administrators collaborate for student success. Boise, ID: Idaho Commission for Libraries. Recuperado de http://libraries.idaho.gov/doc/idaho-school-library-impact-study-2009

Lance, K.C. y Schwarz, B. (2012). How Pennsy/vania school libraries pay off: investments in student achievement and academic standards, PA School Library Project. Philadelphia: HSLC. Recuperado de http://paschoollibraryproject.org/research

Lance, K.C., Schwarz, B. y Rodney, M.J. (2014). How libraries transform schools by contributing to student success: evidence linking South Carolina school libraries and PASS \& HSAP results. Columbia, S.C.: South Carolina Association of School Librarians. Recuperado de http://www.scasl.net/the-south-carolina-impactstudy

Lance, K.C., Schwarz, B. y Rodney, M. J. (2017). Community college libraries \& librarians and student success. Findings from surveys of librarians \& other library staff, students, and faculty, plus a professional development survey of library leaders. Washington: Institute of Museum and Library Services. Recuperado de https://www.edgecombe.edu/files/pdfs/librarians-and-student-success/ccllsscombined-report-2017-05-29.pdf

Lance, K.C., Welborn, L. y Hamilton-Pennell, C. (1993). The impact of school library media centers on academic achievement. Castle Rock, Colorado: Hi Willow Research and Publishing.

Land $\varnothing y$, A. y Raade, J. (2014). Indicators for benchmarking in Norwegian academic libraries: testing the usability of national collection data. Qualitative and Quantitative Methods in Libraries, 4, 811-820. Recuperado de http://www.qqml.net/papers/December 2014 Issue/343QQML Journal 2014 LandoyandRaade Dec 811-820.pdf

Larsen, D., Wallace, S. y Pankl, L. (2018). Mapping library values and student learning outcomes: alignment with university pedagogical goals and practices. Journal of information literacy, 12(1), 109-117. doi: 10.11645/12.1.2399

Lee, S.-J. y Chung, H.-K. (2012). Analysing altruistic motivations in public library valuation using contingent valuation method. Library \& Information Science Research, 34, 72-78.

Leimkuhler, F.F. (1972). Library operations research: a process of discovery and justification. Library Quarterly, 42, 84-96.

Levin, Driscoll \& Fleeter (2006). Value for money: Southwestern Ohio's return from investment in public libraries. Columbus, Ohio: Levin, Driscoll \& Fleeter. Recuperado de http://www.9libraries.info/docs/EconomicBenefitsStudy.pdf

Levine, M.M. (1980). The circulation/acquisition ratio: an input-output measure for libraries. Information Processing \& Management, 16(1), 313-315. 
Lewis, K. R. (2019). The role of questioning and deep thinking in the learner-ready school library. Knowledge Quest, 47(3), 4-5.

Library Council of New South Wales. (2008). Enriching communities: the value of public libraries in New South Wales. Sidney: Library Council of New South Wales. Recuperado de http://www.sl.nsw.gov.au/public-library-services/enrichingcommunities-value-public-libraries-nsw

Liebst, A. y Feinmark, D. (2016). Tools of academic library assessment: the user survey. Journal of Library Administration, 56(6), 748-755.

Lin, H., Pang, N. y Luyt, B. (2015). Is the library a third place for young people? Journal of Librarianship \& Information Science, 47(2), 145-155.

Line, M.B. (2001). How well are national libraries doing? Alexandria, 13(2), 67-69.

Lithgow, S.D. y Hepworth, J.B. (1993). Performance measurement in prison libraries: research methods, problems and perspectives. Journal of Librarianship and Information Science, 25(2), 61-69.

Logan, S., Medford, E. y Hughes, N. (2011). The importance of intrinsic motivation for high and low ability readers' reading comprehension performance. Learning and Individual Differences, 21(1), 124-128.

Lonsdale, M. (2003). Impact of school libraries on student achievement: a review of the research. Victoria: Australian Council for Educational Research. Recuperado de http://www.asla.org.au/site/DefaultSite/filesystem/documents/research.pdf

López Gijón, J. (1996). Evaluar para mejorar la calidad en la biblioteca pública. En Evaluación de los servicios bibliotecarios: VII Jornadas sobre Bibliotecas Públicas, 1,2,3 de junio de 1995, San Sebastián (pp. 78-105). Donostia: Asociación de Bibliotecarios y Documentalistas de Guipúzcoa.

López Gijón, J., Ávila Fernández, B., Pérez Gálvez, I.J. y Herrera Viedma, E. (2010). La calidad en las bibliotecas universitarias biomédicas según sus usuarios. El Profesional de la Información, 19(2), 255-259.

López Gijón, J. y Vílchez Pardo, J. (1994). Generación automática de indicadores para la evaluación y toma de decisiones en servicios bibliotecarios. En IV Jornadas Españolas de Documentación Automatizada, 1994, Gijón (pp. 271-277). Oviedo: Universidad de Oviedo.

Lorga, A.R. (2014). Las desigualdades de los resultados de las pruebas PISA debido al desempeño del profesor; las diferencias entre los países. Fuentes, Revista de la Facultad de Ciencias de la Educación, 15, 45-74.

Lozano, G.M. (2014). Modelo de alfabetización informacional en educación primaria con el apoyo de las bibliotecas escolares como centros de recursos para el aprendizaje, la investigación y el ocio (CRAIO) (Tesis doctoral, Universidad Carlos III de Madrid). Recuperado de https://orff.uc3m.es/bitstream/handle/10016/19714/Tesis Gloria Mercedes L ozano.pdf 
Luria Roig, M. y Pintor González, J. (2013). El retorno a la inversión de la Red de Bibliotecas Municipales de la provincia de Barcelona (2007-2011). En XIII Jornadas Españolas de Documentación, Fesabid'13, 24-25 mayo 2013, Toledo (pp. 10-30). Madrid: Fesabid. Recuperado de http://fesabid.org/documentos/fesabid13-actas.pdf

Luther, J. (2008). University investment in the library: what's the return? a case study at the University of Illinois at Urbana-Champaign. San Diego, CA: Elsevier. Recuperado de https://libraryconnect.elsevier.com/articles/universityinvestment-library-what-s-return-case-study-university-illinois-urbanachampaign

Luther, M. (2016). Total library assessment. Journal of Library Administration, 56(2), 158-170.

Lynch, M.J. (1983). Measurement of public library activity: the search for practical methods. Wilson Library Bulletin, 57(5), 388-393.

MacEachern, R. (2001). Measuring the added value of library and information services: The New Zealand approach. IFLA Journal, 27(4), 232-237.

Madsen, C. y Hurst, M. (2018). Contextualizing library assessment within a broader ecosystem: proposed models for linking the strategic to the micro. Performance Measurement and Metrics, 19(1), 18-29. doi: 10.1108/PMM-09-2017-0042

Majarrez, C. A., Cigna, J., Bajaj, B. y Milam, D.P. (Ed.). (2007). Making cities stronger: public library contributions to local economic development. Evanston, IL: Urban Libraries Council. Recuperado de http://communitywealth.org/content/making-cities-stronger-public-library-contributions-localeconomic-development

Malo de Molina Martin Montalvo, T. y Quintana Martínez, I. (1995). La calidad de los servicios en las bibliotecas del CSIC. En 5es Jornades Catalanes de Documentació, 1995, Barcelona (pp. 61-85). Barcelona: Sociedad Catalana de Documentació i Informació (SOCADI), Col.legi Oficial de BibliotecarisDocumentalistes de Catalunya.

Manžuch, Z y Macevičiūtè, E. (2016). Performance evaluation as a tool for strategic decisions about serving visually impaired users: the case of the Lithuanian Library for the Blind. Library \& Information Science Research, 38, 161-169.

Markless, S. y Streatfield, D. (2001). Developing performance and impact indicators and targets in public and education libraries. International Journal of Information Management, 21(2), 167-179.

Markless, S. y Streatfield, D. (2007). Evaluating the impact of your library. London: Facet Publishing.

Marks, G.N. (2005). Cross-national differences and accounting for social class inequalities in education. International Sociology, 20(4), 483-505.

Marraud González, G. (2006). Gestión de la calidad en la biblioteca de la universidad de Vigo. Boletín de la ANABAD, 56(1), 155-176. 
Marshall, J.G. (1992). The impact of the hospital library on clinical decision making: the Rochester study. Bulletin of the Medical Library Association, 80(2), 169-178.

Marshall, J.G. (2007). Measuring the value and impact of health library and information services: past reflections, future possibilities. Health Information and Libraries Journal, 24(S1), 4-17.

Marshall, J.G., Sollenberger, J., Easterby-Gannett, S., Morgan, L.K., Kiem, M.L., Cavanaugh, S.K., ... Hunter, S. (2013). The value of library and information services in patient care: results of a multisite study. Journal of the Medical Library Association, 101(1), 38-46.

Martha, J. F. F., Nunes, S. C., Fernandes, P. R., Júnior, Gois, G. G. R., Santana, M. M. B., Veloso, R. M. P. y Santos, W. A. d. S. (2019). Bibliotecário escolar e fake news: evidências da contribuição da biblioteca escolar. Biblionline, João Pessoa, 15(1), 122-135. Recuperado de https://periodicos.ufpb.br/index.php/biblio/article/view/43786/22734

Martín-Lagos López, M. D. (2018). Educación y desigualdad: una metasíntesis tras el 50 aniversario del Informe Coleman. Revista de Educación, 380, 186-209. doi: 10.4438/1988-592X-RE-2017-380-377

Martínez García, J.S. (2010). Origen social y logro educativo: una mirada a través de PISA. En Sociología de la educación secundaria (pp. 107-122). Barcelona: Graó.

Martins, L. y Veiga, P. (2010). Do inequalities in parents' education play an important role in PISA students' achievement score disparities? Economics of Education Review, 29(6), 1016-1033.

Marzal, M.A., Parra, P. y Colmenero, M.J. (2011). La medición de impacto y evaluación de programas de alfabetización en información para bibliotecas escolares. Revista Española de Documentación Científica, 34(2), 190-211.

Marzal García Quismondo, M.A., Colmenero Ruiz, M.J. y Jorge García Reyes, C. (Eds.). (2016). CIBES 2015, I Congreso Iberoamericano de Bibliotecas Escolares: Educación por competencias: reto del milenio para la interculturalidad y la inclusión social. Madrid: Universidad Carlos III. Recuperado de http://hdl.handle.net/10016/23973

Marzoli, R. y Papa, O. (2019). Quando la biblioteca scolastica fa la differenza. Biblioteche Oggi, 37(1), 28-36. Recuperado de http://www.bibliotecheoggi.it/rivista/index

Massísimo i Sánchez de Boado, A. (2004). Evaluación de colecciones en las bibliotecas universitarias (II): métodos basados en el uso de la colección. Anales de Documentación, 7, 171-183.

Massot Lafon, I., Dorio Alcaraz, I. y Sabariego Puig, M. (2016). Estrategias de recogida y análisis de la información. En Metodología de la investigación educativa (pp. 321-358). Madrid: La Muralla.

Mathur, M. (2005). Advent of digital libraries and measuring their performance: a review. DESIDOC Bulletin of Information Technology, 25(2), 19-25. 
Matthews, J.R. (2002). The bottom line: determining and communicating the value of the special library. Westport, Connecticut: Libraries Unlimited.

Matthews, J.R. (2004). Measuring for results: the dimensions of public library effectiveness. Westport, Connecticut: Libraries Unlimited.

Mays, R., Tenopir, C. y Kaufman, P. (2010). Lib-Value: measuring value and return on investment of academic libraries. Research Library Issues, 271, 36-40.

McCallum, I. y Quinn, S. (2004). Valuing libraries. The Australian Library Journal, 53(1), 55-69.

McClure, C. y Bertot, J. (1998). Public library use in Pennsy/vania: identifying uses, benefits and impacts. Harrisburg, PA.: Pennsylvania State Dept. of Education.

McClure, C., Bertot, J. y Zweizig, D.L. (1994). Public libraries and the Internet: study results, policy issues, and recommendations. Washington: National Commission on Libraries and Information Science. Recuperado de http://plinternetsurvey.org/sites/default/files/publications/1994_plinternet.pdf

McClure, C., Fraser, B., Nelson, T.W. y Robbins, J.B. (2001). Economic benefits and impacts from public libraries in the State of Florida. Final report. Tallahassee, FL: Florida State University.

McClure, C.R., Owen, A., Zweizig, D.L., Lynch, M.J. y Van House, N.A. (1987). Planning and role setting for public libraries: a manual of options and procedures. Chicago, IL: American Library Association.

McClure, C.R. y Reifsnyder, B. (1984). Performance measures for corporate information centers. Special Libraries, 75(1), 193-204.

McDougall, A., Saxena, S. y Tate, M. (2011). Dollars, sense and public libraries: technical report. The landmark study of the socio-economic value of Victorian public libraries. Melbourne: State Library of Victoria. Recuperado de http://www.libraries.vic.gov.au/downloads/Dollars Sense and Public Libraries $\angle 20110322$ sl techrep full final.pdf

Mclntosh, S. y Vignoles, A. (2001). Measuring and assessing the impact of basic skills on labour market outcomes. Oxford Economic Papers, 53(3), 453-481.

Mclntyre, B. (1994). Measuring excellence in public libraries. Australasian Public Libraries and Information Services, 7(3), 135-155.

McMenemy, D. (2007). What is the true value of a public library? Library Review, 56(4), 273-277.

McPherson, K. (2008). Shaping global critically with school libraries. School Libraries Worldwide, 14(2), 35-44.

Medeiros, D. y Oliveira Lucas, E. R. de (2016). As bibliotecas nacionais latino americanas e o capital social. Perspectivas em Ciência da Informação, 21(4), 202-224.

Meera, B.M. (1998). Performance measurement: criteria for quality improvement in library and information services. Library Science with a Slant to Documentation and Information Studies, 35(3), 149-156. 
Mehra, B., Bishop, B.W. y Partee, R.P. (2017). Small business perspectives on the role of rural libraries in economic development. The Library Quarterly, 87(1), 17-35.

Mehrjerdi, Y.Z. (2017). Library performance evaluation in a dynamic environment using patron satisfaction. The Electronic Library, 35(2), 374-390.

Melo, L.B., Pires, C. y Taveira, A. (2008). Recognizing best practice in Portuguese higher education libraries. IFLA Journal, 34(1), 34-54.

Meunier, P. (agosto, 2004). Recent developments in Quebec concerning the normalization and performance measure of public library services. Comunicación presentada en World Library and Information Congress: 70th IFLA General Conference and Council, Buenos Aires. Recuperado de http://archive.ifla.org/IV/ifla70/papers/189f-Meunier.pdf

Midwinter, A. y McVicar, M. (1990). Public libraries and performance indicators: origins, developments and issues. Library Review, 39(5), 10-22.

Midwinter, A. y McVicar, M. (1996). Performance information for Scottish public library authorities. Library Review, 45(3), 25-30.

Miller, J. (2014). A comparative study of public libraries in Edinburgh and Copenhagen and their potential for social capital creation. Libri, 64(4), 316-326.

Ministerio de Educación (España). (2010). Bibliotecas Escolares, Premios 2009. Madrid: Ministerio de Educación. Recuperado de https://www.mecd.gob.es/servicios-alciudadano-mecd/catalogo/educacion/centros-docentes/premios.html

Miret, I. (Dir.), Baró, M., Mañá, T., Vellosillo, I. y Martín, E. (2013). Las bibliotecas escolares en España: dinámicas 2005-2011. Madrid: Fundación Germán Sánchez Ruipérez, Ministerio de Educación, Cultura y Deporte. Recuperado de http://fundaciongsr.org/recursos-2/

Missingham, R. (2005). Libraries and economic value: a review of recent studies. Performance Measurement and Metrics, 6(3), 142-158.

Montenegro, M., Clasing, P., Kelly, N., González, C., Jara, M., Alarcón, R., ... Saurina, E. (2016). Library resources and students' learning outcomes: do all the resources have the same impact on learning? The Journal of Academic Librarianship, 42(5), 551-556.

Montgomery, S.E. y Miller, J. (2011). The third place: the library as collaborative and community space in a time of fiscal restraint. College \& Undergraduate Libraries, 18(2/3), 228-238.

Moore, D.S. (2009). Estadística aplicada básica. Barcelona: Antoni Bosch.

Moore, N. (1989). Measuring the performance of public libraries: a draft manual. Paris: General Information Programme and UNISIST, United Nations Educational, Scientific and Cultural Organization.

Moorefield-Lang, H. y Kitzie, V. (2018). Makerspaces for all: serving LGBTQ makers in school libraries. Knowledge Quest, 47(1), 46-50.

Morales Vallejo, P. (2008). Estadística aplicada a las ciencias sociales. Madrid: Universidad Pontificia de Comillas. 
Morena de Diago, B. (2013). Mystery shopping: indicadores de estudio en bibliotecas. Revista General de Información y Documentación, 23(2), 369-386. Recuperado de http://revistas.ucm.es/index.php/RGID/article/download/369-386/40940

Moreno Martínez, J.J. y García Reche, G. (2006). Aplicación transversal del modelo de excelencia de la calidad EFQM en los procesos de evaluación en bibliotecas universitarias de Andalucía. Boletín de la ANABAD, 56(1), 41-52.

Morris, A., Sumsion, J. y Hawkins, M. (2002). Economic value of public libraries in the UK. Libri, 52(2), 78-87.

Morse, P.M. (1968). Library effectiveness: a systems approach. Cambridge (Massachusetts): M.I.T. Press.

Moscoso, P. y Martínez del Valle, C. (2009). Análisis comparado de los procesos de evaluación de bibliotecas universitarias españolas. Documentación de las Ciencias de la Información, 32, 155-178.

Müller, W. y Karle, W. (1993). Social selection in educational systems in Europe. European Sociological Review, 9(1), 1-23.

Mullis, I.V.S. y Martin, M.O. (Eds.). (2015). PIRLS 2016 assessment framework (2nd ed.). Chestnut Hill, MA: Boston College, TIMSS \& PIRLS International Study Center, International Association for the Evaluation of Educational Achievement. Recuperado de http://timssandpirls.bc.edu/pirls2016/framework.html

Murray, T. E. y Vilches, K. (2017). ROIs and surveys in special libraries: one corporate experience. Journal of Library Administration, 57(4), 461-467. doi: 10.1080/01930826.2017.1300457

Nelson, J. (2010). Library staffing benefits Latino student achievement. CSLA Journal, 34(1), 14-16.

Nitecki, D.A. y Abels, E.G. (2013). Exploring the cause and effect of library value. Performance Measurement and Metrics, 14(1), 17-24.

Noonan, D.S. (2003). Contingent valuation and cultural resources: a meta-analytic review of the literature. Journal of Cultural Economics, 27(3), 159-176.

Notten, N. y Kraaykamp, G. (2010). Parental media socialization and educational attainment: resource or disadvantage? Research in Social Stratification and Mobility, 28, 453-464.

Ntlotlang, T. y Grand, B. (2016). The role of libraries in the dissemination of health information in Botswana: a study of Mochudi and Molepolole public libraries. Library Review, 65(4/5), 320-349.

Nurse, R, Baker, K. y Gambles, A. (2018). Library resources, student success and the distance-learning university. Information and Learning Science, 119(1/2), 77-86. doi: 10.1108/ILS-03-2017-0022

Oakleaf, M. (2010). The value of academic libraries. Chicago: Association of College \& Research Libraries. Recuperado de http://www.ala.org/ala/mgrps/divs/acrl/issues/value/val_report.pdf 
Oakleaf, M. (2018). The problems and promise of learning analytics for increasing and demonstrating library value and impact. Information and Learning Science, 119(1/2), 16-24. doi: 10.1108/ILS-08-2017-0080

O'Connor, P. (2002). Determining the impact of health library services on patient care: a review of the literature. Health Information and Libraries Journal, 19(1), 1-13.

Odasso, P. (2007). The social inclusion function of the school library. School Libraries Worldwide, 13(2), 18-31.

Odera-Kwach, B. y Ngulube, P. (2011). Quality management framework for evaluating academic libraries in Kenya. South African Journal of Libraries and Information Science, 77(2), 116-124.

Ögland, M. (2010). Measure and Evaluate: about statistics and efficiency at public libraries. Scandinavian Public Library Quarterly, 43(4), 24-25. Recuperado de http://slq.nu/?article=sweden-measure-and-evaluate-about-statistics-andefficiency-at-public-libraries

Okocha, K.F. (1994). Academics and the power of information: the comparable effects of information of information group term papers among collective students. African Journal of Library, Archives and Information Services, 4(2), 159-162.

Oldenburg, R. (1989). The great good place: café, coffee shops, community centers, beauty parlors, general stores, bars, hangouts, and how they get you through the day. New York: Paragon House.

Omella Claparols, E., Permanyer Bastardas, J. y Vilagrosa Alquézar, E. (2009). Instrumentos básicos para la planificación estratégica del servicio de biblioteca pública. BiD: Textos Universitaris de Biblioteconomía i Documentació, 23. Recuperado de http://www.ub.edu/bid/23/omella2.htm

O'Neil, R.M. (1994). Total Quality Management in libraries: a sourcebook. Englewood, Colo.: Libraries Unlimited.

Organización de las Naciones Unidas para la Educación, la Ciencia y la Cultura. (1981). Questionnaire on statistics of libraries, pt. II: Libraries of institutions of higher education and school libraries. Recuperado de http://unesdoc.unesco.org/images/0005/000527/052793eb.pdf

Organización de las Naciones Unidas para la Educación, la Ciencia y la Cultura. (1983). Questionnaire on statistics of libraries, pt. 3: Specialized libraries. Recuperado de http://unesdoc.unesco.org/images/0006/000621/062128sb.pdf

Organización de las Naciones Unidas para la Educación, la Ciencia y la Cultura. (1992). Questionnaire on statistics of libraries, pt. I: National, other major nonspecialized and public libraries. Recuperado de http://unesdoc.unesco.org/images/0009/000970/097036eb.pdf

Organización Internacional de Normalización. (1974). ISO 2789:1974, Information and documentation. International library statistics. Ginebra: ISO.

Organización Internacional de Normalización. (1987). ISO 9004:1987, Quality management and quality system elements. Guidelines. Ginebra: ISO. 
Organización Internacional de Normalización. (1991). ISO 2789:1991, Information and documentation. International library statistics. Ginebra: ISO.

Organización Internacional de Normalización. (1998). ISO 11620:1998, Information and documentation. Library performance indicators. Ginebra: ISO.

Organización Internacional de Normalización. (2000a). ISO 9000:2000, Quality management systems. Fundamentals and vocabulary. Ginebra: ISO.

Organización Internacional de Normalización. (2000b). ISO 9001:2000, Quality management systems. Requirements. Ginebra: ISO.

Organización Internacional de Normalización. (2003a). ISO 2789:2003, Information and documentation. International library statistics. Ginebra: ISO.

Organización Internacional de Normalización. (2003b). ISO 11620:2003/Amd.1, Information and documentation. Library performance indicators. Ginebra: ISO.

Organización Internacional de Normalización. (2006). ISO 2789:2006, Information and documentation. International library statistics. Ginebra: ISO.

Organización Internacional de Normalización. (2008). ISO 11620:2008, Information and documentation. Library performance indicators. Ginebra: ISO.

Organización Internacional de Normalización. (2009). ISO/TR 28118:2009, Information and documentation. Performance indicators for national libraries. Ginebra: ISO.

Organización Internacional de Normalización. (2012). ISO/TR 11219: 2012, Information and documentation. Qualitative conditions and basic statistics for library buildings. Space, function and design. Ginebra: ISO.

Organización Internacional de Normalización. (2013a). ISO 2789: 2013, Information and documentation. International library statistics. Ginebra: ISO.

Organización Internacional de Normalización. (2013b). ISO/TR 14873:2013, Information and documentation. Statistics and quality issues for web archiving. Ginebra: ISO.

Organización Internacional de Normalización. (2014a). ISO 11620: 2014, Information and documentation. Library performance indicators. Ginebra: ISO.

Organización Internacional de Normalización. (2014b). ISO 16439: 2014, Information and documentation. Methods and procedures for assessing the impact of libraries. Ginebra: ISO.

Organización Internacional de Normalización. (2019). ISO 21248:2019 Information and documentation, Quality assessment for national libraries. Ginebra: ISO.

Organización para la Cooperación y el Desarrollo Económicos (2006). Intellectual assets and value creation: implications for corporate reporting. Paris: OCDE. Recuperado de http://www.oecd.org/corporate/ca/corporategovernanceprinciples/37811196.p df

Organización para la Cooperación y el Desarrollo Económicos. (2009). PISA 2009 Assessment Framework Key competencies in reading, mathematics and science. Paris: OECD. Recuperado de http://www.oecd.org/pisa/pisaproducts/44455820.pdf 
Organización para la Cooperación y el Desarrollo Económicos. (2012). PISA 2009 Technical Report. Paris: OECD Publishing. doi: 10.1787/9789264167872-en

Orr, R.H. (1973). Measuring the goodness of library services: a general framework for considering quantitative measures. Journal of Documentation, 29(3), 315-332.

Pacios Lozano, A. R. (1995). Sistemas de calidad total en bibliotecas y unidades de información. Boletín de la ANABAD, 45(2), 107-116.

Pacios Lozano, A. R. (1997). ISO 9000 and the total quality management models. Library Management, 18(3), 148-150.

Pacios Lozano, A. R. (2000). A customer orientation checklist: a model. Library Review, 49(4), 173-178.

Paley, J., Cottrill, J., Errecart, K., White, A., Schaden, C., Schrag, T., ... Streatfield, D. (2015). The evolution of Global Libraries' performance measurement and impact assessment systems. Performance Measurement and Metrics, 16(2), 132-158.

Panday, V. (2014). Total quality management (TQM): a special reference to library. International Journal of Digital Library Services, 4(3), 37-43.

Parasuraman, A. (2002). Foreword. Performance Measurement and Metrics, 3(2). doi: 10.1108/pmm.2002.27903baa.001

Parasuraman, A., Zeithaml, V. A. y Berry, L.L. (1985). A conceptual model of service quality and its implications for future research. The Journal of Marketing, 49(4), 41-50.

Passonneau, S.M. (2013). Library assessment activities: using ISO 11620 to review the assessment data of academic libraries in North America. Performance Measurement and Metrics, 14(3), 175-196.

Patton, M.Q. (2002). Qualitative research \& evaluation methods ( $3^{\text {rd }} \mathrm{ed}$ ). London: Sage Publications.

Payne, P. y Conyers, A. (2005). Measuring the impact of higher education libraries: the LIRG/SCONUL Impact Implementation Initiative. Library and Information Research, 29(91), 1-7. doi: 10.29173/lirg180

Pensiero, N. (2011). Parent-child cultivation and children's cognitive and attitudinal outcomes from a longitudinal perspective. Child Indicators Research , 4(3), 413437.

Pereira, C.A., Santos Rego, M.A. y Lorenzo Moledo, M. de M.(2013). Alumnos autóctonos y de origen inmigrante en PISA: variables de rendimiento. Revista Gallegoportuguesa de Psicoloxía y Educación, 21, 95-109.

Pérez López, A. (2002). La evaluación de colecciones: métodos y modelos. Documentación de las Ciencias de la Información, 25, 321-360. Recuperado de http://revistas.ucm.es/index.php/DCIN/article/view/DCIN0202110321A/19474

Pilerot, O. (2018). The practice of public library-work for newly arrived immigrants. Information Research, 23(4), 1806. Recuperado de http://www.informationr.net/ir/23-4/isic2018/isic1806.html 
Pinto Molina, M. (1998). Criterios de calidad total en la biblioteca según el modelo europeo. En X Jornadas Bibliotecarias de Andalucía, 28 al 30 de mayo, 1998, Jerez de la Frontera (pp. 111-126). Málaga: Asociación Andaluza de Bibliotecarios.

Pinto Molina, M., Balagué Mola, N. y Anglada i de Ferrer, L.M. (2007). Evaluación y calidad en las bibliotecas universitarias: experiencias españolas entre 19942006. Revista Española de Documentación Científica, 30(3), 364-383.

Pintor, J. (2013). El valor público de las bibliotecas de la Red de Bibliotecas Municipales de la Diputación de Barcelona (RBM). En XIII Jornadas Españolas de Documentación, Fesabid'13, 24-25 mayo 2013, Toledo (pp. 44-52). Madrid: Fesabid. Recuperado de http://fesabid.org/documentos/fesabid13-actas.pdf

Poll, R. (2001a). Performance indicators for the digital library. Liber Quarterly, 11(3), 244-258.

Poll, R. (2001b). Performance measures for library networked services and resources. The Electronic Library, 19(5), 307-314.

Poll, R. (2001c). Performance, processes and costs: managing service quality with the Balanced Scorecard. Library Trends, 49(4), 709-717.

Poll, R. (agosto, 2001d). Managing Service Quality with the Balanced Scorecard. Comunicación presentada en 67th IFLA Council and General Conference, Boston. Recuperado de http://files.eric.ed.gov/fulltext/ED459732.pdf

Poll, R. (2003). Impact / outcome measures for libraries. Liber Quarterly, 13, 329-342.

Poll, R. (2007). Benchmarking with quality indicators: national projects. Performance Measurement and Metrics, 8(1), 41-53.

Poll, R. (2008a). Comparing the incomparable? performance measures for national libraries. Alexandria, 20(3), 163-170.

Poll, R. (2008b). Ten years after: measuring quality revised. Performance Measurement \& Metrics, 9(1), 26-37.

Poll, R. (2008c). The cat's pyjamas? performance indicators for national libraries. Performance Measurement and Metrics, 9(2), 110-117.

Poll, R. (2010). NUMERIC: statistics for the digitisation of European cultural heritage. Program, 44(2), 122-131.

Poll, R. (2011). I dati che abbiamo e i dati che potremmo avere: nuovi sviluppi nella valutazione delle biblioteche. Bollettino AIB, 51(4), 369-380.

Poll, R. (2012). Can we quantify the library's influence? Creating an ISO standard for impact assessment. Performance Measurement and Metrics, 13(2), 121-130.

Poll, R. (2014). Did you enjoy the library? Impact surveys in diverse settings. Performance Measurement and Metrics, 15(1/2), 4-12.

Poll, R. y Payne, P. (2006). Impact measures for libraries and information services. Library Hi Tech, 24(4), 547-562.

Poll, R. y te Boekhorst, P. (2007). Measuring Quality. Performance measurement in libraries ( $2^{\text {nd }}$ rev. ed.). München: K.G. Saur. 
Pourahmad, A.A., Neshat, M. y Hasani, M.R. (2016). Using LibQUAL model for improving the level of students' satisfaction from quality of services in academic libraries: a case study in North Khorasan Province, Iran. Journal of Information \& Knowledge Management, 15(1). doi: 10.1142/S0219649216500118

Powell, R.R. (2006). Evaluation research: an overview. Library Trends, 55(1), 102-120.

Pricewaterhousecoopers Llp. (2005). Laser Foundation. Libraries Impact Project. Recuperado http://www.bl.uk/aboutus/acrossuk/workpub/laser/news/awards2004/laserfin al6.pdf

Proctor, R., Usherwood, B. y Sobczyk, G. (1996). What do people do when their public library service closes down? an investigation into the impact of the Sheffield Libraries strike. British Library Research and Innovation Report, 6224.

Puente Lanzarote, L., Campo Hilario, C. y Ruiz de Luzuriaga Peña, M. (2001). Indicadores de rendimiento para la evaluación de un servicio de bases de datos en línea. Scire, 7(1), 89-114.

Putnam, R.D. (2000). Bowling alone: the collapse and revival of American community. New York: Simon \& Schuster Paperbacks.

Putnam, R.D., Feldstein, L.M. y Cohen, D. (2003). Branch libraries: the heartbeat of the community. En Better together: restoring the American community (pp. 34-54). New York: Simon \& Schuster.

Puy Moreno, M.V. (2000). Evaluación del servicio de obtención del documento de la biblioteca universitaria de Sevilla. En XI Jornadas Bibliotecarias de Andalucía, 1820 mayo, 2000, Sevilla (pp. 263-274). Málaga: Asociación Andaluza de Bibliotecarios.

Quantitative Resources, LLC., Miller, J., Want, J. y Whitacre, L. (2003). Show-me connection: how school library media center services affect student achievement. Jefferson City, MO: Department of Elementary and Secondary Education. Recuperado de https://dese.mo.gov/sites/default/files/libraryresearch.pdf

Quick, S., Prior, G., Toombs, B., Taylor, L. y Currenti, R. (2013). Cross-European survey to measure users' perceptions of the benefits of ICT in public libraries: final report. Washington: University of Washington Information School. Recuperado de http://hdl.handle.net/1773/22718

Ramsden, B. (2016). Ethnographic methods in academic libraries: a review. New Review of Academic Librarianship, 22(4), 355-369.

Rankin, C. (2012). The potential of generic social outcomes in promoting the positive impact of the public library: evidence from the National Year of Reading in Yorkshire. Evidence Based Library and Information Practice, 7(1), 7-21.

Reading, J. (2016). Providing enhanced information skills support to students from disadvantaged backgrounds: Western Sydney University Library outreach program. The Journal of Academic Librarianship, 42, 694-704. 
Redfern, M. (1990). Giving an account: performance indicators for libraries. Library Review, 39(5), 7-9.

Redse, T. y Ra, E. (2011). Indicators for Norwegian public libraries. Scandinavian Public Library Quarterly, 44(1). Recuperado de http://slq.nu/?article=norwayindicators-for-norwegian-public-libraries

Reid, R.H. (2012). Community libraries let us praise the last great civic place. National Civic Review, 101(4), 39-40.

Reilly, R. (1997). The impact of Sheffield public library closures on young children. Recuperado de http://dagda.shef.ac.uk/dispub/dissertations/1996-97/reilly.pdf

Renard, P. (2008). La normalisation des statistiques et des indicateurs: de l'inventaire à l'évaluation. Bulletin des Bibliothèques de France, 53(3), 29-34.

Revill, D.H. (1987). Availability as a performance measure for academic libraries. Journal of Librarianship and Information Science, 19(1), 14-29.

Reynolds, T. (2013). To what extent does a corporate information unit impact upon the company in which it is based? Performance Measurement and Metrics, 14(1), 61-70.

Richard, S. (1992). Library use of performance indicators. Library Review, 41(6), 22-36.

Robertson, N. D. (2019). Expanding school library collections: the makerspace edition. Knowledge Quest, 48(2), 8-14.

Robinson, A. (1998). Performance evaluation in Irish public libraries. An Leabharlann, 14(3-4), 101-114.

Robledo Ramón, P., Fidalgo Redondo, R. y Méndez del Río, M. (2019). Evaluación de la comprensión lectora a partir del análisis de la práctica del profesorado y la interacción docente-estudiante. Revista de Educación, 384, 97-120.

Rodney, M.J., Lance, K.C. y Hamilton-Pennell, C. (2002). Make the connection: quality school library media programs impact academic achievement in lowa. Bettendorf, IA: Mississippi Bend Area Education Agency. Recuperado de http://www.iowa aeaonline.org/pages/uploaded_files/Make\%20The\%20Connection.pdf

Rodney, M.J., Lance, K.C. y Hamilton-Pennell, C. (2003). The impact of Michigan school librarians on academic achievement: kids who have libraries succeed. Lansing, Mich.: Library of Michigan.

Rodríguez, D. y Norberg, L. (2014). Assessing library impact on student learning outcomes: a case study using the Understanding Library Impacts Protocol. Qualitative and Quantitative Methods in Libraries, 4, 829-842. Recuperado de http://www.qqml.net/papers/December_2014_Issue/345QQML_Journal_2014_ RodriguezandNorberg_Dec_829-842.pdf

Rubin, R.J. (2006). Demonstrating results: using outcome measurement in your library. Chicago: American Library Association.

Russell, K. (2008). Evidence-based practice and organizational development in libraries. Library Trends, 56(4), 910-930. 
Saarti, J. y Juntunen, A. (2013). Managing and optimizing the service processes with a set of quality indicators: case of University of Eastern Finland Library. Qualitative and Quantitative Methods in Libraries, 2, 167-174. Recuperado de http://www.qqml.net/papers/June 2013 Issue/228QQML Journal 2013 Saarti Juntunen 2167 174.pdf

Sabariego Puig, M. (2016). La investigación educativa: génesis, evolución y características. En Metodología de la investigación educativa (pp. 49-85). Madrid: La Muralla.

Saines, S., Harrington, S., Boeninger, C., Campbell, P., Canter, J. y McGeary, B. (2019). Reimagining the research assignment: faculty - librarian collaborations that increase student learning. College \& Research Libraries News, 80(1), 14-41. doi: 10.5860/crln.80.1.14

Salisbury, F. y Peasley, J. (2018). Measuring the academic library: Translating today's inputs and outputs into future impact and value. Information and Learning Science, 119(1/2), 109-120. doi: 10.1108/ILS-07-2017-0068

Sandín Esteban, M.P. (2010). Investigación cualitativa en educación: fundamentos y tradiciones. Madrid: McGraw Hill.

Saracevic, T. y Kantor, P.B. (1997a). Studying the value of library and information services. Part I. Establishing a theoretical framework. Journal of the American Society for Information Science, 48(6), 527-542.

Saracevic, T. y Kantor, P.B. (1997b). Studying the value of library and information services. Part II. Methodology and taxonomy. Journal of the American Society for Information Science, 48(6), 543-563.

Sardelli, A. (1999). ISO 9000: tecnica della qualità e biblioteche. Biblioteche oggi, 17(6), 50-62.

Savage, D., Piotrowski, P. y Massengale, L. (2017). Academic librarians engage with assessment methods and tools. Libraries and the Academy, 17(2), 403-417.

Saxrud, B. (2015). Not there yet. Scandinavian Library Quarterly, 48(1-2), 8-9. Recuperado de http://slq.nu/?article=volume-48-no-1-2-2015-22

Scholastic Inc. (2004). School Libraries Work! New York: Scholastic Library Publishing. Recuperado de http://www.scholastic.com

Scholastic Inc. (2006). School Libraries Work! (2 ${ }^{\text {nd }}$ ed.). New York: Scholastic Library Publishing. Recuperado de http://www.scholastic.com/ems/slp/102605/images/slw2 oct05.pdf

Scholastic Inc. (2008). School Libraries Work! (3rd ed.). New York: Scholastic Library Publishing. Recuperado de http://www2.scholastic.com/content/collateral resources/pdf/s/slw3 2008.pdf

Scholastic Inc. (2016). School Libraries Work! a compendium of research supporting the effectiveness of school libraries. New York: Scholastic Library Publishing. Recuperado de http://www2.scholastic.com/content/collateral resources/pdf/s/slw3 2008.pdf 
Schrader, A.M. y Brundin, M.R. (2012). National statistical and values profile of Canadian libraries: report to CLA Executive Council. Ottawa: Canadian Library Association. Recuperado de http://cla.ca/wpcontent/uploads/NationalValuesProfileCanadianLibrariesReportfinal.pdf

Schubert, F. y Becker, R. (2010). Social inequality of reading literacy. A longitudinal analysis with cross-sectorial data of PIRLS 2001 and PISA 2000 utilizing the pair wise matching procedure. Research in Social Stratification and Mobility, 28, 109133.

Scott, E.S. (agosto, 2002). How good is your school library resource centre? an introduction to performance measurement. Comunicación presentada en 68th IFLA Council and General Conference, Glasgow. Recuperado de http://files.eric.ed.gov/fulltext/ED472866.pdf

Scott, R. (2011). The role of public libraries in community building. Public Library Quarterly, 30(3), 191-227.

Seaman, B. (2005). El impacto económico de la cultura. En R. Towse (Ed.), Manual de economía de la cultura (pp. 403-417). Madrid: Fundación Autor.

Sebastiani, M. (1993). Dall 'analisi del sistema alla biblioteca efficace. Biblioteche Oggi, $10,40-45$.

Segesova, L. (2000). Survey of the performance of Slovak technical libraries and information centres in 1999. Kniznice a Informacie, 32(7-8), 258-265.

Seissl, M. (agosto, 2006). Benchmarking efforts in Austrian university libraries. Comunicación presentada en World Library and Information Congress: 72nd IFLA General Conference and Council, Seoul. Recuperado de http://2014nvclcf.chinalibs.net/Upload/Pusfile/j0180.pdf

Seppänen, A.-P. y Laitinen, M. (2012). Libraries do make a difference: common principles in showing the impact of different types of libraries. Qualitative and Quantitative Methods in Libraries, 1, 3-11.

Serna, M., Rodríguez, A. y Etxaniz, X. (2017). Biblioteca escolar y hábitos lectores en los escolares de Educación Primaria. Ocnos, 16(1), 18-49. doi: 10.18239/ocnos_2017.16.1.1205

Serpell, R., Sonnenschein, S., Baker, L. y Ganapathy, H. (2002). Intimate culture of families in the early socialization of literacy. Journal of Family Psychology, 16(4), 391-405.

Servet, M. (2010). Les bibliothèques troisième lieu: une nouvelle génération d'établissements culturels. Bulletin de Bibliothèques de France, 55(4), 57-66.

SGS Economics and Planning. (2012). The library dividend: technical report. A study of the socio-economic value of Queensland public libraries. Queensland: State Library of Queensland. Recuperado de http://www.plconnect.slq.qld.gov.au/_data/assets/pdf_file/0009/225864/thelibrary-dividend-technical-report.pdf 
SGS Economics and Planning. (2013a). National welfare \& economic contributions of public libraries. Canberra: SGS Economics \& Planning. Recuperado de https://www.alia.org.au/sites/default/files/Contribution\%20of\%20Australian\%2 OPublic\%20Libraries\%20Report.pdf

SGS Economics and Planning. (2013b). The community returns generated by Australian health libraries. Canberra: SGS Economics \& Planning. Recuperado de https://www.alia.org.au/advocacy-and-campaigns/advocacy-campaigns0/australian-health-libraries-return-investment

Shapiro, B.J. (1991). Access and performance measures in research libraries in the 1990s. Journal of Library Administration, 15(3), 49-63.

Sharman, A. (2017). Using ethnographic research techniques to find out the story behind international student library usage in the Library Impact Data Project. Library Management, 38(1), 2-10.

Shenton, A.K. (2011). Two pupil-centred approaches to the assessment of school libraries. Performance Measurement and Metrics, 12(1), 38-49.

Shepherd, P.T. (2003). COUNTER: from conception to compliance. Learned Publishing, 16(3), 201-205.

Sheppard, M. (1990). Some thoughts concerning a structural framework for performance indicators. Australian Academic and Research Libraries, 21(1), 4447.

Shimoyama, K., Nishiura, M., Naka, H., Tsuji, K. y Itsumura, H. (2013). Does evaluation improve performance? a case study of Japanese public libraries. Qualitative and Quantitative Methods in Libraries, 3, 293-303. Recuperado de http://www.qqml.net/papers/September_2013_Issue/238QQML_Journal_2013 _Shimoyama_etal_3_293_303.pdf

Shreeve, S. y Chelin, J. (2014). Value and impact of librarians' interventions on student skills development. New Review of Academic Librarianship, 20, 204-232.

Siddiqi, A., Subramanian, S.V., Berkman, L., Hertzman, C. y Kawachi, I. (2007). The welfare state as a context for children's development: a study of the effects of unemployment and unemployment protection on reading literacy scores. International Journal of Social Welfare, 16(4), 314-325.

Simón de Blas, C., Arias Coello, A. y Simón Martín, J. (2007). Aplicación de la técnica DEA en la medición de la eficiencia de las bibliotecas de la Universidad Complutense de Madrid. Revista Española de Documentación Científica, 30(1), 9-23.

Simons, H. (2011). El estudio de caso: teoría y práctica. Madrid: Morata.

Sin, S.-C.J. y Vakkari, P. (2015). Perceived outcomes of public libraries in the U.S. Library \& Information Science Research, 37, 209-219.

Sipilä, S. (2015). Strong libraries, strong societies. El Profesional de la Información, 24(2), 95-101. 
Small, R.V. y Snyder, J. (2010). Research instruments for measuring the impact of school libraries on student achievement and motivation. School Libraries Worldwide, 16(1), 61-72.

Small, R.V., Snyder, J. y Parker, K. (2009). The impact of New York's school libraries on student achievement and motivation: phase I. School Library Media Research, 12. Recuperado de www.ala.org/aasl/slr

Smalley, T.N. (2004). College success: high school librarians make the difference. The Journal of Academic Librarianship, 30(3), 193-198.

Smith, E.G. (2001). Texas school libraries: standards, resources, services, and students' performance. Austin: EGS Research \& Consulting. Recuperado de https://www.tsl.texas.gov/ld/pubs/schlibsurvey/index.html

Smith, E.G. (2006). Student learning through Wisconsin school library media centers: case study report. Austin: EGS Research \& Consulting. Recuperado de http://imt.dpi.wi.gov/files/imt/pdf/finalcasestudy.pdf

Soria, K.M., Peterson, K., Fransen, J. y Nackerud, S. (2017). The impact of academic library resources on first-year students' learning outcomes. Research Library Issues, 290, 5-20.

Soulen, R.R. y Wine, L.D. (2018). Building resilience in new and beginning teachers: contributions of school librarians. School Libraries Worldwide, 24(2), 80-91.

Spectrum Strategy Consultants and Indepen (2004). Measuring our value: results of an independent economic impact study commissioned by the British Library to measure the Library's direct and indirect value to the UK economy. London: British Library. Recuperado de http://www.bl.uk/aboutus/stratpolprog/increasingvalue/measuringourvalue fu $\underline{\text { II.pdf }}$

Spencer, M.E. y Watstein, S.B. (2017). Academic library spaces: advancing student success and helping students thrive. Libraries and the Academy, 17(2), 389-402.

Stake, R.E. (1998). Investigación con estudio de casos. Madrid: Morata.

Stanley, T. y Knowles, J. (2016). Demonstrating value in research libraries: the shared service standards initiative. Performance Measurement and Metrics, 17(2), 188193.

Stavridis, S. y Tsimpoglou, F. (2012). EFQM in academic libraries: the application of a quality management model at the University of Cyprus Library. Liber Quarterly, 22(1), 64-77.

Stefl-Mabry, J. y Radlick, M. (abril, 2016). Digging much deeper: school library factors that impact achievement. Comunicación presentada en Annual Meeting Public Scholarship to Educate Diverse Democracies, Washington, D.C. Recuperado de https://www.researchgate.net/publication/299462675

Stejskal, J., Hájek, P. y Rehak, T. (2016). The economic value of book loans - the case of the Municipal Library of Prague. Libri, 66(4), 303-311. 
Stephens, D. (1992). The State Library of Queensland. Australian Academic and Research Libraries, 23(2), 113-122.

Stewart, P. (2018). School library design, facilities and resources for sustainable cognitive and social development of students: an evaluative case study. School Libraries Worldwide, 24(2), 30-45.

Stolarick, K. y Silk, K. (2013). So much more: the economic impact of the Toronto Public Library on the City of Toronto. Toronto: Martin Prosperity Institute, University of Toronto.

Recuperado

de http://martinprosperity.org/media/TPL\%20Economic\%20Impact_Dec2013_LR_F INAL.pdf

Stone, G., Pattern, D. y Ramsden, B. (2011). Does library use affect student attainment? a preliminary report on the Library Impact Data Project. Liber Quarterly, 21(1), 5-22.

Stone, G. y Ramsden, B. (2013). Library Impact Data Project: looking for the link between library usage and student attainment. College \& Research Libraries, 74(6), 546-559.

Streatfield, D. (2002). Getting at the impact of services. En S. Brewer (Ed.), Value and impact studies: getting the benefit (pp. 37-42). Loughborough: Capital Planning Information.

Streatfield, D. (2012). Impact planning and assessment of public libraries: a country level perspective. Performance Measurement and Metrics, 13(1), 8-14.

Streatfield, D., Andrade Blanco, P., Chiranov, M., Dryzaite, I., Kochanowicz, M., Liubyva, T. y Tkachuk, Y. (2015). Innovative impact planning and assessment through global libraries. Performance Measurement and Metrics, 16(2), 177-192.

Streatfield, D., Paberza, K., Lipeikaite, U., Chiranov, M, Devetakova, L. y Sadunisvili, R. (2012). Developing impact planning and assessment at national level: addressing some issues. Performance Measurement and Metrics, 13(1), 58-65.

Stroobants, J. y Bouckaert, G. (2014). Benchmarking local public libraries using nonparametric frontier methods: a case study of Flanders. Library \& Information Science Research, 36(3-4), 211-224.

Stubbs, K. (1981). University libraries: standards and statistics. College and Research Libraries, 42(6), 527-538.

Suárez, D. (2010). Evaluating qualitative research studies for evidence-based library and information practice. Evidence Based Library and Information Practice, 5(2), 7585.

Sumsion, J., Hawkins, M. y Morris, A. (2003). Estimating the economic value of library benefits. Performance Measurement and Metrics, 4(1), 13-27.

Svendsen, G.L.H. (2013). Public libraries as breeding grounds for bonding, bridging and institutional social capital: the case of branch libraries in rural Denmark. Sociologia Ruralis, 53(1), 52-73. 
Swanson, J. y Rinehart, A.K. (2016). Data in context: using case studies to generate a common understanding of data in academic libraries. The Journal of Academic Librarianship, 42, 97-101.

Swanson, R.W. (1975). Performing evaluation studies in information science. Journal of the American Society for Information Science, 26(3), 140-156.

Taladriz Mas, M. (2013). Los servicios de información y el retorno de la inversión: cómo Ilegar a conocerlo. El Profesional de la Información, 22(4), 281-285.

Tejedor, J. y Etxeberria, J. (2006). Análisis inferencial de datos en educación. Madrid: La Muralla.

Tenopir, C. (2011). Beyond usage: measuring library outcomes and value. Library Management, 33(1-2), 5-13.

Tenopir, C. (2013). Building evidence of the value and impact of library and information services: methods, metrics and ROI. Evidence Based Library and Information Practice, 8(2), 270-274.

Tessler, A. (2013). Economic valuation of the British Library. Oxford: Oxford Economics. Recuperado

de http://www.bl.uk/aboutus/stratpolprog/increasingvalue/britishlibrary economi cevaluation.pdf

Thompson, B., Cook, C. y Heath, F. (2003a). Two short forms of the LibQUAL+ survey assessing users' perceptions of library service quality. Library Quarterly, 73(4), 453-465.

Thompson, B., Cook, C. y Heath, F. (2003b). Structure of perceptions of service quality in libraries: a LibQUAL+ study. Structural Equation Modeling, 10, 456-464.

Thompson, B., Cook, C. y Kyrillidou, M. (2005). Concurrent validity of LibQUAL+ scores: what do LibQUAL+ scores measure? Journal of Academic Librarianship, 31(6), 517-522.

Thorpe, A., Lukes, R., Bever, D.J. y He, Y. (2016). Library on student success: connecting the dots. Libraries and the Academy, 16(2), 373-392.

Todd, R. (agosto, 2002). School librarians as teachers: learning outcomes and evidencebased practice. Comunicación presentada en 68th IFLA Council and General Conference, Glasgow. Recuperado de http://archive.ifla.org/IV/ifla68/papers/084-119e.pdf

Todd, R.J. y Kuhlthau, C.C. (2005). Student learning through Ohio school libraries, part 1: How effective school libraries help students. School Libraries Worldwide, 11(1), 63-88.

Tójar Hurtado, J.C. (2006). Investigación cualitativa: comprender y actuar. Madrid: La Muralla.

Town, J.S. y Kyrillidou, M. (2013). Developing a values scorecard. Performance Measurement and Metrics, 14(1), 7-16.

Town, S. (2018). The Value Scorecard. Information and Learning Science, 119(1/2), 2538. doi: 10.1108/ILS-10-2017-0098 
Towse, R. (Ed.). (2005). Manual de economía de la cultura. Madrid: Fundación Autor.

Urquhart, C. (2015). Reflections on the value and impact of library and information services: Part 1: Value identification and value creation. Performance Measurement and Metrics, 16(1), 86-102.

Urquhart, C. (2018). Principles and practice in impact assessment for academic libraries. Information and Learning Science, 119(1/2), 121-134. doi: 10.1108/ILS-06-20170053

Urquhart, C. y Hepworth, J. (1995). The value of information supplied to clinicians by health libraries: devising an outcomes-based assessment of the contribution of libraries to clinical decision-making. Health libraries review, 12(3), 201-213.

Urquhart, C. y Tbaishat, D. (2016). Reflections on the value and impact of library and information services: Part 3: towards an assessment culture. Performance Measurement and Metrics, 17(1), 29-44.

Urquhart, C. y Turner, J. (2016). Reflections on the value and impact of library and information services: Part 2: impact assessment. Performance Measurement and Metrics, 17(1), 5-28.

Vakkari, P. (2014). Models explaining the perceived outcomes of public libraries. Journal of Documentation, 70(4), 640-657.

Vakkari, P., Aabø, S., Audunson, R., Huysmans, F., Kwon, N., Oomes, M y Sin, S.-C.J. (2016). Patterns of Perceived Public Library Outcomes in Five Countries. Journal of Documentation, 72(2), 342-361.

Vakkari, P., Aabø, S., Audunson, R., Huysmans, F. y Oomes, M. (2014). Perceived outcomes of public libraries in Finland, Norway and the Netherlands. Journal of Documentation, 70(5), 927-944.

Vakkari, P. y Serola, S. (2012). Perceived outcomes of public libraries. Library \& Information Science Research, 34(1), 37-44.

Valdés, M. (2013). ¿Leen de forma voluntaria y recreativa los niños que logran un buen nivel de comprensión lectora? OCNOS, 10, 71-89.

Valles, M. S. (2014). Entrevistas cualitativas. Madrid: CIS.

Valls Pasoia, A. y Casado, L. (1994). El cambio hacia la calidad de servicio. Boletín de la Asociación Andaluza de Bibliotecarios, 10(35), 55-70.

Van House, N.A. (1987). Output measures for public libraries: a manual of standardized procedures. Chicago: American Library Association.

Van House, N.A. (1989). Output measures in libraries. Library Trends, 38(2), 268-279.

Van House, N.A. y Childers, T. (1990). Dimensions of public library effectiveness, 2, Library performance. Library and Information Science Research, 12(2), 131-153.

Van House, N. A. y Childers, T.A. (1993). The public library effectiveness study: the complete report. Chicago, IL: American Library Association.

Van House, N.A. y Childers, T.A. (1994). The use of public library roles for effectiveness evaluation. Library and Information Science Research, 16(1), 41-58. 
Van House, N.A., Weil, B. y McClure, C.R. (1990). Measuring academic library performance: a practical approach. Chicago, IL: American Library Association.

Vance, J.M., Kirk, R. y Gardner, J.G. (2012). Measuring the impact of library instruction on freshmen success and persistence: a quantitative analysis. Communications in Information Literacy, 6(1), 49-58.

Vårheim, A. (2009). Public libraries: places creating social capital? Library Hi Tech, 27(3), 372-381.

Vårheim, A. (2011). Gracious space: library programming strategies towards immigrants as tools in the creation of social capital. Library \& Information Science Research, 33, 12-18.

Vårheim, A. (2014a). Trust and the role of the public library in the integration of refugees: The case of a Northern Norwegian city. Journal of Librarianship and Information Science, 46(1), 62-69.

Vårheim, A. (2014b). Trust in libraries and trust in most people: social capital creation in the public library. The Library Quarterly, 84(3), 258-277.

Vårheim, A. (2017). Public libraries, community resilience, and social capital. Information Research, 22(1). Recuperado de http://www.informationr.net/ir/22-1/colis/colis1642.html

Vårheim, A., Steinmo, S. e Ide, E. (2008). Do libraries matter? public libraries and the creation of social capital. Journal of Documentation, 64(6), 877-892.

Vaughan, L.Q. (1997). The impact of the public library on business success: an analysis based on medium-sized businesses in Ontario. Canadian Journal of Information and Library Science, 22(2), 16-29.

Vaughan, L.Q., Tague-Sutcliffe, J. y Tripp, P. (1996). The value of the public library to small businesses. $R Q, 36(2), 262-269$.

Vernis Domenech, A. (1996). La evaluación como herramienta de cambio para las bibliotecas. En Evaluación de los servicios bibliotecarios: VII Jornadas sobre Bibliotecas Públicas, 1,2,3 de junio de 1995, San Sebastián (pp. 30-42). Donostia: Asociación de Bibliotecarios y Documentalistas de Guipúzcoa.

Verwiebe, R. y Riederer, B. (2013). The reading literacy of immigrant youth in western societies: a multilevel analysis based on PISA 2000 to 2009. Zeitschrift für Soziologie, 42(3), 201-221.

Vilà Baños, R. y Bisquerra Alzina, R. (2016). El análisis cuantitativo de los datos. En Metodología de la investigación educativa (pp. 251-263). Madrid: La Muralla.

Vílchez Pardo, J. (1997). El control en la gestión bibliotecaria. Boletín de la Asociación Andaluza de Bibliotecarios, 13(46), 9-27.

Vonhof, C. y Bertele, M. (2017). Excellent library: a holistic quality model and certificate for libraries: concept and experiences from Germany. International Information \& Library Review, 49(1), 19-30.

Wallace, V.E. (2001). Outcomes assessment in academic libraries. College \& Undergraduate Libraries, 8(2), 59-71. 
Walwyn, O. y Rowley, J. (2011). The value of therapeutic reading groups organized by public libraries. Library \& Information Science Research, 33(4), 302-312.

Wang, Y. y Liu, Y. (2012). Exploring performance indicators for university libraries in Taiwan. Journal of Library and Information Science, 38(1), 43-64.

Warschauer, M., Knobel, M. y Stone, L. (2004). Technology and equity in schooling: deconstructing the digital divide. Educational Policy, 18(4), 562-588.

Wavell, C., Baxter, G., Johnson, I. y Williams, D. (2002). Impact evaluation of museums, archives and libraries: available evidence project. Aberdeen: The Robert Gordon University for Resource, The Council for Museums, Archives and Libraries. Recuperado de https://www.rgu.ac.uk/4E339E80-595A-11E1BF5B000d609cb064

Weightman, A.L. y Williamson, J. (2005). The value and impact of information provided through library services for patient care: a systematic review. Health Information and Libraries Journal, 22(1), 4-25.

Weiner, S. (2009). The contribution of the library to the reputation of a university. The Journal of Academic Librarianship, 35(1), 3-13.

Wells, J. (1995). The influence of library usage on undergraduate academic success. Australian Academic and Research Libraries, 26(2), 121-128.

White, L.N. (2007a). Unseen measures: the need to account for intangibles. The Bottom Line, 20(2), 77 - 84.

White, L.N. (2007b). A kaleidoscope of possibilities: strategies for assessing human capital in libraries. The Bottom Line, 20(3), 109-115.

White, L.N. (2007c). Imperfect reflections: The challenges in implementing human capital assessment in libraries. The Bottom Line, 20(4), 141-147.

Whitmire, E. (1998). Development of critical thinking skills: an analysis of academic library experiences and other measures. College and research Libraries, 59(3), 267-273.

Williams, D., Wavell, C., Baxter, G., MacLennan, A. y Jobson, D. (2005). Implementing impact evaluation in professional practice: a study of support needs within the museum, archive and library sector. International Journal of Information Management, 25, 533-548.

Williams, D., Wavell, C. y Coles, L. (2001). Impact of school library services on achievement and learning: critical literature review of the impact of school library services on achievement and learning to inform the work of the DfES Task Group set up to implement actions contained in the Government's response to Empowering the Learning Community. London: The Council for Museums, Archives \& Libraries. Recuperado de https://openair.rgu.ac.uk/handle/10059/1382

Williams, D., Wavell, C. y Morrison, K. (2013). Impact of school libraries on learning critical review of published evidence to inform the Scottish education community. Glasgow: Scottish Library \& Information Council. Recuperado de 
http://scottishlibraries.org/media/1211/impact-of-school-libraries-on-learning2013.pdf

Williams, P. y Edwards, J. (2011). Nowhere to go and nothing to do: how public libraries mitigate the impacts of parental work and urban planning on young people. Australasian Public Libraries and Information Services, 24(4), 142-152.

Wilson, V. (2016). A new path: research methods. Evidence Based Library and Information Practice, 11(1-S), 36-38.

Winkworth, I. (1990). Performance indicators for polytechnic libraries. Library Review, 39(5), 23-41.

Wong, S.H.R. y Webb, T.D. (2011). Uncovering meaningful correlation between student academic performance and library material usage. College \& Research Libraries, 72(4), 361-370.

Wu, M. (2005). The role of plausible values in large-scale surveys. Studies in Educational Evaluation, 31(2-3), 114-128. doi: 10.1016/j.stueduc.2005.05.005

Wu, M. (2010). Measurement, sampling, and equating errors in large-scale assessments. Educational Measurements: Issues and Practice, 29(4), 15-27. doi: 10.1111/j.1745-3992.2010.00190.x

Young, R. (2012). More than just books: the role of public libraries in building community and promoting civic engagement. National Civic Review, Winter, 3032.

Yubero Jiménez, S. y Larrañaga Rubio, E. (2010). El valor de la lectura en relación con el comportamiento lector. Un estudio sobre los hábitos lectores y el estilo de vida en niños. OCNOS, 6, 7-20.

Zorica, M.B., Ivanjko, T. y Spiranec, S. (2014). Mystery shopping in libraries, are we ready? Qualitative and Quantitative Methods in Libraries, 2, 433-442. Recuperado de http://www.qqml.net/papers/June 2014 Issue/327QQML Journal 2014 Zoric aetal June 433-442.pdf

Zovko, M. y Čelić-Tica, V. (2012). Performance indicators of school libraries. Vjesnik Bibliotekara Hrvatske, 55(1), 101-116.

Zweizig, D., Johnson, D.W., Robbins, J. y Besant, M. (1996). The tell it! manual: the complete program for evaluating library performance. Chicago: American Library Association.

Zweizig, D. y Rodger, E.J. (1982). Output measures for public libraries: a manual of standardized procedures. Chicago: American Library Association.

\section{Listado de legislación}

Comisión Europea. (2012). Un nuevo concepto de educación: invertir en las competencias para lograr mejores resultados socioeconómicos: comunicación de la Comisión al Parlamento Europeo, al Consejo, al Comité Económico y Social 
Europeo y al Comité de las Regiones. COM (2012) 669 final. Recuperado de https://eur-lex.europa.eu/resource.html?uri=cellar:dd6fddb9-95b5-4828-b8d4d71d4c00d48f.0005.03/DOC 1\&format=PDF

España. (2006). Ley Orgánica 2/2006, de 3 de mayo, de Educación. BOE, n.106, de 4 de mayo. Recuperado de https://www.boe.es/buscar/act.php?id=BOE-A-20067899

España. (2014). Real Decreto 126/2014, de 28 de febrero, por el que se establece el currículo básico de la educación primaria. BOE, n. 52, 1 de marzo. Recuperado de http://www.boe.es/boe/dias/2014/03/01/pdfs/BOE-A-2014-2222.pdf

España. (2015). Real Decreto 1105/2014, de 26 de diciembre, por el que se establece el currículo básico de la educación secundaria obligatoria y del bachillerato. BOE, n.3, 3 de enero. Recuperado de http://www.boe.es/diario boe/txt.php?id=BOEA-2015-37 
Anexos 